\title{
ANALYSIS AND FEASIBILITY STUDY OF A MULTIPLE-PASS HEAT AND ENERGY RECOVERY VENTILATOR WITH INTEGRATED ECONOMIZER FOR RESIDENTIAL USE
}

\author{
By \\ Jun Long Zhang \\ B.Eng (Mechanical Engineering) \\ Ryerson University, 2012 \\ A thesis \\ presented to Ryerson University \\ In partial fulfillment of the \\ requirements for the degree of \\ MASTER OF APPLIED SCIENCE
}

In the program of

Mechanical and Industrial Engineering

Toronto, Ontario, Canada, 2014

(C) Jun Long Zhang, 2014 


\section{Author's Declaration}

\section{AUTHOR'S DECLARATION FOR ELECTRONIC SUBMISSION OF A THESIS}

I hereby declare that I am the sole author of this thesis. This is a true copy of the thesis, including any required final revisions, as accepted by my examiners.

I authorize Ryerson University to lend this thesis to other institutions or individuals for the purpose of scholarly research

I further authorize Ryerson University to reproduce this thesis by photocopying or by other means, in total or in part, at the request of other institutions or individuals for the purpose of scholarly research.

I understand that my thesis may be made electronically available to the public. 


\title{
ANALYSIS AND FEASIBILITY STUDY OF A MULTIPLE-PASS HEAT AND ENERGY RECOVERY VENTILATOR WITH INTEGRATED ECONOMIZER FOR RESIDENTIAL USE
}

\author{
Jun Long Zhang \\ Master of Applied Science \\ Program of Mechanical and Industrial Engineering \\ Ryerson University, Toronto, Ontario, Canada, 2014
}

\begin{abstract}
The feasibility of a novel total energy recovery ventilator (HERV) was studied, through the use of an Excel-based screening tool developed for cost analysis, and through TRNSYS simulations for performance analysis. Cost analysis indicated that the HERV almost always outperformed the conventional systems, whereas its attractiveness could be limited by its high capital investment. Simulation results indicated that the counter-flow HERV provided better control of house humidity towards the setpoint, in the meantime, minimized the annual energy use. The performance of heat recovery (HRV) and energy recovery (ERV) ventilators was investigated side-by-side at the Archetype Sustainable Twins-House located in Toronto, Canada. The ERV sensible efficiency ranged from $76.4 \%$ to $78.5 \%$ at an outdoor temperature of $-20^{\circ} \mathrm{C}$ and $5^{\circ} \mathrm{C}$ respectively, while the $\mathrm{HRV}$ efficiency ranged from $91.0 \%$ to $95.0 \%$ at $-16.6^{\circ} \mathrm{C}$ and $0.7^{\circ} \mathrm{C}$ respectively. Freezing caused a dramatic drop in the efficiency that was found to be as low as $50 \%$.
\end{abstract}




\section{Acknowledgements}

The author would like to express his deepest appreciation to Dr. Alan S. Fung for his kind support, guidance and encouragement throughout the project. The author also express his gratitude to Mr. David Nixon, Gil Amdurski and Dahai Zhang of the Toronto and Region Conservation Authority for their tremendous help implementing the instrumentation and the monitoring system at the TRCA Archetype Sustainable Twins-House.

The author would also like to acknowledge the financial support from the Natural Sciences and Engineering Research Council (NSERC) of Canada Smart Net-Zero Energy Buildings Research Network (SNEBRN), Mitacs/Accelerate Ontario, and ASHRAE.

The author would finally like to thank my respected parents and my family for the unconditional love and support and for allowing me to realize my own potential. All the support they have provided me over the years was the greatest gift anyone has ever given me. 


\section{Table Contents}

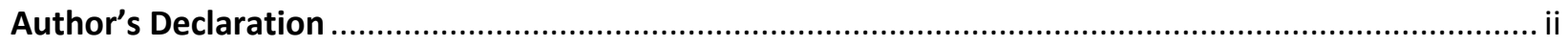

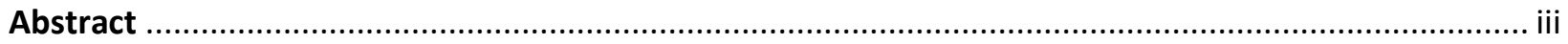

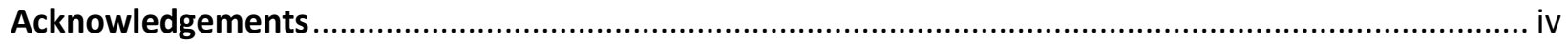

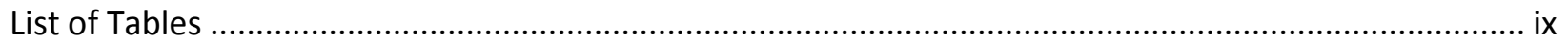

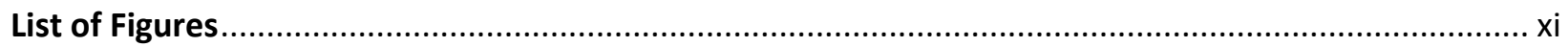

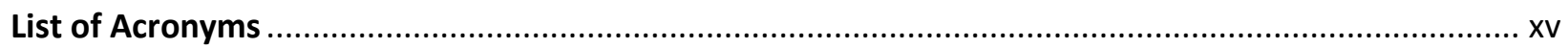

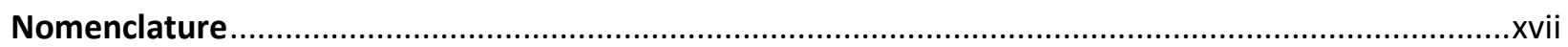

Chapter \#1 - Introduction and Objectives …............................................................................... 1

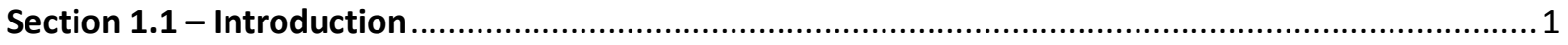

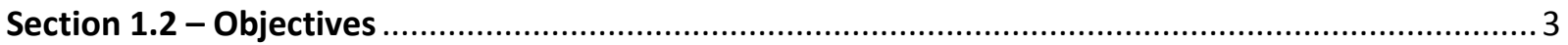

Section 1.3 - Energy-Efficient Improvements in Canada .............................................................. 4

Section 1.4 - Thermal Comfort and Design Principle for Ventilation ............................................... 5

Section 1.5 - Heat and Energy Recovery Ventilation System ...................................................... 7

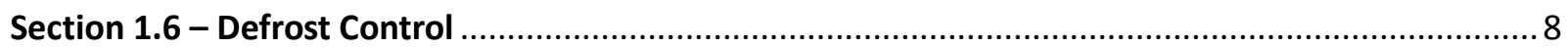

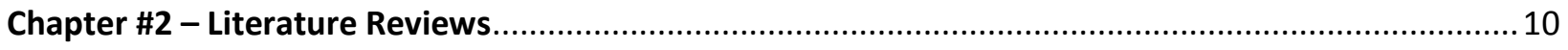

Section 2.1 - Heat Recovery and Energy Recovery Ventilators ...................................................... 10

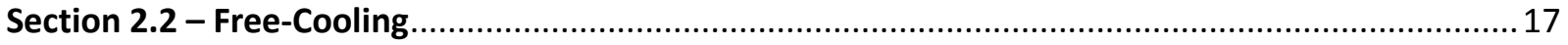

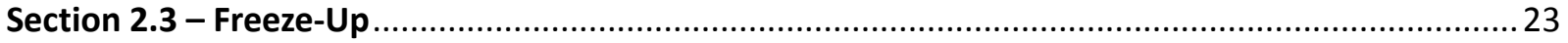

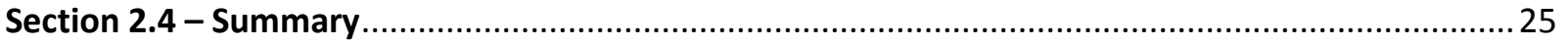

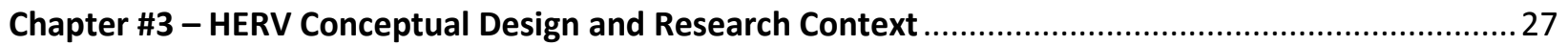

Section 3.1 - The Concepts of Integrated Heat and Energy Recovery Ventilator (HERV) ...................227

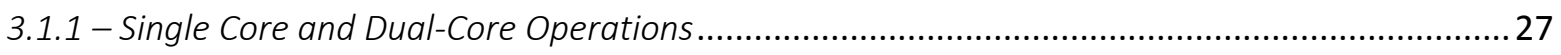

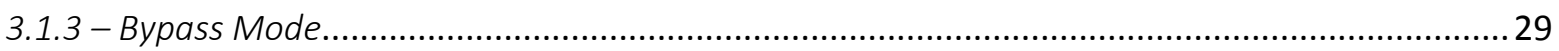

Section 3.2 - TRCA Archetype Sustainable House ........................................................................29

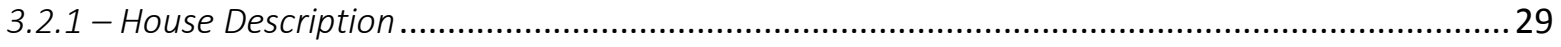

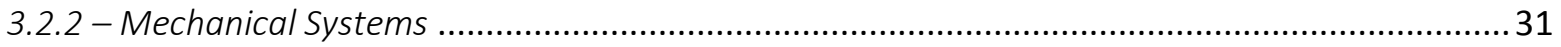

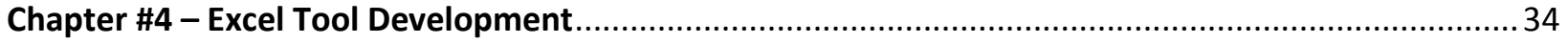

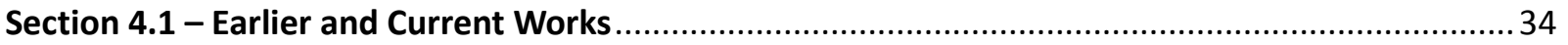

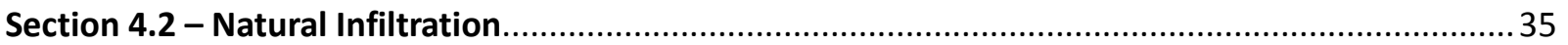

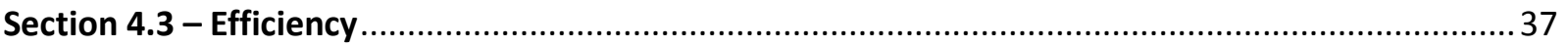

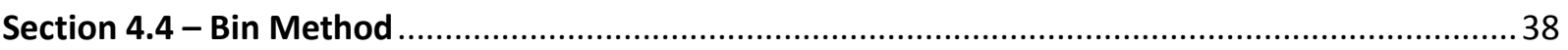

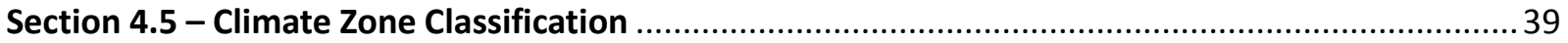




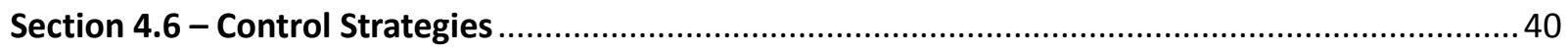

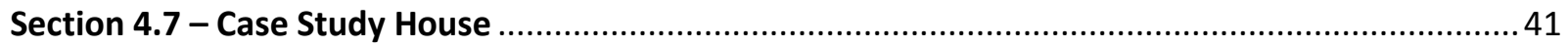

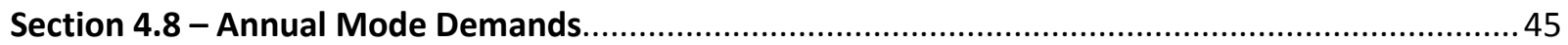

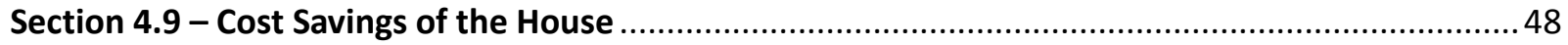

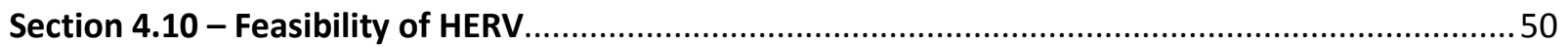

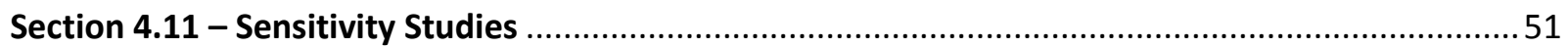

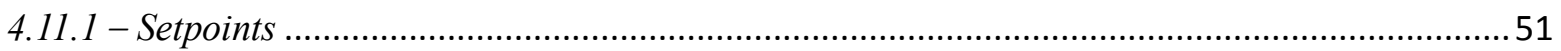

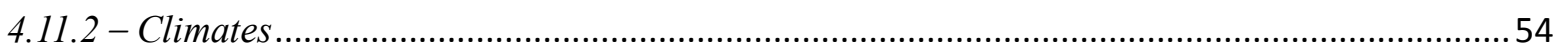

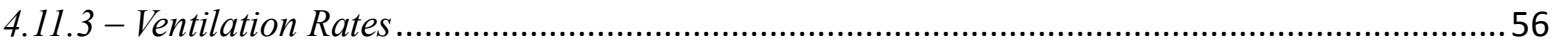

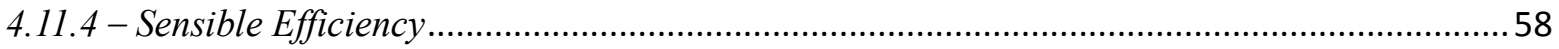

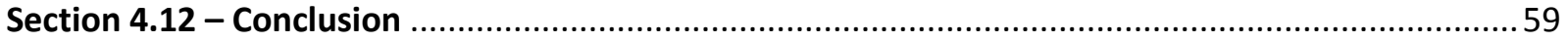

Chapter \#5 - Preliminary TRNSYS Modeling and Simulation (WINTER 2013) ...................................61

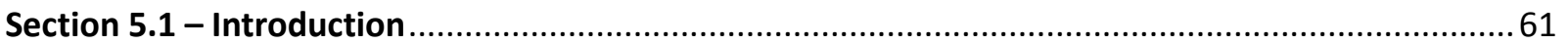

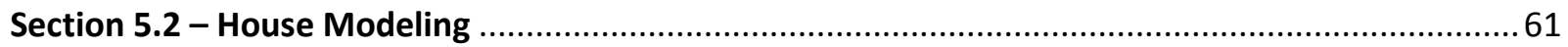

Section 5.3 - Computer Modelling of HERV Using TRNSYS ..........................................................63

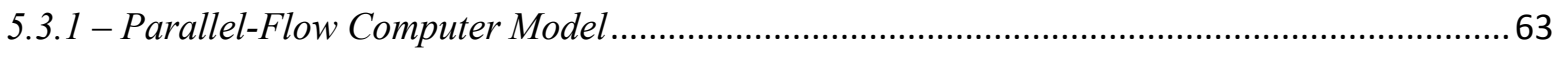

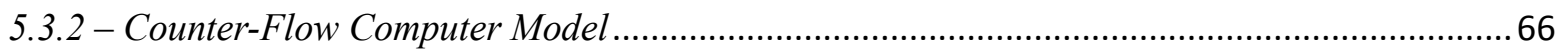

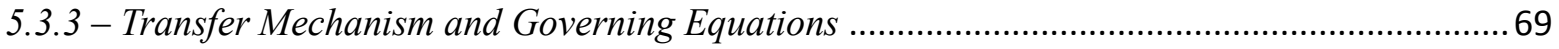

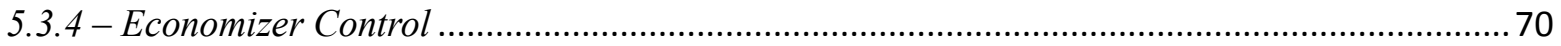

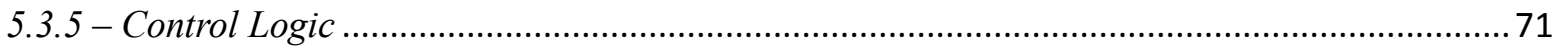

Section 5.4 - Preliminary Simulation of the HVAC Equipment .................................................... 75

5.4.1 - Comparing House Cooling and Heating Consumptions ...................................................... 75

5.4 .2 - Comparing House Humidity Ratio .................................................................................... 83

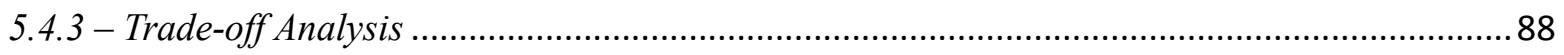

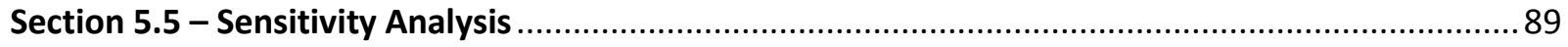

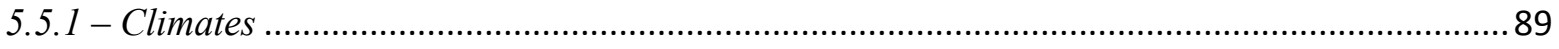

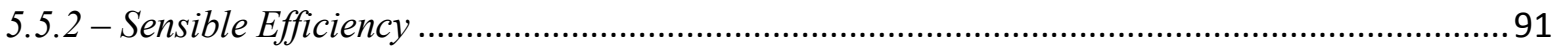

5.5 .3 - Ventilation Rates ......................................................................................................... 93

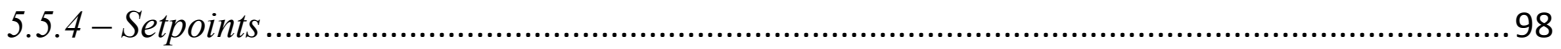

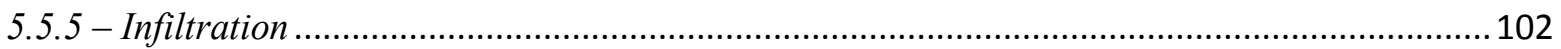

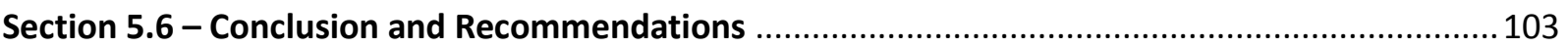

Chapter 6 - Winter Experiment and Data Analysis (Winter 2014) ................................................. 105

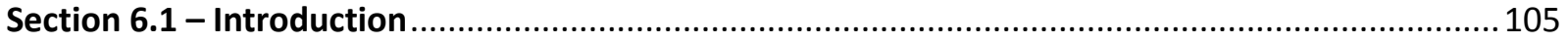


Section 6.2 - Monitoring Systems: Heat Recovery Ventilation System ....................................... 105

Section 6.3 - Monitoring Systems: Energy Recovery Ventilation System ..................................... 107

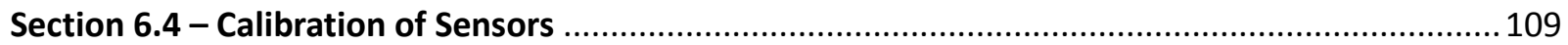

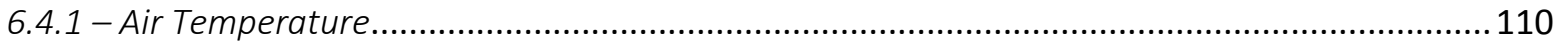

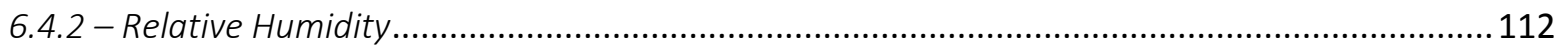

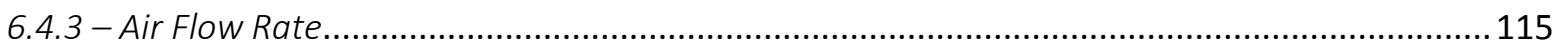

Section 6.5 - Winter Experiment: Energy Recovery Ventilator ...................................................... 116

6.5.1 - Data analysis: Sensible and Latent Efficiencies ............................................................... 116

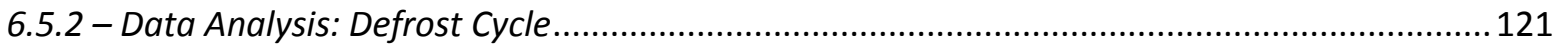

Section 6.6 - Winter Experiment: Heat Recovery Ventilator ...................................................... 131

6.6.1 - Encountered Problems during Winter Test Period .............................................................. 131

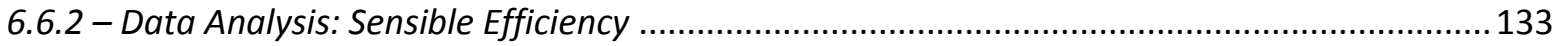

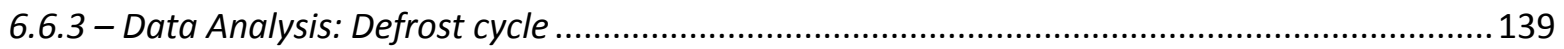

Section 6.7 - Winter Experiment: Sensible and Enthalpy Core Freezing........................................ 145

Chapter 7 - Study of Defrost Cycle Using TRNSYS Simulation (Spring 2014) .................................... 150

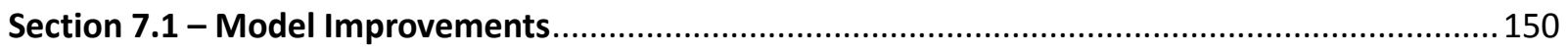

Section 7.2 - Heat Recovery Ventilator (Toronto) ................................................................... 150

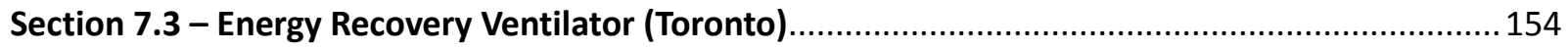

Section 7.4 - System performance in Selected Canadian Regions ................................................ 157

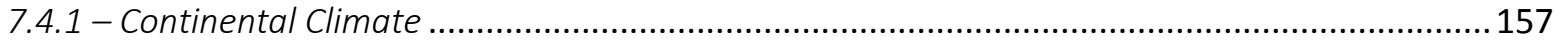

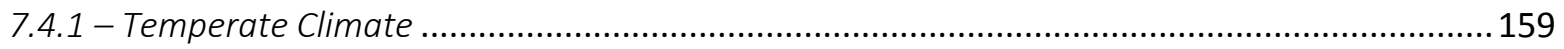

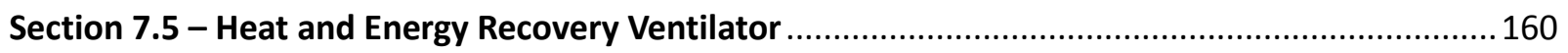

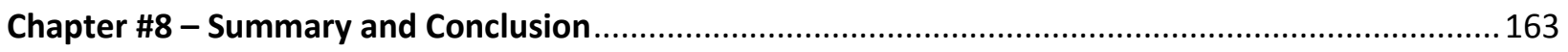

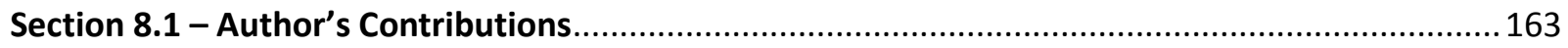

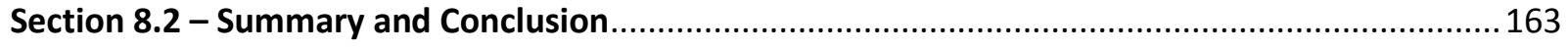

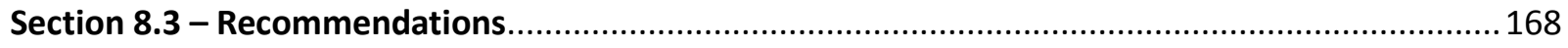

Appendix A - Supplemental Information for Ebat .......................................................................... 170

Section A1 - Required Heating and Cooling Load ................................................................... 170

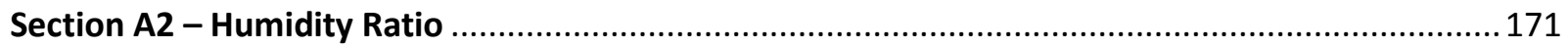

Section A3 - Furnace/AC Energy Consumption ...................................................................... 172

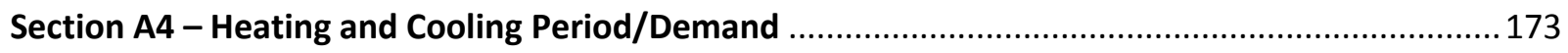

Section A5 - Unit Price of Natural Gas and Electricity ............................................................ 175

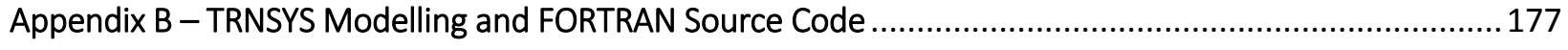


Section B1 - Introduction of TRNSYS Studio

Section B2 - FORTRAN Source Code for TRNSYS Type-291 .178

Section B3 - FORTRAN Source Code for TRNSYS Type-283 . 191

Appendix C - Experimental Uncertainty Analysis ... 197

Appendix D - Calibration Procedures and Suggestions... 205

Appendix E - Major Equipment Photos 208

References: 


\section{List of Tables}

Table 3.2.1 - Structural features of the TRCA Archetype Sustainable Twin Houses (Barua, 2010; Safa,

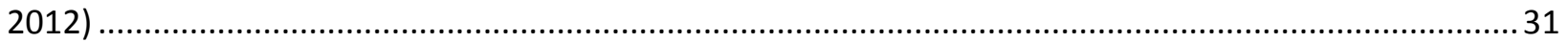

Table 3.2.2 - Detail specifications of HVAC equipment in TRCA Archetype Sustainable House-A ............ 32

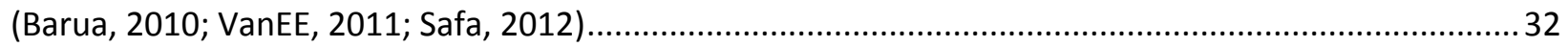

Table 3.2.3 - Detail specifications of HVAC equipment in TRCA Archetype Sustainable House-B............. 33

(Barua, 2010; VanEE, 2011; Safa, 2012, Alzahrani, 2014) .................................................................. 33

Table 4.2.1 - Leakage infiltration ratio $\left(N_{0}\right)$ for different cities in North America ....................................3

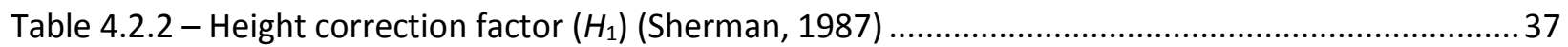

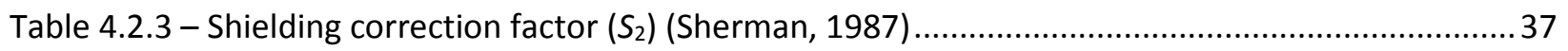

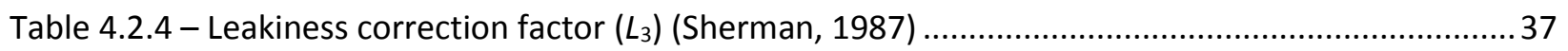

Table 4.2.5 - $\mathrm{ACH}_{50}$ for different types of house (Fung, Guler, Aydinalp \& Ugursal, 2000) ..................... 37

Table 4.4.1 - Sample bin table........................................................................................................ 39

Table 4.6.1 - Conditional statements of each operation mode in different season ................................ 41

Table 4.7.1 - Average solar heat gain through windows (kJ/hour) ......................................................42

Table 4.7.2 - Average solar heat gain through windows for other cities in U.S. (kJ/hour) ...................... 42

Table 4.7.3 - Average solar heat gain through windows for other cities in Canada (kJ/hour) ..................43

Table 4.8.1 - Heating and cooling period for Köppen climate $A$ and $E$.................................................45

Table 4.8.2 - Heating and cooling season for Köppen climate B, C, and D ..........................................46

Table 4.9.1 - Zone-by-zone analysis for the three mechanical ventilation systems ................................50

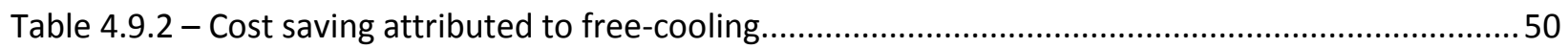

Table 4.10 .1 - Operating cost ratio for the three systems .................................................................. 51

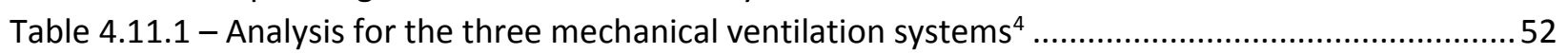

Table 4.11.2 - Sensitivity analysis for Miami with different humidity settings .......................................52

Table 4.11.3 - Analysis for the three mechanical ventilation system ${ }^{5}$..............................................5

Table 4.11.4 - Zone-by-zone analysis for the three mechanical ventilation systems ...............................55

Table 4.11 .5 - Cost saving attributed to free-cooling............................................................................5 56

Table 4.11.6 - Cost savings of the HERV with different overall sensible efficiency .................................59

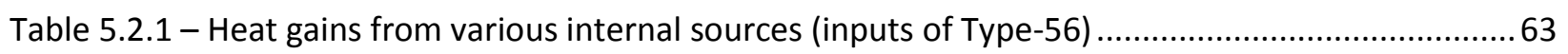

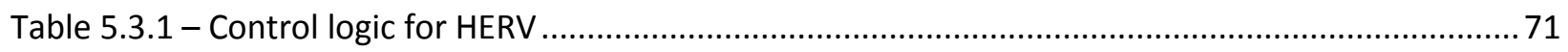

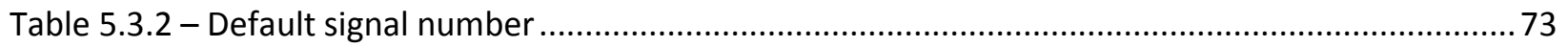

Table 5.5.1 - Sensible cooling consumption for the house at different locations ...................................90

Table 5.5.2 - Saved energy percentage in the cooling period relative to direct ventilation......................90

Table 5.5.3 - Sensible heating consumption for the house at different locations....................................91

Table 5.5.4 - Saved energy percentage in the heating period relative to direct ventilation (\%) ...............91

Table 5.5.5 - Estimated efficiencies under different airflow rate .........................................................94

Table 5.5.6 - Hourly free-cooling potential at different setpoints (Toronto)......................................... 100

Table 5.5.7 - House cumulative cooling consumption at various infiltration rate (Toronto) ................... 103

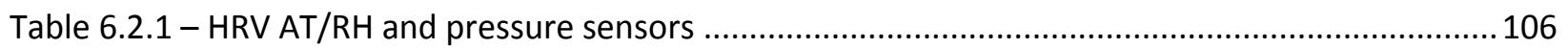

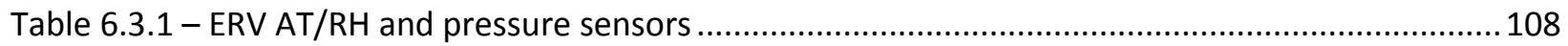

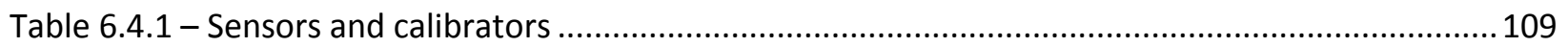

Table 6.4.2 - Calibrated result of AT/RH sensors based on calibration bath temperature setting..........111

Table 6.4.3 - Calibrated result of AT/RH sensors based on room temperature (calibrator thermometer) 
Table 6.4.4 - Reference humidity of the salt in different temperature (Vaisala, 2006)

Table 6.4.5 - Calibrated result of AT/RH sensors based on calibration salts at $22.8^{\circ} \mathrm{C}$......

Table 6.4.6 - Calibrated result of AT/RH sensors based on calibration salts at $22^{\circ} \mathrm{C}$ (ERV)...... 114

Table 6.4.7 - Calibrated result of AT/RH sensors based on calibration salts at $22^{\circ} \mathrm{C}$ (HRV)

Table 6.5.1 - Frequency of inside-outside humidity difference during the test period (ERV) 121

Table 6.5.2 - Air conditions before/during/after defrost cycle (ERV) . 125

Table 6.6.1 - Air conditions before/during/after defrost cycle (HRV)..... 141

Table 7.2.1 - Heating demand and consumption of the house (HRV) .152

Table 7.3.1 - Heating demand of the house (ERV) 156

Table 7.3.2 - Comparison between two difference threshold temperature of defrost cycle. 157

Table 7.4.1 - Saved energy attributed to defrost control (Edmonton) 159

Table 7.4.3 - Saved energy attributed to defrost control (Montreal)..... 159

Table 7.4.4 - Saved energy attributed to defrost control (Vancouver) ..................................................160

Table A.3.1 - Furnace age-based efficiency (RESNET, 2013) 173

Table A.4.1 - Heating and cooling period for Eureka and West Palm Beach ........................................ 174

Table A.4.2 - Heating and cooling period for Köppen climate B, C, and D........................................ 174

Table A.4.3 - Calculated HDD, CDD, maximum and minimum temperature of different regions ........... 175

Table A.5.1 - Natural gas charges from Enbridge (Enbridge, 2013) .................................................. 176

Table A.5.2 - Electricity charges from Toronto Hydro (Toronto Hydro, 2013)...................................... 176

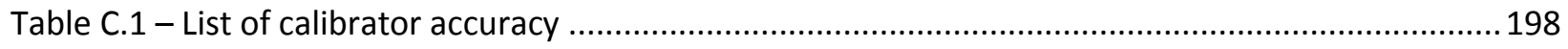

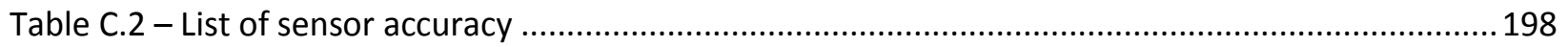

Table C.3 - Mathematical operation of propagating uncertainty (Harvey, 2000) ................................ 198

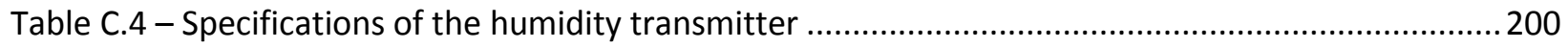

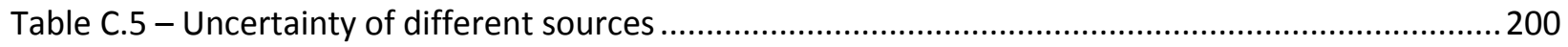

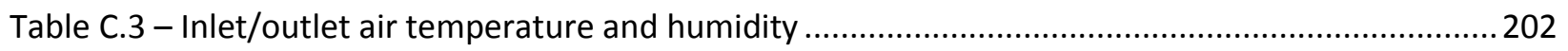

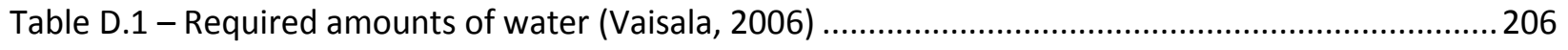




\section{List of Figures}

Figure 1.1.1 - Distribution of Canadian secondary energy consumption in 2010 (NRCan, 2013) ............... 1

Figure 1.4.1 - Indoor environment indicator (left) and energy-performance indicator (right)

(Santamouris, \& Wouters, 2006)

Figure 1.5.1 - Fully ducted (top left), extended (top right), simplified standard (bottom left) and simplified cross-furnace (bottom right) HRV installation (Hill, 1999) ................................................... 8

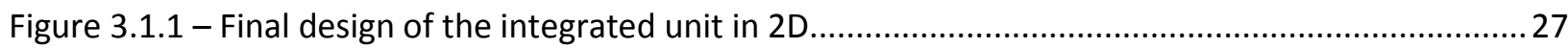

Figure 3.1.2 - Airflow for the sensible mode (counter-flow arrangement) .........................................28

Figure 3.1.3 - Airflow for the latent mode (counter-flow arrangement) ...............................................2

Figure 3.1.4 - Airflow for the dual-core mode (counter-flow arrangement) ..........................................2 29

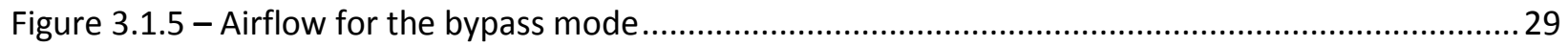

Figure 3.2.1 - Toronto Regional Conservation Authority's (TRCA) Archetype Sustainable House ............ 30

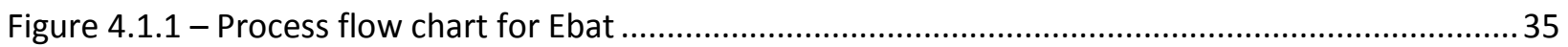

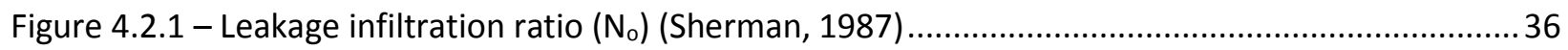

Figure 4.7.1 - Performance curve of the case study HRV and ERV (VanEE, 2011) ................................44

Figure 4.7.2 - Performance curve of unit size 3 GE ECM motor (Nailor Industries Inc., 2009) ................. 45

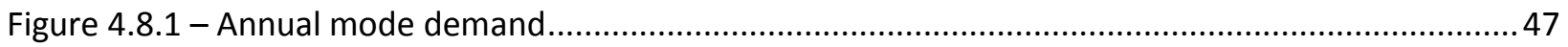

Figure 4.8.2 - Daily average ambient temperature during cooling season ...........................................47

Figure 4.8.3 - Daily average ambient humidity ratio during cooling season ....................................... 48

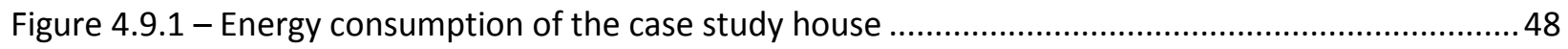

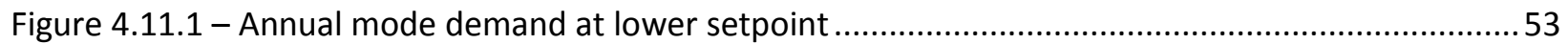

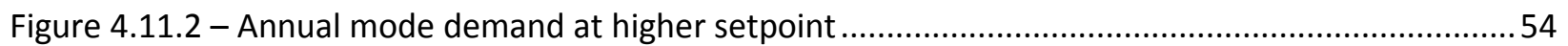

Figure 4.11.3 - Annual mode demand for additional cities.................................................................5

Figure 4.11.4 - Cost benefit of the system at different airflow rate ......................................................5

Figure 4.11.5 - PSD between the HERV and ERV for cooling period ...................................................5

Figure 4.11.6 - PSD between the HERV and ERV for heating period ..................................................58

Figure 5.1.1 - TRNSYS icon for the Type 270 (left panel) and 291 (right panel) HERV ............................61

Figure 5.2.1 - Toronto Regional Conservation Authority's (TRCA) Archetype Sustainable House A .........62

Figure 5.3.1 - Simple scheme showing the parallel-flow HERV....................................................63

Figure 5.3.2 - Psychrometric chart representing state points of fresh air and exhaust air during dual-core

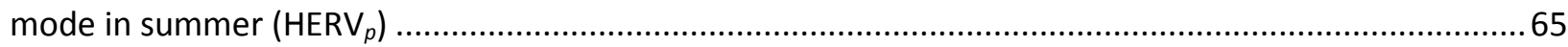

Figure 5.3.3 - Psychrometric chart representing state points of fresh air and exhaust air during dual-core

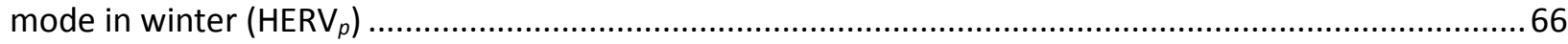

Figure 5.3.4 - Simple scheme showing the counter-flow HERV ...........................................................6 66 Figure 5.3.5 - Psychrometric chart representing state points of fresh air and exhaust air during dual-core mode in summer $\left(\mathrm{HERV}_{c}\right)$

Figure 5.3.6 - Psychrometric chart representing state points of fresh air and exhaust air during dual-core

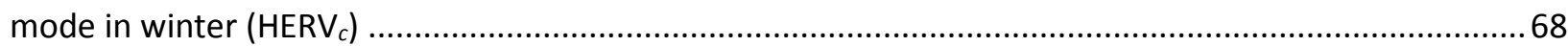

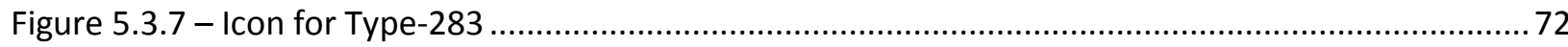

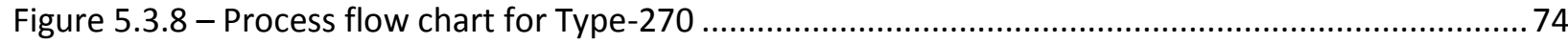

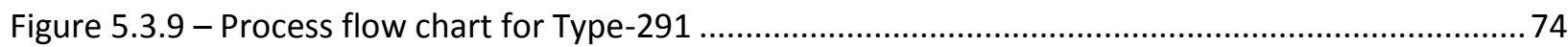

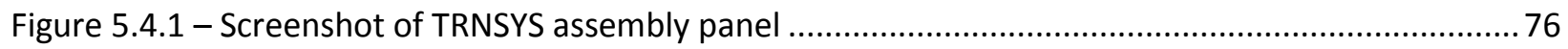

Figure 5.4.2 - Cooling consumption of the house (Toronto): HERV vs. HRV vs. ERV .............................. 78

Figure 5.4.3 - Cooling consumption of the house (Toronto): HERV vs. HRV vs. ERV ...............................78 
Figure 5.4.4 - Cooling consumption of the house (Miami): HERV vs. HRV vs. ERV .................................. 79

Figure 5.4.5 - Free-cooling hours of the $\mathrm{HERV}_{c}$ in Miami ...................................................................... 79

Figure 5.4.6 - Cooling consumption of the house (Las Vegas): HERV vs. HRV vs. ERV .............................. 80

Figure 5.4.7 - Heating consumption of the house (Las Vegas): HERV vs. HRV vs. ERV ............................ 80

Figure 5.4.8 - Cooling consumption of the house (Vancouver): HERV vs. HRV vs. ERV ............................8 81

Figure 5.4.9 - Heating consumption of the house (Vancouver): HERV vs. HRV vs. ERV ........................... 81

Figure 5.4.10 - Heating consumption of the house (Iqaluit): HERV vs. HRV vs. ERV................................ 82

Figure 5.4.11 - Humidity of the house (Miami): HERV ${ }_{c}$ Vs. HRV vs. ERV ............................................. 83

Figure 5.4.12 - Humidity of the house (Las Vegas): HERV ${ }_{c}$ Vs. HRV vs. ERV ........................................... 84

Figure 5.4.13 - Humidity of the house during cooling period (Vancouver): HERV $c$ Vs. HRV vs. ERV ...........85

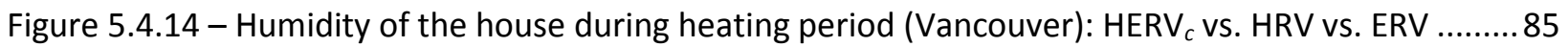

Figure 5.4.15 - Humidity of the house during cooling period (Toronto): HERV ${ }_{c}$ Vs. HRV vs. ERV .............. 86

Figure 5.4.16 - Humidity of the house during heating period (Toronto): HERV $c$ Vs. HRV vs. ERV ..............87

Figure 5.4.17 - Humidity of the house (Iqaluit): HERV ${ }_{c}$ Vs. HRV vs. ERV ............................................ 87

Figure 5.4.18 - Cooling (left) and heating (right) consumption of the house with and without the single

core modes

Figure 5.4.19 - Humidity ratio with and without the single core modes during cooling (left) and heating (right) period, Toronto .89

Figure 5.5.1 - Humidity of the house (Edmonton): HERV $c$ vs. HRV vs. ERV .........................................91

Figure 5.5.2 - Cooling consumption of the house at different sensible efficiencies (Toronto) .................92

Figure 5.5.3 - Heating consumption (left panel) and percent energy savings (right panel) of the house at different efficiencies (Toronto). .93

Figure 5.5.4 - Cooling consumption at different flow rate (Toronto)

Figure 5.5.5 - Cooling consumption and saved energy percentage: left top for $1 \mathrm{x}$, right top for $1.5 \mathrm{x}$, left bottom for 2.0x, and right bottom for $2.5 \mathrm{x}$

Figure 5.5.6 - Heating consumption and saved energy percentage: left top for $1 \mathrm{x}$, right top for $1.5 \mathrm{x}$, left bottom for 2.0x, and right bottom for $2.5 \mathrm{x}$ 96 Figure 5.5.7 - Humidity of the Archetype Sustainable House-A: left top for 1x, right top for 1.5x, left bottom for 2.0x, and right bottom for $2.5 \mathrm{x}$ .96

Figure 5.5.8 - Humidity of the Archetype Sustainable House-A: left top for $1 \mathrm{x}$, right top for $1.5 \mathrm{x}$, left bottom for 2.0x, and right bottom for $2.5 \mathrm{x}$ .97

Figure 5.5.9 - Cooling consumption and saved energy percentage: left top for $1 \mathrm{x}$, right top for $2.5 \mathrm{x}$..... 98 Figure 5.5.10 - Heating consumption and saved energy percentage: left top for $1 x$, right top for $2.5 x \ldots 98$ Figure 5.5.11 - Cumulative cooling consumption (left panel) and monthly potential of free-cooling (right panel) at different house setpoints (Toronto) 99

Figure 5.5.12 - Cumulative heating consumption at different house setpoints (Toronto).....................101 Figure 5.5 .13 - House humidity ratio, left panel for $19^{\circ} \mathrm{C}$ and $30 \% \mathrm{RH}$, and right panel for $23^{\circ} \mathrm{C}$ and $30 \%$

RH setpoints 102

Figure 6.2.1 - House-A heat recovery ventilator airflows (VanEE, 2011) ...........................................106

Figure 6.3.1 - House-B energy recovery ventilator airflows (VanEE, 2011) .......................................... 108

Figure 6.4.1 - Screenshot of live display for the ERV system within ASH-B .......................................110

Figure 6.4.2 - Off-line calibrated result based on Precision Micro-Calibration Bath temperature settings 112

Figure 6.4 .3 - Calibrated relative humidity for sensor at supply inlet duct ....................................... 114 
Figure 6.4.4 - Monitored volumetric airflow rate of ASH-B, supply air duct (left panel) and return air duct (right panel)

Figure 6.4.5 - Monitored volumetric airflow rate of ASH-A, supply air duct (left panel) and return air duct

(right panel). 116

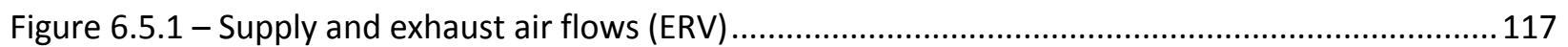

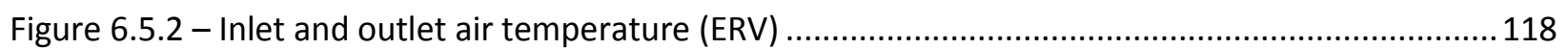

Figure 6.5 .3 - Inlet and outlet air humidity (ERV) ........................................................................... 118

Figure 6.5.4 - Monitored and manufacturer supplied sensible efficiencies at different inlet fresh air

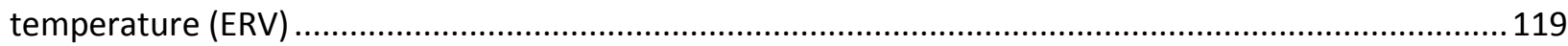

Figure 6.5.5 - Sensible efficiency vs. inside-outside temperature difference (ERV) ...............................119

Figure 6.5.6 - Latent efficiency at different inlet fresh air temperature (ERV) .................................... 120

Figure 6.5.7 - Latent efficiency vs. inside-outside humidity difference (ERV) ........................................ 121

Figure 6.5.8 - House-B energy recovery ventilator airflow during defrost cycle (VanEE, 2011).............. 122

Figure 6.5.9 - Air temperature and fan power draw during defrost cycle (ERV) ................................. 123

Figure 6.5.10 - Air humidity and fan power draw during defrost cycle (ERV) ....................................... 123

Figure 6.5.11 - Sensible and latent efficiencies during defrost cycle (ERV) ......................................... 124

Figure 6.5.12 - Experimental results showing the onset temperature of defrost cycle, Feb 26, 2014 (ERV)

126

Figure 6.5.13 - Patterns of outlet fresh air temperature before/during/after defrost cycle for $-20^{\circ} \mathrm{C} \mathrm{AT} f l$

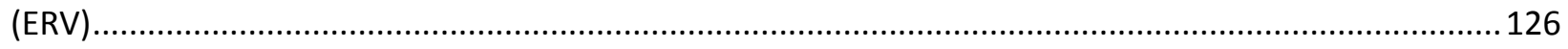

Figure 6.5.14 - Patterns of outlet fresh air temperature before/during/after defrost cycle..................127

Figure 6.5.15 - Sensible efficiency patterns for different $A T_{f i}(E R V): 1^{\text {st }}$ section ................................... 127

Figure 6.5.16 - Sensible efficiency patterns for different $A T_{f i}(E R V): 2^{\text {nd }}$ section ...................................128

Figure 6.5.17 - Outlet fresh and exhaust air humidity before/during/after defrost cycle (ERV).............129

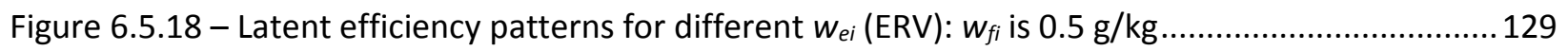

Figure 6.5 .19 - Latent efficiency patterns for different $w_{f i}(E R V): 1^{\text {st }}$ section ...................................... 130

Figure 6.5.20 - Latent efficiency patterns for different $w_{f i}(E R V): 2^{\text {nd }}$ section ...................................... 130

Figure 6.6.1 - Ice formation inside the sensible core of the HRV......................................................132

Figure 6.6.2 - Sensible efficiency and fan power draw during cold days without defrost cycle (HRV)....132

Figure 6.6.3 - Fresh and exhaust airflow rate during cold days without defrost cycle (HRV).................133

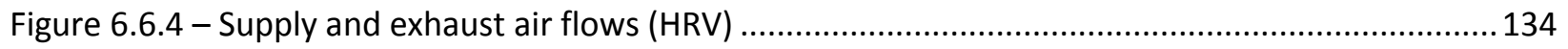

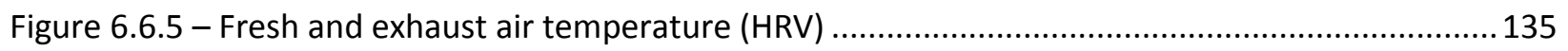

Figure 6.6.6 - Fresh and exhaust air humidity (HRV) ......................................................................... 135

Figure 6.6.7 - Experimental and manufacturer supplied sensible efficiency at different inlet fresh air

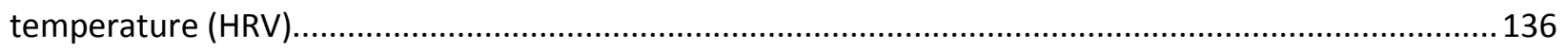

Figure 6.6.8 - Sensible efficiency vs. inside-outside temperature difference (HRV)............................. 136

Figure 6.6.9 - Latent efficiency vs. inside-outside temperature difference (HRV) ................................. 137

Figure 6.6.10 - House-A heat recovery ventilator airflow during defrost cycle (VanEE, 2011) ...............140

Figure 6.6.11 - Air temperature and fan power draw during defrost cycle (HRV) ...............................140

Figure 6.6.12 - Air humidity and fan power draw during defrost cycle (HRV) ....................................... 141

Figure 6.6.13 - Outlet fresh air temperature pattern at different stages (HRV) ................................... 142

Figure 6.6.14 - Outlet fresh air temperature pattern at different outside temperatures (HRV) ............ 143

Figure 6.6.15 - Sensible efficiency patterns for different $A T_{f i}(H R V): 1^{\text {st }}$ section ................................... 143

Figure 6.6.16 - Sensible efficiency patterns for different $A T_{f i}(H R V): 2^{\text {nd }}$ section ................................. 144 
Figure 6.6.17 - Latent efficiency patterns for different $w_{f i}(H R V): 1^{\text {st }}$ section....................................... 144

Figure 6.6.18 - Latent efficiency patterns for different $w_{f i}(H R V): 2^{\text {nd }}$ section ...................................... 145

Figure 6.7.1 - Hourly exhaust airflow rate without defrost control (ERV 86 cfm) .................................146

Figure 6.7.2 - Hourly sensible and latent efficiencies without defrost control (ERV $86 \mathrm{cfm}$ ) .................146

Figure 6.7.3 - Hourly exhaust airflow rate without defrost control (ERV $112 \mathrm{cfm}$ ) ...............................147

Figure 6.7.4 - Hourly sensible and latent efficiencies without defrost control (ERV $112 \mathrm{cfm})$...............147

Figure 6.7.5 - Hourly temperature and airflow rate without defrost control (HRV $147 \mathrm{cfm}$ ).................148

Figure 6.7.6 - Hourly sensible efficiency without defrost control (HRV $147 \mathrm{cfm}$ ) ................................149

Figure 7.2.1 - HRV efficiency validation: left panel for sensible efficiency, right panel for latent efficiency

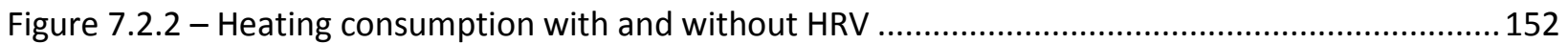

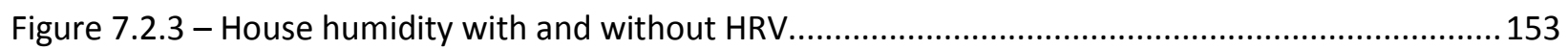

Figure 7.2.4 - Cumulative (left panel) and monthly (right panel) heating consumption based on constant

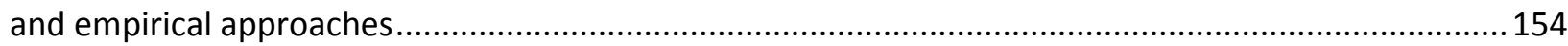

Figure 7.3.1 - ERV efficiency validation: left panel for sensible efficiency, right panel for latent efficiency

Figure 7.3.2 - Heating consumption with and without ERV ........................................................... 155

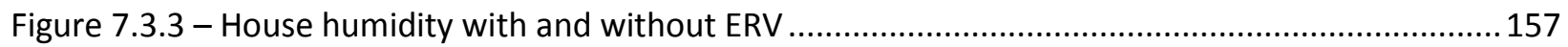

Figure 7.4.1 - House heating consumption: left panels - Edmonton, right panels - Montreal...............158

Figure 7.4.2 - House heating consumption in Vancouver: left panels - HRV, right panels - ERV ........... 160

Figure 7.5.1 - Simulation results: left panel - heating consumption, right panel - house humidity....... 161

Figure 7.5.2 - Side-by-side comparison between constant-efficiency-based and empirical-based model:

left panel - heating consumption, right panel - house humidity (Toronto) ........................................... 161

Figure 7.5.3 - Side-by-side comparison between constant-efficiency-based and empirical-based model:

left panel - heating consumption, right panel - house humidity (Montreal) ........................................ 162

Figure 7.5.4 - Side-by-side comparison between constant-efficiency-based and empirical-based model:

left panel - heating consumption, right panel - house humidity (Edmonton) ....................................... 162

Figure B.1 - Flow chart illustrating the input-output connections .....................................................177

Figure C.1 - Relative and standard uncertainties at different air temperatures .................................199

Figure C.2 - Linear relationship between sensor readings and reference values: left panel - HRV, right

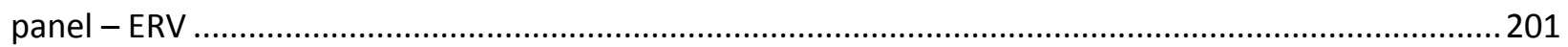

Figure C.3 - Estimated uncertainties due to calibration equation: left panel - HRV, right panel - ERV .201

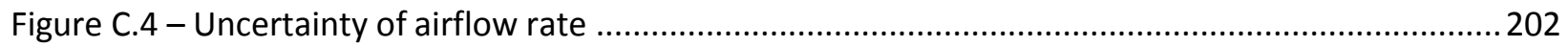

Figure D.1 - Equipment for Air temperature and humidity calibrations..............................................205

Figure D.2 - Preparation of salt solutions (McDuffee \& Shakya, 2010) ............................................... 206

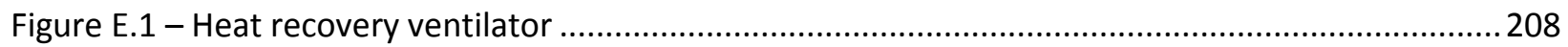

Figure E.2 - Air handling unit (left panel) and air-source heat pump (right panel) for the Archetype

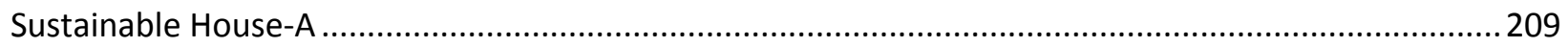

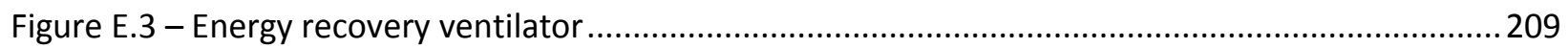

Figure E.4 - Air handling unit for the Archetype Sustainable House-B ...............................................210

Figure E.5 - Ground source heat pump for the Archetype Sustainable House-B.................................. 210 


\begin{tabular}{|c|c|}
\hline $\mathrm{A} / \mathrm{C}$ & Air Conditioning \\
\hline $\mathrm{ACH}$ & Air Change per Hour \\
\hline AFUE & Annual Fuel Utilization Efficiency \\
\hline AHU & Air Handling Unit \\
\hline ASHRAE & American Society of Heating, Refrigeration, and Air-Conditioning Engineers \\
\hline ASHP & Air-Source Heat Pump \\
\hline AT & Air Temperature \\
\hline BILD & Building Industry and Land Development \\
\hline BTU & British Thermal Unit \\
\hline $\mathrm{COP}$ & Coefficient of Performance \\
\hline DAQ & Data Acquisition System \\
\hline DB & Dry Bulb \\
\hline $\mathrm{ECM}$ & Electrically Commutated Motor \\
\hline ELT & Entering Load Temperature \\
\hline ERV & Energy Recovery Ventilator \\
\hline EST & Entering Source/Sink Temperature \\
\hline EWT & Entering Water Temperature \\
\hline GSHP & Ground-Source Heat Pump \\
\hline HRV & Heat Recovery Ventilator \\
\hline HVAC & Heating, Ventilation, and Air Conditioning \\
\hline $\mathrm{kW}$ & Kilowatt \\
\hline $\mathrm{kWh}$ & Kilowatt Hour \\
\hline
\end{tabular}


LEED Leadership in Energy and Environmental Design

NI National Instrument

NRCan Natural Resources Canada

$\mathrm{Pa} \quad$ Pascal (Pressure Unit $\mathrm{N} / \mathrm{m}^{2}$ )

RH Relative Humidity

RSI Relative Strength Index

SEER Seasonal Energy Efficiency Ratio

SQL $\quad$ Structured Query Language

TRCA Toronto and Region Conservation Authority

UA Transmission Heat Loss Coefficient of the Surface (W/K)

WB Wet Bulb 


\section{Nomenclature}

\begin{tabular}{|c|c|}
\hline $\mathrm{AT}_{o}$ & Outdoor Air Temperature $\left({ }^{\circ} \mathrm{C}\right)$ \\
\hline $\mathrm{AT}_{s}$ & Setpoint Air Temperature $\left({ }^{\circ} \mathrm{C}\right)$ \\
\hline $\mathrm{AT}_{f i}$ & Air temperature of fresh airstream entering heat exchanger $\left({ }^{\circ} \mathrm{C}\right)$ \\
\hline $\mathrm{AT}_{f o}$ & Air temperature of fresh airstream leaving heat exchanger $\left({ }^{\circ} \mathrm{C}\right)$ \\
\hline $\mathrm{AT}_{e i}$ & Air temperature of exhaust airstream entering heat exchanger $\left({ }^{\circ} \mathrm{C}\right)$ \\
\hline $\mathrm{AT}_{e o}$ & Air temperature of exhaust airstream leaving heat exchanger $\left({ }^{\circ} \mathrm{C}\right)$ \\
\hline$c$ & Relative concentration of insert gas in supply airflow \\
\hline $\mathrm{HERV}_{\mathrm{c}}$ & Heat and Energy Recovery Ventilator with a counter-flow arrangement \\
\hline $\mathrm{HERV}_{\mathrm{p}}$ & Heat and Energy Recovery Ventilator with a parallel-flow arrangement \\
\hline$q$ & Heat Transfer (kJ/hour) \\
\hline$q_{a}$ & Total Heat Transfer for a Particular Bin $(\mathrm{kJ})$ \\
\hline$N_{b i n}$ & Occurrence Frequency for a Particular Bin \\
\hline$\dot{\mathrm{Q}}$ & Volumetric Airflow Rate (cfm) \\
\hline$\dot{\mathrm{Q}}_{\text {inf }}$ & Infiltration Rate (cfm) \\
\hline$\dot{\mathrm{Q}}_{m e c h}$ & Mechanical Ventilation (cfm) \\
\hline$\dot{\mathrm{Q}}_{\text {req }}$ & Required House Ventilation (cfm) \\
\hline $\mathrm{RH}_{s}$ & Setpoint Relative Humidity (\%) \\
\hline$w_{o}$ & Outdoor Humidity Ratio ( $\mathrm{g} \mathrm{H}_{2} \mathrm{O} / \mathrm{g}$ dry air, if not specified) \\
\hline$w_{s}$ & Setpoint Humidity Ratio ( $\mathrm{g} \mathrm{H}_{2} \mathrm{O} / \mathrm{g}$ dry air, if not specified) \\
\hline$w_{f i}$ & Humidity ratio of fresh airstream entering heat exchanger $\left(\mathrm{g} \mathrm{H}_{2} \mathrm{O} / \mathrm{g}\right.$ dry air $)$ \\
\hline$w_{\text {fo }}$ & Humidity ratio of fresh airstream leaving heat exchanger $\left(\mathrm{g} \mathrm{H}_{2} \mathrm{O} / \mathrm{g}\right.$ dry air) \\
\hline
\end{tabular}




$\begin{array}{ll}w_{e i} & \text { Humidity ratio of exhaust airstream entering heat exchanger }\left(\mathrm{g} \mathrm{H}_{2} \mathrm{O} / \mathrm{g} \text { dry air }\right) \\ w_{e o} & \text { Humidity ratio of exhaust airstream leaving heat exchanger }\left(\mathrm{g} \mathrm{H}_{2} \mathrm{O} / \mathrm{g} \text { dry air }\right) \\ \text { VHR } & \text { Ventilation Heat Recovery }\end{array}$

Greek Letters:

$\begin{array}{ll}\varepsilon^{\prime} & \text { Weighted Annual Efficiency } \\ \varepsilon_{\mathrm{a}} & \text { Weighted Annual Thermal Efficiency } \\ \varepsilon_{e^{\prime}} & \text { Effective enthalpy efficiency } \\ \varepsilon_{L} & \text { Latent Efficiency } \\ \varepsilon_{s} & \text { Sensible Efficiency } \\ \eta_{L} & \text { Leakage ratio }\end{array}$

Symbols:

$\begin{array}{ll}\Delta \mathrm{AT} & \text { Air Temperature Difference }\left({ }^{\circ} \mathrm{C}\right) \\ \Delta w & \text { Humidity Ratio Difference }(\mathrm{kg} / \mathrm{kg})\end{array}$

Subscripts:

act Actual

avg Average

cond Conduction Heat Gain/Loss

$e i \quad$ Exhaust Inlet

em Exhaust Middle

eo $\quad$ Exhaust Outlet

fen Transparent Fenestration Surface 


$\begin{array}{ll}f i & \text { Fresh Inlet } \\ f m & \text { Fresh Middle } \\ f o & \text { Fresh Outlet } \\ \text { inf } & \text { Infiltration Heat Gain/Loss } \\ \text { int } & \text { Internal Heat Gain/Loss } \\ \text { max } & \text { Maximum } \\ n g & \text { Natural Gas } \\ \text { opq } & \text { Opaque Surface } \\ \text { ss } & \text { Sensible efficiency of sensible core } \\ \text { se } & \text { Sensible efficiency of enthalpy core } \\ \text { tot } & \text { Total Energy } \\ \text { ven } & \text { Ventilation Heat Gain/Loss }\end{array}$




\section{Chapter \#1 - Introduction and Objectives}

\section{Section 1.1 - Introduction}

Many of our homes, either conventional or energy-efficient type, may require year-round thermal control for the indoor spaces. In Canada, due to its cold climate, heating is almost always required in the winter to provide and maintain a comfortable living environment. As a result, space heating consumes approximately $62.6 \%$ of the total required energy in the residential sector (NRCan, 2013), as shown in Figure 1.1.1. Therefore, to improve overall energy use efficiency and to reduce energy consumption associated with the residential sector, houses are increasingly being built as airtight energy-efficient houses (e.g., R-2000) that minimize unnecessary heat loss. The airtight well-insulated envelope, however, leads to a dilemma for indoor air quality, which has caused a rise in demand for the increasingly popular residential heat and energy recovery ventilation systems. This mechanical equipment allows the potential of waste heat from exhaust air to be utilized before it is released to the local surroundings.

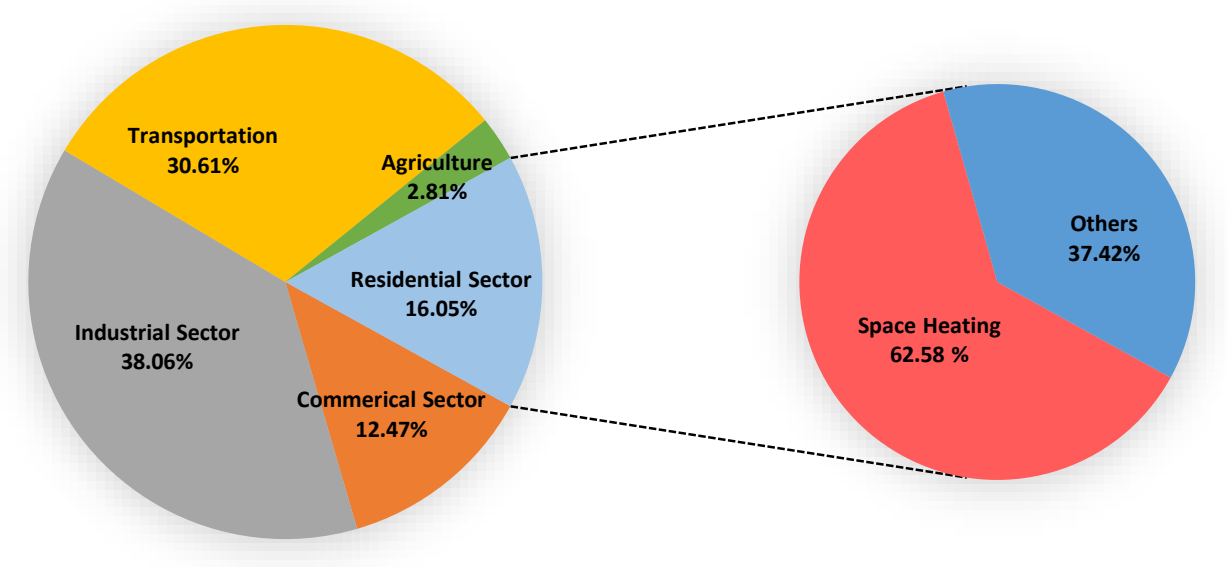

Figure 1.1.1 - Distribution of Canadian secondary energy consumption in 2010 (NRCan, 2013)

Mechanically vented supply air often requires air treatments (e.g., preheating) before it is delivered to the conditioned spaces. In contrast, the stale air being exhausted contains a considerable amount of energy, which can be reused. The heat recovery ventilators (HRVs) take advantage of the temperature difference between the two airflows to transfer sensible heat from one to another. This essentially preconditions the supply air to reduce dependency on the furnace and air conditioner, leading eventually to lower energy usage and a healthy home. The HRVs, however, do not provide assistance to the regulation of humidity of incoming air and produce significant amounts of 
condensation as a result of high sensible recovery efficiency. Therefore, the opinion of Home Ventilating Institute is to use HRV in homes where the primary concern is high humidity in winter. On the other hand, the energy recovery ventilators (ERVs) operate using the same general principle as the HRVs, but they take additional advantage of the humidity difference between the airflows to transfer both sensible and latent heat contained within the air (GreenAngel ENERGY, 2012). The excessive indoor moisture can potentially impact the health of the occupants (e.g., mold growth), and can deteriorate the structure of a building (Dieckmann, 2008). To prevent these issues, a dehumidifier is needed to reduce the level of humidity in the supply air. The ERV, in this case, alleviates the energy use for moisture control by using an enthalpy core made of water permeable membranes that allows for some of the excessive moisture to be removed. Therefore, many manufacturers recommend ERV for hot and humid regions (e.g., dPoint Technologies, Lifebreath, VanEE, Carrier, and Imperial). In cold winter, warm stale air is often cooled down to its dew point at which condensation is initiated, followed by ice build-up. The impacts associated with ice formation vary depending on the scale. In the extreme case, the sensible/enthalpy core could be permanently damaged from the expansion of ice (ASHRAE, 2008). Therefore, HRVs and ERVs used in North America are required to have a built-in defrost cycle to prevent core from freezing during cold days. The residential HRVs and ERVs all try to serve the same purpose, but one may be more efficient than the others depending on the core design and/or other factors (e.g., indoor factors or personal preference).

After extensive research on the current designs with regards to theory, usage, advantages and disadvantages, current existing HRVs and ERVs were found to have two potential performance deficiencies:

1. One of the deficiencies of current designs is the lack of ability to avoid redundant heat and/or moisture exchange. For instance, it was evidenced that the ERV provides better overall savings than the HRV in hot and humid days by transferring some of the water vapor in the incoming air to the exhaust air (Ouazia, Julien, Swinton \& Manning, 2006). However, this statement could be invalid if the humidity in the house is not already ideal due to the lack of a dehumidifier. In this case, the ERV could potentially do more harm than good, i.e., the dryer incoming air is humidified by the exhaust air. Therefore, this essentially reduces the flexibility and efficiency of the systems, and hence, needs to be resolved. 
2. It was found to be advantageous to bypass cool incoming air to benefit from free-cooling in summer whenever possible (Bulut \& Aktacir, 2011). This can be achieved through the use of an air-side economizer that controls a proper amount of air to be pulled into the conditioned spaces for direct free-cooling. These economizers, however, are usually disfavored in residential homes because of their large size and limited operating environment. This has sprouted the idea of combining the economizer control into the ventilation heat recovery. This pending design possesses the same capability of commercial economizers and residential HRVs/ERVs. Therefore, instead of having two independent systems that serve the same general purpose, the combined approach is versatile and potentially cuts total expense by reducing the need of additional infrastructure.

As a result, a versatile total energy recovery ventilator is desired, which takes into account the performance deficiencies of the current designs and the potential of free-cooling. The main purpose of the present study is to investigate the feasibility of a novel HVAC component: an innovative and versatile multiple-pass heat and energy recovery ventilation unit (namely HERV) with an integrated air-side economizer.

\section{Section 1.2 - Objectives}

The main objective of this study is to investigate the feasibility of an integrated heat and energy recovery ventilator with built-in economizer designed to be adoptable to various operating conditions. To achieve this goal, it is necessary to carry out a comprehensive study on every aspect of its thermal performance. In addition, this study also covers a preliminary investigation of the thermal performance of the HRV and ERV at the TRCA Archetype Sustainable Twins-House. The detailed objectives of this thesis are listed below:

1. Development of an Excel-based analysis tool (Ebat) for cost analysis.

The Excel based analysis tool aims at providing a preliminary cost analysis for the proposed HERV system. This program is able to import hourly weather data and is developed to provide a quick estimate on which system is most likely to be useful in a certain region without having an expert to develop and run a detailed simulation.

2. The annual performance of the HERV and a comparison between the novel and conventional systems using TRNSYS energy modeling.

A parallel-flow arrangement HERV model (see Figure 5.3.1) is first developed using the 
constant-efficiency minimum capacitance method, followed by a counter-flow arrangement HERV (see Figure 5.3.4) which is also built in a similar manner, but an iterative method is applied to estimate the unknown midpoint temperatures. The goal is to determine the feasibility of the HERVs by simulating the annual performance of each system in in different regions of North America.

3. Experimental studies of both the HRV and ERV at the research houses.

The first portion of the work is attributed to the collection of data from sensors installed on both equipment. The goal is to obtain 4-5 weeks of data in the heating season. The second portion is attributed to the analysis of performance of the systems using data collected. The aim here is to develop heating performance curves for both systems. Points of interest are the efficiency of the systems during normal operation and defrost cycle, as well as the impacts of core freezing.

4. The seasonal performance of the heat/energy recovery ventilator and a comparison of the two systems using TRNSYS energy modeling.

The existing HRV and ERV models in TRNSYS HVAC library will be modified using the performance curves obtained from the data collection. The objective is to simulate the seasonal performance of each system in different Canadian regions. Finally, the demand and impacts of defrost control will be investigated using the results of the simulation.

\section{Section 1.3 - Energy-Efficient Improvements in Canada}

In Canada, due to the increased emphasis on energy conservation, energy efficiency improvements (e.g., thermal insulation, heating equipment) have gained the priority for more efficient energy use in order to sustain the incoming high energy demand. Since 1990, the number of appliances used in residential houses has increased by $49 \%$ (NRCan, 2011); however, many statistics revealed that the total amount of energy a household consumed is actually decreasing. According to the Survey of Household Energy Use (NRCan, 2006 \& 2010), the average energy use intensity for single detached houses decreased from $1.00 \mathrm{GJ} / \mathrm{m}^{2}$ in 2003 to $0.93 \mathrm{GJ} / \mathrm{m}^{2}$ in 2007. Similarly, double/row houses decreased from 0.95 to $0.73 \mathrm{GJ} / \mathrm{m}^{2}$. In terms of heated area, the intensity for houses that have a heated area of $232 \mathrm{~m}^{2}$ or higher was found to be $26 \%$ lower. In addition, the imposed and voluntary restrictions on housing standards of practice (e.g., OBC) and energy-consuming items (e.g., Energy Star) have brought an average savings of $\$ 660$ per Canadian household in 2009 
(NRCan, 2011). In addition to the energy-efficient designs, the use of renewable energy sources is also widely recommended in order to attain self-satisfaction or so called Net-Zero Energy (NZE) state. An NZE home implies that the house is able to produce on-site as much energy as it consumes (CanmetENERGY, 2008). In May 2013, the Canadian government (ecoENERGY Innovation Initiative), in partnership with the building industry have funded $\$ 4$ million for NetZero Energy Housing projects that aim to demonstrate an affordable and marketable Net-Zero Energy use home (Ottawa Sun, 2013). The TRCA Archetype Sustainable House B is a nearly netzero energy home, for which $42 \%$ of the total energy consumption comes from utility suppliers while $58 \%$ of the needs can be furnished by the PV system and wind turbine (Dembo, Fung, $\mathrm{Ng}$, \& Pyrka, 2010). Many proposed sustainable solutions might not contribute significantly to the overall energy reduction, and perhaps the targeted conservation movements cannot begin soon due to the high expenses of the newly discovered alternatives (Bradshaw, 2006). In Canada, with the increasing energy demand, the price of currently used energy sources is also expected to increase (National Energy Board, 2013), leading the sustainable solutions to a more competitive state.

\section{Section 1.4 - Thermal Comfort and Design Principle for Ventilation}

The human body is constantly generating and giving off heat. The amounts that it generates or dissipates depend on many factors - from environmental factors such as air temperature, humidity and air movement to occupant-related factors such as activity and clothing level (Wujek \& Dagostino, 2009). The state of thermal comfort is said to be achieved when heat is dissipated from the body at a rate that maintains a thermal balance with the environment (Corky, 2003). However, a study from Karjalainen (2012) revealed that different genders can experience the indoor environmental conditions in a different manner. Pellerin and Candas (2003) pointed out that, females are more sensitive to thermal aspects (e.g., the skin temperature of females is usually lower than males in cold condition). The definition of thermal comfort is therefore a subjective matter, and the unique thermal preference makes the indoor climate control impossible to meet the wellbeing of every occupant. As a result, standards such as ASHRAE Standard 55 have decided to define a range of thermal comfort that will be acceptable to the majority (approximately 80\%) rather than every occupant in a conditioned space.

Occupants that live in a well-insulated space strongly rely on the HVAC systems to provide comfortable indoor environment. However, the total amount that they consume sometimes could 
change their roles from promising technology to merely high-cost and high-expense attached facilities. Therefore, it is necessary to understand what HVAC systems should be targeting, from both environment and energy points of view. The indoor environment and energy-performance design principles are indicators that allow the "quality" of HVAC systems to be evaluated from two different points of interest. Firstly, the indoor environment principle divides human healthiness into physiological and psychosocial, and one must be satisfied before addressing the next need, as shown in Figure 1.4.1 (left panel). Meanwhile, the physiological healthiness can be majorly fulfilled if both biochemical (indoor air quality) and thermal (air temperature etc.) comfort are met. On the other hand, the psychosocial part concerns the safety of the equipment. From the energy point of view, as illustrated in Figure 1.4.1 (right panel), minimizing the total energy demand is of the primary concern. This can be accomplished through the use of demand controlled ventilation strategy, with the assistance of heat recovery. In general, there is a trade-off between environment and energy that is needed occasionally in order to achieve certain indoor conditions. For example, a low polluted or a less humid space can be achieved from high ventilation rate, but the energy needed to condition the fresh air increases substantially. In practice, VanEE series HRVs/ERVs have a relative humidity setting that allows the system to maintain the house humidity by increasing the airflow whenever the humidity level is higher than setpoint. This essentially improves the comfort level of the house, but ends up with higher fresh air load and motor power draw. Finally, the hierarchy also suggests to use of renewable energy sources for reducing the dependency on fuels.

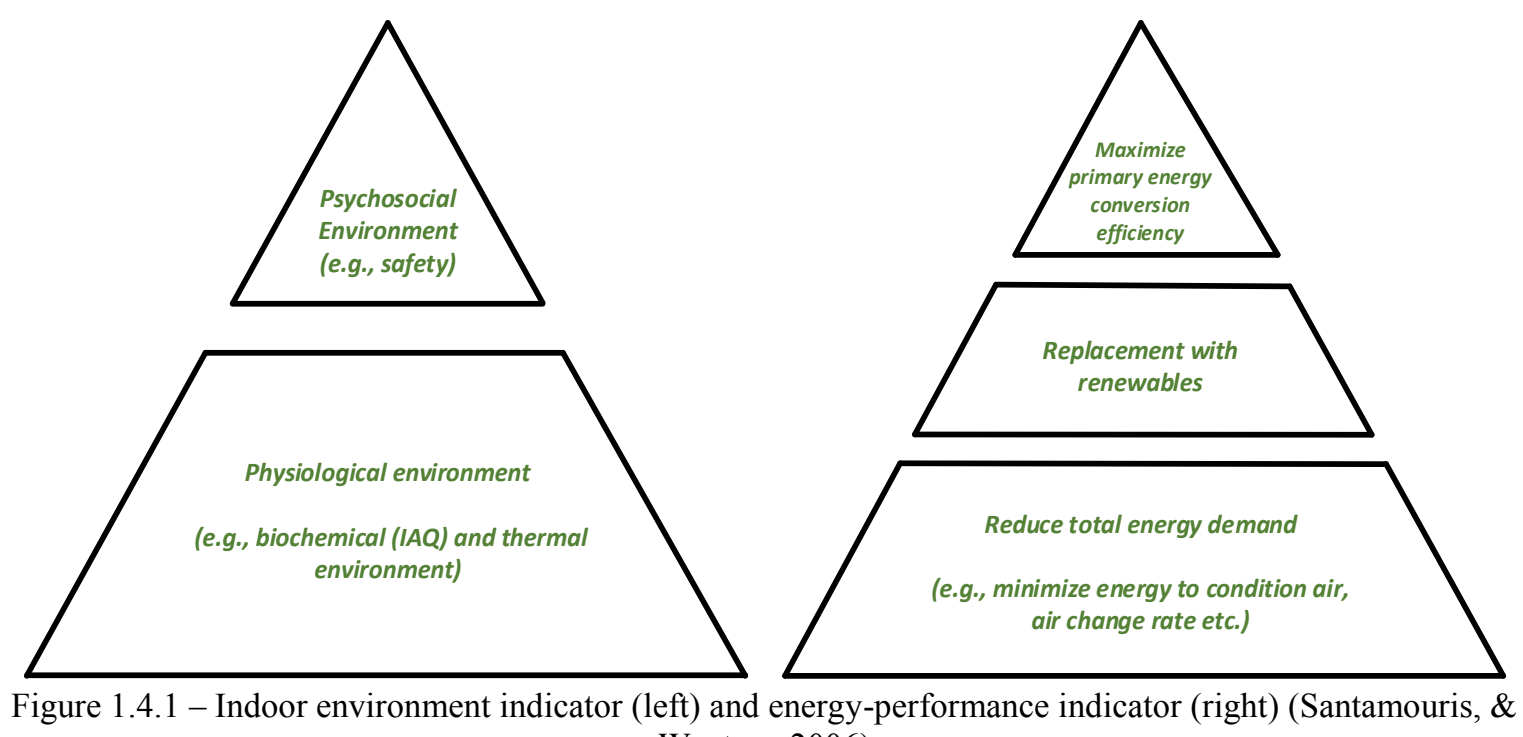

Wouters, 2006) 


\section{Section 1.5 - Heat and Energy Recovery Ventilation System}

There are two approaches for ventilation heat recovery: regenerative and recuperative. The regenerative approach refers to any design that transfers heat via heat-accumulating surfaces that are repeatedly exposed to either the warm or cold airflow (Santamouris \& Wouters, 2006). A wellknown regenerative heat recovery system is the rotary wheel, which is commonly used in commercial buildings because of its large size and additional power draw to rotate the mechanical wheel. The rotary wheel can be further divided into two types: Hygroscopic (enthalpy wheel) and non-hygroscopic rotor (heat wheel). The heat-accumulating surfaces of the enthalpy wheel are coated with sorbent to allow enthalpy transfer from one airstream to another. Both the heat and enthalpy wheel require periodic operation and maintenance to prevent fouling, and the undesirable leakage between the two airstreams (Santamouris \& Wouters, 2006). On the other hand, the recuperative approach commonly refers to the designs that separate the airflow using either water permeable or impermeable fixed plates, and heat/enthalpy is transferred by means of conduction. In addition, due to the accumulation of deposits on heat transfer surfaces, the fixed-plate type also requires periodic maintenance to keep up the maximum performance. The layer of deposits creates additional resistance to heat transfer, and it causes the rate of heat transfer and air flow to decrease (Cengel \& Ghajar, 2011).

According to the research conducted by Hill (1999), the HRV system used in Canada can be installed in four different ways, as illustrated in Figure 1.5.1. The fully ducted installation exhausts air from the highly contaminated spaces such as kitchen, while the outdoor fresh air is brought into living rooms directly. The extended installation also exhausts indoor stale air in a similar manner; however, the outdoor fresh air will be mixed with return air before distributing to the living areas. In addition, the simplified standard installation exhausts a portion of return air, while mixing the rest with the pre-conditioned fresh air from HRV. Finally, the simplified cross-furnace installation provides continuous mixing of the outdoor supply air with the return air, at the same time exhausting some of that mixed air from the supply air stream. The potential problem of extended and simplified installations is the imbalance between the supply and exhaust air flow if the heat recovery system is coupled with a variable speed air handling unit. 

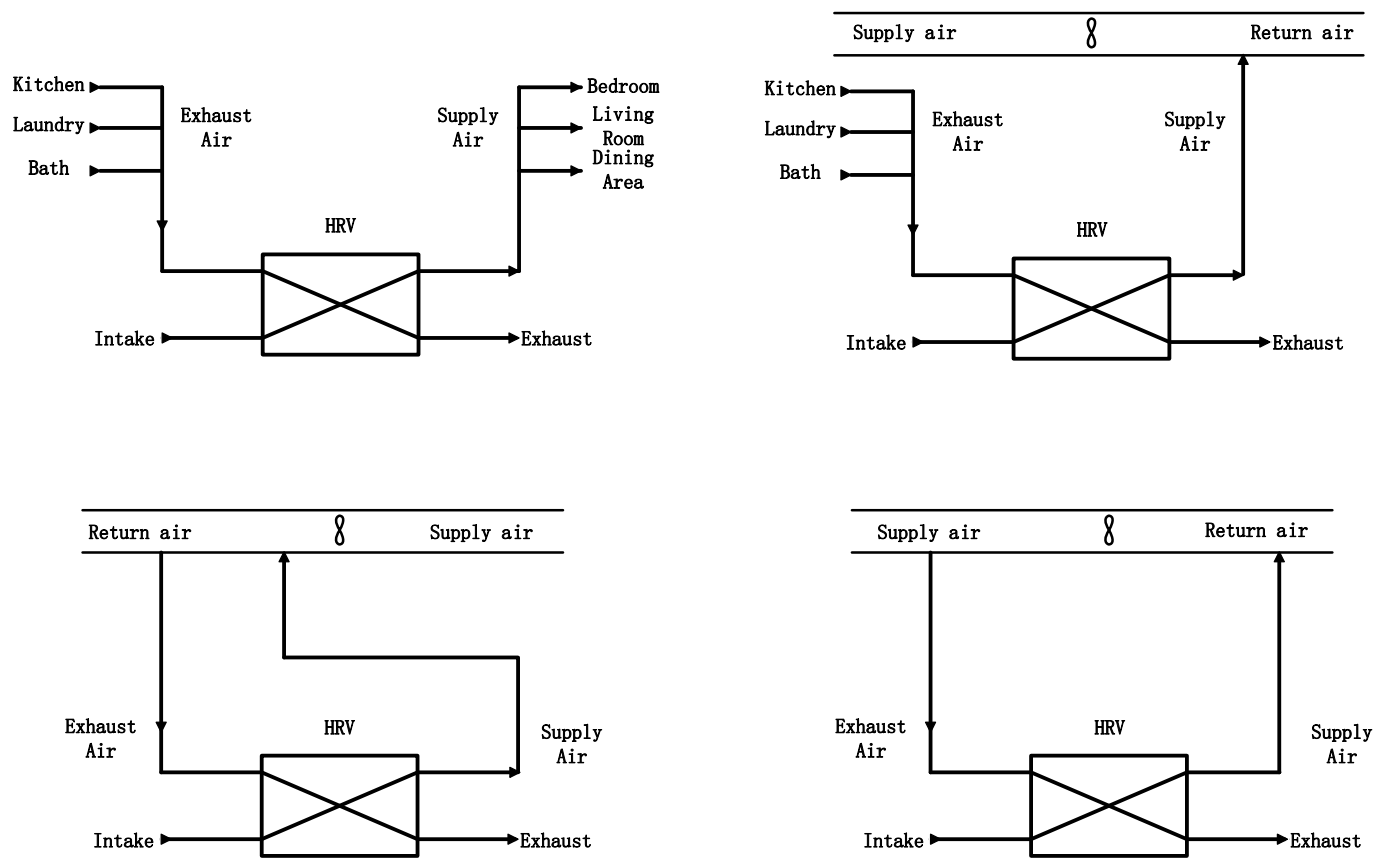

Figure 1.5.1 - Fully ducted (top left), extended (top right), simplified standard (bottom left) and simplified crossfurnace (bottom right) HRV installation (Hill, 1999)

\section{Section 1.6 - Defrost Control}

Ice and frost buildup inside the heat recovery system is inevitable for use in cold regions. This phenomenon is detrimental to the performance of the system, and the heat exchange core could be seriously damaged with time. Therefore, preventive action such as defrost control is introduced that aims to thaw the ice inside the channels of the core. As known, the heat recovery system takes advantage of the temperature gradient between the airflow. Therefore, if the warm stale air is cooled below its dew point, it contains more water vapour than it is able to hold. Thereafter, the excessive water vapour condenses to water droplets on the heat transfer surface, followed by freeze-up if the surfaces fall below freezing (ASHRAE, 2008). These evolving processes bring the impacts to the heat transfer process from initially beneficial to eventually detrimental. Condensation boosts the process of heat transfer, but the condensed water vapour on the heat transfer surfaces reduces the core channel space, leading to the increase of pressure drop (ASHRAE, 2008). On the other hand, ice buildup can impede or block the exhaust airflow, leading to pressurization of the indoor space (Jesper, Jørgen, \& Svend, 2005). Regarding this issue, Fisk et al. (1985) had pointed out that the drop rate of thermal efficiency for cross-flow and counterflow air-to-air heat exchanger is, on average, $7.35 \%$ and $1.3 \%$ per hour, respectively. 
There are many types of defrost mechanisms with sensors within the heat/energy recovery unit. They are available for preventing ice buildup on the heat transfer surfaces, yet none of them is optimal. Currently, the most common defrost methods used in fixed-plate heat recovery system are: preheating the supply air, increasing exhaust air flow rate, and warm air recirculation. Preheating the cold supply air above the threshold temperature is accomplished using a controlled auxiliary heat source (e.g., electrical heating or water heated coil). This approach consumes additional energy, which could be quite significant in arctic climates (Jesper, Jørgen, \& Svend, 2005). The second approach utilizes waste heat to warm up the heat transfer surfaces, as well as to melt ice formed inside the core channels. The drawback is the imbalanced ventilation, which depressurizes indoor space. Finally, the strategy of warm air recirculation is to recirculate the exhausted warm air, and the indoor space remains unventilated during defrosting operation. The warm air is blown into the heat recovery system to thaw the formed ice, and returns again to the conditioned space through a bypass damper. However, the recirculated air accompanies moisture from the melted ice, which might cause temporary high indoor humidity level. 


\section{Chapter \#2 - Literature Reviews}

\section{Section 2.1 - Heat Recovery and Energy Recovery Ventilators}

Heat recovery and energy recovery ventilators are mechanical equipment that utilize waste heat from stale air to achieve economic and control advantages. Many studies in the literature have investigated the performance and related subjects of heat recovery systems using various methods. In all cases seen in literature, the recovery system is mainly composed of the blowing fans, the core (either sensible or enthalpy core), and the filters. The performance of heat recovery systems can be given by the effectiveness (or sensible and latent efficiency), which is defined as the ratio of the actual amount of heat recovered from the stale air to the total amount of such heat in this air as it reaches the exchanger (Shurcliff, 1988). However, for the tested or studied systems, system efficiency is usually applied that takes into account all the external and internal heat gains and losses (Energy Star, 2011).

In many cases, the air-conditioning system is responsible to remove excessive moisture from the incoming fresh air in hot and humid regions (e.g., South China). As a result, it usually consumes a large amount of electricity. Zhang et al. (1999) from Tsinghua University, China conducted a significant pioneering study on the feasibility analysis of a cross-flow HRV system that employed porous hydrophilic membrane core, which allowed simultaneous heat and mass transfer between the airflow. The study began with the development of a mathematical model, followed by computer program that was written to compute finite-difference simulations of the model. The permeability and thermal diffusivity for the membrane are respectively $2.55 \times 10^{-5} \mathrm{~kg} / \mathrm{m}^{2} \mathrm{~s}$ and $3.44 \times 10^{-6} \mathrm{~m}^{2} / \mathrm{s}$, and the effective diffusivity of water in the membrane is $4.8 \times 10^{-10} \mathrm{~m}^{2} / \mathrm{s}$. Simulation results indicated that a counter-flow membrane based HRV is $7.5 \%$ more efficient than a cross-flow in terms of enthalpy effectiveness. In comparison to the paper core ERV, the membrane based held overwhelming superiority. In addition, a prototype was built around a Carrier sensible heat recovery ventilation system, and experiments were conducted at two different airflow rate: 0.01 $\mathrm{kg} / \mathrm{s}$ and $0.05 \mathrm{~kg} / \mathrm{s}$. For both cases, the calculated values well fit the measured results. This study also covered a brief information about an energy saving analysis for a commercial building in Beijing (humid continental climate) using the Designer's Simulation Toolkit (DeST). On an annual basis, the membrane HRV reduce $23.5 \%$ of the energy demand for the tested building, which is about $5.5 \%$ better than the sensible only HRV. 
Another similar study was conducted by Zhang et al. (2000) to investigate the characteristics of a HRV that used water permeable membrane. A general mathematical model was developed to analyze the performance, as well as the characteristics of the proposed system. Through the developed model, the criteria for selecting an ideal membrane can be established. The model showed that, higher $\mathrm{D}_{\mathrm{AB}}{ }^{1}$ and higher partition coefficient (hydrophilic material $-\mathrm{kg} \mathrm{H} \mathrm{H}_{2} \mathrm{O} / \mathrm{kg}$ membrane material) resulted in higher water vapor transfer flux through the membrane layer. In addition, the thinner the membrane layer, both heat and moisture transfer were found to be higher. In other word, if the membrane thickness approached zero, both sensible and latent heat transfer would approach their maxima. Thereafter, the resulted predicted from the model were validated experimentally using the results from United Technology Research Center, and good agreements were found. As an illustration, the computed results show that a membrane based HRV had a sensible and latent effectiveness of $72 \%$ and $58 \%$ respectively, where the outside air was $35.1^{\circ} \mathrm{C}$, $55 \% \mathrm{RH}$ and inside condition is $26.6^{\circ} \mathrm{C}, 15.8 \% \mathrm{RH}$. Under the same circumstance, the mathematical model predicted that the corresponding effectiveness are $71 \%$ and $60 \%$.

Dieckmann et al. (2003) conducted a background study that provided short description on the energy recovery technique. Energy recovery systems are often implemented with forced ventilation system, unitary air conditioners, and air-handling units. For an energy recovery system to operate effectively, the exhaust airflow rate must be equal to at least $75 \%$ of the supply airflow. In addition, to avoid unexpected heat transfer, the heat gains/losses in the exhaust ductwork must be small. For a fixed-plate energy recovery system, the pressure drop was usually ranging from 25 to 375 Pascal, which significantly increased the required ventilation fan energy.

Another study was done by (Min et al., 2010). A mathematical model was built to numerically investigate the effects of membrane space (channel height) and thickness on the thermal-hydraulic performance of a membrane based ERV. The outdoor air temperature and relative humidity were assumed to be $35^{\circ} \mathrm{C}$ and $63.8 \%$, while the indoor air temperature and relative humidity were $27^{\circ} \mathrm{C}$ and $47.3 \%$. For a fixed air velocity, as the channel height increased, the airflow rate also increased, leading to a higher heat transfer rate. However, this effect was opposed by the decreasing total heat transfer rate. Therefore, calculated results showed that the heat transfer rate increased initially as

\footnotetext{
${ }^{1} D_{A B}$ is the binary diffusion coefficient of water for the membrane material.
} 
the height increased, and it decreased when the effect of smaller total heat transfer surface area overcame the effect of higher airflow rate. The resulted also found that, as the channel height and/or the air velocity increased, both the latent-to-sensible heat ratio ${ }^{2}$ and the enthalpy effectiveness decreased. In addition, for a fixed channel height, as the membrane thickness increased, the same trends were observed because of higher thermal, moisture and airflow resistances.

Roulet et al. (2001) conducted a study to examine the global performance of heat recovery with air handling units (AHU). The authors made distinction between the nominal efficiency and the global efficiency of the heat recovery system. The nominal efficiency measured the thermal performance of heat recovery with balanced inlet and outlet airflow rate. Conversely, the global efficiency measured the thermal performance of whole system, consisting the ventilated space and the mechanical system. The numerical expression developed showed that the global efficiency of heat recovery could be significantly affected by the exfiltration of the ventilated space, and the internal leak from exhaust to supply ducts. Measurements were conducted in 10 large units and 3 wall-mount small units. Results showed that, in the worst case for system that had exfiltration ratio $\left(\gamma_{\text {exf }}\right)^{3}$ and leak ratio $\left(R_{x S}\right)^{4}$ of $91 \%$ and $6 \%$, the global efficiency was found to be $42 \%$ lower than its nominal value. Even in the best case $\left(\gamma_{\text {exf }}=14 \%, R_{x s}=2 \%\right)$, global efficiency is still $12 \%$ lower. On average, the global efficiency of the 13 units was only $43 \%$, while the nominal efficiency was $70 \%$. In addition, a so called specific net energy saving (SNES) was also introduced that measured the energy saving per cubic meter of supplied outdoor air averaged over a heating period. The computed SNES showed that the saving for the worst case above was negative, which meant that the heat recovery system consumed more energy than it saved.

Gieseler et al. (2002) used transient simulation TRNSYS to investigate the potentials of an air-toair heat recovery system (HRV), an earth heat exchanger (EHX) and a combined HRV/EHX system for a low energy sample house in Europe. The sample house had total volume of $619 \mathrm{~m}^{3}$, airflow rate of $255 \mathrm{~m}^{3} /$ hour, U-values of 0.12 and $0.8 \mathrm{~W} / \mathrm{m}^{2} \mathrm{~K}$ for opaque and transparent surfaces, respectively. TRNSYS simulations were carried out for four locations that had different heating

\footnotetext{
${ }^{2}$ Ratio of latent heat transfer to the sensible heat transfer

${ }^{3}$ A ratio of exfiltration rate to the airflow rate of the whole system

${ }^{4}$ A ratio of leak rate to the exhaust airflow rate
} 
degree days ${ }^{5}$ (December 17, 1998 to March 31, 1999) - Mannheim (2740 HDD), Trier (3254 HDD), Klagenfurt (4031 HDD) and Stockholm (4508 HDD). Results indicated that, for an earth heat exchanger consisted of $9 \times 10$ meter pipe used in both Klagenfurt and Stockholm, the primary energy savings were almost identical. This implies that the dependency of an earth heat exchanger on HDD is small. In contrast, the savings of air-to-air heat exchanger showed a strong dependency on the heating degree days. As an illustration, the primary energy saved by a $65 \%$ efficiency heat recovery system in Mannheim was $3586 \mathrm{kWh} /$ year, while the same system in Stockholm was found to save $5763 \mathrm{kWh}$ primary energy per year. Finally, the efficiency of an integrated HRV/EHX system was also studied. The integrated system aimed to lower the electric energy used for defrosting, and to improve overall thermal efficiency. Results indicated that, combining the two designs resulted in higher primary energy savings. For the same illustration, primary energy savings were $3852 \mathrm{kWh} /$ year and $6483 \mathrm{kWh} /$ year for Mannheim and Stockholm, respectively. However, in terms of cost efficiency ${ }^{6}$, the combined system experienced a loss of competiveness against the air-to-air heat exchanger in all the tested regions due to its high initial cost.

The thermal efficiencies of HRV and ERV were investigated experimentally by Ouazia et al. (2006) in summer. The two systems were installed separately in two nearly identical research twin houses located at the Canadian Center for Housing Technology (CCHT). The houses were two-story wood-frame house with $210 \mathrm{~m}^{2}$ of indoor area that met R-2000 standard. The rate of infiltration was $1.1 \mathrm{ACH}$ at 50 Pascal, thermostat setpoint temperature in summer was $24^{\circ} \mathrm{C}$, and the daily occupancy created moisture was estimated to be $1.81 \mathrm{~L} /$ day. The two units were operated identically over two weeks for two different airflow rates (65 and $115 \mathrm{cfm})$, and the A/C electricity consumptions were recorded and compared. During test period, the average outdoor air temperature was $22^{\circ} \mathrm{C}$ with an average relative humidity of $66 \%$. The observed indoor air temperatures were found to be closed in the two houses (around $23^{\circ} \mathrm{C}$ ), but the indoor relative humidity for the ERV-equipped home were slightly lower (average 4.27\%). In overall, the average $\mathrm{A} / \mathrm{C}$ electricity consumption ${ }^{7}$ for ERV-equipped home at $65 \mathrm{cfm}$ was about $7.97 \%$ lower than that of HRV, and the average cooling consumption ${ }^{8}$ was $5.45 \%$ lower. At $115 \mathrm{cfm}$ airflow rate, the

\footnotetext{
${ }^{5}$ Difference of $20^{\circ} \mathrm{C}$ and mean outdoor temperature $\left(<12^{\circ} \mathrm{C}\right)$

${ }^{6}$ Cost Efficiency $(\$ / k W h)=$ Total Investment Costs / Annual Saved Primary Energy

${ }^{7}$ Compressor and condensing fan only

${ }^{8}$ Energy consumed by A/C, furnace fan, and HRV or ERV
} 
average $\mathrm{A} / \mathrm{C}$ consumption difference was $12.4 \%$, while the cooling consumption was $8.02 \%$ lower than the HRV home. Finally, the measured trends indicated that the ERV system might have higher energy saving potential under more extreme summer conditions.

Marsik et al. (2008) used MATLAB Simulink to evaluate the air quality and energy consumption of a HRV-equipped house in Alaska. In general, outdoor air was assumed to be clean for ventilation strategies, but this was not always true especially for regions that had forest fires during summer months (e.g., Alaska) - carbon monoxide and particulate matter $\left(\mathrm{PM}_{2.5}\right)$ were the major concern in these regions. A dynamic model was developed to study the real-time energy consumption and indoor $\mathrm{PM}_{2.5}$ levels for three cases - building relied on natural ventilation, HRV, and HRV with additional MERV-13 filter. The model-predicted indoor $\mathrm{PM}_{2.5}$ concentration was verified by the actual measurements, resulting in a correlation coefficient of 0.95 . For a $540 \mathrm{~m}^{3}$ residential house in Fairbanks with 4 occupants, simulation results showed, relying on HRV resulted in an energy savings of 55\% (\$310) higher than the naturally ventilated home. In addition, HRV-equipped home had an average annual $\mathrm{PM}_{2.5}$ concentration of $12.3 \%$ lower. Considering the treatments of breathing $\mathrm{PM}_{2.5}$ for each person was $\$ 41.05 \mathrm{USD} / \mu \mathrm{gm}^{-3}$, the MERV-13 filter led to a saving associated with breathing $\mathrm{PM}_{2.5}$ of respectively $\$ 411$ and $\$ 690$ higher than the naturally ventilated home and HRV home with standard filter.

A study was conducted by Liu et al. (2010) to investigate the feasibility of ERV in China for five climatic regions based on the China Design Code - Extremely cold (e.g., Harbin), cold (e.g., Beijing), hot summer but cold winter (e.g., Shanghai), hot summer and warm winter (e.g., Guangzhou), and warm (e.g., Kunming). Two coefficients, weighted sensible coefficient and weighted latent coefficient, were numerically defined and used to quantitatively measure the impacts of sensible and latent heat recovery on the overall system performance. In summer ${ }^{9}$, the average weighted sensible and latent coefficients of the five climates were 0.358 and 0.642 . For regions that are hot in summer, the weighted latent coefficient was as high as 0.751 (Hong Kong). In contrast, for warm regions such as Kunming, the two coefficients were found to be closed. For winter ${ }^{10}$, the average weighted sensible and latent coefficients were determined to be 0.69 and 0.31 , respectively. In overall, results imply that the enthalpy exchanger is a feasible choice in China to

\footnotetext{
${ }^{9}$ Design indoor condition - temperature $25^{\circ} \mathrm{C}, 60 \% \mathrm{RH}$

${ }^{10}$ Design indoor condition - temperature $18^{\circ} \mathrm{C}, 50 \% \mathrm{RH}$
} 
meet the varying seasonal demands. This study also covered an energy analysis for ERV operating from October to March (8:00 - 18:00) using simulation program EnergyPlus. The study background was an apartment in Beijing that had $50 \mathrm{~m}^{2}$ livable area with $0.5 \mathrm{ACH}$. In addition, the design indoor air temperature and relative humidity were set to be $20 \pm 2^{\circ} \mathrm{C}$ and $60 \pm 10 \%$, respectively. As an illustration, for ERV with 35\% enthalpy efficiency, the energy consumption for December was found to be $9.4 \%$ lower. As the enthalpy efficiency increased to $75 \%$, the energy saving increased further by $6.8 \%$ (total $16.2 \%$ ). Therefore, highly efficient ERV system is energy efficient, but not economically efficient.

Dodoo et al. (2011) investigated the annual primary energy saving for ventilation heat recovery (VHR) in a 4-story wood frame building. The building consisted of 16 apartments and the total heated floor area was $1190 \mathrm{~m}^{2}$. This building was modelled to both conventional and passive house standard, and the simulation software ENORM was used to calculate the final energy use of these houses with and without VHR. The heat recovery efficiency was $85 \%$, supply airflow rate was $1540 \mathrm{~m}^{3} /$ hour and the climate data of Växjö was used. In terms of annual final energy use ${ }^{11}$, results showed that the VHR-equipped passive building consumed 55.32\% lower than the same building without VHR, which was more effective than the conventional building for only $21.62 \%$ reduction. In addition, the software ENSYST was used to quantify the annual operation primary energy needed to provide the final energy use in different buildings. In this study, four different end-use heating systems were considered - resistance heating, heat pump, and district heating with 50\% and $90 \% \mathrm{CHP}^{12}$. Results showed that the district heated (90\% CHP) buildings had the lowest primary energy use for space heating, while the building with resistance heating consumed the most. However, in terms of primary energy saving for VHR, the resistance heated passive building with VHR consumed 55\% less primary energy than the same building without VHR. Conversely, the saving for VHR in district heated (90\% CHP) passive building was only $16 \%$. Overall, the primary energy reduction was found to be dependent on the type of heating system, while VHR gave substantial final energy reduction.

Jose et al. (2011) experimentally studied the performance of a sensible polymer plate heat exchanger (PHE) for balance ventilation systems in residential building. The duct walls in the PHE

\footnotetext{
${ }^{11}$ Space heating and ventilation electricity only

12 Combined heat and power
} 
core was made of polystyrene, and the total heat transfer area was $19.4 \mathrm{~m}^{2}$. The experimental facility consisted of a cooling unit at the supply air circuit to reproduce the desired outdoor air temperature, while the humidity remained uncontrolled. In addition, electric heater and steam generator were implemented at the exhaust air circuit to reproduce the desired indoor air conditions. This study contained two sets of experiments, one for the evaluation of thermal performance of PHE, while the other was for an experimental parametric analysis. The first experiment was conducted by setting the fresh inlet air temperature at $5^{\circ} \mathrm{C}$, while the relative humidity was measured to be nearly constant at $95 \%$. Stale inlet temperature and relative humidity were controlled to be $25^{\circ} \mathrm{C}$ and $50 \%$, respectively. In addition, the airflow rate was $125 \mathrm{~m}^{3} / \mathrm{h}$, and the experiment lasted four hours. Results showed that the heat transfer rate and thermal efficiency were decreasing initially with time (efficiency decreased 5.5\%), but they became stable after 3 hours operation. Under steady operation, the thermal efficiency of the PHE was measured to be $80 \%$, and the heat transfer rate was $672 \mathrm{~W}$. In addition, the condensate flow rate drained from the PHE remained nearly constant between 0.31 and $0.38 \mathrm{~kg} / \mathrm{h}$. By increasing the supply air temperature with increment of $2.5^{\circ} \mathrm{C}$ (others remained constant), experimental results revealed that the heat transfer rate decreased linearly as the inlet air temperature increased. Also, the thermal efficiency was found to be initially constant, but gradually decreased after the supply air temperature exceeds $15^{\circ} \mathrm{C}$ because of no condensation. By varying the relative humidity of the exhaust air $(25 \%-70 \%)$, both heat transfer rate and efficiency increased between $50 \%$ and $70 \%$, while the condensate flow rate increased linearly with increasing humidity. Finally, varying the airflow rate from $50 \mathrm{~m}^{3} / \mathrm{h}$ to $175 \mathrm{~m}^{3} / \mathrm{h}$ caused the heat transfer rate to increase by $65 \%$, but the efficiency dropped from $94 \%$ to $78 \%$.

Another study was conducted by Juodis (2006) to investigate the impact of heat gains and losses on the efficiency of heat recovery system. In general, the performance and so the payback period of a heat recovery system vary depending on several factors: equipment properties, building envelop, and local climate. However, in a large well-insulated conditioned space ${ }^{13}$, the above two concerns are also sensible to the heat gains and losses posed by both interior and exterior elements. In Juodis study, two external air temperature values were introduced, which defined certain conditions at which the demand of heat recovery diminished - the decline start point temperature

\footnotetext{
${ }^{13}$ Ventilation heat loss is many times more than the transmission loss
} 
$\left(\theta_{\mathrm{A}}\right)$ and the thermal balance point temperature $\left(\theta_{\mathrm{B}}\right)$. The temperature $\theta_{\mathrm{A}}$ referred to a condition when the heat supplied for non-recovered ventilation air from a primary heat source was compensated by the heat gain of a premise. Therefore, any step further (higher outdoor temperature) implied that a portion of recovered heat were needless, and the efficiency of heat recovery diminished. Furthermore, $\theta_{\mathrm{B}}$ was the outdoor temperature at which the heat losses of a space were covered completely by the heat gain of a premise, and so the heat recovery became useless. As outdoor temperature increased further, overheating resulted and cooling might be required. The results predicted from a mathematical model indicated that, high heat gain/loss ratio would bring forward the onset of conditions $\theta_{\mathrm{A}}$ and $\theta_{\mathrm{B}}$, which meant that the larger amount of recovered heat would have been wasted.

A literature study was conducted by Händel (2011) to analyze the implication of ventilation heat recovery in nearly zero energy houses. Ventilation is often the major source of heat loss for low energy and passive houses. Therefore, heat recovery becomes the most effective and the only means of saving energy in ventilation system. In winter, heating requirement could be satisfied by many heating sources, among those, solar heat gains through windows and heat dissipated by occupants are considered to be $100 \%$ renewable sources. In addition, part of the power electricity from the grid, geothermal energy and biomass are also renewable. In other word, a portion of ventilation heat recovery come from these renewable sources.

\section{Section 2.2 - Free-Cooling}

Free-cooling is an economical method of using outdoor cool air to assist in or achieve direct house cooling. In Florida 1999, 384 surveyed single-family homes, apartments and condominiums claimed that, using direct cooling rather than air-conditioner in cooling season resulted in an average savings of $777 \mathrm{kWh}$ per month (Santamouris, \& Wouters, 2006). However, high dependency on the local climate also causes disfavor of this approach in some regions (e.g., very humid regions). In general, for regions that have high diurnal temperature variation, the night-time free cooling is usually recommended to reduce the cooling load of next day. Recently, the use of phase change materials for free-cooling is widely studied. This technique makes daytime freecooling possible by discharging coldness that has been stored in the system at night.

An early study was carried out by Blondeau et al. (1997) to investigate the potential of nigh-time ventilation in summer for improving indoor comfort. The case study building was a 3 level 
university building (University Institute of Technology) in La Rochelle, and the experimental zone was the second level, which composed of four rooms, namely zone A (volume $=170 \mathrm{~m}^{3}$ ), zone B $\left(160 \mathrm{~m}^{3}\right)$, zone $\mathrm{C}\left(205 \mathrm{~m}^{3}\right)$ and the unventilated reference zone $\left(205 \mathrm{~m}^{3}\right)$. Night-time ventilation began from 21:00 to $8: 00$ for 22 consecutive days and the airflow rate was $4500 \mathrm{~m}^{3} / \mathrm{h}$. Results showed that the diurnal indoor temperature for tested zones A and B (away from reference zone) remained $1.5^{\circ} \mathrm{C}$ to $2^{\circ} \mathrm{C}$ lower. In addition, due to the heat transmission through the partition walls, the indoor temperature of zone $\mathrm{C}$ (adjacent to reference zone) gradually increased and reached the temperature of reference zone. Results also confirmed that the cooling efficiency was better in small volume rooms. The author concluded that the small volume space had more evenly airflow distribution, leading to higher heat transfer coefficient and faster wall cooling during night-time ventilation. Finally, the energy analysis for the experimental results revealed that, for zone B, the daily energy removal from the building during the night varied from 7 to $55 \mathrm{kWh}$ depending on the indoor and outdoor temperature difference.

A study was conducted to examine the efficiency of night-time ventilation, when applied to the urban environment (Geros, Santamouris, Karatasou, Tsangrassoulis \& Papanikolaou, 2005). Air temperature, wind velocity and direction of 10 urban canyons located in the city of Athens were measured experimentally in summer. Resulted showed that, air temperatures inside the 10 canyons were higher than the ones outside the canyons in nighttime because the canyon geometries obstruct structural materials from cooling through long-wave radiation. In addition, the canyon geometries also reduce wind speed and modify wind direction. This study also simulated the cooling load and air change rate of a $144 \mathrm{~m}^{3}$ study room using the software TRNSYS and AIOLOS based on the measured climatic data. Results indicated that the cooling load inside the canyons was always higher and varied depending on the characteristics of the canyons. In the extreme case, the cooling load difference was $88.8 \%$ in Omirou. In addition, the study room inside the Omirou canyon was found to be $1.4^{\circ} \mathrm{C}$ hotter during the night when natural ventilation was applied. The authors concluded that the night-time ventilation technique is less efficient in urban canyons due to higher outdoor temperature and lower wind velocity. They also suggested that, an appropriate climatic data must be selected for the study of free-cooling in urban environment.

A study was done by Bulut et al. (2011) to quantitatively determine the potential of temperaturebase air-side economizer in Istanbul, Turkey. The study began with an analysis of Istanbul's long 
term climate data. The maximum and minimum temperature observed were $34.5^{\circ} \mathrm{C}$ and $-4.5^{\circ} \mathrm{C}$. Thereafter, bin method was employed to arrange the weather data in temperature bins of $3^{\circ} \mathrm{C}$ increments, and the monthly free-cooling hours were estimated based on the counted bin hours for outdoor temperature that fallen within the region of free-cooling. Statistical results showed that the potential of free-cooling was very high during the transition months (April, May and October), while remained relatively low in July and August unless at high supply air temperature $\left(\mathrm{T}_{\text {supply }}\right)$ setpoint (in this study $24^{\circ} \mathrm{C}$ ). For instance, the potential in July was only $1 \%$ at $\mathrm{T}_{\text {supply }}=15^{\circ} \mathrm{C}$ and increased to $46.6 \%$ (347 hours per month) at $\mathrm{T}_{\text {supply }}=24^{\circ} \mathrm{C}$. It is worthwhile that free cooling in July and August usually happened during nighttime period due to the cooler outdoor temperature. Finally, the use of air-side economize in Istanbul resulted in an annual cost saving of $\$ 342$ at $\mathrm{T}_{\text {supply }}$ $=24^{\circ} \mathrm{C}$, and reduced to $\$ 256$ per year at $\mathrm{T}_{\text {supply }}=15^{\circ} \mathrm{C}$. The author concluded that the HVAC systems which have a free cooling option is preferred for appropriate climates.

Another study was done by Shaviv et al. (2001) to investigate the impact of thermal mass and night-time ventilation on the maximum indoor temperature. A time-dependent model was developed for a typical Israeli apartment building, and simulations were conducted using the software ENERGY. The overall analysis was based on the simulation results of four levels of nighttime ventilation $(0,5,20$ and $30 \mathrm{ACH})$ and thermal mass (light, medium-light, semi-heavy and heavy-weight mass) in four cities in Israel that have different diurnal temperature variation in August (Geva Carmel $-9.5^{\circ} \mathrm{C}$, Nahariya $-8.8^{\circ} \mathrm{C}$, Gaza $-6.9^{\circ} \mathrm{C}$ and Tel Aviv $-7.9^{\circ} \mathrm{C}$ ). Results showed that the building temperature decreased as the level of night-time ventilation increased, but the rate of reduction began to diminish when the airflow rate exceeded $20 \mathrm{ACH}$. Therefore, powerful vent is not necessary for efficient free-cooling. Results also showed that the apartment building with light structure (no thermal mass) behaved like heat trap, while the semi-heavy (concrete floor, ceiling and external walls) building with night ventilation resulted in a maximum indoor temperature of $5^{\circ} \mathrm{C}$ lower than the light structure. Finally, by plotting the $\Delta \mathrm{T}_{\max }{ }^{14}$ against the diurnal temperature variation $\mathrm{T}_{\mathrm{swing}}$, a linear relation was found between the two. Therefore, the authors concluded that, night-time ventilation is an effective cooling strategy for well-insulated building and regions that have great diurnal temperature variation.

\footnotetext{
${ }^{14}$ Maximum temperature difference between indoor and outdoor
} 
A study was conducted by Yang et al. (2008) to quantitatively demonstrate the effective of thermal mass and night-time ventilation on cooling load. A mathematical model was built for a $4 \times 3 \times 2.7$ $\mathrm{m}^{3}$ small room that employed air conditioning at daytime and free-cooling at nighttime. The nighttime ventilation began from 18:00 to 8:00 at rate of $1 \mathrm{ACH}$, indoor setpoint temperature $\left(\mathrm{T}_{\text {set }}\right)$ was 297.15 K and daytime internal heat source was $240 \mathrm{~W}$. The time constant was introduced to determine the heat storage capacity of thermal mass and phase shift of the peak-cooling load. Based on the mean outdoor air temperature of $308.15 \mathrm{~K}$, calculated results showed that the combination of using thermal mass and night-time ventilation reduced cooling load significantly. When the time constant was higher than 400, results indicated that the daytime cooling load was reduced as much as $60 \%$. Thermal mass (concrete brick) began to release heat at around 16:00, and the indoor temperature began to increase once air conditioner was off at 18:00. By free cooling the small room, the indoor temperature declined from maximum (around $310 \mathrm{~K}$ ) at 19:00 to minimum (301 $\mathrm{K})$ at 3:00 in the following day. In addition, for small indoor and outdoor temperature difference, free cooling the space caused the indoor temperature to drop below the setpoint, and hence, heating was needed.

The predominant use of sandcrete blocks and extensive use of glazing in the warm-humid subSaharan countries has caused indoor air temperature, in general, to be higher than the outdoor environment. A study was conducted by Amos-Abanyie et al. (2013) to investigate the impacts of thermal mass, free-cooling and window-to-floor ratio (WFR) on the peak indoor air temperature (PIAT). Three control models were developed for a 2.4 (height) $\times 1.2$ (width) $\times 2.4$ (depth) $\mathrm{m}^{3}$ case study structure, one with each of the three different thermal masses: solid sandcrete block (SSB), baked brick $(\mathrm{BB})$ and concrete. Simulation was carried out for Kumasi during the warmest months (November to March inclusive) using the software EnergyPlus. Simulation results revealed that, increased thermal mass had positive impact on the PIAT. The PIAT for concrete structure (54\% WFR) was found to be $3.02^{\circ} \mathrm{C}$ and $2.37^{\circ} \mathrm{C}$ lower than the SSB and $\mathrm{BB}$ structures, respectively. When the window size decreased from $54 \%$ to $0 \%$, the PIAT for the same concrete structure dropped insignificantly (about $1^{\circ} \mathrm{C}$ ). The effect of night-time ventilation was assessed for various airflow rates considering 10, 20 and $30 \mathrm{ACH}$. In the first case, the PIAT and overheated hours for the concrete structure with $54 \%$ WFR was $3.191^{\circ} \mathrm{C}$ cooler and $38.7 \%$ shorter, respectively. As the airflow rate increased to $20 \mathrm{ACH}$, insignificant PIAT reduction resulted $\left(0.053^{\circ} \mathrm{C}\right.$ better $)$ and high 
power vent is therefore not needed for efficient free-cooling. In conclusion, night-time ventilation exhibited to be unnecessary in light thermal mass structure (SSB) especially for large WFR, because such structure behaved like a heat trap. Finally, the author concluded that the combined effects of thermal mass, window size, and free-cooling can synergistically improve indoor thermal comfort in warm-humid climates.

A study was conducted to demonstrate the advantage of using a "free-running" temperature instead of the balance temperature in the bin method for energy estimation (Ghiaus \& Allarda, 2006). The free-running temperature refers to the indoor temperature of a building at which no HVAC systems are used for heating and cooling purposes. In general, balance point temperature is used in bin method for energy estimation, the use of this setpoint implies that the indoor temperature is controlled at a constant value, as shown in the following control logic for cooling:

$$
\delta_{\text {cool }}= \begin{cases}1, & \text { if } T_{\text {outdoor }}>T_{\text {balance }} \\ 0, & \text { if } T_{\text {outdoor }} \leq T_{\text {balance }}\end{cases}
$$

In contrast, the proposed idea is to allow the indoor condition to be controlled based on the nonconstant free-running temperature $\left(\mathrm{T}_{f r}\right)$, and it also sprouts the control strategy for free-cooling.

$$
\begin{gathered}
\delta_{\text {cool }}= \begin{cases}1, & \text { if } T_{f r}>T_{\text {set }} \\
0, & \text { if } T_{f r} \leq T_{\text {set }}\end{cases} \\
\delta_{\text {free-cooling }}= \begin{cases}1, & \text { if } T_{\text {fr }}>T_{\text {set }} \text { and } T_{\text {outdoor }}<T_{\text {set }} \\
0, & \text { if not }\end{cases}
\end{gathered}
$$

The $\mathrm{T}_{\text {set }}$ in this case is the summer indoor setpoint temperature. Another advantage of this approach is that, the building aspect that influences the results of energy estimation is decoupled, because it is characterized by the temperature difference in free-running.

A case study was conducted by Inard et al. (2011) to evaluate the free-running temperature approach for free-cooling control. The study was based on 14 office rooms for an office building located at Freiburg, Germany. Observed data were gathered during the monitoring campaign in summer 2003 (June 1 to August 31). The results showed that roughly $60 \%$ of the outdoor air temperatures were below $25^{\circ} \mathrm{C}$, which implied that there was a potential for free-cooling. By 
plotting the observed outdoor temperature against the free-running temperature of the building, a linear relation was found. As an illustration:

$$
\left(T_{f r}\right)_{\text {room\# } 1}=a+b T_{\text {out }}=2.13^{\circ} \mathrm{C}+1.0085 T_{\text {out }}
$$

On the other hand, by replacing the balance temperature with the free-running temperature in the bin method, numerical model showed that the free-running temperature is linearly related to the outdoor air temperature and the thermal properties of the studied building $\left(Q_{\text {gain }} / K_{\text {tot }}\right)$ :

$$
T_{f r}=a+b T_{o u t}=\overline{\left(\frac{Q_{\text {galn }}}{K_{\text {tot }}}\right)}+T_{\text {out }}
$$

The heat gain $Q_{\text {gain }}(\mathrm{W})$ and $K_{\text {tot }}\left(\mathrm{W} /{ }^{\circ} \mathrm{C}\right)$ represent the heat gains from solar and internal sources and total cooling loss coefficient of the building, respectively. The numerical model assumes $b=$ 1 , which is actually not as shown in experimental relation for $b=1.0085$. Study also showed that the coefficient $b$ for the 14 office rooms varied from 1.0085 to 1.0293 , which meant the maximum error between the theoretical and experimental $b$ was only $2.93 \%$. The author concluded that freerunning temperature approach is reliable and applicable.

A study was conducted by Kang et al. (2003) to investigate the potential of an innovative phase change material passive cooling system (NVP) for daytime free-cooling. The NVP system is used to store cold during night-time ventilation, and it discharges to the space in daytime to achieve free-cooling. The NVP system was installed in a $29.7 \mathrm{~m}^{3}$ room with indoor heat source of 200-250 $\mathrm{W}$ and one window facing the west. The indoor temperature variations were observed and compared with three neighbor rooms - R1 (beside the test room) ${ }^{15}$, R2 (far away from the test room) $)^{16}$, and R3 (on top of the test room) ${ }^{17}$. For period from June 24 to July 4, collected results showed that the tested room had the shortest duration (11\%) for indoor temperature that exceed $30^{\circ} \mathrm{C}$, while others had 24\% (R1), 34\% (R2) and 55\% (R3). In addition, the tested room also had the longest duration $(62 \%)$ for indoor temperature that below $28^{\circ} \mathrm{C}$, while others had respectively $39 \%, 16 \%$ and $0 \%$.

\footnotetext{
$15101.25 \mathrm{~m}^{3}$ (usually no people) and 2 windows for west

${ }^{16} 101.25 \mathrm{~m}^{3}$ (0 2 people) and 1 window for south, 2 for east

$1729.7 \mathrm{~m}^{3}$ (0 2 people) and 1 window for north
} 
Another study was carried out by Mosaffa et al. (2013) to study the potential of a multiple PCM heat storage system using COMSOL Multiphysics. The storage system consisted of a number of rectangular channels for the air, separated by PCM slabs. The simulations were based on the climate of Tabriz, Iran that has daytime and night-time mean temperature of $36^{\circ} \mathrm{C}$ and $25^{\circ} \mathrm{C}$, respectively. Simulation results showed that, for system that used composited $\mathrm{PCM}\left(\mathrm{CaCl}_{2} \cdot 6 \mathrm{H}_{2} \mathrm{O}\right.$ + RT25), the outlet air temperature maintained below $27^{\circ} \mathrm{C}$ for about 8 hours. This was more efficient than the other combinations of $\mathrm{CaCl}_{2} \cdot 6 \mathrm{H}_{2} \mathrm{O}$, RT25 and Paraffin $\mathrm{C}_{18}$. Results also found that the outlet air temperature dropped as the length and the thickness of the PCM slabs increased because of higher heat capacity. However, the increased size of slabs led to higher pressure drop and duration of solidification process, resulting in higher fan electricity consumption. In addition, by increasing the air channel height from $2.4 \mathrm{~mm}$ to $3.2 \mathrm{~mm}$, fan electricity consumption was found to decrease by $8.94 \%$, and it increased thereafter. Therefore, the drawback of increased slab size could be compensated using a channel height of $3.2 \mathrm{~mm}$.

\section{Section 2.3 - Freeze-Up}

Ice build-up inside the air-to-air heat/energy recovery system is a common phenomenon in cold regions (e.g., North America). Early study revealed that the onset of freezing is when supply airflow temperature $-6^{\circ} \mathrm{C}$ for counter-flow heat exchanger, $-3^{\circ} \mathrm{C}$ to $-7^{\circ} \mathrm{C}$ for cross-flow heat exchanger and -8 to -12 for cross-flow energy exchanger (Fisk, Chant, Archer, Hekmat, Offermann, \& Pedersen, 1984). Thermal performance and the core of the system are found to be degraded with time, leading to additional costs in term of fan energy consumption and core replacement. This problem is crucial especially for highly efficient units. Currently, there are limited sources in regarding the study of defrost techniques that can be applied into the heat/energy recovery ventilators. This section provides few studies that relate to the freezing protection techniques.

A study was conducted to investigate the potential of residential air-to-air heat recovery system in terms of thermal performance and energy savings (Fisk, \& Turiel, 1983). In the study, the authors addressed various problems (e.g., unbalanced airflow and filters are clogged by dust/particulates) that could degrade the thermal performance of the unit. Among those, freezing inside the system is an important problem that significantly affect the heating load in winter. The tested cross-flow heat recovery model was assumed to have a freezing protection system (turn off supply fan) to 
defrost the unit at time fraction of $20 \%{ }^{18}$ when the onset of freezing was $-6.7^{\circ} \mathrm{C}$. A sensitivity study of defrost control was performed in Minneapolis to evaluate the economic impact of defrost control. Results showed that, by increasing $50 \%$ of the original defrost time, the net present benefit (NPB) was decreased by $\$ 104$ for house heated with natural gas, and vice versa. This was mainly due to the depressurization of indoor space as a result of stopping the supply airflow, causing additional air to leak into the space that contributed to the ventilation heating load. On the other hand, increasing the onset temperature from $-6.7^{\circ} \mathrm{C}$ to $0^{\circ} \mathrm{C}$ caused the NPB to decrease by $\$ 169$ for the same house.

An innovative study was done in regarding the use of PCM to prevent ice build-up inside the airto-air heat recovery ventilator (Qarnia, Lacroix, \& Mercadier, 2001). The pending idea was to place the PCM layer in between the cold and hot airflows to achieve defrost control, and an electric heating plate (converts electricity into heat) was located separating the PCM from the cold airflow. The idea was that, electric load was constantly applied electric heating plate during the heat storage period, and the PCM release heat during discharge period (onset of freezing) to precondition the cold airflow. A mathematical model was developed to examine the effect of electric loads and the thickness of PCM on the process of defrosting. The numerical results indicated that, for commonly used heat recovery unit, the PCM with thickness of $3 \mathrm{~mm}$ and electric load of $300 \mathrm{~W} / \mathrm{m}^{2}$ successfully prevented frosting. Moreover, the PCM was still valid when the thickness was set to $6 \mathrm{~mm}$ with no electric load. In this case, the thermal performance of the heat recovery system was worse due to the increased thermal resistance of the PCM wall.

The impacts of ice build-up and control strategies were studied experimentally by Jesper et al. (2005). Experiment was conducted in a typical Danish single-family house in winter with a heat recovery ventilation system that had built-in defrost control. The defrost strategy is to lower the supply airflow rate when the outlet exhaust air temperature drops below $3^{\circ} \mathrm{C}$, and the process continues until the temperature is above $5^{\circ} \mathrm{C}$. From the observed data, ice formation occurred when the outdoor temperature dropped below $-5^{\circ} \mathrm{C}$, outlet supply air dropped from initially $16^{\circ} \mathrm{C}$ to eventually as low as $5^{\circ} \mathrm{C}$ for 5 to 8 consecutive days, and the thermal efficiency dropped correspondingly from $80 \%$ to $30 \%$. Moreover, a laboratory test was also conducted to verify the

\footnotetext{
${ }^{18}$ Defrost hour divided by total hour when outdoor temperature is below the onset of freezing
} 
effect of condensation and ice on the airflow. The inlet fresh and exhaust air temperatures were set to be respectively $-5^{\circ} \mathrm{C}$ and $21^{\circ} \mathrm{C}$ with relative humidity of $42 \%$, and the defrost control was deactivated. Results showed that the exhaust airflow rate decreased 37.14\% (35 1/s to 22 1/s) in 14 hours. This implies that, when the above-mentioned defrost control is applied, the recovered heat would be significantly affected due to the lower airflow rates (obstructed exhaust airflow rate and controlled supply airflow rate). The author concluded that a better defrost control is needed for the system to be used efficiently in cold climates. This study also covered a brief description about other defrost strategies. For dual-core heat exchanger, the frozen core can be suspended for defrosting while the other maintains normal working.

\section{Section 2.4-Summary}

Strictly speaking, there was not literature directly related to the presented research topic. Instead, the reviews of literature focused on the topics related the free-cooling and the conventional heat recovery designs. These reviews provided substantial helped in identifying the disadvantages of the current designs of heat recovery ventilator, which was very useful in determining the need for the HERV and the considerations that must be taken into account in order to achieve better quality of ventilation heat recovery. The followings list the major contributors for the development of the concept design of the integrated HERV:

1. The study conducted by Ouazia et al. revealed that the ERV provides better overall energy savings than the HRV in hot and humid days due to the lower energy use for cooling and dehumidification. This study has inspired research idea such as questioning the viability of the above statement for other indoor and outdoor scenarios, e.g., house without either or both temperature or/and humidity controls. It provided an opportunity to address the scenarios at which the conventional systems could be infeasible.

2. Juodis (2006) found that the ventilation heat recovery becomes useless when the heat gains are enough to compensate all the losses and demands. This statement has inspired the author to develop more comprehensive control logics for the HERV that take into account the house indoor conditions in order to avoid redundant works.

3. Bulut and Aktacir (2011) showed that there is high potential of free-cooling for temperate climate. In Canada, regions such as Vancouver and Edmonton all experience warm summer months, and hence, free-cooling could be a feasible and beneficial option of cooling. In Toronto, outdoor temperature is usually cool at nighttime period. Therefore, it is beneficial 
to bring in colder outdoor air for a refreshing start to the next day.

4. Jesper et al. (2005) conducted an experimental study on the impacts of core freezing. It has brought author's attention to the design of a more efficient, and yet frost resisted HERV unit that can provide more efficient heat recovery and mechanical ventilation in cold winter months. 


\section{Chapter \#3 - HERV Conceptual Design and Research Context}

\section{Section 3.1 - The Concepts of Integrated Heat and Energy Recovery Ventilator (HERV)}

A HERV prototype was built with an undergraduate capstone design team (JAVK) in winter 2013 (Malesevic, Olt, Tanielian \& Crosbie, 2013). A simple 2-D schematic of the prototype is presented in Figure 3.1.1. To achieve demand-controlled ventilation, the HERV was designed to be able to operate in four different operating modes that take advantage of outside air differently - sensible, latent, dual-core, and bypass modes. As a result, the final design was more complex as many dampers were required in order to regulate and guide the flow of air through the desired path. Demand-controlled ventilation allows the proposed system to avoid redundant heat and moisture exchange that otherwise has to be processed in the air handling unit. First of all, the single-core sensible mode was designed for the conditions at which the sensible heat recovery is strongly required, while the latent mode is for conditions with high demand on latent heat recovery. The dual-core mode was designed to provide simultaneously maximum sensible and latent heat exchange. Finally, for particular external ambient conditions where direct cooling can be applied, the bypass mode is used. This approach prevents redundant heat recovery in cooling period, or sometimes in heating period when indoor enthalpy is higher than the indoor setpoint due to high heat gains/losses ratio.

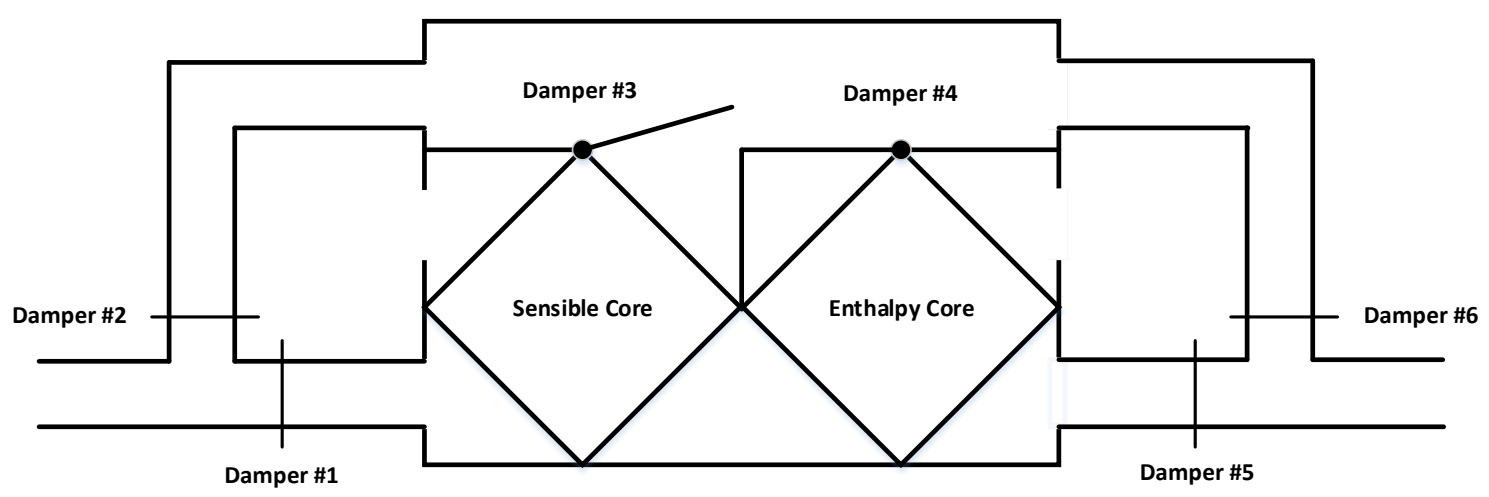

Figure 3.1.1 - Final design of the integrated unit in 2D

\subsection{1 - Single Core and Dual-Core Operations}

When the HERV is running single-core sensible mode (see Figure 3.1.2 for the flow paths), both damper \#1 and \#3 (see Figure 3.1.1 for damper\#) are open to direct fresh outdoor air into the sensible core to achieve sensible heat recovery. In the meantime, damper \#4 remains shut to disable the enthalpy core, and the conditioned air is directed to the supply chain through damper \#6. On 
the other hand, the exhaust airstream, after the completion of heat transfer, expels to the outdoor through the enthalpy core. Figure 3.1.3 illustrates the flow paths for single-core latent mode. Unlike the other, the fresh airstream needs to pass through damper \#2 and \#4 before it can actually reach the core. Lastly, the dual-core mode is simply the combination of the two single-core modes designed for conditions when both the sensible and latent heat recovery are required, as shown in Figure 3.1.4. For efficient heat recovery and mechanical ventilation, the HERV is needed to be frost tolerant in cold winter months. To achieve this goal, the enthalpy core was decided to be placed ahead of the sensible core to allow water vapor from the exhaust airstream to be transferred before passing into the sensible core. In other words, the dryer exhaust airstream reduces the chance of condensation or the amount of condensate, thus causing freezing to start slower than the conventional HRV.

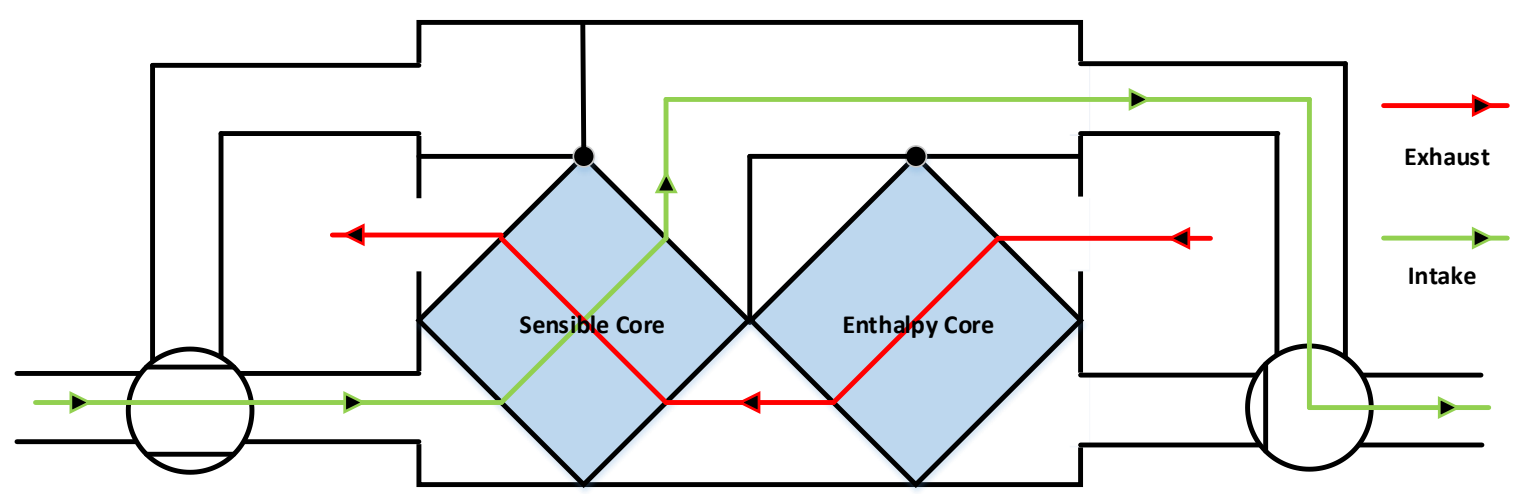

Figure 3.1.2 - Airflow for the sensible mode (counter-flow arrangement)

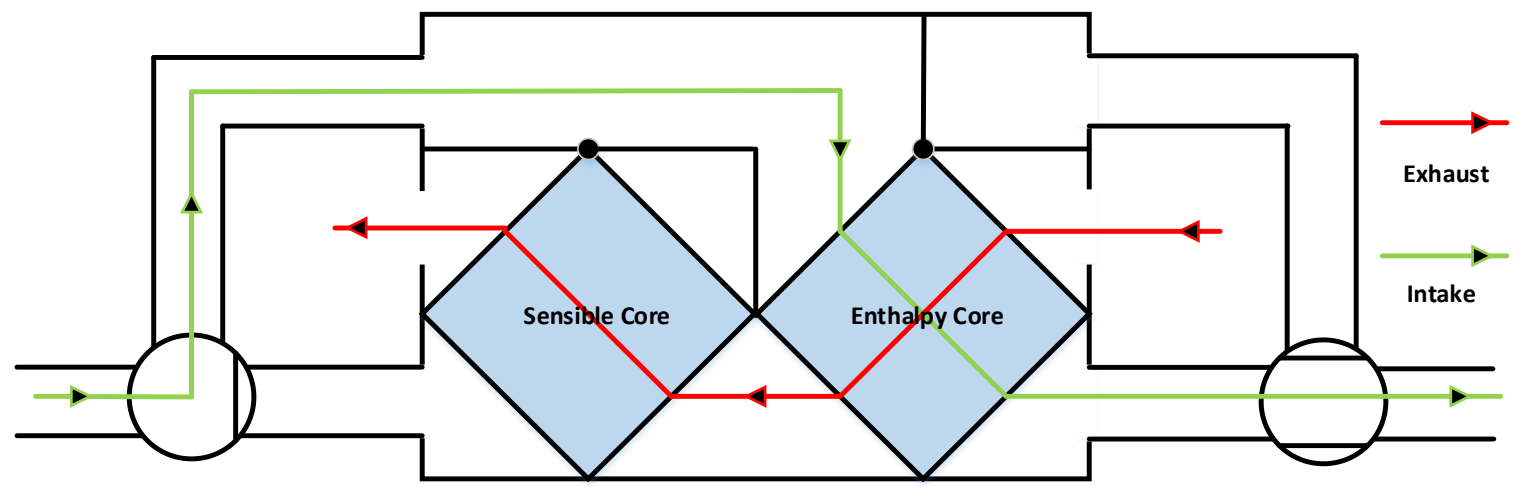

Figure 3.1.3 - Airflow for the latent mode (counter-flow arrangement) 


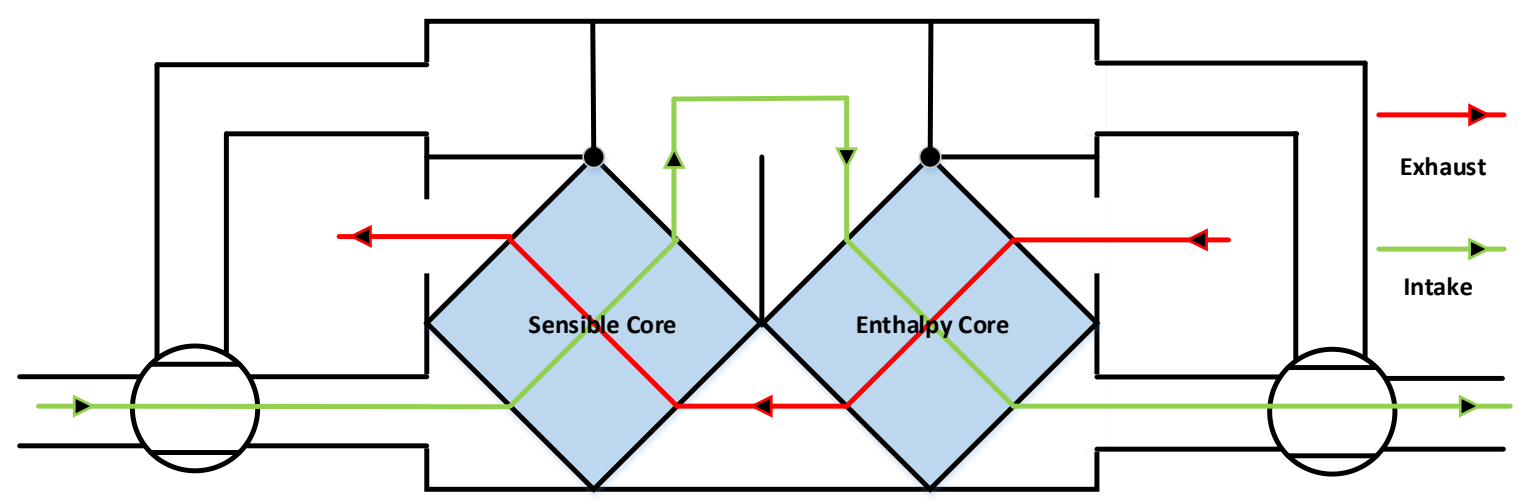

Figure 3.1.4 - Airflow for the dual-core mode (counter-flow arrangement)

\subsection{3 - Bypass Mode}

The purpose of air-side economizer makes it best suited in regions that have large diurnal temperature difference. The built-in bypass mode functions similar to commercial economizer, without paying a large amount of additional cost for a new individual system. The damper states in this case are opposite to the dual-core mode, such that most the dampers remain shut except the damper \#2 and \#6 which are used to direct the supply air completely around the two cores, and hence, no heat transfer takes place under this operation.

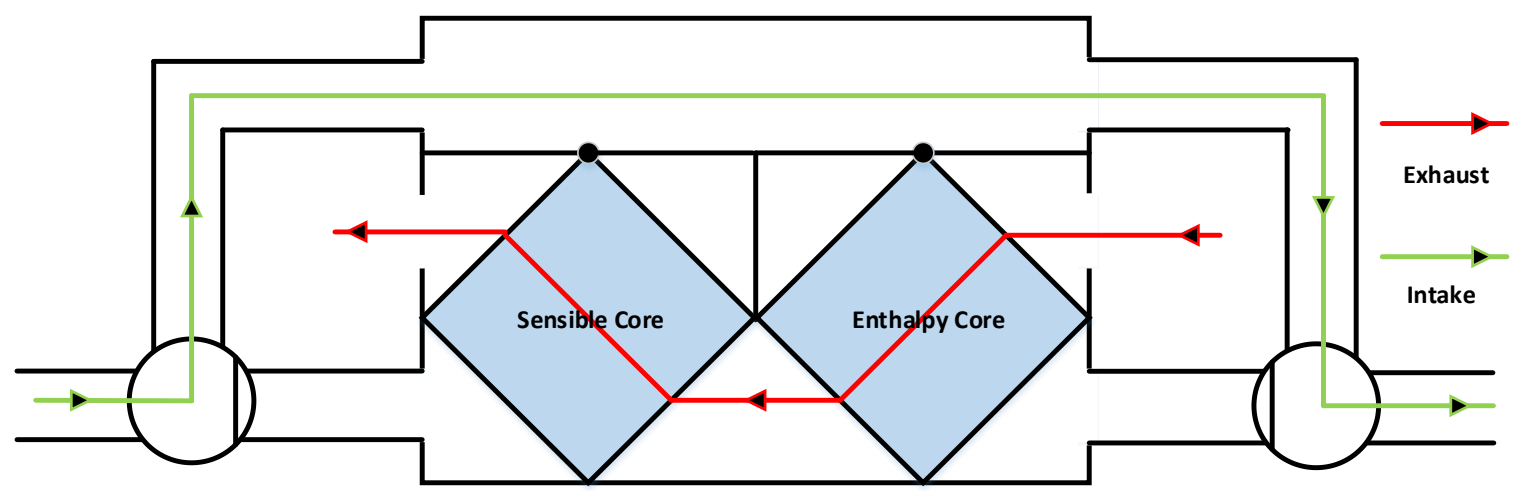

Figure 3.1.5 - Airflow for the bypass mode

\section{Section 3.2 - TRCA Archetype Sustainable House}

\subsection{1 - House Description}

The Archetype Sustainable House is a semi-detached twin-house located at Vaughan, Ontario. The twin houses, named "House-A" and "House-B", were developed by Toronto and Region Conservation Authority (TRCA) in partnership with the Building Industry and Land Development Association (BILD). Two different sets of HVAC systems were installed in each of these twin houses: current practice and technologies in House-A, and sustainable and innovative technologies 
for future practice in House-B (Barua, 2010). Amongst a variety of sustainable technologies within the twin houses, two pieces of equipment are studied in this thesis: heat recovery ventilator in House A, and an energy recovery ventilator in House B. A long term monitoring system has been implemented to monitor both the equipment using a data acquisition (DAQ) system, and analyzed using LabVIEW platform. Data from various sensors installed in the system are collected every 5 seconds. (Zhang, Barua, \& Fung, 2011). In addition, the structural features of House-B will be used as the inputs to the Excel-based analysis tool for the cost benefit analysis, while the HERV TRNSYS models will be simulated along with the House-A model developed by Safa (2012). Figure 3.2.1 shows the northwest side view of the Archetype sustainable House with House-A on the right-hand side and House-B on the left-extreme side. In addition, House-A is equipped with a two-stage variable capacity air-to-air heat pump for space heating and cooling, while House-B is equipped with a horizontal-loop coupled ground source heat pump. Both twin houses have been LEED Platinum certified, and were specially designed and built with advanced materials to minimize heat loss and environmental impacts during operation. Currently, the houses are used to demonstrate an affordable, low-energy house that can be mass-produced with a small ecological footprint (Dembo, Fung, Ng \& Pyrka, 2010).

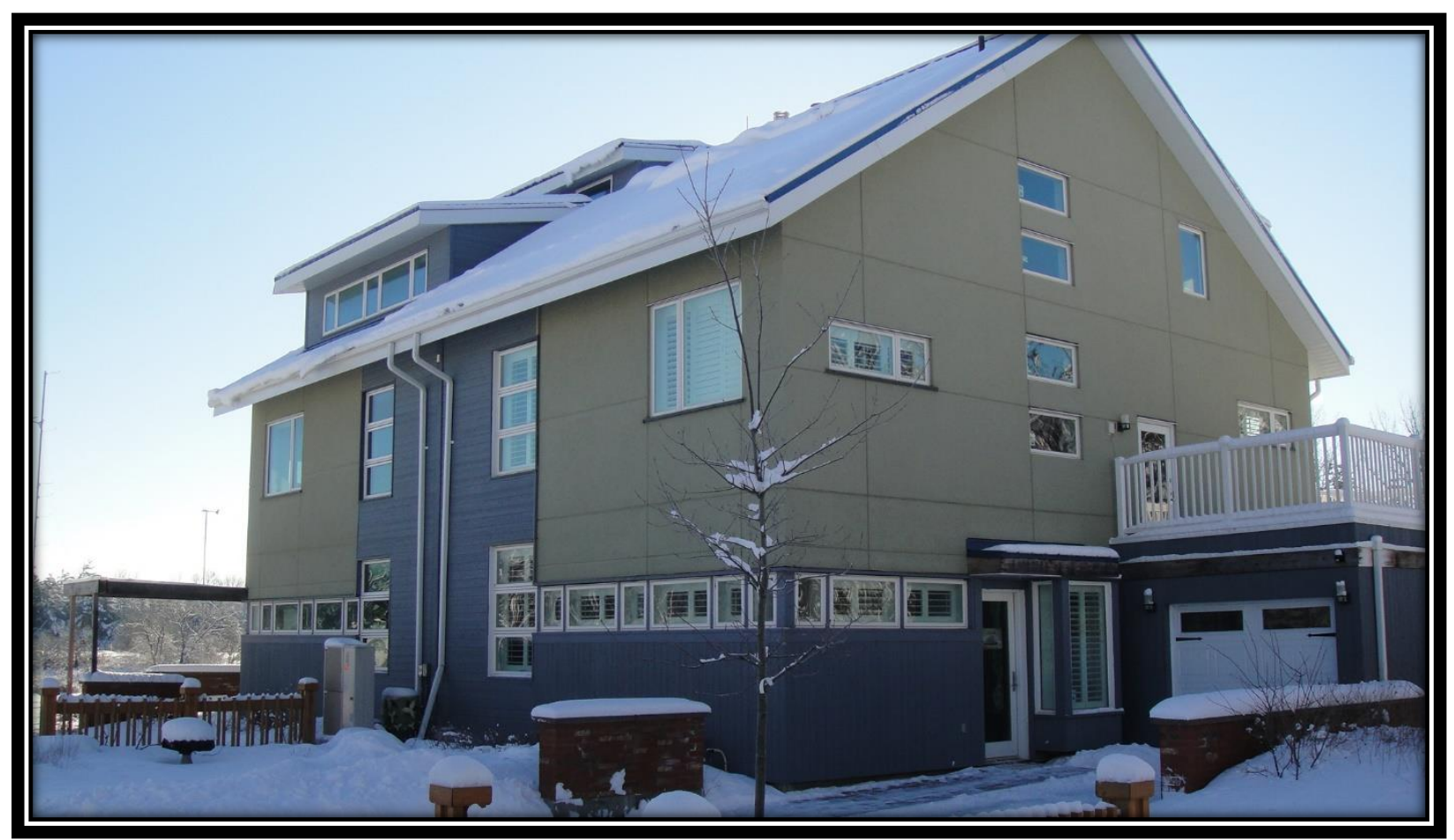

Figure 3.2.1 - Toronto Regional Conservation Authority's (TRCA) Archetype Sustainable House 
Although the two houses are equipped with two different sets of HVAC systems, but they appear to be similar in terms of level of thermal resistance. Table 3.2.1 lists the structural features of the twin houses. The major difference between the twin houses is the window type where House-B has triple glazed windows with aluminum-clad wood frames, while House-A has double glazed windows with fiberglass frames. According to depressurization test, the airtightness of House-A and House-B are respectively $1.317 \mathrm{ACH}_{50}$ and 1.214 $\mathrm{ACH}_{50}$ (Dembo, Fung, Ng \& Pyrka, 2010). Accordingly, Chen et al. (Chen, Mistry, Popal \& Saiyed, 2012) estimated the required mechanical ventilation of House-A and House-B to be approximately $113 \mathrm{cfm}(53 \mathrm{~L} / \mathrm{s})$ and $117 \mathrm{cfm}(55 \mathrm{~L} / \mathrm{s})$, respectively.

Table 3.2.1 - Structural features of the TRCA Archetype Sustainable Twin Houses (Barua, 2010; Safa, 2012)

\begin{tabular}{|c|c|c|}
\hline Features & House-A & House-B \\
\hline Story & 3 and 1 basement & 3 and 1 basement \\
\hline Floor Area & $344.45 \mathrm{~m}^{2}\left(3708 \mathrm{ft}^{2}\right)$ & $321.04 \mathrm{~m}^{2}\left(3444 \mathrm{ft}^{2}\right)$ \\
\hline Volume & $932.57 \mathrm{~m}^{3}\left(34824 \mathrm{ft}^{3}\right)$ & $1035.94 \mathrm{~m}^{3}\left(36584 \mathrm{ft}^{3}\right)$ \\
\hline Above Grade Walls & RSI 5.64 (R32) & RSI 5.64 (R32) \\
\hline Basement Walls & RSI 3.54 (R20) & RSI 3.54 (R20) \\
\hline Basement Slab & RSI 1.76 (R10) & RSI 1.76 (R10) \\
\hline Roof & RSI 7 (R40) & RSI 7 (R40) \\
\hline Windows & 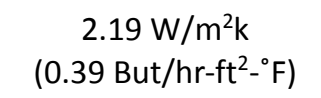 & 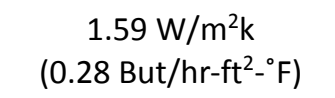 \\
\hline Overall UA Value & $160 \mathrm{~W} / \mathrm{K}$ & $172 \mathrm{~W} / \mathrm{K}$ \\
\hline
\end{tabular}

*Heating at $-7^{\circ} \mathrm{C}$ outdoor and $21^{\circ} \mathrm{C}$ indoor air based on TRNSYS House model

\subsection{2 - Mechanical Systems}

Heat recovery ventilators have been commonly used in air-tight energy-efficient houses for the recovery of sensible heat from the exhaust air into incoming supply to reduce the energy demand for conditioning of the outdoor air. Therefore, House-A is equipped with a highly efficient HRV for ventilation, and a two-stage variable capacity air-to-air heat pump with a direct expansion coil AHU for delivery of conditioned air (Safa, 2012). In contrast, House-B is equipped with an ERV to provide better overall performance with both sensible and latent heat recovery, and a horizontalloop coupled ground source heat pump for space heating and cooling. Table 3.2.2 and 3.2.3 list the technical information on the heat recovery system, heat pump system and air handing unit for House-A and House-B, respectively. 
Table 3.2.2 - Detail specifications of HVAC equipment in TRCA Archetype Sustainable House-A (Barua, 2010; VanEE, 2011; Safa, 2012)

\begin{tabular}{|c|c|}
\hline Equipment & Technical Information \\
\hline $\begin{array}{l}\text { Air Source Heat Pump (ASHP) } \\
\text { Mitshubishi Electric: PUZ-HA36NHA }\end{array}$ & $\begin{array}{l}\text { Cooling capacity: } 3.52 \mathrm{COP}, 9.82 \mathrm{~kW} \text { at } 26.7^{\circ} \mathrm{C} \mathrm{DB} \text { and } \\
19.4^{\circ} \mathrm{C} \text { WB indoor, and } 35^{\circ} \mathrm{C} \mathrm{DB} \text { and } 23.9^{\circ} \mathrm{C} \text { WB } \\
\text { outdoor } \\
\text { Heating capacity: } 3.27 \mathrm{COP}, 11.06 \mathrm{~kW} \text { at } 21.1^{\circ} \mathrm{C} \mathrm{DB} \text { and } \\
15.6^{\circ} \mathrm{C} \text { WB indoor, and } 8.3^{\circ} \mathrm{C} \mathrm{DB} \text { and } 6.1^{\circ} \mathrm{C} \text { WB } \\
\text { outdoor }\end{array}$ \\
\hline $\begin{array}{l}\text { Air Handling Unit (AHU) - House A } \\
\text { Mitshubishi Electric: PKA-A36KA(L) }\end{array}$ & $\begin{array}{l}\text { Multi Speed Fan: } \\
\text { Airflow (Dry): } 705-810-920^{19} \mathrm{cfm} \\
\text { Airflow (Wet): } 635-730-830 \mathrm{cfm} \\
\text { Cooling capacity: } 8.73 \mathrm{~kW}(2.5 \mathrm{tons}) \\
\text { Heating capacity: } 16.73 \mathrm{~kW}(57.48 \mathrm{MBH}) \text { at } 377.14 \mathrm{~L} / \mathrm{s} \\
(800 \mathrm{cfm}) \text { and } 82.22^{\circ} \mathrm{C}\left(180^{\circ} \mathrm{F}\right) \mathrm{EWT}\end{array}$ \\
\hline $\begin{array}{l}\text { Heat Recovery Ventilation System (HRV) } \\
\text { VanEE: High Efficiency Series-3000 HE }\end{array}$ & $\begin{array}{l}\text { Heat Exchange Surface Area: } 17.1 \mathrm{~m}^{2}\left(184 \mathrm{ft}^{2}\right) \\
\text { Type: Counter-flow } \\
\text { Core Material: Polypropylene } \\
\text { Energy performance: } \\
80 \% \text { sensible recovery efficiency at } 55 \mathrm{~L} / \mathrm{s}(117 \mathrm{cfm}) \\
\text { and } 0^{\circ} \mathrm{C} \text { outdoor air temperature } \\
\text { Defrost cycle: } 6 \text { defrosting min. per } 60 \text { operating min. at } \\
-5^{\circ} \mathrm{C} \text { to }-15^{\circ} \mathrm{C}, 6 \text { defrosting min per } 32 \text { operating min at } \\
-15^{\circ} \mathrm{C} \text { to }-27^{\circ} \mathrm{C}\end{array}$ \\
\hline
\end{tabular}

${ }^{19}$ Low-Mid-High 
Table 3.2.3 - Detail specifications of HVAC equipment in TRCA Archetype Sustainable House-B (Barua, 2010; VanEE, 2011; Safa, 2012, Alzahrani, 2014)

\begin{tabular}{|c|c|}
\hline Equipment & Technical Information \\
\hline $\begin{array}{l}\text { Ground Source Heat Pump (GSHP) } \\
\text { Water Furnace International, Inc.: EW } 042 \text { R12SSA }\end{array}$ & $\begin{array}{l}\text { Heating Capacity: } 12.66 \mathrm{~kW}(43.2 \mathrm{MBH}) \text { at }-1.1^{\circ} \mathrm{C}\left(30^{\circ} \mathrm{F}\right) \\
\mathrm{EST}, 37.7^{\circ} \mathrm{C}\left(100^{\circ} \mathrm{F}\right) \mathrm{ELT} \text { and } 1.04 \mathrm{Liters} / \mathrm{sec}(16.5 \mathrm{GPM}) \\
\text { source flow rate } \\
\text { Cooling Capacity: } 13.04 \mathrm{~kW}(44.5 \mathrm{MBH}) \text { at } 26.6^{\circ} \mathrm{C} \\
\left(80^{\circ} \mathrm{F}\right) \mathrm{EST}, 14.65^{\circ} \mathrm{C}\left(50^{\circ} \mathrm{F}\right) \mathrm{ELT} \text {, and } 1.04 \mathrm{Liters} / \mathrm{sec}(16.5 \\
\text { GPM) source flow rate } \\
\text { Length of Horizontal Loops: } 366 \mathrm{~m}\left(1200^{\prime}\right) \text {, Number of } \\
\text { loops: } 2 \text {, Depth of each loop: } 1.83 \mathrm{~m}\left(6^{\prime}\right) \\
\text { Length of Vertical Loops: } 152 \mathrm{~m}\left(500^{\prime}\right) \text {, Number of loops: } \\
\text { 2, Depth of each loop: } 76.2 \mathrm{~m}\left(250^{\prime}\right)\end{array}$ \\
\hline $\begin{array}{l}\text { Buffer Tank } \\
\text { GSW Water Heating: CST-80 }\end{array}$ & 270 Litres (71 US gallon) \\
\hline $\begin{array}{l}\text { Air Handling Unit (AHU) - House B } \\
\text { Ecologix Heating Technologies Inc.: C3-06 }\end{array}$ & $\begin{array}{l}\text { Multi Speed Fan, Multi-Zone Air Distribution } \\
\text { Cooling Capacity: } 5.27 \text { to } 12.3 \mathrm{~kW}(1.5 \text { to } 3.5 \text { tons) } \\
\text { Heating Capacity: } 16.73 \mathrm{~kW}(57.48 \mathrm{MBH}) \text { at } 800 \mathrm{cfm} \\
\text { and } 82^{\circ} \mathrm{C} \text { Entering Water Temperature }\end{array}$ \\
\hline $\begin{array}{l}\text { Energy Recovery Ventilation System (ERV) } \\
\text { VanEE: Gold Series Series-2001 ERV }\end{array}$ & $\begin{array}{l}\text { Heat Exchange Surface Area: } 14.51 \mathrm{~m}^{2}\left(156 \mathrm{ft}^{2}\right) \\
\text { Type: Cross-flow } \\
\text { Core Material: Enthalpic transfer media } \\
\text { Energy performance: } \\
69 \% \text { sensible recovery efficiency at } 52 \mathrm{~L} / \mathrm{s}(110 \mathrm{cfm}) \text { and } \\
0^{\circ} \mathrm{C} \text { outdoor air temperature } \\
45 \% \text { latent recovery efficiency at } 52 \mathrm{~L} / \mathrm{s}(110 \mathrm{cfm}) \text { and } \\
0^{\circ} \mathrm{C} \text { outdoor air temperature } \\
\text { Defrost cycle: } 6 \text { defrosting min. per } 32 \text { operating min. at } \\
-5^{\circ} \mathrm{C} \text { to }-15^{\circ} \mathrm{C}, 6 \text { defrosting min. per } 20 \text { operating min. } \\
\text { at }-15^{\circ} \mathrm{C} \text { and colder }\end{array}$ \\
\hline
\end{tabular}




\section{Chapter \#4 - Excel Tool Development}

\section{Section 4.1 - Earlier and Current Works}

In 2012, Chen et al. proposed a conceptual design for HERV in a parallel flow arrangement (Chen, Mistry, Fung \& Leong, 2012). The paper concluded that such a design is a feasible option for dry and continental climates. In this study, an Excel-based analysis tool (Ebat) was described, which was developed to estimate quantitatively the feasibility of the HERV in a counter-flow arrangement. The design schematics of the counter-flow HERV are shown in Figures 3.1.2 - 3.1.5. Basically, the developed analysis tool has four divisions: Inputs, Database, Computations, and Outputs. Users need to fill in the required inputs (e.g., house envelope, etc.) for building load calculations, and the program automatically transforms these inputs into outputs by deploying the databases and the computational functions programmed in it. The lists of inputs and outputs are shown in Figure 4.1.1. In addition, the tool provides a comparison between a conventional HRV/ERV defined by users and the HERV in order to clarify the pros and cons of these systems for different climate conditions. This chapter consists of a short exposition for methodology and formulas used in Ebat, followed by a case study that intended to study the proposed HERV using the accessible HRV and ERV performances as the default performance data. 


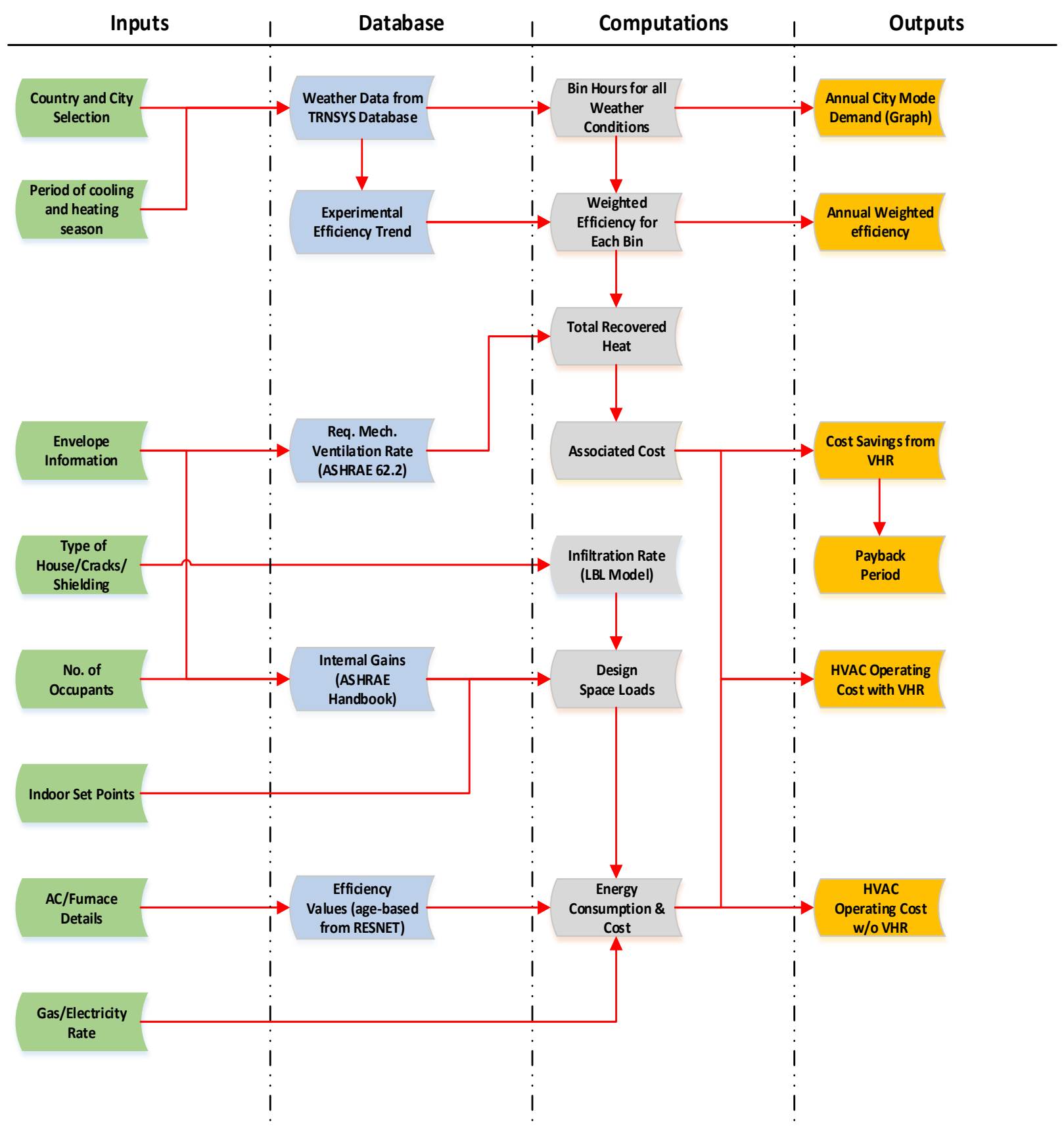

Figure 4.1.1 - Process flow chart for Ebat

\section{Section 4.2 - Natural Infiltration}

Air infiltration is often measured in terms of air change per hour ( $\mathrm{ACH})$, which describes the rate the air in a space is replaced by outside air. This measurement is needed to calculate the sensible and latent heat gains of a house, as well as the net mechanical ventilation rate. An exact calculation of annual $\mathrm{ACH}$ is impractical because the instantaneous $\mathrm{ACH}$ varies continuously over time. To simplify the process of analysis, an average ACH was used. In 1987, based on the Kronvall-Persily 
estimation model and the LBL infiltration model, Sherman (1987) derived an equation for the estimation of annual average air change rate $\left(\mathrm{ACH}_{\text {avg }}\right)$ in dwellings using hourly air change rate at $50 \mathrm{~Pa}\left(\mathrm{ACH}_{50}\right)$ and leakage-infiltration ratio $\left(\mathrm{N}_{\mathrm{o}}\right)$.

$$
\mathrm{ACH}_{\mathrm{avg}}=\frac{\mathrm{ACH}_{50}}{N_{\mathrm{o}} H_{1} S_{2} L_{3}}
$$

The leakage-infiltration ratio $\left(\mathrm{N}_{\mathrm{o}}\right)$ is a site climate indicator that accounts for the physical and environmental properties of single family houses. The typical leakage-infiltration ratio can be obtained from the plot of leakage-infiltration indicator (see Figure 4.2.1), which was developed by Sherman for typical houses. Table 4.2.1 lists some of the $\mathrm{N}_{\mathrm{o}}$ factors that were used in Ebat. For a particular house, correction factors for building height $\left(\mathrm{H}_{1}\right.$, see Table 4.2.2), site shielding $\left(\mathrm{S}_{2}\right.$, see Table 4.2.3), and leak type ( $\mathrm{L}_{3}$, see Table 4.2.4) can be used to correct the indicator $\mathrm{N}_{\mathrm{o}}$. Furthermore, the above expression requires house air change rate at $50 \mathrm{~Pa}\left(\mathrm{ACH}_{50}\right)$, which in general can be obtained from blower door test. However, this test is uncommon to many households because it is usually unnecessary and/or costly. As a result, an alternative approach was proposed by providing a customized option that allows the program to determine the associated $\mathrm{ACH}_{50}$ of a house based on its air tightness type. According to Fung et al. (Fung, Guler, Aydinalp \& Ugursal, 2000), the air tightness of residential houses can be grouped into four main types - loose, average, present and energy efficient house. The associated $\mathrm{ACH}_{50}$ for each air tightness type are presented in Table 4.2.5.

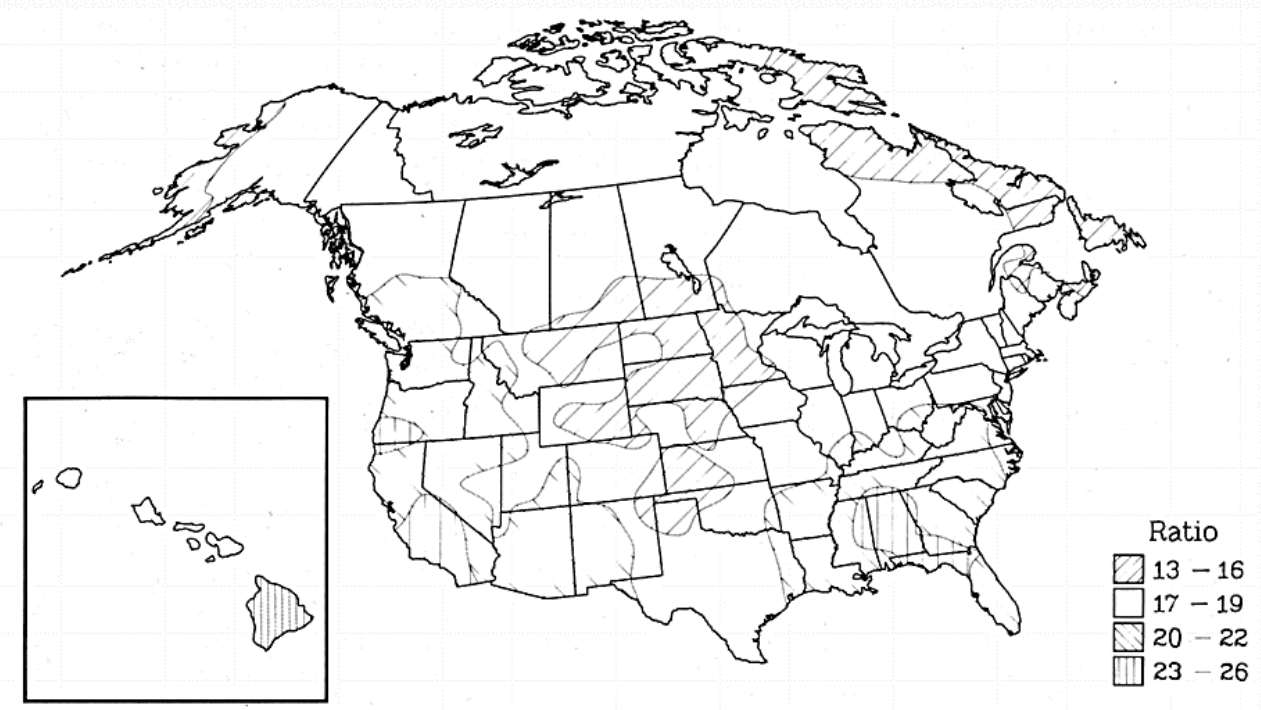

Figure 4.2.1 - Leakage infiltration ratio $\left(\mathrm{N}_{\mathrm{o}}\right)$ (Sherman, 1987) 
Table 4.2.1 - Leakage infiltration ratio $\left(N_{\mathrm{o}}\right)$ for different cities in North America

\begin{tabular}{ll|ll}
\hline \multicolumn{1}{c}{ U.S. } & & \multicolumn{2}{c}{ Canada } \\
\hline Phoenix & 22 & Edmonton & 19 \\
\hline Los Angeles & 25 & Vancouver & 22 \\
\hline San Francisco & 22 & Winnipeg & 16 \\
\hline Colorado Springs & 19 & Fredericton & 19 \\
\hline Miami & 22 & St Johns & 16 \\
\hline Atlanta & 22 & Halifax & 19 \\
\hline Chicago & 19 & Toronto & 19 \\
\hline Indianapolis & 19 & Montreal & 19 \\
\hline Boston & 19 & Saskatoon & 19 \\
\hline Minneapolis & 16 & Inuvik & 19 \\
\hline St Louis & 19 & Churchill & 19 \\
\hline Las Vegas & 22 & Eureka & 19 \\
\hline New York City & 19 & Mould Bay & 19 \\
\hline Oklahoma City & 19 & Whitehorse & 19 \\
\hline Salt Lake City & 19 & Summerland & 19 \\
\hline West Palm Beach & 22 & Iqaluit & 16 \\
\hline Albuquerque & 22 & & \\
\hline
\end{tabular}

Table 4.2.2 - Height correction factor $\left(H_{1}\right)$ (Sherman, 1987)

\begin{tabular}{ccccc}
\hline \# of stories & 1 & 1.5 & 2 & 3 \\
\hline$H_{1}$ & 1.0 & 0.9 & 0.8 & 0.7 \\
\hline
\end{tabular}

Table 4.2.3 - Shielding correction factor $\left(S_{2}\right)$ (Sherman, 1987)

\begin{tabular}{cccc}
\hline & Well shielded & Normal & Exposed \\
\hline$S_{2}$ & 1.2 & 1.0 & 0.9 \\
\hline
\end{tabular}

Table 4.2.4 - Leakiness correction factor $\left(L_{3}\right)$ (Sherman, 1987)

\begin{tabular}{cccc}
\hline & Tight & Normal & Loose \\
\hline$L_{3}$ & 1.4 & 1.0 & 0.7 \\
\hline
\end{tabular}

Table 4.2.5 - $\mathrm{ACH}_{50}$ for different types of house (Fung, Guler, Aydinalp \& Ugursal, 2000)

\begin{tabular}{l|l}
\hline House Type & $\mathrm{ACH}_{\mathbf{5 0}}$ \\
\hline Loose & 10.35 \\
Average & 4.55 \\
Present & 3.57 \\
Energy-Efficient & 1.5 \\
\hline
\end{tabular}

\section{Section 4.3 - Efficiency}

The sensible and latent efficiencies are important parameters for the estimate of system 
performance. These parameters generally vary depending on the outdoor weather conditions, and hence, correlations are needed. Two projects led by Ryerson University already tested the potential of HRV in Mattamy house (Cohen, 2010) and ERV in TRCA Archetype Sustainable House-B (Zhang, Barua \& Fung, 2011). For the case study presented in this chapter, the performance data of the HRV and ERV were applied into the tool as the default performance data. A linear equation was developed from the monitored sensible efficiencies of the HRV in Mattamy house. Equation (4.3.1) demonstrates the linear relationship between sensible efficiency $\left(\varepsilon_{S}\right)$ and outdoor air temperature $\left(\mathrm{AT}_{o}\right)$. For outdoor air temperature that drops below $0^{\circ} \mathrm{C}$, this equation predicts that there is a sensible efficiency lower than $65 \%$, and vice versa. In order to clearly identify the potential of the HRV and ERV in different climatic conditions, Eq. 4.3.1 was also used to predict the sensible efficiency of the ERV, and hence, both systems used in the case study would have the same potential of sensible heat recovery.

$$
\varepsilon_{s}=0.6561+\left(0.0058 \mathrm{AT}_{o}\right)
$$

The linear equation for latent efficiency $\left(\varepsilon_{L}\right)$ was developed based on the ERV monitored data.

$$
\varepsilon_{L}=0.4542+\left(0.005417 \mathrm{AT}_{o}\right)
$$

The HERV used for the case study was assumed to be consisting of a similar sensible and enthalpy core, so both Equation (4.3.1) and (4.3.2) were adopted to predict the efficiency of each core. It is worth noticing that the efficiency equations of HRV, ERV and HERV could be replaced by the users accordingly in the future. Besides, according to ASHRAE Handbook (2008), a multiple-pass heat exchanger is about 1.2 times more efficient than a single core heat exchanger. This approximation was adopted, meaning that the sensible efficiency of the HERV was 1.2 times higher than the HRV and ERV. Based on the efficiencies for all possible outdoor weather conditions, the sensible and latent heat being exchanged across the process $(q)$ can be determined by multiplying the efficiency $(\varepsilon)$ to the maximum available heat for recovery $\left(q_{\max }\right)$.

$$
q=q_{\max } \varepsilon
$$

\section{Section 4.4 - Bin Method}

Energy calculations sometimes are computed using the average outdoor conditions to provide a 
quick prediction on the heating and cooling loads for a structure. However, for HVAC equipment whose performance depends on outdoor weather conditions, this energy-estimating method becomes insufficient as the thermal efficiency of the system may not be constant. Therefore, bin method was applied to evaluate separately the recovered heat at different outdoor conditions. Historically, bin method has been adopted by Kavanaugh and Lambert (2004) into their heat pump energy evaluation program to calculate the annual energy use for ground-coupled heat pumps. In this study, Ebat was designed to be able to import hourly weather data. These data were then sorted in air temperature (row) and relative humidity (column) bins of $2^{\circ} \mathrm{C}$ and $5 \%$ increments, respectively. A sample bin table is given in Table 4.4.1.

Table 4.4.1 - Sample bin table

\begin{tabular}{c|cccc}
\hline \multicolumn{4}{c}{$\phi_{\circ}$ Range } \\
\hline $\mathrm{AT}_{\circ}$ Range & $45 \%$ & $50 \%$ & $55 \%$ & $60 \%$ \\
\hline $20^{\circ} \mathrm{C}$ & & & & \\
$22^{\circ} \mathrm{C}$ & \multicolumn{3}{c}{ Frequency of each bin } \\
$24^{\circ} \mathrm{C}$ & \multicolumn{3}{c}{} \\
$26^{\circ} \mathrm{C}$ & \multicolumn{3}{c}{} \\
$28^{\circ} \mathrm{C}$ & & & \\
\hline
\end{tabular}

For each bin, the total bin hour $\left(N_{b i n}\right)$ of each particular outdoor condition was counted. Therefore, the annual total exchanged energy $\left(q_{a}\right)$ for each temperature-humidity bin can be determined.

$$
q_{a}=N_{b i n} q
$$

In addition, the counted bin hours also enabled the estimation of weighted annual efficiency of the system. This value can be calculated based on the weighted number of each bin hour of the year.

$$
\varepsilon_{\mathrm{a}}=\sum \frac{N_{b i n}}{8760} \varepsilon
$$

\section{Section 4.5 - Climate Zone Classification}

The dual-core total recovery ventilator (TRV) is an existing product that resembles the proposed HERV. The TRV, according to the manufacturer's recommendation, is feasible for markets with temperate climate (Lifebreath, 2009). The proposed HERV was designed to contain a built-in economizer, and hence, was also thought to be feasible for other climates. The Köppen climate classification system was applied to sort the cities of North America into various climatic zones. 
This classification system was to further aid in the prediction of HERV behaviours in these general zones. The Köppen climate classification system was introduced by a German climatologist named Wladimir Köppen in 1900. With the temperature and precipitation index, as well as the five vegetation groups defined by De Candolle, Köppen classified the world's climate with three letters (Peel, Finlayson \& McMahon, 2007). The first letter represents a particular climate zone, while the second and third letters explain the precipitation and annual air temperature of that zone. The following are the five major Köppen climate zones:

A. The tropical climate

- Miami and West Palm Beach.

B. The dry climate

- Albuquerque, Las Vegas and Lethbridge.

C. The temperate climate

- San Francisco, Nanaimo and Vancouver.

D. The continental climate

- Toronto, Edmonton and Montreal.

E. The polar climate

- Iqaluit and Eureka.

\section{Section 4.6 - Control Strategies}

The project scope requires the HERV to be able to operate in four different modes: sensible, latent, dual-core, and bypass mode. Therefore, it made the control, as well as the overall calculations became more complex. As a result, simple control strategies were developed and implemented into the spreadsheet tool to help select the appropriate operating mode. These controls evaluate the difference between the indoor and outdoor air conditions. The sensible mode is needed when moisture recovery is not needed, while the latent mode is needed if $\Delta \mathrm{AT} \approx 0$. Therefore, the dualcore mode is desired only if both of the above conditions are met simultaneously, while the system allows direct free-cooling if they are not met. For indoor setpoint temperature of $23^{\circ} \mathrm{C}$ and relative humidity of $50 \%$, the conditions that trigger the bypass mode are:

$$
\mathrm{AT}_{o} \leq 23^{\circ} \mathrm{C} \text { and } w_{o} \leq 0.00871 \mathrm{~kg} / \mathrm{kg}
$$


Table 4.6.1 - Conditional statements of each operation mode in different season

\begin{tabular}{|c|c|c|c|}
\hline Control & Mode & Temperature Controls & Humidity Controls \\
\hline \multirow{4}{*}{$\begin{array}{l}\text { Cooling } \\
\text { Season }\end{array}$} & Bypass & $A T_{o}<A T_{s}$ & $w_{o}<w_{s}$ \\
\hline & Sensible & $A T_{o}>A T_{s}$ & $w_{o}<w_{s}$ \\
\hline & Latent & $A T_{o} \approx A T_{S}$ & $w_{o}>w_{s}$ \\
\hline & Dual-core & $A T_{o}>A T_{s}$ & $w_{o}>w_{s}$ \\
\hline \multirow{4}{*}{$\begin{array}{l}\text { Heating } \\
\text { Season }\end{array}$} & Bypass & ---- & ---- \\
\hline & Sensible & $A T_{o}<A T_{s}$ or $A T_{o}>A T_{s}$ & $w_{o} \approx w_{s}$ \\
\hline & Latent & $A T_{o} \approx A T_{s}$ & $w_{o}>w_{s} \quad$ or $\quad w_{o}<w_{s}$ \\
\hline & Dual-core & $A T_{o}<A T_{s}$ or $A T_{o}>A T_{s}$ & $w_{o}>w_{s}$ or $w_{o}<w_{s}$ \\
\hline
\end{tabular}

\section{Section 4.7 - Case Study House}

The next step upon the completion of program description was to provide a feasibility study of the HERV in a case study house. The inputs of house envelope was based on the TRCA Archetype Sustainable House-B (ASH-B) located in Vaughan, Ontario. This house has achieved a LEED for Homes Platinum certification, and it is currently used to demonstrate the potentials of an affordable energy efficient house that can be mass-produced with a small ecological footprint (Dembo, Fung, Ng \& Pyrka, 2010). The structural features of House-B are listed in Table 3.2.1. The internal heat gain of the house was measured to be $23.6 \mathrm{kWh}$ per day (Safa, 2012), and was assumed to be constant throughout the calculations.

Heat gains through transparent fenestration surfaces are constituted by thermal conduction and solar irradiation. The former depends on the ambient air temperature, as well as the properties of the glass. The peak heat gain due to solar irradiation can be estimated if the site latitude and the details (e.g., orientation) of the windows are known. In general, windows might not be evenly distributed across opaque surfaces, and solar heat gain through each transparent surface vary depending on the material properties, the interior and/or the exterior attachments. Therefore, in order to reduce the required details for building load calculation, solar gain for the ASH-B was obtained via the transient simulation program TRNSYS (output NTYPE 74 QTSPAS $^{20}$ ). However, a steady-state model is generally incapable of describing a dynamic model, and hence, the average

\footnotetext{
${ }^{20}$ Total solar radiation passing the glass surface (transmission and absorption).
} 
solar gain for the studied period was considered in the steady-state calculations. The average solar gains for different regions across North America are listed in Tables 4.7.1 - 4.7.3.

Table 4.7.1 - Average solar heat gain through windows (kJ/hour)

\begin{tabular}{cccccc}
\hline Months & $\begin{array}{c}\text { Miami } \\
\text { (Zone A) }\end{array}$ & $\begin{array}{c}\text { Las Vegas } \\
\text { (Zone B) }\end{array}$ & $\begin{array}{c}\text { Vancouver } \\
\text { (Zone C) }\end{array}$ & $\begin{array}{c}\text { Toronto } \\
\text { (Zone D) }\end{array}$ & $\begin{array}{c}\text { Iqaluit } \\
\text { (Zone E) }\end{array}$ \\
\hline Jan. & 3878 & 3806 & 1260 & 2430 & 499 \\
Feb. & 4435 & 4560 & 2318 & 3325 & 2105 \\
Mar. & 4922 & 5266 & 3489 & 4076 & 3632 \\
Apr. & 5126 & 6090 & 4430 & 4602 & 5835 \\
May & 5514 & 6767 & 6047 & 5691 & 7118 \\
Jun. & 5725 & 7303 & 6461 & 6172 & 6672 \\
Jul. & 5723 & 6883 & 6323 & 5877 & 6150 \\
Aug. & 5128 & 6257 & 5266 & 5346 & 4654 \\
Sep. & 4613 & 5633 & 4127 & 4251 & 3493 \\
Oct. & 4515 & 4949 & 2685 & 3258 & 1770 \\
Nov. & 3995 & 4202 & 1519 & 1867 & 552 \\
Dec. & 3738 & 3575 & 1000 & 1737 & 206 \\
\hline
\end{tabular}

Table 4.7.2 - Average solar heat gain through windows for other cities in U.S. (kJ/hour)

\begin{tabular}{ccccccc}
\hline Months & $\begin{array}{c}\text { West Palm Beach } \\
\text { (Zone A) }\end{array}$ & $\begin{array}{c}\text { Albuquerque } \\
\text { (Zone B) }\end{array}$ & $\begin{array}{c}\text { Phoenix } \\
\text { (Zone B) }\end{array}$ & $\begin{array}{c}\text { Atlanta } \\
\text { (Zone C) }\end{array}$ & $\begin{array}{c}\text { San Francisco } \\
\text { (Zone C) }\end{array}$ & $\begin{array}{c}\text { Los Angeles } \\
\text { (Zone C) }\end{array}$ \\
\hline Jan. & 3805 & 3851 & 3805 & 3205 & 2722 & 3365 \\
Feb. & 4165 & 4328 & 4571 & 3900 & 3540 & 4083 \\
Mar. & 4690 & 5253 & 5093 & 4505 & 4152 & 4531 \\
Apr. & 4943 & 6095 & 6074 & 5145 & 5046 & 5139 \\
May & 5390 & 6769 & 6628 & 5701 & 5661 & 5346 \\
Jun. & 5336 & 7360 & 6971 & 5960 & 5860 & 5284 \\
Jul. & 5314 & 6626 & 6285 & 5882 & 5868 & 5671 \\
Aug. & 4979 & 6072 & 5774 & 5446 & 5172 & 5391 \\
Sep. & 4732 & 5279 & 5482 & 4573 & 4791 & 4614 \\
Oct. & 4386 & 4963 & 4957 & 4305 & 4073 & 4126 \\
Nov. & 3890 & 4142 & 4102 & 3590 & 3021 & 3663 \\
Dec. & 3553 & 3705 & 3567 & 3046 & 2520 & 3279 \\
\hline
\end{tabular}


Table 4.7.3 - Average solar heat gain through windows for other cities in Canada (kJ/hour)

\begin{tabular}{cccccc}
\hline Months & $\begin{array}{c}\text { Montreal } \\
\text { (Zone D) }\end{array}$ & $\begin{array}{c}\text { Halifax } \\
\text { (Zone D) }\end{array}$ & $\begin{array}{c}\text { St. Johns } \\
\text { (Zone D) }\end{array}$ & $\begin{array}{c}\text { Whitehorse } \\
\text { (Zone E) }\end{array}$ & $\begin{array}{c}\text { Eureka } \\
\text { (Zone E) }\end{array}$ \\
\hline Jan. & 2214 & 2162 & 1717 & 676 & 0 \\
Feb. & 3316 & 3089 & 2568 & 1921 & 0 \\
Mar. & 4204 & 4059 & 3484 & 3439 & 2013 \\
Apr. & 4704 & 4590 & 4281 & 5162 & 2680 \\
May & 5661 & 5372 & 5198 & 6252 & 0 \\
Jun. & 6151 & 5928 & 5804 & 7042 & 0 \\
Jul. & 5985 & 5806 & 5854 & 6164 & 0 \\
Aug. & 5131 & 5104 & 4932 & 4866 & 193 \\
Sep. & 4283 & 4295 & 4000 & 3344 & 2712 \\
Oct. & 3102 & 3229 & 2546 & 1951 & 336 \\
Nov. & 1775 & 2098 & 1655 & 830 & 0 \\
Dec. & 1760 & 1685 & 1299 & 431 & 0 \\
\hline
\end{tabular}

In general, the mechanical ventilation to be provided can be calculated by subtracting the natural infiltration rate from the total ventilation required for the house. This correlation can be expressed in following manner:

$$
\dot{Q}_{m e c h}=\dot{Q}_{r e q}-\dot{Q}_{i n f}
$$

As mentioned, natural infiltration can be determined from the equations listed in Section 4.2 for different regions across North America. To accurately predict the annual consumption of the studied HRV and ERV systems, correlations were obtained from the manufacture datasheets. The performance curves are shown in Figure 4.7.1, and the correlations for both systems are:

$$
\begin{aligned}
& E_{E R V}=0.0063\left(\dot{Q}_{m e c h}\right)^{2}-0.8846\left(\dot{Q}_{\text {mech }}\right)+114.54 \\
& E_{H R V}=0.0025\left(\dot{Q}_{\text {mech }}\right)^{2}+0.1167\left(\dot{Q}_{\text {mech }}\right)+49.314
\end{aligned}
$$

Furthermore, the rate of required ventilation for the case study house was $0.0708 \mathrm{~m}^{3} / \mathrm{s}$. The total price of natural gas from Enbridge was $\$ 0.243$ per cubic meter (see Table A.5.1), and the price of electricity from Toronto Hydro was $\$ 0.128$ per $\mathrm{kWh}$ (see Table A.5.2).

Finally, a few assumptions/settings were made for the case study:

1. Effects attributable to condensation and freezing were neglected.

2. Total four occupants - two adults and two children. 
3. Cooling season setpoints: dry bulb temperature $=23^{\circ} \mathrm{C}$ and relative humidity $=50 \%$.

4. Heating season setpoints: dry bulb temperature $=21^{\circ} \mathrm{C}$ and relative humidity $=30 \%$.

5. SEER for air conditioning system was assumed to be 15 .

6. A new gas furnace was used for space heating, and the corresponding efficiency was $78 \%$ based on RESNET Mortgage Industry National HERS Standards (Residential Energy Services Network, 2013).

7. Unit size 3 GE ECM motor was used, which consumes approximately $0.1 \mathrm{~W} / \mathrm{cfm}$ at $150 \mathrm{cfm}$ (or $0.0708 \mathrm{~m}^{3} / \mathrm{s}$ ), see Figure 4.7.2.

8. A Ryerson capstone design team roughly assembled a HERV prototype (Malesevic, Olt, Tanielian \& Crosbie, 2013). The investment cost of the proposed HERV system was assumed to be $\$ 2,500$ according to the total cost of the components needed to assemble the prototype.

9. The HRV within the Mattamy house cost \$1170, while the ERV within the Archetype Sustainable House-B cost $\$ 1610$.

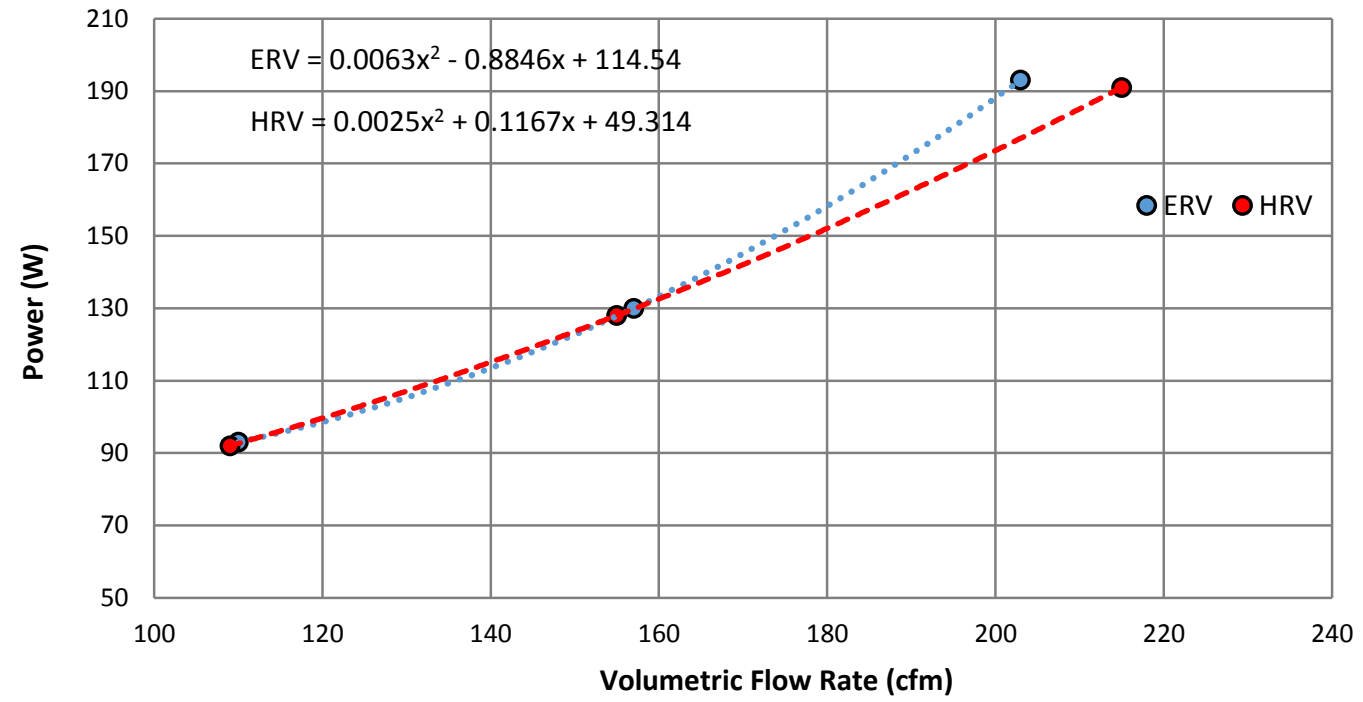

Figure 4.7.1 - Performance curve of the case study HRV and ERV (VanEE, 2011)

*Experimental measurements obtained from ERV at the TRCA Archetype Sustainable House B for one day period reveal that the average power consumption of ERV is $86.3 \mathrm{~W}$ at $101 \mathrm{cfm}$. The above performance curve predicts the ERV has a power consumption of $86.6 \mathrm{~W}$ at $101 \mathrm{cfm}$, which is $0.35 \%$ higher than the measured value. 
Watts per cfm for $3552 \& 3$

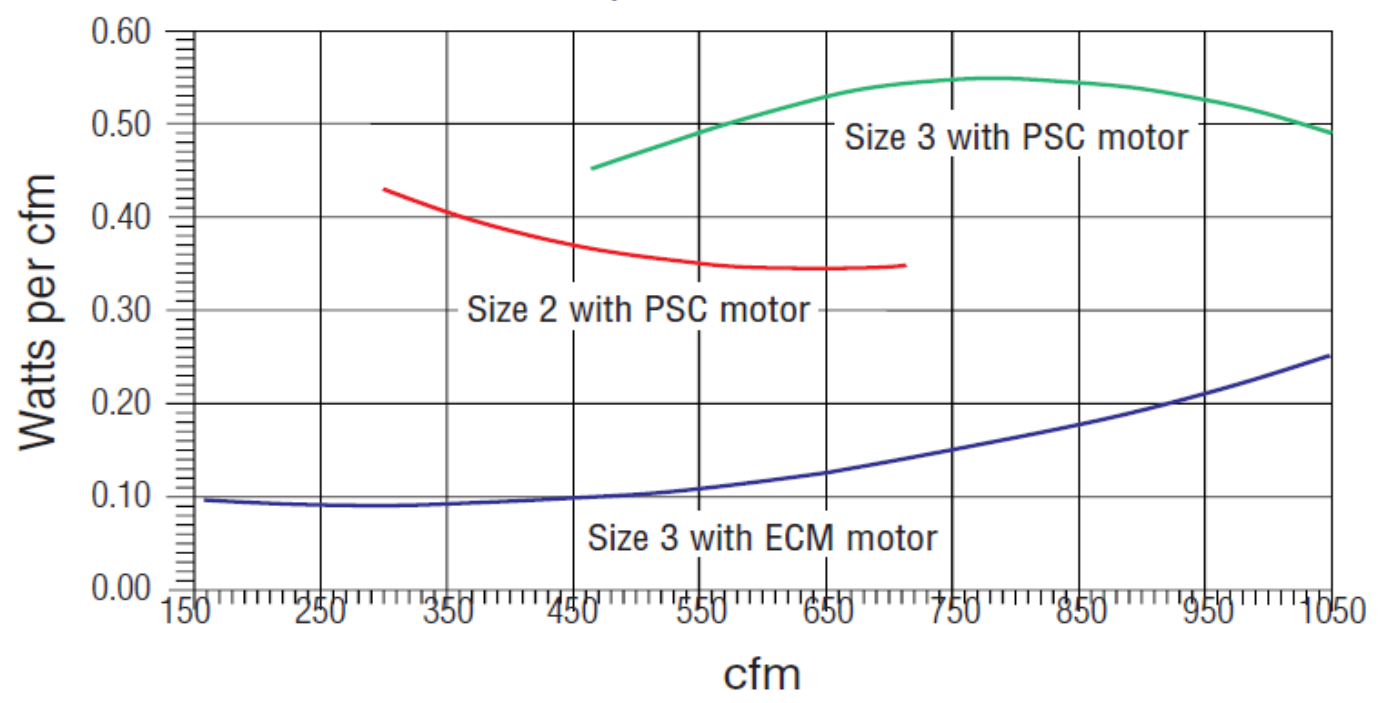

Figure 4.7.2 - Performance curve of unit size 3 GE ECM motor (Nailor Industries Inc., 2009)

\section{Section 4.8 - Annual Mode Demands}

The case study covered different regions across North America, and so the periods of cooling and heating seasons were needed to determine separately in order to account for the regional climate changes. According to the TM2 weather data located in TRNSYS database, the cooling and heating periods for different regions were defined accordingly. Tables 4.8.1 and 4.8.2 present the defined seasonal periods for the selected five cities, corresponding to the five Köppen climate zones. In Miami, due to the constant high ambient temperature throughout the year, heating was neglected. In contrast, cooling was assumed to be unnecessary for Iqaluit as the outdoor temperature rarely requires severe cooling for a consecutive period of time. The TM2 weather files record that the daily minimum temperature is $11^{\circ} \mathrm{C}$ in Miami, while the maximum temperature is $14^{\circ} \mathrm{C}$ in Iqaluit.

Table 4.8.1 - Heating and cooling period for Köppen climate A and E

\begin{tabular}{|c|c|c|c|c|c|c|c|}
\hline \multirow{2}{*}{$\begin{array}{l}\text { Climate } \\
\text { Zones }\end{array}$} & \multirow{2}{*}{ Cities } & \multicolumn{3}{|c|}{ Cooling Season } & \multicolumn{3}{|c|}{ Heating Season } \\
\hline & & Begin & $\begin{array}{c}\text { End } \\
\text { (Inclusive) }\end{array}$ & $\begin{array}{c}\text { Min. Temperature } \\
\left({ }^{\circ} \mathrm{C}\right)\end{array}$ & Begin & $\begin{array}{c}\text { End } \\
\text { (inclusive) }\end{array}$ & $\begin{array}{c}\text { Max. Temperature } \\
\left({ }^{\circ} \mathrm{C}\right)\end{array}$ \\
\hline$A$ & Miami & Jan. $1^{\text {st }}$ & Dec. $31^{\text {st }}$ & $11.0\left(\operatorname{Jan} .3^{\text {rd }}\right)$ & ---- & ---- & ---- \\
\hline$E$ & Iqaluit & ---- & ---- & ---- & Jan. $1^{\text {st }}$ & Dec. $31^{\text {st }}$ & 14.0 (Jul. $21^{\text {st }}$ ) \\
\hline
\end{tabular}


Table 4.8.2 - Heating and cooling season for Köppen climate B, C, and D

\begin{tabular}{|c|c|c|c|c|c|c|c|}
\hline \multirow{2}{*}{$\begin{array}{l}\text { Climate } \\
\text { Zones }\end{array}$} & \multirow[b]{2}{*}{ Cities } & \multicolumn{3}{|c|}{ Cooling Season } & \multicolumn{3}{|c|}{ Heating Season } \\
\hline & & Begin & $\begin{array}{c}\text { End } \\
\text { (inclusive) }\end{array}$ & $\begin{array}{c}\text { Temperature* } \\
\left({ }^{\circ} \mathrm{C}\right)\end{array}$ & Begin & $\begin{array}{c}\text { End } \\
\text { (inclusive) }\end{array}$ & $\begin{array}{c}\text { Temperature* } \\
\left({ }^{\circ} \mathrm{C}\right)\end{array}$ \\
\hline B & Las Vegas & Apr. $1^{\text {st }}$ & Oct. $31^{\text {st }}$ & 22 & Nov. $1^{\text {st }}$ & Mar. $31^{\text {st }}$ & 13 \\
\hline C & Vancouver & May $20^{\text {th }}$ & Sep. $30^{\text {th }}$ & 16 & Oct. $1^{\text {st }}$ & May $19^{\text {th }}$ & 10 \\
\hline D & Toronto & May $20^{\text {th }}$ & Sep. $30^{\text {th }}$ & 21 & Oct. $1^{\text {st }}$ & May $19^{\text {th }}$ & 8 \\
\hline
\end{tabular}

*daily average outdoor temperature at the beginning of the period

The noteworthy advantage of the spreadsheet program is its capability of illustrating the need of each operating mode graphically based on the counted bin hours. This illustration allows us to better understand the potential of the defined heat/energy recovery ventilation systems. Type-A climate zone (Miami) is characterized as humid and constantly high temperatures throughout the year (Peel, Finlayson \& McMahon, 2007). Figure 4.8.1 shows that the sensible heat recovery might not be significant for $30.6 \%$ of the year (equivalent to the sum of latent and bypass modes), while latent heat recovery was almost always required. Overall, results appears to be squinting towards enthalpy recovery. For Las Vegas, free cooling the house with dry air might significantly reduce indoor humidity level, and hence, the bypass mode was turned off.

Cities that pertain to temperate and continental climates in general have temperature above $10^{\circ} \mathrm{C}$ during the hottest months (Peel, Finlayson \& McMahon, 2007). The selected representatives for these climate types were Vancouver and Toronto, respectively. The associated weather conditions are given in Figures 4.8.2 and 4.8.3. The ambient temperature of Vancouver is lower than that of Toronto, meaning that bypassing supply air is more beneficial. Figure 4.8.1 shows that the frequency of bypass mode was 30\% in Vancouver, while Toronto had a lower frequency (20\%) due to the hotter and wetter ambient conditions. Finally, the estimated demands indicate that the house often required dual-core mode to minimize space load attributable to ambient air. However, this information may not reflect the actual saving potential of the heat recovery systems. For example, dual-core mode was required $90.7 \%$ of the year in Iqaluit, but it is believed that the sensible part of this amount was actually dominating. Therefore, even though the HRV did not recover latent heat, the dominated sensible portion should be satisfied $90.7 \%$ of the time, leading to savings that would be better than the humid region (e.g., Miami). This hypothesis will be verified and discussed in the following section. 


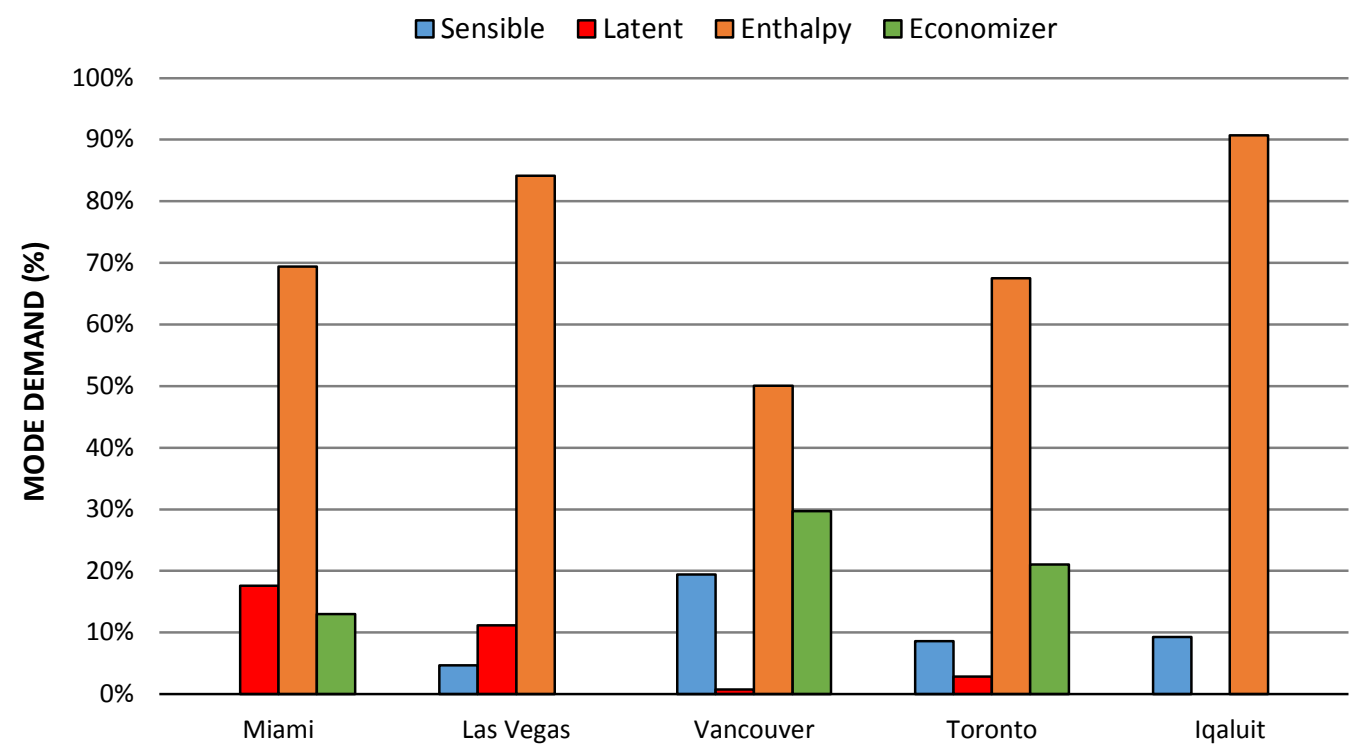

Figure 4.8.1 - Annual mode demand

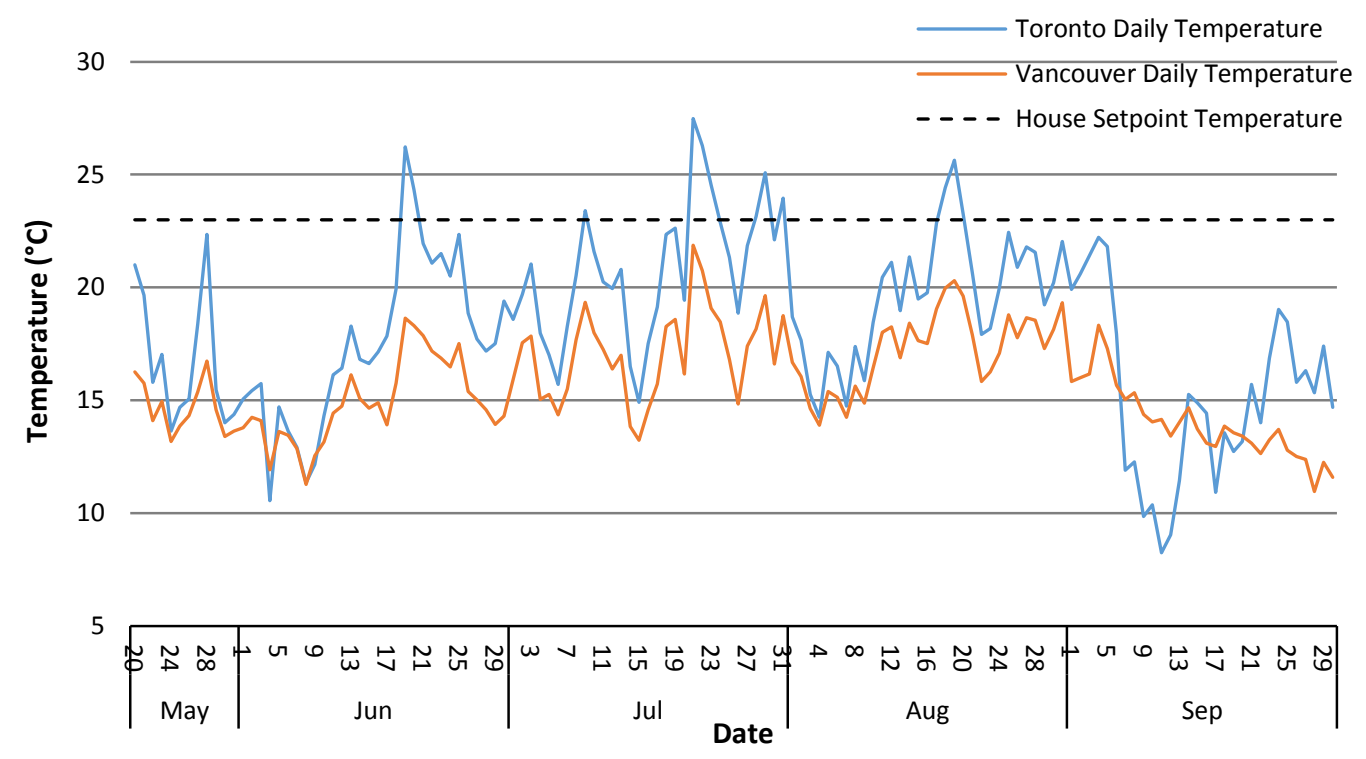

Figure 4.8.2 - Daily average ambient temperature during cooling season 


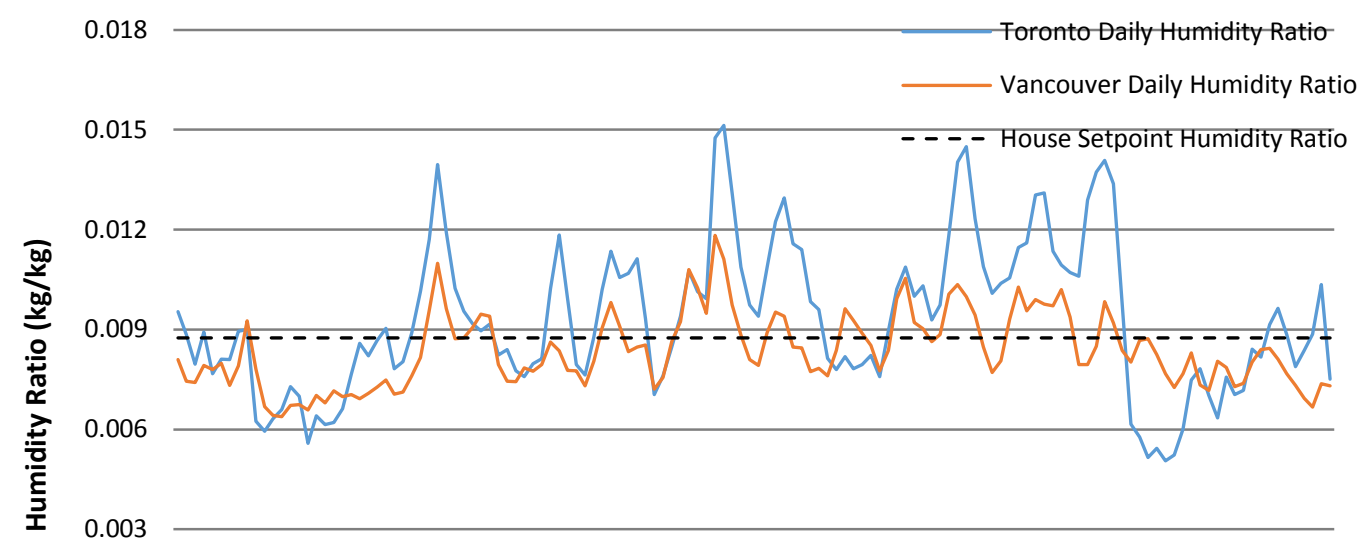

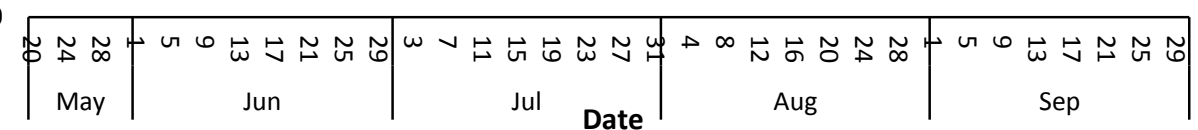

Figure 4.8.3 - Daily average ambient humidity ratio during cooling season

\section{Section 4.9 - Cost Savings of the House}

The next step of the study was to determine the cost savings of the house based on the energy consumptions of the house, as well as the associated cost savings. Figure 4.9.1 shows the total energy consumptions of the house based on the energy use for furnace, air conditioner, dehumidifier and humidifier.

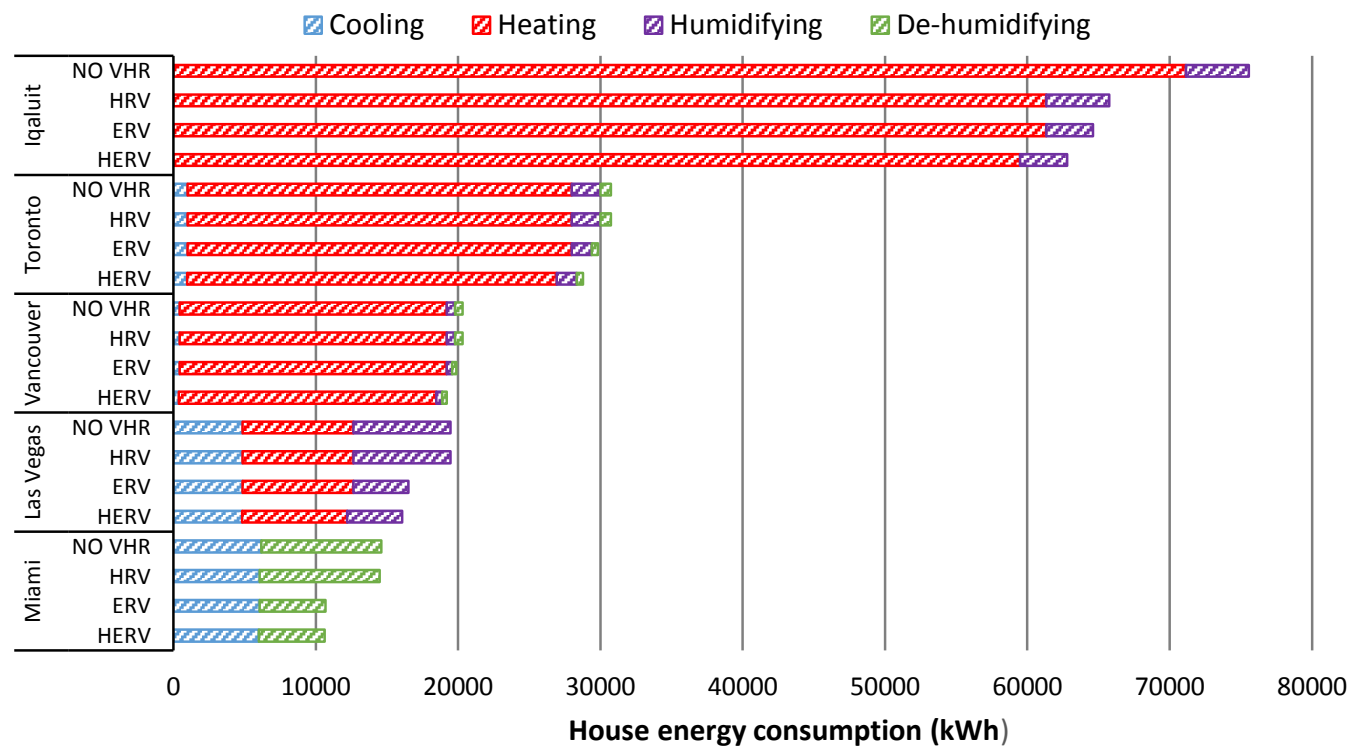

Figure 4.9.1 - Energy consumption of the case study house

For Miami, the ERV-equipped house consumed 45\% less energy for dehumidification than the HRV's, and the cost associated with this difference was \$684, as shown in Table 4.9.1. As 
mentioned, both the HRV and ERV systems were assumed to have the same potential of sensible heat recovery, so a negative cost saving in the HRV-equipped house can be attributed to the high demand in latent heat recovery. In contrast, the HERV house consumed about $6000 \mathrm{kWh}$ for temperature control and $4600 \mathrm{kWh}$ for humidity control. In addition, the cost savings of the HERV was estimated to be $\$ 503$ per year, which was $22 \%$ higher than the ERV (see Table 4.9.1, $9^{\text {th }}$ column). However, this difference was not high enough to offset the high capital cost, resulting in a longer payback time (about 13 months longer).

In Figure 4.8.1, the demands of latent mode for Canadian regions were relatively lower than that of the United States. However, the demands of dual-core mode were dominated, and hence, there was no direct evidence to clarify whether or not the demand of latent heat recovery/removal decreased in cold regions. In Figure 4.9.1, heating consumption was dominated for regions of Canada, while the energy use for humidity control was relatively less important. To determine the significance of latent load, the percent difference in energy use between the HRV and ERV was used. The percent difference was estimated to be $3 \%$ for Iqaluit that has cold and dry climate, and $18 \%$ for Las Vegas that has hot and dry climate. Therefore, it is clear that the space latent load and so the demand of latent heat recovery became less important in Canada. However, due to the high operating cost for humidity control, Table 4.9.1 shows that the cost savings of the ERV for Iqaluit was still $\$ 148$ higher than the HRV.

Vancouver has a moderate seasonality, both the HRV and ERV were found to be infeasible according to the calculated cost savings. In addition, the percent saving difference was $210 \%$, meaning that the HERV completely outperformed the single core designs. For Toronto, the percent difference was $74 \%$ and the payback period of HERV was about 1 year shorter than the ERV. Table 4.9.2 presents the cost savings attributed to free-cooling. On a yearly basis, free-cooling savings accounted for $7 \%$ of total savings for Vancouver and $3 \%$ for Toronto. In addition, these savings accounted for 13.2 and 3.6 months reduction of system payback period. 
Table 4.9.1 - Zone-by-zone analysis for the three mechanical ventilation systems

\begin{tabular}{|c|c|c|c|c|c|c|c|c|}
\hline \multirow[b]{2}{*}{ Zone } & \multirow[b]{2}{*}{ City } & \multicolumn{3}{|c|}{ Annual Cost Savings (\$) } & \multicolumn{3}{|c|}{ Payback Period (year) } & \multirow{2}{*}{$\begin{array}{l}\text { Percent saving } \\
\text { difference b/w } \\
\text { HERV and ERV }\end{array}$} \\
\hline & & HERV & ERV & HRV & HERV & ERV & HRV & \\
\hline A & Miami & 503 & 411 & -95 & 5.0 & 3.9 & ----* & $22 \%$ \\
\hline B & Las Vegas & 469 & 369 & -22 & 5.3 & 4.4 & ---- & $27 \%$ \\
\hline C & Vancouver & 155 & 50 & -4 & 16.1 & ---- & ---- & $210 \%$ \\
\hline $\mathrm{D}$ & Toronto & 260 & 149 & 28 & 9.6 & 10.8 & --- & $74 \%$ \\
\hline E & Iqaluit & 419 & 301 & 153 & 6.0 & 5.4 & 7.6 & $39 \%$ \\
\hline
\end{tabular}

*'----': payback period is longer than 20 years or negative payback.

Table 4.9.2 - Cost saving attributed to free-cooling

\begin{tabular}{ccccc}
\hline Zone & City & Cost Saving (\$) & Percent Saving (\%) & Payback Reduction (months) \\
\hline A & Miami & 5 & 1 & 0.6 \\
\hline C & Vancouver & 10 & 7 & 13.2 \\
\hline D & Toronto & 7 & 3 & 3.6 \\
\hline
\end{tabular}

\section{Section 4.10 - Feasibility of HERV}

To make a precise comparison between the energy efficiency and the investment recovery of systems, the operating cost ratio (OCR) was obtained, as shown in Table 4.10.1. This ratio measures the expense of the system as a percentage of revenue. By implementing the ECM motors, the OCRs for the HERV system were found to be always lower, and hence, it can be realized that the system was running more cost-efficient than the single core systems. In both Miami and Iqaluit, the HERV system required longer payback period than the ERV even through the corresponding OCRs were small. In comparison, the system had the shortest payback period in both Vancouver and Toronto, corresponding to 16.5 and 9.8 years. Therefore, the integrated HERV system was recommended for Köppen climate Zone-C (temperate) and Zone-D (continental). Finally, although the initial investments of the heat/energy recovery systems were included, the maintenance costs, however, were excluded from the calculations. The lack of available historical data for this new concept was the prime reason of this exclusion. Finally, the calculated OCRs and payback period also reveal that the HRV was making underwriting profit only in cold regions such as Iqaluit. The ERV, on the other hand, provided greater help in Miami. Overall, both the HRV and ERV systems resulted in higher OCR in the temperate climate: the ERV system had an OCR of 67\% in Vancouver, 
while the HRV had $102 \%$.

Table 4.10.1 - Operating cost ratio for the three systems

\begin{tabular}{ccccc}
\hline & & \multicolumn{3}{c}{ Operating cost ratio (\%) } \\
\hline Zone & City & HERV & ERV & HRV \\
\hline A & Miami & 5 & 21 & 704 \\
\hline B & Las Vegas & 5 & 23 & 125 \\
\hline C & Vancouver & 15 & 69 & 104 \\
\hline D & Toronto & 9 & 42 & 79 \\
\hline E & Iqaluit & 5 & 24 & 37 \\
\hline
\end{tabular}

\section{Section 4.11 - Sensitivity Studies}

\subsection{1 - Setpoints}

Heating and cooling consumptions of houses depend on several factors. These include personal preference for indoor settings, local climate conditions, fuel price, and so forth. This section presents a sensitivity study to determine the system cost savings at different indoor setpoints:

Changed cooling setpoint to $21^{\circ} \mathrm{C}$ and $50 \% \mathrm{RH}$, and heating setpoints to $19^{\circ} \mathrm{C}$ and $30 \% \mathrm{RH}$ :

In this case, systems performance were determined for house with cooler and dryer indoor setpoints. Figure 4.11.1 illustrates the demands of the five selected cities. By lowering the humidity and temperature setpoints in the summer, free-cooling potential in Miami, Vancouver, and Toronto went down. For example, demand of the integrated bypass mode for Vancouver dropped from 30\% (see Figure 4.8.1) to 20\%. Miami has hot and humid climate, and hence, both sensible and latent loads were expected to be higher for a cooler and dryer indoor environment. Figure 4.11.1 shows that the demand of latent mode decreased from $18 \%$ to $8.6 \%$, but dual-core mode increased from $69 \%$ to $83 \%$. Therefore, the demands of both sensible and latent heat recovery were actually increasing from the overall perspective. It was difficult to make a direct comparison between two scenarios using cost savings, instead, the percent saving difference (PSD) between the HERV and ERV was used. For Miami, the PSD decreased from 22\% (see Table 4.9.1) to 18\% (see Table 4.11.1). This implies that, either or both the increased sensible and latent demand(s) have caused the HERV to be less cost-efficient. To verify this hypothesis, the cost benefits for Las Vegas were analyzed similarly. Las Vegas has hot and dry climate, and hence, the decrease in humidity setpoint 
should have opposite effect on PSD if it was the major source of the saving reduction. In Figure 4.11.1, the demands of Las Vegas were nearly identical to Miami, except the bypass mode was turned off to prevent drought. In Table 4.9.1, the PSD was found to be $27 \%$ for Las Vegas, and it increased to $34 \%$ (see Table 4.11.1). Therefore, it is clear that the higher demand in latent heat recovery for Miami was the factor that lowered the competitiveness of the HERV. To reinforce the above statement, calculations were carried out for different humidity while fixing the temperature at $21^{\circ} \mathrm{C}$, as shown in Table 4.11.2. For lower humidity setting (in this case $40 \%$ ), the PSD decreased from $18 \%$ to $14 \%$. In contrast, as humidity increased, the exchanged latent heat decreased, leading to a higher cost difference between the two systems.

Table 4.11.1 - Analysis for the three mechanical ventilation systems ${ }^{4}$

\begin{tabular}{|c|c|c|c|c|c|c|c|c|}
\hline \multirow[b]{2}{*}{ Zone } & \multirow[b]{2}{*}{ City } & \multicolumn{3}{|c|}{ Annual Cost Savings (\$) } & \multicolumn{3}{|c|}{ Payback Period (year) } & \multirow{2}{*}{$\begin{array}{l}\text { Percent saving } \\
\text { difference b/w } \\
\text { HERV and ERV }\end{array}$} \\
\hline & & HERV & ERV & HRV & HERV & ERV & HRV & \\
\hline$A$ & Miami & 632 & 536 & -69 & 4.0 & 3.0 & --- & $18 \%$ \\
\hline B & Las Vegas & 392 & 292 & -18 & 6.4 & 5.5 & ---- & $34 \%$ \\
\hline C & Vancouver & 139 & 43 & -22 & 18.0 & ---- & ---- & $223 \%$ \\
\hline $\mathrm{D}$ & Toronto & 248 & 142 & 16 & 10.1 & 11.4 & ---- & $75 \%$ \\
\hline$E$ & Iqaluit & 368 & 254 & 136 & 6.8 & 6.3 & 8.6 & $45 \%$ \\
\hline
\end{tabular}

Table 4.11.2 - Sensitivity analysis for Miami with different humidity settings

\begin{tabular}{cccccccc}
\hline & & \multicolumn{2}{c}{ Annual Cost Savings (\$) } & \multicolumn{2}{c}{ Payback Period (year) } & $\begin{array}{c}\text { Percent saving } \\
\text { difference b/w } \\
\text { HERV and } \\
\text { ERV }\end{array}$ \\
\hline \multirow{2}{*}{ City } & RH\% & HERV & ERV & HERV & ERV & 2.3 & $14 \%$ \\
\cline { 2 - 7 } & $40 \%$ & 791 & 696 & 3.2 & 3.0 & $18 \%$ \\
\hline
\end{tabular}




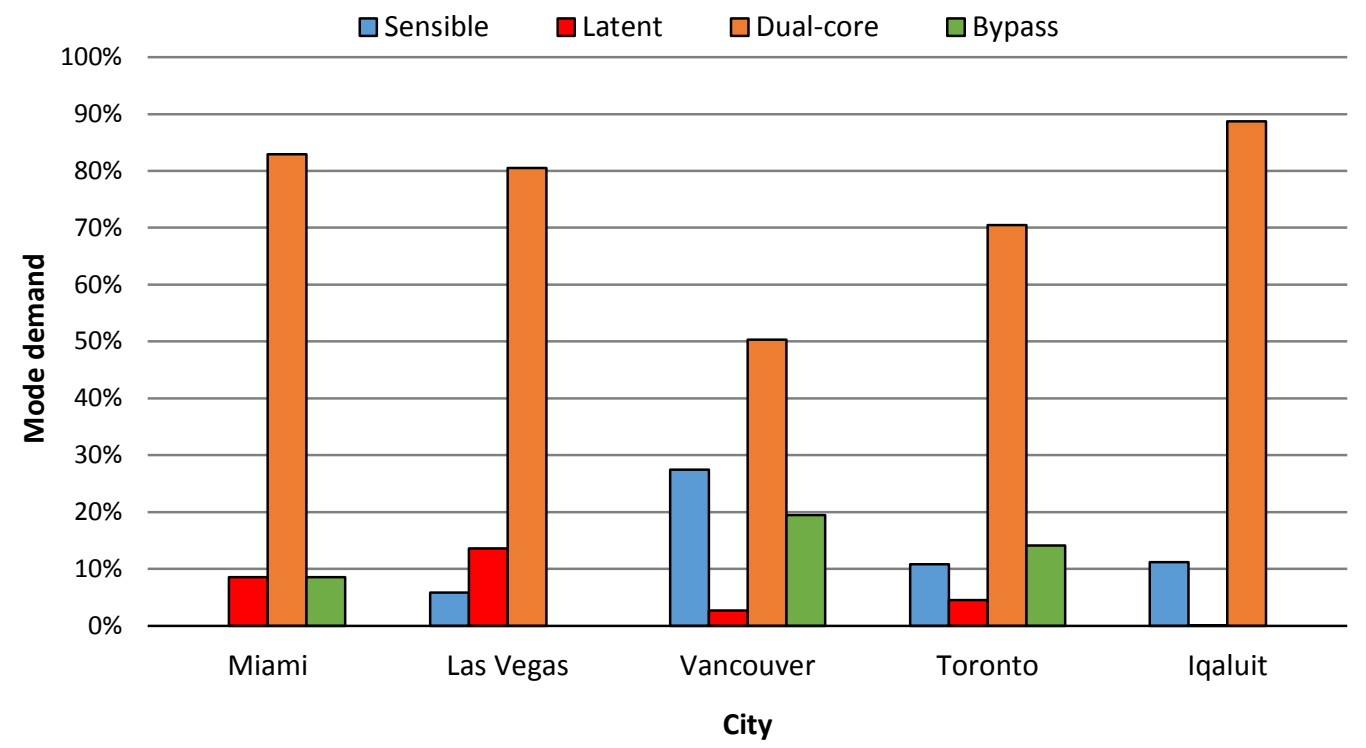

Figure 4.11.1 - Annual mode demand at lower setpoint ${ }^{21}$

Changed cooling setpoint to $25^{\circ} \mathrm{C}$ and $50 \% \mathrm{RH}$, and heating setpoints to $23^{\circ} \mathrm{C}$ and $30 \% \mathrm{RH}$ :

In this case, systems performance were determined for house with hotter and wetter indoor setpoints. Figure 4.11.2 illustrates the demands of the five selected cities. It is clear that the higher the setpoints, the greater the potential of free-cooling, i.e., the demand of the bypass mode for Vancouver increased to $35 \%$. In addition, savings presented in Table 4.11 .3 also show that the percent difference varied completely opposite to those presented in Table 4.11.1. For Miami, percent difference appears to be higher than any of the cases present above. For others, at higher setpoints, resulted in less advantage over the ERV. Therefore, when latent heat recovery becomes a major concern, the HERV experiences substantial loss of competitiveness against the ERV.

${ }^{21}$ cooling: $\mathrm{T}_{s}=21^{\circ} \mathrm{C}, \mathrm{RH}_{s}=50 \% /$ Heating: $\mathrm{T}_{s}=19^{\circ} \mathrm{C}, \mathrm{RH}_{s}=30 \%$ 


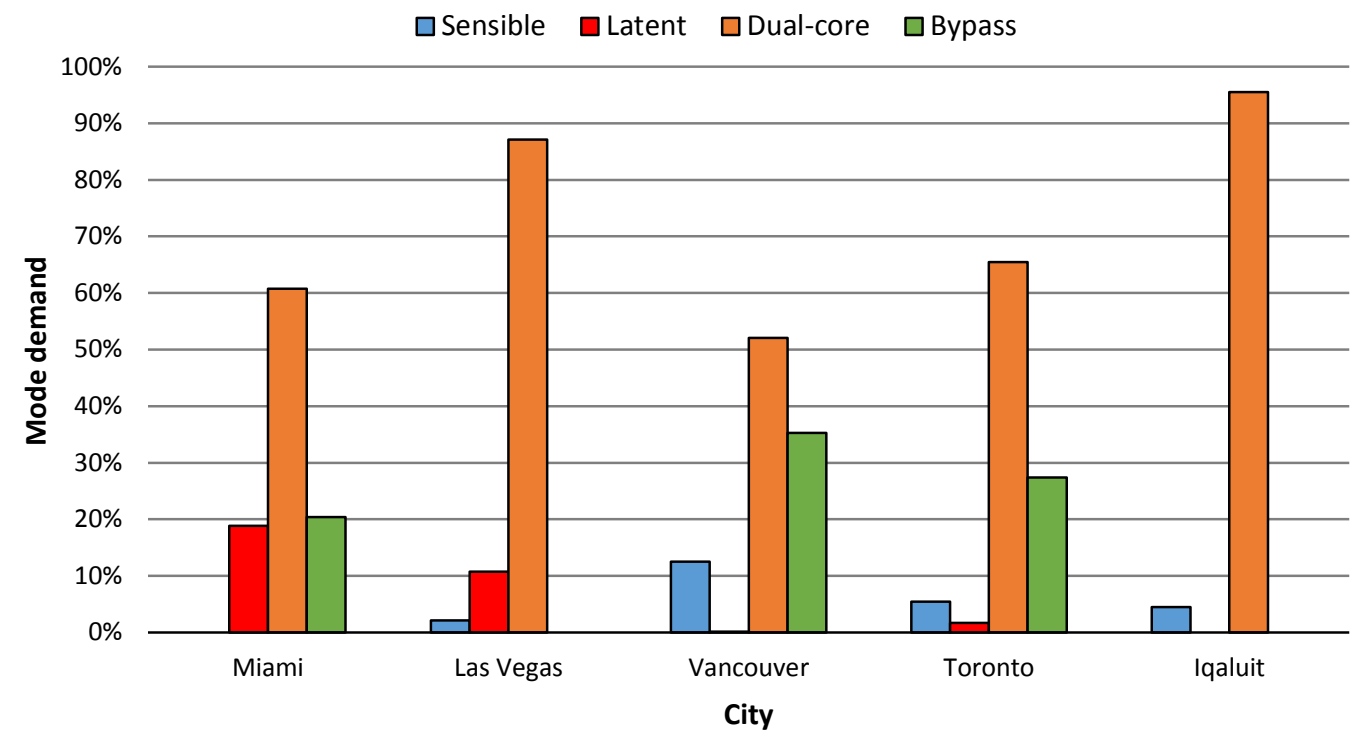

Figure 4.11.2 - Annual mode demand at higher setpoint ${ }^{22}$

Table 4.11.3 - Analysis for the three mechanical ventilation systems ${ }^{5}$

\begin{tabular}{|c|c|c|c|c|c|c|c|c|}
\hline \multirow[b]{2}{*}{ Zone } & \multirow[b]{2}{*}{ City } & \multicolumn{3}{|c|}{ Annual Cost Savings (\$) } & \multicolumn{3}{|c|}{ Payback Period (year) } & \multirow{2}{*}{$\begin{array}{l}\text { Percent saving } \\
\text { difference b/w } \\
\text { HERV and ERV }\end{array}$} \\
\hline & & HERV & ERV & HRV & HERV & ERV & HRV & \\
\hline A & Miami & 374 & 283 & -119 & 6.7 & 5.7 & ---- & $32 \%$ \\
\hline B & Las Vegas & 562 & 462 & -23 & 4.4 & 3.5 & ---- & $22 \%$ \\
\hline C & Vancouver & 190 & 79 & 16 & 13.2 & ---- & --- & $140 \%$ \\
\hline D & Toronto & 287 & 170 & 42 & 8.7 & 9.5 & ---- & $69 \%$ \\
\hline $\mathrm{E}$ & Iqaluit & 477 & 354 & 171 & 6.7 & 5.7 & --- & $35 \%$ \\
\hline
\end{tabular}

\subsection{2-Climates}

Upon the completion of the cost saving analysis, sensitivity analysis was conducted to verify the performance of the HERV in other regions across North America. The seasonal periods for these cities are presented in Appendix A, while the estimated results are presented in Figure 4.11.3 and Tables 4.11.4 and 4.11.5. The trend of these results resemble those presented in Section 4.8 and 4.9, especially for climate Type-A where the variations were found to be small. The HERV had the shortest payback period in regions that have temperate climate, however, discrepancy was detected. For both San Francisco and Nanaimo, the integrated bypass mode was actually turned off because they have dry summer and humidifier was needed. According to the Köppen-Geiger climate type

${ }^{22}$ cooling: $\mathrm{T}_{s}=25^{\circ} \mathrm{C}, \mathrm{RH}_{s}=50 \% /$ Heating: $\mathrm{T}_{s}=23^{\circ} \mathrm{C}, \mathrm{RH}_{s}=30 \%$ 
map for North America (Peel, Finlayson \& McMahon, 2007), these cities belong to a sub-climate type which differs from Vancouver. The sub-climate are defined by the second and third letters of the Köppen climate classification. Both San Francisco and Nanaimo belong to sub-climate Type$\mathrm{C} s b$, where the second letter $s$ and the third letter $b$ denote dry and warm summer, respectively. In contrast, Vancouver belongs to a slightly different sub-climate Type-C $f b$ that has humid $(f)$ and warm $(b)$ summer.

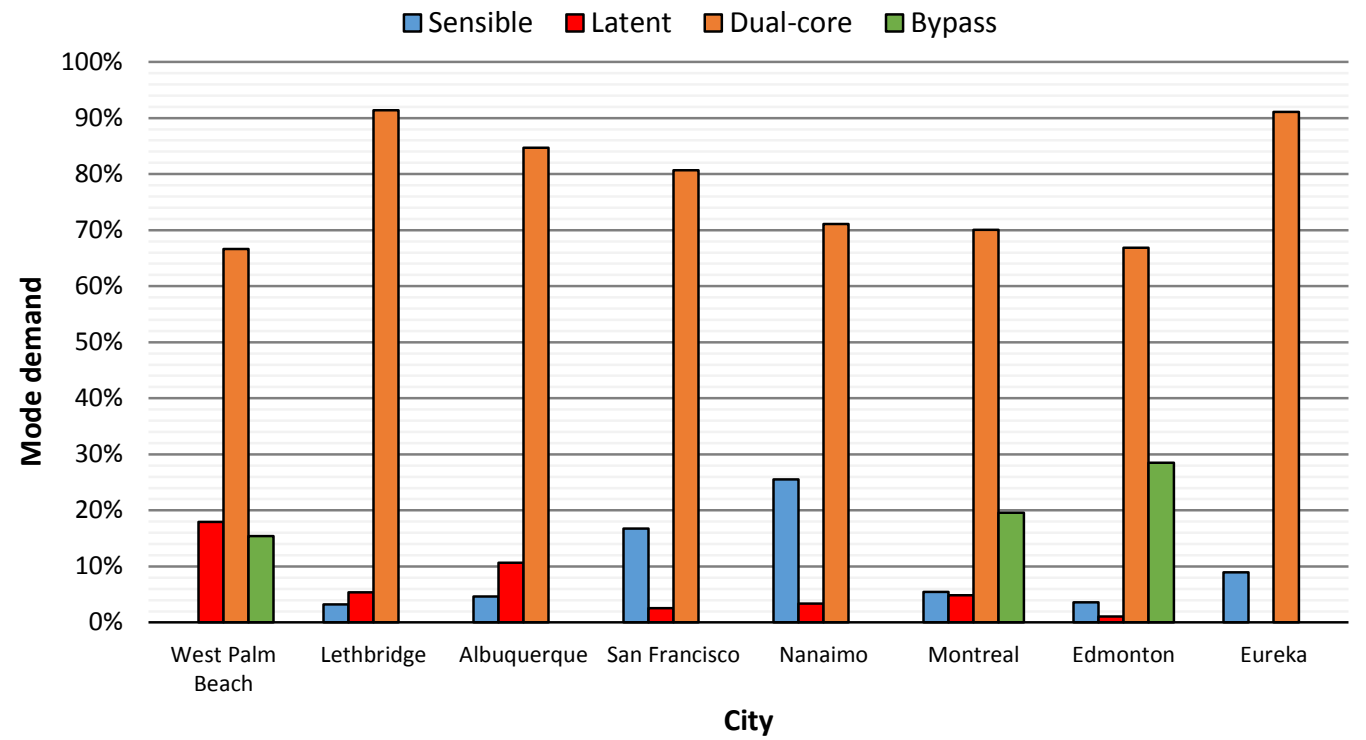

Figure 4.11.3 - Annual mode demand for additional cities

Table 4.11.4 - Zone-by-zone analysis for the three mechanical ventilation systems

\begin{tabular}{|c|c|c|c|c|c|c|c|c|}
\hline Zone & City & HERV & HERV & HERV & HERV & ERV & HRV & $\begin{array}{c}\text { Percent } \\
\text { difference b/w } \\
\text { HERV and ERV }\end{array}$ \\
\hline A & West Palm Beach & 473 & 381 & -101 & 5.3 & 4.2 & --- & $24 \%$ \\
\hline B & Albuquerque & 355 & 253 & -11 & 7.0 & 6.4 & --- & $40 \%$ \\
\hline $\mathrm{C}$ & San Francisco & 191 & 99 & -39 & 13.1 & 16.2 & ---- & $93 \%$ \\
\hline $\mathrm{D}$ & Edmonton & 307 & 187 & 58 & 8.1 & 8.6 & ---- & $65 \%$ \\
\hline$E$ & Eureka & 323 & 238 & 126 & 7.7 & 6.8 & 9.3 & $36 \%$ \\
\hline
\end{tabular}


Table 4.11.5 - Cost saving attributed to free-cooling

\begin{tabular}{ccccc}
\hline Zone & City & Cost Saving (\$) & $\begin{array}{c}\text { Percent Saving } \\
\text { (\%) }\end{array}$ & $\begin{array}{c}\text { Payback Reduction } \\
\text { (months) }\end{array}$ \\
\hline A & West Palm Beach & 6 & 1 & 0.8 \\
\hline D & Montreal & 6 & 2 & 2.4 \\
\hline D & Edmonton & 7 & 3 & 2.4 \\
\hline
\end{tabular}

\subsection{3 - Ventilation Rates}

The effects of airflow rate on the benefits attributed to the bypass mode (or economizer option) was also studied. Taking Toronto as an example, increasing the default airflow rate of free-cooling $(52 \mathrm{~L} / \mathrm{s})$ by twofold and threefold, the cost benefits of the system were investigated. Figure 4.11.4 illustrates the cost benefit of the HERV for free-cooling at different airflow rate. Results show that the savings (without motor expense) increased from \$278 to \$293 when increasing the airflow rate of free-cooling from $1 \mathrm{x}$ to $3 \mathrm{x}$. At the same time, however, it also increased the motor power draw from $\$ 25$ to $\$ 36$. In addition, results also show that the operating cost ratio increased accordingly from $8.8 \%$ to $12.2 \%$. From the overall perspective, high power vent produced greater cooling savings but higher motor power draw, and hence, might not be necessary for efficient free-cooling unless the savings are sufficient to offset the expenses.

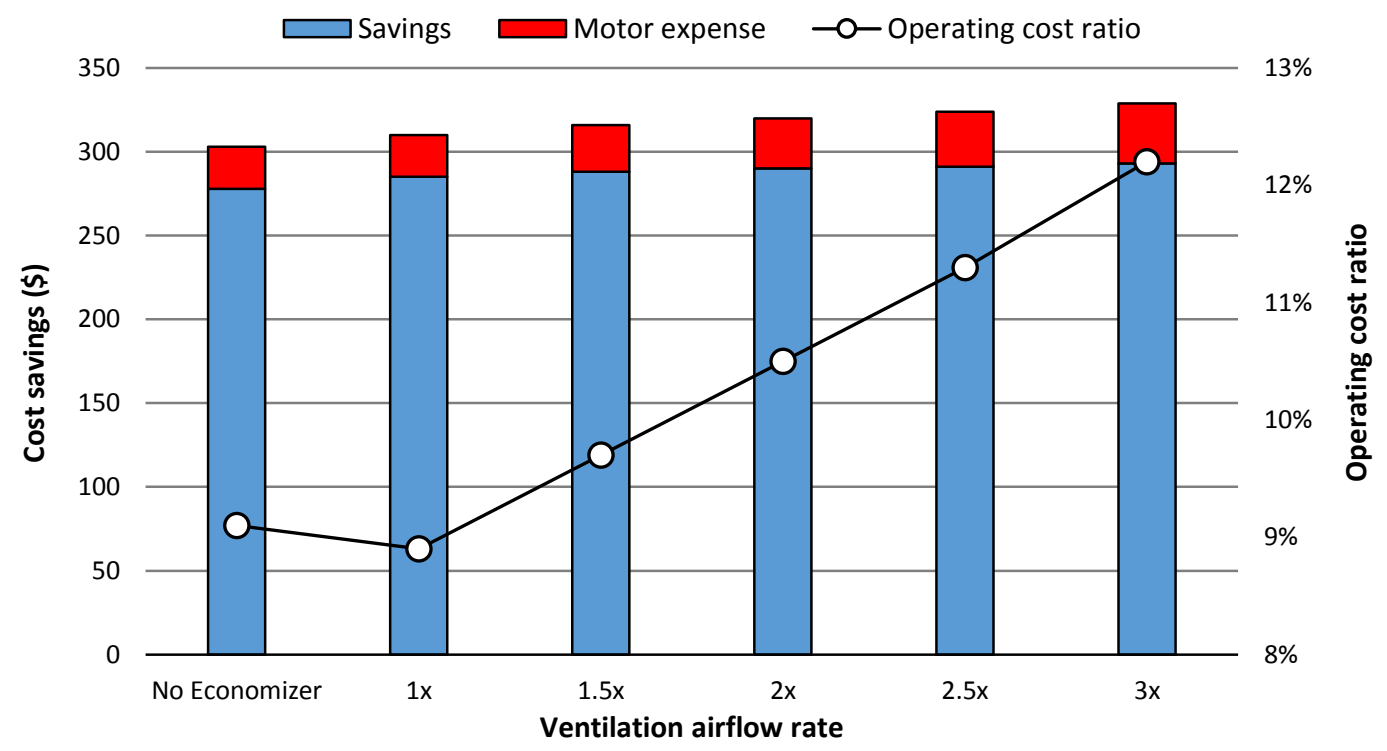

Figure 4.11.4 - Cost benefit of the system at different airflow rate

Sensitivity analysis was also carried out to determine the effects of house ventilation airflow rate on the seasonal PSD between the HERV and ERV. The house airflow rate varied from 1x (52 L/s) 
to $3 \mathrm{x}(156 \mathrm{~L} / \mathrm{s})$ and the cost savings were record. For cooling period, Figure 4.11.5 reveals that as the house airflow rate increased, the seasonal cost savings attributed to the HERV increased as well. In contrast, the ERV resulted in negative savings and continued to fall along with the ventilation airflow rate, and hence, higher PSD resulted. The increase in negative cost savings can be explained by 1) the higher motor power draw, 2) the lower demand of sensible heat recovery, and 3) the redundant heat recovery. In comparison, 1) the HERV implemented ECM motors to minimize motor power draw, 2) the HERV had relatively higher sensible efficiency under dualcore mode, and 3) the HERV with integrated economizer control prevented redundant sensible heat recovery. Therefore, the advantages of the HERV for cooling period would become more obvious under higher house ventilation airflow rate. Figure 4.11.6 illustrates the PSD for heating period. In this case, both the HERV and ERV resulted in positive cost savings. It is interesting to note that the cost savings of the ERV decreased for $3 \mathrm{x}$ house airflow rate. This can be explained by the high power consumption of the PSC motors at high speed; the power consumption was based on the correlation obtained from the specification sheet of the ERV, as shown in Figure 4.7.1. From the overall perspective, the major factor that significantly affected the PSD between the two systems at high ventilation airflow rate was the motors. A more detailed analysis for the effects of increased ventilation will be carried out in Chapter 5 using the developed TRNSYS model of the HERV.

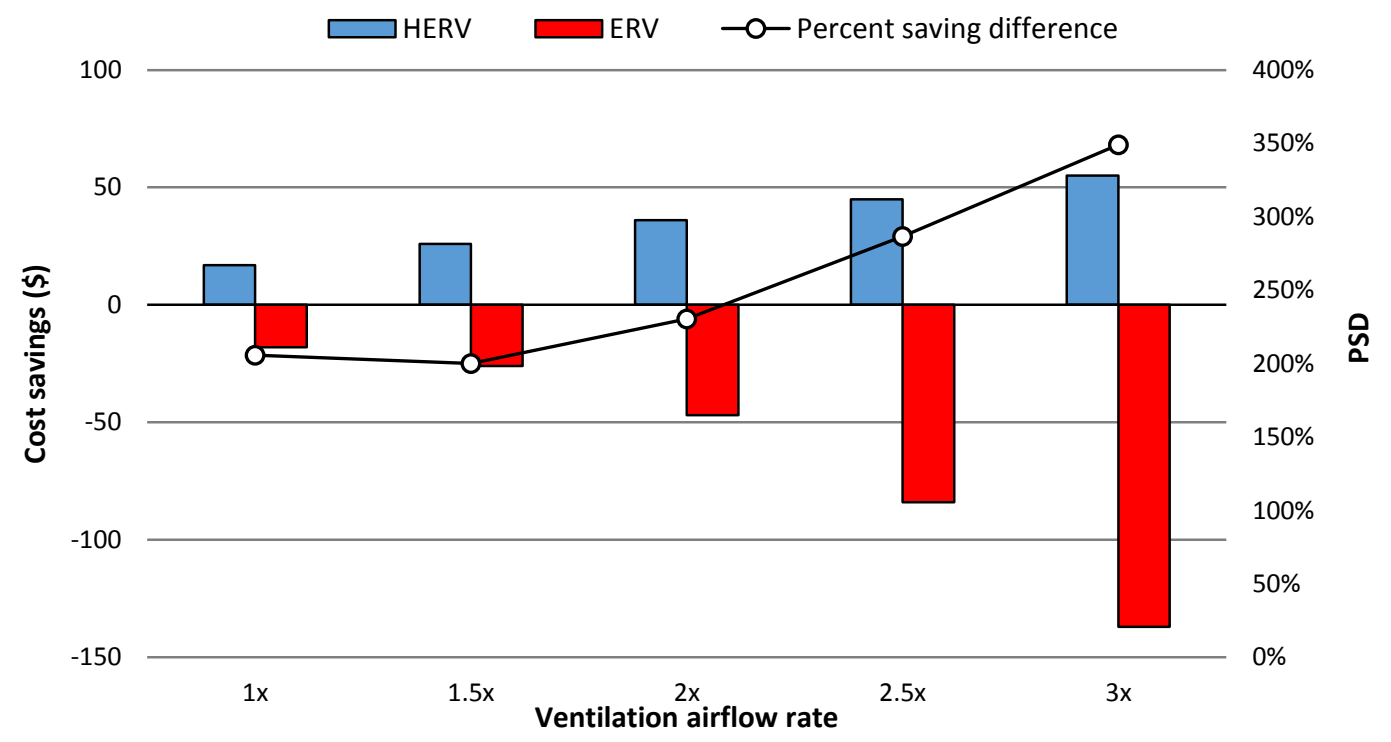

Figure 4.11.5 - PSD between the HERV and ERV for cooling period 


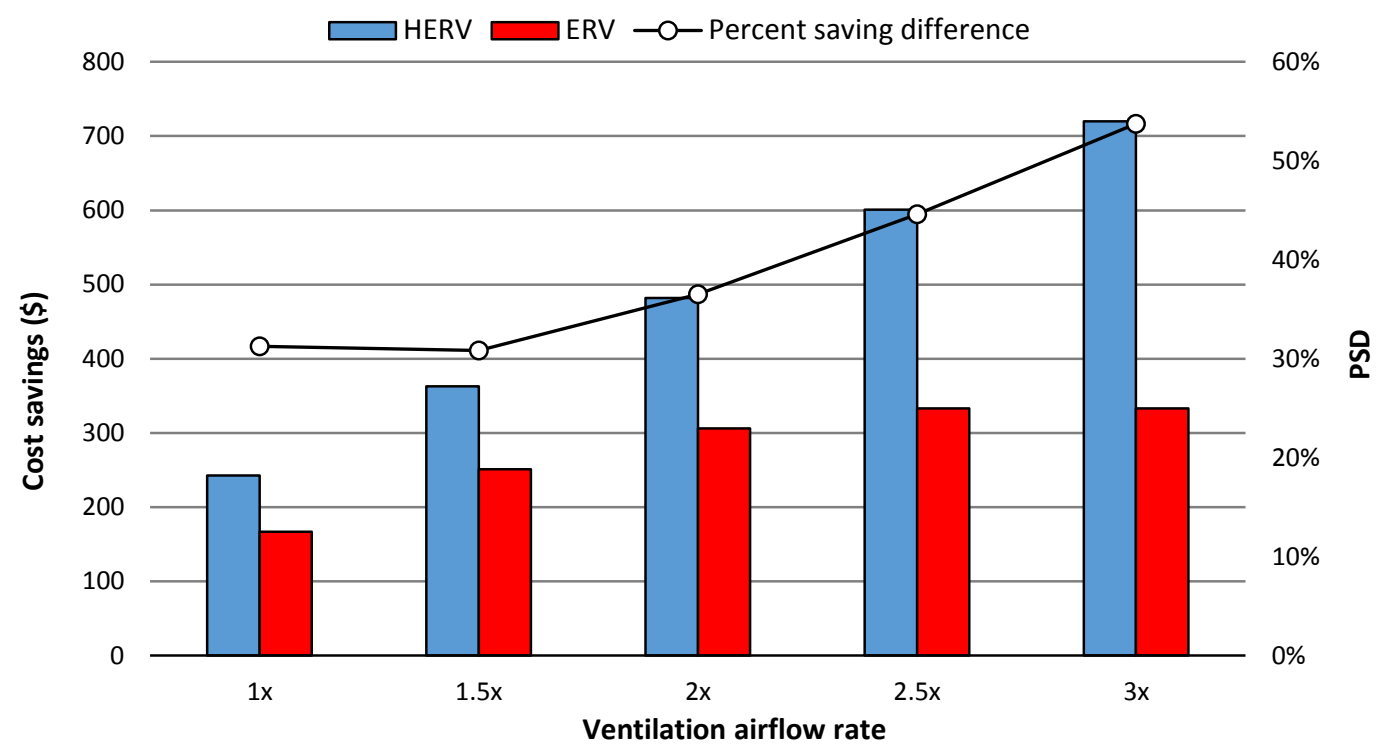

Figure 4.11.6 - PSD between the HERV and ERV for heating period

\subsection{4 - Sensible Efficiency}

For the case study presented above, the HERV was assumed to have an overall sensible efficiency 1.2 times higher than the single core HRV (or higher than the value obtained from Eq. 4.3.1). In this section, sensitivity was carried out to investigate the effect of the "additional" sensible heat recovery on the overall savings and feasibility of the proposed system. Table 4.11.6 presents the calculated cost savings for HERV with different assumed dual-core efficiency: 1.05, 1.1, 1.15 and 1.2 times. For regions of the United States, savings were found to be insensitive to the changes of dual-core efficiency, even though the dual-core mode was required more $60 \%$ of the time (see Figure 4.8.1). That is, from efficiency 1.05 to 1.2 times, the annual cost savings of Miami changed from $\$ 500$ to $\$ 503$, and the payback period remained nearly the same. This can be explained by the high demand on the latent heat recovery, and hence, the savings were less sensitive towards the increased sensible heat exchange. For Canadian regions, however, annual cost savings were sensitive towards the dual-core efficiency. From efficiency 1.05 to 1.2, the percent difference of the cost savings ranged from $7.3 \%$ (Toronto) to $8.3 \%$ (Iqaluit). In addition, the change of efficiency reduced the payback period by around 1 year for both Vancouver and Toronto, and 6 months for Iqaluit. From the overall perspective, the HERV could be a feasible option for both temperate and continental, even in the worst case where the dual-core efficiency was small (1.05). 
Table 4.11.6 - Cost savings of the HERV with different overall sensible efficiency

\begin{tabular}{|c|c|c|c|c|c|c|c|c|c|c|}
\hline \multirow[b]{2}{*}{ Zone } & \multirow[b]{2}{*}{ City } & \multicolumn{4}{|c|}{ Annual cost savings (\$) } & \multirow{2}{*}{$\begin{array}{c}\text { Percent } \\
\text { difference } \\
\text { b/w } 1.05 \\
\text { and } 1.2\end{array}$} & \multicolumn{4}{|c|}{ Payback period (year) } \\
\hline & & 1.05 & 1.1 & 1.15 & 1.2 & & 1.05 & 1.1 & 1.15 & 1.2 \\
\hline$A$ & Miami & 500 & 501 & 501 & 503 & 0.6 & 5.0 & 5.0 & 5.0 & 5.0 \\
\hline B & Las Vegas & 457 & 461 & 465 & 469 & 2.6 & 5.5 & 5.4 & 5.4 & 5.3 \\
\hline C & Vancouver & 143 & 147 & 151 & 155 & 7.7 & 17.5 & 17 & 16.5 & 16.1 \\
\hline $\mathrm{D}$ & Toronto & 241 & 248 & 254 & 260 & 7.3 & 10.4 & 10.1 & 9.8 & 9.6 \\
\hline $\mathrm{E}$ & Iqaluit & 384 & 396 & 407 & 419 & 8.3 & 6.5 & 6.3 & 6.1 & 6.0 \\
\hline
\end{tabular}

\section{Section 4.12 - Conclusion}

In this study, the feasibility of an integrated heat and energy ventilation (HERV) with a built-in economizer was evaluated quantitatively using an Excel based analysis tool. Under wellconditioned house, the calculated results showed that the proposed HERV was recommended for both temperate and continental climates. In addition, the HERV often resulted in a lower OCR, however, the system sometimes experienced a substantial loss of competitiveness against the ERV due to the high capital cost and demand of latent heat recovery (e.g., Miami). Results also revealed that the ERV was suitable and recommended for hot and humid regions, while the HRV was more efficient in cold regions. With the current leaning towards energy conservation, the proposed approach is valuable for future net-zero energy building design in North America. In theory, the findings from this chapter contribute to the field of energy conservation by providing a preliminary study to support the pending thought that integrating the HERV with an economizer could be promising. In practice, the development of Ebat provides an easy-to-use and yet, editable analysis tool for non-technical users to provide a quick estimate of system performance for evaluation without having an expert to develop and run a detailed simulation.

The performance data of the HRV and ERV systems in the research houses were used as the default data in the Excel tool because the data was accessible from the previous research. The HRV/ERV efficiencies in the tool were designed to be replaceable by the users in the future. As part of this investigation, a detailed TRNSYS model will be developed, and more experimental results will be collected. That means the results presented in this chapter are only part of the preliminary results of the overall project and many of the parameters used in the tool can be changed as needed. Finally, 
the major limitation of the presented analysis was the exclusion of the extreme outdoor conditions. TRNSYS adopts the typical meteorological year (TMY) weather data that compose of historic weather data taken from a number of years in the past. In other words, these weather data represent typical rather than extreme outdoor conditions. Therefore, the TMY data are not suited for building energy analysis in the worst-case conditions occurring at a location. 


\section{Chapter \#5 - Preliminary TRNSYS Modeling and Simulation (WINTER 2013)}

\section{Section 5.1 - Introduction}

This chapter was devoted to the development of computer models for HERV system in a parallelflow (see Figure 5.3.1) and counter-flow (see Figure 5.3.4) arrangements using constant-efficiency method. Han (2009) revealed that the sensible efficiency of HRV would become nearly constant when excluding the effect of motor heat gain. The internal heat gain of HERV is unknown, and hence, the use of constant-efficiency enables comparisons to be made among all different devices (e.g., HRV, ERV, and HERV) without considering the effects of the additional heat gained from fan motor. These models were created as components to be used in the transient simulation program TRNSYS, along with the house model of TRCA Archetype Sustainable House-A. All the computer models were written in FORTRAN, which contain the mathematical abstract of the modelled equipment. Thereafter, a FORTRAN compiler Parallel Studio XE 2011 was used to turn the component code into a 32-bit dynamic link library (DLL). The parallel-flow HERV (HERV $))$ model was called TRNSYS Type-270, and the counter-flow HERV (HERV $)_{c}$ model was called Type-291. The icons for these two models are presented in Figure 5.1.1.

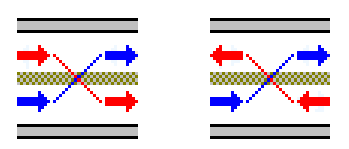

Figure 5.1.1 - TRNSYS icon for the Type 270 (left panel) and 291 (right panel) HERV

Currently, HRVs and ERVs are usually designed in a cross-flow arrangement (e.g., VanEE, Lifebreath, and Carrier), and their performances have been studied in various literature articles (Zhang \& Jiang, 1999; Zhang, Jiang, Zhang, Deng \& Jin, 2000; Ouazia, Swinton, Julien \& Manning, 2006). However, the potential of the proposed HERV remains unknown. The presented study considered the HERV in both parallel-flow and counter-flow arrangements in order to derive a general conclusion for such a novel HVAC component to be used in different regions of North America. This chapter consists of a short exposition of the methodology, followed by a case study that intended to provide an exploratory analysis in order to generalize the potential of the HERVs.

\section{Section 5.2 - House Modeling}

The completed HERV models (both Type-270 and Type-291) were chosen to be simulated in the context of airtight environment where mechanical ventilation plays a significant role for indoor air quality control. In this case, the Archetype Sustainable House-A (ASH-A) was selected for the 
case study. The architectural appearance of the house is shown in Figure 5.2.1. The ASH-A is equipped with common technologies currently in the residential building market that aims at demonstrating the potentials of reducing the amount of energy needed to sustain future housing (Dembo, Fung, Ng \& Pyrka, 2010).

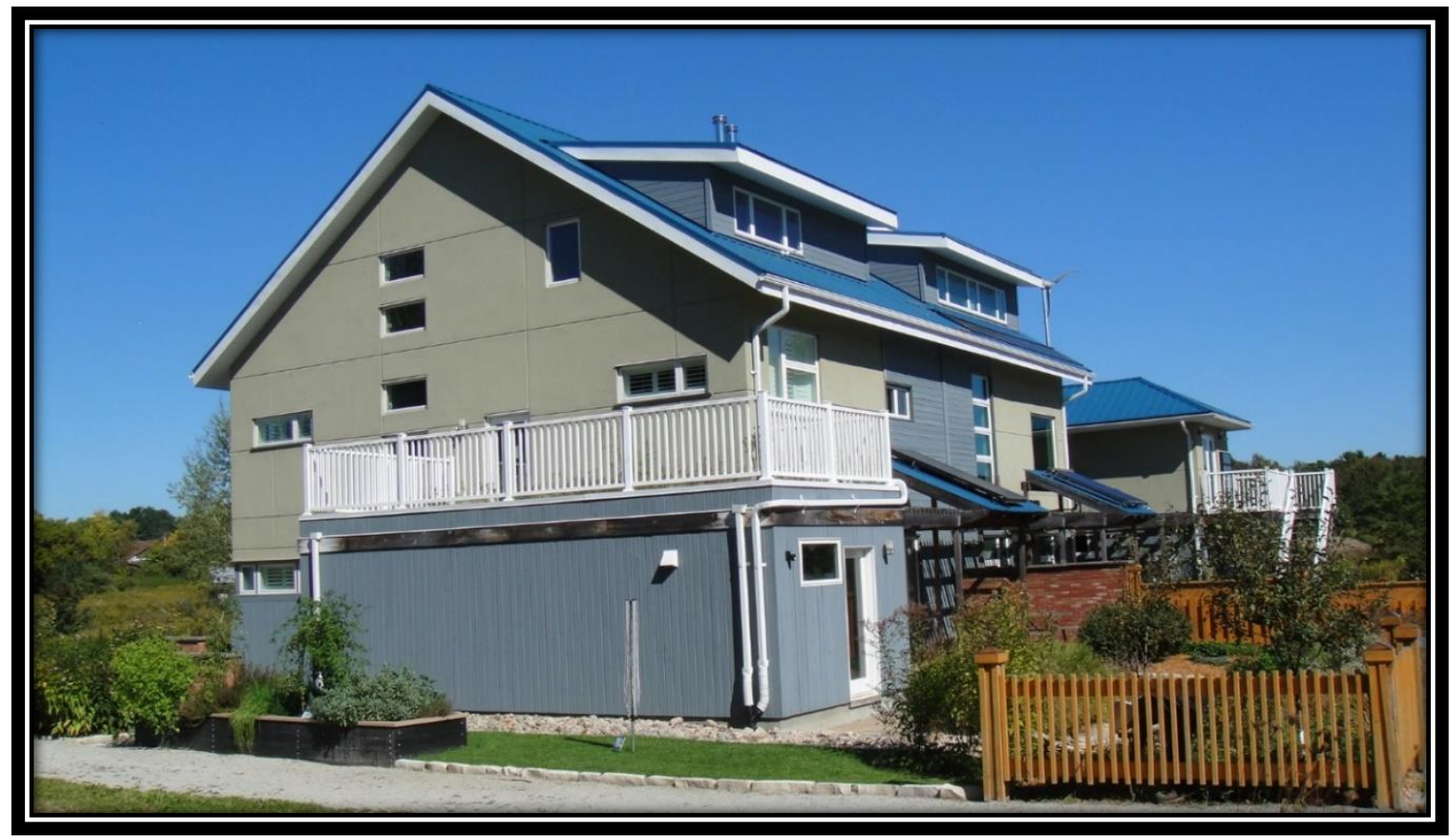

Figure 5.2.1 - Toronto Regional Conservation Authority's (TRCA) Archetype Sustainable House A

The ASH-A was modeled and validated by Safa (2012) using TRNBuild with known building envelope characteristics. The house was modelled as a TRNSYS component Type-56 multi-zone building model, which allows transient estimates of thermal behavior of a house divided into different thermal zones (Solar Energy Laboratory, 2005). The ASH-A model contains four thermal zones that correspond to four floors of the house, all served by a two-stage variable capacity air source heat pump (ASHP) identical to the configuration in the actual building. This model considers the details of the house properties, appliances and ventilation equipment in order to simulate accurately its performance. The details of house and HVAC equipment specifications are listed in Table 3.2.1 and 3.2.2. It is worth noticing that the ASHP was also modeled and validated by Safa (2012) based on the data collected from monitoring the ASHP.

The internal heat gains from electrical appliances and occupants play a great role in affecting the comfort level, as well as the energy use for space heating and cooling. The inputs of heat gains for 
House-A can be categorized into four types, as shown in Table 5.2.1. These values indicate that the major appliance (e.g., fridge) contributes $46.3 \%$ of the total convective power. Besides, the internal heat gain from to occupants was obtained according to the load profiles created using incandescent light bulbs with schedules (Safa, 2012). It is worth noticing that the heat gain from mechanical ventilation system (e.g., HERV) is excluded; the incompletion of the HERV prototype is the reason to this exclusion.

Table 5.2.1 - Heat gains from various internal sources (inputs of Type-56)

\begin{tabular}{cccc}
\hline Heat Gain Type & $\begin{array}{c}\text { Radiative Power } \\
\text { (kJ/hour) }\end{array}$ & $\begin{array}{c}\text { Convective Power } \\
\text { (kJ/hour) }\end{array}$ & $\begin{array}{c}\text { Absolut Humidity } \\
\text { (kJ/hour) }\end{array}$ \\
\hline Major Appliances & 0 & 900 & 0 \\
Interior Lighting & 225 & 225 & 0 \\
Occupants & 144 & 216 & 0.232 \\
Other Appliances & 0 & 450 & 0 \\
\hline
\end{tabular}

\section{Section 5.3 - Computer Modelling of HERV Using TRNSYS}

\subsection{1 - Parallel-Flow Computer Model}

In parallel-flow HERV, both hot and cold airstreams enter the system at the same end and travel perpendicularly to one another through sensible and enthalpy cores. The simplified scheme of a parallel-flow HERV is illustrated in Figure 5.3.1.

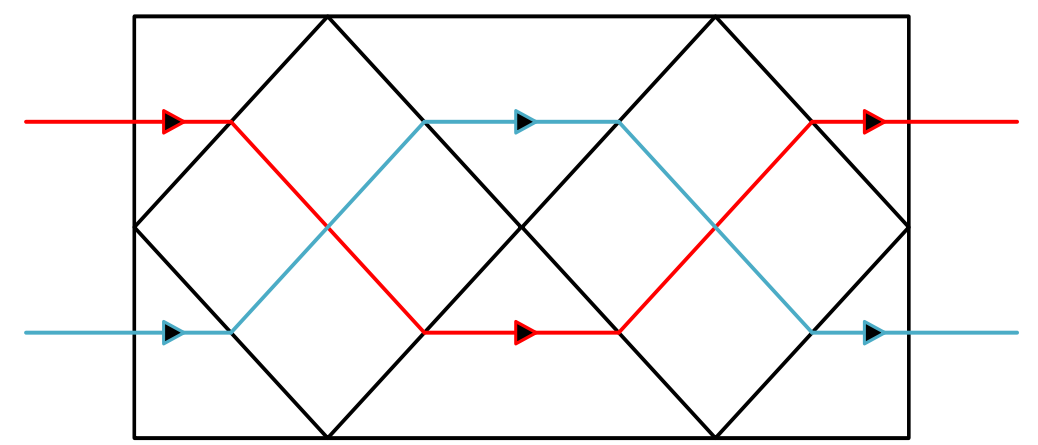

Figure 5.3.1 - Simple scheme showing the parallel-flow HERV

The TRNSYS component is defined with a number of time-dependent and time-independent input variables (in the form of INPUTS and PARAMETERS, respectively) and output variables. Therefore, the Type-270 model was built based on 4 PARAMETERS, 13 INPUTS and 17 OUTPUTS. The input variables contain the following basic INPUTS: 
1. Supply and exhaust air temperatures $\left[{ }^{\circ} \mathrm{C}\right]$.

2. Supply and exhaust air relative humidity [\%].

3. Supply and exhaust volumetric air flow rates $[\mathrm{kg} / \mathrm{hour}]$.

4. Supply and exhaust air pressures [atm].

5. Supply and exhaust air pressure drop of the airflows [atm].

6. ON/OFF signal of the system, economizer control [--].

7. Flow control signal [--].

Supply air is introduced from the local surroundings, while the exhaust air is a mix of air from the four zones of ASH-A. In addition, the flow signal is used to control the amount of exhaust volumetric air flow rate in order to meet or achieve the need of each operation mode. The list of PARAMETERS (time-independent inputs) of the component include:

1. Sensible and latent efficiencies [--].

2. Rated power of the modeled equipment $[\mathrm{kJ} / \mathrm{hour}]$.

Finally, the output variables of the component contain the followings:

1. Air temperature $\left[{ }^{\circ} \mathrm{C}\right]$ and relative humidity $[\%]$ at the outlet of the first core.

2. Air temperature and relative humidity at the outlet of the system (second core).

3. Humidity ratio [--] at the outlet of first and second core.

4. Supply and exhaust air pressure $[\mathrm{Pa}]$.

5. Sensible heat, latent heat and total energy transfer across the exchange processes $[\mathrm{kJ} / \mathrm{hour}]$.

On a hot day, the $\operatorname{HERV}_{p}$ allows hot and humid outside air to be preconditioned using the cool and dry stale air. This situation is reversed during cold days. The validity of the HERV system, therefore, can be accessed based on house demand on HVAC equipment. To understand the idea of a parallel-flow HERV enthalpy transfer, psychrometrics of enthalpy exchange are illustrated in Figure 5.3.2 and 5.3.3 to depict the properties of fresh air at different stages. Figure 5.3.2 reveals that, when supply air is cooled without the loss or gain of moisture, the process yields a straight horizontal line on the chart (from the state point F1 to F2) ${ }^{23}$. The exchange process inside an

\footnotetext{
${ }^{23}$ In this study, state point F1 to F2 is named primary air treatment, while F2 to F3 is named secondary air treatment.
} 
enthalpy core involves both sensible and latent heat transfer (from the state point F2 to F3); the sensible heat transfer is associated with an increase in dry bulb temperature, and the latent heat transfer is associated with a decrease in humidity ratio. The overall sensible efficiency can be estimated as:

$\varepsilon_{S} \approx \frac{(28.78-33.90)}{(22.07-33.90)} \times 100$

$\varepsilon_{S} \approx 43.3 \%$

The simple calculation implies that the secondary air treatment is useful only for dehumidification, but is redundant for cooling because air temperature is higher than the first treatment. In the winter, similar results are obtained (see Figure 5.3.3, the state point F1 to F2 and the point F2 to F3). Air temperature decreases as it progresses to the second core. In other words, the $\operatorname{HERV}_{p}$ is an economically infeasible choice because we are paying more for less.

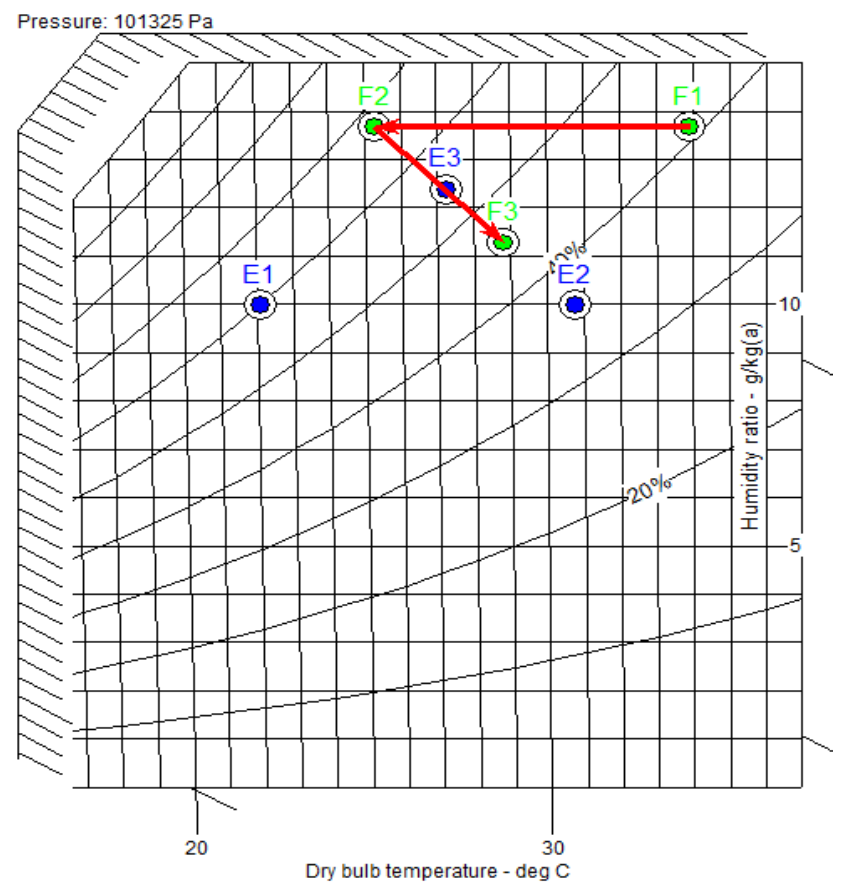

Figure 5.3.2 - Psychrometric chart representing state points of fresh air and exhaust air during dual-core mode in summer $\left(\mathrm{HERV}_{p}\right)$

*Outside air conditions are $33.9^{\circ} \mathrm{C}$ and $41 \% \mathrm{RH}$ (F1), inside air conditions are $22.1^{\circ} \mathrm{C}$ and $59.6 \% \mathrm{RH}$ (E1). Sensible efficiency of the sensible core is $74 \%$, while the enthalpy core has $65 \%$ for both sensible and latent efficiencies. 


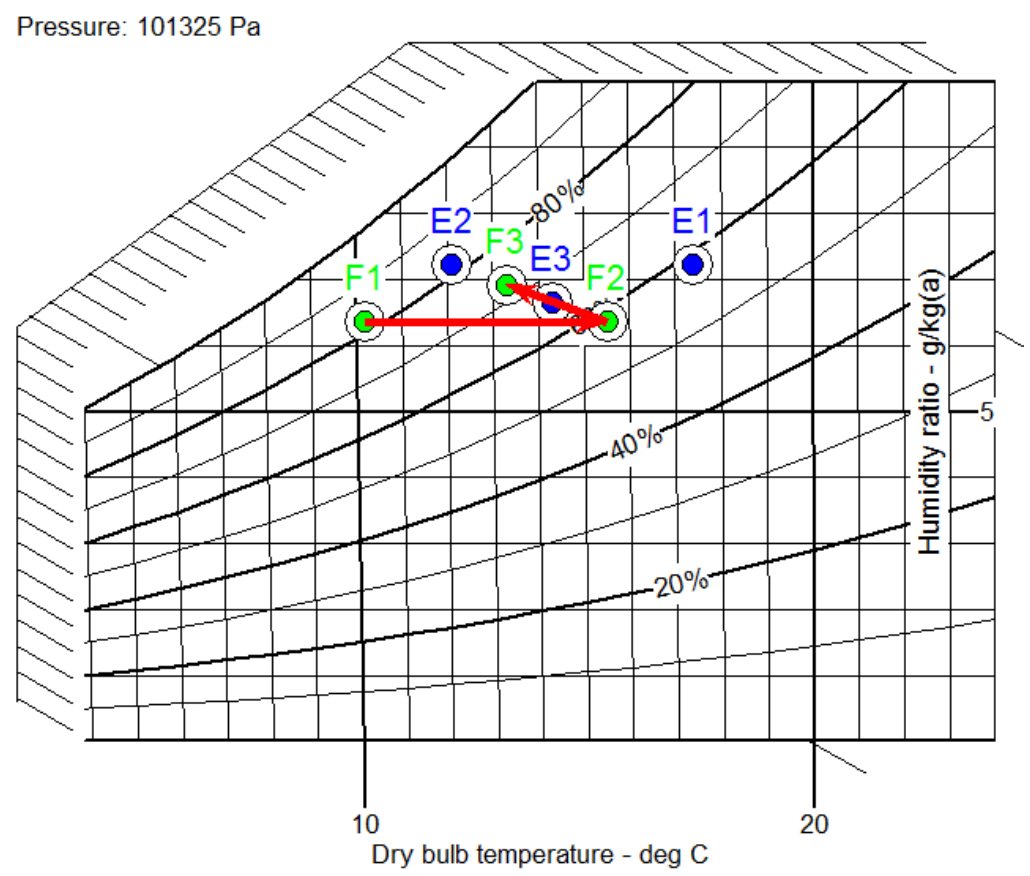

Figure 5.3.3 - Psychrometric chart representing state points of fresh air and exhaust air during dual-core mode in winter $\left(\mathrm{HERV}_{p}\right)$

*Outside air conditions are $10.2^{\circ} \mathrm{C}$ and $82.1 \% \mathrm{RH}$ (F1), inside air conditions are $17.4^{\circ} \mathrm{C}$ and $58.3 \% \mathrm{RH}$ (E1). Sensible efficiency of the sensible core is $74 \%$, while the enthalpy core has $65 \%$ for both sensible and latent efficiencies.

\subsection{2 - Counter-Flow Computer Model}

In counter-flow HERV, both hot and cold airstreams enter the system at the different ends and travel perpendicularly to one another through sensible and enthalpy cores. The simplified scheme of counter-flow HERV is illustrated in Figure 5.3.4.

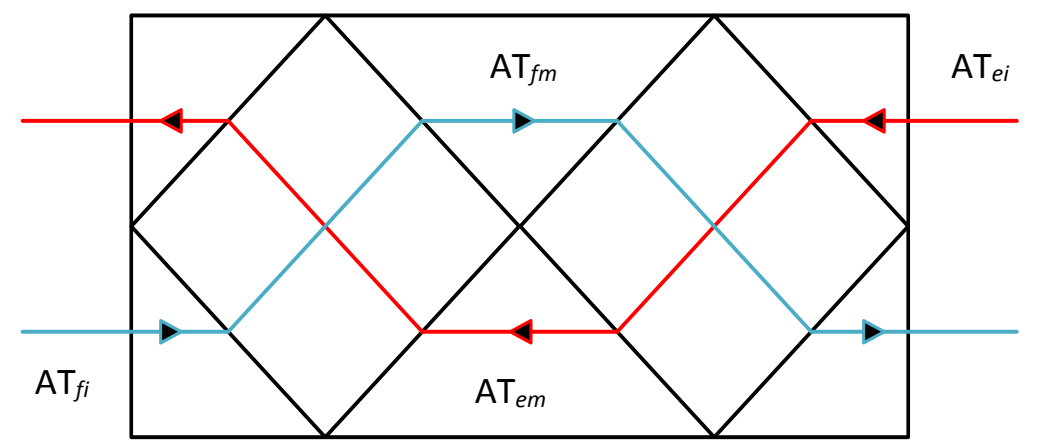

Figure 5.3.4 - Simple scheme showing the counter-flow HERV

The model for counter-flow HERV was modeled based on the same numbers of PARAMETER, INPUTS and OUTPUTS as the Type-270. However, the flow arrangement makes the outlet states of hot and cold air difficult to predict; airflow of one stream exchanges heat/enthalpy with the air that has been previously processed, see Figure 5.3.4. In other words, the states of moist air at each 
end of the system become impossible to be predicted from the method introduced in Section 5.3.1. As a result, iteration method was applied along with the constant-efficiency method. By considering the heat capacity rates of both the incoming airstreams are the same, initial guesses for the states of moist air at the middle of the system can be estimated.

$$
\begin{aligned}
& A T_{f m}=A T_{f i}+\frac{\left(A T_{e m}-A T_{f i}\right) C_{m i n} \varepsilon_{s s}}{m_{s} C_{p f}} \approx A T_{f i}+\left(A T_{e m}-A T_{f i}\right) \varepsilon_{s s} \\
& A T_{e m}=A T_{e i}-\frac{\left(A T_{e i}-A T_{f m}\right) C_{m i n} \varepsilon_{s e}}{m_{s} c_{p e}} \approx A T_{e i}-\left(A T_{e i}-A T_{f m}\right) \varepsilon_{s e}
\end{aligned}
$$

Within a certain tolerance, TRNSYS kernel continues to iterate until the convergence of all components during each time step is reached, by making sure that the values of the output array (OUTPUTS) for each component have stopped changing.

The process of enthalpy exchange is illustrated in Figure 5.3.5. The secondary air treatment in counter-flow arrangement is beneficial because it further reduces dry bulb temperature of fresh air, while remove excessive moisture at the same time. The advantage of the second core in this case is completely exploited. The resulting sensible efficiency of the system can be estimated:

$\varepsilon_{S} \approx \frac{(24.23-33.90)}{(22.05-33.90)} \times 100$

$\varepsilon_{S} \approx 81.6 \%$

Therefore, for a HRV that has $74 \%$ of sensible efficiency, the counter-flow HERV could outperform it by the secondary air treatment. In terms of system performance, the counter-flow HERV is worthy of consideration that could lead to further energy savings. 


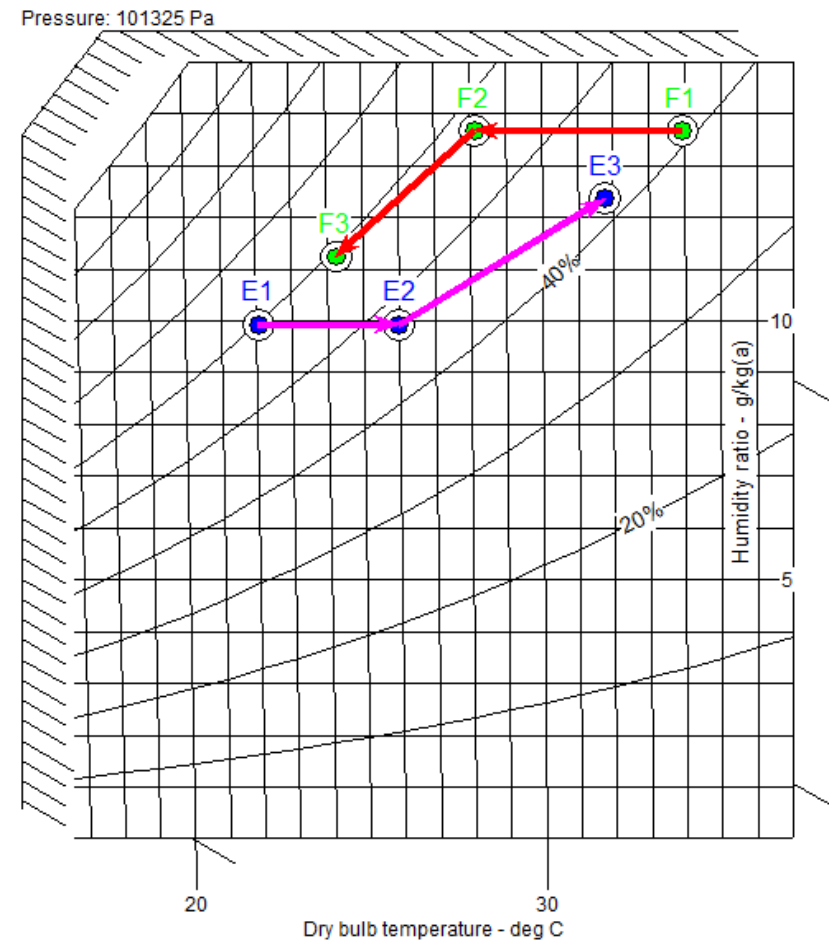

Figure 5.3.5 - Psychrometric chart representing state points of fresh air and exhaust air during dual-core mode in summer $\left(\mathrm{HERV}_{c}\right)$

*Outside air conditions are $33.9^{\circ} \mathrm{C}$ and $41 \% \mathrm{RH}(\mathrm{F} 1)$, inside air conditions are $22.1^{\circ} \mathrm{C}$ and $59.8 \% \mathrm{RH}$ (E1). Sensible efficiency of the sensible core is $74 \%$, while the enthalpy core has $65 \%$ for both sensible and latent efficiencies.

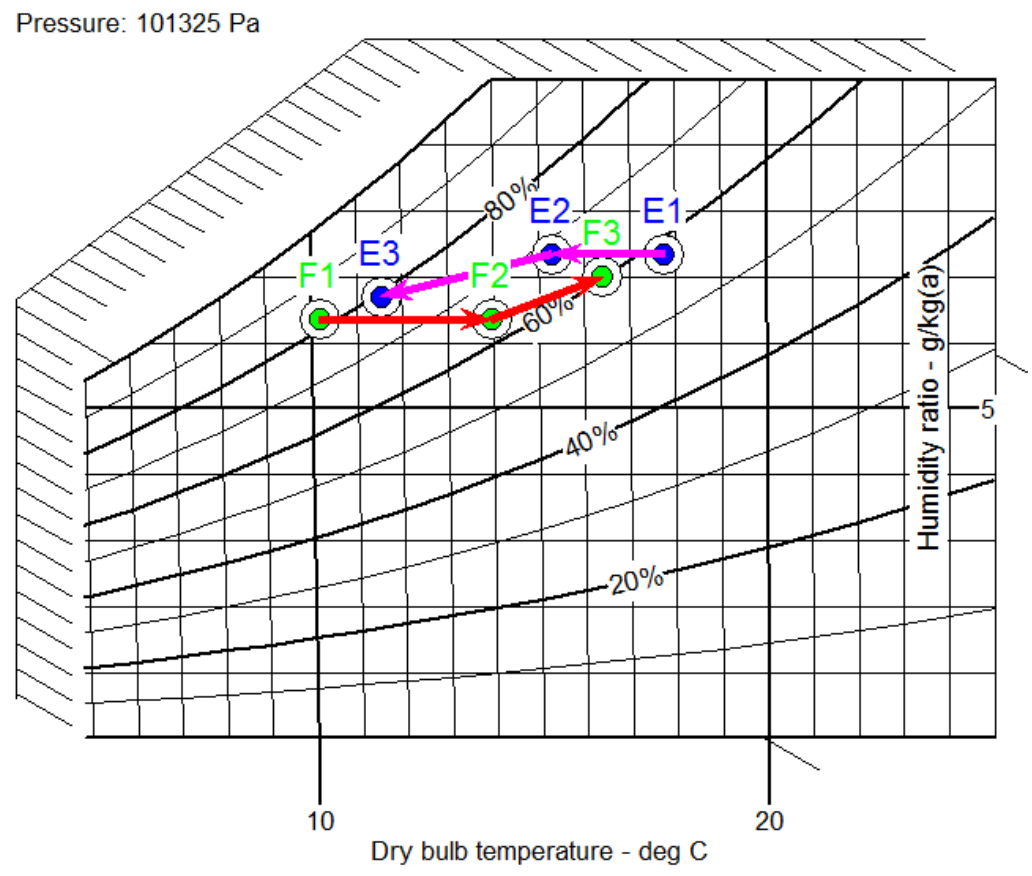

Figure 5.3.6 - Psychrometric chart representing state points of fresh air and exhaust air during dual-core mode in winter $\left(\mathrm{HERV}_{c}\right)$

*Outside air conditions are $10.2^{\circ} \mathrm{C}$ and $82.1 \% \mathrm{RH}(\mathrm{F} 1)$, inside air conditions are $17.7^{\circ} \mathrm{C}$ and $58.0 \% \mathrm{RH}$ (E1). Sensible efficiency of the sensible core is $74 \%$, while the enthalpy core has $65 \%$ for both sensible and latent efficiencies. 


\subsection{3 - Transfer Mechanism and Governing Equations}

The dominating heat transfer mechanism for a recuperative type heat recovery system is heat conduction, while water vapor is transferred across the water permeable membranes (absorption and desorption). The sensible efficiency for heat transfer across the sensible core can be interpreted based on the smaller $c_{p} m$, as shown in Equation (5.3.3).

$$
\varepsilon_{\mathrm{s}}=\frac{m_{s} c_{p f}\left(\mathrm{AT}_{f, o}-\mathrm{AT}_{f, i}\right)}{C_{\min }\left(\mathrm{AT}_{e, i}-\mathrm{AT}_{f, i}\right)}=\frac{m_{e} c_{p e}\left(\mathrm{~T}_{e, i}-\mathrm{T}_{e, o}\right)}{C_{\min }\left(\mathrm{T}_{e, i}-\mathrm{T}_{f, i}\right)}
$$

The actual sensible heat transfer rate between the two primary air streams can be estimated from Equation 5.3.4. This equation states that the rate of heat transfer $\left(q_{s}\right)$ from the system is a function of the sensible efficiency (or thermal conductivity of the fixed plates):

$$
q_{s}=\varepsilon_{\mathrm{s}} C_{\min }\left(A T_{e, i}-A T_{f, i}\right)
$$

In TRNSYS, the properties of the two input airstreams can be determined through:

1. DryAirProperties subroutine (inside the 32-bit dynamic link library) that takes the dry bulb temperature $(\mathrm{K})$ and air pressure $(\mathrm{kPa})$ as arguments and calculates various properties (e.g., heat capacitance) of dry air.

2. MoistAirProperties subroutine that requires three properties of the moist air (e.g., air pressure, air temperature and relative humidity) as arguments and calculates the other properties (e.g., enthalpy or humidity ratio) of moist air based on the Ideal Gas Law and the correlations defined in ASHRAE Handbook Fundamentals (see Equation 4.6.3 and 4.6.4).

For sensible only heat transfer, humidity ratio remains the same across the heat exchange process. Therefore, the enthalpies of the outlet air streams can be estimated from:

$$
\begin{aligned}
& h_{e, o}=h_{e, i}-\frac{q_{s}}{m_{e}} \\
& h_{s, o}=h_{s, i}+\frac{q_{s}}{m_{s}}
\end{aligned}
$$

Similarly, the definitions of latent efficiency and humidity ratio of the moist air can be 
interconnected and estimated from:

$$
\varepsilon_{\mathrm{L}}=\frac{m_{f}\left(w_{f, i}-w_{f, o}\right)}{m_{\min }\left(w_{f, i}-w_{e, i}\right)}=\frac{m_{e}\left(w_{e, o}-w_{e, i}\right)}{m_{\min }\left(w_{f, i}-w_{e, i}\right)}
$$

In other words, the actual rate of latent heat (moisture) transfer between the two input airstreams can be expressed as the followings:

$$
q_{L}=\varepsilon_{\mathrm{L}} m_{\min } h_{f g}\left(w_{f, i}-w_{e, i}\right)
$$

Therefore, the outlet enthalpies for an enthalpy (total energy) exchange core should take into account the rate of moisture transfer, which is different from the sensible core. The following equations were applied to determine the outlet enthalpies and humidity ratio.

$$
\begin{gathered}
h_{e, o}=h_{e, i}-\frac{q_{s}}{m_{e}}+\frac{q_{L}}{m_{e}} \\
h_{s, o}=h_{f, i}+\frac{q_{s}}{m_{f}}-\frac{q_{L}}{m_{f}} \\
w_{e, o}=w_{e, i}+\frac{q_{L}}{m_{e}} \\
w_{s, o}=w_{f, i}-\frac{q_{L}}{m_{f}}
\end{gathered}
$$

\subsection{4-Economizer Control}

Airtight energy-efficient houses with high heat gains often require cooling even during cold days because transmission heat losses of the house is small. As a results, cooler ventilation air is desired in order to offset the heat gains from residential appliances and/or solar radiation. In the scenario, i.e., high internal heat gains but low outdoor air temperature, cooling load might be higher because the supply air temperature is increased due to heat recovery. In other words, heat recovery is actually wasting energy, which contradicts the motivation of green design. Conclusively, direct ventilation could be the simplest way to relieve the problem. The air-side economizer in heat recovery ventilator is an approach that utilizes dampers to direct the cool supply air completely around the two cores when outdoor conditions allow. However, this solution concerns only the sensible heat, which might not be the most effective way for energy savings because humidity is 
another important parameter affecting the comfort level and thereby the energy consumption for de-/humidification. Therefore, instead of using a dry bulb temperature-based control, an enthalpybased control was proposed. In the dynamic models, the idea of air-side economizer was realized by assuming that the properties of the supply air that enters the conditioned space is equivalent to that of the outdoors. The equal amount of stale air drawn from the four thermal zones were mixed using Type-648 (return air plenum), which automatically calculated the properties of the mixed stale air. This model was slightly modified in order to be compatible with the versatile multi-speed HERV units.

\subsection{5 - Control Logic}

In order to automate the operation modes defined in Section 3.1, a detailed control logics were developed, as listed in Table 5.3.1. These control logics can be grouped into two sets: humiditybased and temperature-based. In the actual scenario, the humidity-based control logics aims at controlling the enthalpy core, while the other logics is intended for the control of sensible core.

Table 5.3.1 - Control logic for HERV

\begin{tabular}{|c|c|c|c|c|}
\hline Control & Logic \# & Control Logics & Sensible core & Enthalpy core \\
\hline \multirow{4}{*}{ Humidity } & $\mathrm{H}_{1}$ & $w_{i}>w_{s} \& w_{i}>w_{o}$ & & OFF \\
\hline & $\mathrm{H}_{2}$ & $w_{i}<w_{s} \& w_{i}<w_{o}$ & & ON \\
\hline & $\mathrm{H}_{3}$ & $w_{i}<w_{s} \& w_{i}>w_{o}$ & & ON \\
\hline & $\mathrm{H}_{4}$ & $w_{i}>w_{s} \& w_{i}<w_{o}$ & & ON \\
\hline \multirow{4}{*}{ Temperature } & $\mathrm{T}_{1}$ & $\mathrm{~T}_{i}>\mathrm{T}_{s} \& \mathrm{~T}_{i}>\mathrm{T}_{o}$ & OFF & \\
\hline & $\mathrm{T}_{2}$ & $\mathrm{~T}_{i}<\mathrm{T}_{s} \& \mathrm{~T}_{i}<\mathrm{T}_{o}$ & OFF & \\
\hline & $\mathrm{T}_{3}$ & $\mathrm{~T}_{i}<\mathrm{T}_{s} \& \mathrm{~T}_{i}>\mathrm{T}_{o}$ & ON & \\
\hline & $\mathrm{T}_{4}$ & $\mathrm{~T}_{i}>\mathrm{T}_{s} \& \mathrm{~T}_{i}<\mathrm{T}_{o}$ & ON & \\
\hline
\end{tabular}

Sensible mode is sufficient for maximum energy savings only if control logic $\# \mathrm{~T}_{3}$ or $\mathrm{T}_{4}$ and $\mathrm{H}_{1}$ is satisfied. In contrast, latent mode is sufficient only if conditions satisfy the control logic \# $\left(\mathrm{T}_{1}\right.$ or $\mathrm{T}_{2}$ ) and $\left(\mathrm{H}_{2}\right.$ or $\mathrm{H}_{3}$ or $\left.\mathrm{H}_{4}\right)$. As a result, dual-core mode is needed only if both humidity and temperature-based logic are turned ON. It can be observed that the conditions for sensible operation is harsh, and therefore might become useless for certain climate conditions (e.g., tropical climate). Bypass mode was designed to minimize the need for mechanical cooling (and/or dehumidification if needed). There are many different ways of economizer control; however, an 
enthalpy-based control was chosen for this study. Control logic, $\mathrm{T}_{2}$ and $\mathrm{H}_{1}$, presented in Table 5.3.1 is partially an enthalpy-based control that is used to prevent unnecessary enthalpy recovery. However, it becomes insufficient if one decides to bypass air at higher flow rate because the indoor humidity level and rate of latent load increases considerably. For instance, bypass mode is turned on, in the meantime, outside air humidity is $0.0091 \mathrm{~kg} / \mathrm{kg}$, setpoint is $0.0087 \mathrm{~kg} / \mathrm{kg}$, and indoor humidity is $0.0096 \mathrm{~kg} / \mathrm{kg}$. As a result of a lower incoming humidity, it is beneficial towards latent load if outdoor air is directly bypassed without the increase of ventilation flow rate. However, if the air is bypassed at higher ventilation flow rate, latent load increases considerably because more air is required to dehumidify. In addition, the indoor humidity might be very high for a house that does not have a dehumidifier. Therefore, to avoid the identified issues above, the following conditional statements were added to improve the control of bypass mode:

$$
\begin{aligned}
& \mathrm{H}_{o}<\mathrm{H}_{s} \& \mathrm{H}_{o}<\mathrm{H}_{i} \\
& \mathrm{H}_{o}>\mathrm{H}_{s} \& \mathrm{H}_{o}>\mathrm{H}_{i}
\end{aligned}
$$

Lastly, a dynamic model named Type-283 was created that transfers the above control statements into TRNSYS. The icon of TRNSYS model is shown in Figure 5.3.7.

Figure 5.3.7 - Icon for Type-283

The time-dependent input variables of the model include:

1. Supply air temperature $\left[{ }^{\circ} \mathrm{C}\right]$.

2. Supply air relative humidity [\%].

3. Supply air pressure [atm].

4. Exhaust air temperature $\left(1^{\text {st }}\right.$ to $3^{\text {rd }}$ floors $)\left[{ }^{\circ} \mathrm{C}\right]$.

5. Exhaust air relative humidity [\%].

6. Exhaust air pressure [atm].

7. ON/OFF control signal of the HERV and economizer mode.

The time-independent input variables (PARAMETERS) include:

1. Indoor setpoint air temperature $\left[{ }^{\circ} \mathrm{C}\right]$. 
2. Indoor setpoint air relative humidity [\%].

3. Air pressures [atm].

The control signal is the only output variable, which would be sent to HERV units to help select the most appropriate operation mode. The control signal was set to vary from number 0 to 4 , corresponding to control modes as mentioned in earlier stage. The details of the signals and default volumetric air flow rate are listed in Table 5.3.2.

Table 5.3.2 - Default signal number

\begin{tabular}{cccc}
\hline $\begin{array}{c}\text { Signal } \\
\text { Number }\end{array}$ & $\begin{array}{c}\text { Corresponding } \\
\text { Mode }\end{array}$ & $\begin{array}{c}\text { Supply Mass } \\
\text { Flow Rate }\end{array}$ & $\begin{array}{c}\text { Exhaust Mass } \\
\text { Flow Rate }\end{array}$ \\
\hline 0 & Off condition & $1 \mathrm{x}$ & $1 \mathrm{x}$ \\
1 & Bypass & $1 \mathrm{x}$ & $1 \mathrm{x}$ \\
2 & Sensible & $1 \mathrm{x}$ & $1 \mathrm{x}$ \\
3 & Latent & $1 \mathrm{x}$ & $1 \mathrm{x}$ \\
4 & Dual-core & $1 \mathrm{x}$ & \\
\hline
\end{tabular}

The process flow diagrams (PFD) were constructed to illustrate the algorithms/processes of the HERV controls, as shown in Figure 5.3.8 and 5.3.9. These plots map out the critical interactions for the operation of sensible, latent, dual-core and bypass modes. The hexagonal blocks in the PFD represent the control algorithms which were transformed into the conditional statements in FORTRAN language. The grey rectangular blocks indicate the output of the conditional statements, while the lines between these blocks represent interactions between these elements. 


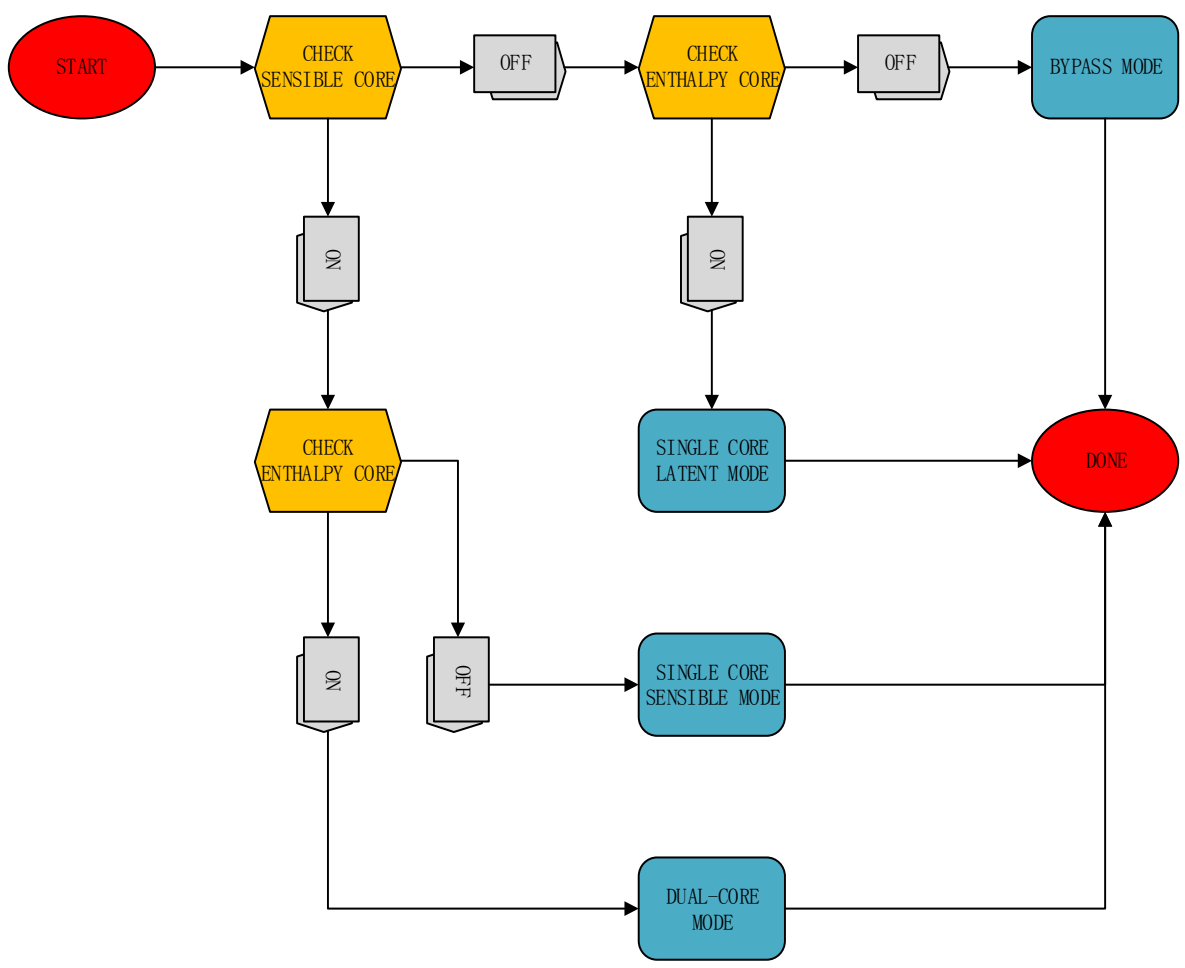

Figure 5.3.8 - Process flow chart for Type-270

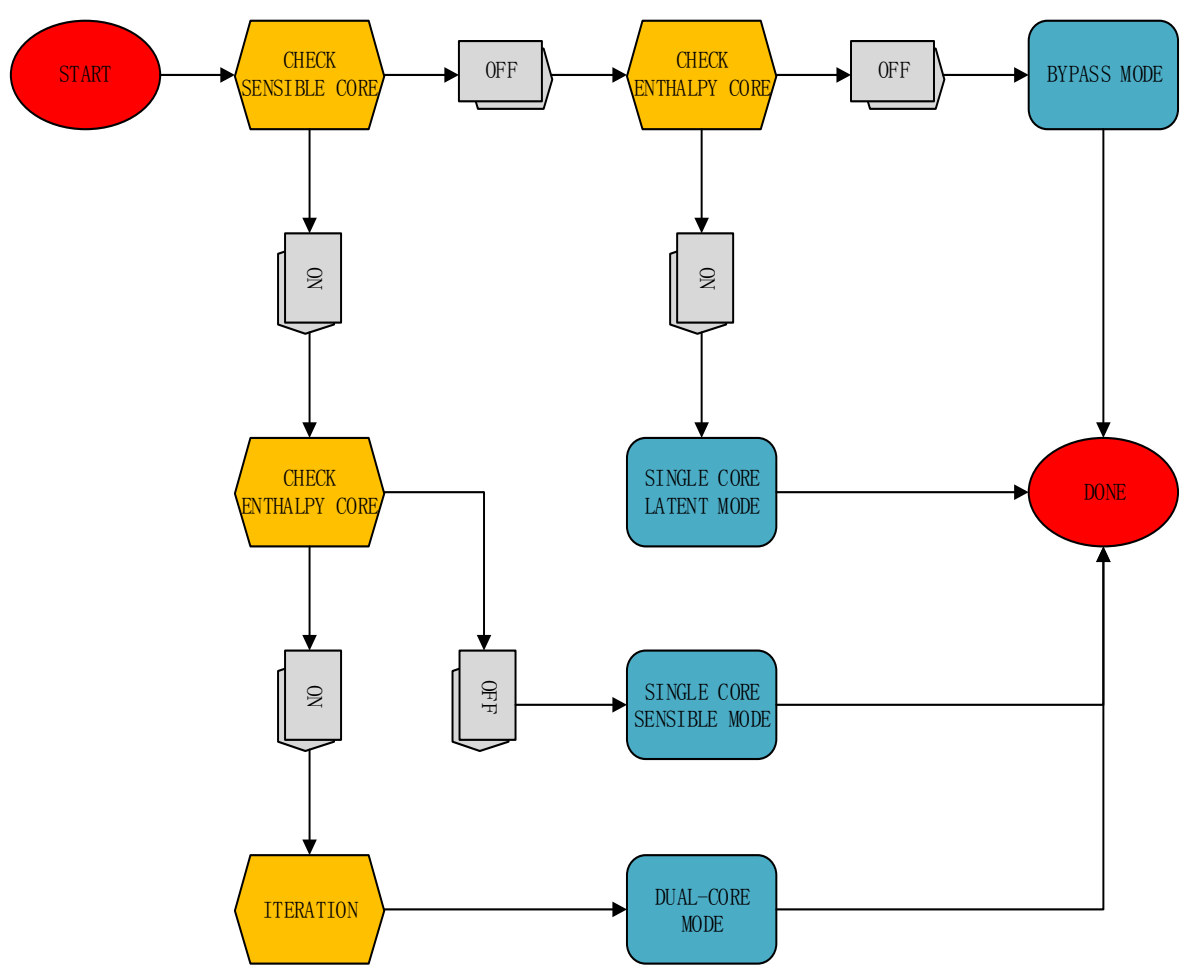

Figure 5.3.9 - Process flow chart for Type-291 


\section{Section 5.4 - Preliminary Simulation of the HVAC Equipment}

\subsection{1 - Comparing House Cooling and Heating Consumptions}

The next step upon the completion of system models was to simulate their performances along with the ASH-A house model, and then compare them to the HRV and ERV within the twin houses. The potential of the HERVs were evaluated through the comparison of the energy consumption (in $\mathrm{kWh})$ and average humidity ratio $(\mathrm{kg} / \mathrm{kg})$ of the house for different climatic conditions. Figure 5.4.1 presents a screenshot of TRNSYS assembly panel including the Type-56 house model and the HERV model. The simulation of house heat recovery with $\mathrm{HERV}_{c}$ mainly relied on four TRNSYS modules: 'HERV' was intended for heat/energy exchange, return air plenum 'Exhaust Air Mixer' was intended for air mixing, module 'Remote' was implemented in order to enable users to manually turn on/off the system, and module 'Controller' was intended to generate signal used for modes selection and flow rate control. The detail descriptions of these modules will be presented in Appendix B.

Internal heat and humidity gains listed in Table 5.2.4 were equally distributed to each zone, and the dry-bulb temperature, relative humidity setpoints and air change rates for the simulation were respectively set to the following values:

Zone 1 (basement):

- Cooling season setpoints: cooling was off, and air change rate was $29.3 \mathrm{cfm}(13.75 \mathrm{~L} / \mathrm{s})$.

- Heating season setpoints: $21^{\circ} \mathrm{C}, 30 \%$ and $29.3 \mathrm{cfm}(13.75 \mathrm{~L} / \mathrm{s})$.

$>$ Zone 2 (first floor), Zone 3 (second floor) and Zone 4 (third floor):

- Cooling season setpoints: $23^{\circ} \mathrm{C}, 50 \%$ and $29.3 \mathrm{cfm}(13.75 \mathrm{~L} / \mathrm{s})$ per zone.

- Heating season setpoints: $21^{\circ} \mathrm{C}, 30 \%$ and $29.3 \mathrm{cfm}(13.75 \mathrm{~L} / \mathrm{s})$ per zone.

According to Toronto TM2 weather data from Meteonorm, the average daily temperature on May $20^{\text {th }}$ is $21^{\circ} \mathrm{C}$, with a peak hourly temperature of $27.1^{\circ} \mathrm{C}$. Therefore, cooling season was assumed to begin on May $20^{\text {th }}$ and end on September $30^{\text {th }}$. Table 4.8.1, 4.8.2, A.4.1 and A.4.2 present the defined seasonal periods for other cities. 


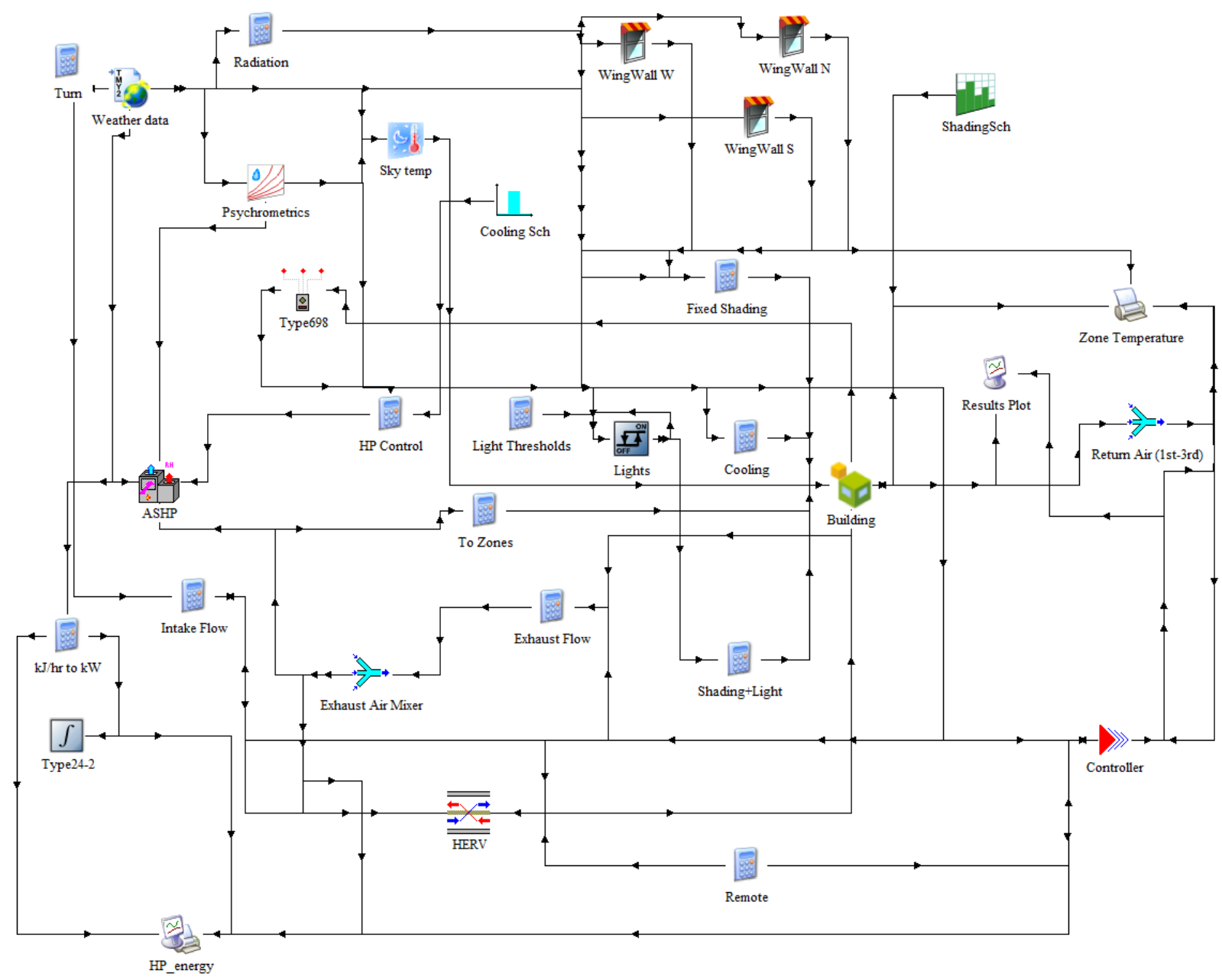

Figure 5.4.1 - Screenshot of TRNSYS assembly panel

\section{Continental Climate - Toronto}

As a default, the sensible efficiency of the HRV model was assumed to be $80 \%{ }^{24}$, while the ERV model was assumed to have $69 \%{ }^{25}$ temperature and $45 \%$ latent efficiency. In addition, both the HERV models were set to have $80 \%$ sensible efficiency for sensible core, and $69 \%$ temperature and $45 \%$ latent efficiency for enthalpy core. The simulation time step was chosen to be 1 minute, and the first investigation was carried out for continental climate, Toronto. Figure 5.4.2 presents the cumulative cooling consumption of the house. Results indicate that the house without ventilation heat recovery (No VHR) resulted in $322 \mathrm{kWh}$ ASHP electricity consumption. The HRV and ERV, however, resulted in an increase in the cooling consumption of $27 \mathrm{kWh}$ (or $8.3 \%$ ) and

24 See Table 3.2.2.

${ }^{25}$ See Table 3.2.3. 
$22 \mathrm{kWh}(6.7 \%)$, meaning that the conventional designs were actually wasting energy. The saved energy percentage reveals that the ERV was more efficient than the HRV, meaning that energy savings in the summer could be achieved by either adopting a less efficient core or bypassing the fresh air. In addition, Figure 5.4.3 shows that the HRV house consumed $4152 \mathrm{kWh}$ for heating, corresponding to a decrease in energy use of 19\%. In contrast, the ERV house resulted in a decrease in energy use of $17.1 \%$, approximately $2 \%$ less than the HRV. On a yearly basis, the HRV and ERV reduced the ASHP consumption by $946 \mathrm{kWh}$ and $856 \mathrm{kWh}$, corresponding to $17.4 \%$ and $15.7 \%$ reduction, respectively.

Figure 5.4.2 also displays the cumulative cooling consumption of $\operatorname{HERV}_{p}$ house with and without free-cooling. The $\mathrm{HERV}_{p}$ with enabled bypass mode (HERVp,b) resulted in $306 \mathrm{kWh}$ cooling consumption, approximately $12.3 \%$ more efficient than the HRV; the bypass mode contributed to the reduction of energy use of $32 \mathrm{kWh}$. Therefore, the built-in bypass mode enhanced the flexibility of the HERV by avoiding unnecessary sensible heat exchange in the summer. In the heating season, Figure 5.4.3 shows that the $\mathrm{HERV}_{p}$ only contributed to $660 \mathrm{kWh}$ reduction on the house heating consumption, which was $313 \mathrm{kWh}$ and $218 \mathrm{kWh}$ less than that of the HRV and ERV, respectively. Therefore, it appears that the $\mathrm{HERV}_{p}$ was economically infeasible for house heating because sensible heat recovery was not maximized.

For $\mathrm{HERV}_{c}$, the built-in bypass mode contributed to a decrease in ASHP electricity consumption of $47 \mathrm{kWh}$, approximately $13.4 \%$ improvement. On the other hand, the $\mathrm{HERV}_{c}$ contributed to 1008 $\mathrm{kWh}$ reduction on heating consumption, which was $348 \mathrm{kWh}$ better than the $\operatorname{HERV}_{p}$. Overall, the $\mathrm{HERV}_{c}$ maximized cooling savings in the summer using its built-in economizer, and heating savings in the winter using its highly efficient sensible/dual-core. Quantitatively, the HERV $c$ reduced the house heating and cooling consumptions attributable to outside air by $1026 \mathrm{kWh}$, approximately $7.8 \%$ and $16.6 \%$ better than the HRV and the ERV, respectively. In conclusion, the $\mathrm{HERV}_{c}$ was found to be feasible to be used in Toronto based on the energy savings associated with sensible loads. 


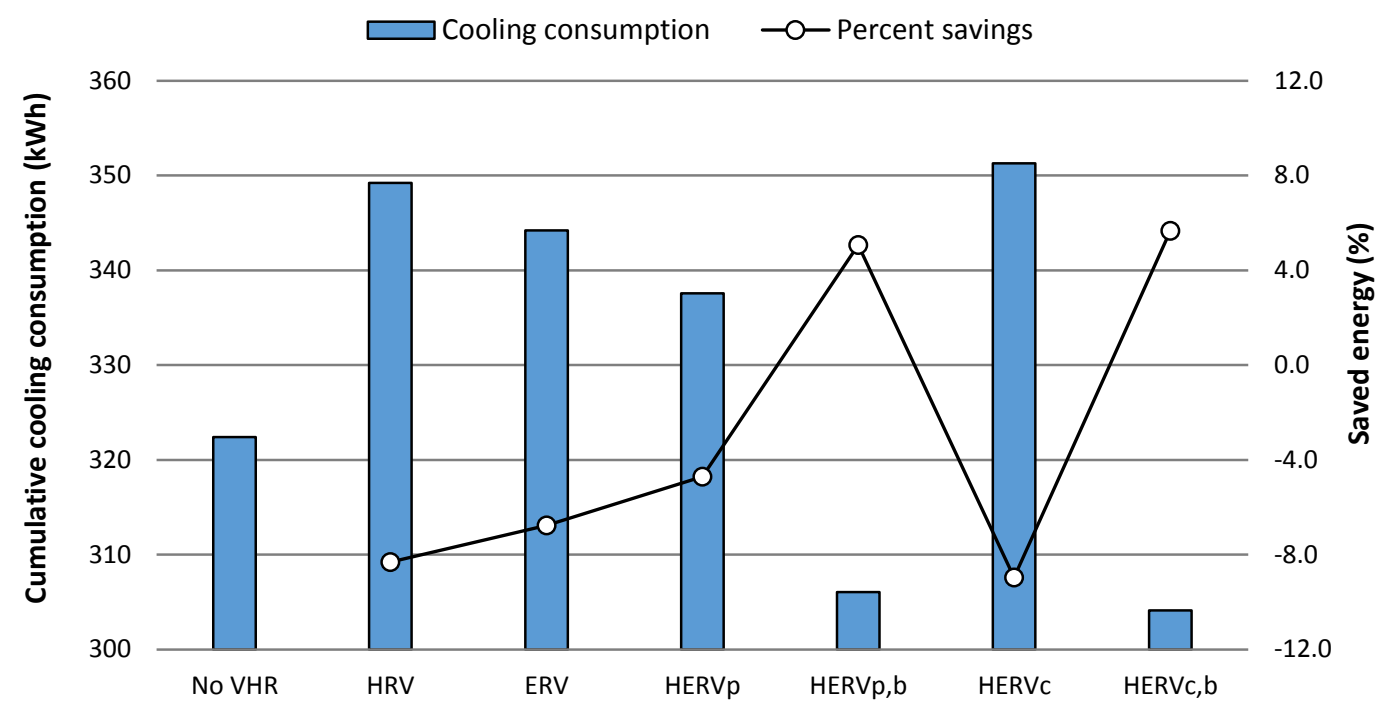

Figure 5.4.2 - Cooling consumption of the house (Toronto): HERV vs. HRV vs. ERV

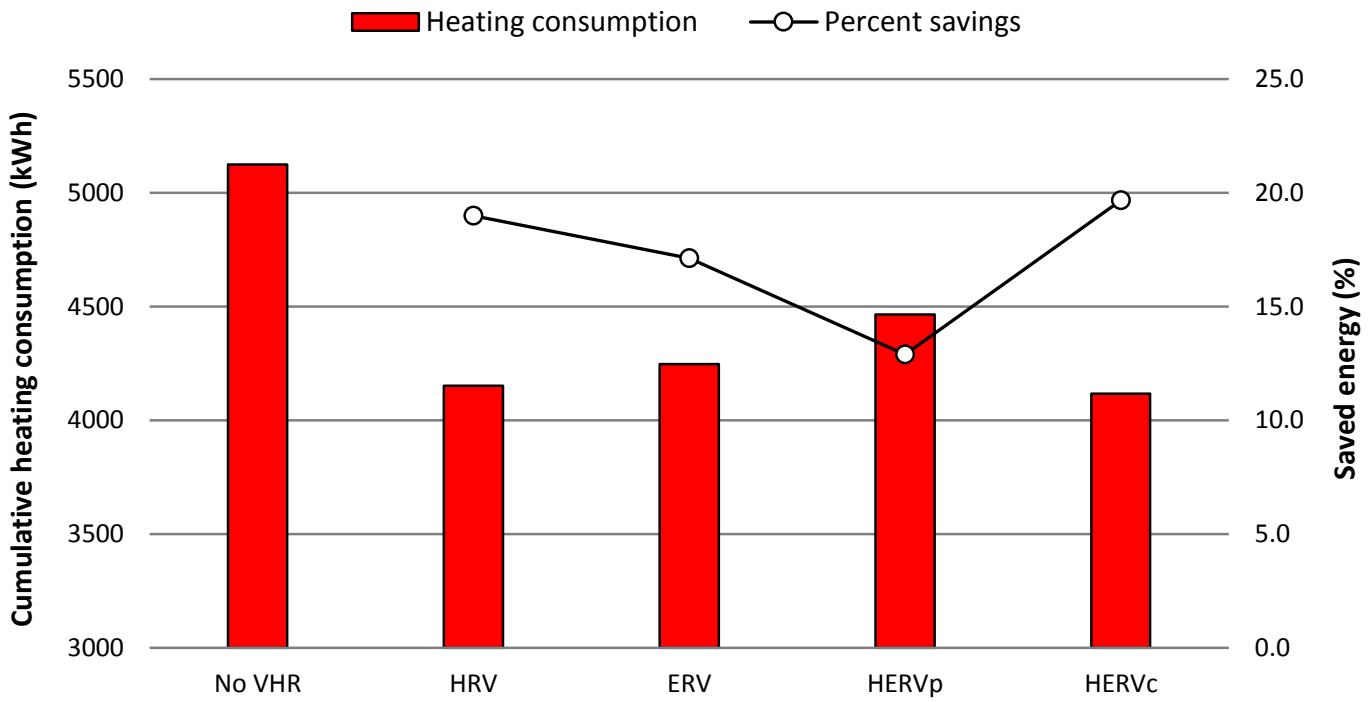

Figure 5.4.3 - Cooling consumption of the house (Toronto): HERV vs. HRV vs. ERV

\section{Tropical Climate - Miami}

Figure 5.4.4 shows the cooling consumption of the ASH-A for tropical climate, Miami. On a yearly basis, the HRV-equipped house consumed $2064 \mathrm{kWh}$ for cooling, which was $9.5 \%$ lower than the house that experienced direct ventilation. In contrast, the ERV-equipped house consumed 2083 $\mathrm{kWh}$, which was only $19 \mathrm{kWh}$ higher than that of the HRV. In other words, the demand of sensible heat exchange was small in this region. For the multiple-pass systems, the bypass mode contributed to a decrease in cooling consumption of $28 \mathrm{kWh}$ for $\mathrm{HERV}_{p}$ house and $25 \mathrm{kWh}$ for $\mathrm{HERV}_{c}$. Therefore, free-cooling provided insignificant contribution to the cooling reduction. Figure 5.4.5 
presents the monthly free-cooling hours associated with the $\mathrm{HERV}_{c}$. It is clear that the bypass mode was nearly unavailable during the hottest months, and tended to be more active during the shoulder months. However, due to constantly high outside temperature throughout the year, the benefit associated with free-cooling was small even though the demand was about $33 \%$ of the year.

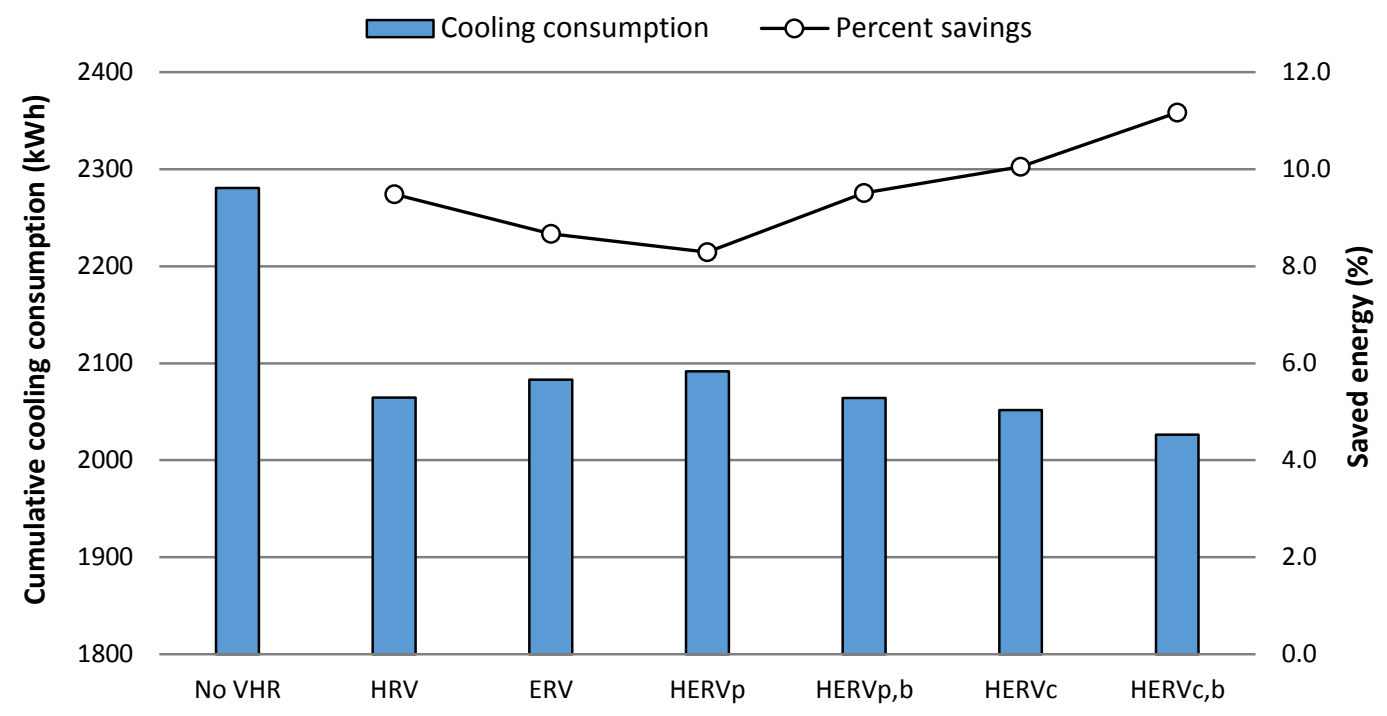

Figure 5.4.4 - Cooling consumption of the house (Miami): HERV vs. HRV vs. ERV

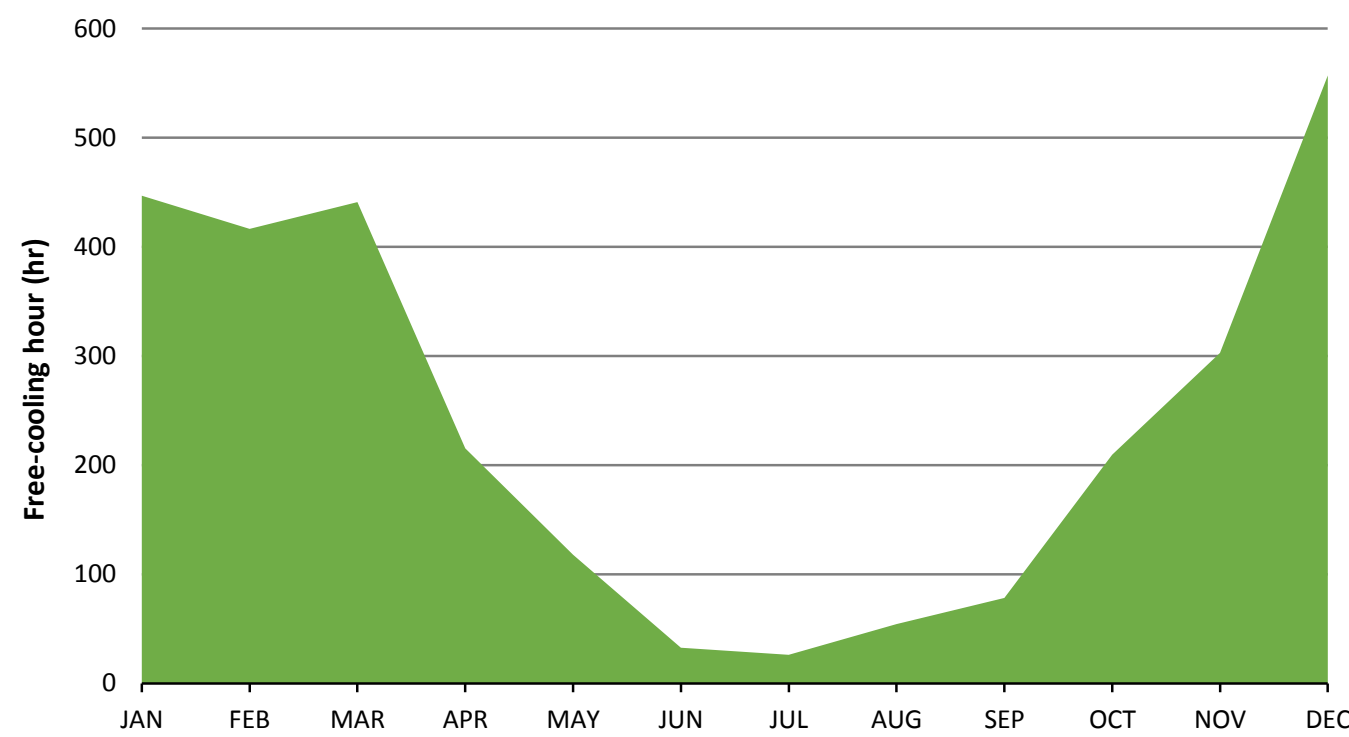

Figure 5.4.5 - Free-cooling hours of the $\mathrm{HERV}_{c}$ in Miami

\section{Dry Climate - Las Vegas}

Figure 5.4.6 shows the cumulative cooling consumption of the ASH-A for dry climate, Las Vegas. The HRV-equipped house consumed $2858 \mathrm{kWh}$ for air conditioning, which was $13.7 \%$ lower than 
the house experiencing direct ventilation. In contrast, the ERV-equipped house consumed 2925 $\mathrm{kWh}$, which was $11.7 \%$ better. The percent savings imply that the demand of sensible heat exchange was small, as similar to Miami. For the HERVs, the bypass mode was turned off because Las Vegas has a desert climate that is hot and dry year round. The simulated results show that the $\mathrm{HERV}_{p}$ resulted in a higher cooling and heating consumptions than both the HRV and ERV, and hence, this configuration was not recommended. The $\mathrm{HERV}_{c}$ resulted in a reduction in the annual electricity consumption of $14.6 \%$, and hence, savings were maximized.

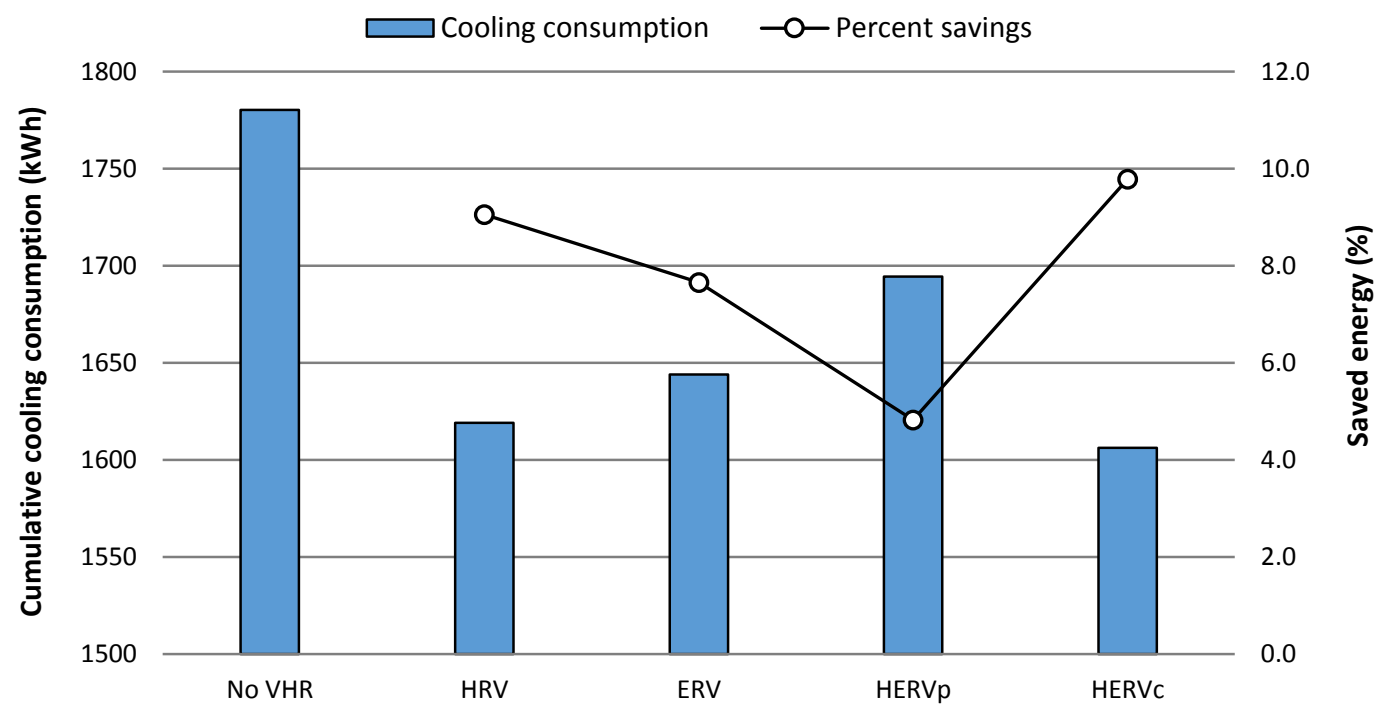

Figure 5.4.6 - Cooling consumption of the house (Las Vegas): HERV vs. HRV vs. ERV

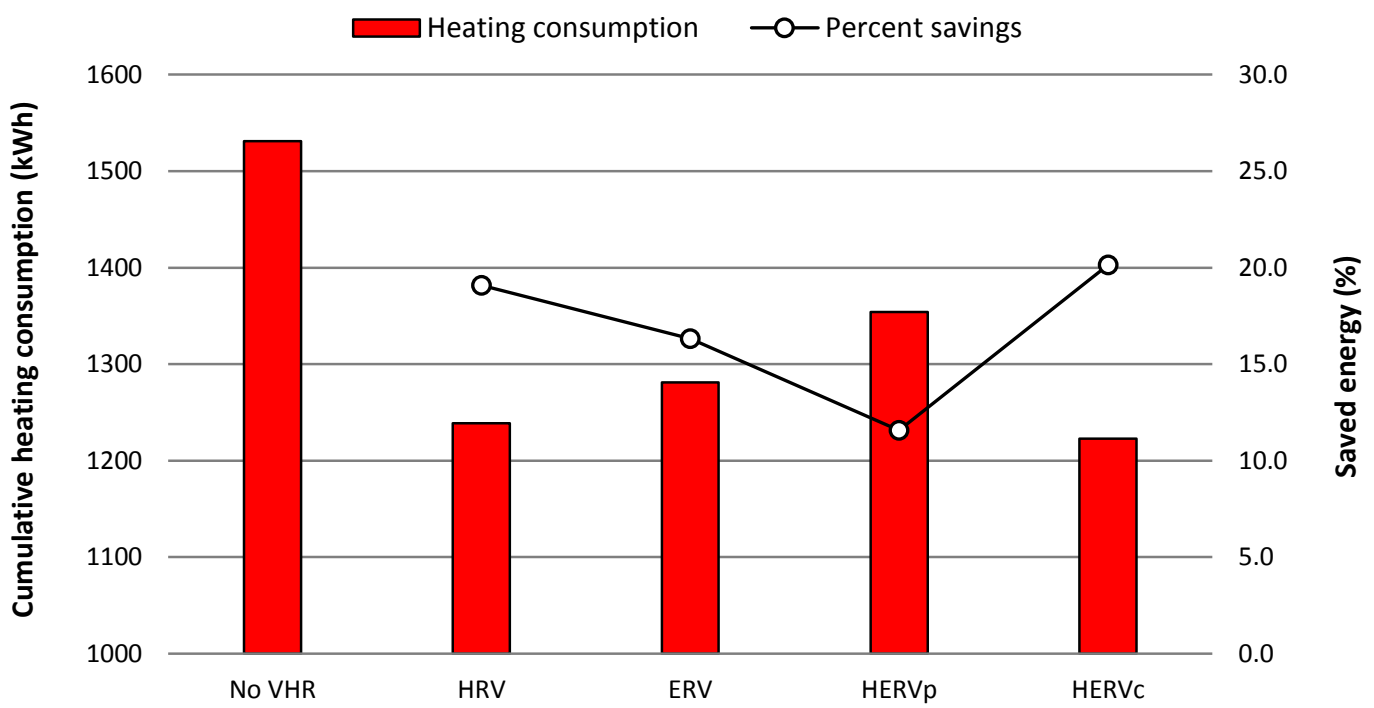

Figure 5.4.7 - Heating consumption of the house (Las Vegas): HERV vs. HRV vs. ERV 


\section{Temperate Climate - Vancouver}

Vancouver was selected as a representative of temperate climate. Figures 5.4.8 and 5.4.9 present the consumption of the house.

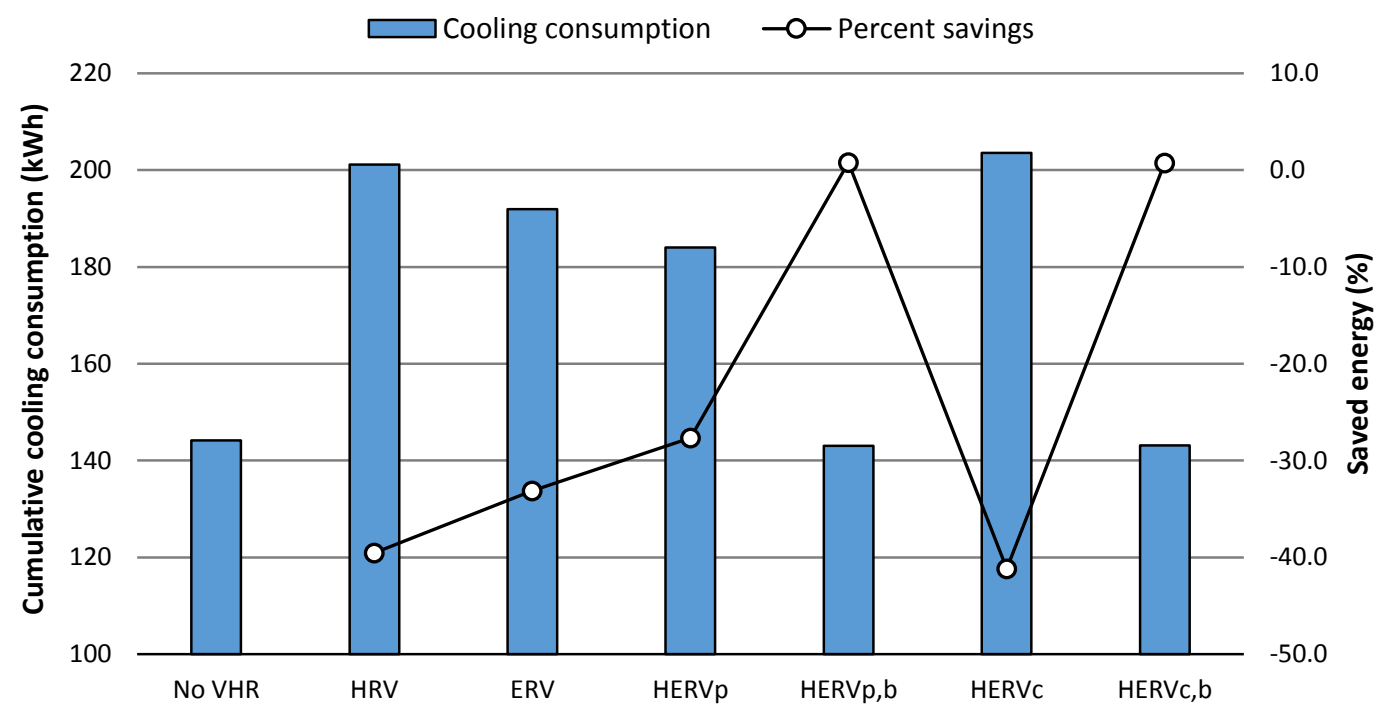

Figure 5.4.8 - Cooling consumption of the house (Vancouver): HERV vs. HRV vs. ERV

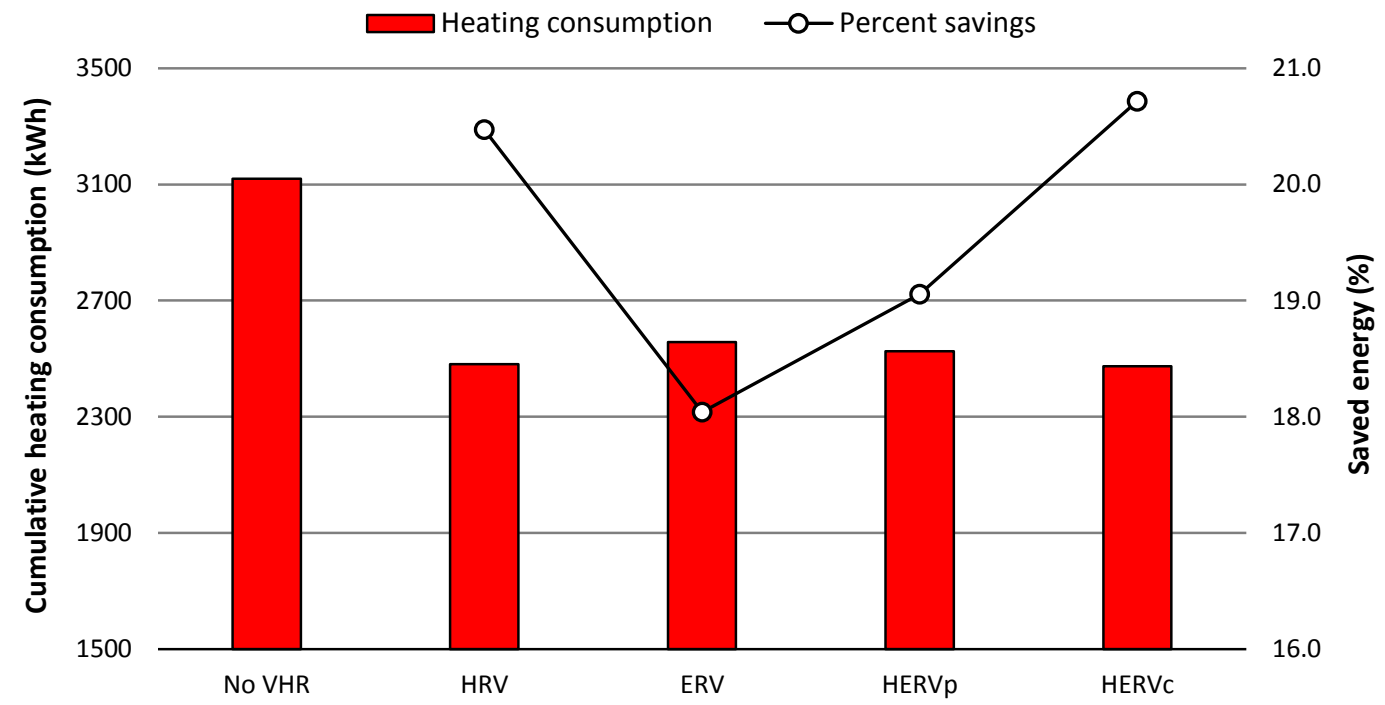

Figure 5.4.9 - Heating consumption of the house (Vancouver): HERV vs. HRV vs. ERV

Due to the local mild climate, cooling consumption was much lower than other types of climate. The HRV-equipped house consumed extra $57 \mathrm{kWh}$ (or 39.6\% relative to the direct ventilated house) for house cooling, while the ERV-equipped house consumed extra $48 \mathrm{kWh}$ (or 33.3\%). Therefore, both the conventional systems provided no contribution on savings, and unnecessary heat recovery 
took place. On the other hands, a similar pattern was also observed for the HERVs (in the figure HERVp and HERVc). However, with an integrated economizer control (HERVp,b and HERVc,b), the house cooling consumption was reduced by $41 \mathrm{kWh}$ (or 22.3\%) for a parallel-flow arrangement and $61 \mathrm{kWh}$ (or 29.9\%) for a counter-flow arrangement. In conclusion, the idea of integrating an economizer control into heat recovery ventilator could be feasible for temperate climate to maximize the house energy savings in summer. In terms of heating consumption, the house with the $\mathrm{HERV}_{c}$ was found to have a maximum reduction comparable to the HRV's.

\section{Polar Climate - Iqaluit}

Iqaluit was selected as a representative of polar climate. Figure 5.4.10 presents the annual heating consumption of the house with different methods of heat recovery.

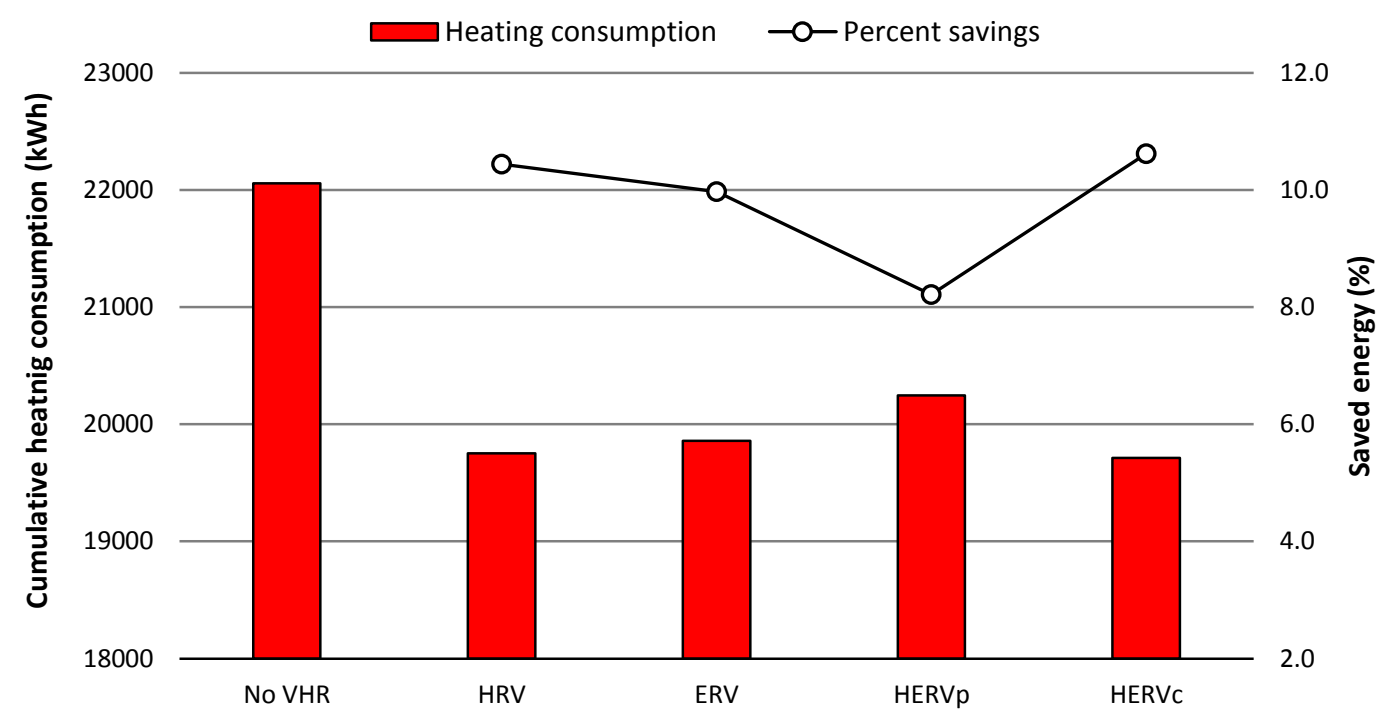

Figure 5.4.10 - Heating consumption of the house (Iqaluit): HERV vs. HRV vs. ERV

On a yearly basis, the house heating consumption was reduced $2304 \mathrm{kWh}$ per year by the HRV and $2199 \mathrm{kWh}$ by the ERV. The $\mathrm{HERV}_{c}$ resulted in a house heating consumption of $144 \mathrm{kWh}$ lower than the ERV and $39 \mathrm{kWh}$ lower than the $\mathrm{HRV}$, therefore, the $\mathrm{HERV}_{c}$ maximized the energy savings attributed to outside air. Again, the HERV with a parallel-flow arrangement was the most inefficient choice. In addition, both HRV and $\mathrm{HERV}_{c}$ resulted in a percent energy savings of 10\%, which was smaller than both Toronto and Vancouver. Therefore, the higher the HDD (see Appendix A.4) the lower the percent energy savings because the heat loss attributed to ventilation would become less important as compared to heat losses from opaque and transparent fenestration surfaces. 


\subsection{2 - Comparing House Humidity Ratio}

\section{Tropical Climate - Miami}

The Archetype Sustainable House-A has neither a humidifier nor a de-humidifier for humidity control. Therefore, comparisons were made using the house monthly humidity ratio. Figure 5.4.11 shows the humidity of the house in Miami. Based on the minimum humidity ratios, the ERVequipped house was wetter than both the $\mathrm{HERV}_{c}$ and HRV's. On average, all houses exceeded the summer humidity setpoint $(8.77 \mathrm{~g} / \mathrm{kg})$, and there were no crucial difference among them because dehumidifier is required. In conclusion, for neither cooling nor humidity did the $\mathrm{HERV}_{c}$ performed significantly different from the HRV and ERV. However, it could still be an adaptable alternative to the conventional ERV when coupled with dehumidifier because it would reduce the latent load as a result of pre-dehumidifying humid fresh air, as similar to ERV.

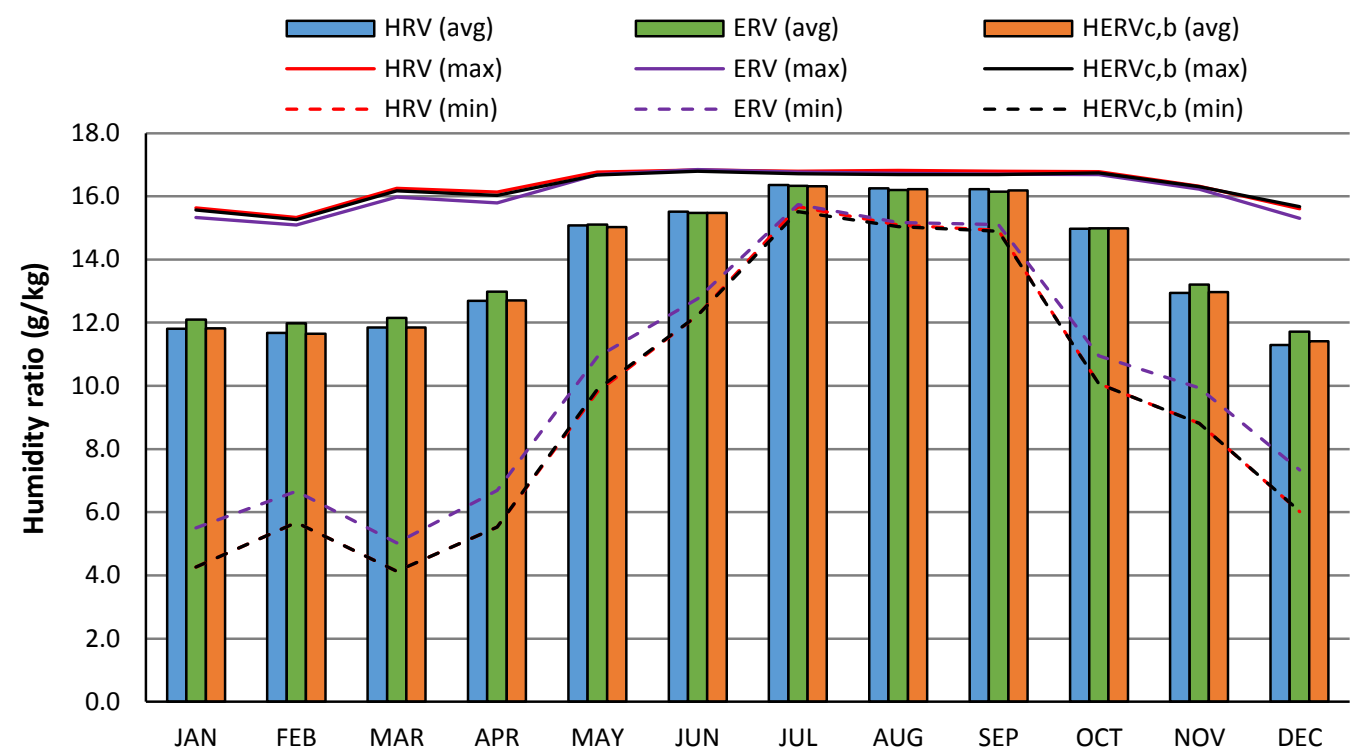

Figure 5.4.11 - Humidity of the house (Miami): $\mathrm{HERV}_{c}$ vs. HRV vs. ERV

\section{Dry Climate - Las Vegas}

The humidity illustrated in Figure 5.4.12 indicates that the house without an enthalpy exchanger can be very dry, i.e., the average relative humidity of $\mathrm{HERV}_{c}$ house in April was $27 \%$ at $23^{\circ} \mathrm{C}$ temperature setpoint, while the HRV house was $23 \%$. Implicitly, the bypass mode was not a good option for Las Vegas (or dry climate) because it would make the house dryer. According to the ASHRAE comfort chart (McQuiston, Parker \& Spitler, 2005), the HRV house was not conducive to thermal comfort during the winter months (Dec. to Mar.) because it was dry. In contrast, both the ERV and $\mathrm{HERV}_{c}$ allowed the house operating at higher level of humidity. Taking everything 
into account (e.g., humidity, heating and cooling consumptions), it is clear that the $\mathrm{HERV}_{c}$ without free-cooling outperformed the HRV by its ability of maintaining the house at higher humidity level. Overall, the $\mathrm{HERV}_{c}$ minimized the energy use attributed to outside air, as well as providing better control of the house humidity, and hence, it was an adaptable design for dry climate. Nevertheless, the amount of difference between the $\mathrm{HERV}_{c}$ and ERV may not be convincing that such a design was worth the extra cost.

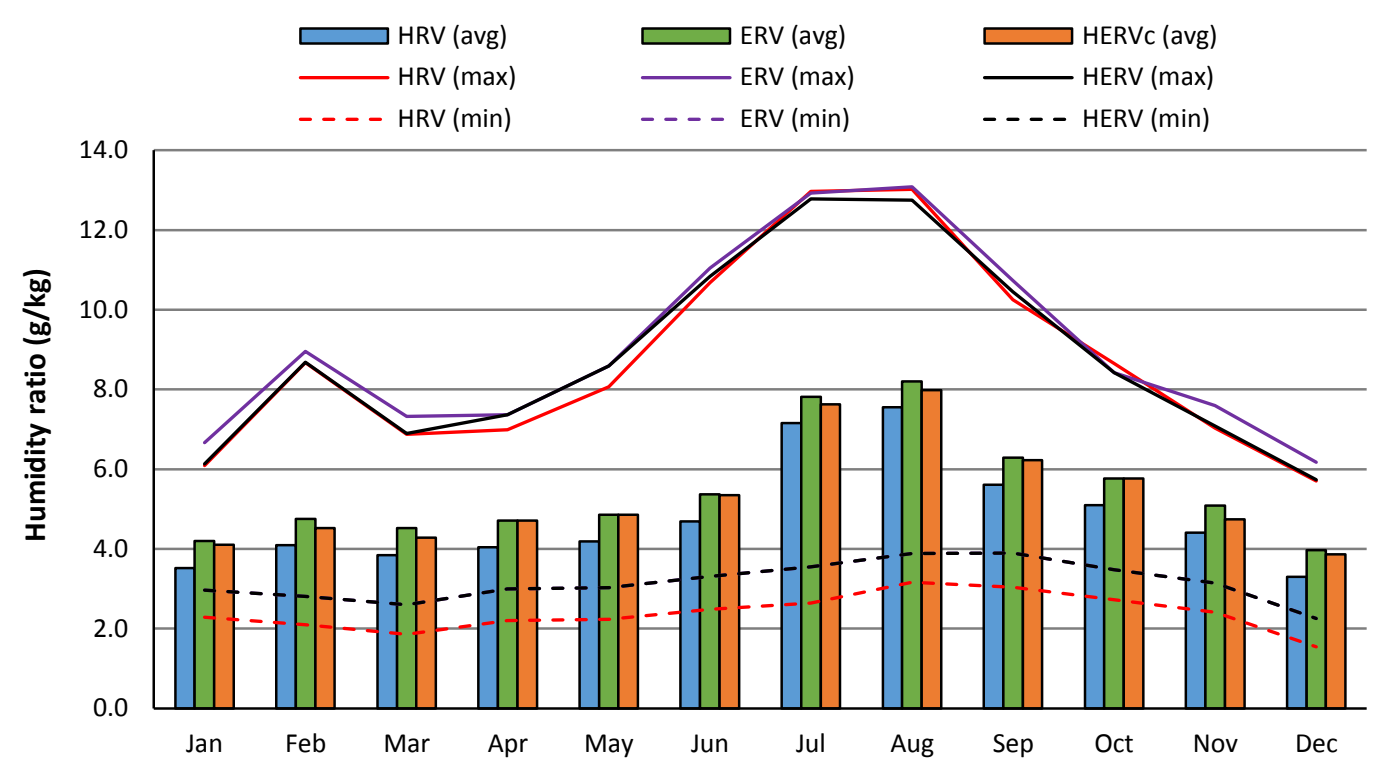

Figure 5.4.12 - Humidity of the house (Las Vegas): $\mathrm{HERV}_{c}$ vs. HRV vs. ERV

\section{Temperate Climate - Vancouver}

Figure 5.4.13 and 5.4.14 illustrate the monthly humidity ratios of the house in Vancouver during the cooling and heating seasons, respectively. Throughout the year, the $\mathrm{HERV}_{c}$ resulted in house average humidity similar to the HRV, while the ERV maintained the house $0.7 \mathrm{~g} / \mathrm{kg}(4 \% \mathrm{RH})$ wetter due to the continuous moisture recovery without taking into consideration the actual demand of the house. During the heating period, all house's average humidity were closed/above the winter setpoint $(4.6 \mathrm{~g} / \mathrm{kg}$ ). According to the ASHRAE comfort chart, the indoor temperature (assumed exactly $21^{\circ} \mathrm{C}$ ) and humidity ratio of these houses were within the acceptable comfort range of the winter period, and hence, humidification was usually not needed for all houses. Nevertheless, the humidity figures reveals that the $\mathrm{HERV}_{c}$ provided a more stable control on the house humidity over the others, i.e., the maxima of the ERV-equipped home were too high that could possibly cause interior window condensation during Dec. to Feb., and in the meantime, the HRV house had low minima that were outside the lower humidity limit of the comfort chart. In contrast, the $\mathrm{HERV}_{c}$ 
house during these periods was neither too dry nor too wet. Among the three types of heat recovery, the HERV showed a greater flexibility and was feasible towards both interior temperature and humidity control of the house in temperate climate.

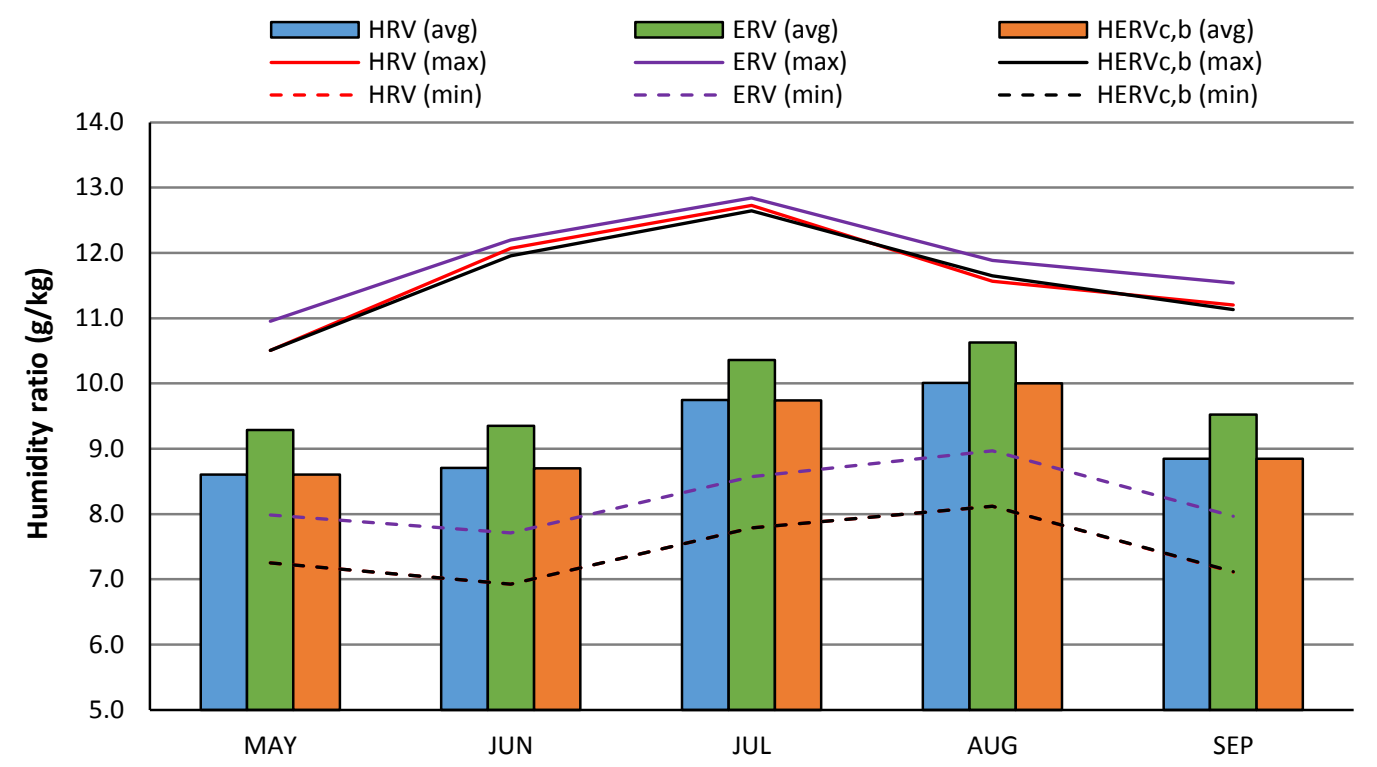

Figure 5.4.13 - Humidity of the house during cooling period (Vancouver): $\operatorname{HERV}_{c}$ vs. HRV vs. ERV

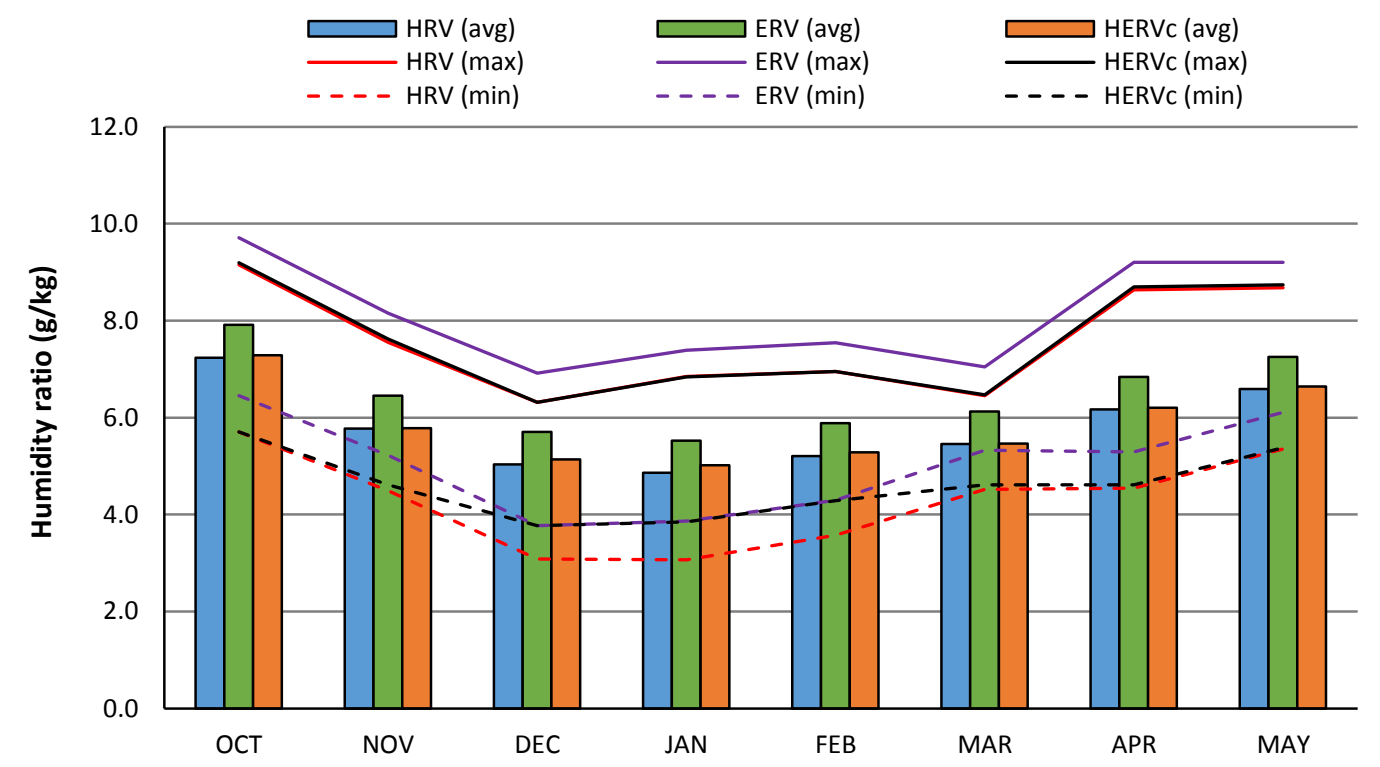

Figure 5.4.14 - Humidity of the house during heating period (Vancouver): $\mathrm{HERV}_{c}$ vs. HRV vs. ERV

\section{Continental Climate - Toronto}

Figure 5.4.15 and 5.4.16 illustrate the house humidity in Toronto, Ontario. According to the minima, the HRV house remained almost $0.8 \sim 1.0 \mathrm{~g} / \mathrm{kg}(5.2 \sim 6.5 \% \mathrm{RH})$ lower than the others in winter. The maxima of the ERV house, however, were $0.4 \mathrm{~g} / \mathrm{kg}(3 \% \mathrm{RH})$ higher. It is worth noting 
that there are gaps among the three in Jan. and Feb; for 30\% RH setpoint, the maximum humidity was $32 \%$ for the ERV, 29.8\% for the $\mathrm{HERV}_{c}$, and 28.5\% for HRV house. Therefore, the HERV provided better control of house humidity. Generally speaking, the ERV was doing more harm than good during the hottest months in summer because the house average humidity was the highest among the three devices. The HRV maintained the house at lower humidity in summer, but became inadequate during the coldest months in winter because the house was the driest (e.g., 17.5\% average $\mathrm{RH}$ at $21^{\circ} \mathrm{C}$ in January). In comparison, the HERV house humidity was not as humid as the ERV in summer, and not as dry as the HRV in winter. The system responded well to the change of outside air conditions. Taking into account both the house energy consumption and humidity, the $\mathrm{HERV}_{c}$ could be a feasible and flexible choice for continental climate.

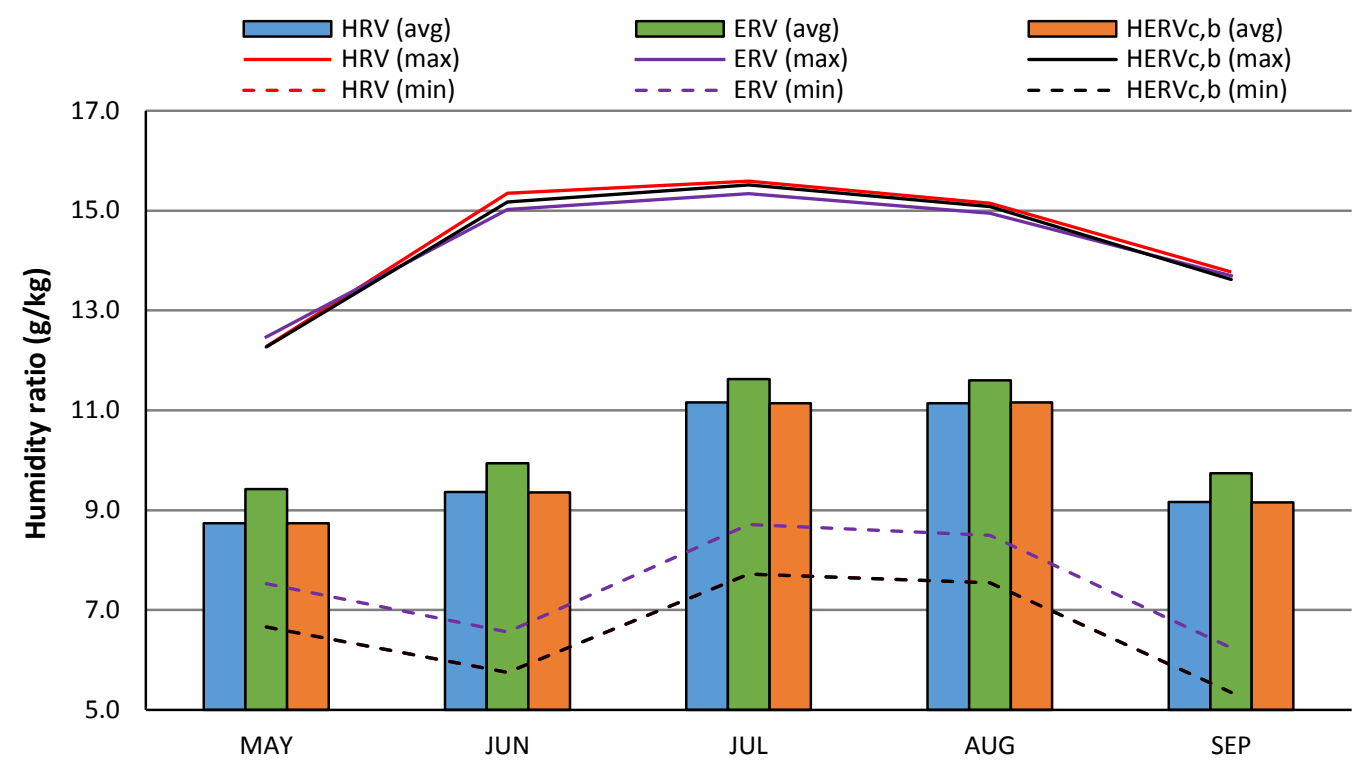

Figure 5.4.15 - Humidity of the house during cooling period (Toronto): $\mathrm{HERV}_{c}$ vs. HRV vs. ERV 


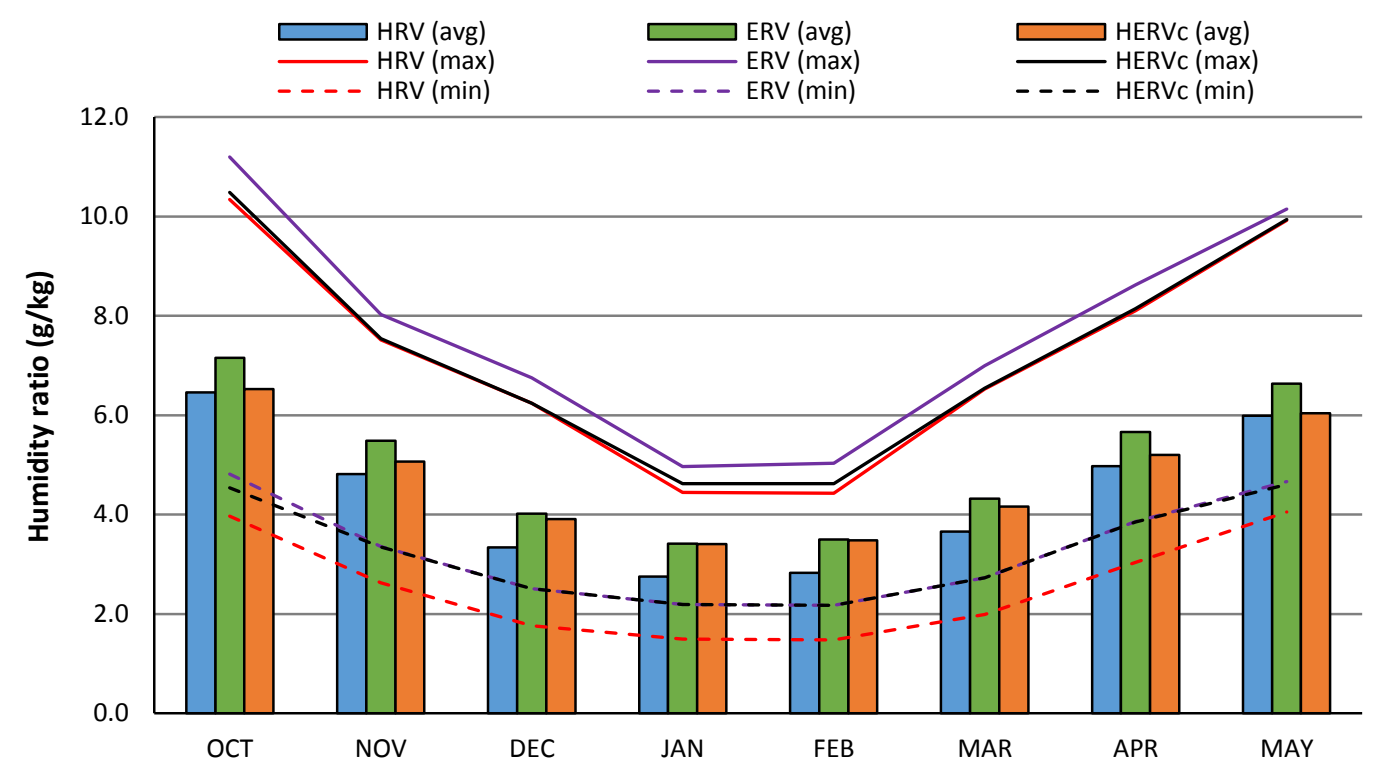

Figure 5.4.16 - Humidity of the house during heating period (Toronto): $\mathrm{HERV}_{c}$ vs. HRV vs. ERV

\section{Polar Climate - Iqaluit}

Figure 5.4.17 illustrates the simulated monthly humidity of the ASH-A with a humidity setpoint of $4.6 \mathrm{~g} / \mathrm{kg}\left(21^{\circ} \mathrm{C}\right.$ and $\left.30 \% \mathrm{RH}\right)$ throughout the year.

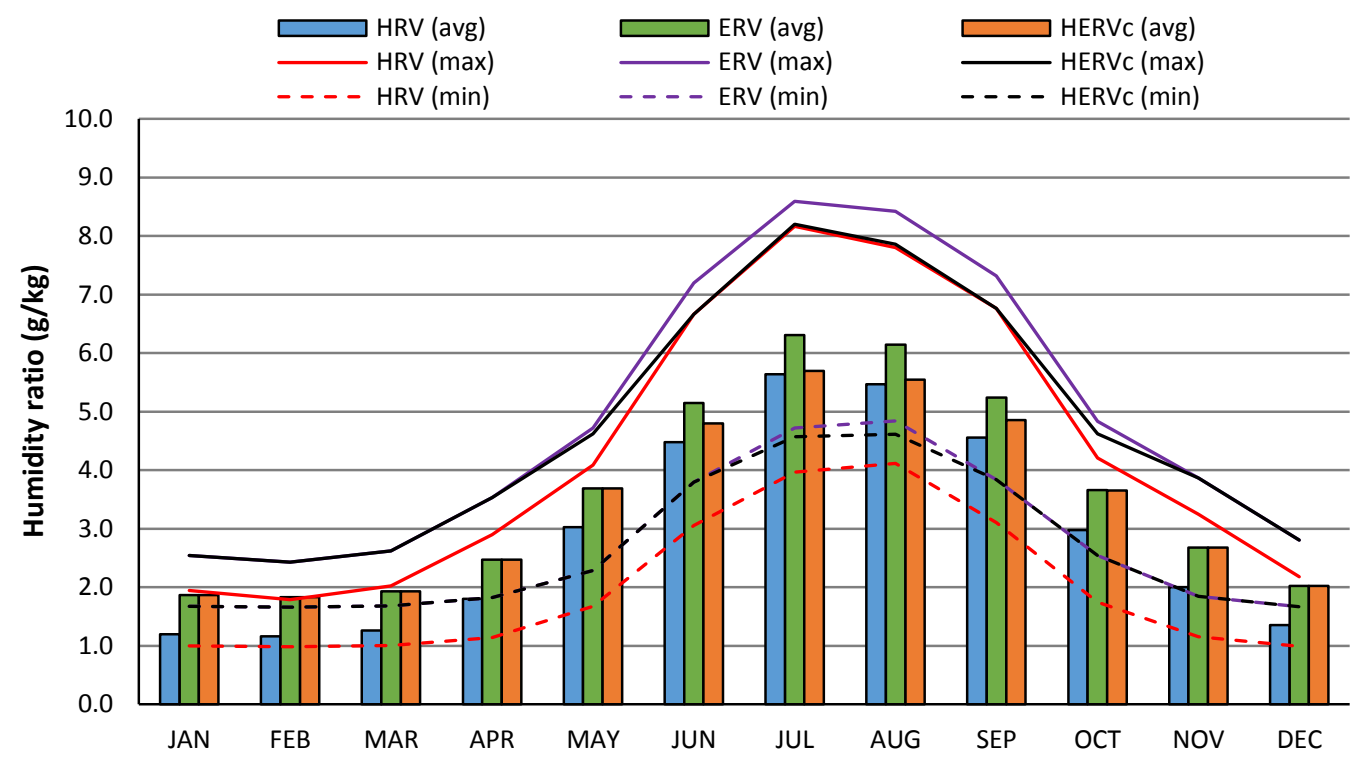

Figure 5.4.17 - Humidity of the house (Iqaluit): $\mathrm{HERV}_{c}$ vs. HRV vs. ERV

In the cold winter months, for house without major moisture sources, the HRV-equipped house had an average of $8 \% \mathrm{RH}$ at $21^{\circ} \mathrm{C}$, and hence, was not a good choice. In contrast, both the $\mathrm{HERV}_{c}$ and ERV retained the house overall humidity at the same and higher level; the illustrated results implicitly indicate that the $\mathrm{HERV}_{c}$ had no advantage over the ERV on the moisture control because 
latent heat recovery was almost always required. In the summer months (e.g., Jun. to Sep.), the gaps among the three cases were also observed. The $\mathrm{HERV}_{c}$ minimized the maxima while keeping the minima at the setpoint $(4.6 \mathrm{~g} / \mathrm{kg})$. In terms of average humidity, the ERV-equipped house in July had $41 \% \mathrm{RH}$ at $21^{\circ} \mathrm{C}$, while the $\mathrm{HERV}_{c}$ had an average of $37 \% \mathrm{RH}$. Overall, the $\mathrm{HERV}_{c}$ performed the designated operations for better control of humidity while minimizing the house heating consumption.

\section{4 .3 - Trade-off Analysis}

The project scope requires the HERVs to be able to operate in four different modes to avoid unnecessary operations. To achieve demand control, trade-off is needed for enthalpy core. During the process of development for both the system and control logics, the enthalpy core was decided to be used only if the moisture exchange is required, meaning that the nature of the core was partially gave up (sensible heat exchange). The presented study aimed to quantitatively explore the amount of the losing and gaining based on interior temperature and humidity. This was done by setting the system to be operated in only the dual-core and bypass modes. Therefore, without the single core controls, sensible heat will be exchanged through both the sensible and enthalpy cores. This essentially reduces the heating consumption of the house attributed to the outside air. Figures 5.4.18 and 5.4.19 illustrate the house energy use and humidity with and without the single core modes. In summer months, energy uses for both cases were nearly the same because freecooling was the major source of energy savings. The maximum humidity, due to condensation, decreased slightly for the case w/o single core modes. In terms of the monthly average humidity, however, the system with single core modes performed better. In winter months, total $17 \mathrm{kWh}$ savings were sacrificed, in return, both the maximum and average humidity were better controlled. Therefore, the concept of the single core modes are correct and promising, but a win-win solution is difficult to achieve. Unless a lower space heating consumption is desired, otherwise the potential of sensible heat recovery of the enthalpy core could be worthwhile to be scarified occasionally to achieve better indoor humidity control. 


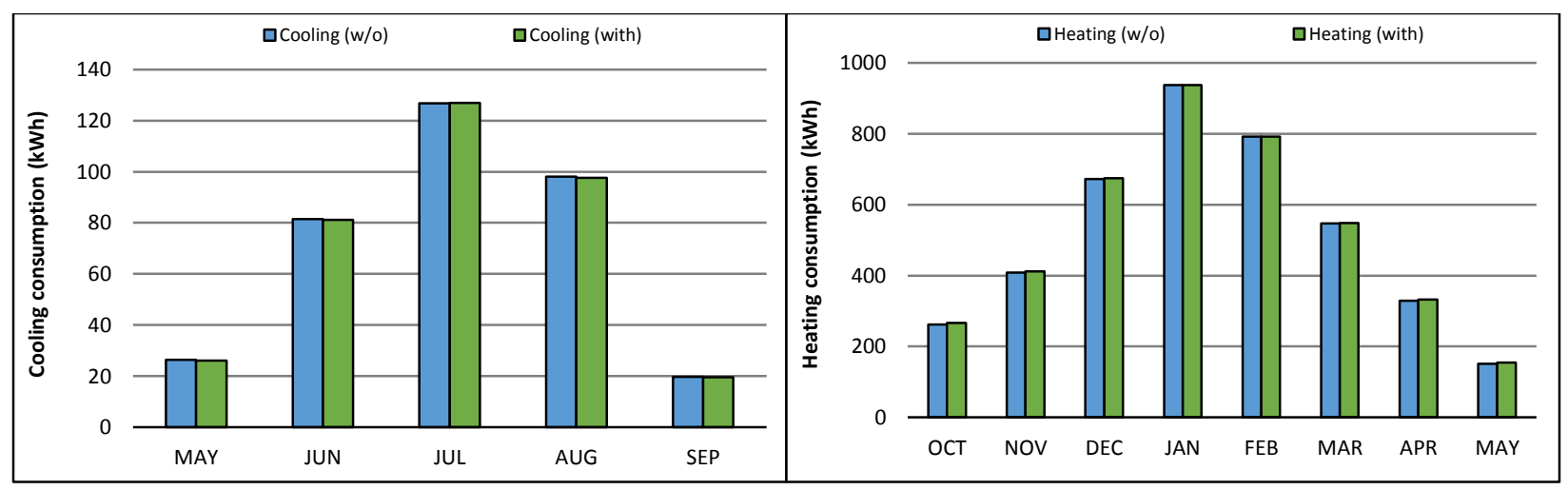

Figure 5.4.18 - Cooling (left) and heating (right) consumption of the house with and without the single core modes

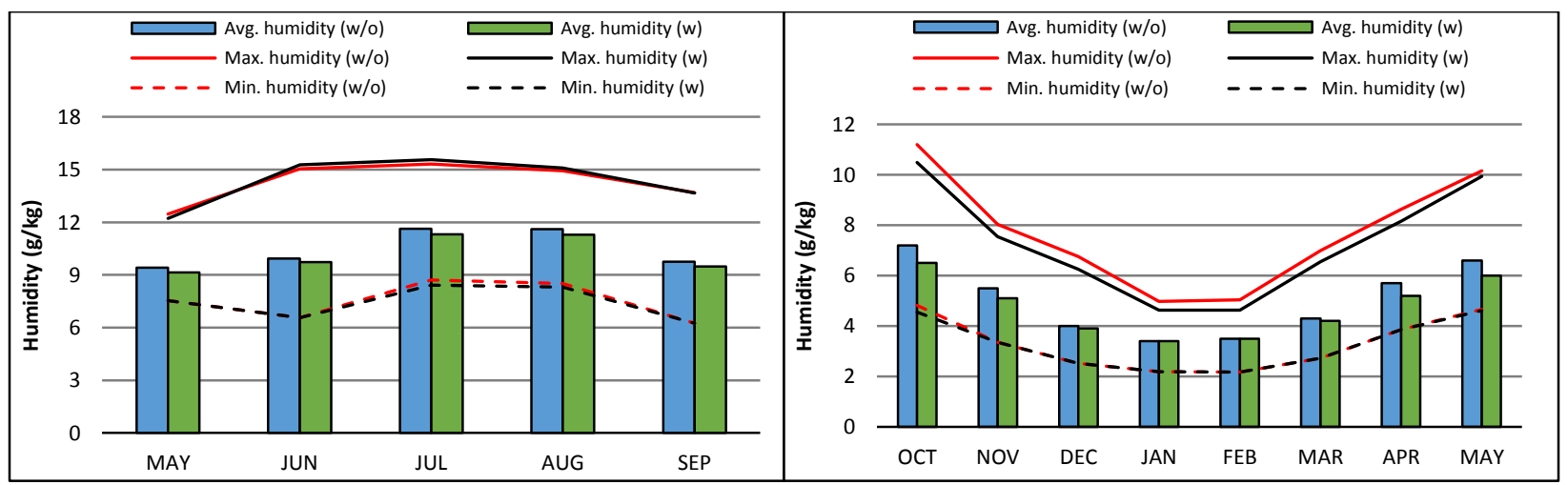

Figure 5.4.19 - Humidity ratio with and without the single core modes during cooling (left) and heating (right) period, Toronto

\section{Section 5.5 - Sensitivity Analysis}

\subsection{1-Climates}

It was necessary to perform a sensitivity analysis to reinforce the relationships between the local climatic characteristics and the output variables in the models. In addition to the five cities studied above, this sub-section investigated and analyzed the output variations among different cities. All the building specifications, heat gains and HVAC equipment remained unchanged unless notified. Tables 5.5.1 to 5.5.4 present the percent energy savings, cooling and heating consumption of the house in different regions across North America. Results indicate that the consumption of each zone resembles those presented in Section 5.4, except with minor discrepancies. For Lethbridge, the bypass mode was turned off due to dry climate, the $\mathrm{HERV}_{p}$ resulted in the lowest cooling consumption as a result of lower overall sensible efficiency (see the analysis in Section 5.3.1). For Albuquerque, however, the $\mathrm{HERV}_{p}$ became the least efficient one even though the city pertains to same general climate zone. Based on the Köppen-Geiger climate type map for North America (Peel, Finlayson \& McMahon, 2007), Lethbridge belong to Bsk (semi-arid climate, and the mean annual 
temperature is less than $18^{\circ} \mathrm{C}$ ), and Albuquerque belong to $\mathrm{B} s h$ (semi-arid climate, and the mean annual temperature is greater than $18^{\circ} \mathrm{C}$ ). Therefore, it is clear that the $\mathrm{HERV}_{p}$ was not suitable for cooling in hot regions, as mentioned in Section 5.4.1. In addition, results also reveal that the $\mathrm{HERV}_{c}$ would be the most inefficient configuration for warm summer if the economizer control is not integrated. For regions that have temperate climate (Type-C) and continental climate (TypeD), free-cooling resulted in an average percent savings of $27.3 \%$ and $16.4 \%$, respectively. Therefore, the built-in economizer control was feasible and beneficial. Figures 5.5.1 illustrate the house humidity with different methods of heat recovery in Edmonton, Alberta. In the summer, e.g., July, the ERV house had an average humidity of $10 \mathrm{~g} / \mathrm{kg}$, while the $\mathrm{HERV}_{c}$ resulted in $9.4 \mathrm{~g} / \mathrm{kg}$ humidity. In the winter, the $\mathrm{HERV}_{c}$ maintained the house humidity at a state that was neither too dry nor too humid (i.e., the HERV house had relatively lower maxima and higher minima). Throughout the year, it is clear that the integrated system provided better humidity control over the others.

Table 5.5.1 - Sensible cooling consumption for the house at different locations

\begin{tabular}{|c|c|c|c|c|c|c|c|c|}
\hline Zone & City & No VHR & HRV & ERV & $\mathrm{HERV}_{p}$ & HERV $_{p+\text { bypass }}$ & $\mathrm{HERV}_{c}$ & HERV $_{c+\text { bypass }}$ \\
\hline$A$ & West Palm Beach & 2281 & 1845 & 1856 & 2092 & 1844 & 1832 & 1808 \\
\hline B & Lethbridge & 264 & 303 & 297 & \multicolumn{2}{|r|}{280} & \multicolumn{2}{|c|}{307} \\
\hline B & Albuquerque & 769 & 744 & 747 & \multicolumn{2}{|r|}{751} & \multicolumn{2}{|c|}{743} \\
\hline $\mathrm{C}$ & San Francisco & 149 & 206 & 197 & 192 & 146 & 208 & 146 \\
\hline $\mathrm{C}$ & Nanaimo & 191 & 244 & 234 & 223 & 185 & 246 & 185 \\
\hline $\mathrm{D}$ & Montreal & 315 & 343 & 337 & 330 & 303 & 345 & 302 \\
\hline $\mathrm{D}$ & Edmonton & 215 & 254 & 247 & 232 & 204 & 256 & 204 \\
\hline
\end{tabular}

Table 5.5.2 - Saved energy percentage in the cooling period relative to direct ventilation

\begin{tabular}{|c|c|c|c|c|c|c|c|}
\hline Zone & City & HRV & ERV & $\mathrm{HERV}_{p}$ & $\mathrm{HERV}_{p+\text { bypass }}$ & $\mathrm{HERV}_{c}$ & HERV $_{\text {c+bypass }}$ \\
\hline$A$ & West Palm Beach & $19 \%$ & $19 \%$ & $8 \%$ & $19 \%$ & $20 \%$ & $21 \%$ \\
\hline $\mathrm{B}$ & Lethbridge & $-15 \%$ & $-13 \%$ & \multicolumn{2}{|r|}{$-6 \%$} & \multicolumn{2}{|c|}{$-16 \%$} \\
\hline B & Albuquerque & $3 \%$ & $3 \%$ & \multicolumn{2}{|r|}{$2 \%$} & \multicolumn{2}{|r|}{$3 \%$} \\
\hline $\mathrm{C}$ & San Francisco & $-38 \%$ & $-32 \%$ & $-29 \%$ & $2 \%$ & $-40 \%$ & $2 \%$ \\
\hline $\mathrm{C}$ & Nanaimo & $-28 \%$ & $-23 \%$ & $-17 \%$ & $3 \%$ & $-29 \%$ & $3 \%$ \\
\hline $\mathrm{D}$ & Montreal & $-9 \%$ & $-7 \%$ & $-5 \%$ & $4 \%$ & $-10 \%$ & $4 \%$ \\
\hline $\mathrm{D}$ & Edmonton & $-18 \%$ & $-15 \%$ & $-8 \%$ & $5 \%$ & $-19 \%$ & $5 \%$ \\
\hline
\end{tabular}


Table 5.5.3 - Sensible heating consumption for the house at different locations

\begin{tabular}{ccccccc}
\hline \multirow{2}{*}{ Zone } & City & No VHR & HRV & ERV & HERV $_{p}$ & HERV $_{c}$ \\
\hline B & Lethbridge & 6191 & 5322 & 5402 & 5621 & 5285 \\
\hline B & Albuquerque & 2884 & 2284 & 2363 & 2559 & 2243 \\
\hline C & San Francisco & 1954 & 1601 & 1648 & 1623 & 1595 \\
\hline C & Nanaimo & 3120 & 2464 & 2551 & 2513 & 2454 \\
\hline D & Montreal & 6205 & 5217 & 5301 & 5529 & 5181 \\
\hline D & Edmonton & 8242 & 7205 & 7287 & 7547 & 7168 \\
\hline E & Eureka & 44765 & 37162 & 37746 & 40084 & 36932 \\
\hline
\end{tabular}

Table 5.5.4 - Saved energy percentage in the heating period relative to direct ventilation (\%)

\begin{tabular}{cccccc}
\hline \multirow{2}{*}{ Zone } & City & HRV & ERV & HERV & HERV \\
& & & & & \\
\hline B & Lethbridge & $14 \%$ & $13 \%$ & $9 \%$ & $15 \%$ \\
\hline B & Albuquerque & $21 \%$ & $18 \%$ & $11 \%$ & $22 \%$ \\
\hline C & San Francisco & $18 \%$ & $16 \%$ & $17 \%$ & $18 \%$ \\
\hline C & Nanaimo & $21 \%$ & $18 \%$ & $19 \%$ & $21 \%$ \\
\hline D & Montreal & $16 \%$ & $15 \%$ & $11 \%$ & $17 \%$ \\
\hline D & Edmonton & $13 \%$ & $12 \%$ & $8 \%$ & $13 \%$ \\
\hline E & Eureka & $17 \%$ & $16 \%$ & $10 \%$ & $17 \%$ \\
\hline
\end{tabular}

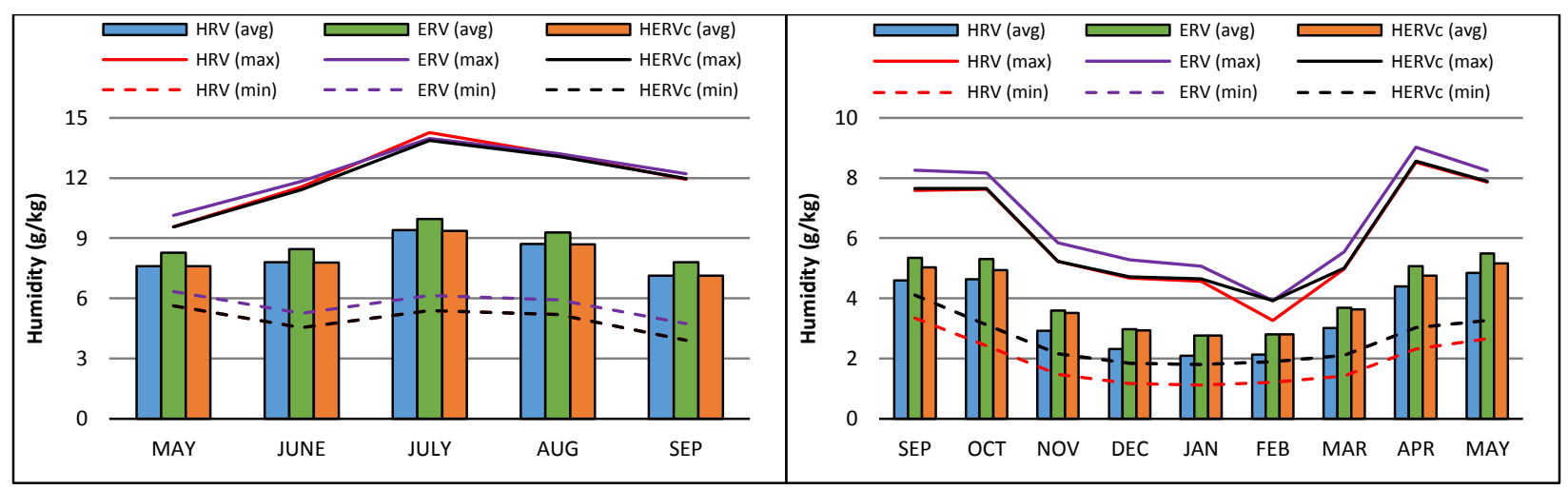

Figure 5.5.1 - Humidity of the house (Edmonton): $\mathrm{HERV}_{c}$ vs. HRV vs. ERV

\subsection{2 - Sensible Efficiency}

As mentioned earlier in the literature review, the study presented by Liu et al. (2010) revealed that the sensible efficiency and saved energy percentage were non-linearly related, meaning that they were not changing with the same rate. This study has inspired the idea of investigating the degree of influence of sensible efficiency on the overall performance of the HERV. Simulations were carried out by varying the sensible efficiency of the sensible core from $45 \%$ to $75 \%$ with an increment of $10 \%$. In the meantime, the sensible efficiency of the enthalpy core was fixed at either 
$45 \%$ or $65 \%$. Toronto, Canada was chosen for the following sensitivity studies because it experiences distinct heating and cooling seasons. The cooling consumptions of the house at different efficiencies are illustrated in Figure 5.5.2. The plot reveals that increased sensible efficiency from $45 / 45 \%$ to $75 / 45 \%{ }^{26}$ resulted in a decrease in cooling consumption of $7 \mathrm{kWh}$. In addition, increasing from $45 / 65 \%$ to $75 \% / 65 \%$ resulted in $6 \mathrm{kWh}$ reduction. The minor change implies that a highly efficient core was not needed because the major source of energy savings was free-cooling. In comparison, the cooling consumption of the HRV house increased along with the efficiency, which means that more unnecessary heat was recovered. Therefore, a built-in economizer control was a promising approach for cooling when outdoor air permitted.

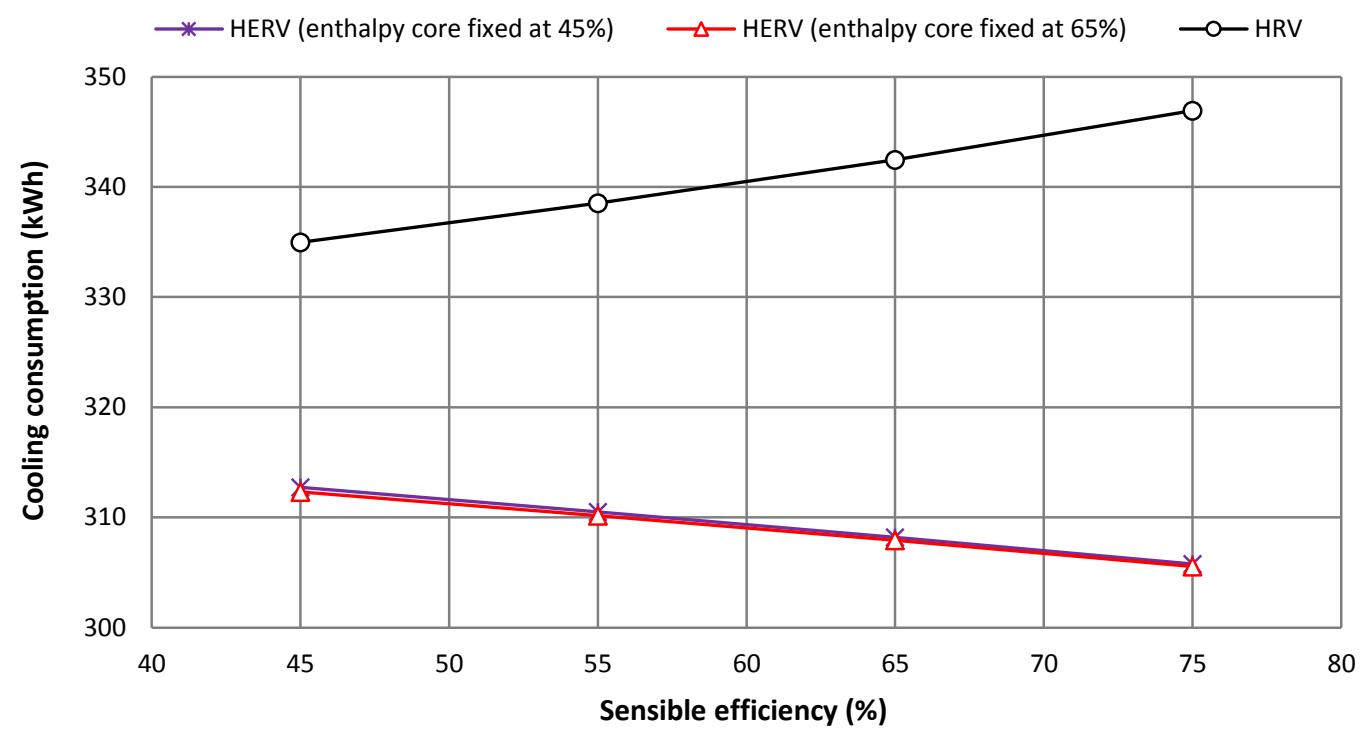

Figure 5.5.2 - Cooling consumption of the house at different sensible efficiencies (Toronto)

Figure 5.5.3 (left panel) presents the heating consumption of the house at different efficiencies. The HRV house required $4510 \mathrm{kWh}$ for heating at $45 \%$ sensible efficiency, and the consumption dropped to $4193 \mathrm{kWh}$ at $75 \%$. In terms of percent energy savings, the increase in sensible efficiency resulted in 6.2\% improvement, as shown in Figure 5.5.3 (right panel). In contrast, the consumption of the $\mathrm{HERV}_{c}$ house was $4363 \mathrm{kWh}$ at $45 / 45 \%$ and $4169 \mathrm{kWh}$ at $75 / 45 \%$, corresponding to $194 \mathrm{kWh}$ difference or 3.8\% energy savings. In addition, increasing from 45/65\% to $75 / 65 \%$ resulted in $139 \mathrm{kWh}$ reduction or $2.8 \%$ energy savings. Therefore, the change of sensible efficiency of the HRV resulted in greater percent energy savings than the HERV $V_{c}$. The

\footnotetext{
${ }^{26}$ Sensible efficiency of the sensible core is $75 \%$, while the enthalpy core is $45 \%$.
} 
use of dual cores reduced the impact resulting from the increase in sensible efficiency, and the more efficient the enthalpy core resulted in smaller effect attributed to the sensible core. More specifically, the counter-flow arrangement makes the impact of each core to be mutually dependent on the other; e.g., when core A becomes more efficient, the impact of core B, at the same time, will be smaller because the temperature difference of the airflows at that core (B) will become smaller. So, when the HERV is running dual-core mode, it is not wise to expect that the system will perform twice as hard as the HRV. In addition, even though the HERV needs to partially give up the nature of the enthalpy core, it may not affect significantly its potential because the sensible core is usually very efficient, and hence, the impact of enthalpy core in terms of sensible heat exchange is much smaller than what is expected.
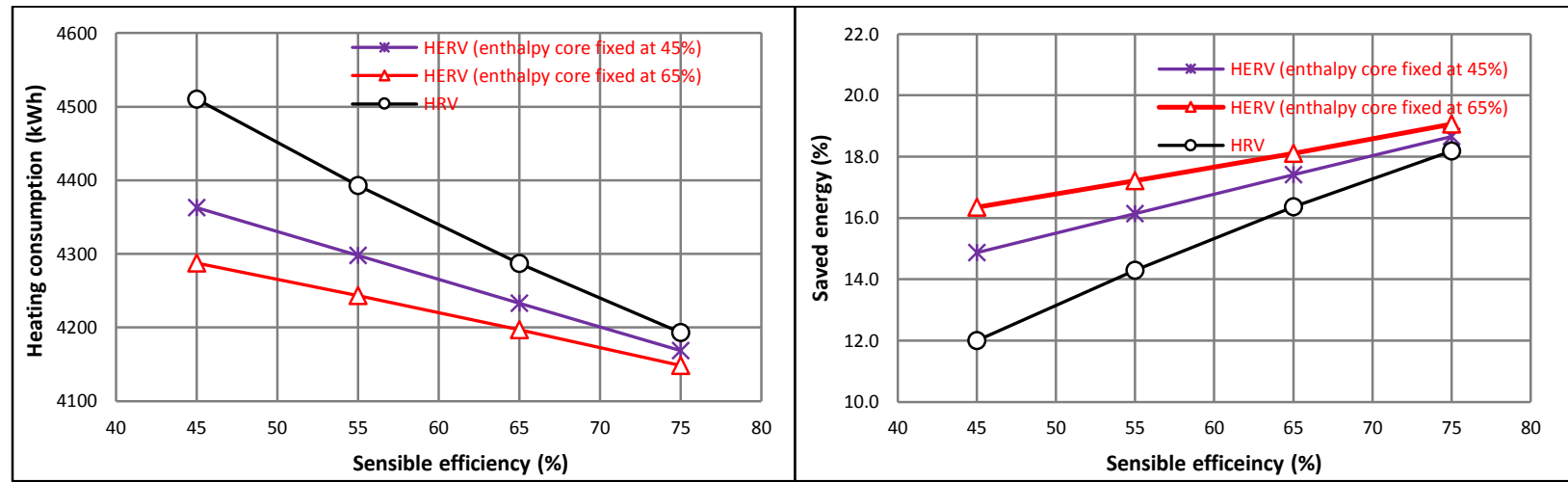

Figure 5.5.3 - Heating consumption (left panel) and percent energy savings (right panel) of the house at different efficiencies (Toronto)

\subsection{3 - Ventilation Rates}

The effects of free-cooling airflow rate on the energy savings were also investigated. Simulations were carried out by varying the airflow rate from $1 x(55 \mathrm{~L} / \mathrm{s})$ to $3 x(165 \mathrm{~L} / \mathrm{s})$. As shown in Figure 5.5.4, the house consumed $351 \mathrm{kWh}$ for cooling without economizer control, with an average humidity of $10.4 \mathrm{~g} / \mathrm{kg}$. The consumption turned out to be $304 \mathrm{kWh}$ while bypassing air at $55 \mathrm{~L} / \mathrm{s}$, and the average humidity reduced to $10.1 \mathrm{~g} / \mathrm{kg}$. As the flow rate increased to $1.5 \mathrm{x}, 2 \mathrm{x}$ and $2.5 \mathrm{x}$, free-cooling contributed to a decrease in consumption of 69, 87 and $102 \mathrm{kWh}$, respectively. On a yearly basis, it is clear the energy savings gradually became lower as the flow rate increased. Therefore, the savings from free-cooling were not linearly related to the ventilation flow rate. Concisely, free cooling the house at high ventilation airflow rate was not economical. 


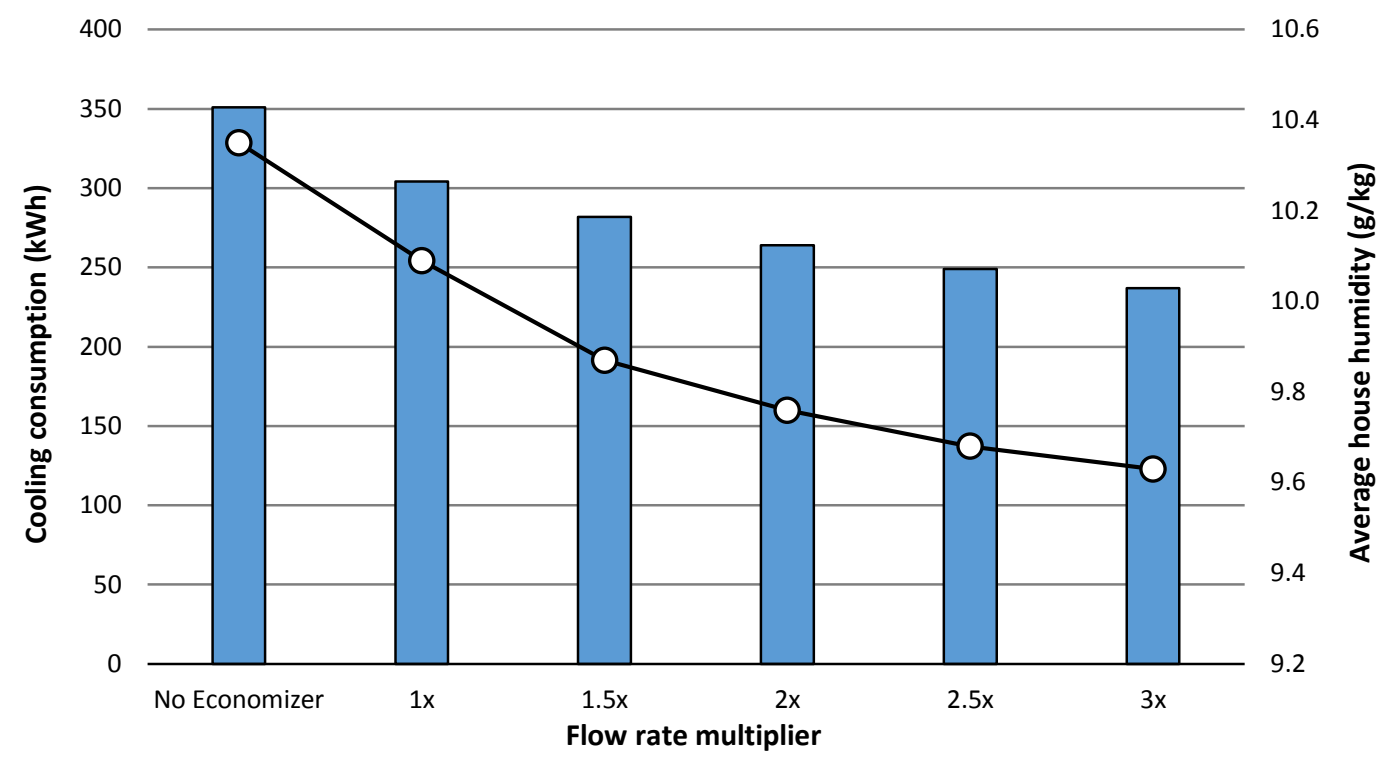

Figure 5.5.4 - Cooling consumption at different flow rate (Toronto)

Analysis was also carried out for different house mechanical ventilations (for both heat recovery and bypass operations) to determine the percent savings from systems. The efficiencies of both HRVs and ERVs decrease at high airflow rate because the fluids experience a small temperature change (Yunus \& Afshin, 2011). Therefore, simulations were carried out for two cases:

1. The house mechanical ventilation increased from $1 \mathrm{x}(55 \mathrm{~L} / \mathrm{s})$ to $2.5 \mathrm{x}(137.5 \mathrm{~L} / \mathrm{s})$, with an increment of $0.5 x$. In addition, the sensible and latent efficiencies of the sensible and enthalpy core changed based on the HRV and ERV product datasheets (VanEE, 2011), Table 5.5.5 lists the efficiencies under different airflow rates.

Table 5.5.5 - Estimated efficiencies under different airflow rate

\begin{tabular}{cccc}
\hline Multiplier & $\begin{array}{c}\text { Airflow rate } \\
(\mathrm{L} / \mathrm{s})\end{array}$ & $\begin{array}{c}\text { Sensible core efficiency } \\
(\%)\end{array}$ & $\begin{array}{c}\text { Enthalpy core efficiencies } \\
(\%)\end{array}$ \\
\hline $1.0 \mathrm{x}$ & 55 & 80 & $69 / 45$ \\
\hline $1.5 \mathrm{x}$ & 82.5 & 75 & $62 / 35$ \\
\hline $2.0 \mathrm{x}$ & 110 & 71 & $58 / 24$ \\
\hline $2.5 \mathrm{x}$ & 137.5 & 68 & $55 / 11$ \\
\hline
\end{tabular}

In Figures 5.5.5, the HERV ${ }_{c}$ house always consumed less than the other, and the amounts of saved energy gradually became significant as the airflow rate increased. For example, the $H_{E R V_{c}}$ house had a cumulative cooling consumption of $304 \mathrm{kWh}$ for venting at $55 \mathrm{~L} / \mathrm{s}$, while the house that experienced direct mechanical ventilation consumed $322 \mathrm{kWh}$. Therefore, the difference was 18 
$\mathrm{kWh}$, and the percent saving was 5.6\%. In contrast, high-speed vented scenario $(137 \mathrm{~L} / \mathrm{s})$ had an energy difference of $91 \mathrm{kWh}$, or alternatively $31.6 \%$ saved energy percentage. Therefore, the savings attributed to the $\mathrm{HERV}_{c}$ exhibited to be independent to the sensible efficiency. Similarly, the saved energy for space heating (see Figures 5.5.6) increased from $1008 \mathrm{kWh}$ to $2818 \mathrm{kWh}$, and the difference of the saved energy between the HRV and HERV increased from $35 \mathrm{kWh}$ to 281 $\mathrm{kWh}$. In other words, the energy savings attributed to the $\mathrm{HERV}_{c}$ became significant for high vented house due to higher fresh air load. The presented percent savings also reveal that the difference between the HERV and ERV became larger as the fresh air load increased. Figures 5.5.7 and 5.5.8 illustrate the humidity of the house at different airflow rates. The house maximum humidity remained nearly identical in the summer, and decreased and overlapped in the winter. In contrast, the differences of average humidity among the three systems gradually diminished as the flow rate increased. This tendency can be explained by the decreased in latent efficiency, and hence, less amounts of redundant moisture were recovered from the stale air.

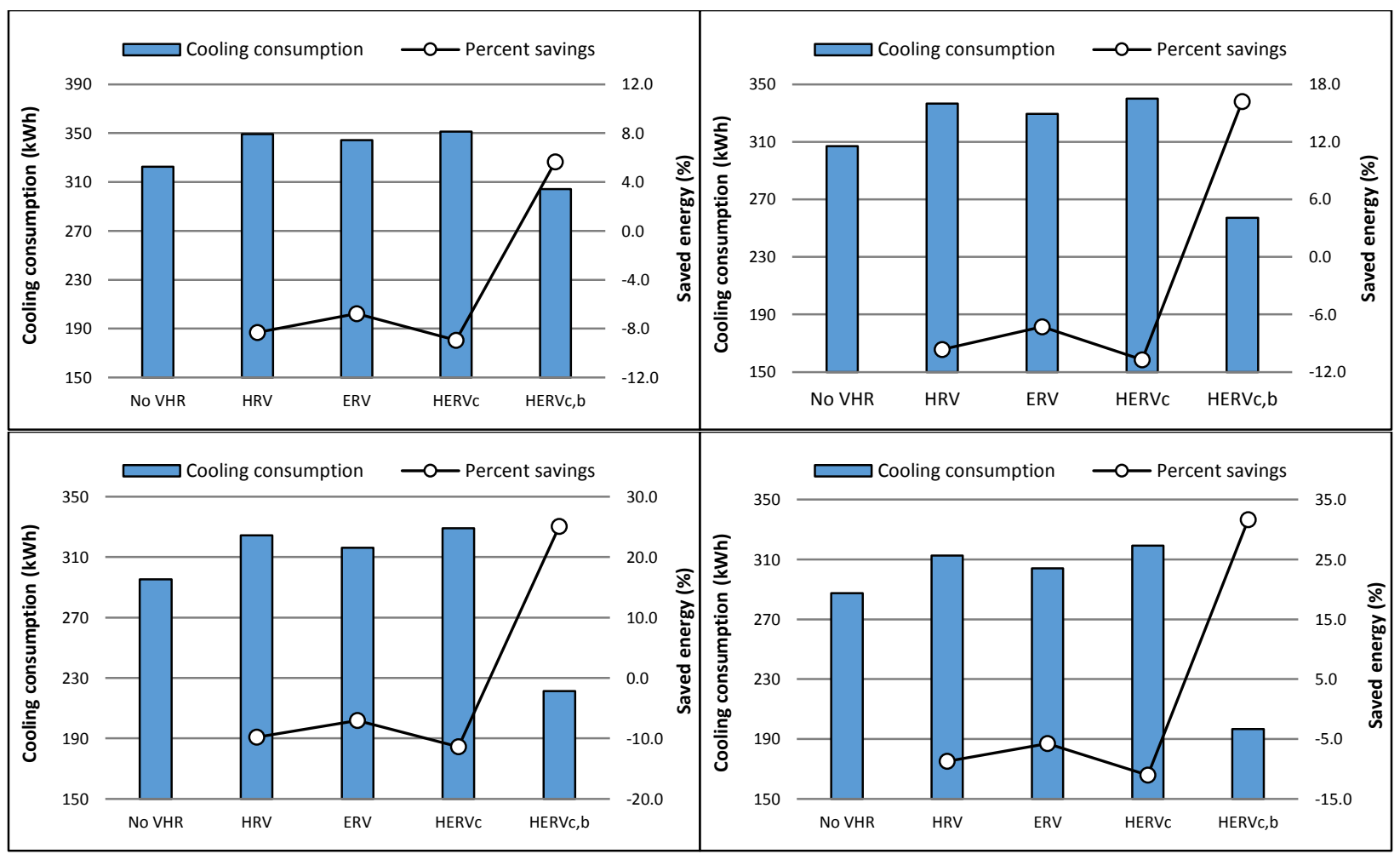

Figure 5.5.5 - Cooling consumption and saved energy percentage: left top for $1 \mathrm{x}$, right top for $1.5 \mathrm{x}$, left bottom for $2.0 \mathrm{x}$, and right bottom for $2.5 \mathrm{x}$ 

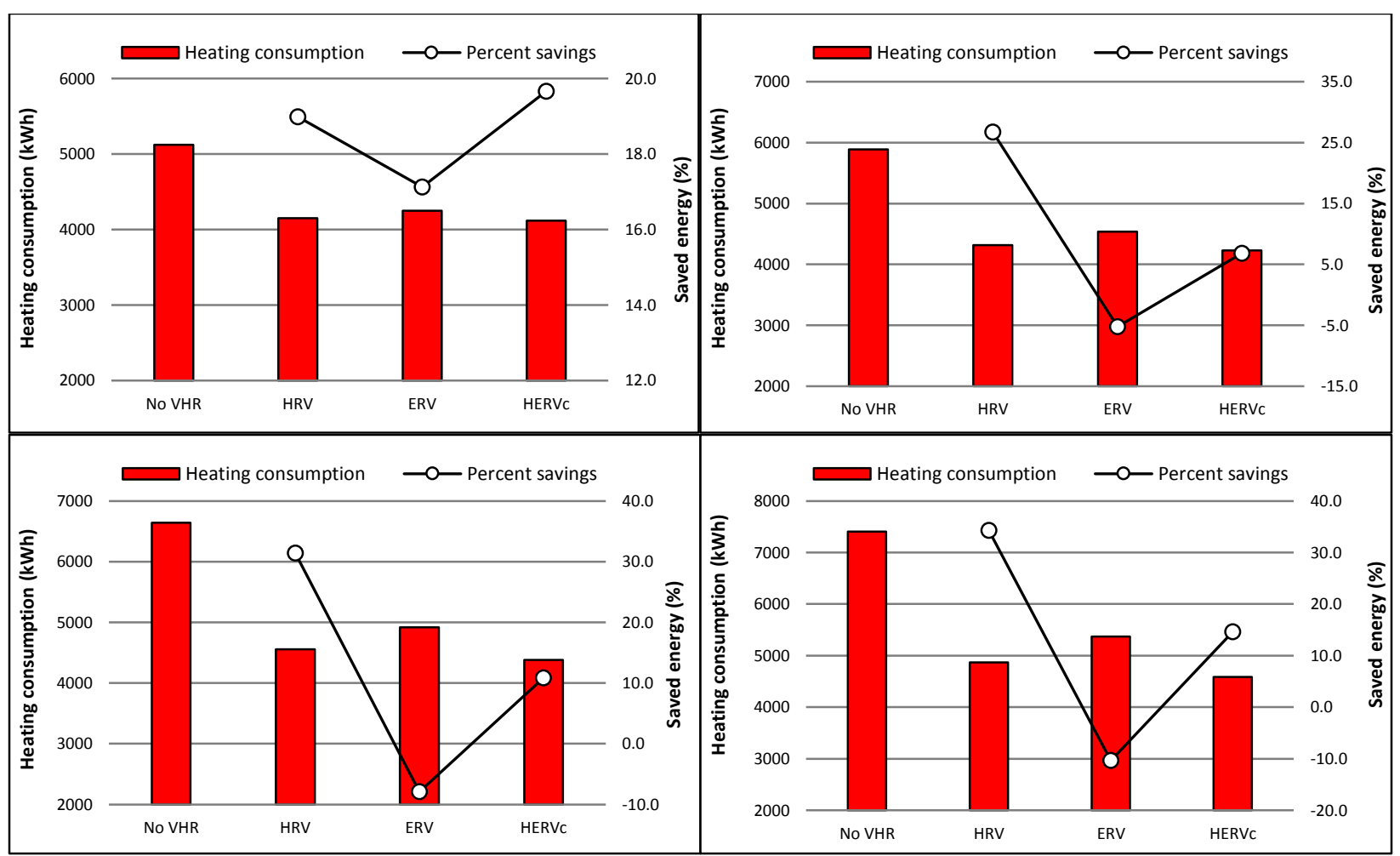

Figure 5.5.6 - Heating consumption and saved energy percentage: left top for $1 \mathrm{x}$, right top for $1.5 \mathrm{x}$, left bottom for $2.0 \mathrm{x}$, and right bottom for $2.5 \mathrm{x}$

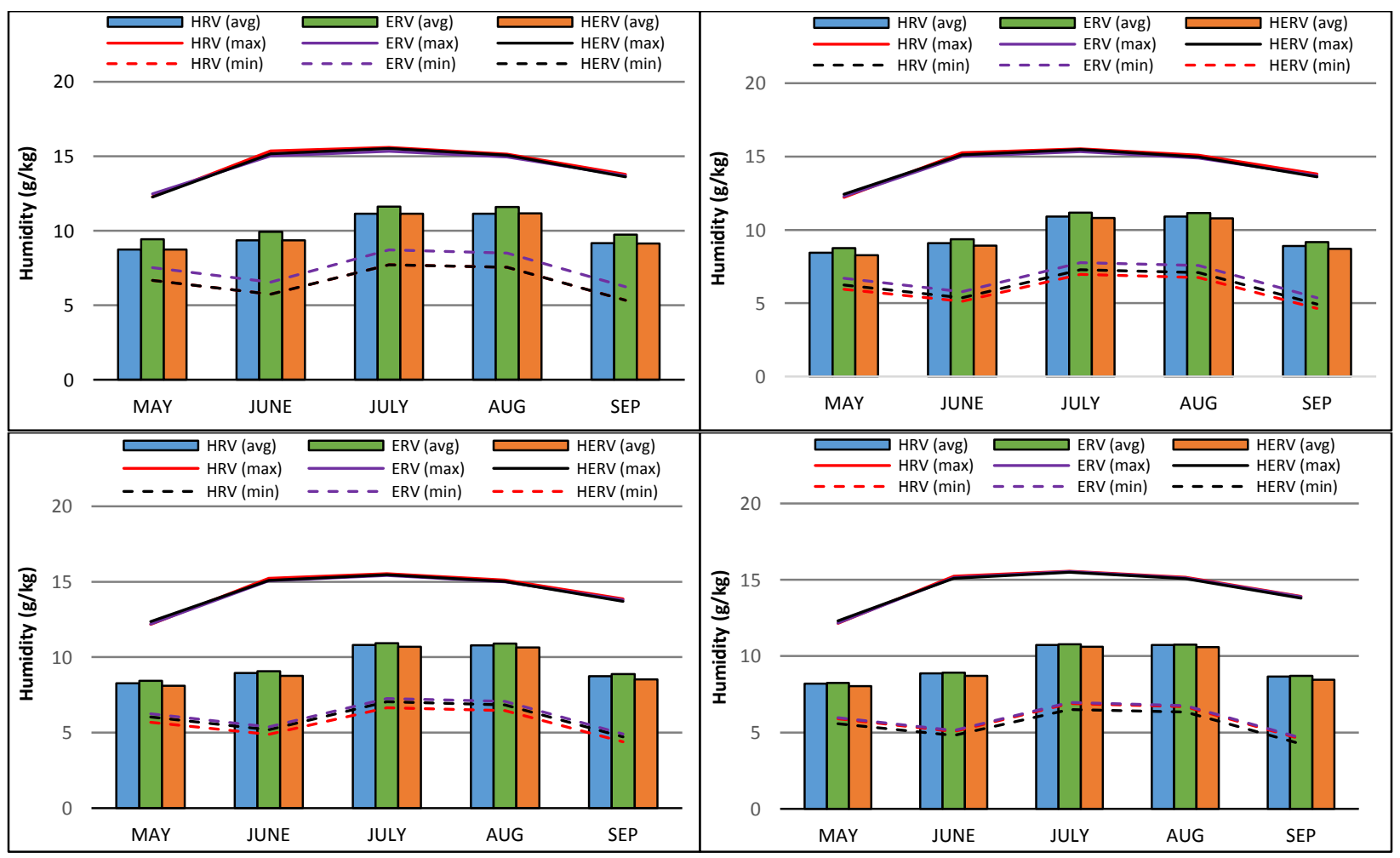

Figure 5.5.7 - Humidity of the Archetype Sustainable House-A: left top for 1x, right top for 1.5x, left bottom for $2.0 \mathrm{x}$, and right bottom for $2.5 \mathrm{x}$ 


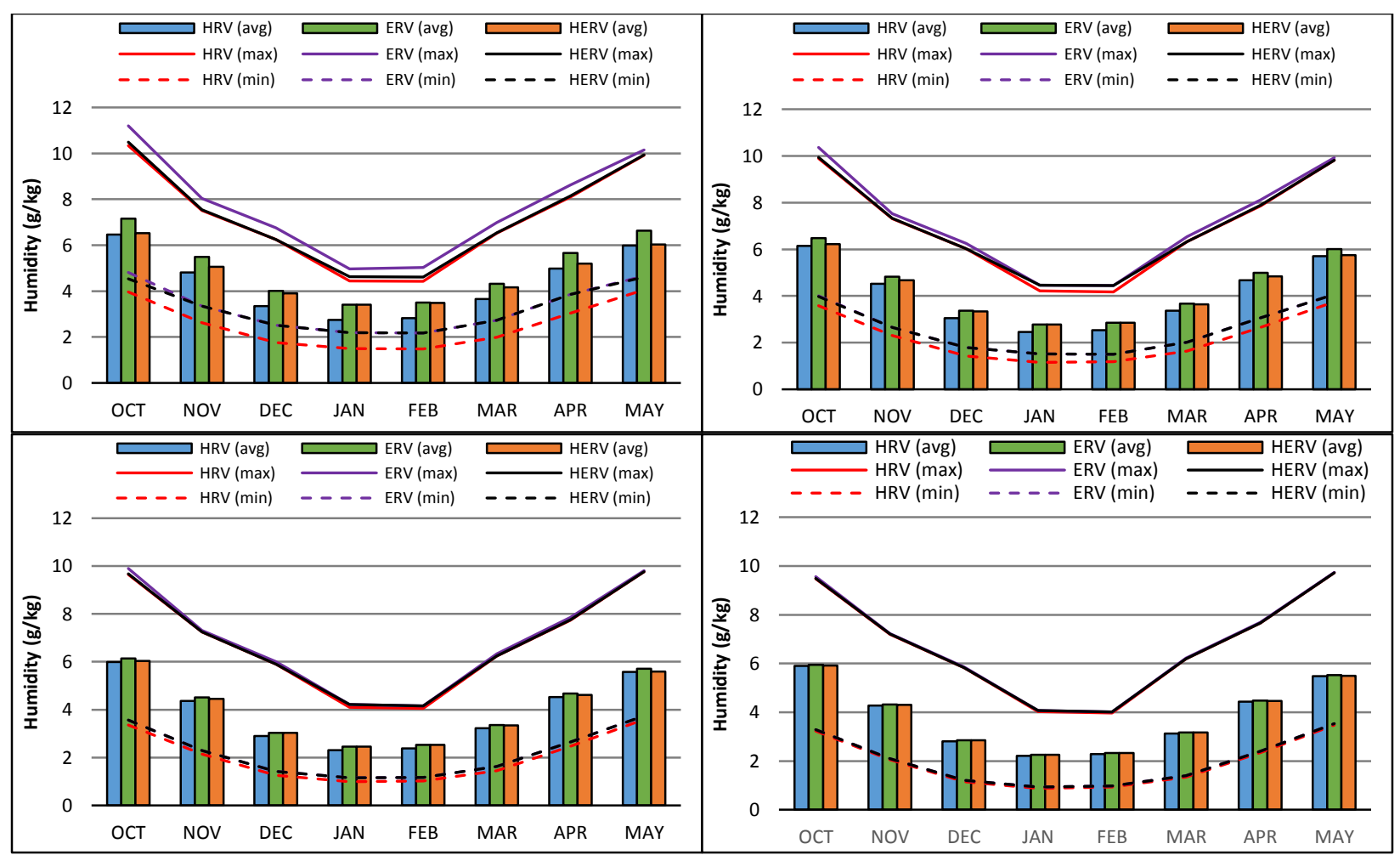

Figure 5.5.8 - Humidity of the Archetype Sustainable House-A: left top for 1x, right top for 1.5x, left bottom for $2.0 \mathrm{x}$, and right bottom for $2.5 \mathrm{x}$

2. The house mechanical ventilation increased from $1 \times(55 \mathrm{~L} / \mathrm{s})$ to $2.5 \times(137.5 \mathrm{~L} / \mathrm{s})$, while the sensible and latent efficiencies remained unchanged.

As shown in Figures 5.5.9 (right panel), the HRV and ERV houses consumed extra 12\% (35 kWh) and $9 \%(26 \mathrm{kWh})$ energy for cooling, respectively. In comparison, the $\mathrm{HERV}_{c}$ with free-cooling consumed $34.7 \%(100 \mathrm{kWh})$ energy less than the direct vented home. In addition, free-cooling contributed to a reduction in cooling consumption of $140 \mathrm{kWh}$ (or $42.7 \%$ ). For low-speed vented house (see Figure 5.5.9 left panel), the $\mathrm{HERV}_{c}$ with free-cooling option consumed only 5.6\% (18 $\mathrm{kWh}$ ) energy less than the direct vented home. Figures 5.5.10 show the heating consumption with $1 \mathrm{x}$ and $2.5 \mathrm{x}$ airflow rate. The saved energy for space heating increased from $1008 \mathrm{kWh}$ to 3094 $\mathrm{kWh}$ as a result of the increased airflow rate. In addition, the difference between the HRV and HERV increased from $35 \mathrm{kWh}$ to $150 \mathrm{kWh}$. Therefore, the benefits attributed to $\mathrm{HERV}_{c}$ became more significant for high vented house due to higher fresh air load, as similar to scenario \#1 presented above. 


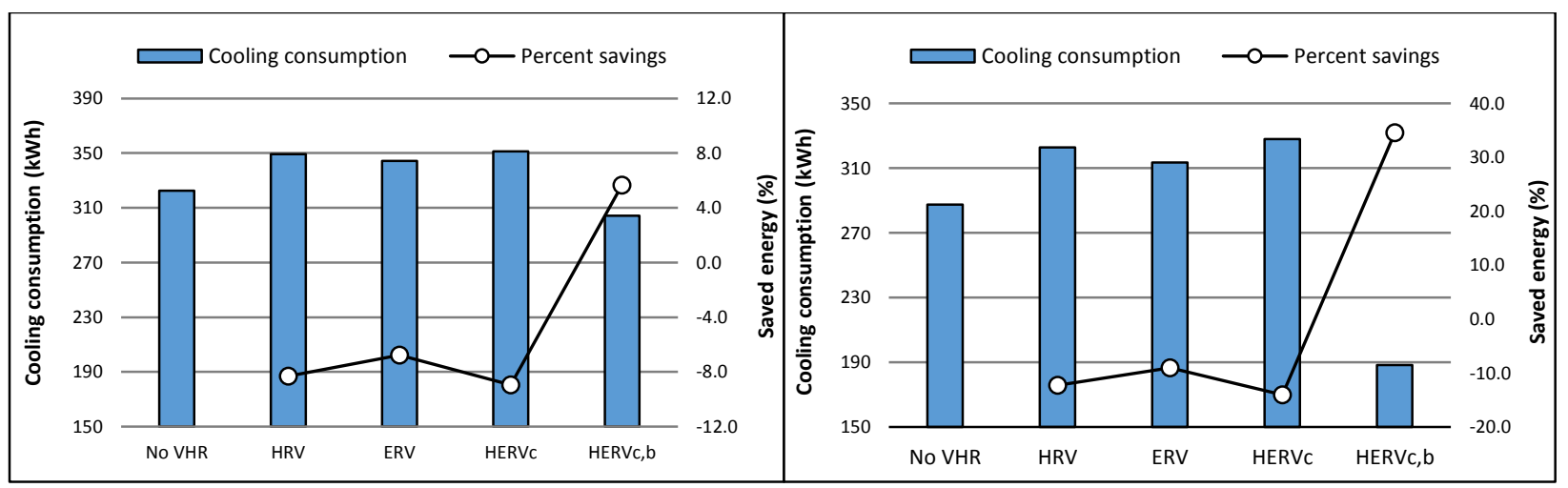

Figure 5.5.9 - Cooling consumption and saved energy percentage: left top for $1 \mathrm{x}$, right top for $2.5 \mathrm{x}$

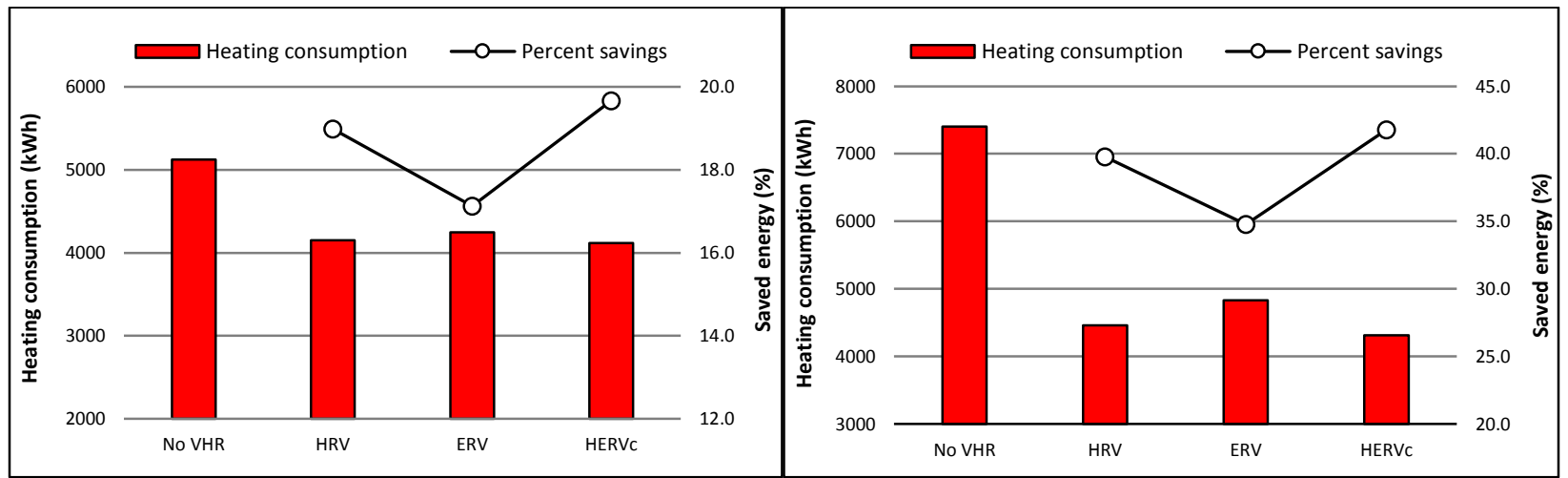

Figure 5.5.10 - Heating consumption and saved energy percentage: left top for $1 \mathrm{x}$, right top for $2.5 \mathrm{x}$

\subsection{4 - Setpoints}

To study the effects of indoor settings on the system performance, simulations were conducted by varying the temperature setpoint. In total, four scenarios were considered:

1. Scenario \#1: cooling dry-bulb temperature $\left(\mathrm{T}_{\text {set }}\right)$ was $21^{\circ} \mathrm{C}$, relative humidity $\left(\mathrm{RH}_{\text {set }}\right)$ was $50 \%$, and the airflow rate remained the same $(13.75 \mathrm{~L} / \mathrm{s}$ per zone).

2. Scenario \#2: cooling dry-bulb temperature $\left(\mathrm{T}_{\text {set }}\right)$ was $25^{\circ} \mathrm{C}$, relative humidity $\left(\mathrm{RH}_{\text {set }}\right)$ was $50 \%$, and the airflow rate remained the same $(13.75 \mathrm{~L} / \mathrm{s}$ per zone).

For scenario \#1, Figure 5.5.11 (left panel) shows that redundant heat recovery was still took place in both the HRV and ERV houses even though the setpoint temperature was turned down to $21^{\circ} \mathrm{C}$. Again, the ERV exhibited to be more efficient than the HRV due to lower sensible efficiency, and hence, less amount of redundant heat that was being recovered. On the other hand, the integrated bypass mode contributed to $46 \mathrm{kWh}$ energy savings or 9\% energy savings, from $511 \mathrm{kWh}$ to 465 $\mathrm{kWh}$. For scenario \#2, free-cooling resulted in $44 \mathrm{kWh}$ savings or $20.9 \%$ energy savings percentage. Therefore, the bypass mode became less effective for house having a lower setpoint. 
To study the cause of effect, the monthly frequency of free-cooling was investigated (see Figure 5.5.11 right panel). For $\mathrm{T}_{s e t}=21^{\circ} \mathrm{C}$, the free-cooling potential remained relatively low in both July and August. This can be explained by the fact that these months are the hottest month in the year, and hence, have the lowest free-cooling potential. However, at $\mathrm{T}_{\text {set }}=25^{\circ} \mathrm{C}$, more than $70 \%$ of the air-conditioned time from July to August was favorable for free-cooling to save cooling electricity consumption. Therefore, the monthly free-cooling potential increased along with the setpoints, that is, the higher the setpoint, the greater was the cooling potential of the outdoor air.
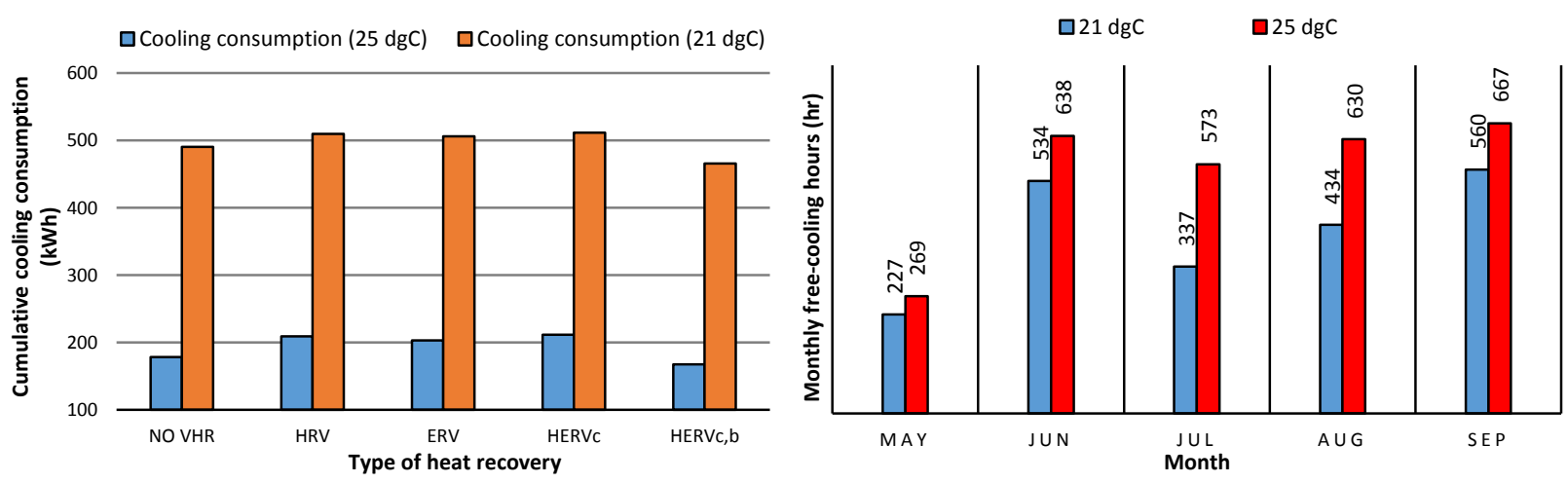

Figure 5.5.11 - Cumulative cooling consumption (left panel) and monthly potential of free-cooling (right panel) at different house setpoints (Toronto)

Bulut and Aktacir (2011) evaluated the potential of free-cooling using percent hourly potential ${ }^{27}$. The same method was adopted to help analyzing the hourly potential for the above two scenarios. In Table 5.5.6, the hourly potentials (\%) were grouped into 6 bins of 4 hours increments. As similar to the results presented above, the potential increased accordingly as the setpoint increased. In addition, the variation also reveals that the potential was high during nighttime period (bin hour 20:00-24:00 to 5:00-8:00), and exhibited to be less sensitive to the changes of indoor setpoints. At the period of 13:00-20:00 in July and August, free-cooling for $\mathrm{T}_{\text {set }}=21^{\circ} \mathrm{C}$ was favorable for less than $20 \%$ of the total 124 hours, and the remaining time was mechanical cooling. For $\mathrm{T}_{\text {set }}=25^{\circ} \mathrm{C}$ at the same period, there were minimum of $50 \%$ of the time the house could be benefited from free-cooling, and hence exhibited to be more sensitive to the setpoints. A similar trend can be observed in other months at the same period, i.e., in June, free-cooling potential increased from $47 \%$ to $77 \%$ at period 13:00-16:00. Therefore, to be more concisely, the change of setpoints significantly affected the potential of daytime free-cooling, while the potential remained nearly

\footnotetext{
${ }^{27}$ hourly potential $(\%)=$ total hours of each bin $/$ total hour for the month $* 100 \%$
} 
unchanged during nighttime period.

Table 5.5.6 - Hourly free-cooling potential at different setpoints (Toronto)

\begin{tabular}{|c|c|c|c|c|}
\hline & & \multicolumn{3}{|c|}{ Free-cooling potential (\%) } \\
\hline \multicolumn{2}{|c|}{ Time Interval } & $\mathrm{T}_{\text {set }}=21^{\circ} \mathrm{C}$ & $\mathrm{T}_{\text {set }}=23^{\circ} \mathrm{C}$ & $\mathrm{T}_{\text {set }}=25^{\circ} \mathrm{C}$ \\
\hline \multirow{7}{*}{ May } & & & & \\
\hline & $1-4$ & 98 & 100 & 100 \\
\hline & $5-8$ & 89 & 95 & 96 \\
\hline & $9-12$ & 76 & 89 & 91 \\
\hline & $13-16$ & 57 & 69 & 83 \\
\hline & $17-20$ & 60 & 78 & 90 \\
\hline & $21-24$ & 93 & 95 & 100 \\
\hline \multirow[t]{6}{*}{ Jun. } & $1-4$ & 97 & 97 & 92 \\
\hline & $5-8$ & 93 & 94 & 92 \\
\hline & $9-12$ & 73 & 84 & 94 \\
\hline & $13-16$ & 47 & 68 & 77 \\
\hline & $17-20$ & 51 & 69 & 79 \\
\hline & $21-24$ & 83 & 91 & 97 \\
\hline \multirow[t]{6}{*}{ Jul. } & $1-4$ & 87 & 92 & 99 \\
\hline & $5-8$ & 89 & 89 & 91 \\
\hline & $9-12$ & 38 & 64 & 76 \\
\hline & $13-16$ & 16 & 27 & 51 \\
\hline & $17-20$ & 18 & 32 & 54 \\
\hline & $21-24$ & 56 & 76 & 90 \\
\hline \multirow[t]{6}{*}{ Aug. } & $1-4$ & 95 & 99 & 99 \\
\hline & $5-8$ & 91 & 92 & 96 \\
\hline & $9-12$ & 55 & 67 & 74 \\
\hline & $13-16$ & 15 & 36 & 65 \\
\hline & $17-20$ & 20 & 46 & 76 \\
\hline & $21-24$ & 73 & 91 & 97 \\
\hline \multirow[t]{6}{*}{ Sep. } & $1-4$ & 92 & 100 & 100 \\
\hline & $5-8$ & 94 & 99 & 100 \\
\hline & $9-12$ & 74 & 82 & 90 \\
\hline & $13-16$ & 53 & 67 & 74 \\
\hline & $17-20$ & 68 & 76 & 93 \\
\hline & $21-24$ & 87 & 94 & 100 \\
\hline
\end{tabular}

3. Scenario \#3: heating dry-bulb temperature $\left(\mathrm{T}_{\text {set }}\right)$ was $19^{\circ} \mathrm{C}$, relative humidity $\left(\mathrm{RH}_{\text {set }}\right)$ was $30 \%$ (or $4.1 \mathrm{~g} / \mathrm{kg}$ ), and the airflow rate remained the same $(13.75 \mathrm{~L} / \mathrm{s}$ per zone).

4. Scenario \#4: heating dry-bulb temperature $\left(\mathrm{T}_{\text {set }}\right)$ was $23^{\circ} \mathrm{C}$, relative humidity $\left(\mathrm{RH}_{\text {set }}\right)$ was $30 \%$ (or $5.2 \mathrm{~g} / \mathrm{kg}$ ), and the airflow rate remained the same $(13.75 \mathrm{~L} / \mathrm{s}$ per zone).

Figure 5.5.12 shows that both the $\mathrm{HERV}_{c}$ and $\mathrm{HRV}$ resulted in maximum energy savings, and hence, more efficient than the ERV. Quantitatively, the $\mathrm{HERV}_{c}$ house with $19^{\circ} \mathrm{C}$ setpoint temperature required $3808 \mathrm{kWh}$ for heating (or 17.3\% energy savings), while the ERV required 
$3938 \mathrm{kWh}$ (or $14.5 \%$ savings). At $23^{\circ} \mathrm{C}$ setpoint, the $\mathrm{HERV}_{c}$ house required $4412 \mathrm{kWh}$ for heating (or $22.0 \%$ energy savings), while the ERV required $4605 \mathrm{kWh}$ (or 18.6\% savings). The difference between the two houses increased from $130 \mathrm{kWh}$ at $19^{\circ} \mathrm{C}$ setpoint to $193 \mathrm{kWh}$ at $23^{\circ} \mathrm{C}$ setpoint. Therefore, the higher the setpoint temperature the greater the benefit received from the HERV ${ }_{c}$.

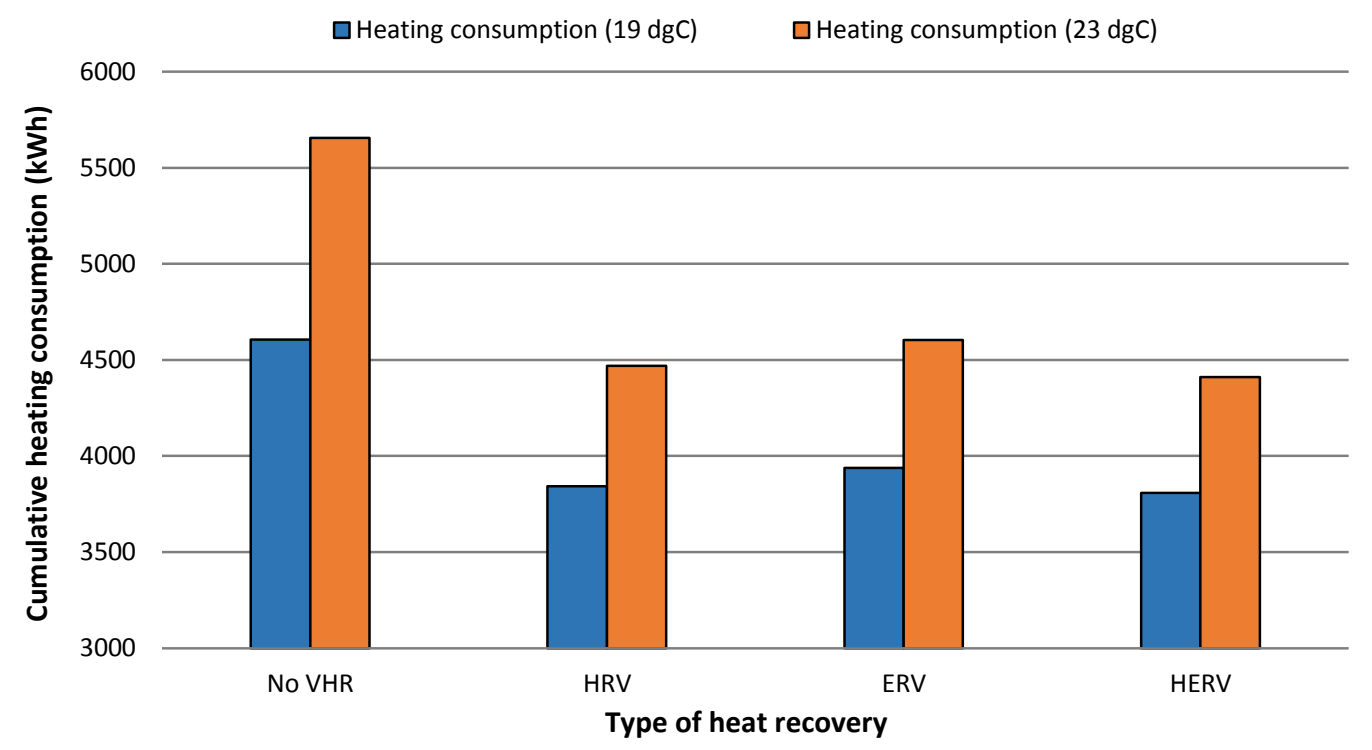

Figure 5.5.12 - Cumulative heating consumption at different house setpoints (Toronto)

Figures 5.5.13 illustrate the house humidity. At $19^{\circ} \mathrm{C}$ and $30 \% \mathrm{RH}$ setpoints (cooler and dryer scenario), the maximum humidity of the $\mathrm{HERV}_{c}$ and HRV houses remained lower than the ERV. In January and February, the HERV $c$ minimized the house maximum humidity to $4.4 \mathrm{~g} / \mathrm{kg}$, which was $0.5 \mathrm{~g} / \mathrm{kg}$ (or $4 \%$ relative humidity at $19^{\circ} \mathrm{C}$ ) lower than the ERV house. At the same period, for $23^{\circ} \mathrm{C}$ and $30 \% \mathrm{RH}$ setpoints (warmer and wetter scenario), the $\mathrm{HERV}_{c}$ maximized the house humidity to $5.0 \mathrm{~g} / \mathrm{kg}$ in order to achieve humidity control. In this case, the HRV became insufficient because the house was very dry. Throughout the year, the demand control feature of the HERV $c$ improved the service quality and satisfy the house demand under different outdoor conditions. 


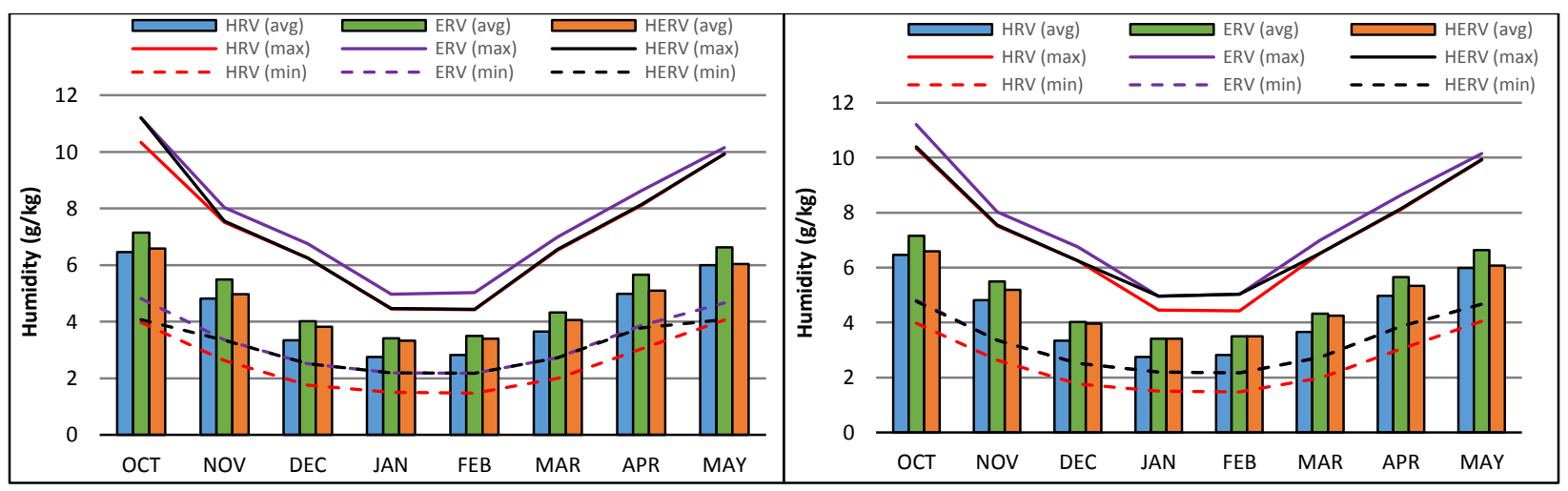

Figure 5.5.13 - House humidity ratio, left panel for $19^{\circ} \mathrm{C}$ and $30 \% \mathrm{RH}$, and right panel for $23^{\circ} \mathrm{C}$ and $30 \% \mathrm{RH}$ setpoints

\subsection{5 - Infiltration}

The next step of the sensitivity analysis was to study the degree of influence of the house insulation and airtightness on the percent energy savings attributed to free-cooling. This was done by either alternating the level of wall insulations or the rate of nature infiltration. In this study, simulations were carried out by varying the infiltration rate from $0.06 \mathrm{ACH}$ to:

1. According to Fung et al. (Fung, Guler, Aydinalp \& Ugursal, 2000), the infiltration rate for loose house type is $10.35 \mathrm{ACH}_{50}$. In addition, based on the LBL equation presented in Chapter 3 , the LBL factor (or the product of the correction factors) for a 3 stories loose house with "normal" exposure is 13.3. Therefore, the $\mathrm{ACH}_{\mathrm{avg}}=10.35 / 13.3=0.78 \mathrm{ACH}$.

2. In the study conducted by Broniek et al. (Broniek, Brozyna \& Stecher, 2010), the net-zero energy house had $0.6 \mathrm{ACH}_{50}$. Taking it as a reference value, the $\mathrm{ACH}_{\text {avg }}$ for a 3 stories net-zero house with "well-shielded" exposure is $0.6 / 18.8=0.032 \mathrm{ACH}$. To account for the lower ventilation due to infiltration, the mechanical ventilation was increased accordingly. The difference in natural infiltration:

$$
\triangle \mathrm{ACH}=(0.06-0.032) A C H=0.028 A C H
$$

In terms of ventilation rate in $\mathrm{cfm}$ :

$$
\Delta \dot{Q}_{\text {mech }}=\frac{A C H * \text { House Volume }}{60}=\frac{(0.028 \mathrm{ACH}) *\left(34820 \mathrm{ft}^{3}\right)}{60 \mathrm{~min} / \mathrm{hr}}=16.2 \mathrm{CFM}
$$

Therefore, the total required mechanical ventilation:

$$
\dot{Q}_{m e c h}=16.2+117=133.2 \operatorname{CFM}(\text { or } 62.6 \mathrm{~L} / \mathrm{s})
$$


According to the specification manual from the manufacturer, the efficiency at $133.3 \mathrm{cfm}$ and $0^{\circ} \mathrm{C}$ supply air temperature is $78 \%$ for the HRV, $66 \%$ (temperature) and $42 \%$ (humidity) for the ERV.

In Section 5.4.1, the energy savings attributed to free-cooling were found to be $45 \mathrm{kWh}$ for the $\operatorname{HERV}_{c}$, this amount was equivalent to $12.8 \%$ percent savings. Table 5.5.7 shows that the house with a $0.78 \mathrm{ACH}$ infiltration rate resulted in an energy savings of $32 \mathrm{kWh}$ from free-cooling, corresponding to $10.2 \%$ saving percentage. In contrast, free cooling the tighter $(0.032 \mathrm{ACH})$ house resulted in $51 \mathrm{kWh}$ (or 14.6\%) energy savings. The results indicate that the free-cooling approach was more effective for airtight house.

Table 5.5.7 - House cumulative cooling consumption at various infiltration rate (Toronto)

\begin{tabular}{cccc}
\hline Infiltration (ACH) & $\mathbf{0 . 0 3 2}$ & $\mathbf{0 . 0 6}$ & $\mathbf{0 . 7 8}$ \\
\hline HERV $_{\boldsymbol{c}}(\mathbf{k W h})$ & 350 & 351 & 313 \\
HERV $_{\text {c+bypass }}(\mathrm{kWh})$ & 299 & 306 & 281 \\
Energy saving percentage (\%) & 14.6 & 12.8 & 10.2 \\
\hline
\end{tabular}

\section{Section 5.6 - Conclusion and Recommendations}

This chapter was devoted to the preliminary system analysis of the HERVs using the developed models based on the constant efficiency approach. Two system models were developed to study system performances for different climatic types. According to the obtained results, the following important conclusions could be derived:

- The HERV ${ }_{c}$ was found to be adaptable to various operating conditions without any distinct performance deficiency, and hence, could be a feasible choice to meet different demands in different regions of North America.

- Demand controlled ventilation provided better use of cool outside air during warm summer days and better humidity control towards the setpoint.

- The savings from free-cooling were not linearly related to the ventilation flow rate.

- Free-cooling exhibited to be more effective for airtight homes.

- The use of dual cores reduced the impact resulting from the increased sensible efficiency, and the more efficient enthalpy core resulted in smaller effect attributed to the sensible core, and vice versa.

- The change of setpoints affected the daytime free-cooling potential, the nighttime potential 
remained nearly the same.

- Energy percent savings became higher for high vented house, and the difference between the HERV and ERV became larger and more significant. 


\section{Chapter 6 - Winter Experiment and Data Analysis (Winter 2014)}

\section{Section 6.1 - Introduction}

A long-term monitoring system within the TRCA Archetype Sustainable Twin-Houses has been implemented to monitor HVAC equipment using a NI based data acquisition (DAQ) system, and analyzed using LabVIEW platform (Zhang, Barua, \& Fung, 2011). Sensors have been installed and then calibrated. However, many of these sensors were broken and were replaced recently, and hence, calibrations were required for the new sensors to ensure the correct readings were obtained. Both the HRV in House-A and the ERV in House-B were monitored simultaneously. Once the data collection was completed, the recorded readings of temperature and relative humidity were used to calculate the associated sensible and latent efficiencies. In addition, the effects of built-in defrost cycle for both the equipment were also observed in order to increase the understanding of and optimize the defrost control. The TRNSYS models developed in Chapter 5 were then improved by implementing the above observed behaviour and the defrost control of the two equipment. Finally, the thermal performance of the proposed HERV systems were re-investigated for different regions across North America. In addition, the different types of sensors (i.e., air temperature/relative humidity, pressure transducers) located at the different ends of the heat recovery systems, calibration methods and the related equations for raw data conversions will be described in this chapter.

\section{Section 6.2 - Monitoring Systems: Heat Recovery Ventilation System}

A schematic of House-A HRV is given in Figure 6.2.1 depicting the supply air ducts, the exhaust air ducts, and the connections with the HRV and the corresponding sensors. According to the manufacturer specification sheet, the HRV has a system efficiency of $74 \%$ at $0^{\circ} \mathrm{C}$, with sensible efficiency of $86 \%$. The HRV contains a built-in defrost mode, which utilizes warm air recirculation to achieve defrosting when needed. The duration and interval of the defrost cycle are given in Table 3.2.2. To analyze the thermal performance of the HRV system using the monitoring systems, data for various operating conditions was obtained (e.g., defrost modes). Data such as supply/return air temperature $\left({ }^{\circ} \mathrm{C}\right)$, outdoor/supply/return relative humidity (\%), inlet/outlet volumetric air flow rate (cfm), and pressure difference across the core was collected. Table 6.2.1 lists the air temperature/relative humidity $(\mathrm{AT} / \mathrm{RH})$ sensors and differential pressure transmitters required for the system analysis. 


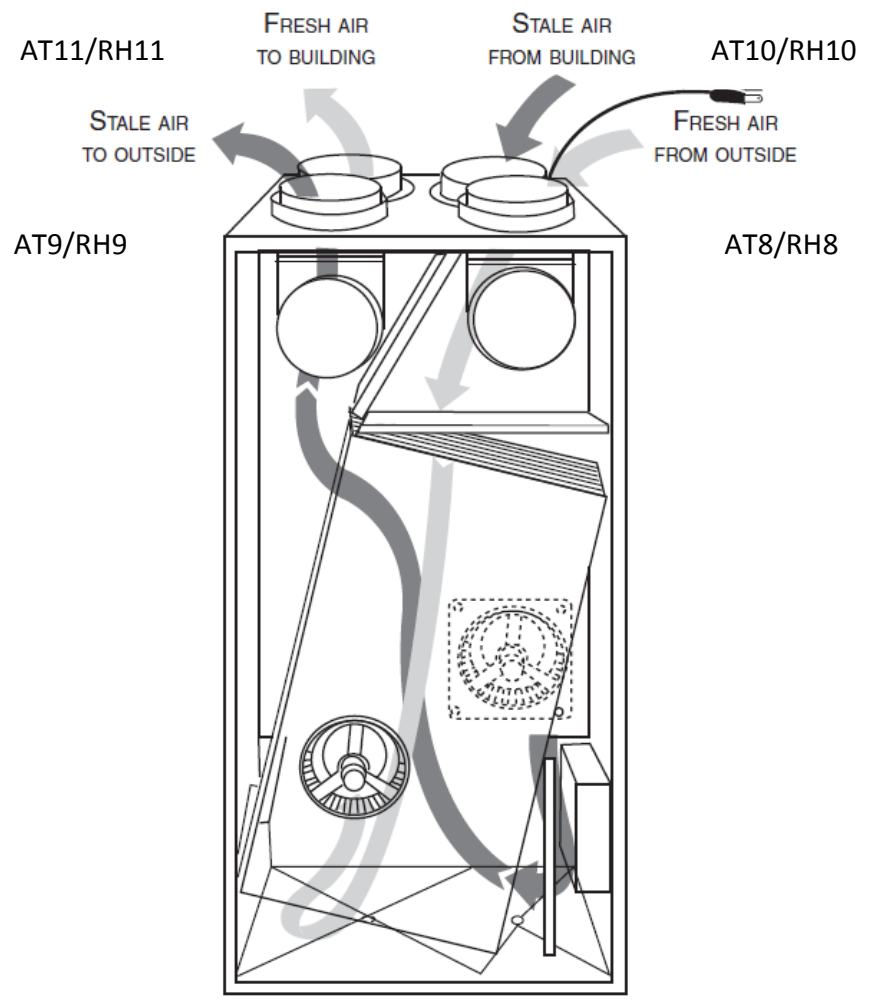

Figure 6.2.1 - House-A heat recovery ventilator airflows (VanEE, 2011)

Table 6.2.1 - HRV AT/RH and pressure sensors

Module: Al-111

\begin{tabular}{|c|c|c|c|c|c|}
\hline Address & Sensor & Type & Manufacture & Model number & Location \\
\hline ACFP1-M4-CHO & $\mathrm{RH} 8$ & Relative Humidity & Dwyer & Series RHP & \\
\hline ACFP1-M4-CH1 & AT8 & Air Temperature & Dwyer & Series RHP & \\
\hline ACFP1-M4-CH2 & RH9 & Relative Humidity & Dwyer & Series RHT & \\
\hline ACFP1-M4-CH3 & AT9 & Air Temperature & Dwyer & Series RHT & Exhaust Outlet \\
\hline ACFP1-M4-CH4 & $\mathrm{RH} 10$ & Relative Humidity & Dwyer & Series RHP & \\
\hline ACFP1-M4-CH5 & AT10 & Air Temperature & Dwyer & Series RHP & Exhaust Inlet \\
\hline ACFP1-M4-CH6 & RH11 & Relative Humidity & Dwyer & Series RHT & Supply Outlet \\
\hline ACFP1-M4-CH7 & AT11 & Air Temperature & Dwyer & Series RHT & \\
\hline ACFP1-M8-CH3 & PD1 & $\begin{array}{c}\text { Differential Pressure } \\
\text { Transmitter }\end{array}$ & Dwyer & Series 677B & Between core \\
\hline ACFP1-M4-CH12 & AF8 & $\begin{array}{l}\text { Differential Pressure } \\
\text { Transmitter }\end{array}$ & Dwyer & Series 677B & Supply Air \\
\hline ACFP1-M4-CH13 & AF9 & $\begin{array}{l}\text { Differential Pressure } \\
\text { Transmitter }\end{array}$ & Dwyer & Series 677B & Exhaust Air \\
\hline
\end{tabular}


The air temperature and relative humidity readings were used for the calculations of sensible efficiency of the HRV. In addition, the above sensors allowed for the determination of the onset temperature of built-in defrost cycle, the recirculated air conditions during defrost operation (i.e., temperature and moisture level after contacting with the freezing core surfaces). These observed parameters also helped for determining whether the defrost cycle of the HRV system was a preventive (prevent ice formation) or targeted action (melt ice).

The data was collected in the winter using a program called LabVIEW, and stored using Microsoft SQL Server. In Barua's (2010) study, the fresh air flow rate was found to be higher than that of the exhaust air because the AHU fan influenced the ERV fan for sucking more air from outdoors. In this experiment, the HRV fan speed control was set to low speed (around $147 \mathrm{cfm}$ ), the supply and exhaust air flow rates were adjusted to be nearly balanced by adjusting the damper valves, as well as setting the AHU fan to be running at constant speed during the test period. The detail specifications of the air handling unit and the other HVAC equipment are shown in Table 3.2.2. House heating was provided by the air-source heat pump, with multiple tabletop humidifiers that were running to regulate the amount of moisture in the air.

\section{Section 6.3 - Monitoring Systems: Energy Recovery Ventilation System}

A schematic of House-B ERV is given in Figure 6.3.1 depicting the supply air ducts, the exhaust air ducts, and the connections with the HRV and the corresponding sensors. According to the manufacturer specification sheet, the ERV has a system efficiency of $69 \%$ at $0{ }^{\circ} \mathrm{C}$, with sensible and latent efficiency of $76 \%$ and $45 \%$. Similar to the HRV, data such as supply/return air temperature $\left({ }^{\circ} \mathrm{C}\right)$, supply/return relative humidity $(\%)$, inlet/outlet volumetric air flow rate $(\mathrm{cfm})$ and pressure difference across the core were collected. Table 6.3.1 lists the air temperature/relative humidity $(\mathrm{AT} / \mathrm{RH})$ sensors and differential pressure transmitters required for the system analysis. 


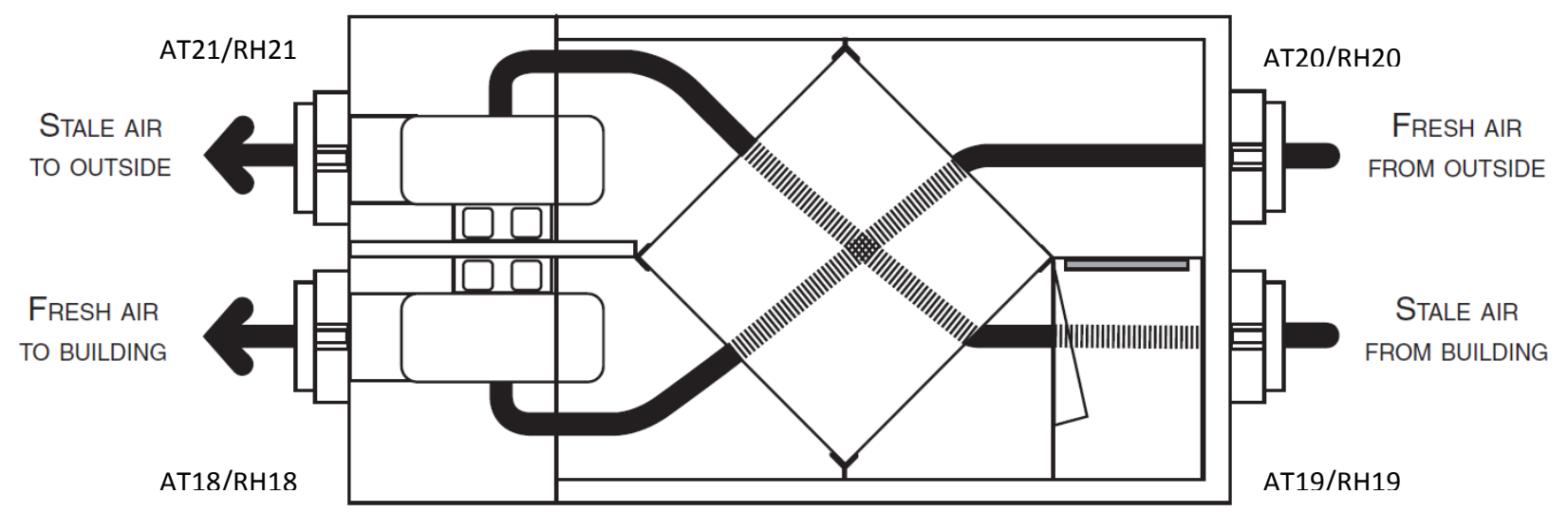

Figure 6.3.1 - House-B energy recovery ventilator airflows (VanEE, 2011)

Table 6.3.1 - ERV AT/RH and pressure sensors

\begin{tabular}{|c|c|c|c|c|c|}
\hline \multicolumn{6}{|c|}{ Module: AI-111 } \\
\hline Address & Sensor & Type & Manufacture & Model number & Location \\
\hline BCFP2-M3-CH4 & RH18 & Relative Humidity & Dwyer & Series RHT & \\
\hline BCFP2-M3-CH5 & AT18 & Air Temperature & Dwyer & Series RHT & Supply Outlet \\
\hline BCFP2-M3-CH2 & RH19 & Relative Humidity & Dwyer & Series RHT & \\
\hline BCFP2-M3-CH3 & AT19 & Air Temperature & Dwyer & Series RHT & Exnaust Iniet \\
\hline BCFP2-M3-CH12 & RH2O & Relative Humidity & Dwyer & Series RHP & \\
\hline BCFP2-M3-CH13 & AT20 & Air Temperature & Dwyer & Series RHP & suppry minet \\
\hline BCFP2-M3-CH6 & $\mathrm{RH} 21$ & Relative Humidity & Dwyer & Series RHT & \\
\hline BCFP2-M3-CH7 & AT21 & Air Temperature & Dwyer & Series RHT & Exhaust Outlet \\
\hline BCFP8-M4-CH5 & PD1 & $\begin{array}{l}\text { Differential Pressure } \\
\text { Transmitter }\end{array}$ & Dwyer & Series 677B & Between core \\
\hline BCFP8-M3-CH8 & AF15 & $\begin{array}{l}\text { Differential Pressure } \\
\text { Transmitter }\end{array}$ & Dwyer & Series 677B & Exhaust Air \\
\hline BCFP8-M3-CH9 & AF16 & $\begin{array}{l}\text { Differential Pressure } \\
\text { Transmitter }\end{array}$ & Dwyer & Series 677B & Supply Air \\
\hline
\end{tabular}

In addition to the sensible efficiency, the air temperature and relative humidity readings were also used for the calculations of humidity ratio, as well as the latent efficiency. Similarly, the readings from the above sensors helped to increase the understanding of the defrost mechanism as well as its effect upon the house humidity level once the defrost cycle was ongoing. During the test period, the ERV fan speed control was also set to low speed (around $88 \mathrm{cfm}$ ), the supply and exhaust air flow rates were also set to be nearly balanced (with small fluctuation), and the fan of the air 
handling unit was set to be running at constant speed. In addition, the house was heated using the ground source heat pump, with multiple tabletop humidifiers that were running to regulate air humidity. The detail specifications of the house air handling unit and the other HVAC equipment are shown in Table 3.2.3.

\section{Section 6.4 - Calibration of Sensors}

Calibration is the process of aligning the raw sensor reading(s) with the "true" value(s) in order to increase the overall accuracy of experimental findings. The off-line calibration is one of the calibration technique that help to identify and correct systematic bias (Feng et al., 2003). In the presented study, the off-line calibration technique was applied for both AR/RH and pressure sensors. A similar calibration technique had already been applied by Barua (2010) during the initial sensor setups in both ASH-A and -B. In the context of off-line calibration, comparisons were made between the collected raw sensor readings and the readings captured by high quality and high-cost hand-held calibrators. The second set of data served as the standards of what the sensors should measure. The goal of the off-line calibration is to determine a compact function that provides the mapping from the raw sensor reading to correct values (Feng et al., 2003). The Dwyer series RHT duct mount air temperature/relative humidity sensors had been calibrated once using the off-line calibration technique after wiring to the DAQ system (Barua, 2010). However, some sensors were broken and were replaced recently to series RHP, and hence, calibrations were required for the new sensors to ensure accurate readings were obtained during winter experiments. The accuracy of the instruments are shown in Table 6.4.1.

Table 6.4.1 - Sensors and calibrators

\begin{tabular}{ll}
\hline Sensors & Calibrators \\
\hline & $\begin{array}{l}\text { Omega CL3515R Calibrator Thermometer } \\
\text { Range: }-200^{\circ} \mathrm{C} \text { to } 1372^{\circ} \mathrm{C}\end{array}$ \\
Dwyer Humidity/Temperature Transmitter & Accuracy: $\pm\left(0.05 \%\right.$ rdg $\left.+0.5^{\circ} \mathrm{C}\right)$ \\
- Series RHP & SIKA Precision Micro-Calibration Bath (Type TPM 165S) \\
- Series RHT & $\begin{array}{l}\text { Range: }-50^{\circ} \mathrm{C} \text { to } 165^{\circ} \mathrm{C} \\
\text { Accuracy: } \pm 0.1^{\circ} \mathrm{C}\end{array}$ \\
& \\
& FLUKE 922 Airflow Meter \\
& Air pressure range: \pm 16 in $\mathrm{H}_{2} \mathrm{O}$ \\
Dwyer Differential Pressure Transmitters & Air pressure accuracy: $\pm 1 \%+0.01$ in $\mathrm{H}_{2} \mathrm{O}$ \\
\hline
\end{tabular}




\subsection{1 - Air Temperature}

Two types of Dwyer air temperature and relative humidity sensors were used for the measurement of air temperature: i) RHT series and ii) RHP series. Two sources of reference temperature were used for the calibration, i.e., a) micro-calibration bath, and b) room temperature. Figure 6.4.1 presents a screenshot of the live display of the LabVIEW program. All sensor readings were obtained from the live channel and/or through Microsoft SQL Server.

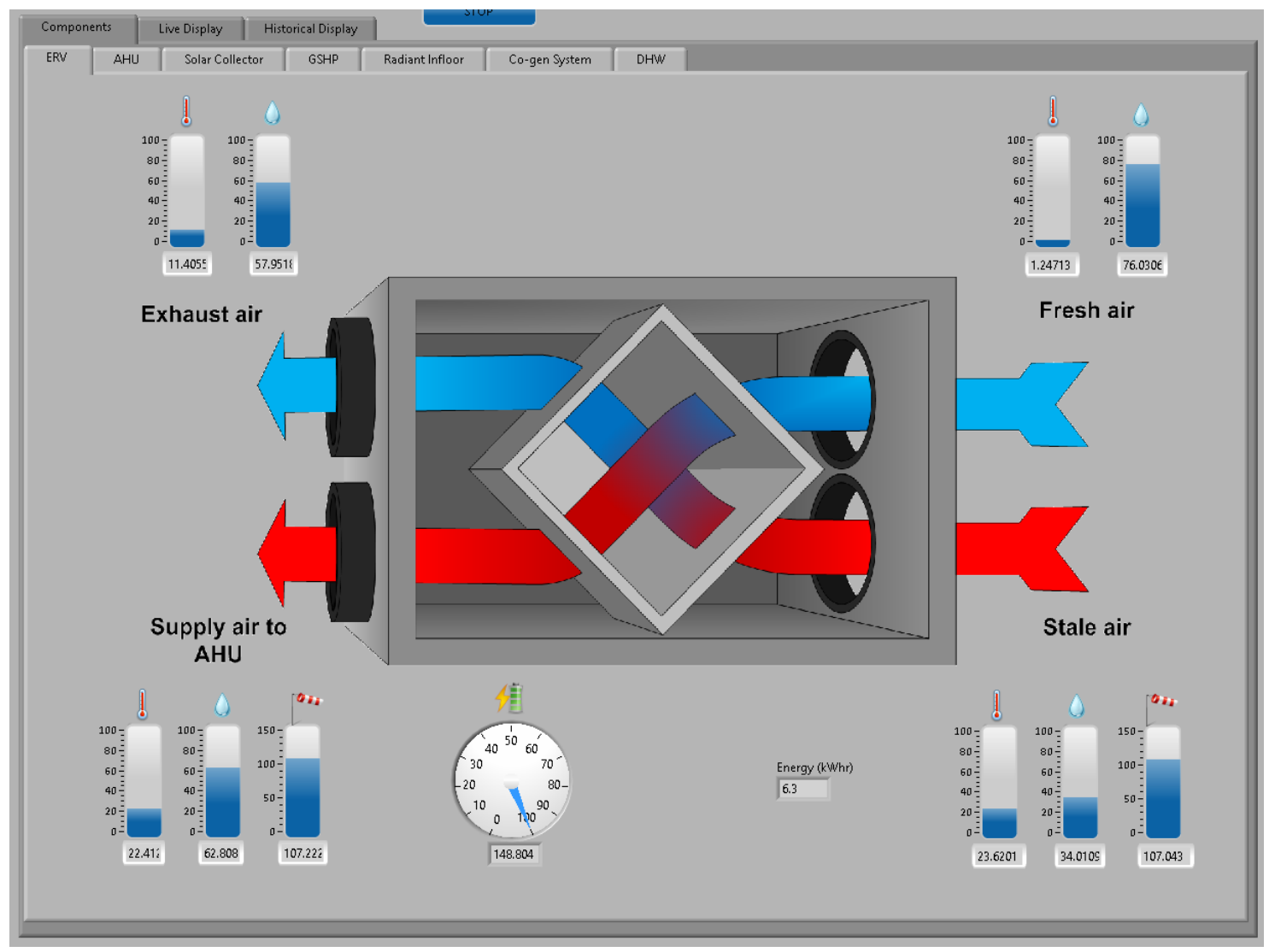

Figure 6.4.1 - Screenshot of live display for the ERV system within ASH-B

The micro-calibration bath can create accurate calibration temperature in the instrument. During the off-line calibration, the bath was set to and maintained at certain setpoint temperature, while the AT/RH sensors were inserted into the bath for 30 minutes to ensure readings have reached to steady state. With the help of this equipment, all temperature sensors were calibrated for different temperature ranges with $10^{\circ} \mathrm{C}$ intervals. The range of calibration depended on its range of use, i.e., the sensor for exhaust inlet air usually reads air temperature in between $19^{\circ} \mathrm{C}$ to $24^{\circ} \mathrm{C}$, calibration range was therefore selected to be $10^{\circ} \mathrm{C}$ to $30^{\circ} \mathrm{C}$. Appendix D contains figures of the calibrator bath and sensors. Table 6.4 .2 shows that the sensors temperature difference have ranged $0.1^{\circ} \mathrm{C}$ to 
$0.7^{\circ} \mathrm{C}$ from reference temperature $\left(20^{\circ} \mathrm{C}\right.$ to $\left.-20^{\circ} \mathrm{C}\right)$. In addition, temperature deviations increased significantly as the reference temperature reached $30^{\circ} \mathrm{C}$.

Table 6.4.2 - Calibrated result of AT/RH sensors based on calibration bath temperature setting

\begin{tabular}{|c|c|c|c|}
\hline & $\begin{array}{l}\text { Measurements } \\
\text { (Sensor) }\end{array}$ & $\begin{array}{l}\text { References } \\
\text { (Calibrator) }\end{array}$ & $\begin{array}{c}\text { Deviations } \\
\left({ }^{\circ} \mathrm{C}\right)\end{array}$ \\
\hline \multirow{6}{*}{ Supply Inlet } & 29.8 & 30.0 & 0.2 \\
\hline & 19.9 & 20.0 & 0.1 \\
\hline & 10.2 & 10.0 & 0.2 \\
\hline & 0.1 & 0.0 & 0.1 \\
\hline & -9.7 & -10.0 & 0.3 \\
\hline & -19.3 & -20.0 & 0.7 \\
\hline \multirow{4}{*}{ Supply Outlet } & 29.1 & 30.0 & 0.9 \\
\hline & 19.7 & 20.0 & 0.3 \\
\hline & 9.7 & 10.0 & 0.3 \\
\hline & -0.2 & 0.0 & 0.2 \\
\hline \multirow{3}{*}{ Exhaust Inlet } & 29.3 & 30.0 & 0.7 \\
\hline & 19.8 & 20.0 & 0.2 \\
\hline & 9.8 & 10.0 & 0.2 \\
\hline \multirow{4}{*}{ Exhaust Outlet } & 19.4 & 20.0 & 0.6 \\
\hline & 9.4 & 10.0 & 0.6 \\
\hline & 0.3 & 0.0 & 0.3 \\
\hline & -10.0 & -10.0 & 0.0 \\
\hline
\end{tabular}

By plotting the above measured temperatures against the references, an equation can be developed and implemented into the LabVIEW program to help estimating the "true" value based on the current sensor temperature(s). As an illustration (i.e., supply inlet), the measured sensor readings can be corrected using a $3^{\text {rd }}$ order polynomial equation for the plotted trend-line shown in Figure 6.4.2. 


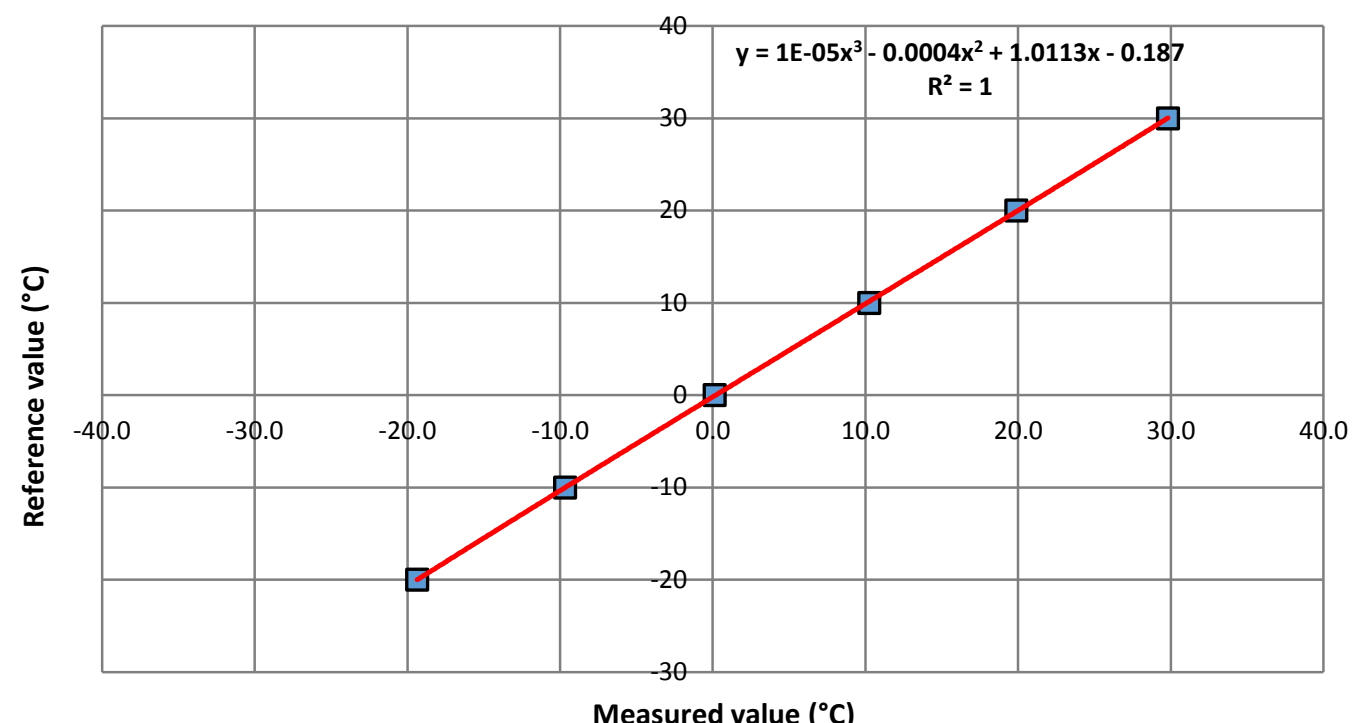

Figure 6.4.2 - Off-line calibrated result based on Precision Micro-Calibration Bath temperature settings

Thereafter, the AT/RH sensors were cross-checked using Omega calibrator thermometer at room temperature. This process aimed to validate the correctness of the calibration presented based on the calibration bath. During calibration, the tips of both the AT/RH sensor and the calibrator were put adjacent to each other, and readings were taken when readings reached steady state. Table 6.4.3 shows that, the AT/RH sensor for supply inlet air appeared to be more accurate, which resembles to those presented in Table 6.4.2. In contrast, the AT/RH sensor located at the exhaust outlet duct resulted in the highest deviation.

Table 6.4.3 - Calibrated result of AT/RH sensors based on room temperature (calibrator thermometer)

\begin{tabular}{cccc}
\hline & Sensor Reading & Calibrator Reading & Deviations \\
\hline Supply Inlet & 21.4 & 21.3 & 0.1 \\
Supply Outlet & 22.6 & 22.8 & -0.2 \\
Exhaust Inlet & 22.6 & 22.8 & -0.1 \\
Exhaust Outlet & 21.8 & 22.2 & -0.4 \\
\hline
\end{tabular}

\subsection{2 - Relative Humidity}

The calibration of relative humidity is challenging because it is temperature-dependent, and hence, it is a complex and time-consuming process (Schellenberg, 2002). This section devoted to a quick calibration of relative humidity with reading adjustment. A very convenient method to calibrate relative humidity is the use of saturated salt solutions (or calibration salts). Saturated solution has 
a fixed concentration at different temperature and does not have to be determined (Omega), and hence, provide a fixed humidity environment for calibration. The relative humidity was calibrated using three saturated salt solutions: $\mathrm{LiCl}(11 \% \mathrm{RH})$ used as the dry end reference, $\mathrm{MgCl}_{2}(33 \%$ $\mathrm{RH})$ used as a check point, and $\mathrm{NaCl}(75 \% \mathrm{RH})$ used as the wet end reference. The selected threepoint calibrations allowed the readings at different levels to be defined and corrected. Table 6.4.4 lists the reference humidity of the three saturated salt solutions at different air temperature. At the calibrating process, the saturated salts were allocated separately into three jars, and the distilled water was selected as solvent. According to McDuffee \& Shakya (2010), there should be about $80-90 \%$ of the salt remain undissolved. Thereafter, the jars were alternatively placed into the removable wire basket of the calibration bath in order to provide fixed temperature environment. In addition, the AT/RH sensor was placed at the headspace of the jar. The calibrating period was selected to be 24 hours to ensure sufficient period of time for stabilization, and the calibration bath was set at $23^{\circ} \mathrm{C}$. The detailed procedures of humidity calibration are presented in Appendix D. As an illustration, Figure 6.4.3 presents the humidity readings of Sodium Chloride (75\%) for 24 hours calibration period. The readings reveal that the sensor output varied quickly from $33.4 \%$ to $70.8 \%$ for the first 7 hours, and it eventually reached to $74.1 \%$ at the end of the test period. Table 6.4.5 presents the calibrated results for RH11 (HRV) and RH20 (ERV). As an illustration, a $2^{\text {nd }}$ order polynomial equation was developed for RH20 and set to the LabVIEW program for reading correction.

Table 6.4.4 - Reference humidity of the salt in different temperature (Vaisala, 2006)

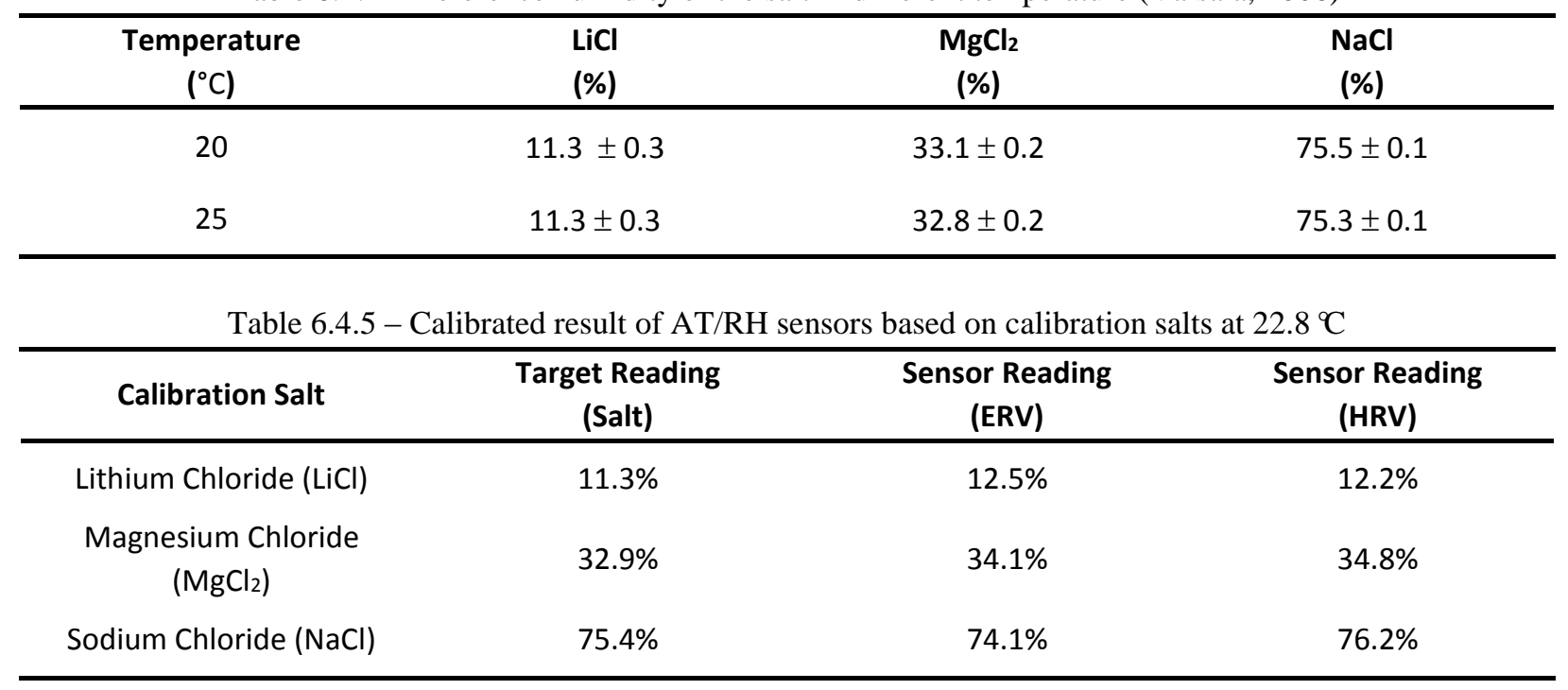




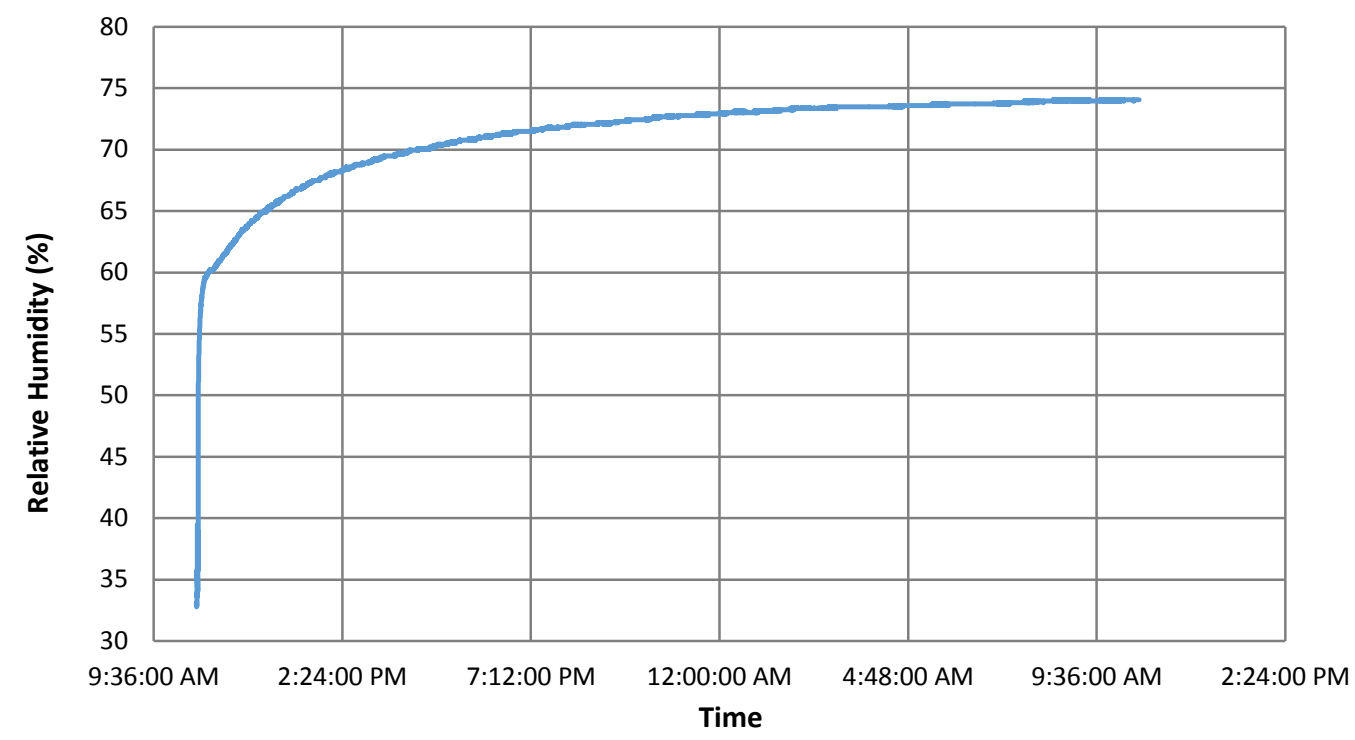

Figure 6.4.3 - Calibrated relative humidity for sensor at supply inlet duct

Due to the long calibration period, salt calibration was only performed for the supply input sensor. For others, calibration was carried out with that pre-calibrated AT/RH sensor based on the room humidity; the tips of all sensors (including the pre-calibrated AT/RH sensor) were put adjacent to each other, and humidity readings were recorded once all readings became stable. Table 6.5.6 and 6.4.7 present the readings of each sensor at room temperature. The offset value of each sensor was set to the LabVIEW program.

Table 6.4.6 - Calibrated result of AT/RH sensors based on calibration salts at $22^{\circ} \mathrm{C}(\mathrm{ERV})$

\begin{tabular}{cccc}
\hline Sensor & Target Reading & Sensor Reading & Deviation \\
\hline Supply Outlet & & $30.1 \%$ & $-1.8 \%$ \\
Exhaust Inlet & Supply Inlet & $29.7 \%$ & $-1.4 \%$ \\
Exhaust Outlet & $28.3 \%$ & $30.2 \%$ & $-1.9 \%$ \\
\hline
\end{tabular}

Table 6.4.7 - Calibrated result of AT/RH sensors based on calibration salts at $22^{\circ} \mathrm{C}$ (HRV)

\begin{tabular}{cccc}
\hline Sensor & Target Reading & Sensor Reading & Deviation \\
\hline Supply Outlet & & $30.9 \%$ & $2.9 \%$ \\
Exhaust Inlet & Supply Inlet & $34.4 \%$ & $-0.6 \%$ \\
Exhaust Outlet & $33.8 \%$ & $33.4 \%$ & $0.4 \%$ \\
\hline
\end{tabular}




\subsection{3 - Air Flow Rate}

Airflow sensor of circular duct consist of two parts: duct mounted airflow measurement station, which connects to the pressure transducer to convert pressure difference from the upstream and static sensing ports of the station to a $\mathrm{mA}$ signal. The pressure transducer output range from 4 to $20 \mathrm{~mA}$ corresponding to 0 to 0.25 " of water column (W.C.). The accuracy of the Dwyer differential pressure transmitter is $\pm 0.4 \%$ in full span, i.e., if the pressure sensor reads $10 \mathrm{~mA}$ (equivalent to $139.3 \mathrm{cfm})$, the "true" value for supply airflow could really be anywhere between $9.96 \mathrm{~mA}(138.8$ $\mathrm{cfm})$ and $10.04 \mathrm{~mA}(139.8 \mathrm{cfm})$. It is clear that the deviation is very small even if the "true" value fell at the upper and lower bounds. Therefore, the monitored sensor readings were checked using the FLUKE 922 Airflow Meter. The pneumatic tubes of the airflow meter were connected to the total and static ports of the airflow measurement station. Figures 6.4.4 show the monitored 23 sets of air flow rate (in cfm) for supply and exhaust air ducts in ASH-B. These readings reveal that the average flow rate for supply air was $89.33 \mathrm{cfm}$, while the return air flow rate was $86.66 \mathrm{cfm}$. On the other hand, the obtained reading from the FLUKE Airflow Meter were respectively 0.039 in. $\mathrm{H}_{2} \mathrm{O}$ and 0.037 in. $\mathrm{H}_{2} \mathrm{O}$. According to Eq. C.6 and Eq. C.7 in Appendix C, these pressure readings were respectively equivalent to $89.86 \mathrm{cfm}$ and $87.52 \mathrm{cfm}$, therefore, the sensor readings were reasonable. It is worth notice that the readings of return air duct were relatively unstable as compared to the supply air duct. This was due to the fact that the flow meter and pressure sensor

for return air duct are installed right after a $90^{\circ}$ bend in duct because of the limited space (see Figure E.3 in Appendix E). In contrast, the supply air duct is long and straight, which allows for the flow to fully develop into a uniform airstream before flowing through the flow meter. A similar analysis was undertaken for the differential pressure sensors within ASH-A. Figures 6.4.5 illustrate the monitored volumetric airflow rate for supply and return air. The average airflow rate for supply and exhaust air ducts were $151.66 \mathrm{cfm}$ and $154.05 \mathrm{cfm}$, respectively. In comparison, the FLUKE 922 Airflow Meter read 0.113 in. $\mathrm{H}_{2} \mathrm{O}$ (or $152.95 \mathrm{cfm}$ ) and 0.112 in. $\mathrm{H}_{2} \mathrm{O}$ (or $152.27 \mathrm{cfm}$ ). Similarly, the deviation was $1.3 \mathrm{cfm}$ for supply airflow and $-1.78 \mathrm{cfm}$ for exhaust airflow, and hence, the sensor readings were reasonable. 

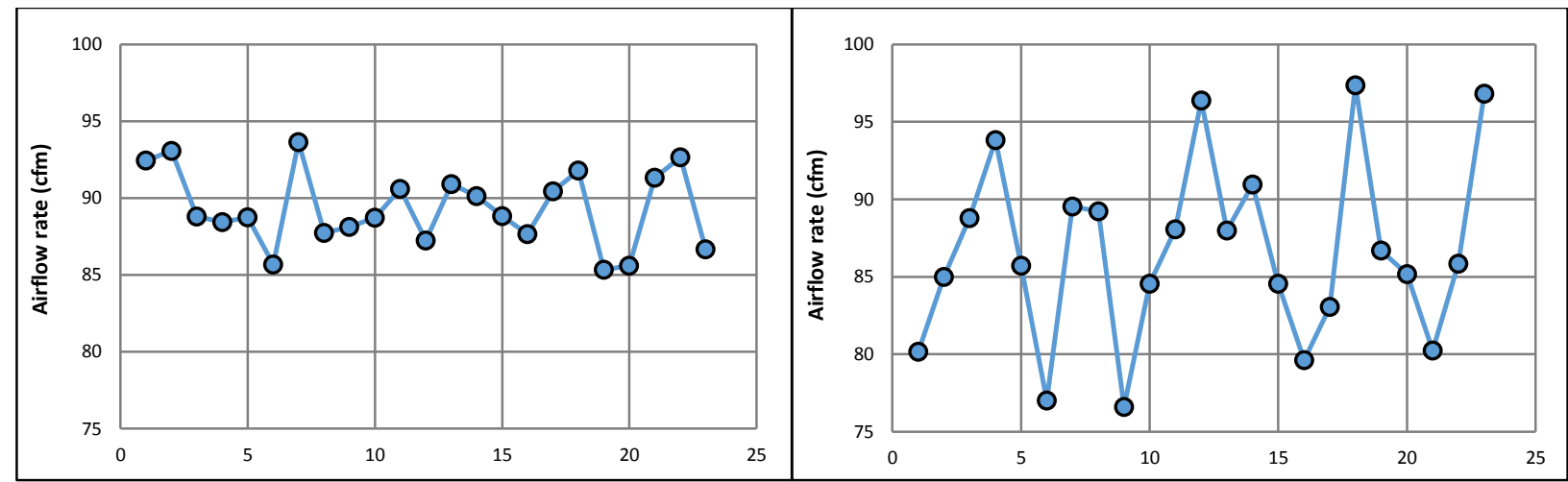

Figure 6.4.4 - Monitored volumetric airflow rate of ASH-B, supply air duct (left panel) and return air duct (right panel)
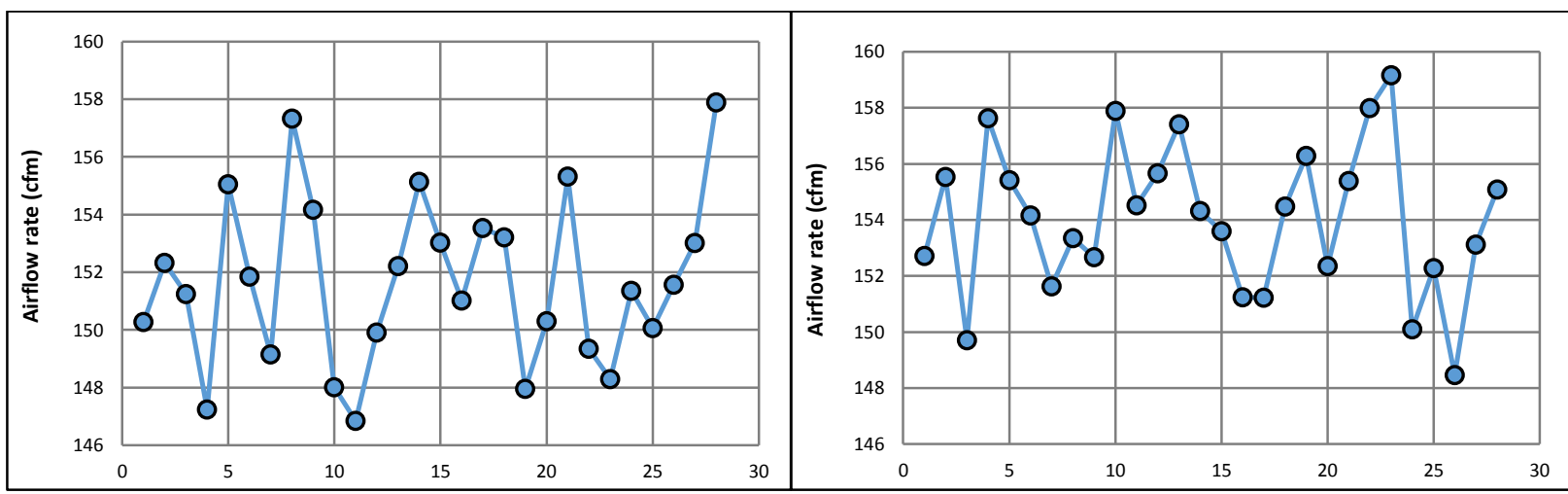

Figure 6.4.5 - Monitored volumetric airflow rate of ASH-A, supply air duct (left panel) and return air duct (right panel)

\section{Section 6.5 - Winter Experiment: Energy Recovery Ventilator}

\subsection{1 - Data analysis: Sensible and Latent Efficiencies}

The winter data collection was originally scheduled to start at the beginning of December 2013 and continue until the end of January in the following year (2014). However, because of some issues with dysfunctional sensors associated with the HRV and ERV, the winter data collection commenced on January $20^{\text {th }}$ through February $26^{\text {th }}$. During this period, the ambient temperature range was between $3{ }^{\circ} \mathrm{C}$ and $-20^{\circ} \mathrm{C}$ and provided a good temperature range to analyze the performance of the equipment during extreme outdoor conditions.

In investigating the performance of the energy recovery ventilator, both the sensible and latent efficiencies were considered. Further investigation of the entire HVAC system in the Archetype Sustainable House will be analyzed using TRNSYS. According to Barua (2010), the supply and return airflow rates of ERV in the Archetype Sustainable House-B were not balanced. The average supply airflow rate was found to be almost always 14\% higher than the return air flow. To avoid 
such problem, the AHU fan was set to constant, and the monitored supply and exhaust air flow rates are illustrated in Figure 6.5.1, as well as the difference between them. The experimental uncertainties of airflow rate are shown in Figure C.5. The plot reveals that the airflow rates remained at $86-90 \mathrm{cfm}$ and were closely balanced. The maximum deviation was found to be 2.8 cfm, or approximately $3 \%$ difference. To calculate the both sensible and latent efficiencies, air flows were assumed to be balanced.

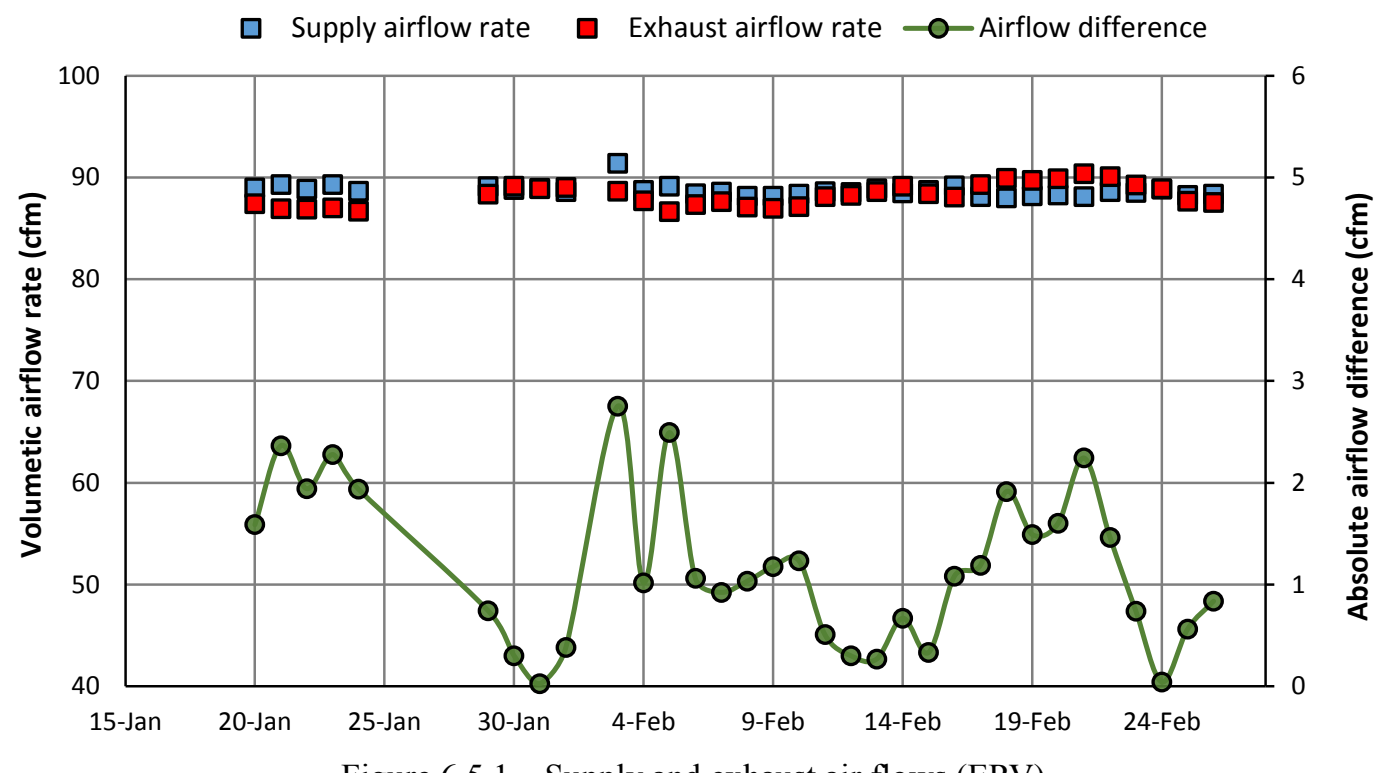

Figure 6.5.1 - Supply and exhaust air flows (ERV)

Figure 6.5.2 illustrates the inlet and outlet air temperature during the test period. The $\mathrm{AT}_{e i}$ varied from $22^{\circ} \mathrm{C}$ to $23^{\circ} \mathrm{C}$, while the inlet $\mathrm{AT}_{f i}$ varied from $2.9^{\circ} \mathrm{C}$ to $-20.1^{\circ} \mathrm{C}$. Similarly, the $w_{e i}$ varied from 4.73 to $6.67 \mathrm{~g} / \mathrm{kg}$, while the $w_{f i}$ varied from 0.56 to $3.74 \mathrm{~g} / \mathrm{kg}$, as shown in Figure 6.6.3. Figure 6.5.4 illustrates the sensible efficiency (SE) of the ERV during the test period. Raw data showed considerable scatter, and hence, the raw data was averaged in temperature/humidity bins so that the scatter can be reduced and the results can be seen more meaningfully. The measured SEs are around 77 to $78 \%$, and exhibited to be quite constant over the temperature range. One way of validating the efficiencies is to compare with the manufacturer's performance data. Figure 6.5.4 also shows the comparison of measured SE with manufacturer supplied SE. The manufacturer data reveals that the SE should remain constant from 0 to $-15^{\circ} \mathrm{C}$. In contrast, the recorded data show a trend similar to the manufacturer's trend at low inlet temperature, and increases slightly at higher temperature. The sensible efficiency of an enthalpy wheel was studied Zhai et al. (2007), which 
reported that the efficiency decreased slightly with colder outside air temperature (from $7^{\circ} \mathrm{C}$ to $\left.2^{\circ} \mathrm{C}\right)$.

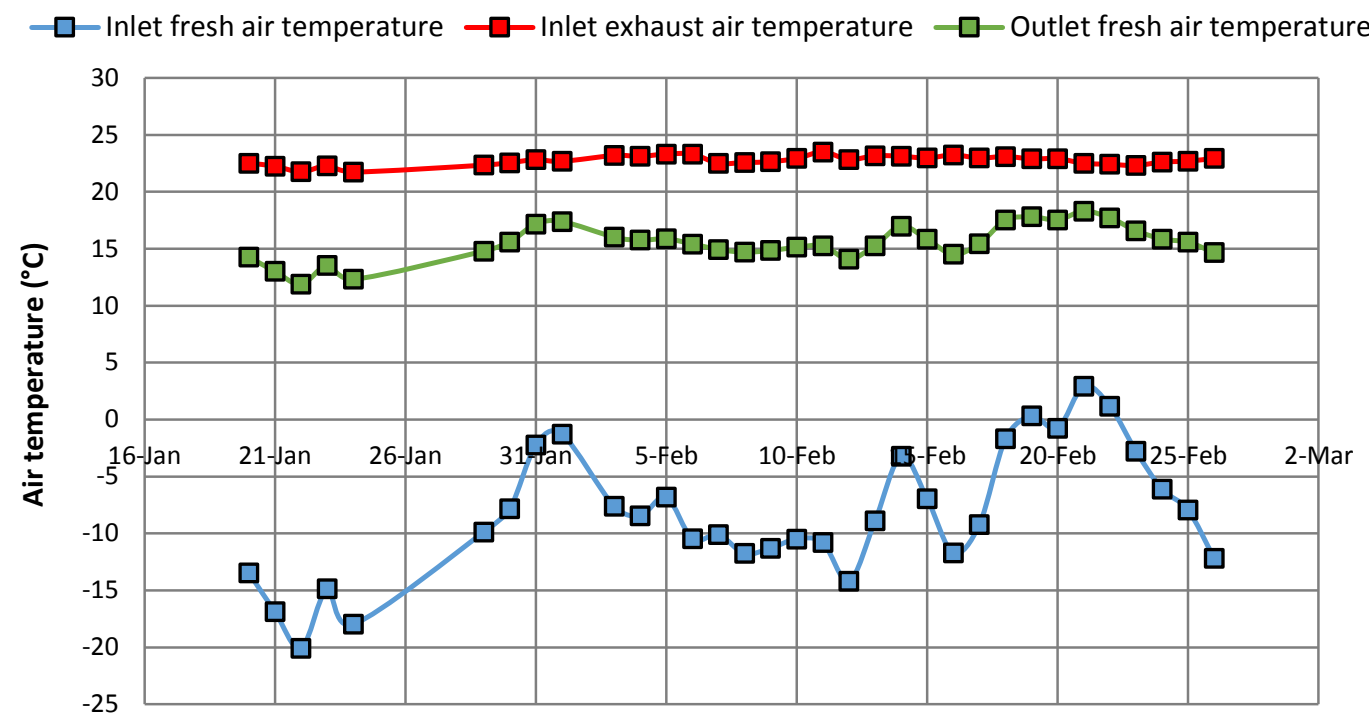

Figure 6.5.2 - Inlet and outlet air temperature (ERV)

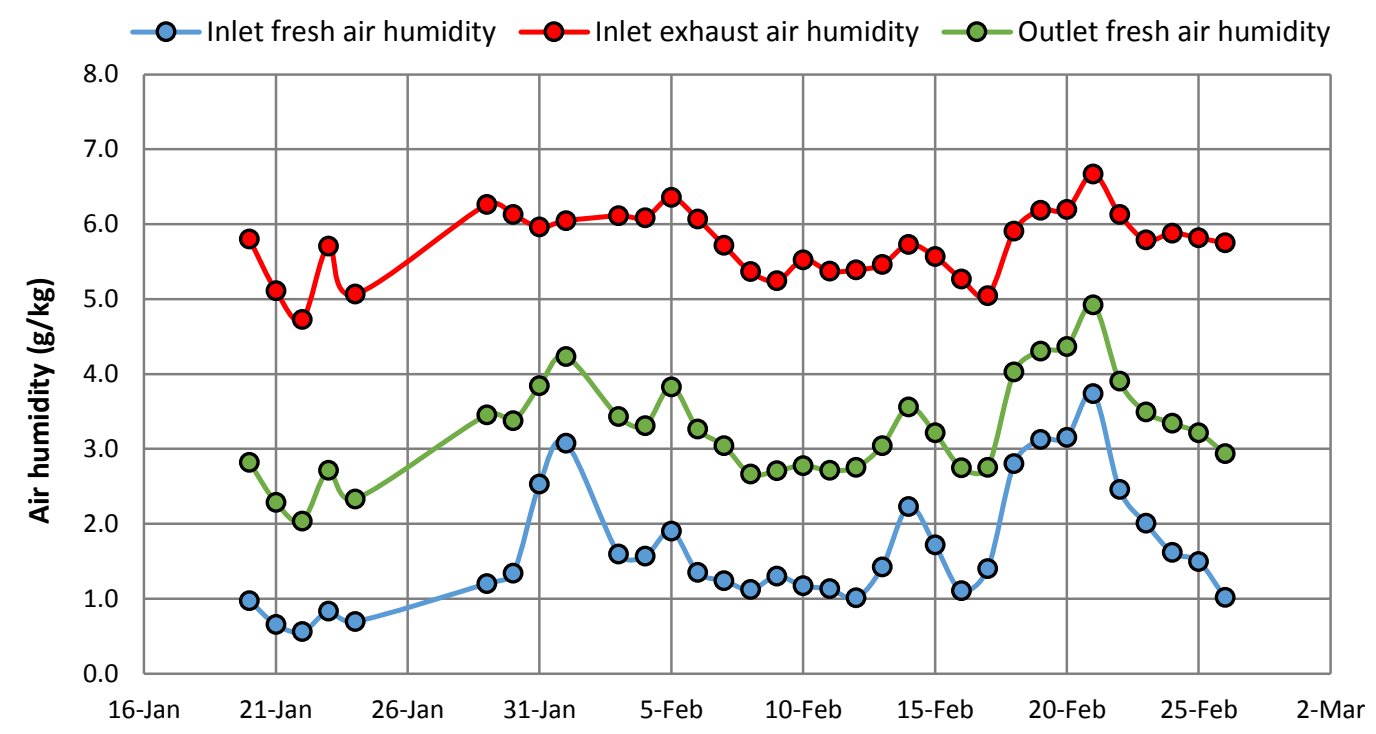

Figure 6.5.3 - Inlet and outlet air humidity (ERV) 


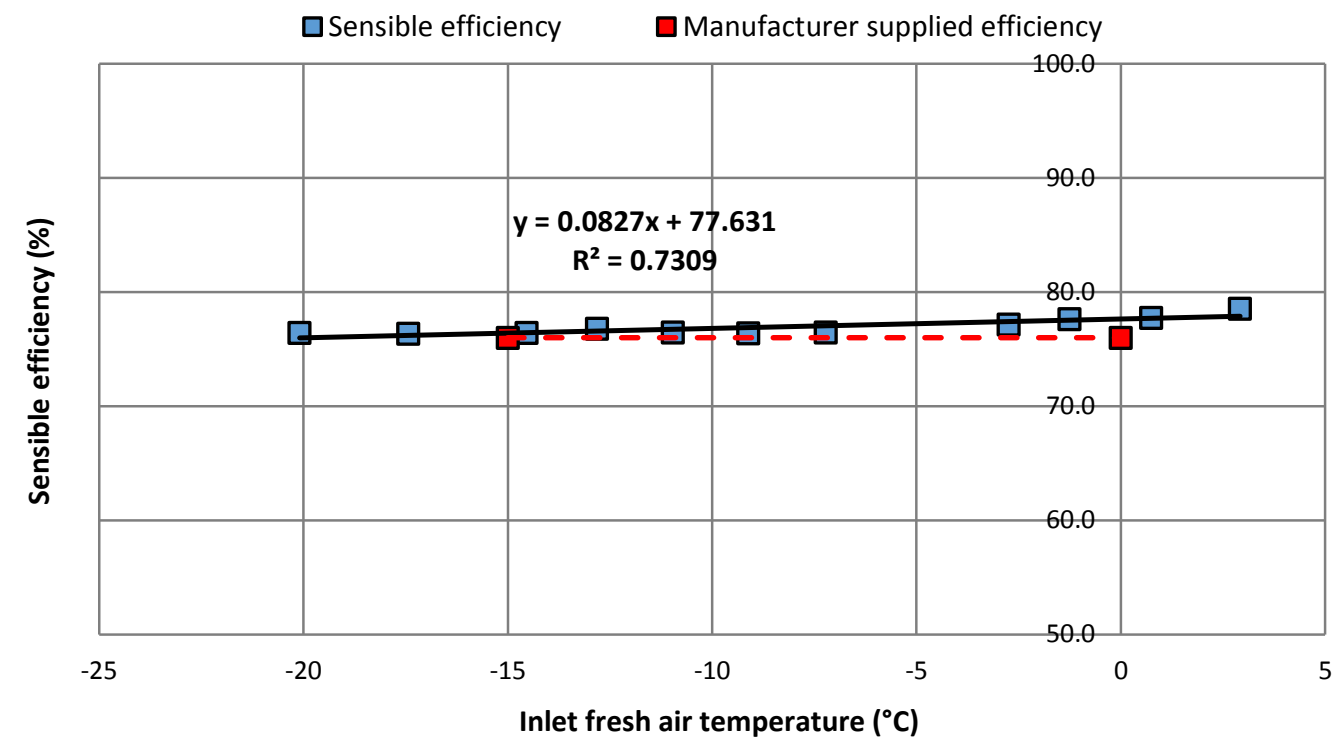

Figure 6.5.4 - Monitored and manufacturer supplied sensible efficiencies at different inlet fresh air temperature (ERV)

Figure 6.5.5 illustrates the relationship between the inside-outside air temperature differences $(\Delta T)$ and the sensible efficiency. As expected, the TE remained nearly constant throughout the test period, and hence, exhibited to be insensitive to the change of inside-outside temperature difference. The same trend had been observed by Han et al. (2007) and Zhang (2010). The presented linear prediction will be implemented into the TRNSYS models to improve the prediction of system performances of the HERV and ERV.

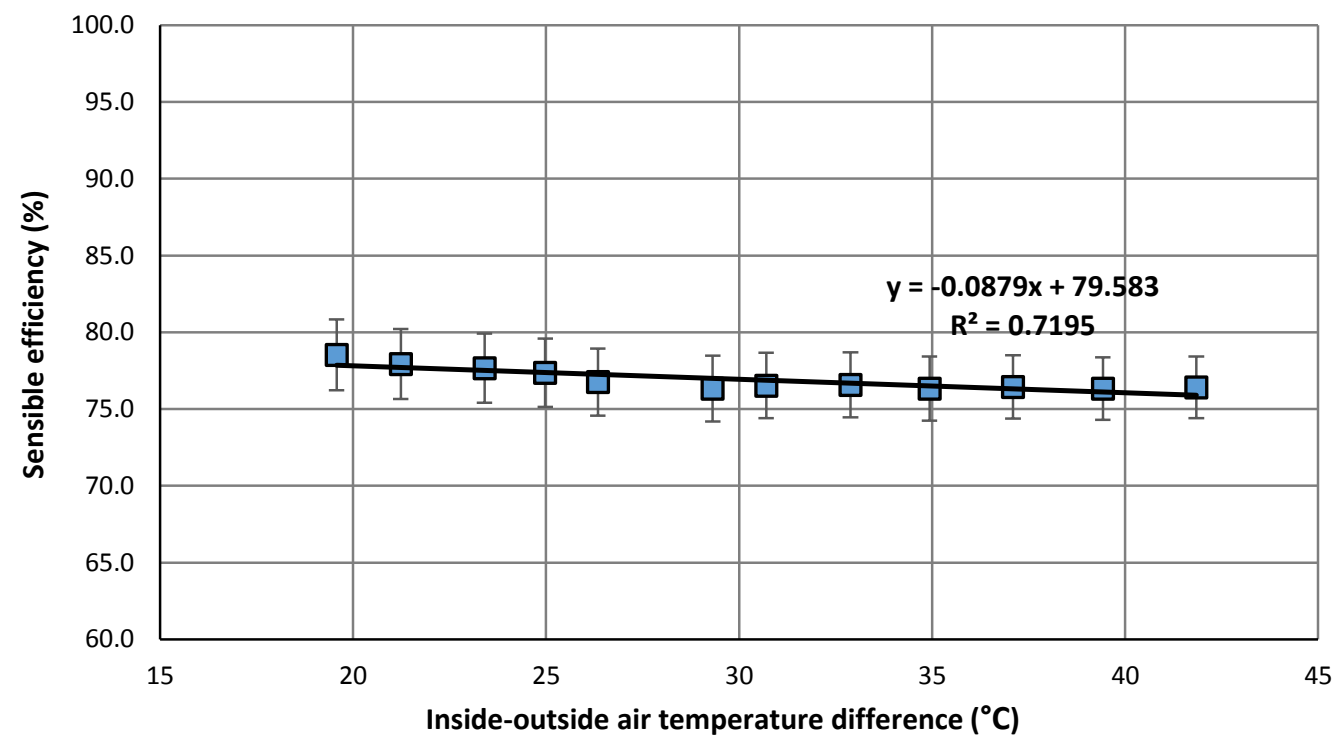

Figure 6.5.5 - Sensible efficiency vs. inside-outside temperature difference (ERV) 
Figure 6.5.6 illustrates the relationship between the latent efficiency (LE) and the inlet fresh air temperature. The curve illustrates that the LE increases with a rise in the inlet air temperature, the measured values ranged from 40 to $35 \%$ during the test period. In contrast, the manufacturer supplied values also indicate that the LE varies inversely to the inlet air temperature, but in a larger scale (from 45 to 26\%) than that of the measured values. According to ASHRAE Handbook (2008), the latent efficiency is a ratio of inlet-outlet fresh air humidity difference to the inside-outside air humidity difference. In other words, without the information of the air humidity, the manufacturer supplied relationship between outside air temperature and latent efficiency might not fully reflect the actual environment during the period of factory field measurements. Table 6.5.1 lists the frequency of the inside-outside air humidity difference. This table reveals that the range of the difference between the inside and outside humidity was actually very small despite the large range of outside air temperature. Approximately 12 days of the test period for which the inside-outside humidity difference was within the range of 4.4 to $4.1 \mathrm{~g} / \mathrm{kg}$, and hence, the measured latent efficiency depicted in Figure 6.5.6 was reasonable. Figure 6.5.7 illustrates the relationship between inside-outside humidity difference and LE; the efficiency increases with a rise in the inside-outside humidity difference.

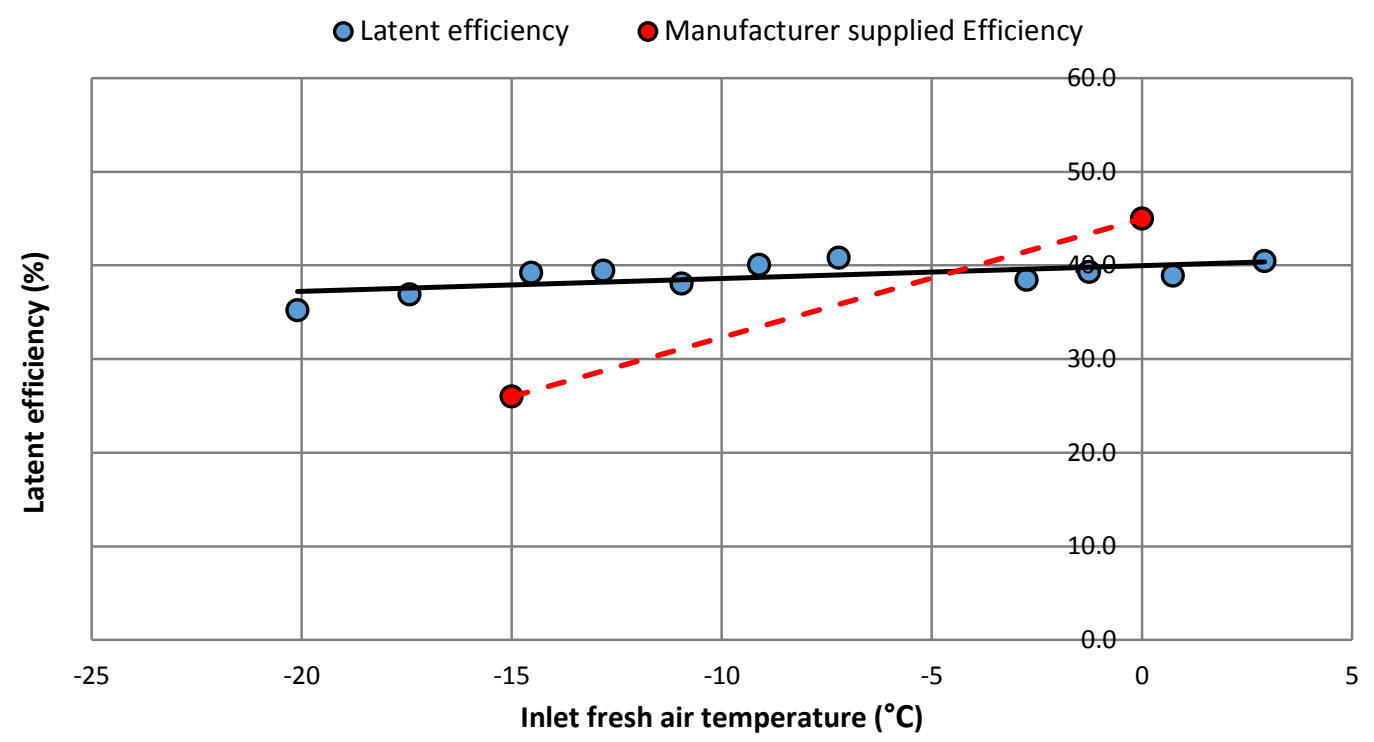

Figure 6.5.6 - Latent efficiency at different inlet fresh air temperature (ERV) 
Table 6.5.1 - Frequency of inside-outside humidity difference during the test period (ERV)

\begin{tabular}{c|c|c|c}
\hline $\begin{array}{c}\text { Humidity difference } \\
(\mathbf{g} / \mathbf{k g})\end{array}$ & Frequency & $\begin{array}{c}\text { Humidity difference } \\
\mathbf{( g / k g})\end{array}$ & Frequency \\
\hline 5.6 & 0 & -4.1 & 3 \\
\hline 5.3 & 1 & -3.8 & 3 \\
\hline 5.0 & 5 & -3.5 & 2 \\
\hline 4.7 & 5 & -3.2 & 5 \\
\hline 4.4 & 9 & -2.9 & 0 \\
\hline
\end{tabular}

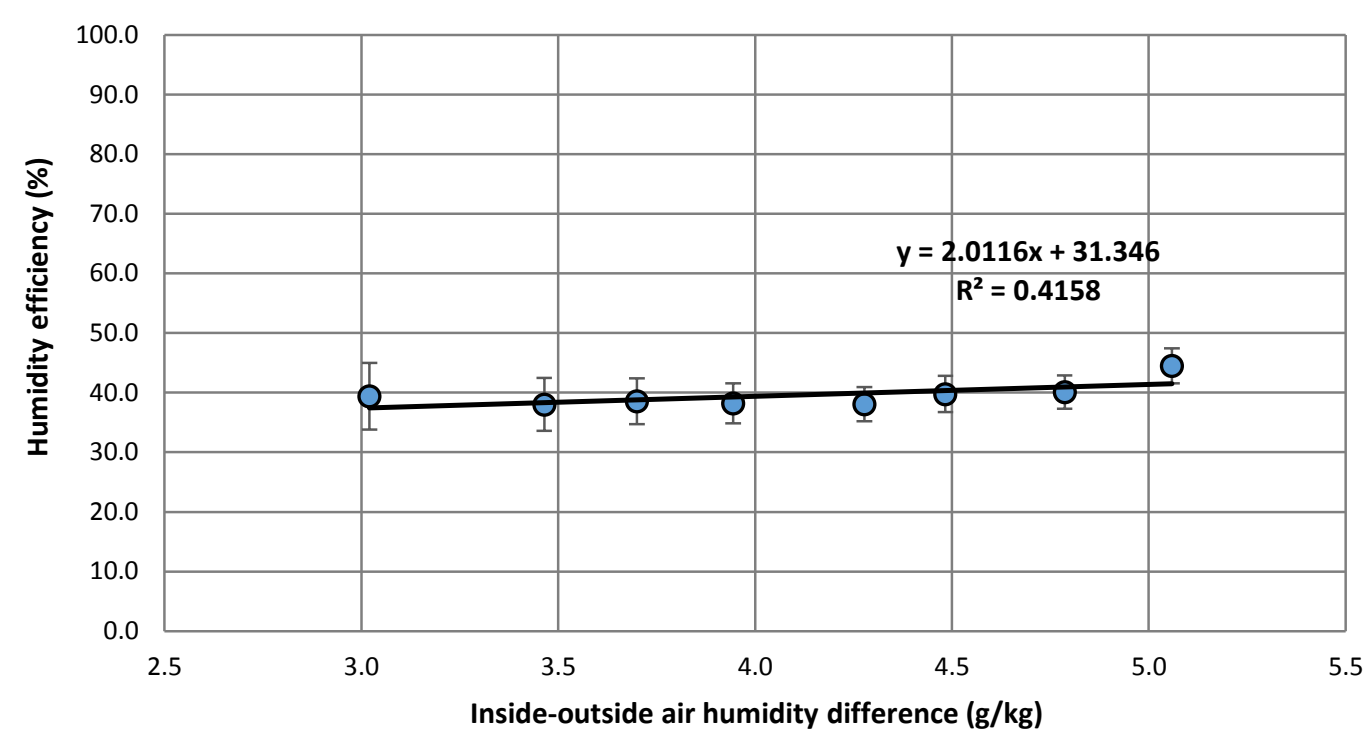

Figure 6.5.7 - Latent efficiency vs. inside-outside humidity difference (ERV)

\subsection{2 - Data Analysis: Defrost Cycle}

In terms of efficiency, the performance of the ERV in the heating season is highly affected by the outdoor air temperature. Theoretically, the warm exhaust air temperature passing through the enthalpy core can drop below its dew point (e.g., $2.8^{\circ} \mathrm{C}$ for $\mathrm{AT}_{e i}$ of $21^{\circ} \mathrm{C}$ and $30 \% \mathrm{RH}$ ) when the outdoor temperature drops below $-5^{\circ} \mathrm{C}$, leading to moisture condensation and freezing. The formation of ice and frost inside the core reduces the flow rate and significantly affects heat recovery. Most ERVs designs adopt a defrost cycle in which warm indoor air is circulated inside the heat exchanger core to melt any ice or frost. Theoretically, the ERV in the Archetype Sustainable House-B has a defrost control that runs 6 minutes for every 32 minutes normal operation. When defrost is required, the damper located on inlet of the system (see Figure 6.5.8) will be activated to recirculate the stale air from building back to the house, and there is no 
introduction of fresh air. In other words, the observed outlet fresh airstreams are basically the exhaust airstreams that pass through the damper and fresh air channels. To study both the inlet/outlet and inside/outside air conditions before and right after the defrost cycle, data recorded on January $23^{\text {rd }}, 2014$ was chosen for analysis since on that day the outdoor temperature was around $-15^{\circ} \mathrm{C}$.

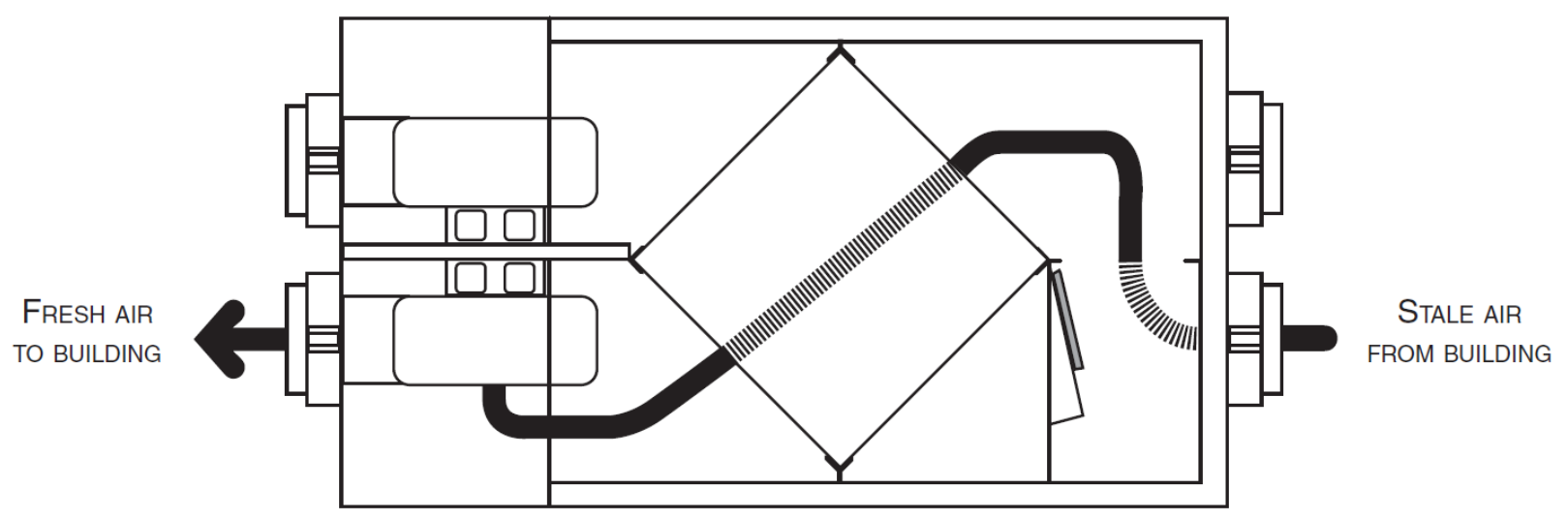

Figure 6.5.8 - House-B energy recovery ventilator airflow during defrost cycle (VanEE, 2011)

To analyze the defrost cycle, it was necessary to look at minutely data over a short period of time. The results and analysis presented below were based on the minutely data of three hours (from 6am to 9am on January $23^{\text {rd }}, 2014$ ). In Figure 6.5.9, the inlet exhaust air and outlet fresh air temperature, and the fan power draw (in Watt) were plotted over the three hours test period. In the figure, the defrost cycle initiated when fan power draw increased from 80 to $120 \mathrm{~W}$, and hence, four defrost cycles were observed. The exhaust air temperature remained nearly constant (22 to $23^{\circ} \mathrm{C}$ ) with small fluctuation, while the temperature of fresh air at the outlet varied similar to fan power draw. Before every defrost cycle, outlet fresh air temperature remained nearly constant at $13^{\circ} \mathrm{C}$, meaning that ice build-up was unlikely to be happened because defrost cycle was providing a preventive treatment. During the defrost cycles, the warm exhaust airstream flowed into fresh air channels to heat up the core surfaces, the outlet fresh air temperature increased from about $13^{\circ} \mathrm{C}$ to a peak temperature of $18^{\circ} \mathrm{C}$. Right after the defrost cycles (the time at which the outside fresh air began to reintroduce), the temperature of fresh air stayed a bit high for a few minutes before they reached steady state again. This phenomenon can be explained by the enthalpy core of the ERV "absorbing" some of heat during the cycle and releasing once it turned back to normal operation. To be consistent in the forthcoming analysis, the zone after the defrost cycle and before 
reaching to the next steady-state was named "transition zone". Figure 6.5.10 illustrates the inlet exhaust and outlet fresh air humidity over the short test period. In this case, transition zones are also observed right after the defrost cycle.

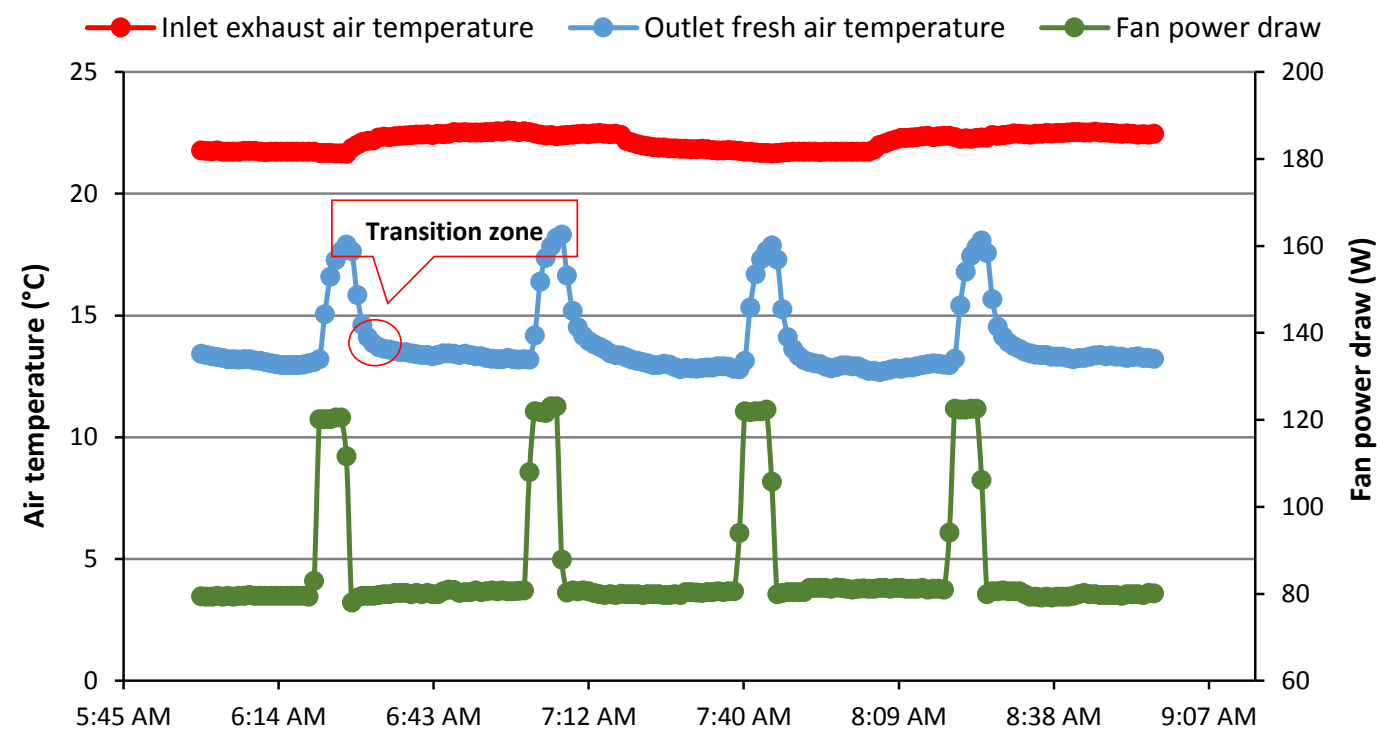

Figure 6.5.9 - Air temperature and fan power draw during defrost cycle (ERV)

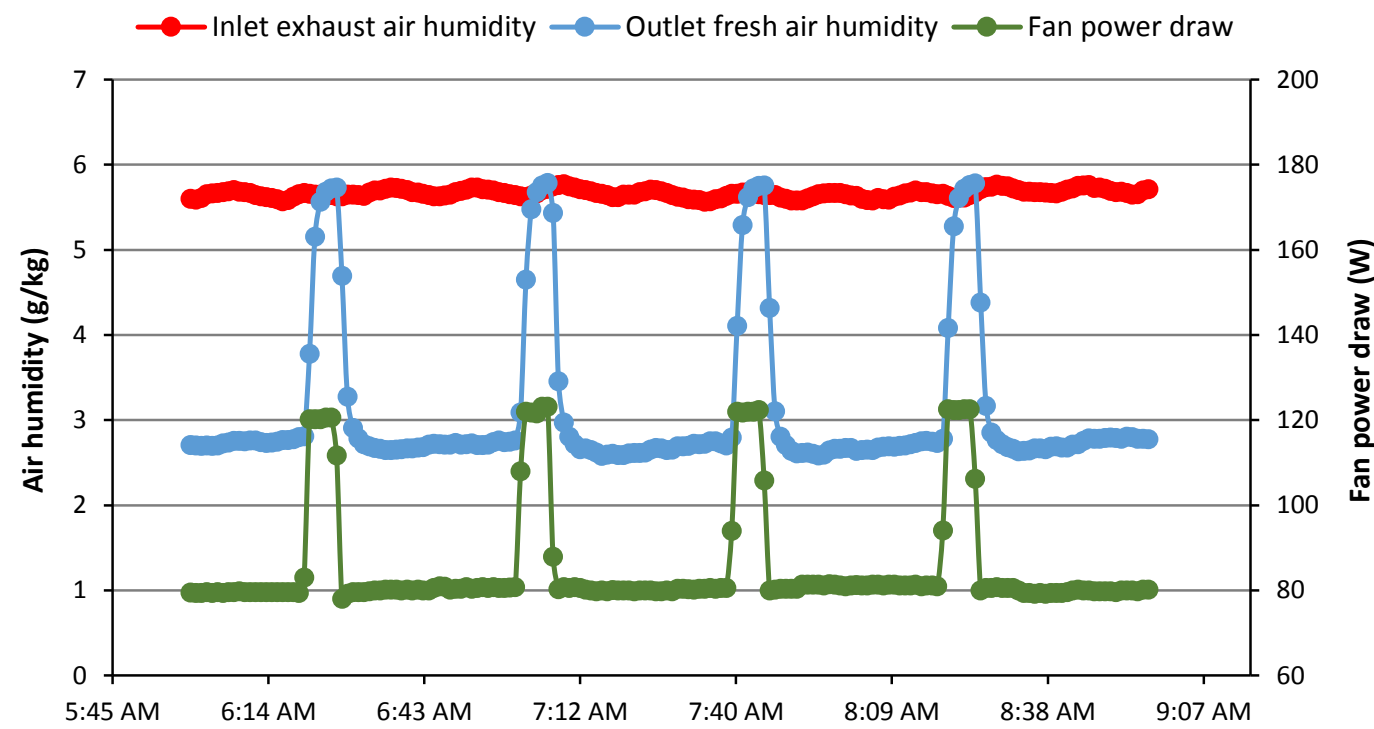

Figure 6.5.10 - Air humidity and fan power draw during defrost cycle (ERV)

Figure 6.5.11 illustrates the sensible and latent efficiencies of the ERV during the three-hour test period. According to ASHRAE Handbook - HVAC Systems and Equipment (2008), frosting fouls initially improves energy transfer but subsequently restricts the exhaust airflow, which in turn reduces the energy transfer rate. It is clear that both sensible and latent efficiencies appear to be 
quite constant and reasonable before the defrost cycle, and hence, the built-in defrost successfully prevent a large scale ice formation that will negatively impact the system performance. For balanced airflow, Equations 6.5.1 and 6.5.2 show the expressions used to calculate efficiencies during normal and defrost operation, respectively. During defrost cycle, the curves show that both the sensible and latent efficiencies became negative. The cold enthalpy core "absorbed" heat from recirculated air to heat up core surfaces by means of convection, at the same time, condensation took place which lowered the air humidity, and thus the recirculated air at the outlet of the system was at a lower enthalpy than the inlet air at exhaust air channel, which explains the negative efficiencies. Right after the defrost cycle, there are peaks in efficiencies for few minutes (transition zone) due to the heat stored in and condensate accumulated on the core surfaces which were picked up by the reintroduced fresh airstream once the ERV was back to normal operation.

$$
\begin{gathered}
\epsilon_{\mathrm{s}}=\frac{T_{f o}-T_{f i}}{T_{r i}-T_{f i}} \text { or } \epsilon_{\mathrm{L}}=\frac{w_{f o}-w_{f i}}{w_{r i}-w_{f i}} \\
\epsilon_{\mathrm{S}}=\frac{T_{f o}-T_{r i}}{T_{r i}} \text { or } \epsilon_{\mathrm{L}}=\frac{w_{f o}-w_{r i}}{w_{r i}}
\end{gathered}
$$

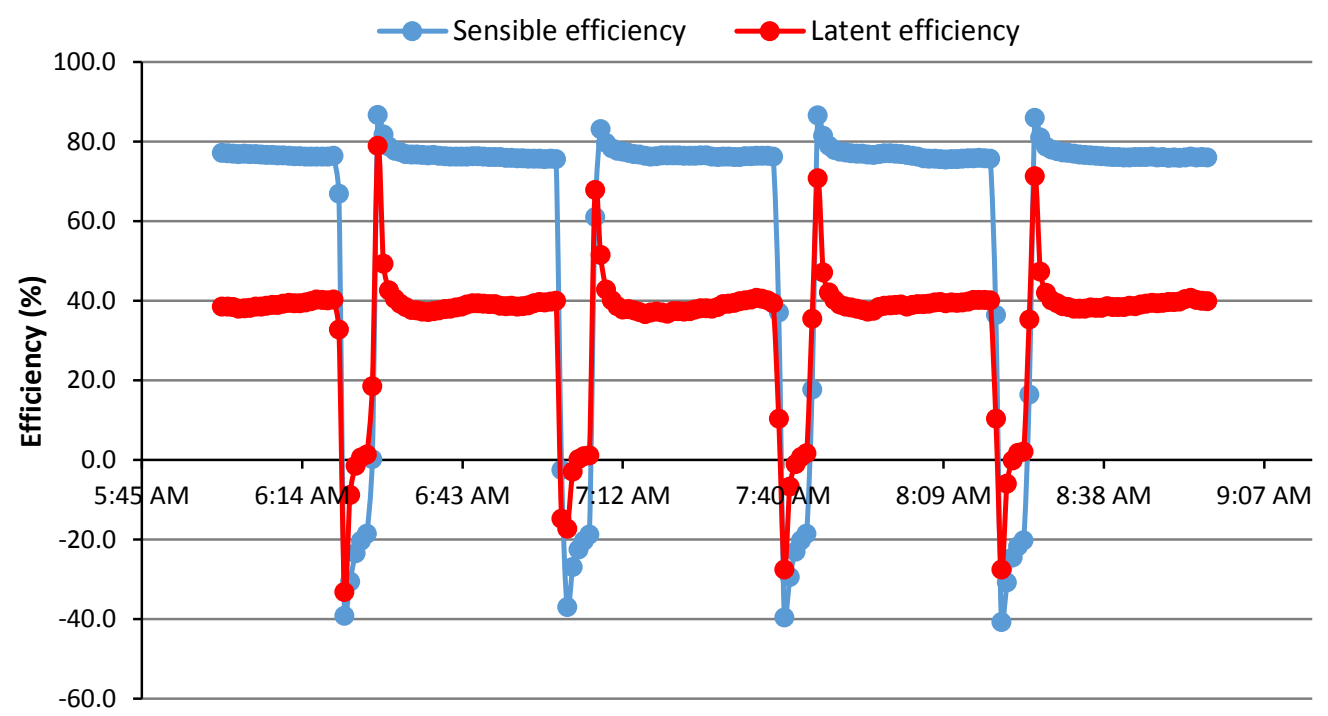

Figure 6.5.11 - Sensible and latent efficiencies during defrost cycle (ERV)

In order to simulate the behaviour of outlet fresh air temperature before/during/after defrost cycle, as well as the effect of defrost cycle on house energy demand and humidity level, temperature and humidity patterns for different outside conditions were required. Experimental results revealed that 
the onset temperature of defrost cycle was actually $-10^{\circ} \mathrm{C}$, which differed from the temperature ($5^{\circ} \mathrm{C}$ ) stated in the manufacturer's specification sheet. Figure 6.5.12 shows that the built-in defrost cycle did not activate until the inlet fresh air temperature was above $-10^{\circ} \mathrm{C}$. Therefore, three generalized trends were developed, corresponding to $-10,-15$ and $-20^{\circ} \mathrm{C}$ outside temperature. As an illustration, Figure 6.5.13 presents two patterns observed when the inlet fresh air temperature was $-20^{\circ} \mathrm{C}$, and the exhaust air temperature was 21.4 and $22.3^{\circ} \mathrm{C}$ for case \#1 and case \#2, respectively. The details of the inside and outside air conditions are presented in Table 6.5.2. According to the fan power draw, defrost cycle happened from minute 1 to 6 . Therefore, the change in the $\mathrm{AT}_{f o}$ was due to the air recirculation that warms up the fresh air channels of the system. Once defrost cycle was terminated, there was a rise in $\mathrm{AT}_{f o}$ due to heat extraction from the core surfaces, and it continued until steady-state was reached (after $15 \mathrm{~min}$ ). The pattern for other $\mathrm{AT}_{e i}$ can be determined through interpolation/extrapolation. Figure 6.5.14 presents the outlet fresh air temperature patterns for $\mathrm{AT}_{f i}$ of $-10,-15$, and $-20^{\circ} \mathrm{C}$, with an $\mathrm{AT}_{e i}$ of $21^{\circ} \mathrm{C}$. Figure 6.5.15 illustrates the generalized sensible efficiency patterns for the three curves. These patterns were then divided into two sections; each section was then quantified and curved-fitted in order to obtain polynomial equations that can be implemented into ERV model to simulate the effect of defrost cycle on the overall energy savings. The first section was designed to contain an interval from 1 to 6 minute for describing the temperature patterns during defrost cycle (see Figure 6.5.15). In contrast, the second section (see Figure 6.5.16) was designated to describe the patterns after defrost cycle: from interval 7 to 15 minute.

Table 6.5.2 - Air conditions before/during/after defrost cycle (ERV)

\begin{tabular}{ccccccc}
\hline & \multicolumn{3}{c}{ Case \#1 } & \multicolumn{3}{c}{ Case \#2 } \\
\hline & AT(FI) & AT(FO) & AT(EI) & AT(FI) & AT(FO) & AT(EI) \\
\hline BEFORE & -19.9 & 11.7 & 21.4 & -20.1 & 12.1 & 22.3 \\
DURING & ---- & ---- & 21.3 & --- & ---- & 22.1 \\
AFTER & -19.8 & ---- & 21.4 & -20.4 & ---- & 20.0 \\
\hline
\end{tabular}




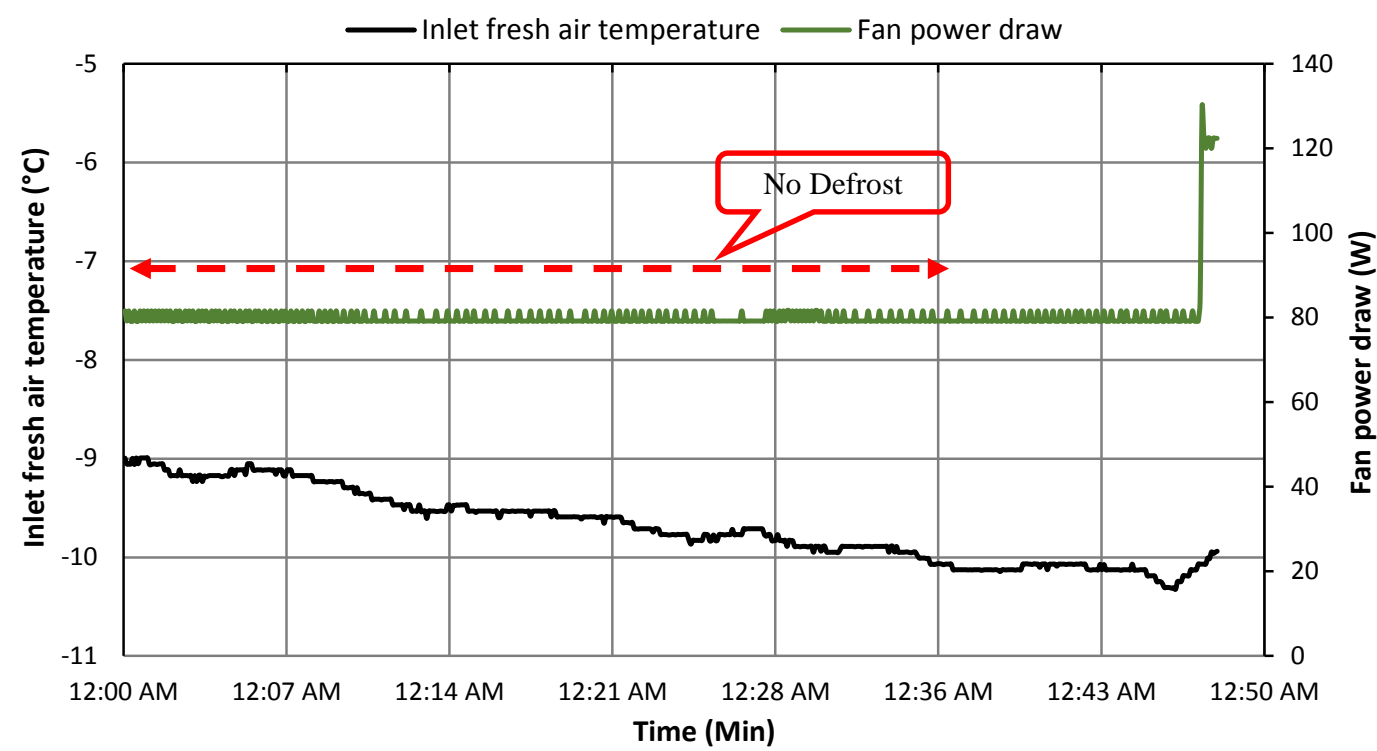

Figure 6.5.12 - Experimental results showing the onset temperature of defrost cycle, Feb 26, 2014 (ERV)

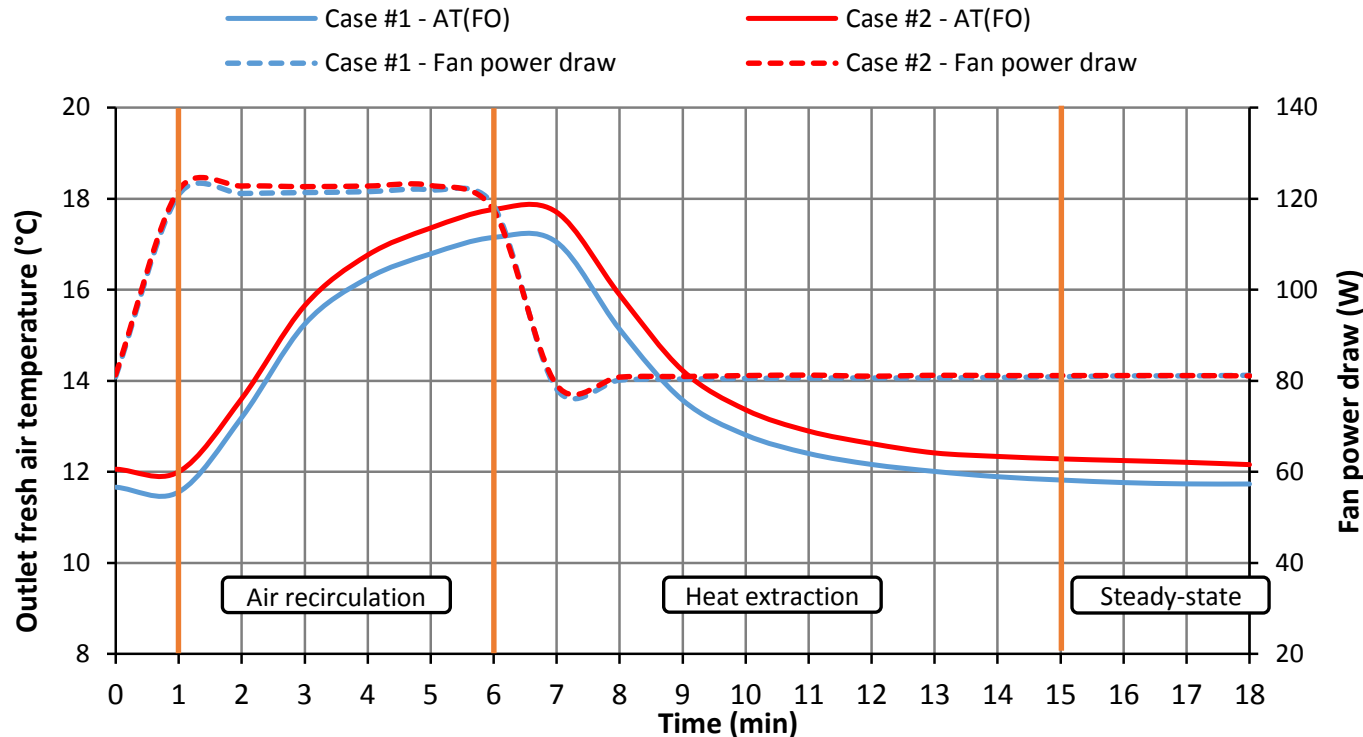

Figure 6.5.13 - Patterns of outlet fresh air temperature before/during/after defrost cycle for $-20^{\circ} \mathrm{C} \mathrm{AT}_{f I}(\mathrm{ERV})$ 


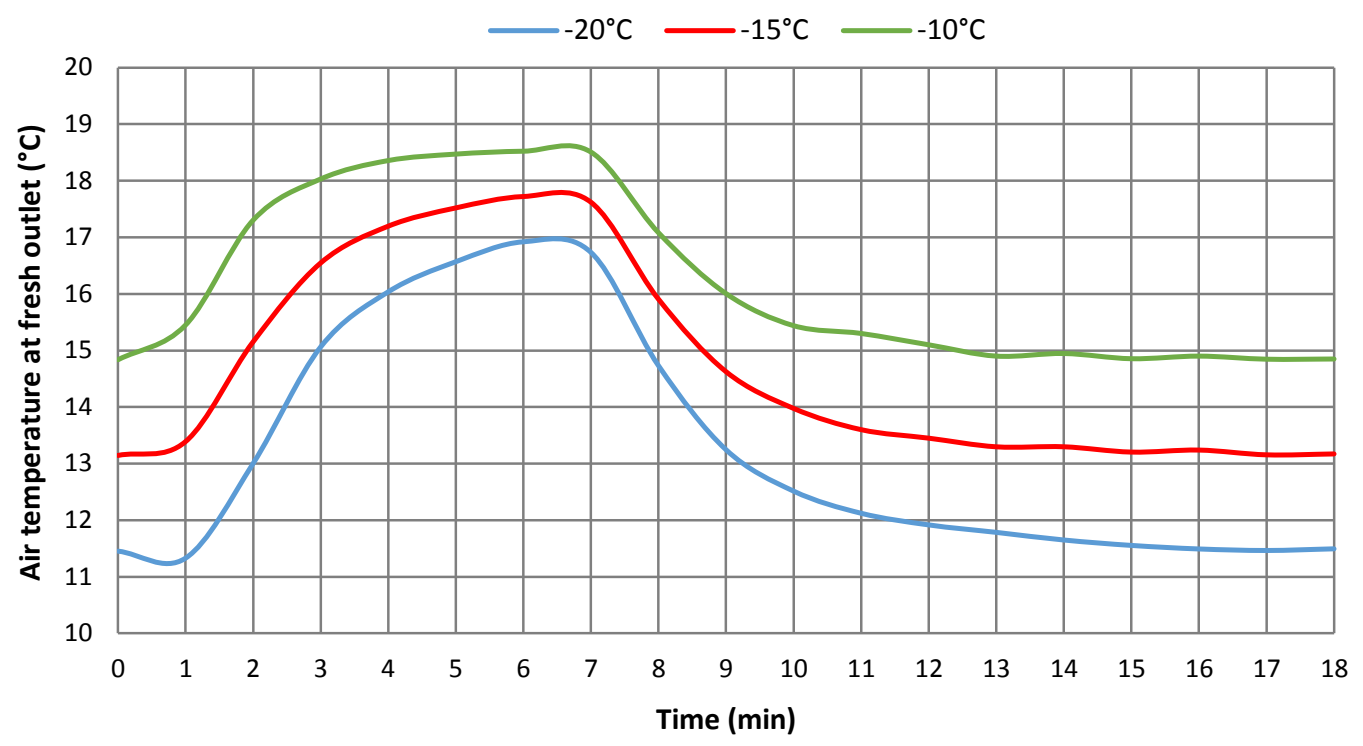

Figure 6.5.14 - Patterns of outlet fresh air temperature before/during/after defrost cycle

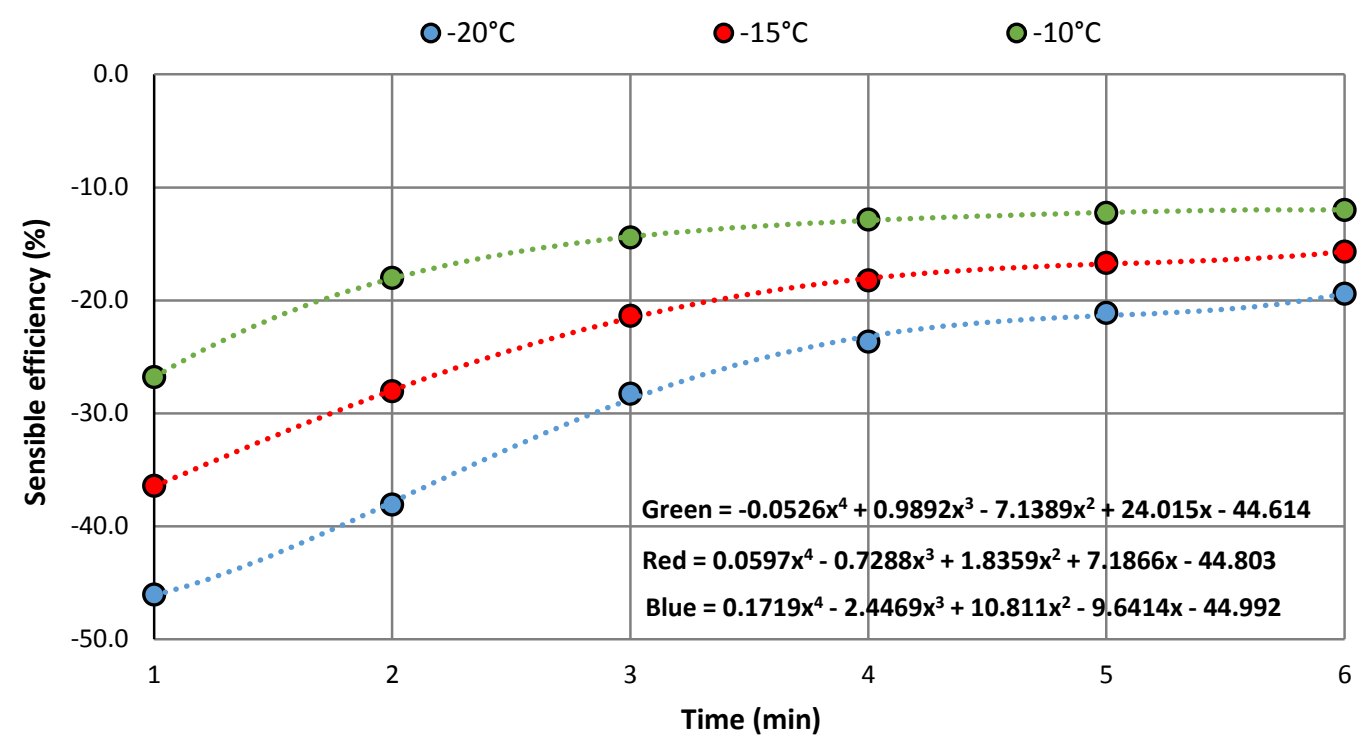

Figure 6.5.15 - Sensible efficiency patterns for different $\mathrm{AT}_{f i}(\mathrm{ERV}): 1^{\text {st }}$ section 


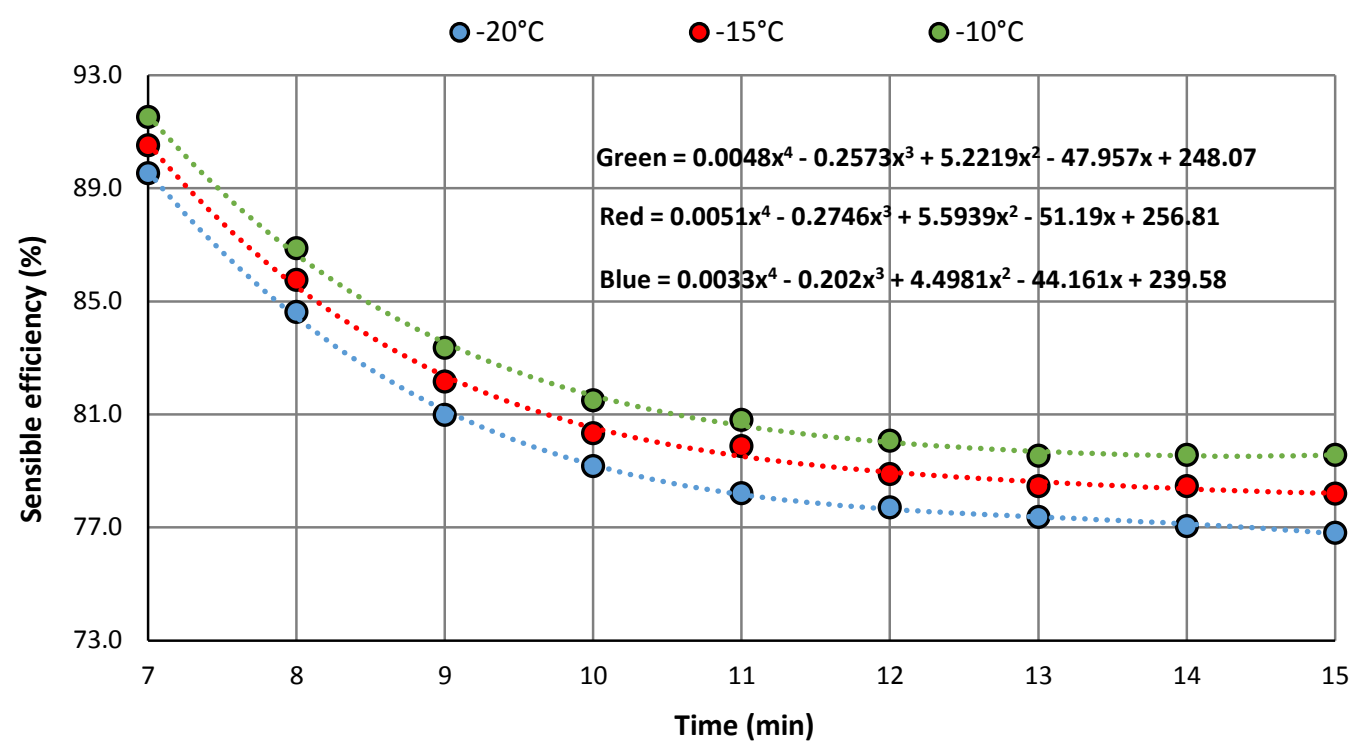

Figure 6.5.16 - Sensible efficiency patterns for different $\mathrm{AT}_{f i}(\mathrm{ERV}): 2^{\text {nd }}$ section

The outlet fresh air humidity patterns, $w_{f o}$, during different stages of defrost process were also determined following the same steps presented above. Figure 6.5.17 shows the humidity patterns of outlet fresh and exhaust air ( $w_{f i}$ and $w_{e i}$ are $0.7 \mathrm{~g} / \mathrm{kg}$ and $5.6 \mathrm{~g} / \mathrm{kg}$, respectively). Due to the melted ice and/or frost on the core surfaces, the humidity of air within the exhaust air channels $\left(w_{e o}\right)$ gradually increases and eventually exceeds that of the fresh air channel after 2 minutes. After defrost cycle, the outlet exhaust air humidity gradually decreases as a result of reintroducing the dryer room air. Similarly, the recirculated warm air that pass through the core surfaces of fresh air channels condenses, leading to lower air humidity at the outlet (e.g., air humidity at the first minute of defrost cycle was $0.6 \mathrm{~g} / \mathrm{kg}$ lower than $w_{e i}$ at $5.6 \mathrm{~g} / \mathrm{kg}$ ). As core surfaces become warmer, the amounts of condensation reduce, resulting in higher air humidity (see humidity pattern from $3^{\text {rd }}$ to $6^{\text {th }}$ minute). After defrost cycle, the outlet fresh air humidity stays a bit high for few minutes due to the evaporation of the condensate accumulated on the core surfaces.

The indoor air temperature of ASH-A is well-controlled by the air-source heat pump, and hence, sensible efficiency patterns can be developed for different $\mathrm{AT}_{f i}$ for a fixed $\mathrm{AT}_{e i}$. The humidity is not controlled, and hence, additional patterns are required for different $\mathrm{AT}_{e i}$. Figure 6.5.18 shows the latent efficiency patterns for $5.0,4.5$, and $4.0 \mathrm{~g} / \mathrm{kg} w_{e i}$, while the $w_{f i}$ is $0.5 \mathrm{~g} / \mathrm{kg}$. It is clear that the change in $w_{e i}$ is not affecting the latent efficiency significantly. To simplify the process of analysis as well as the ERV model, the three patterns in Figure 6.5.18 are averaged in order to develop a generalized pattern to describe the latent efficiency at $0.5 \mathrm{~g} / \mathrm{kg} w_{f i}$. Figure 6.5 .19 shows 
the $1^{\text {st }}$ section of the latent efficiency patterns for $0.5,0.7,0.9 \mathrm{~g} / \mathrm{kg} w_{f i}$, while Figure 6.5 .20 shows the $2^{\text {nd }}$ section of the patterns.

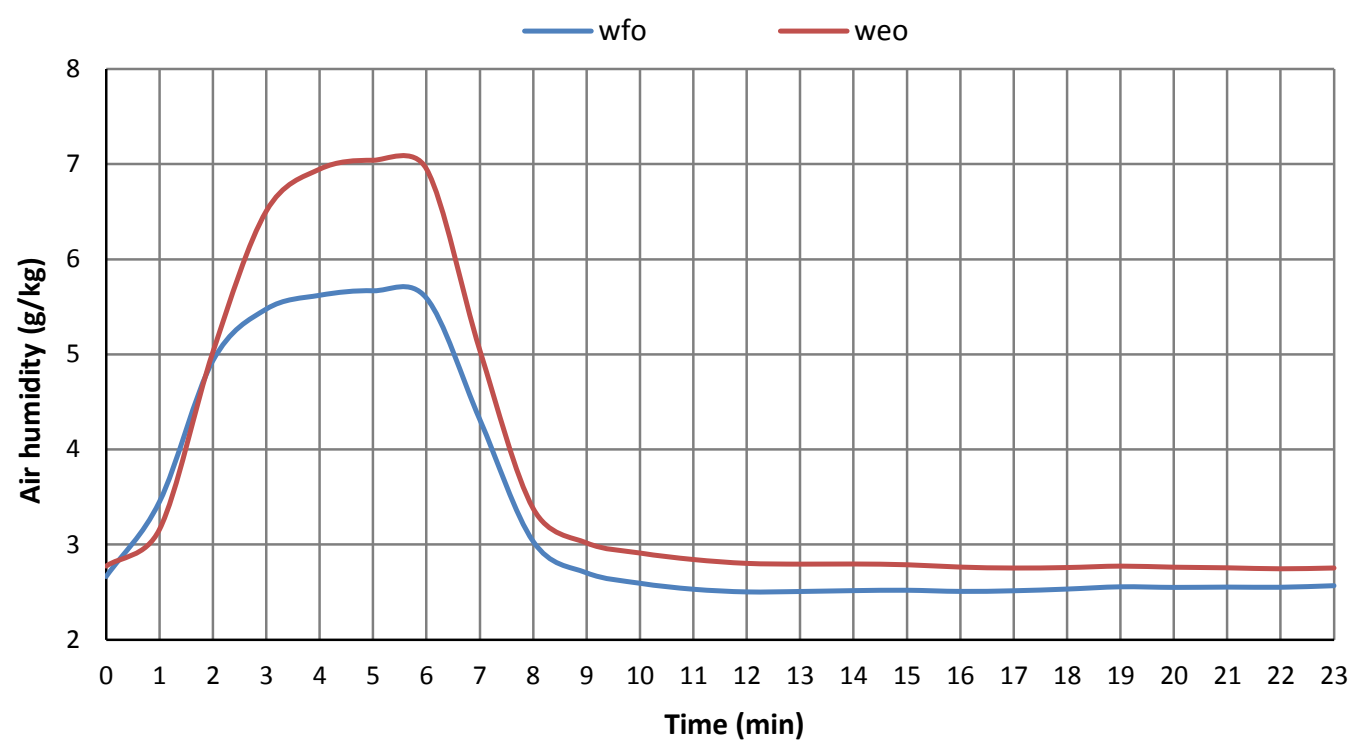

Figure 6.5.17 - Outlet fresh and exhaust air humidity before/during/after defrost cycle (ERV)

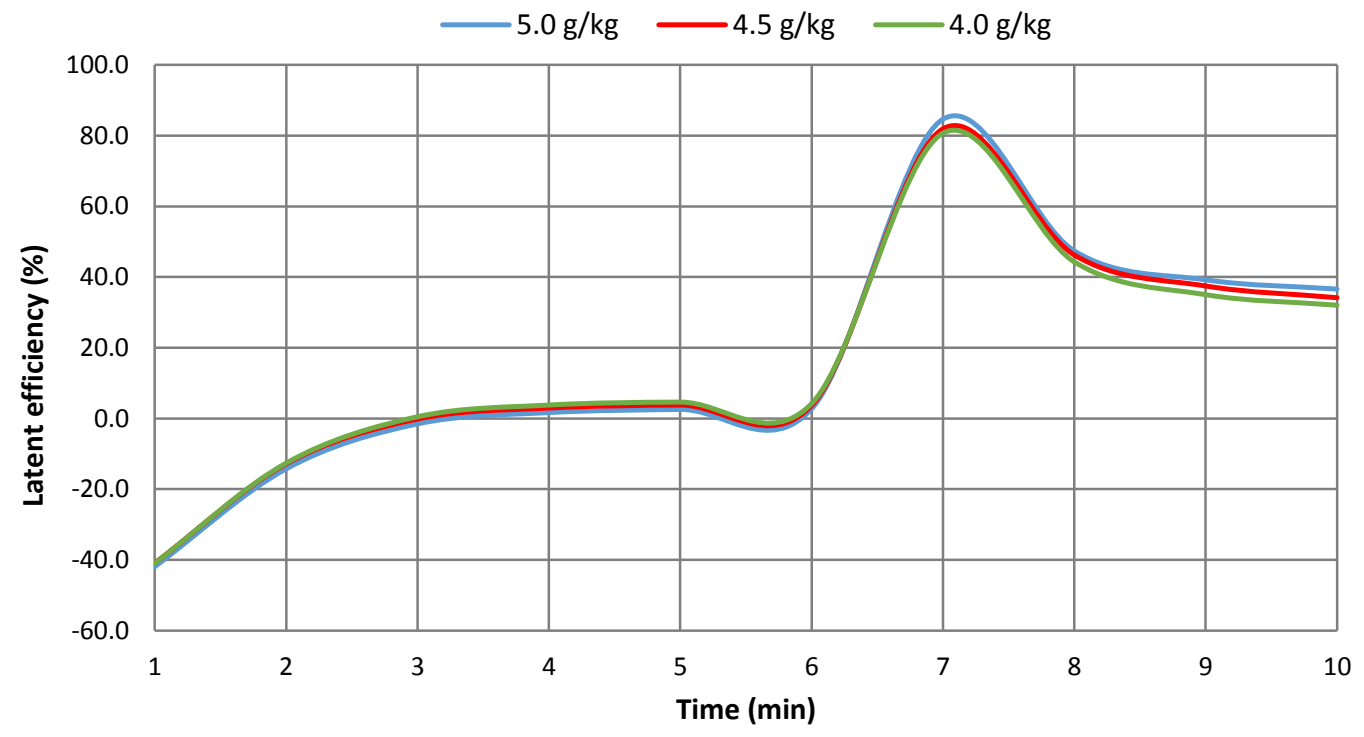

Figure 6.5.18 - Latent efficiency patterns for different $w_{e i}(\mathrm{ERV}): w_{f i}$ is $0.5 \mathrm{~g} / \mathrm{kg}$ 


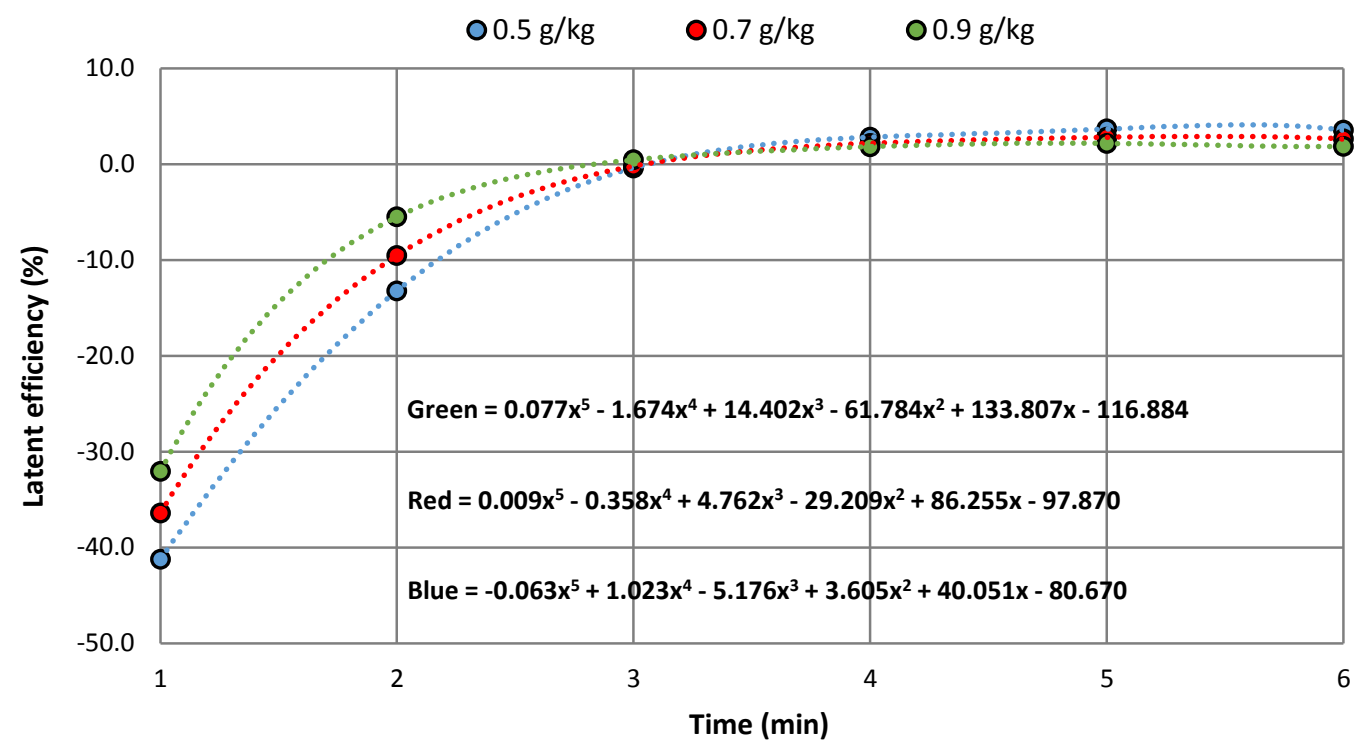

Figure 6.5.19 - Latent efficiency patterns for different $w_{f i}(\mathrm{ERV}): 1^{\text {st }}$ section

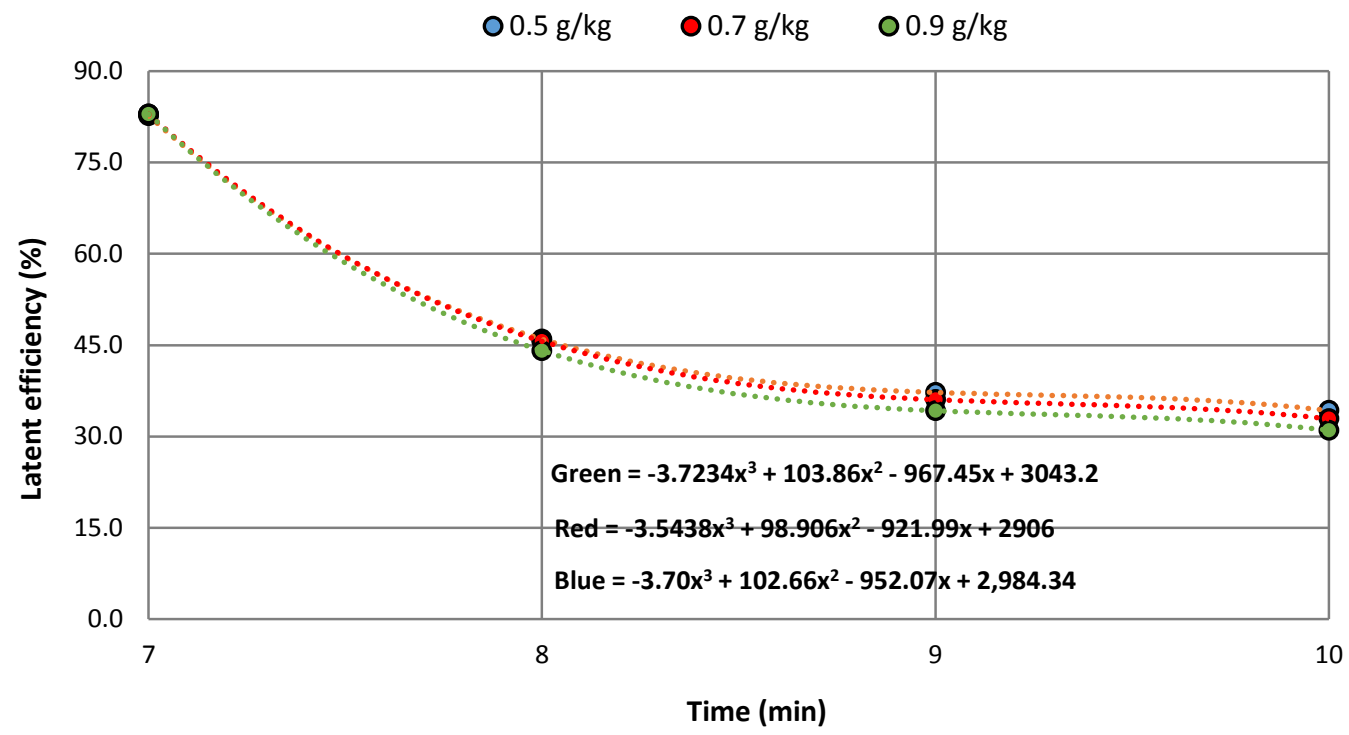

Figure 6.5.20 - Latent efficiency patterns for different $w_{f i}(E R V): 2^{\text {nd }}$ section

Throughout the analysis of observations for defrost cycle, four conclusions can be generated:

1. The observations confirmed that the sensible heat within the recirculated exhaust airstream was "stored" in the core surfaces during defrost cycle, and was slowly released to the fresh airstream afterwards.

2. The defrost cycle activated when the inlet fresh air temperature hit $-10^{\circ} \mathrm{C}$, and it ran 6 minutes for every 32 minutes normal operation.

3. The built-in defrost cycle was a routine that activated every 32 minutes, and hence, the built- 
in defrost cycle was more likely to be used to prevent large scale ice formation.

4. The melted ice/frost on the exhaust core channels increased the humidity of exhaust air. Section 6.6 - Winter Experiment: Heat Recovery Ventilator

\subsection{1 - Encountered Problems during Winter Test Period}

The winter data collection for the HRV in Archetype Sustainable House-A also commenced on January $20^{\text {th }}$ through February $26^{\text {th }}$. However, due to technical issues, the Microsoft SQL Server uncontrollably kept shutting down periodically, and hence, a small portion of sensor readings of the HRV were not stored ${ }^{28}$. In addition, due to the malfunction of defrost cycle, ice formation inside the sensible core (see Figure 6.6.1) was observed from January $21^{\text {st }}, 2014$ to $22^{\text {nd }}$ morning, which significantly affected the daily sensible efficiency due to imbalance airflow. Therefore, the readings for these period were removed from the raw data, and the raw sensor readings started from January $22^{\text {nd }}$ afternoon to February $26^{\text {th }}, 2014$. Figure 6.6.2 illustrates the sensible efficiency and fan power draw on January 21 and 22 where the supply air temperature dropped from -16 to $23^{\circ} \mathrm{C}$. The fan power remained constant at $192-194 \mathrm{~W}$, meaning that no defrost cycle was taking place. During this period, the calculated sensible efficiency decreased over time, that was, the scale of ice formation on the core surfaces increased. Figure 6.6.3 illustrates the fresh and exhaust airflow rate during the malfunctioned periods. As expected, the exhaust airflow rate decreased over time due to ice blockage. In contrast, the fresh airflow rate remained constant throughout the period. It is worth noticing that the difference between the two airflow rates were initially big, meaning that ice has already formed and restricted the exhaust airflow, but data was not stored due to the auto shut-down of program.

\footnotetext{
${ }^{28}$ The most extreme case: the data for January $20^{\text {th }}, 2014$ was missing.
} 


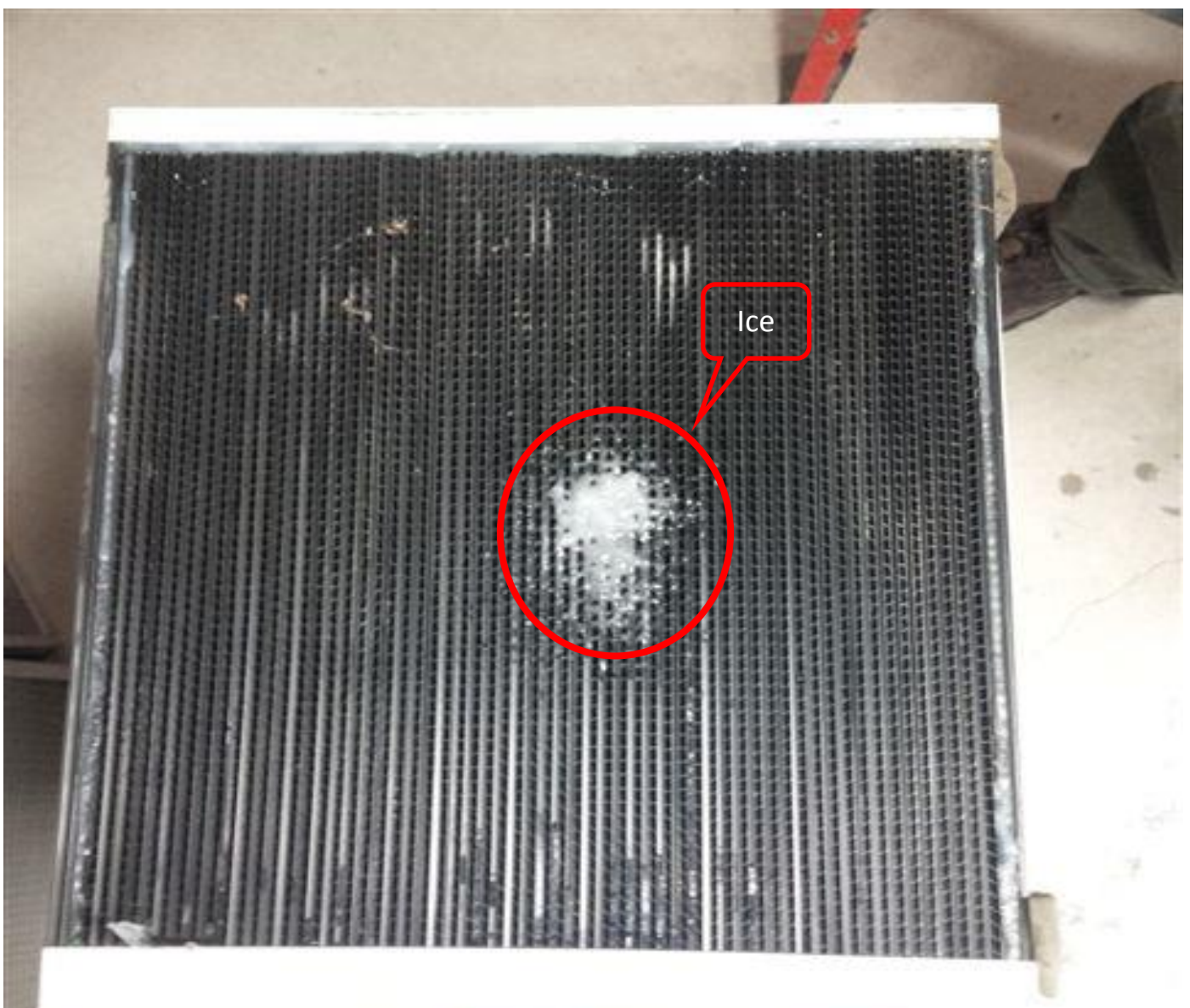

Figure 6.6.1 - Ice formation inside the sensible core of the HRV

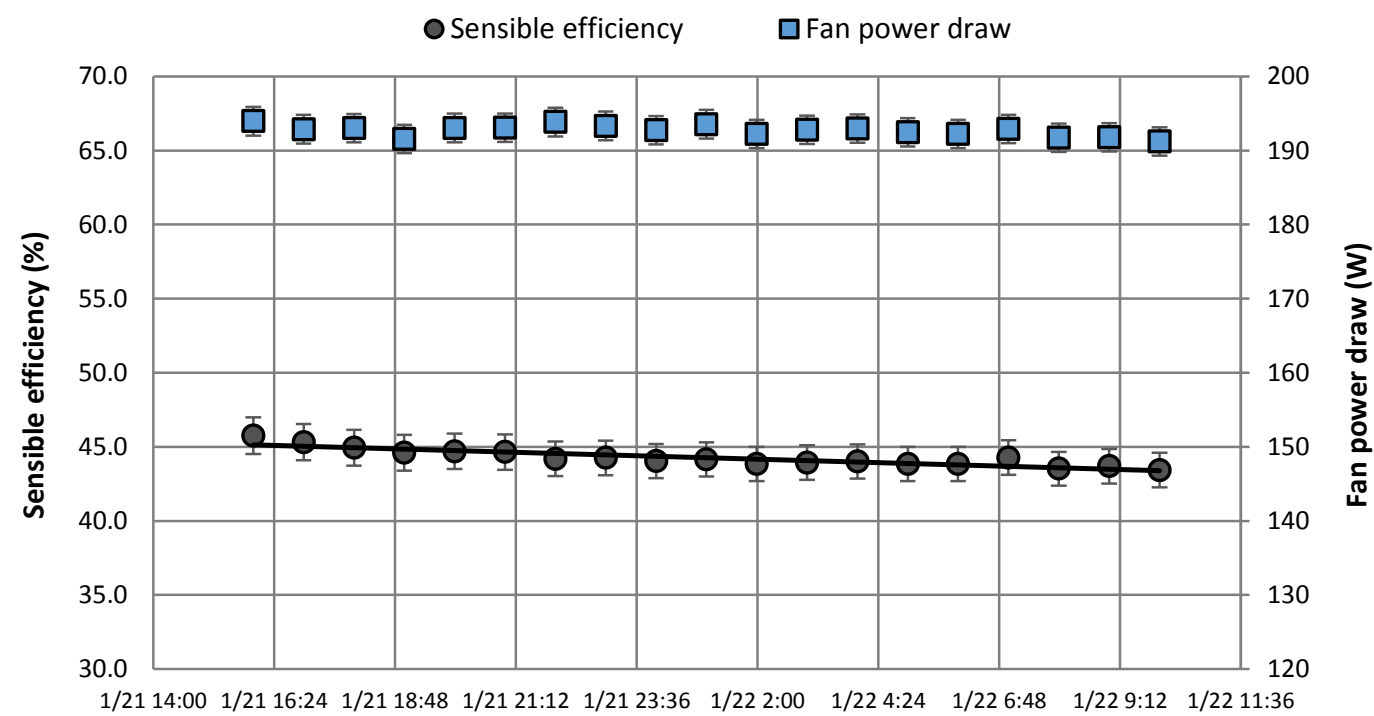

Figure 6.6.2 - Sensible efficiency and fan power draw during cold days without defrost cycle (HRV) 


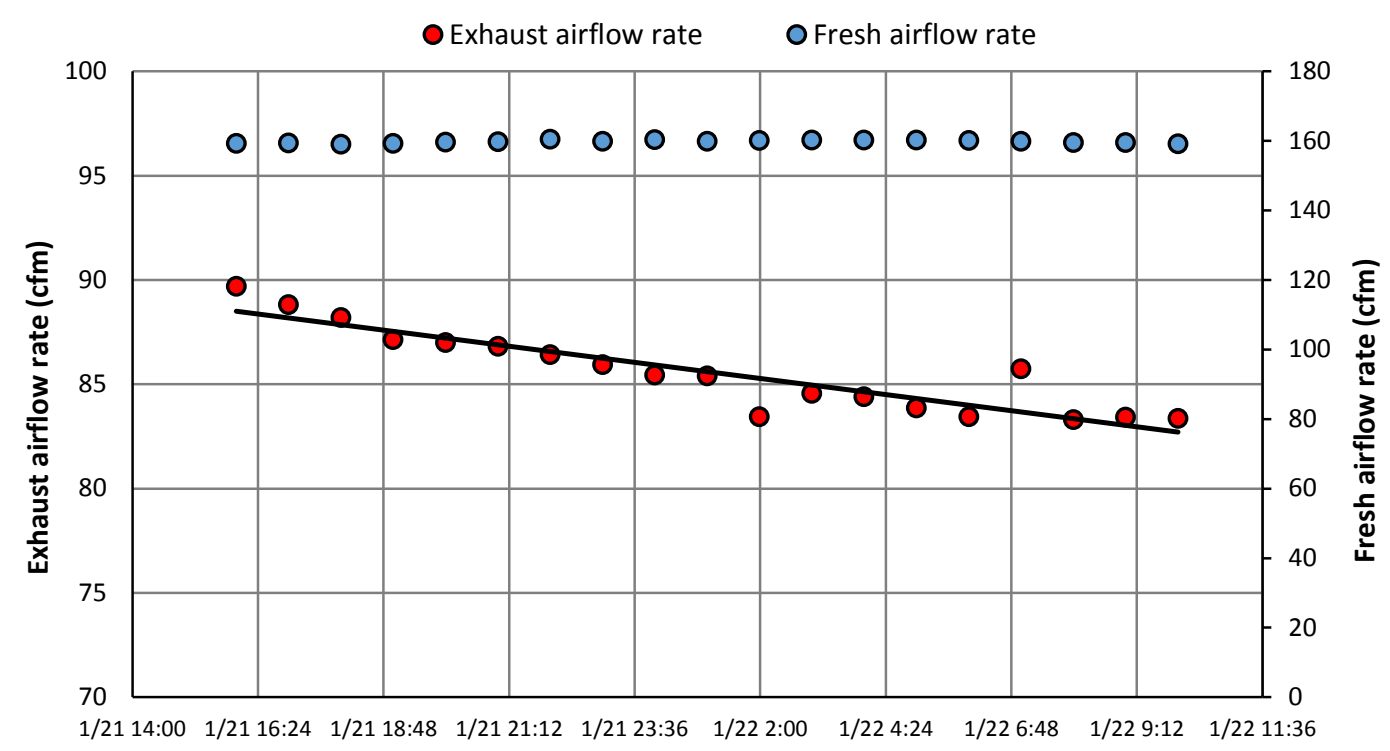

Figure 6.6.3 - Fresh and exhaust airflow rate during cold days without defrost cycle (HRV)

\subsection{2 - Data Analysis: Sensible Efficiency}

In investigating the sensible efficiency of the heat recovery ventilator, the sensible efficiency was considered. Further investigation of the entire HVAC system in the Archetype Sustainable House will be analyzed using TRNSYS. Similarly, the performance curve of the core efficiency will be validated using the manufacturer supplied sensible efficiency. To avoid imbalance air flow rate, the AHU fan was also set to constant, and the monitored supply and exhaust air flow rates are illustrated in Figure 6.6.4, as well as the difference between them. Overall, the airflow rates remained at $147 \mathrm{cfm}$ and were closely balanced. The maximum deviation was found to be 7.06 $\mathrm{cfm}$, and was equivalent to $5 \%$ difference. This maximum difference was considered to be an outlier because it occurred occasionally. To calculate the sensible efficiency, air flows were assumed to be balanced. 


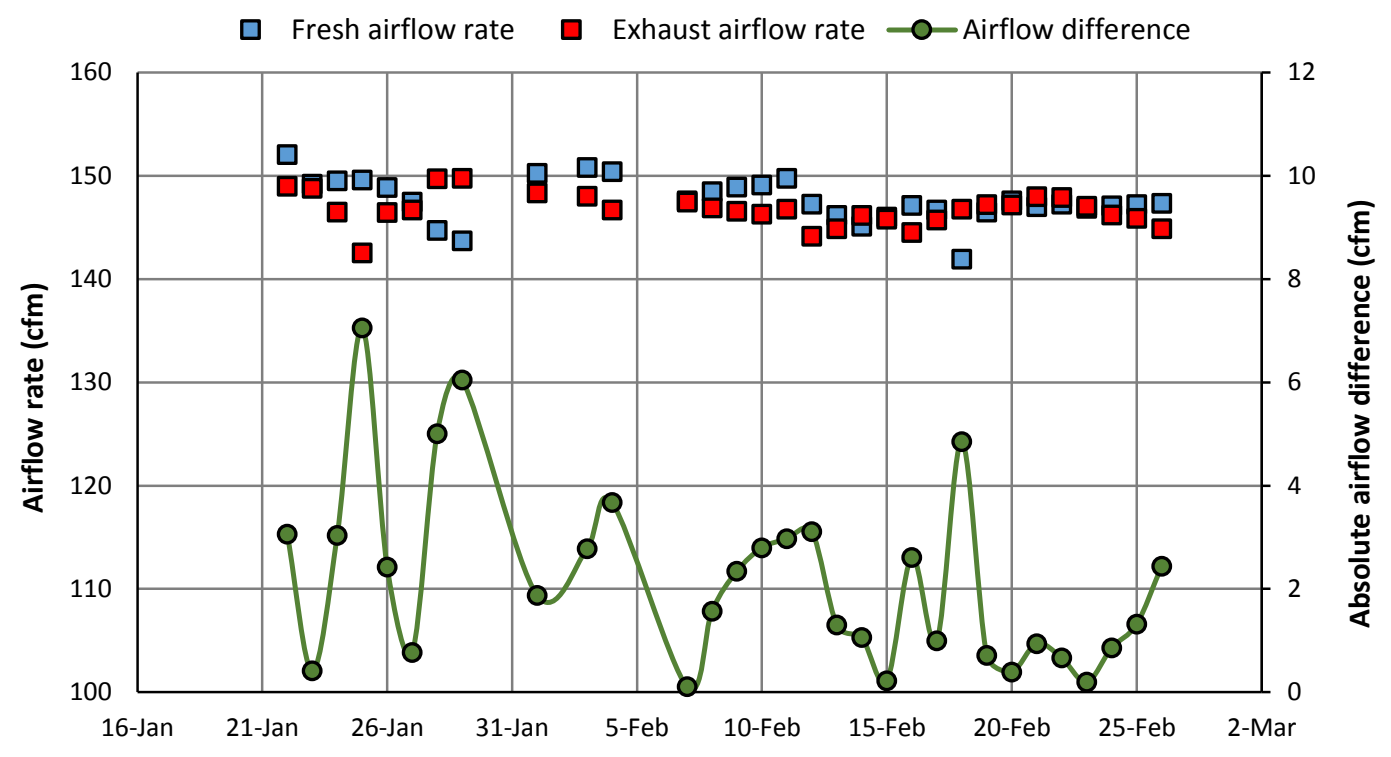

Figure 6.6.4 - Supply and exhaust air flows (HRV)

Figure 6.6.5 illustrates the inlet and outlet air temperatures during the test period. The $\mathrm{AT}_{e i}$ varied from 20 to $24^{\circ} \mathrm{C}$, while the $\mathrm{AT}_{f i}$ varied from $-16.6^{\circ} \mathrm{C}$ to $1.1^{\circ} \mathrm{C}$. In the meantime, the $w_{e i}$ varied from $4.5 \mathrm{~g} / \mathrm{kg}$ to $5.8 \mathrm{~g} / \mathrm{kg}$, while the $w_{f i}$ varied from $0.8 \mathrm{~g} / \mathrm{kg}$ to $2.8 \mathrm{~g} / \mathrm{kg}$, as shown in Figure 6.6.6. It is worth noticing that the outlet fresh air humidity remained 2 times (or above) higher than that of the inlet, which was unexpected for sensible only air-to-air heat exchanger. Therefore, there must be cross-leakage inside the HRV which has caused an increase in fresh air humidity. Figure 6.6.7 illustrates the sensible efficiency of the HRV during the test period. Raw data showed considerable scatter, and hence, the raw data was averaged in temperature/humidity bins so that the scatter can be reduced and the results can be seen more meaningfully. The measured sensible efficiency (SE) varied from $91 \%$ at $-17^{\circ} \mathrm{C}$ to $95 \%$ at $0.7^{\circ} \mathrm{C}$, and it exhibited to be more sensitive to the change of $\mathrm{AT}_{f i}$ than the ERV (see Figure 6.5.4). Figure 6.6.7 also shows the comparison between measured SE with manufacturer supplied SE. The manufacturer data states that, at $117 \mathrm{cfm}$, the HRV has a sensible efficiency of $94 \%$ at $0^{\circ} \mathrm{C}$ and it drops down to $89 \%$ at $-25^{\circ} \mathrm{C}$. These two points form a linear relation that establishes a general trend for the HRV under different inlet temperatures. The measured values suggest a trend similar to the manufacturer's measurements, and hence, they are reasonable. In addition, the manufacturer also states that the $\mathrm{SE}$ of the $\mathrm{HRV}$ at $0^{\circ} \mathrm{C}$ and $147 \mathrm{cfm}$ should be $90 \%$, while the calculated sensible efficiency from the observed temperatures was $95.4 \%$. Again, this confirms that there was cross-leakage inside the HRV, which has caused an increase in fresh air temperature. In addition to the cross-leakage, the internal heat gain from fan motor 
and/or uncertainty may also affect the readings of outlet fresh air temperature. Figure 6.6.8 illustrates the relationship between the inside-outside air temperature difference and the calculated sensible efficiency. As expected, the SE decreased with a rise in air temperature difference, as similar to Figure 6.5.5.

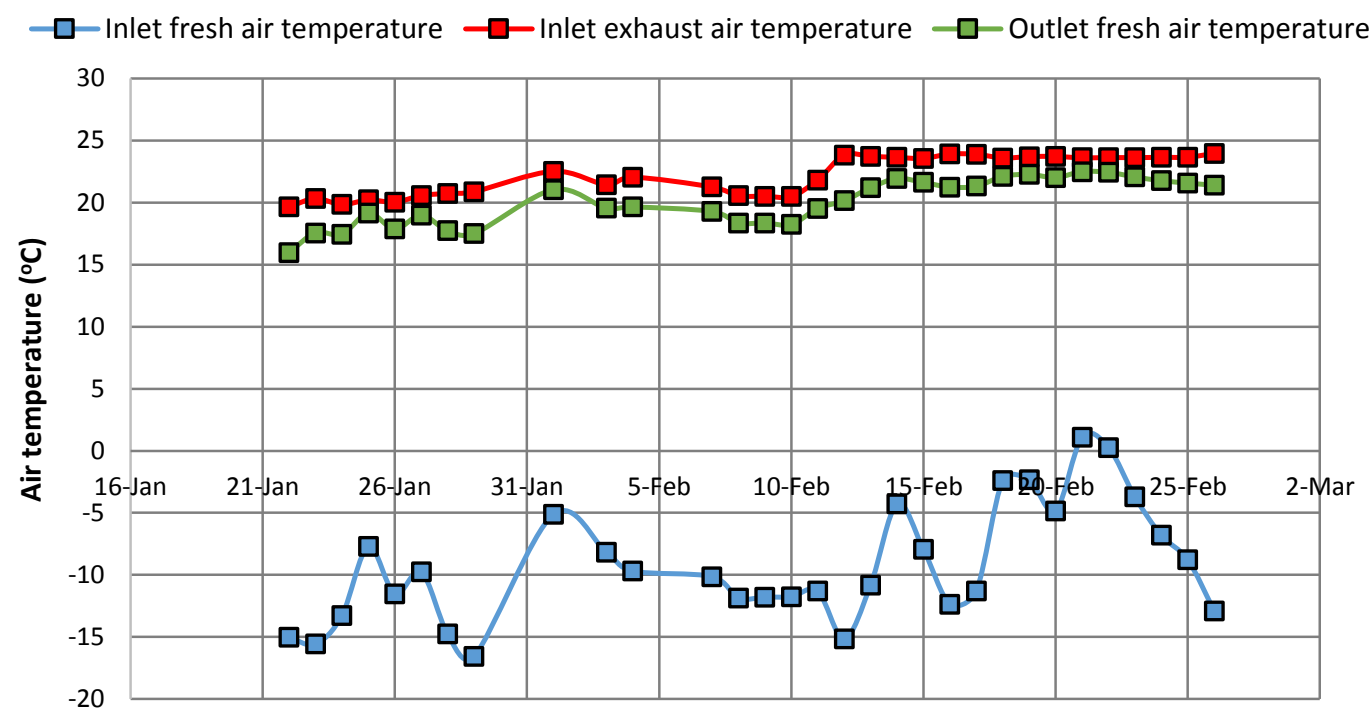

Figure 6.6.5 - Fresh and exhaust air temperature (HRV)

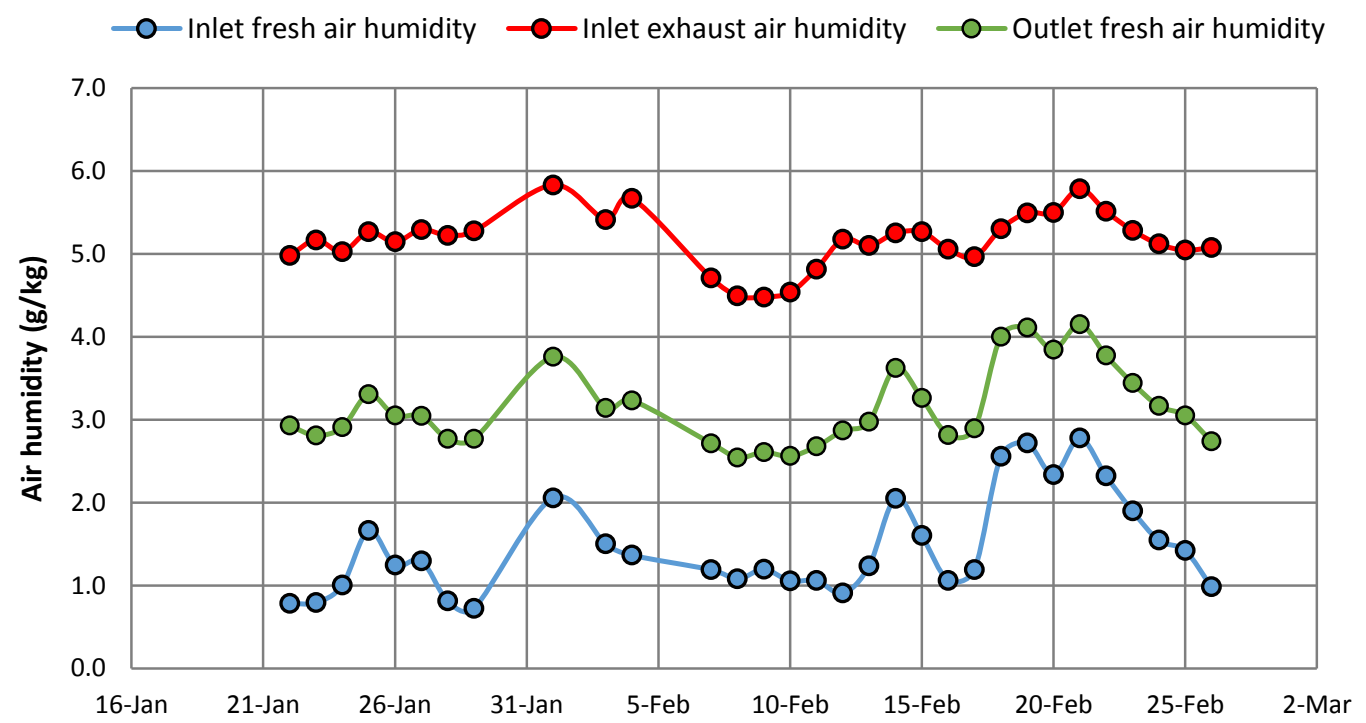

Figure 6.6.6 - Fresh and exhaust air humidity (HRV) 


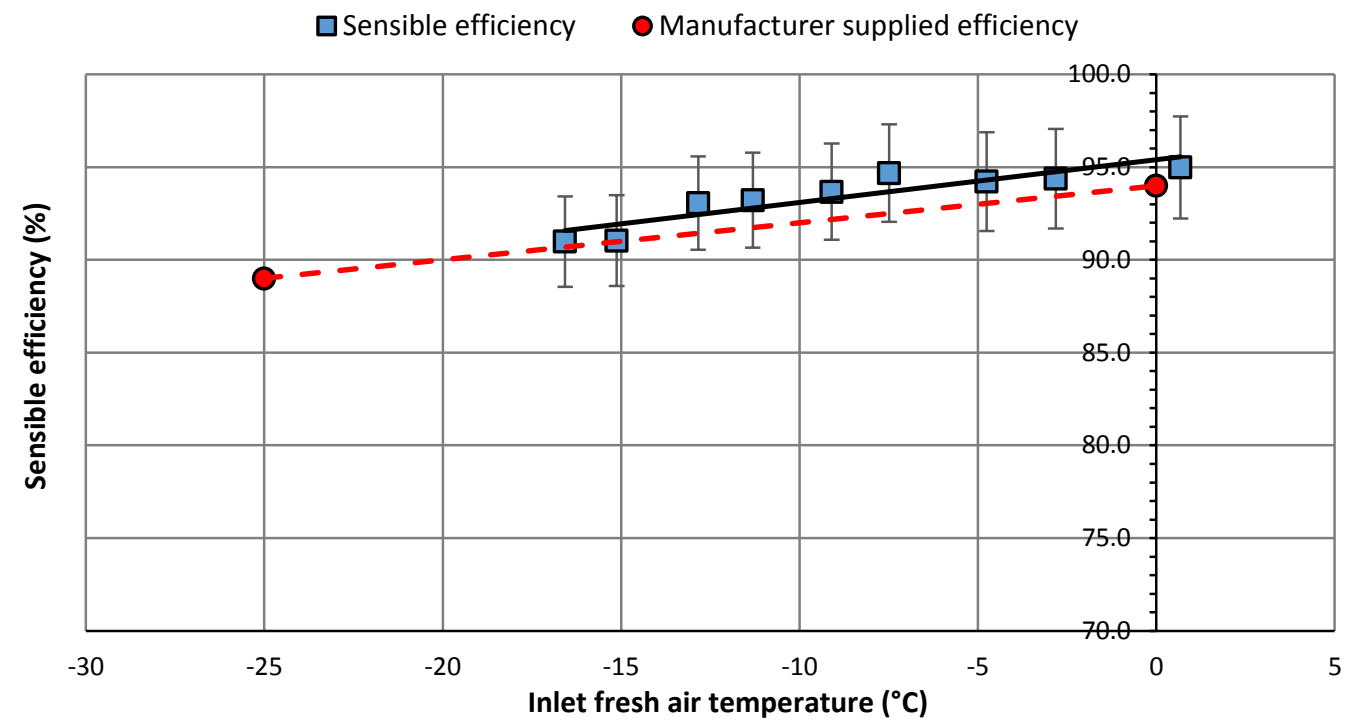

Figure 6.6.7 - Experimental and manufacturer supplied sensible efficiency at different inlet fresh air temperature (HRV)

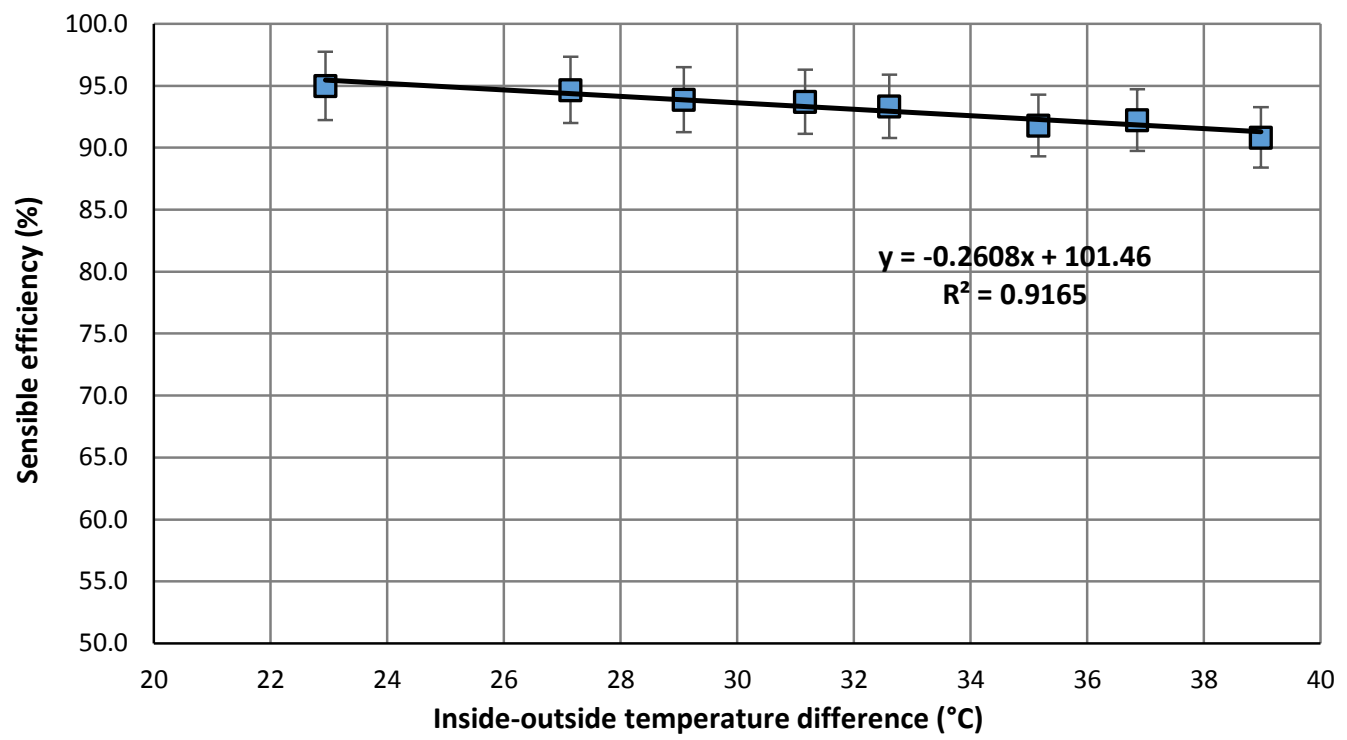

Figure 6.6.8 - Sensible efficiency vs. inside-outside temperature difference (HRV)

Due to the leakage inside the HRV, the outlet fresh air humidity increased significantly. In order to predict the rise in the outlet humidity attributed to internal cross leakage, the leakage ratio was used as substitution of latent efficiency. In other words, the linear relation established in Figure 6.6.9 was implemented into the HRV model to predict the $w_{f o}$ based on the inside-outside air humidity difference. 


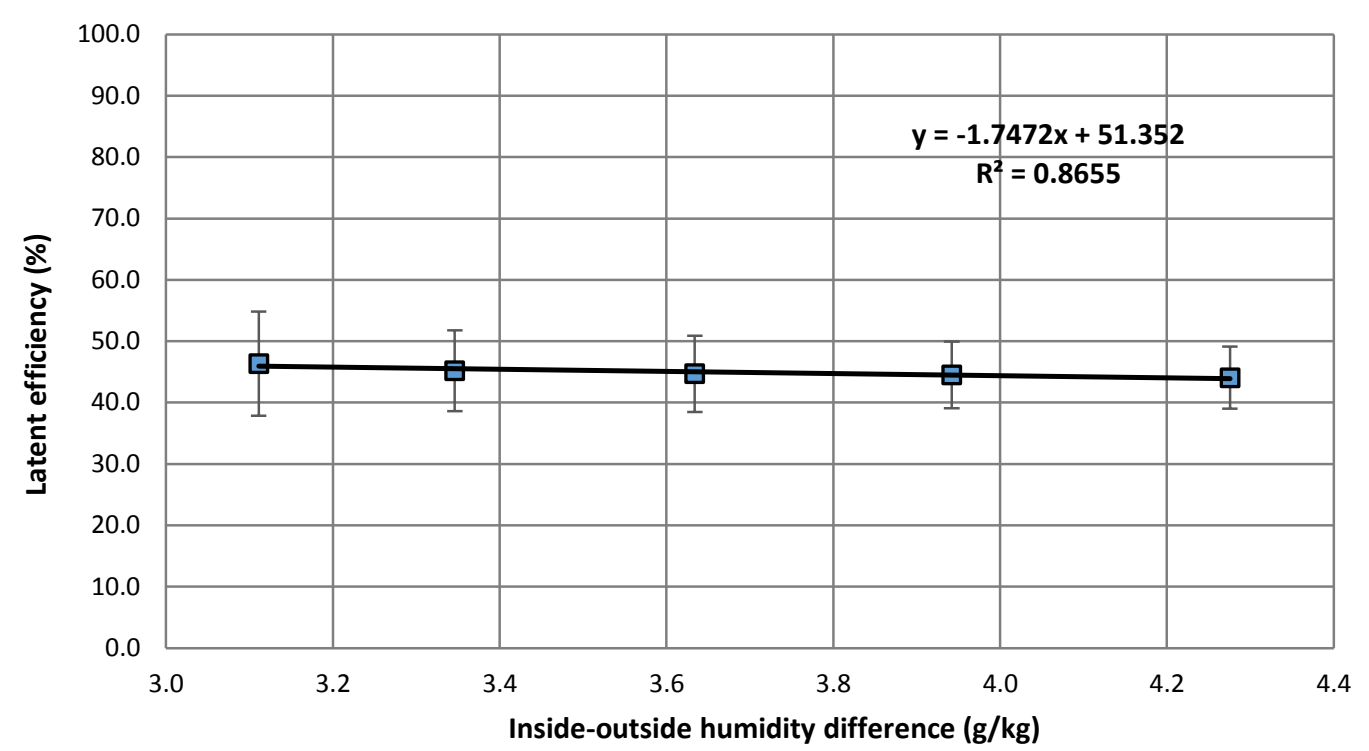

Figure 6.6.9 - Latent efficiency vs. inside-outside temperature difference (HRV)

Cross-leakage may result in cross contamination of particles, odors, and condensate between two airstreams (XeteX, 2009). According to ASHRAE Handbook (2008), the leakage ratio can be estimated beforehand by the tracer gas method according to Eq. 6.6.1, where the parameters $\mathrm{c}_{f}, \mathrm{c}_{f o}$ and $\mathrm{c}_{e i}$ are the relative concentrations of inert gas at different ducts. This ratio represents an exhaust air leakage based on observed relative concentration of inert gas in supply airflow. The effective enthalpy efficiency, according to Han et al. (2007), represents the performance of energy transfer between supply and exhaust airstreams excluding that by leakage. The effective efficiency $\left(\varepsilon_{e}{ }^{\prime}\right)$ of the HRV can be calculated using Eq. 6.6.2. In the meantime, the enthalpy efficiency $\left(\varepsilon_{e}\right)$ can be estimated from Eq. 6.6.3 as introduced by Zhang (2008).

$$
\begin{gathered}
\eta_{L}=\frac{c_{f o}-c_{f i}}{c_{e i}-c_{f i}} \\
\varepsilon_{e^{\prime}}=\frac{\varepsilon_{e}-\eta_{L}}{1-\eta_{L}}
\end{gathered}
$$

where

$$
\varepsilon_{e}=\frac{\varepsilon_{S}+\varepsilon_{L}\left(2501 \frac{\Delta \omega}{\Delta T}\right)}{1+\left(2501 \frac{\Delta \omega}{\Delta T}\right)}
$$

The leakage ratio $\left(\eta_{L}\right)$ can be estimated using back-substitution. As an illustration, the sensible and latent efficiencies are $95 \%\left(\mathrm{AT}_{f i}=0.7^{\circ} \mathrm{C}\right.$, as shown in Figure 6.6.7) and $45.6 \%$ (from the same bin matrix), the corresponding inside-outside air temperature and humidity differences are $22.94^{\circ} \mathrm{C}$ and $3.09 \mathrm{~g} / \mathrm{kg}$. The enthalpy efficiency, according to Eq. 6.6.3, is therefore: 
$\varepsilon_{e}=\frac{0.95+0.45 *\left(2501 *\left(\frac{3.09 * 10^{-3}}{22.94}\right)\right)}{1+\left(2501 *\left(\frac{3.09 * 10^{-3}}{22.94}\right)\right)} * 100 \%$

$\varepsilon_{e}=82.6 \%$

Combining both Eq. 6.6.2 and 6.6.3, and assume:

The sensible efficiency excluding the effect of cross-leakage is $90 \%$, which is considered to be the same as the manufacturer supplied efficiency at $0^{\circ} \mathrm{C}$ and $147 \mathrm{cfm}$.

The latent efficiency excluding the effect of cross-leakage is $0 \%$, meaning that no mass transfer due to leakage.

$\frac{\varepsilon_{e}-\eta_{L}}{1-\eta_{L}}=\frac{\varepsilon_{s^{\prime}}+\varepsilon_{L^{\prime}}\left(2501 \frac{\Delta \omega}{\Delta T}\right)}{1+\left(2501 \frac{\Delta \omega}{\Delta T}\right)}$

$\frac{0.826-\eta_{L}}{1-\eta_{L}}=\frac{0.9+0 *\left(2501 *\left(\frac{3.09 * 10^{-3}}{22.94}\right)\right)}{1+\left(2501 *\left(\frac{3.09 * 10^{-3}}{22.94}\right)\right)}$

$\eta_{L} \approx 46.5 \%$

The back-substitutions show that the leakage ratio of the HRV was 46.5\%, which may not be practical unless the device was severely deficient, e.g., geometric irregularity. There should be other source(s) which has contributed to the rise in sensible efficiency (e.g., unequal airflows). The differential pressure transmitter for exhaust air was installed at the outlet duct, meaning that the inlet exhaust airflow could be higher than the fresh airflow (and then leak to fresh airstream), which could affect the sensible efficiency. Therefore, full inspection is required in the future studies in order to better understand the problems inside the HRV. The use of tracer gas method allows to identify and quantify the cross-leakage. In addition, the installation of additional sensors could be helpful in studying both the leakage and source of other problems, however, it is not recommended due to high expense:

1. Install $\mathrm{AT} / \mathrm{RH}$ sensors at each vacuum (the region at which airstream passes through) to observe the air condition right before/after heat exchange. Comparisons can be made between readings from both internal and duct-mount sensors in order to verify the leakage.

2. Install additional differential pressure transmitters to ensure that the inlet and outlet airflow rates for both airstreams are observed. The inlet-outlet airflow difference can be used to 
determine the direction of leakage (from exhaust to supply, or vice versa).

\subsection{3 - Data Analysis: Defrost cycle}

Theoretically, for inlet fresh air temperature between -15 to $-5{ }^{\circ} \mathrm{C}$, the HRV in the ASH-A runs 6 minutes warm air recirculation for every 1 hour interval to prevent sensible core from freezing. Figure 6.6.10 illustrates the path of the exhaust air, and there is no introduction of fresh air. During defrost period, the observed outlet fresh airstream is basically the exhaust airstream after passing through the core channels. In addition, this figure reveals that a portion of exhaust air will be sent to the exhaust air channels, which differs from the ERV. To study both the inlet/outlet and inside/outside air conditions before and right after the defrost cycle, data recorded on January $23^{\text {rd }}$, 2014 was chosen for analysis since on that day the outdoor temperature was around $-15^{\circ} \mathrm{C}$.

To analyze the defrost cycle, it was necessary to look at minutely data over a short period of time. The results and analysis presented below were based on the minutely data of three hours (from 0 am to 3 am on January $\left.23^{\text {rd }}, 2014\right)$. In Figure 6.6.11, the temperature of exhaust air from house, temperature of fresh air, and the fan power draw (in Watt) were plotted over the three hours test period. In the figure, the defrost cycle initiated when fan power draw increased from 210 to $450 \mathrm{~W}$, and hence, seven defrost cycles were observed, meaning that the interval of defrost cycle was 20 minutes. Therefore, the defrost cycle runs 6 minutes for every 20 minutes normal operation. Figure 6.6.11 also shows that the inlet exhaust $\left(20^{\circ} \mathrm{C}\right)$ air temperature remained nearly constant with small fluctuation. Before the defrost cycles, outlet fresh air temperature remained nearly constant at $17^{\circ} \mathrm{C}$. During the defrost cycles, warm exhaust airstream flowed into both fresh and exhaust air channels to heat up the core surfaces, the outlet fresh air temperature decreased from initially $17^{\circ} \mathrm{C}$ to $13^{\circ} \mathrm{C}$, and continue to increase throughout the defrost period. Right after the defrost cycles, the temperature of fresh air stayed a bit high for a few minutes as similar to the ERV. Figure 6.6.12 illustrates the inlet exhaust and outlet fresh air humidity over the short test period. It was evidenced that the peak outlet fresh air humidity (during defrost) exceeded that of the exhaust air stream, and hence, the recirculated air accompanies moisture from the melted ice, which caused temporarily higher moisture content. Last but not the least, due to internal cross leakage, the humidity of fresh air at the outlet remained above the maximum limit of water vapour that air can hold at $-15^{\circ} \mathrm{C}$ inlet fresh air temperature $\left(1.18 \mathrm{~g} / \mathrm{kg}\right.$ at $-15^{\circ} \mathrm{C}$ and $\left.100 \% \mathrm{RH}\right)$. 


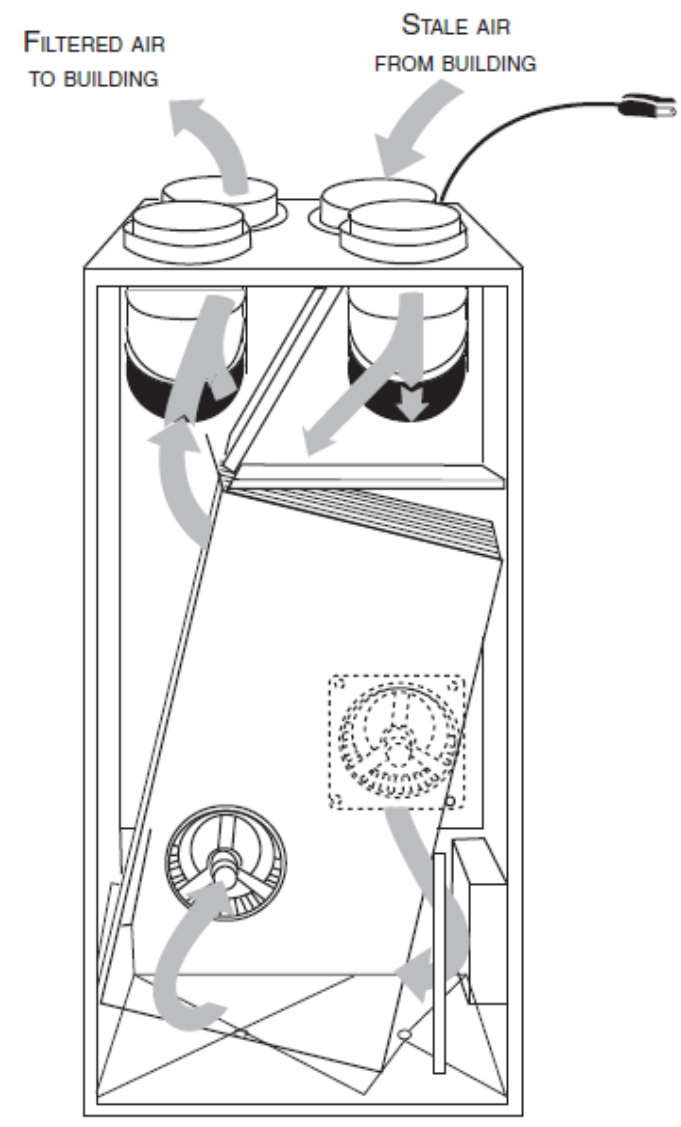

Figure 6.6.10 - House-A heat recovery ventilator airflow during defrost cycle (VanEE, 2011)

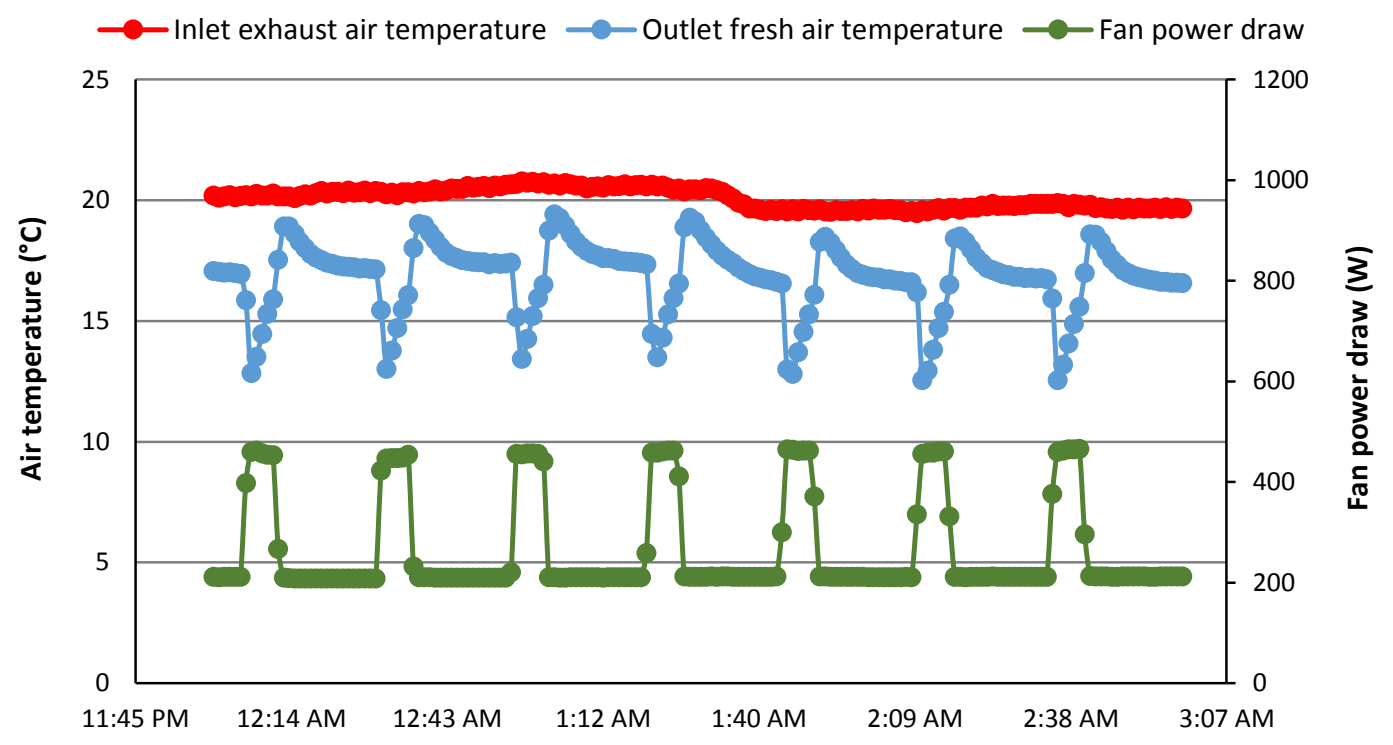

Figure 6.6.11 - Air temperature and fan power draw during defrost cycle (HRV) 


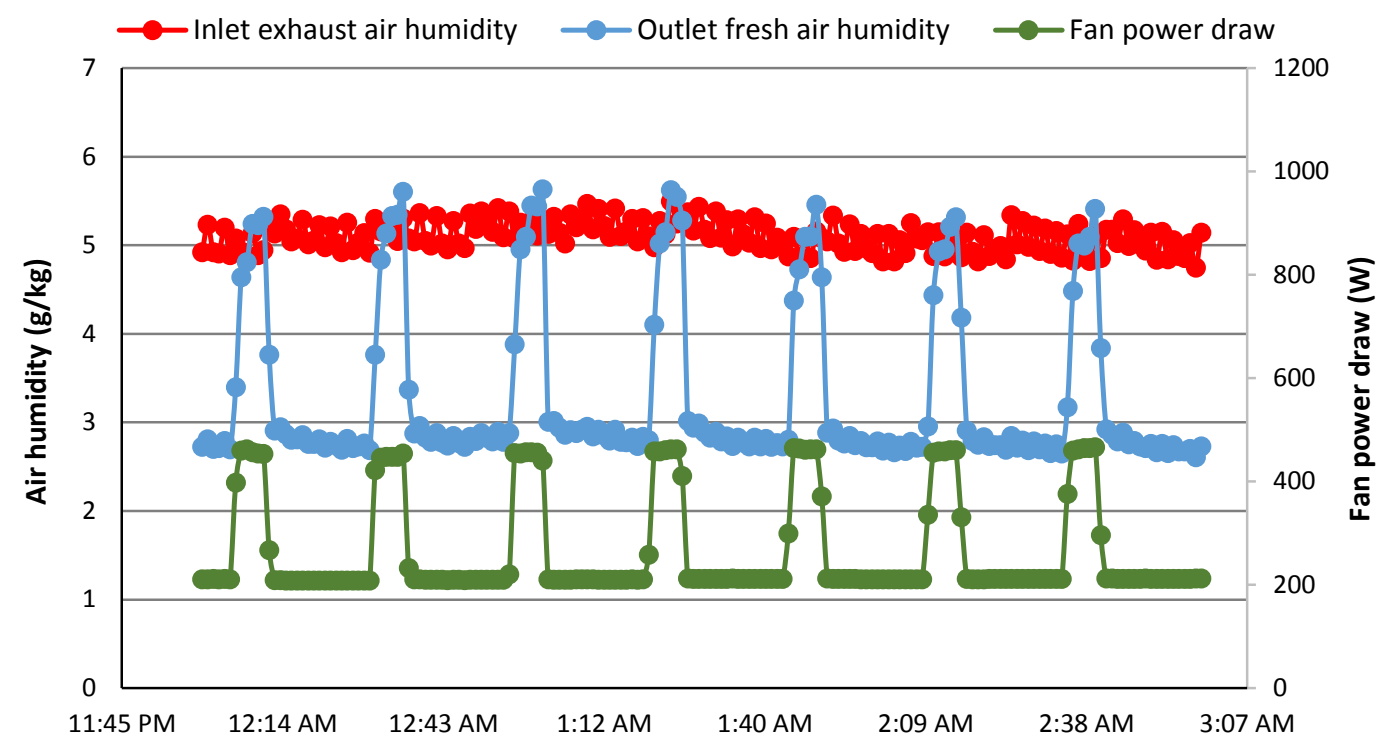

Figure 6.6.12 - Air humidity and fan power draw during defrost cycle (HRV)

Investigation was also extended to determine the outlet fresh air temperature patterns, $\mathrm{AT}_{f o}$, during different stages of defrost cycle. As an illustration, Figure 6.6.13 presents the patterns for which the inlet exhaust air was around $19.6^{\circ} \mathrm{C}$ (see Table 6.6.1). According to the fan power draw, defrost cycle happened between 1 and 6 min. Therefore, the change in the $\mathrm{AT}_{f o}$ was attributed to the air recirculation (about $20^{\circ} \mathrm{C}$ ) that warmed up the entire ventilation system. Once defrost cycle was terminated, there was a rise in $\mathrm{AT}_{f o}$ due to the heat gain from the casing, core surfaces, and fan motor; this pattern continued until steady-state is reached (after $18 \mathrm{~min}$ ). Figure 6.6 .13 also illustrates the pattern for case \#2 where the inlet exhaust air is around $24.0^{\circ} \mathrm{C}$. This plot exhibits a pattern similar to the case \#1. The setpoint temperature for the simulation presented in Chapter 5 was $21^{\circ} \mathrm{C}$. Therefore, the generalized temperature patterns for $-20^{\circ} \mathrm{C}_{\mathrm{AT}_{f i}}$ with $21^{\circ} \mathrm{C} \mathrm{AT}_{e i}$ can be determined by interpolating between the two patterns. For defrost other than $-20^{\circ} \mathrm{C}$, the generalized patterns can be obtained through the same procedure adopted above.

Table 6.6.1 - Air conditions before/during/after defrost cycle (HRV)

\begin{tabular}{ccccccc}
\hline \multicolumn{3}{c}{ Case \#1 } & \multicolumn{3}{c}{ Case \#2 } \\
\hline AT(FI) & AT(FO) & AT(EI) & AT(FI) & AT(FO) & AT(EI) \\
\hline BEFORE & -20.2 & 15.6 & 19.6 & -20.3 & 19.7 & 24.0 \\
DURING & ---- & ---- & 19.5 & --- & ---- & 24.0 \\
AFTER & -20.1 & ---- & 19.3 & -19.6 & ---- & 24.2 \\
\hline
\end{tabular}




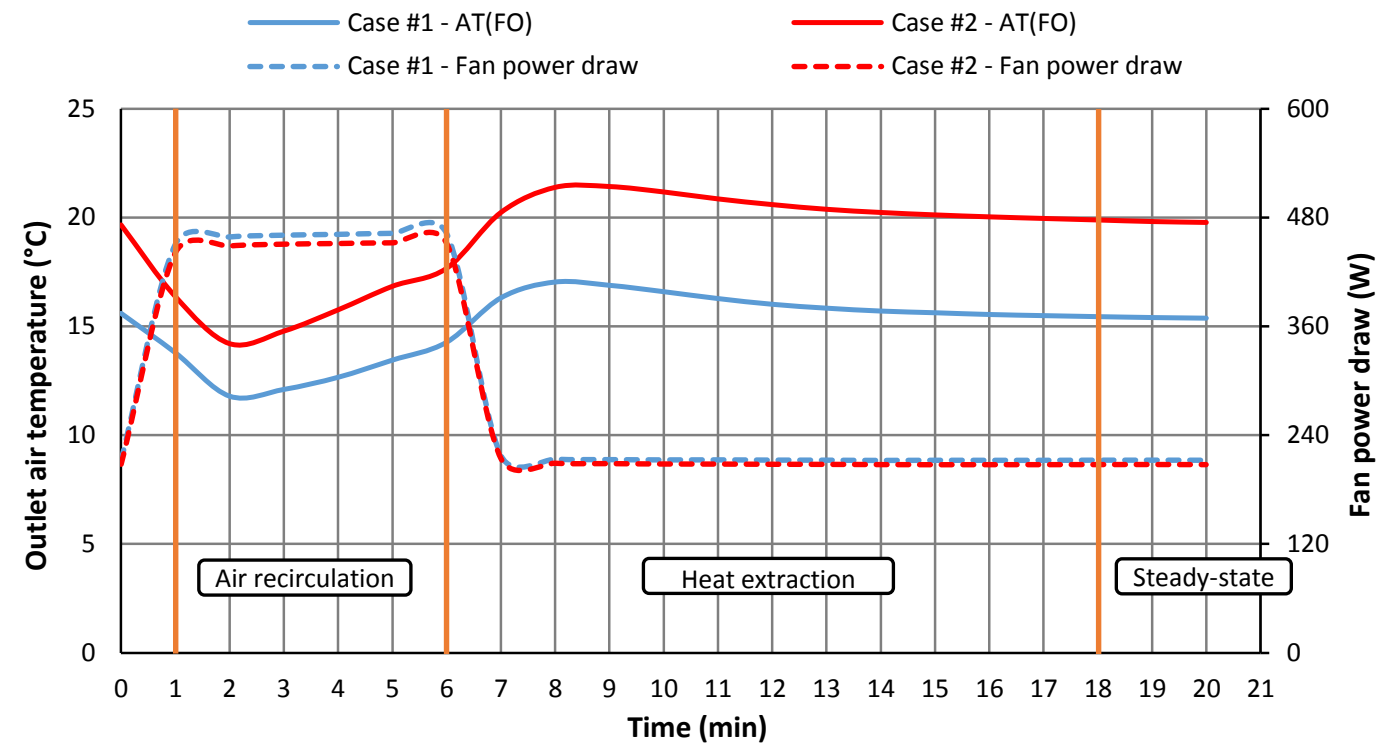

Figure 6.6.13 - Outlet fresh air temperature pattern at different stages (HRV)

Figure 6.6.14 illustrates the temperature patterns for different outdoor air temperature; the indoor air temperature is fixed $21^{\circ} \mathrm{C}$. Similarly, the sensible efficiency patterns were developed and divided into two sections; each section was quantified and curve fitted to obtain a set of polynomial equations, which will be implemented into the HRV model to simulate the effect of defrost cycle on the overall energy savings. The first section was designed to describe the patterns during defrost cycle (see Figure 6.6.15): from interval 1 to 6 minute. In contrast, the second section (see Figure 6.6.16) was designated to describe the patterns after defrost cycle: from interval 7 to 18 minute. It is worth noticing that the temperature pattern (see Figure 6.6.14) for $-5^{\circ} \mathrm{C} \mathrm{AT}_{f i}$ at minute $8-10$ exceeded the $\operatorname{AT}_{e i}\left(21^{\circ} \mathrm{C}\right)$, consequently the sensible efficiency exceeded $100 \%$ at these periods. The motor heat gain was the major source of causing this phenomenon. In the study of a paper core heat exchanger, Yoo et al. (2005) estimated that the motor heat gain was $40 \%$ to $50 \%$ energy of the its power consumption; taking this estimation as premise, the temperature rise attributed to motor heat gain of the $\mathrm{HRV}$ is $0.9^{\circ} \mathrm{C}$ to $1.1^{\circ} \mathrm{C}$. 


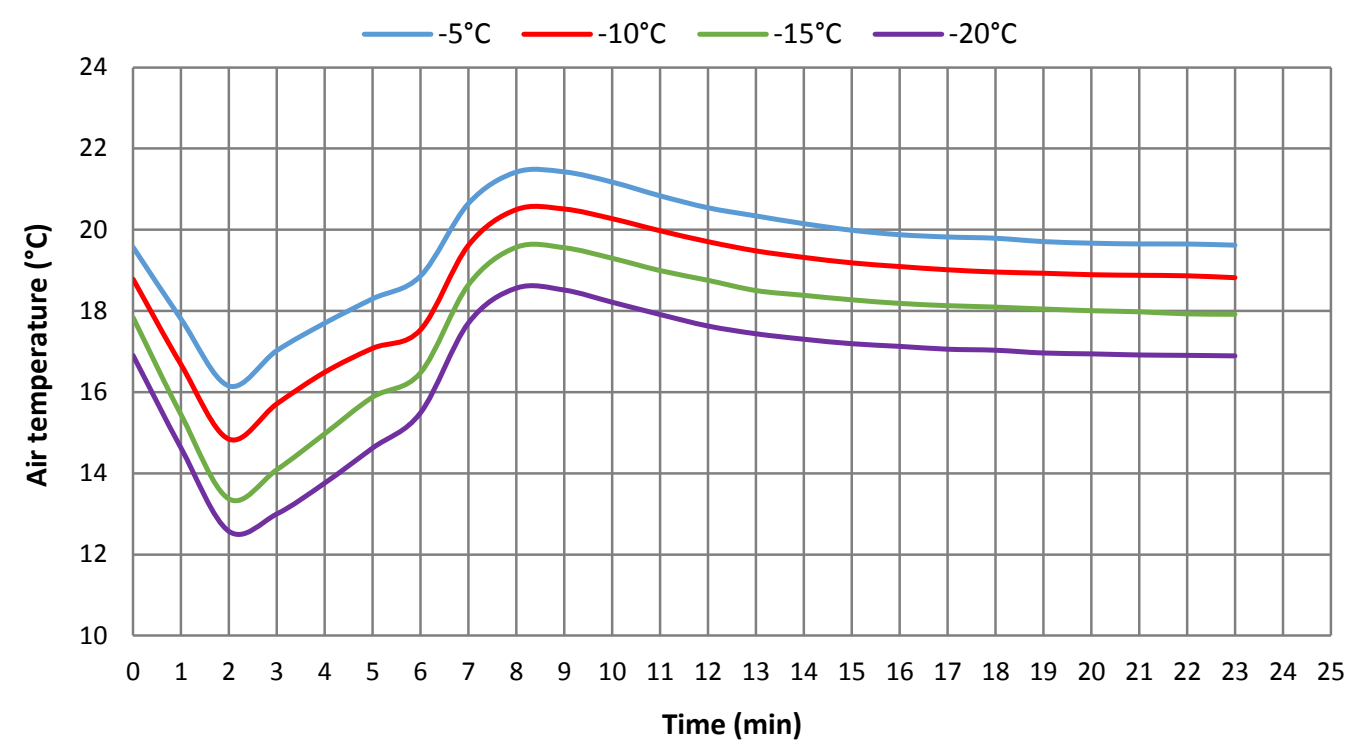

Figure 6.6.14 - Outlet fresh air temperature pattern at different outside temperatures (HRV)

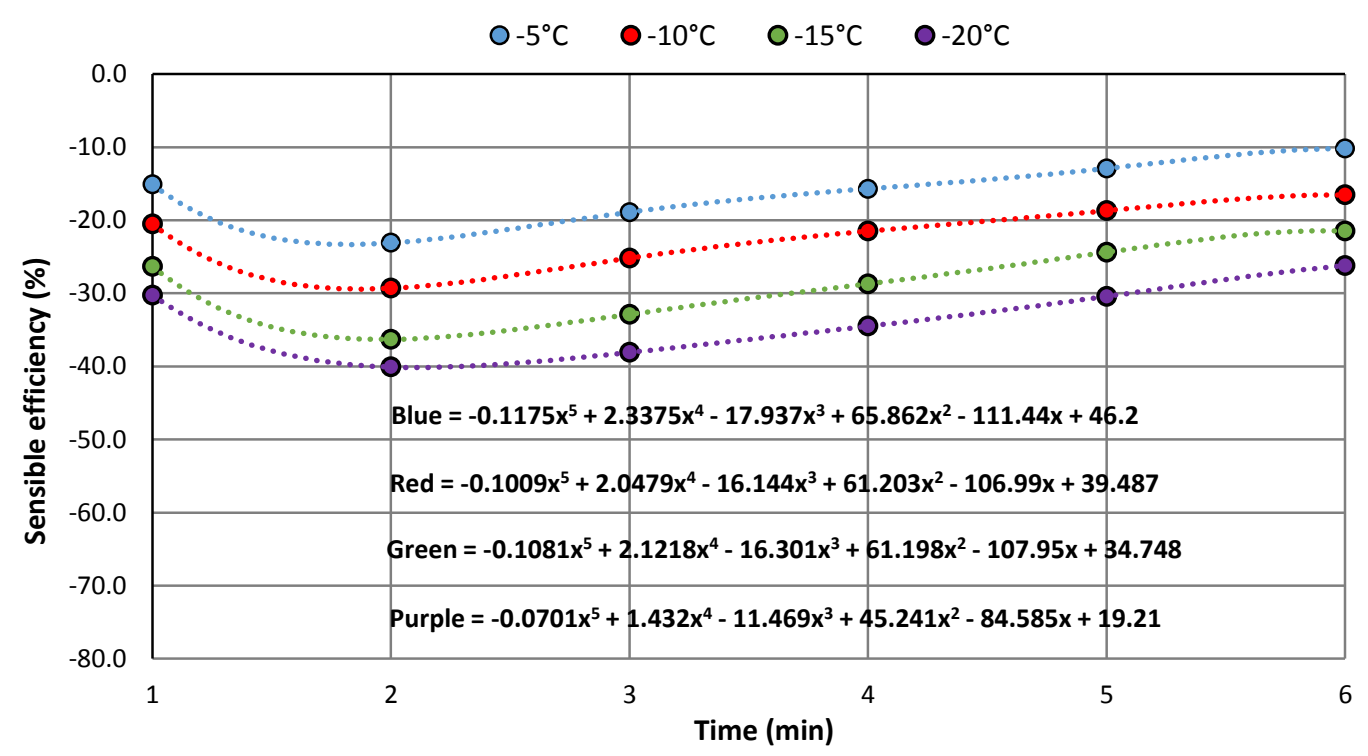

Figure 6.6.15 - Sensible efficiency patterns for different $\mathrm{AT}_{f i}(\mathrm{HRV}): 1^{\text {st }}$ section 


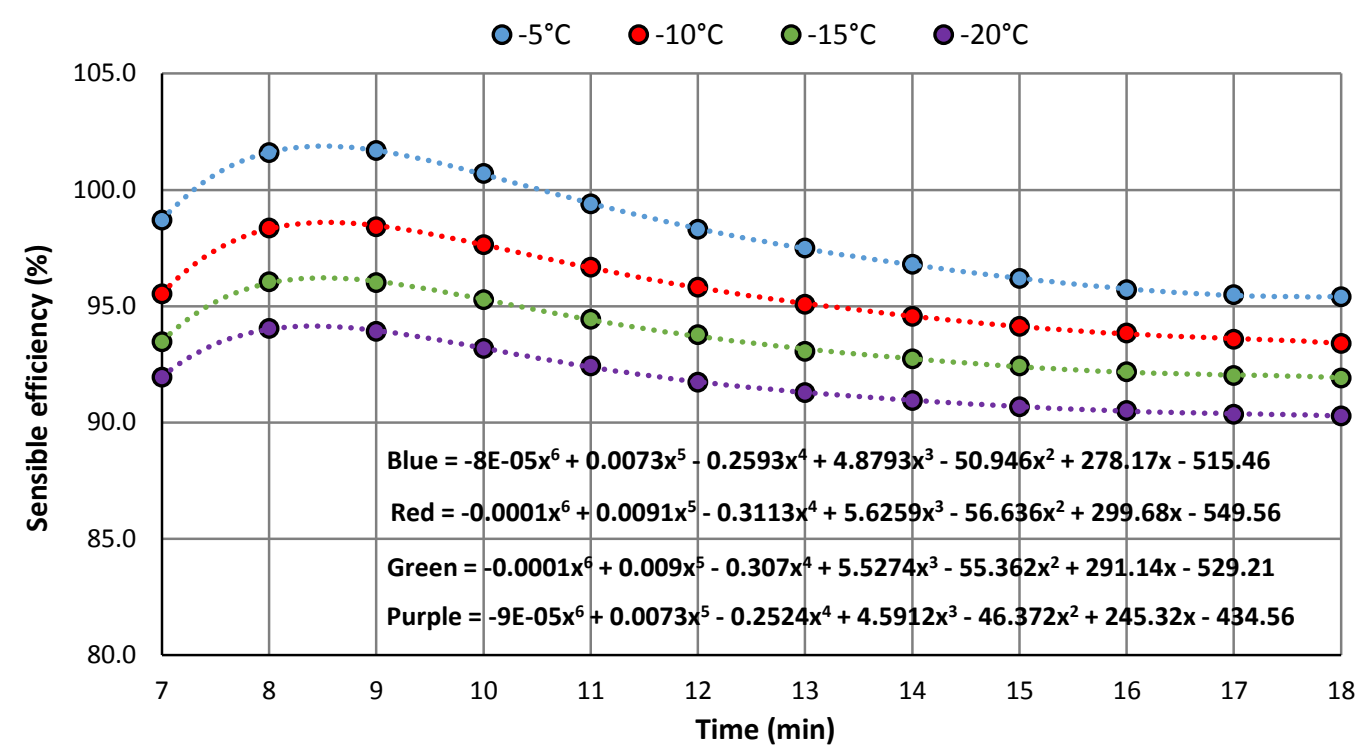

Figure 6.6.16 - Sensible efficiency patterns for different $\mathrm{AT}_{f i}(\mathrm{HRV}): 2^{\text {nd }}$ section

The defrost principle of the HRV is slightly different from that of the ERV, as shown in Figure 6.6.10. In this case, the melted ice/frost on the exhaust channel could be influential to the humidity of the recirculated air. Follow the same procedure presented in Section 6.5.2, three generalized curves were developed which will be implemented into the HRV model to simulate the effect due to the increased humidity. Figure 6.6.17 and 6.6.18 show the generalized polynomial curves and equations for latent efficiency during and after defrost cycle.

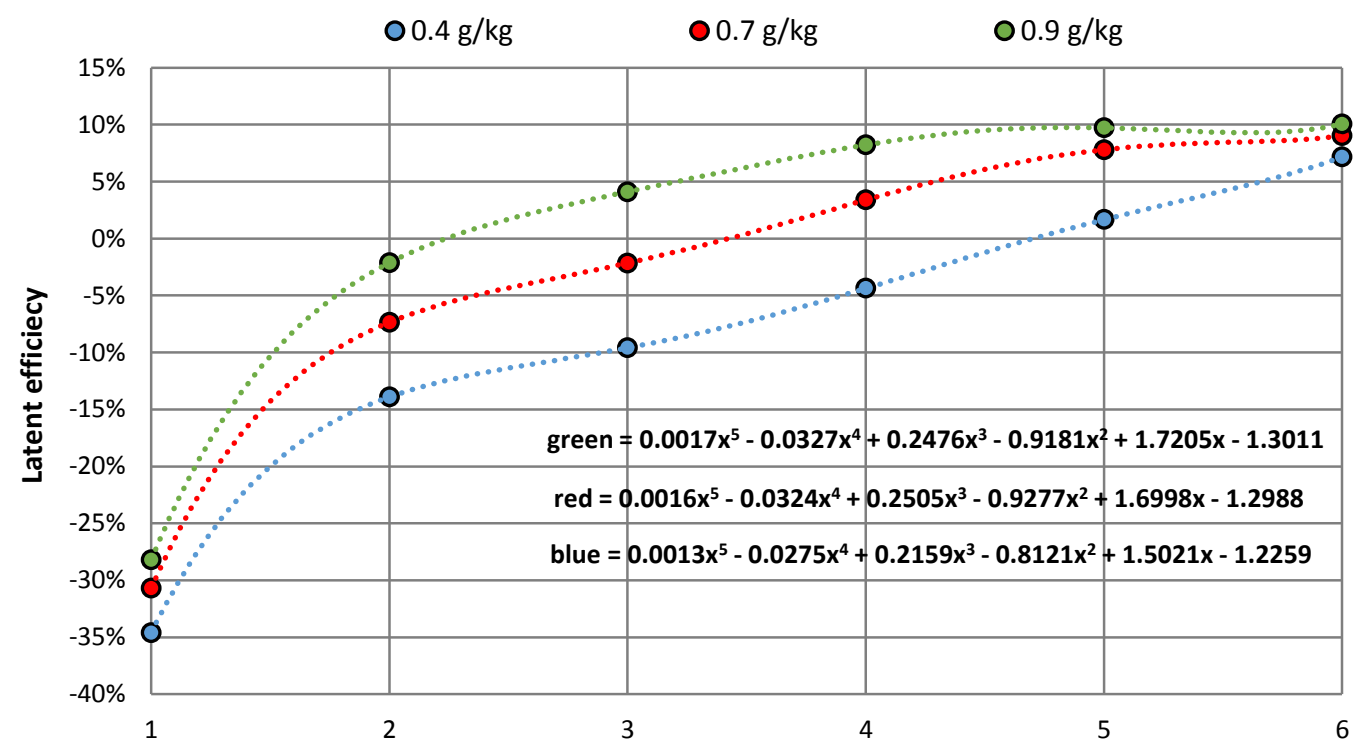

Figure 6.6.17 - Latent efficiency patterns for different $w_{f i}(\mathrm{HRV}): 1^{\text {st }}$ section 


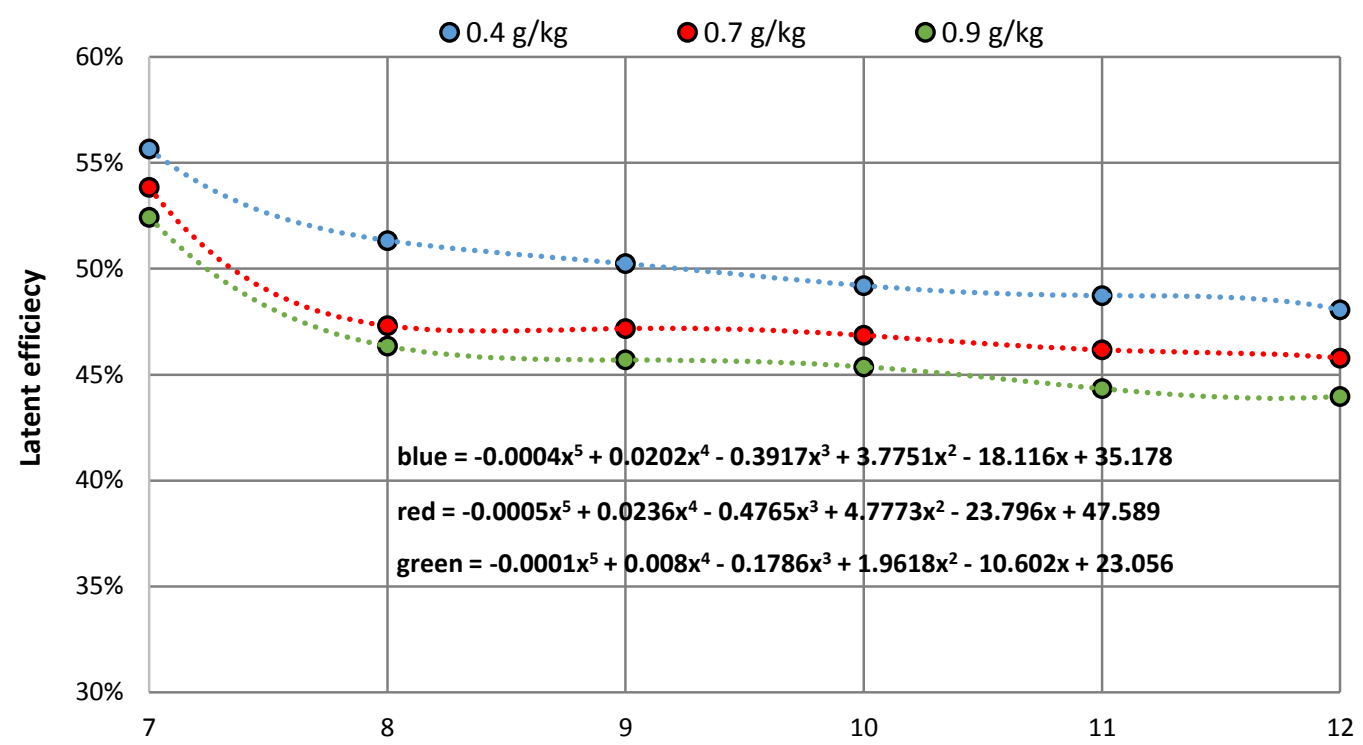

Figure 6.6.18 - Latent efficiency patterns for different $w_{f i}(\mathrm{HRV}): 2^{\text {nd }}$ section

Throughout the analysis of observations during defrost cycle, four conclusions can be generated:

1. The observations confirmed that the sensible heat within the recirculated exhaust air was stored in the core surfaces during defrost cycle, and was slowly releasing afterwards.

2. The recirculated exhaust air initially experienced a substantial drop in temperature due to larger area required to be heated up, and it increased afterwards.

3. The defrost cycle activated when the inlet fresh air temperature hit $-5^{\circ} \mathrm{C}$, and it ran 6 minutes for every 20 minutes normal operation.

4. The defrost cycle was a routine that activated every 20 minutes, and hence, the built-in defrost cycle was more likely to be used to prevent large scale ice formation.

\section{Section 6.7 - Winter Experiment: Sensible and Enthalpy Core Freezing}

Due to the delay of winter experiments as well as the concern of rising in outside temperature in the spring (March), the scheduled experiments for core freezing were planned to be suspended. Fortunately, the severe cold weather condition in the early March 2014 resolved all the problems. The experiments for core freezing commenced on March $1^{\text {st }}$ and end on March $4^{\text {th }}$. In this period, the built-in air temperature sensors of both the HRV and ERV were disconnected, in other words, defrost controls were deactivated. Changes in system thermal performance due to core freezing were observed through investigating the exhaust airflow rate, and latent efficiency for a range of weather conditions at $86 \mathrm{cfm}$ (low-speed) and $112 \mathrm{cfm}$ (high-speed) for the ERV, and $147 \mathrm{cfm}$ for the HRV. 
During the test period for $86 \mathrm{cfm}$, the inlet fresh air temperature ranged from $-3.7^{\circ} \mathrm{C}$ to $-18.16^{\circ} \mathrm{C}$, and the exhaust air remained nearly constant at $23^{\circ} \mathrm{C}$ (average relative humidity of air: $30.2 \%$ ). As shown in Figure 6.7.1, there was no sign indicating a noticeable fall in the hourly exhaust airflow rate. Even when the $\mathrm{AT}_{f i}$ dropped below $-16^{\circ} \mathrm{C}$, e.g., at around 3/2 23:02, the airflow dropped only by $3.2 \mathrm{cfm}$ (from $85.85 \mathrm{cfm}$ to $82.66 \mathrm{cfm}$ ). Similarly, Figure 6.7 .2 shows that the sensible efficiency decreased from $77 \%$ to eventually $72 \%$, while the latent efficiency remained nearly constant. Therefore, results imply that the scale of ice formation was small during the test period.

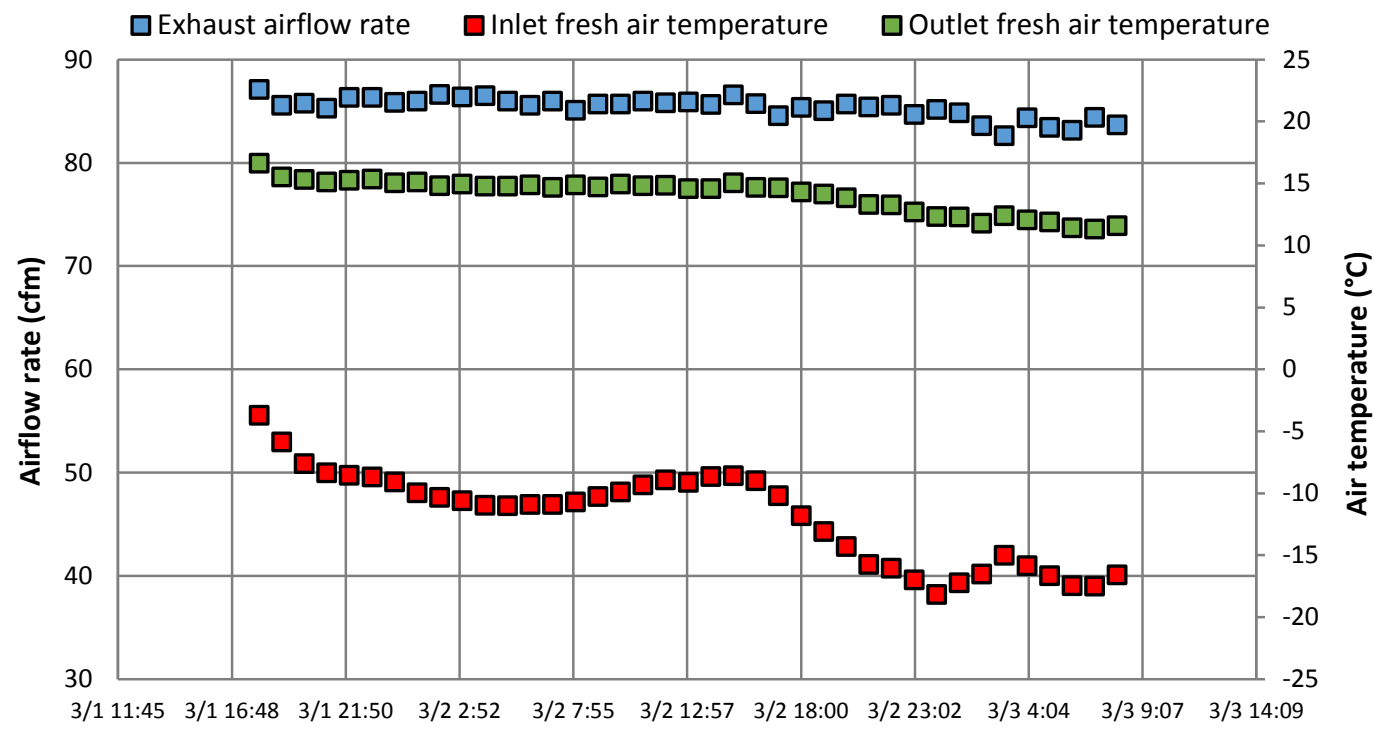

Figure 6.7.1 - Hourly exhaust airflow rate without defrost control (ERV $86 \mathrm{cfm}$ )

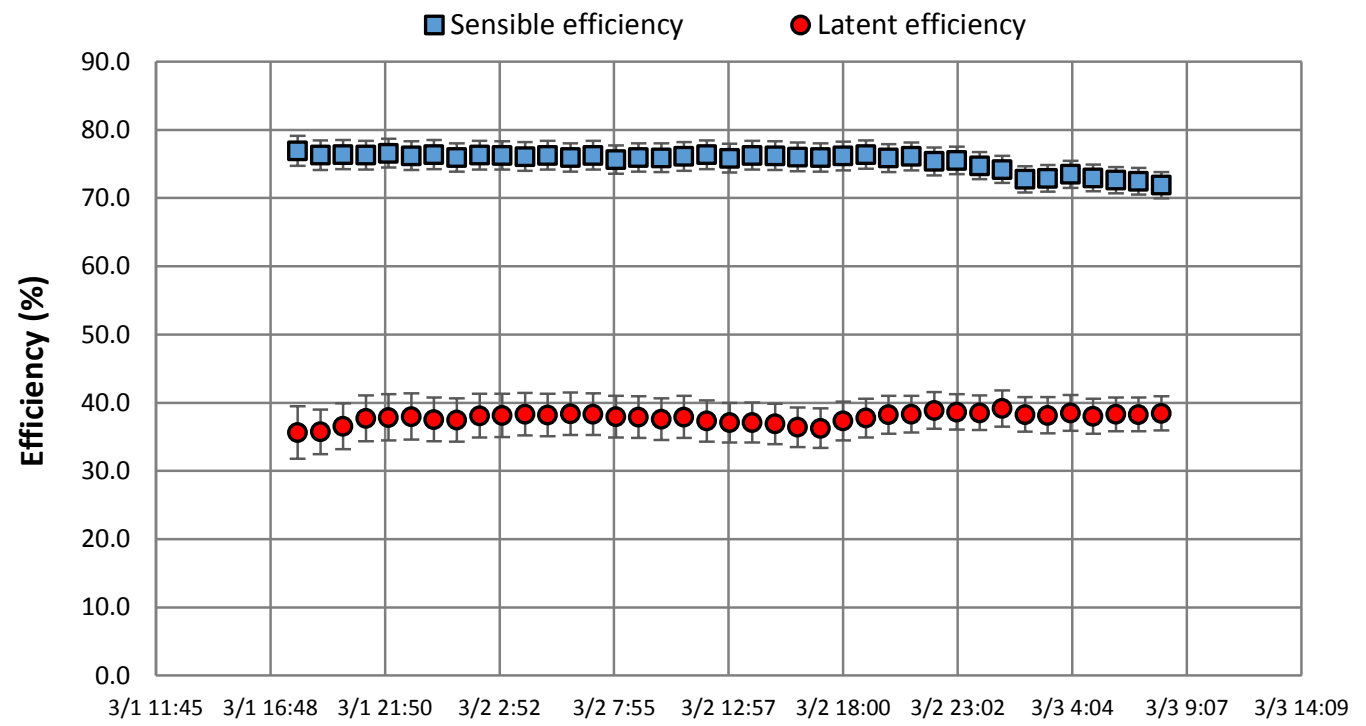

Figure 6.7.2 - Hourly sensible and latent efficiencies without defrost control (ERV $86 \mathrm{cfm}$ ) 
The high-speed experiment was conducted on between March $3^{\text {th }}$ evening to March $4^{\text {th }}$ Morning, where the $\mathrm{AT}_{f i}$ varied from $-11^{\circ} \mathrm{C}$ to $-20^{\circ} \mathrm{C}$. The average exhaust air was $22.4^{\circ} \mathrm{C}$ with an average relative humidity of $33 \%$. As shown in Figure 6.7.3, the exhaust airflow rate started to fall when $\mathrm{AT}_{f i}$ reached $-16^{\circ} \mathrm{C}$ and it continued for 9 hours along with the $\mathrm{AT}_{f i}$, to a level of $77 \mathrm{cfm}$ at $-20^{\circ} \mathrm{C}$. Therefore, the scale of ice formation was much greater than that of low-speed. As $\mathrm{AT}_{f i}$ increased above $-16^{\circ} \mathrm{C}$, there was a sign of recovery of exhaust airflow rate due to the decreased condensate. In Figure 6.7.4, both the sensible and latent efficiencies were reduced accordingly, to a level of $50 \%$ and $28 \%$ respectively, and during this time the outlet fresh air temperature was very low.

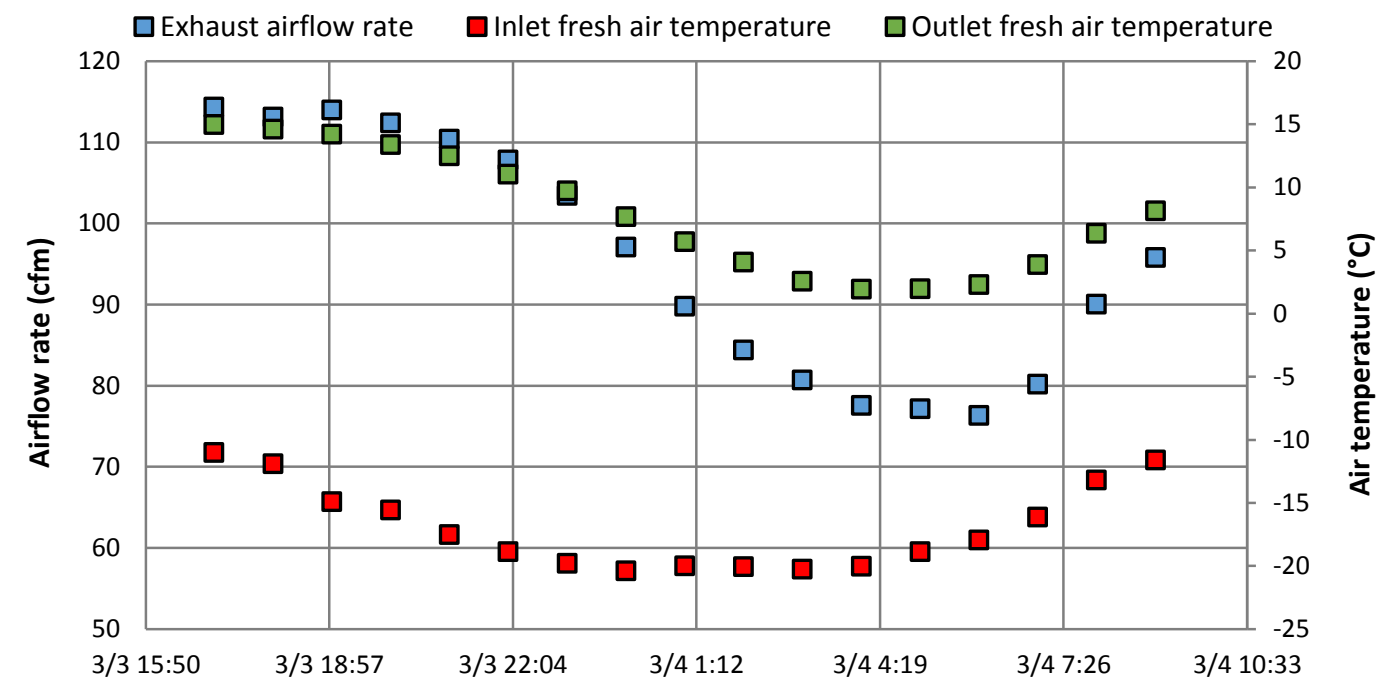

Figure 6.7.3 - Hourly exhaust airflow rate without defrost control (ERV $112 \mathrm{cfm}$ )

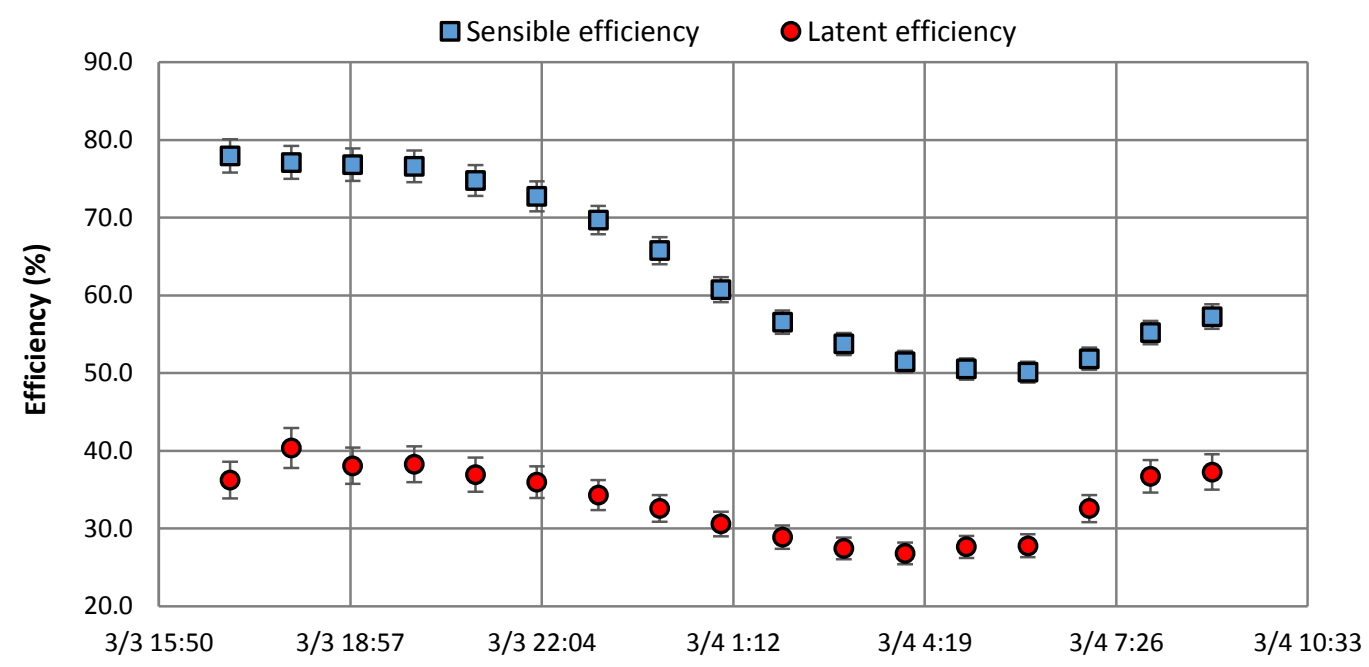

Figure 6.7.4 - Hourly sensible and latent efficiencies without defrost control (ERV $112 \mathrm{cfm}$ ) 
The same experiment was also carried out for the HRV within the ASH-A. In the meantime, the inlet fresh air temperature varied from $-11^{\circ} \mathrm{C}$ to $-20^{\circ} \mathrm{C}$, while the average exhaust air temperature and humidity were $23.5^{\circ} \mathrm{C}$ and $27.1 \%$ respectively. Unfortunately, due to the uncontrollable shut down of the Microsoft SQL Server after the working hour, a small portion of data was missing. As shown in Figure 6.7.5, the decrease in the $\mathrm{AT}_{f i}\left(\right.$ from $-10.8^{\circ} \mathrm{C}$ at $3 / 316: 00$ to $-20.3^{\circ} \mathrm{C}$ at $3 / 4$ 3:00) caused both the exhaust airflow rate and outlet fresh air temperature to be $18 \mathrm{cfm}$ and $9.5^{\circ} \mathrm{C}$ lower, respectively. As the $\mathrm{AT}_{f i}$ increased (from $-20.3^{\circ} \mathrm{C}$ at $3 / 43: 00$ to $-11.8^{\circ} \mathrm{C}$ at $3 / 49: 00$ ), the exhaust airflow rate increased negligibly. During the ascent stage, the sensible efficiency decreased from $65 \%$ to $49 \%$, and remained nearly constant despite the change in the inlet fresh air temperature (see Figure 6.7.6). Therefore, the effect attributed to ice formation was more severe inside the HRV. Consequently, the high-speed test $(180 \mathrm{cfm})$ was not performed due to the concern of damaging the sensible core attributed to ice expansion.

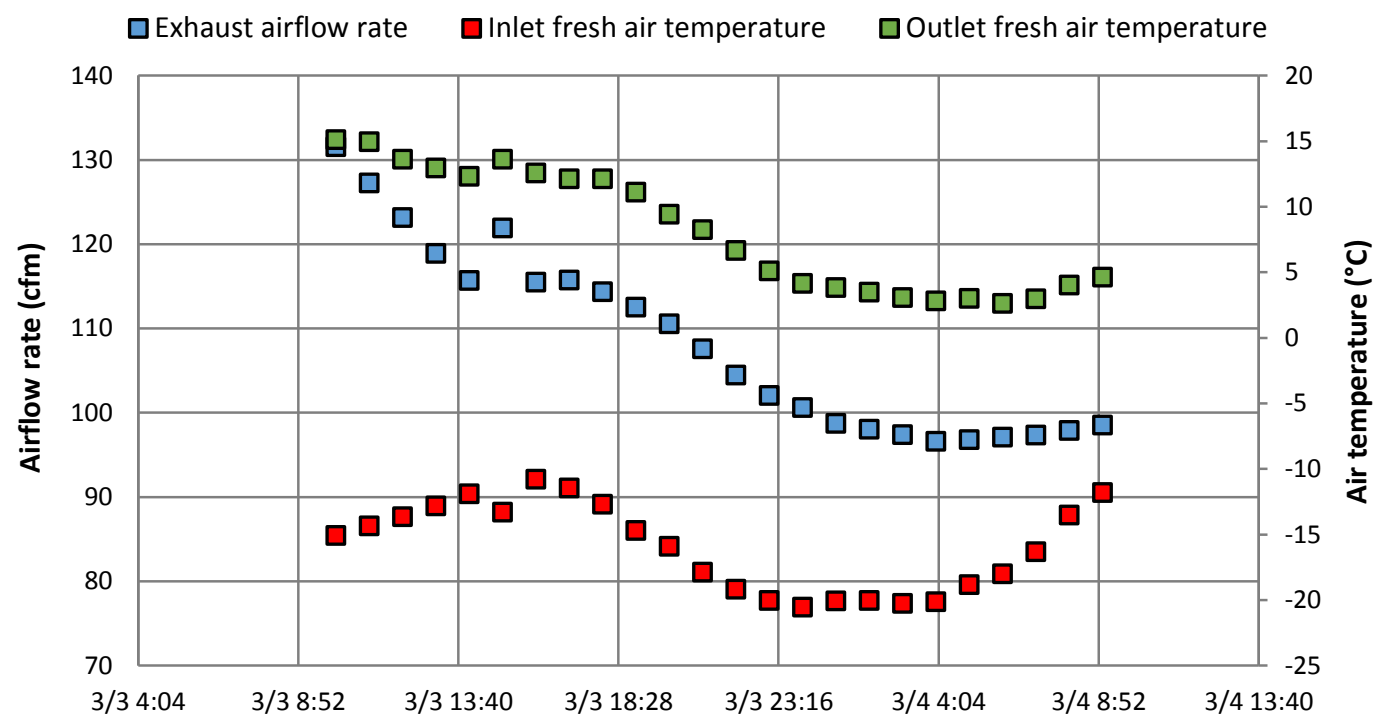

Figure 6.7.5 - Hourly temperature and airflow rate without defrost control (HRV $147 \mathrm{cfm}$ ) 


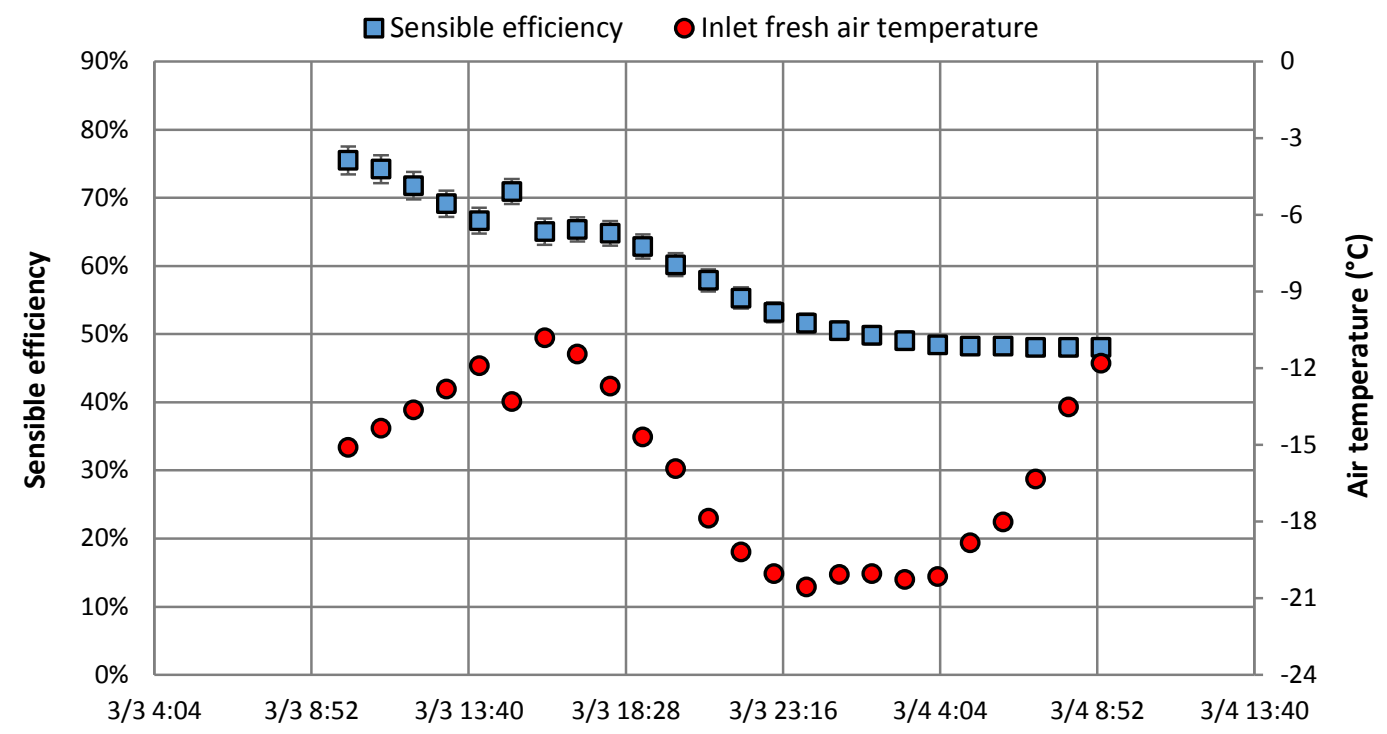

Figure 6.7.6 - Hourly sensible efficiency without defrost control (HRV $147 \mathrm{cfm}$ )

According to the observations from the core freezing experiments, the following conclusion can be made:

1. For enthalpy core, the scale of ice formation and therefore its effects were small at low-speed mode. This phenomenon implied that nearly all of the removed moisture from the exhaust airstream was transferred to the fresh airstream rather than condensed.

2. At high-speed mode, however, the scale and effect of ice formation increased significantly due to the increase in mass flow rate, and hence, greater amounts of condensed moisture from the exhaust air stream.

3. There was a sign of recovery of airflow rate and efficiency for the ERV as the $\mathrm{AT}_{f i}$ became warmer. For the HRV, the increase in exhaust airflow and sensible efficiency were very small. 


\section{Chapter 7 - Study of Defrost Cycle Using TRNSYS Simulation (Spring 2014)}

\section{Section 7.1 - Model Improvements}

In order to model the control strategy of the defrost control, it is necessary to count the number of minutes that the defrost control has continued during a given time step. In addition, after a certain number of minutes, it is necessary to reset the counter to zero (e.g., at the end of defrost control, 6 minutes). To achieve these manipulations during simulation, the data storage routine was used. There are two types of data storage: "Static" and "Dynamic" storage. In the former, the stored value is not going to change throughout the simulation or that is going to change only sporadically. In the later, the final calculated value is stored and used as the new initial value for the next time step (Solar Energy Laboratory, 2012). In this case, the "Dynamic" storage subroutine suits the purpose, and hence, was chosen to be used in the models. Once the outside air temperature exceeds the threshold temperature of defrost control, countdown begins and lasts for 32 (ERV) or 20 (HRV) minutes. The defrost operation is then initiated if the countdown is completed, and hence, the onset depends on the final value from the previous time step. Once defrost proceeds, another countdown begins and lasts for 6 minutes. At the end, the stored values are set to zero until the next activation.

The "InterpolateData" is a utility routine used to interpolate the data from external text based files that have been assigned a FORTRAN local unit number in the TRNSYS input file. Nevertheless, this routine is not able to extrapolate beyond the range of data given in the external file (Solar Energy Laboratory, 2012). As a result, this routine was not adopted. In the FORTRAN program, the following relationship was implemented to obtain, through interpolation or extrapolation, the sensible and latent efficiencies at each time step during and after defrost control:

$$
\frac{x_{2}-x_{1}}{x_{3}-x_{1}}=\frac{y_{2}-y_{1}}{y_{3}-y_{1}}
$$

Given two points $\left(\mathrm{x}_{1}, \mathrm{y}_{1}\right)$ and $\left(\mathrm{x}_{3}, \mathrm{y}_{3}\right)$, the linear interpolation $\left(\mathrm{x}_{2}, \mathrm{y}_{2}\right)$ is the straight line between these points. Alternatively, given two points $\left(\mathrm{x}_{2}, \mathrm{y}_{2}\right)$ and $\left(\mathrm{x}_{3}, \mathrm{y}_{3}\right)$, the linear extrapolation $\left(\mathrm{x}_{1}, \mathrm{y}_{1}\right)$ is the straight extended from these points.

\section{Section 7.2 - Heat Recovery Ventilator (Toronto)}

From the results of the data collection, two curves were developed illustrating the sensible and latent efficiencies of the HRV with respect to the inside-outside air conditions. These curves were used to validate the HRV model by matching the TRNSYS hourly efficiency of the HRV at various 
operating conditions with the developed curves from the data. The settings of simulation remained the same as of Chapter 5, except the fresh and exhaust airflow rates were adjusted to $147 \mathrm{cfm}(69.1$ L/s). Figure 7.2.1 left panel illustrates the TRNSYS hourly sensible efficiency of the HRV at different inside-outside temperature differences in January. It is clear that the trend of the HRV model matched the linearly curve of the observed data. Figure 7.2.1 right panel shows the hourly latent (due to leakage) efficiency at different inside-outside humidity differences. The absence of humidifier resulted in small difference in humidity between inside and outside environment, which shifted the trend to the left side of the figure. The trend of the model still followed that of the experimental finding.
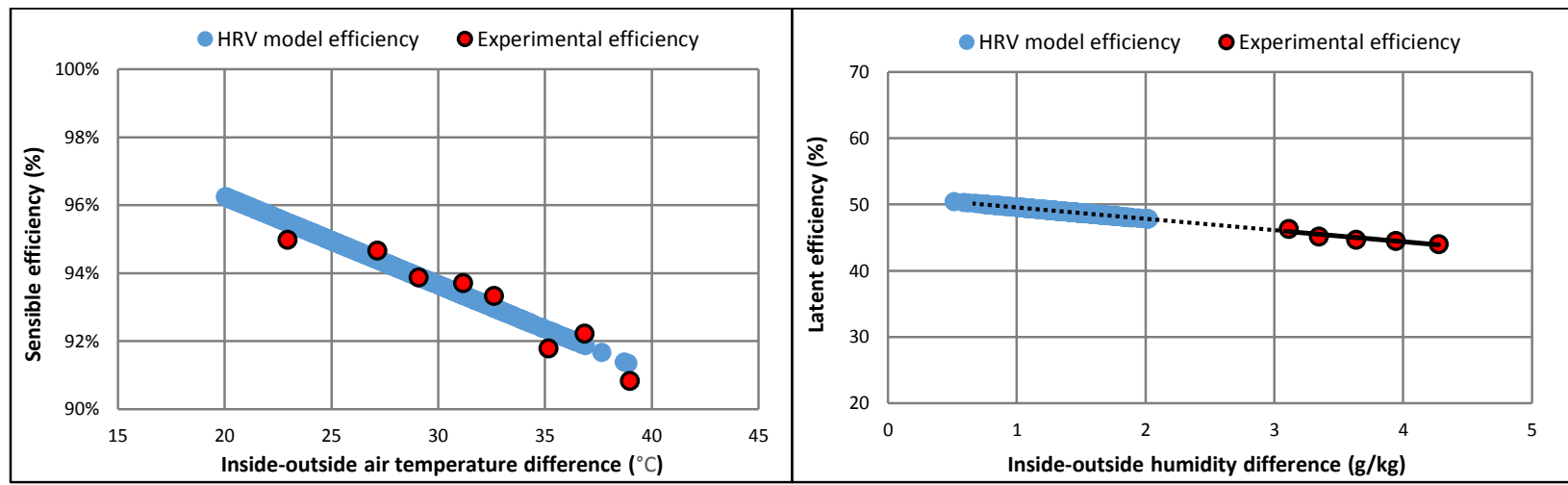

Figure 7.2.1 - HRV efficiency validation: left panel for sensible efficiency, right panel for latent efficiency

As shown in Figure 7.2.2, the house consumed a total of 5515.7 $\mathrm{kWh}$ per year for heating without heat recovery. In comparison, the HRV w/o defrost control was capable of reducing $1493.1 \mathrm{kWh}$ heat consumption per year, equivalent to $27.1 \%$ energy savings. Table 7.2.1 lists the house heating demand/consumption differences between the HRV with and without defrost cycle. The frequency of defrost cycle was counted to be 307.1 hours per year, of which 250 hours $(81.4 \%)$ belonged to cold winter months (Dec., Jan., and Feb.). In addition, the house heating demand ${ }^{29}$ was $74.7 \mathrm{kWh}$ lower, of which $80.7 \%$ belonged to the coldest months. In terms of the rate of energy savings ${ }^{30}$, however, defrost cycles resulted in an average rate of $0.017 \mathrm{kWh}$ per hour defrost cycle in the cold winter months and $0.082 \mathrm{kWh}$ per hour for the others. It is clear that the benefit of air recirculation became smaller for the cold winter month. According to Safa (2012), the disadvantage of airsource heat pump is the decrease of heat output and COP in colder climates, the study of air-source

\footnotetext{
${ }^{29}$ TRNSYS NTYPE 32 (SQHEAT) outputs the sum of sensible heating demand.

${ }^{30}$ Rate of Energy Savings = Energy Savings / Frequency.
} 
heat pump in the TRCA Archetype Sustainable House-A revealed that the ASHP heating COP ranged from 1.79 at $-19^{\circ} \mathrm{C}$ to 5.0 at around $9^{\circ} \mathrm{C}$. Therefore, the ASHP without a supplemental heat source could be challenging at low outdoor temperature because it could not meet the setpoint temperature, and hence, the effect of warm air recirculation was smaller than transitional months (Nov., Mar., and Apr.). Annual fan power draw was found to be higher, which offset the savings. In Chapter 6, the fan power draw of the HRV was found to be $0.21 \mathrm{~kW}$ and $0.46 \mathrm{~kW}$ for normal and defrost operations, respectively. This means that for every 0.0167 hour (or 1 minute) defrosting, the HRV consumes extra $0.0042 \mathrm{kWh}$. In other words, the HRV consumed extra $76.8 \mathrm{kWh}$ per year for defrost controls.

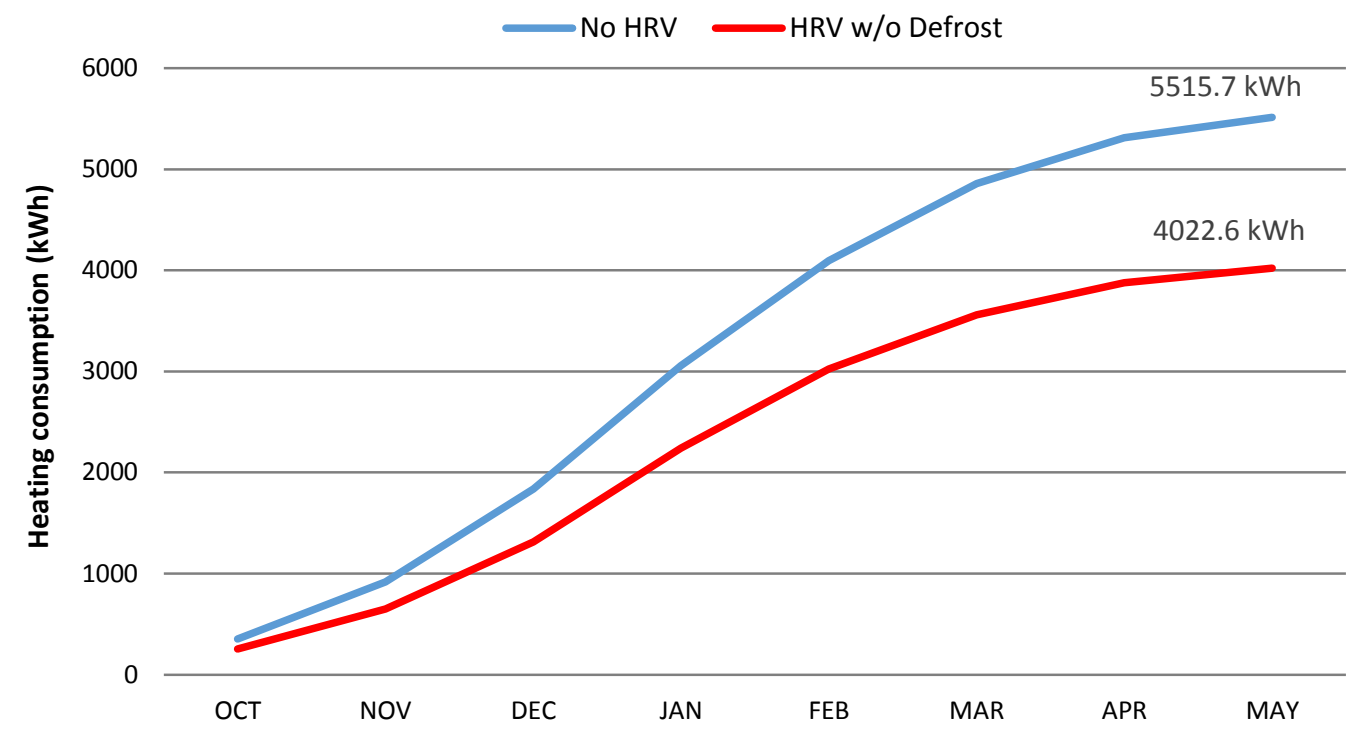

Figure 7.2.2 - Heating consumption with and without HRV

Table 7.2.1 - Heating demand and consumption of the house (HRV)

\begin{tabular}{cccc}
\hline Months & $\begin{array}{c}\text { Frequency } \\
\text { (hour) }\end{array}$ & $\begin{array}{c}\text { Heating Demand } \\
\text { Reduction (kWh) }\end{array}$ & $\begin{array}{c}\text { Energy Savings } \\
\text { (kWh) }\end{array}$ \\
\hline Oct. & 0 & 0 & 0 \\
\hline Nov. & 11.2 & 2.7 & 0.7 \\
\hline Dec. & 64.4 & 15.2 & 1.3 \\
\hline Jan. & 102.0 & 24.9 & 1.6 \\
\hline Feb. & 83.6 & 20.2 & 1.2 \\
\hline Mar. & 42.9 & 10.8 & 2.2 \\
\hline Apr. & 3.0 & 0.8 & 0.4 \\
\hline May & 0 & 0 & 0.0 \\
\hline Sum & 307.1 & 74.7 & 7.4 \\
\hline
\end{tabular}


Figure 7.2.3 shows the house humidity (average, maximum, and minimum) w/ and w/o defrost control. Again, due to the leakage inside the HRV, the house overall humidity increased (w/ HRV), e.g., the average humidity in Jan. increased from $17 \% \mathrm{RH}$ to $20.8 \% \mathrm{RH}$ at $21^{\circ} \mathrm{C}$. After defrost cycle, the reintroduction of indoor air as well as the introduction of the melted ice as form of moisture caused the house minimum humidity to be higher, e.g., the minimum humidity in Jan. increased from $12.9 \% \mathrm{RH}$ to $15.2 \% \mathrm{RH}$ at $21^{\circ} \mathrm{C}$. Overall, defrost cycle reduced the chance of ice formation and increased fan energy use as a result of high-speed ventilation. Also, the house humidity was improved, leading to better comfort level of occupants. Air recirculation could significantly deteriorated indoor air quality, especially for HRV houses because sensible core usually has higher threshold temperature of freezing, and hence, higher demand in defrost control for preventive purpose, e.g., re-entering smelling air and/or carbon dioxide $\left(\mathrm{CO}_{2}\right)$ from kitchen, washroom, and attic.

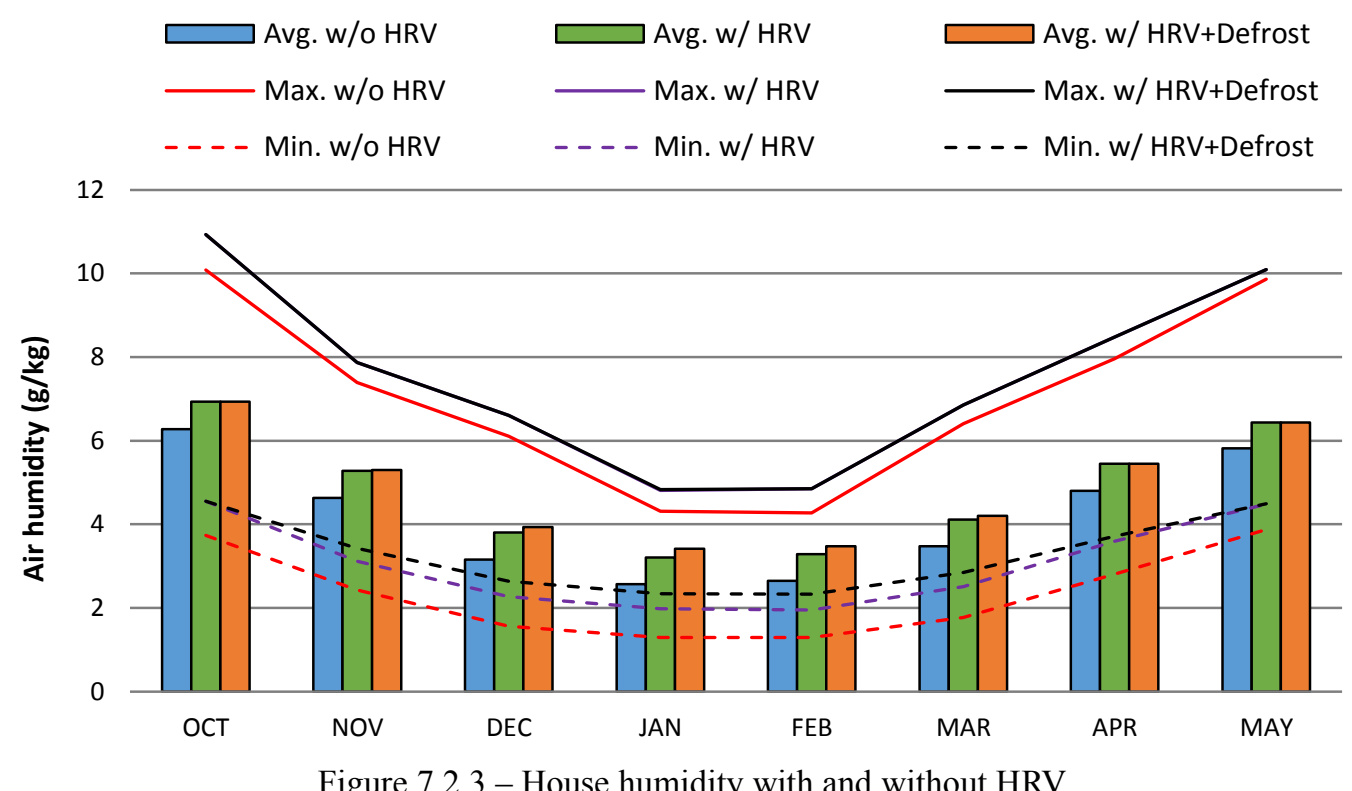

Simulations were also computed using both constant- and empirical-efficiency approaches in order to determine the practicality of the results presented in Chapter 5. Figure 6.6.8 shows that the calculated efficiencies vary from $91 \%$ to $95 \%$, taking average and set the constant efficiency to be 93\%. As shown in Figure 7.2.4 left panel, empirical-efficiency approach (w/o defrost) resulted in $1457 \mathrm{kWh}$ energy savings, corresponding to $26.4 \%$ reduction in heating consumption. In comparison, constant-efficiency approach resulted in $1493.1 \mathrm{kWh}$, equivalent to $27.1 \%$ reduction in heating consumption. Therefore, the overall difference is $36 \mathrm{kWh}$, which is about $2.4 \%$ 
$(36 \div 1493.1)$ of the total savings. Figure 7.2.4 right panel shows the monthly heating consumption, it is clear that the monthly differences are very small, especially during transitional months (Oct., Nov., and May) where the demand of heat recovery is lower due to higher outside air temperature. Overall, the constant-efficiency approach provides a good overview of the potential of heat/energy recovery ventilators.
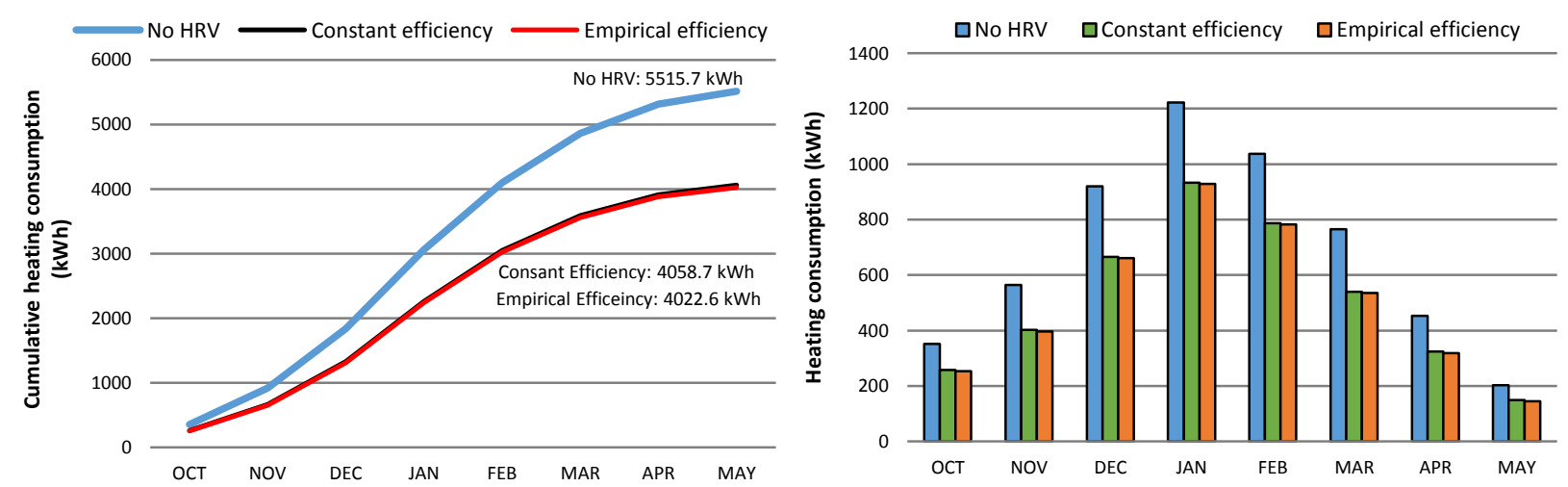

Figure 7.2.4 - Cumulative (left panel) and monthly (right panel) heating consumption based on constant and empirical approaches

\section{Section 7.3 - Energy Recovery Ventilator (Toronto)}

From the results of the data collection, two curves were developed illustrating the sensible and latent efficiencies of the ERV with respect to the inside-outside difference. These curves were used to validate the ERV model by matching the TRNSYS hourly efficiency of the ERV at various operating conditions with the developed curves from the data. The settings of simulation remained the same as of Chapter 5, except the fresh and exhaust airflow rates were adjusted to $88 \mathrm{cfm}$ (41.4 L/s). As shown in Figure 7.3.1 left panel, the trend of the ERV model matched the linearly curve of the observed data. Figure 7.3.1 right panel shows the hourly latent efficiency at different insideoutside humidity differences. Again, the absence of humidifier resulted in very small difference in humidity between inside and outside environment, which shifted the trend to the left side of the figure. The trend of the model, however, still followed that of the experimental finding. 

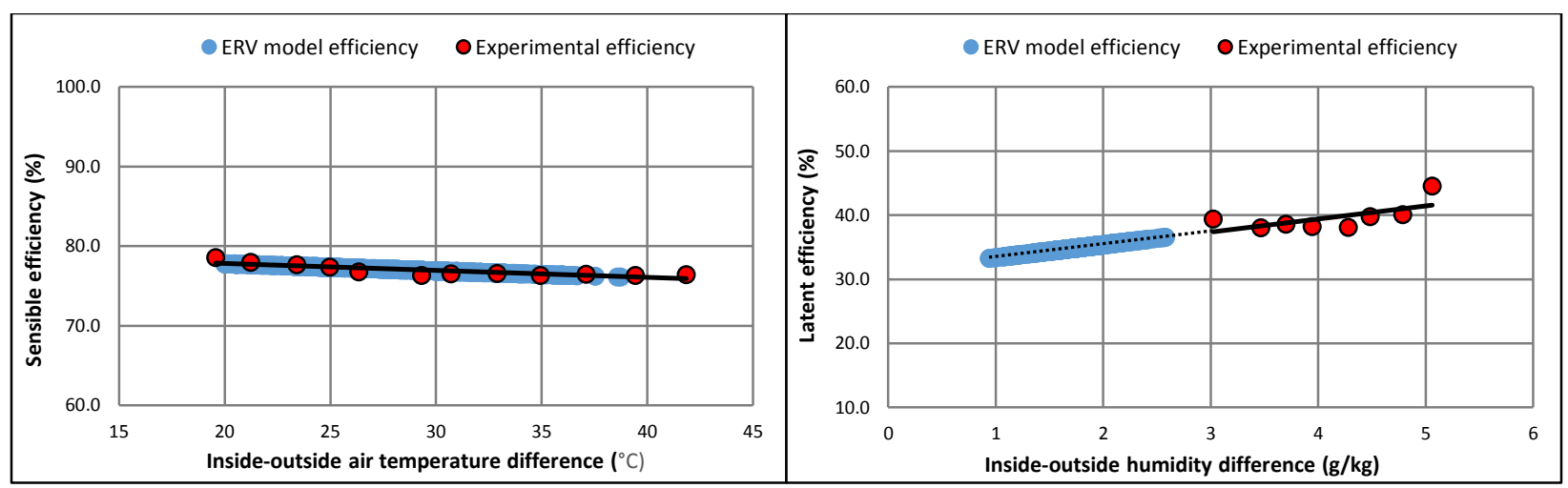

Figure 7.3.1 - ERV efficiency validation: left panel for sensible efficiency, right panel for latent efficiency

As shown in Figure 7.3.2, the house with the ERV was found to be consuming a total of 4764.2 kWh per year for heating without energy recovery. In comparison, the ERV w/o defrost control was capable of reducing $640.7 \mathrm{kWh}$ heat consumption per year, equivalent to $13.4 \%$ energy savings. Table 7.3.1 shows the monthly house heating demands with and without defrost cycle. The frequency of defrost cycle was counted to be 879 times per year, or alternatively, 87.9 hours per year. Therefore, the demand was about one third of the HRV, and the house heating demand was $43.2 \mathrm{kWh}$ lower. In terms of heating consumption, however, defrost cycles led to $0.06 \mathrm{kWh}$ energy savings. This can be explained by the fact that:

1. The threshold temperature of defrost cycle is $-10^{\circ} \mathrm{C}$, leading to lower demand of defrost control.

2. The low heat output of the ASHP in the cold winter months resulted in insignificant effect on the energy savings.

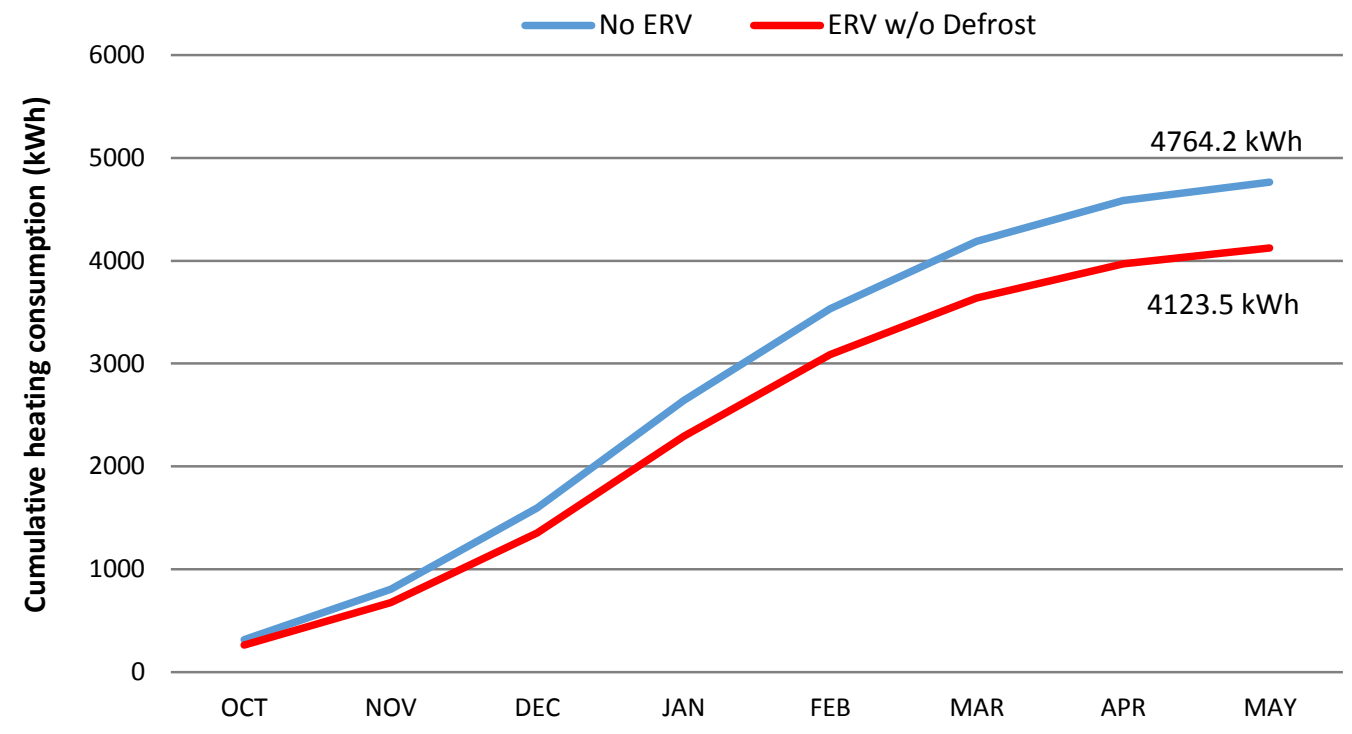

Figure 7.3.2 - Heating consumption with and without ERV 
Table 7.3.1 - Heating demand of the house (ERV)

\begin{tabular}{cccc}
\hline Months & $\begin{array}{c}\text { Frequency } \\
\text { (hour) }\end{array}$ & $\begin{array}{c}\text { Heating Demand } \\
\text { Reduction (kWh) }\end{array}$ & $\begin{array}{c}\text { Energy Savings } \\
\text { (kWh) }\end{array}$ \\
\hline Oct. & 0 & 0 & 0 \\
\hline Nov. & 0 & 0 & 0 \\
\hline Dec. & 14.8 & 7.2 & 0 \\
\hline Jan. & 37.8 & 18.5 & 0.06 \\
\hline Feb. & 30.0 & 15.0 & 0 \\
\hline Mar. & 5.3 & 2.5 & 0 \\
\hline Apr. & 0 & 0 & 0 \\
\hline May & 0 & 0 & 0 \\
\hline Sum & 87.9 & 43.2 & 0.06 \\
\hline
\end{tabular}

In Chapter 6, the fan power draw of the ERV was found to be $0.08 \mathrm{~kW}$ and $0.123 \mathrm{~kW}$ for normal and defrost operations, respectively. This means that for every 0.0167 hour (or 1 minute) defrosting, the HRV consumes extra $0.00072 \mathrm{kWh}$. Alternatively, the ERV consumed extra $3.8 \mathrm{kWh}$ per year for defrost controls. Figure 7.3.3 shows the house humidity (average, maximum, and minimum) w/ and w/o defrost control. Again, defrost cycles caused the house minimum humidity to be higher as similar to the HRV, e.g., the minimum humidity in Jan. increased from $15.4 \% \mathrm{RH}$ to $17.7 \% \mathrm{RH}$ at $21^{\circ} \mathrm{C}$. Also, there were no change of humidity in Nov. and Apr. because the lower threshold temperature and so defrost control was not needed. Overall, defrost cycle reduced the chance of ice formation and slightly increased fan energy use as a result of high-speed ventilation. In addition, the lower demand in defrost cycle could reduce the chance of deteriorating indoor air quality due to air recirculation.

Simulation was also carried out for $-5^{\circ} \mathrm{C}$ defrost threshold temperature, as similar to the HRV. The sensible efficiency during and after defrost cycle was obtain using extrapolation. The defrost frequency and house heating consumption are given in Table 7.3.2 for both $-5^{\circ} \mathrm{C}$ and $-10^{\circ} \mathrm{C}$ threshold temperatures. At $-5^{\circ} \mathrm{C}$, the frequency of defrost control increased by more than twofold, from 69.6 to 207.9 hours. In addition, the frequency was found to be respectively 43.4 hours for Dec. and 69.4 hours for Jan. with respectively $0.6 \mathrm{kWh}$ and $0.9 \mathrm{kWh}$ energy savings, and hence, the average energy-saving rate was $0.013 \mathrm{kWh}$ per hour defrost cycle. In transitional months, e.g., Nov. and Mar., the average rate was estimated to be $0.041 \mathrm{kWh}$ per hour defrost cycle. It can be seen that the increase in the demand of defrost cycle in warmer months resulted in higher energy savings, which is consistent to the HRV. 


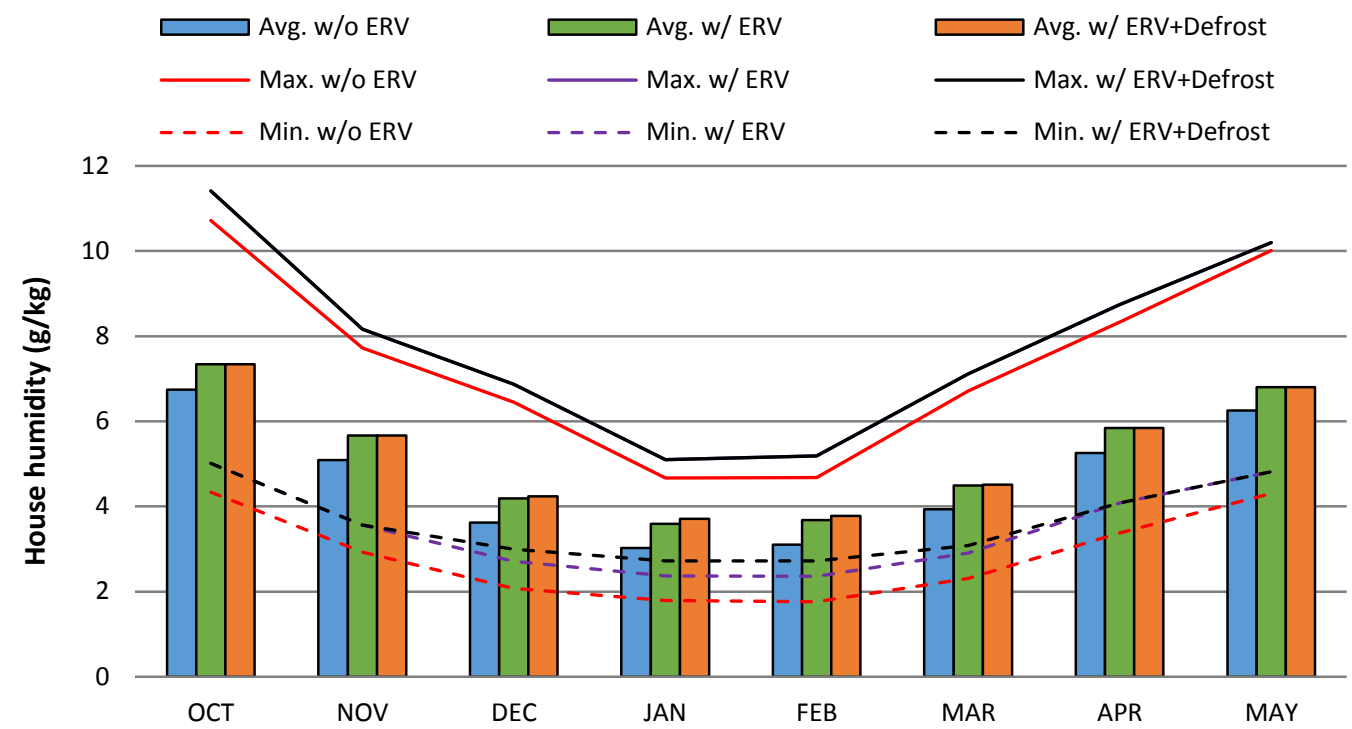

Figure 7.3.3 - House humidity with and without ERV

Table 7.3.2 - Comparison between two difference threshold temperature of defrost cycle

\begin{tabular}{|c|c|c|c|c|}
\hline \multirow[b]{2}{*}{ Months } & \multicolumn{2}{|c|}{$-10^{\circ} \mathrm{C}$ threshold temperature } & \multicolumn{2}{|c|}{$-5^{\circ} \mathrm{C}$ threshold temperature } \\
\hline & $\begin{array}{c}\text { Frequency } \\
\text { (hour) }\end{array}$ & $\begin{array}{c}\text { Energy Savings } \\
\text { (kWh) }\end{array}$ & $\begin{array}{c}\text { Frequency } \\
\text { (hour) }\end{array}$ & $\begin{array}{c}\text { Energy Savings } \\
\text { (kWh) }\end{array}$ \\
\hline Oct. & 0 & 0 & 0 & 0 \\
\hline Nov. & 0 & 0 & 7.4 & 0.4 \\
\hline Dec. & 14.8 & 0 & 43.4 & 0.7 \\
\hline Jan. & 37.8 & 0.06 & 69.4 & 0.9 \\
\hline Feb. & 30.0 & 0 & 56.9 & 0.8 \\
\hline Mar. & 5.3 & 0 & 28.8 & 1.3 \\
\hline Apr. & 0 & 0 & 2.0 & 0.2 \\
\hline May & 0 & 0 & 0 & 0 \\
\hline Sum & 87.9 & 0.06 & 207.9 & 4.3 \\
\hline
\end{tabular}

Section 7.4 - System performance in Selected Canadian Regions

\subsection{1 - Continental Climate}

The HRV and ERV models were then simulated in other Canadian regions to obtain the seasonal performance. Along with the metropolitan Toronto weather file used in the initial simulation, the weather files of Edmonton and Montreal were also utilized in the model. The heating degree days of the selected region are given in Table A.4.3. The heating consumption of the HRV and ERV hours are shown in Figures 7.4.1. The HRV reduced 1780.7 kWh (or 20.1\%) and 1585.3 kWh (23.7\%) heating consumption in Edmonton and Montreal, respectively. Therefore, the higher the HDD the lower the percent energy savings because the heat loss attributed to ventilation would 
become less important. Similarly, the ERV reduced $603.2 \mathrm{kWh}$ (or 7.7\%) heating consumption in Edmonton and $613.1 \mathrm{kWh}(10.6 \%)$ in Montreal.

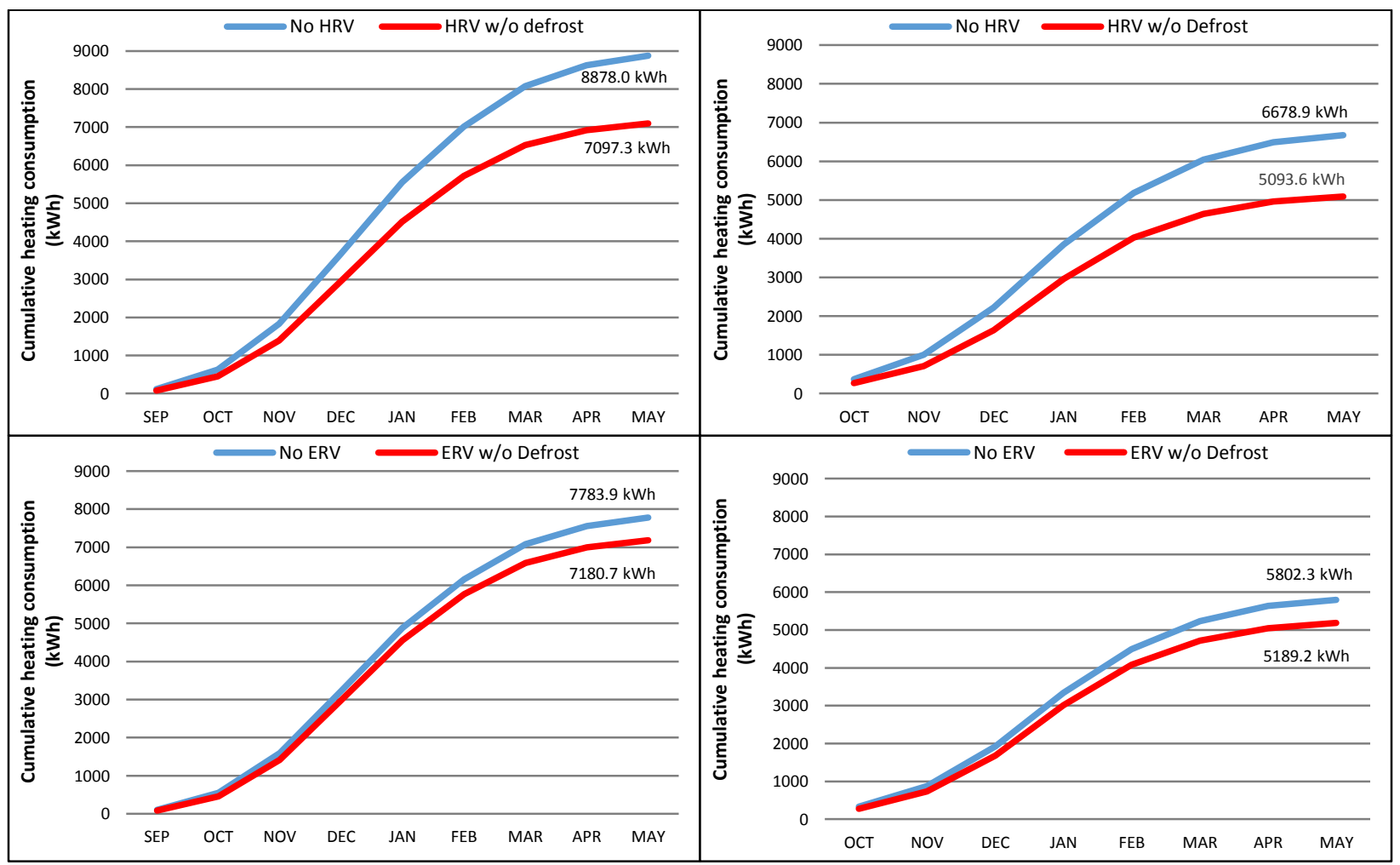

Figure 7.4.1 - House heating consumption: left panels - Edmonton, right panels - Montreal

The frequency of and energy savings attributed to defrost cycle in the selected Canadian regions are given in Table 7.4.1 for Edmonton and Table 7.4.2 for Montreal. The HRV frequently required defrost control, and the demand increased along with the HDD. Warm air recirculation resulted in a decrease in heating demand of $161.91 \mathrm{kWh}$, however, the total amounts of energy that it saved varied depending on the outside temperature, e.g., defrost control of the HRV resulted in $5.35 \mathrm{kWh}$ savings in Edmonton, and $5.69 \mathrm{kWh}$ in Montreal, and so it appears that the lower the HDD the higher the saved energy. In addition, the rated energy savings also revealed that the energy saved per defrost cycle in the coldest months was much smaller than the others, e.g., the HRV resulted in a rated saving of $0.005 \mathrm{kWh}$ per hour defrost cycle January, and $0.014 \mathrm{kWh}$ per hour in March. Again, this can be explained by the fact that the ASHP in the TRCA Archetype Sustainable HouseA performed poorly in cold days (Safa, 2012). Therefore, the effect of the reduced heating demand attributed to warm air recirculation was very small in cold days. 
Table 7.4.1 - Saved energy attributed to defrost control (Edmonton)

\begin{tabular}{ccccccc}
\hline Months & \multicolumn{2}{c}{ HRV } & & \multicolumn{2}{c}{ ERV } \\
\cline { 2 - 7 } & $\begin{array}{c}\text { Frequency } \\
\text { (hour) }\end{array}$ & $\begin{array}{c}\text { Heating } \\
\text { Demand } \\
(\mathrm{kWh})\end{array}$ & $\begin{array}{c}\text { Energy Savings } \\
(\mathrm{kWh})\end{array}$ & $\begin{array}{c}\text { Frequency } \\
\text { (hour) }\end{array}$ & $\begin{array}{c}\text { Heating } \\
\text { Demand } \\
(\mathrm{kWh})\end{array}$ & $\begin{array}{c}\text { Energy Savings } \\
(\mathrm{kWh})\end{array}$ \\
\hline Sep. & 0 & 0 & 0 & 0 & 0 & 0 \\
\hline Oct. & 25.6 & 5.96 & 0.34 & 0 & 0 & 0 \\
\hline Nov. & 78.4 & 19.40 & 0.46 & 38.0 & 18.19 & 0.030 \\
\hline Dec. & 109.9 & 38.33 & 0.54 & 61.0 & 34.92 & 0.085 \\
\hline Jan. & 124.9 & 41.50 & 0.68 & 61.1 & 34.78 & 0.034 \\
\hline Feb. & 112.6 & 31.94 & 1.37 & 49.0 & 26.08 & 0.031 \\
\hline Mar. & 68.6 & 17.25 & 0.98 & 28.8 & 14.34 & 0.030 \\
\hline Apr. & 34.2 & 7.38 & 0.96 & 1.7 & 0.65 & 0 \\
\hline May & 0.2 & 0.15 & 0.02 & 0 & 0 & 0 \\
\hline Sum & 554.4 & 161.91 & 5.35 & 239.6 & 129.0 & 0.21 \\
\hline
\end{tabular}

Table 7.4.3 - Saved energy attributed to defrost control (Montreal)

\begin{tabular}{ccccccc}
\hline Months & \multicolumn{2}{c}{ HRV } & & \multicolumn{2}{c}{ ERV } \\
\cline { 2 - 7 } & $\begin{array}{c}\text { Frequency } \\
\text { (hour) }\end{array}$ & $\begin{array}{c}\text { Heating } \\
\text { Demand } \\
(\mathrm{kWh})\end{array}$ & $\begin{array}{c}\text { Energy Savings } \\
(\mathrm{kWh})\end{array}$ & $\begin{array}{c}\text { Frequency } \\
\text { (hour) }\end{array}$ & $\begin{array}{c}\text { Heating } \\
\text { Demand } \\
(\mathrm{kWh})\end{array}$ & $\begin{array}{c}\text { Energy Savings } \\
(\mathrm{kWh})\end{array}$ \\
\hline Oct. & 0 & 0 & 0 & 0 & 0 & 0 \\
\hline Nov. & 16.4 & 3.80 & 0.60 & 1.4 & 0.52 & 0 \\
\hline Dec. & 102.1 & 25.12 & 1.30 & 32.8 & 16.30 & 0.059 \\
\hline Jan. & 125.8 & 34.97 & 1.17 & 57.0 & 29.96 & 0.002 \\
\hline Feb. & 105.1 & 27.13 & 0.95 & 47.3 & 23.96 & 0.028 \\
\hline Mar. & 52.5 & 12.83 & 1.51 & 11.3 & 5.49 & 0.027 \\
\hline Apr. & 0.9 & 0.26 & 0.16 & 0 & 0 & 0 \\
\hline May & 0 & 0 & 0 & 0 & 0 & 0 \\
\hline Sum & 402.8 & 104.12 & 5.69 & 149.8 & 60.37 & 0.116 \\
\hline
\end{tabular}

\subsection{1 - Temperate Climate}

The HRV and ERV models were also simulated in other regions that have temperature climate. In this study, the weather file of Vancouver was utilized in the models. As shown in Figures 7.4.2, the HRV used in Vancouver reduced $961 \mathrm{kWh}$ (or 28.9\%) and the ERV reduced $440.9 \mathrm{kWh}(15.2 \%)$ heating consumption. Since Vancouver has a HDD of 3003 (see Table A.4.3), and hence, the percent savings were higher than the regions that have a continental climate, e.g., Edmonton, Montreal and Toronto. Table 7.4.4 shows the demand of defrost control of the HRV and ERV. The HRV used in this region rarely needed a defrost control because the TMY2 weather file reports a minimum temperature of $-5.7^{\circ} \mathrm{C}$. The total defrost frequency was found to be 2.5 hours, resulting 
in a decrease in the heating consumption of $0.39 \mathrm{kWh}$. In comparison, the results also revealed that the ERV used in Vancouver can perform properly without the defrost cycle (demand was 0) because the threshold temperature is much $4.3^{\circ} \mathrm{C}$ lower than the regional minimum temperature.
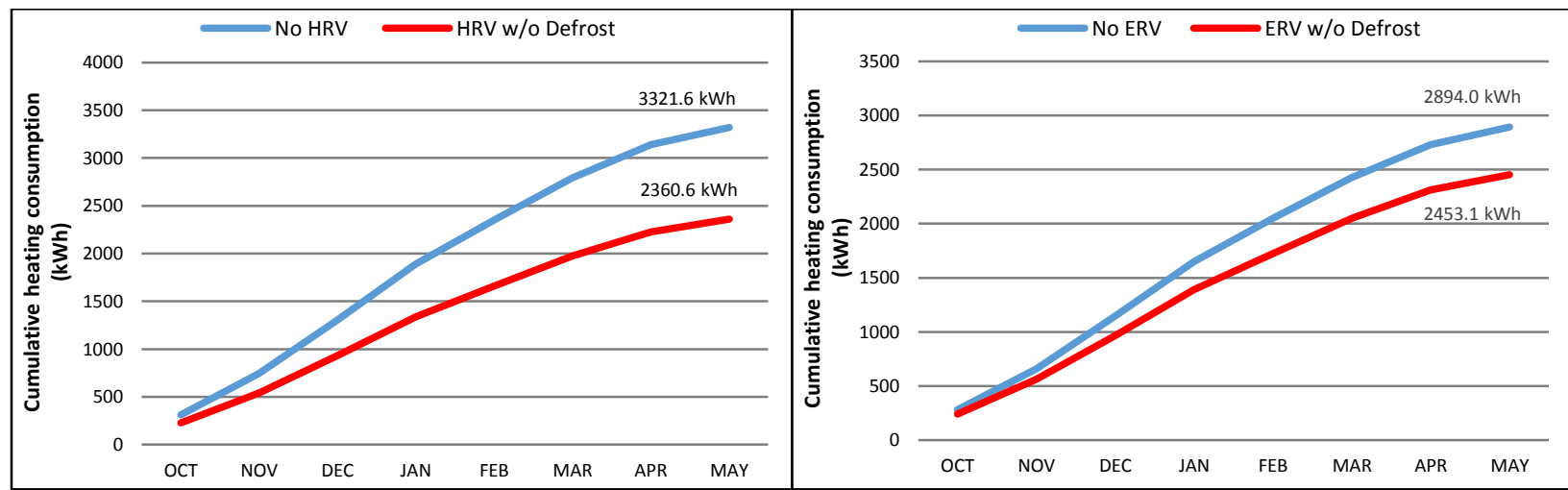

Figure 7.4.2 - House heating consumption in Vancouver: left panels - HRV, right panels - ERV

Table 7.4.4 - Saved energy attributed to defrost control (Vancouver)

\begin{tabular}{ccccccc}
\hline Months & \multicolumn{3}{c}{ HRV } & \multicolumn{3}{c}{ ERV } \\
\cline { 2 - 7 } & $\begin{array}{c}\text { Frequency } \\
\text { (hour) }\end{array}$ & $\begin{array}{c}\text { Heating } \\
\text { Demand } \\
(\mathrm{kWh})\end{array}$ & $\begin{array}{c}\text { Energy Savings } \\
(\mathrm{kWh})\end{array}$ & $\begin{array}{c}\text { Frequency } \\
\text { (hour) }\end{array}$ & $\begin{array}{c}\text { Heating } \\
\text { Demand } \\
(\mathrm{kWh})\end{array}$ & $\begin{array}{c}\text { Energy Savings } \\
(\mathrm{kWh})\end{array}$ \\
\hline Oct. & 0 & 0 & 0 & 0 & 0 & 0 \\
\hline Nov. & 0 & 0 & 0 & 0 & 0 & 0 \\
\hline Dec. & 0.3 & 0.081 & 0.033 & 0 & 0 & 0 \\
\hline Jan. & 2.2 & 0.643 & 0.357 & 0 & 0 & 0 \\
\hline Feb. & 0 & 0 & 0 & 0 & 0 & 0 \\
\hline Mar. & 0 & 0 & 0 & 0 & 0 & 0 \\
\hline Apr. & 0 & 0 & 0 & 0 & 0 & 0 \\
\hline May & 0 & 0 & 0 & 0 & 0 & 0 \\
\hline Sum & 2.5 & 0.722 & 0.39 & 0 & 0 & 0 \\
\hline
\end{tabular}

\section{Section 7.5 - Heat and Energy Recovery Ventilator}

Comparisons were also made among the conventional (ERV) and novel ( $\left.\mathrm{HERV}_{c}\right)$ designs using the empirical sensible and latent efficiencies from the experimental results. The sensible efficiency of the HRV, due to the effects of leakage, was not used in this case. Instead, the HERV $\mathrm{H}_{c}$ model was modified using both the sensible and latent efficiencies of the ERV. The ventilation rate was $88 \mathrm{cfm}(41.4 \mathrm{~L} / \mathrm{s})$, and other setting remained unchanged. Figure 7.5.1 left panel shows the monthly house heating consumption for different methods of mechanical ventilation. It is clear that the difference of heating between the HERV and ERV were very small, e.g., the total difference was only $41.7 \mathrm{kWh}$. This could be explained by the non-linearly relationship between the sensible 
efficiency and energy savings, as studied in Section 5.5.2. In terms of humidity level, it is clear that the humidity of the house with the HERV tended to be better controlled towards the setpoint $\left(21^{\circ} \mathrm{C}\right.$ and $\left.30 \% \mathrm{RH}\right)$. Throughout the simulation of the heating period, the sensible efficiency of both sensible and enthalpy cores varied from $77 \%$ to $80 \%$, with an average of $78.5 \%$. In contrast, the latent efficiency varied from $30.2 \%$ to $37.7 \%$, with an average of $34.3 \%$. Applying these average efficiencies, and simulation was performed to investigate the potential difference between the constant-efficiency-based and empirical-based models. Figure 7.5.2 shows the monthly heating consumption between the two cases in Toronto. The total difference was about $0.2 \mathrm{kWh}$, which was mainly attributed to the mutual dependency of the two cores that led to the smaller effect of the increased sensible efficiency. Figure 7.5.2 left panel reveals that the small deviation between the two models. Therefore, the use of constant-efficiency for the $\mathrm{HERV}_{c}$ provided a fair amount of insights that is considered relevant and informative in the literature.
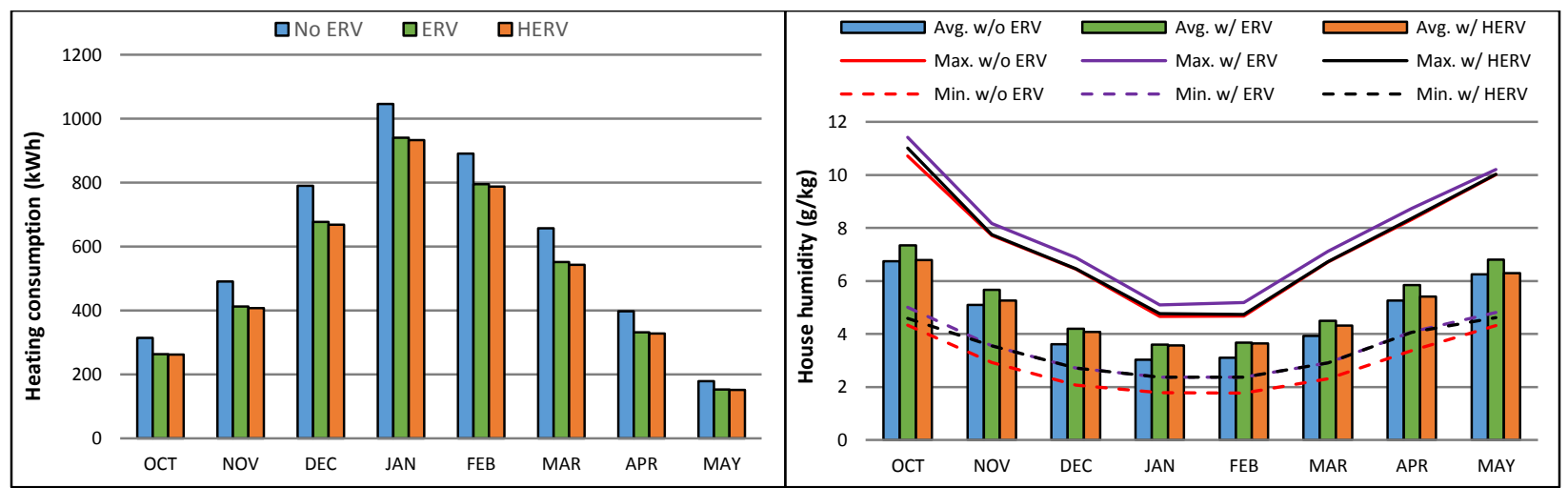

Figure 7.5.1 - Simulation results: left panel - heating consumption, right panel - house humidity
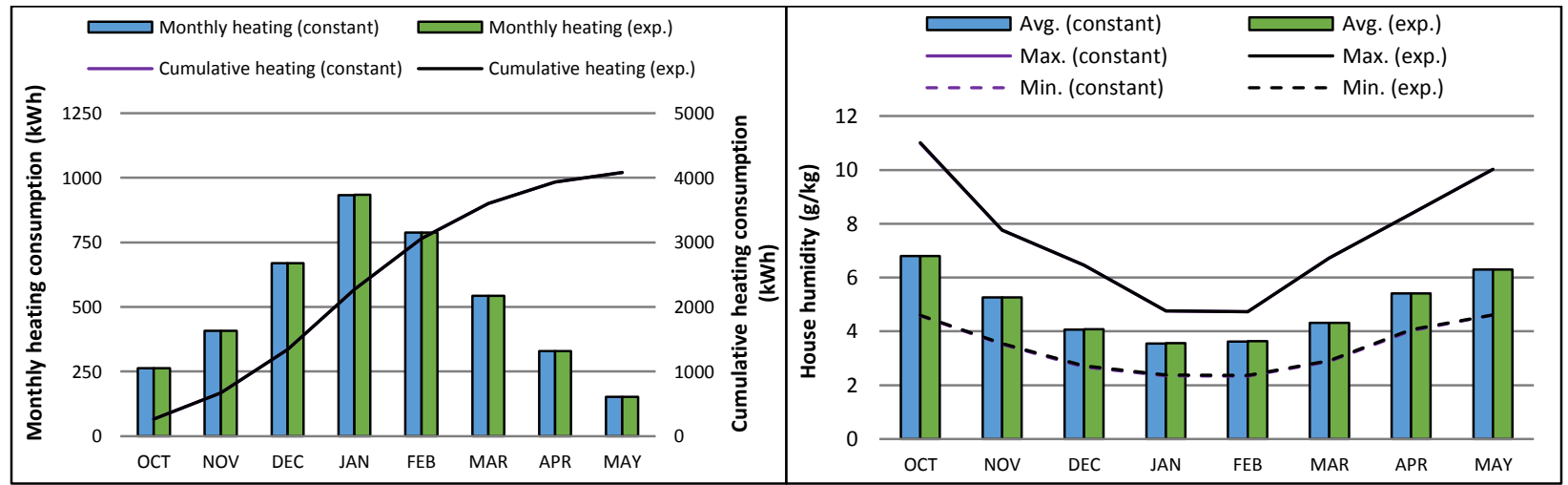

Figure 7.5.2 - Side-by-side comparison between constant-efficiency-based and empirical-based model: left panel heating consumption, right panel - house humidity (Toronto) 
Simulations were also carried out for regions other than Toronto with the same efficiencies, as shown in Figures 7.5.3 and 7.5.4. These results again reveal that the deviations between the two models were small even in a colder regions, e.g., Edmonton.
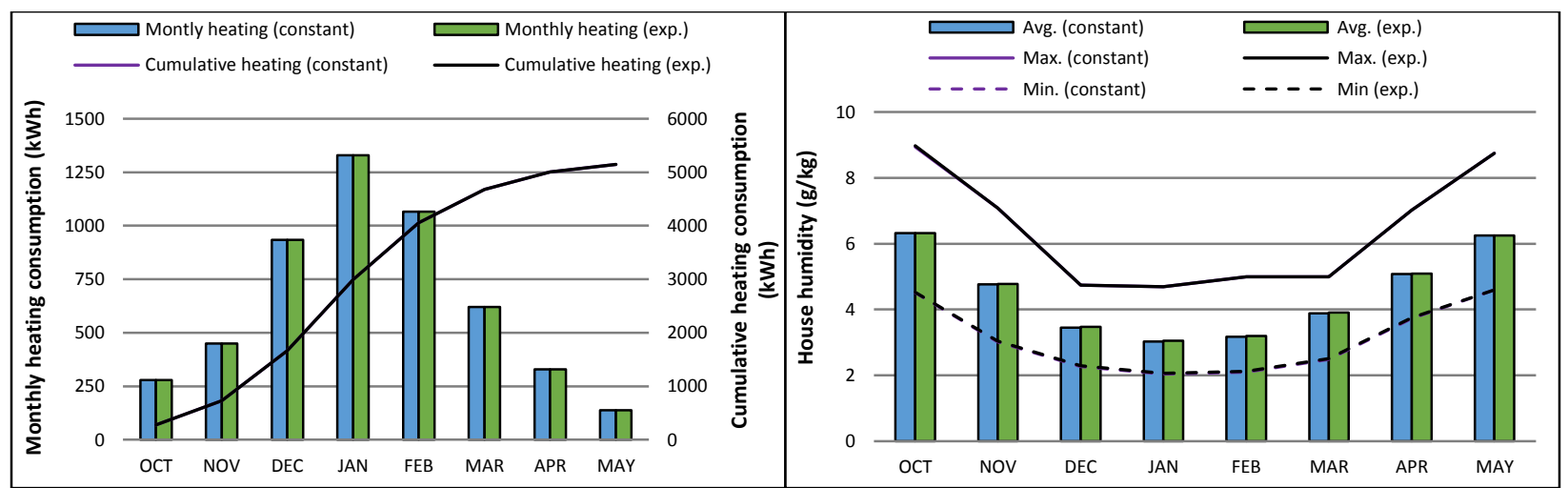

Figure 7.5.3 - Side-by-side comparison between constant-efficiency-based and empirical-based model: left panel heating consumption, right panel - house humidity (Montreal)

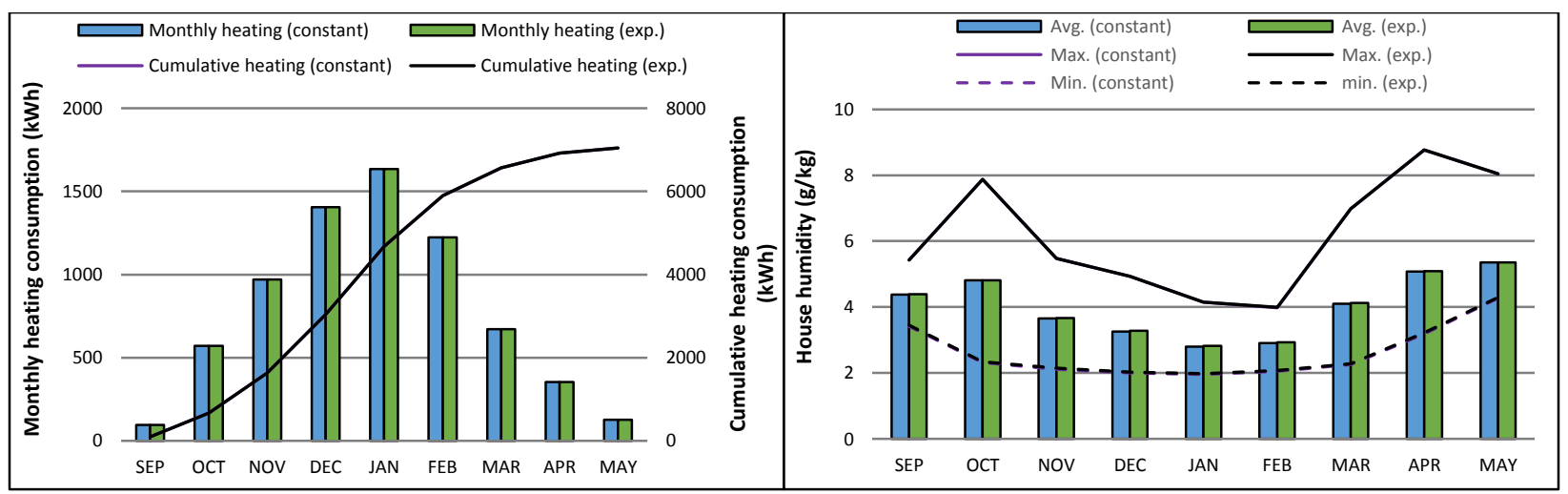

Figure 7.5.4 - Side-by-side comparison between constant-efficiency-based and empirical-based model: left panel heating consumption, right panel - house humidity (Edmonton) 


\section{Chapter \#8 - Summary and Conclusion}

\section{Section 8.1 - Author's Contributions}

This study focused on the feasibility analysis of a novel HVAC component: multiple-pass heat and energy recovery ventilator with integrated economizer control. This study consisted of three parts: steady-state analysis, dynamic simulation analysis, and experimental plus dynamic analysis. The Archetype Sustainable House project presented the opportunity to study the residential mechanical ventilators: heat recovery ventilator and energy recovery ventilator. In this regard, the author has performed and achieved the following tasks:

1. Development of an Excel-based analysis tool for quick estimation of system potential and payback period.

2. Involved in the development of the HERV conceptual design and the associated control strategies.

3. Development of system models for transient simulation program TRNSYS. Improvement and implementation of the control strategies.

4. Validating the collected data from all related sensors in the Archetype Sustainable House, through cross-checking and performing calibration.

5. Providing AT/RH calibration procedures and suggestions so that future students will have information on how to do it properly.

6. Assisted in and implemented the Data Acquisition (DAQ) system in the Archetype Sustainable House. Regular monitoring to insure the quality of the data collected during the test.

7. Determination of the errors of all measured and derived data through uncertainty analysis.

8. Thermal performance analysis of the HRV and the ERV within the Archetype Sustainable Houses, and comparing the results with the manufacturer's data and available publications.

9. Improvement of the developed TRNSYS system models with the collected and derived data. Analysis of the effects of defrost cycle on the ASHP electricity consumption.

\section{Section 8.2 - Summary and Conclusion}

With the current leaning towards airtight energy-efficient house, heat recovery ventilators (HRV) and/or energy recovery ventilators (ERV) have become extremely important for maintaining continuous mechanical ventilation, as well as reducing energy required to condition the incoming fresh air. The conventional designs, however, lack of flexibility to meet the house demands especially when experiencing distinct four seasons. The project presented the opportunity to study 
the feasibility of a novel HVAC component for residential use: a multiple-pass heat and energy recovery ventilator with integrated air-side economizer control (HERV). To achieve this study purpose, an Excel-based analysis tool was developed for a quick estimate of system payback period for a given house envelope and climate condition. In addition, TRNSYS 17 was utilized to model the HERV with a parallel- and counter-flow arrangements including controller. The HERVs were initially modeled using constant efficiency method which was intended to exclude the effect of heat gain from fan motor. The systems were simulated in different Canadian regions, and the feasibility and flexibility of each flow arrangement, built-in economizer control, and single core modes were investigated using results of the TRNSYS simulation. The results of presented study demonstrated that the HERV could be a viable and energy-efficient alternative to conventional systems for house ventilation applications. The constant-efficiency method was then doublechecked using the efficiency trends determined from the collected data to determine the potential deviation between the two approaches. Lastly, the HRV and ERV in the Archetype Sustainable Houses presented the opportunity to study and compare two conventional types of residential ventilation devices. The implementation of a comprehensive monitoring system allowed for detailed performance analyses of these equipment. Data was collected from the monitoring system every 5 seconds in a test period that was conducted over 4-5 weeks. Points of interest for both the HRV and ERV were the efficiency of both systems during normal and defrost operation, and the impacts of ice formation inside the core channels as there is no related literature. Further analysis was also done to investigate problems and potential improvements of the equipment. Throughout the study, the following conclusions were obtained:

\section{$>$ Steady-state analysis}

- The payback period of the HERV was estimated to be 9.6 years in Toronto and 16.1 years in Vancouver. In comparison, both the conventional designs resulted in longer payback period, e.g., the capital cost of the ERV can be recovered in 10.8 years for use in Toronto. Therefore, the HERV was recommended for regions that have continental climate or temperate climate.

- According to the operating cost ratios, the HERV was always making underwriting profit. The high initial investment $(\$ 2,500)$, however, caused the HERV to have longer payback period and hence be less attractive than the ERV. The initial investment was an estimate 
based on to the unit price of the each material needed to assemble the HERV, therefore, no economies of scale.

- The HERV was found to be less attractive for tropical climate, e.g., Miami, because such climate type can result in lower demand for heat exchange due to the relatively constant temperature of $18^{\circ} \mathrm{C}$ year-round. In contrast, the humid outside air more or less limited the overall demand to be dominated by latent heat exchange. In this case, the HERV became less competitive against the ERV due to the heavily reliance on enthalpy core.

- For a well-conditioned house, the ERV was found to be feasible for hot and humid region, e.g., payback period in Miami was estimated to be 1 year shorter than the HERV, while the HRV was more efficient in cold regions.

- The air-side economizer used in Toronto and Vancouver provided an opportunity to avoid unnecessary sensible heat recovery in summer, resulting in an additional cost savings that lowered the payback period of the HERV.

\section{$>$ Dynamic simulation analysis}

- For dual-core design, the counter-flow arrangement was the correct way to approach since both heating and cooling consumptions attributed to outside air were minimized throughout the year. In contrast, the parallel-flow arrangement tended to make a temperature balance between the fresh and exhaust airstreams, which resulted in an overall sensible efficiency lower than that of single core design. Therefore, the HERV with a parallel-flow arrangement degraded system's potential.

- In Canadian regions (e.g., Toronto and Iqaluit), the use of single core sensible and latent modes provided better control of the house humidity towards the setpoint. Therefore, the control logics developed for different modes were adequate. In comparison, the ERV was found to be doing more harm than good in summer.

- The HERV ${ }_{c}$ was found to be adaptable to various operating conditions.

- The use of dual cores reduced the impact resulting from the increased sensible efficiency. The more efficient the enthalpy core, the smaller the effect attributed to the sensible core, e.g., $30 \%$ difference in sensible efficiency of the sensible core resulted in a percent energy savings of less than $5 \%$.

- In terms of cooling consumption, both the HRV and ERV used in Toronto and Vancouver were found to be quite redundant; the higher the sensible efficiency the higher the cooling 
energy use. In contrast, the bypass mode of the $\mathrm{HERV}_{c}$ contributed to a decrease in cooling consumption of $13.4 \%$ in Toronto and $29.9 \%$ in Vancouver. The built-in economizer therefore improved the flexibility and competitiveness of the HERV for ventilation in summer months.

- High power vent during bypass mode further reduced the house cooling consumption and humidity, but the saved amounts gradually diminished at higher ventilation.

- The potential of free-cooling in Toronto was found to be higher than $90 \%$ at the midnight and early morning. The potential during daytime hours appeared to be more sensitive to the change of house setpoints, while the nighttime potential remained nearly the same.

\section{Experimental analysis}

- The winter experiments in both ASH-A and -B were operated successfully without serious defects during the test periods.

- The sensible efficiencies of the ERV in the TRCAASH-B remained nearly constant at $76 \%$ to $77 \%$ during the test periods despite the change of outside temperature. In addition, the latent efficiencies of the system varied from $38 \%$ to $44 \%$ along with the inside-outside air humidity difference.

- The sensible efficiencies of the HRV in the TRCA ASH-A varied between $91 \%$ and $95 \%$ throughout the test periods, and hence, exhibited to be more sensitive to the change of outside air temperature than the ERV. Heat gains from cross-leakage and fan motor were the major causes.

- The defrost cycle of the ERV was found to be activated only if outside temperature dropped below $-10^{\circ} \mathrm{C}$, while the onset temperature of the $\mathrm{HRV}$ was found to be $-5^{\circ} \mathrm{C}$.

- The enthalpy/sensible core surfaces absorbed heat from the recirculated exhaust air during defrost cycle, and released them to intake airstream once the ERV/HRV turned back to normal operation. Therefore, the temperature of fresh airstream stayed a bit high for a few minutes before reaching steady state again.

- The accumulated condensation on the core surfaces during warm air recirculation was pick up by the fresh airstream through the means of evaporation once the system turned back to normal operation.

- The study of defrost cycle can be divided into three portions that describe the change of outlet fresh air temperature at different stages: 
1. Air recirculation stage (during defrost): warm exhaust airstream is direct using damper(s) to warm up the fresh air core channel. The observation revealed that the outlet air temperature gradually increased as a result of higher core surface temperature.

2. Heat extraction stage (after defrost): outlet fresh air temperature was found to increase initially due to the release of sensible heat from the core surfaces, and then gradually decreased.

3. Steady-state stage (after defrost): the outlet fresh air temperature finally reaches a constant temperature that remains unchanged in time.

- The malfunction of defrost cycle for the HRV resulted in severe ice formation, causing the sensible efficiency and exhaust airflow rate to be as low as $43 \%$ and $83 \mathrm{cfm}$, respectively.

- The ERV was found to be more frost-tolerant, while the HRV experienced a sharp decrease in thermal performance for a longer period of time. For the ERV operated at $114 \mathrm{cfm}$ with -15 to $-20^{\circ} \mathrm{C}$ outside air temperature, the sensible efficiency dropped from $78 \%$ to $51 \%$, and recovered as temperature increased. In contrast, the HRV operated at $147 \mathrm{cfm}$ resulted in $48 \%$ sensible efficiency and remained constant despite the change of outside temperature.

- According to TRNSYS simulations, the demand of defrost cycle of the HRV was found to be 3.5 times higher the ERV. The use of air recirculation led to higher minimum humidity, e.g., for $\mathrm{HRV}$, the minimum value increased from $12.9 \%$ to $15.2 \%$ at $21^{\circ} \mathrm{C}$, and lower house heating demand, e.g., $74.7 \mathrm{kWh}$ reduction.

- ASHP performed poorly in cold days, and hence, the impact (or savings per hour defrost cycle) of warm air recirculation was found to be dependent on outside temperature. The lower the outside air temperature, the smaller the impact of the warm air recirculation. In addition, the impact was also found to be dependent on the threshold temperature of defrost control as evidenced by the simulation results of the ERV at -5 and $-10^{\circ} \mathrm{C}$ thresholds.

This study has contributed a fair amount of insights that is considered new in the literature. The collaboration works with the undergraduate capstone design team (JAVK) provided a precious opportunity to work towards the design and construction of a multiple-pass HERV that is compact, innovative, versatile and efficient for various operating conditions. The payback period of the novel HVAC component was estimated using the developed Excel-based screening tool, and the TRNSYS model of HERV with a different flow arrangement was simulated in various Canadian climates for better understanding of how the system can perform in different zones. Most 
importantly, the simulation and cost analysis informs homeowners and manufacturers interested in installing and producing such systems about the feasibility of their investment. The TRCA Archetype Twin Houses have allowed for a direct and side-by-side comparison of equipment performance in a real residential setting. These equipment include a heat recovery ventilator and an energy recovery ventilator designed for residential applications. Issues with sensor installations of the HRV were mentioned, which could be valuable to the future study of residential mechanical ventilator in the Archetype Houses. In addition, the impacts of both defrost cycle and core freezing were studied through experiment and TRNSYS simulation, areas that are very uncommon in the literature. This information is beneficial to home owners and consultants to help better understand the principle of defrost control, the severity of malfunctioned defrost control during cold days, and the pros and cons of warm air recirculation.

\section{Section 8.3 - Recommendations}

The following recommendations were made for improving the performance of the HRV and ERV and future researches of the novel HERV:

$>$ It is highly recommended that a more powerful Data Acquisition Systems with more computational power and storage capabilities should be installed for future work to reduce the risk of data loses and errors. If not, the monitoring program and SQL database should be checked every day to ensure that they are running and the data is saving properly.

$>$ Same series of HRV is highly recommended (e.g., VanEE 2001 HRV corresponding to VanEE 2001 ERV in ASH-B) because the current VanEE 3000 HE HRV in AHS-A is of a higher order design that offers more efficient heat exchange and uses different defrost mechanism.

$>$ It is recommended to conduct more experiments and interpolation in order to complete mapping of performance with a full range of air flow rate.

$>$ It is highly recommended to use more saturated salt solution (e.g., $\mathrm{K}_{2} \mathrm{SO}_{4}=97.3 \% \mathrm{RH}$ at $25^{\circ} \mathrm{C}$ ) to improve accuracy at the wet extreme.

$>$ Instead of running multiple tabletop humidifiers, it is recommended to use whole house humidifier to provide better control of the house humidity. This enables complete mapping of latent efficiency of the systems with a wider range of humidity difference.

$>$ It is recommended to obtain and use more sensible and latent efficiencies for other conventional HRV and ERV (e.g., other brands) to confirm the potential of the proposed HERV.

$>$ It is recommended to use tracer gas method to measure the actual cross-leakage inside the HRV, 
or replace with a similar HRV (e.g., same series, VanEE 2001 HRV) in order to have a direct comparison of the cost performance.

$>$ It is recommended to finalize the HERV prototype with the future recruited capstone design team. The works include:

- Improve insulation level of both interior and exterior surfaces.

- Minimize internal leakage.

- Automate dampers and implement controller.

- Experimental performance evaluation of the prototype under both laboratory condition and in the TRCA Archetype Sustainable House. 


\section{Appendix A - Supplemental Information for Ebat}

\section{Section A1 - Required Heating and Cooling Load}

This section provided supplemental information, e.g., equations and assumptions, for the Excelbased analysis tool. To study the impacts of heat/energy recovery on space loads, it is necessary to calculate the rate at which energy must be added to/removed from a space, or in other word, heating and cooling loads are needed. According to ASHRAE Standard, both sensible heating and cooling loads of a house are the sum of heat gains/losses from occupants, appliances and ventilation, as well as the heat gains through opaque and transparent fenestration surfaces. In contrast, the latent load of a house is the sum of internal and ventilation heat gains/losses (ASHRAE, 2009).

$$
\begin{gathered}
q_{s}=\mathrm{N}_{b i n}\left(q_{o p q}+q_{f e n}+q_{v e n t}+q_{\text {int }}\right) \\
q_{L}=\mathrm{N}_{\text {bin }}\left(q_{\text {vent }}+q_{\text {int }}\right)
\end{gathered}
$$

In general, ventilation heat gains/losses of a house can be calculated from Eq. A.1.3 for sensible heat, and Eq. A.1.4 for latent heat. For a house that employs ventilation heat recovery, the load attributable to mechanical ventilation for a particular outdoor condition is simply the total amount as prescribed subtracts the total amount that is recovered, see Eq. A.1.5.

$$
\begin{gathered}
\left(q_{\text {vent }}\right)_{s}=\mathrm{N}_{\text {bin }} \times 1.2 \times \dot{\mathrm{Q}} \times \Delta T \\
\left(q_{\text {vent }}\right)_{L}=\mathrm{N}_{b i n} \times 3010 \times \dot{\mathrm{Q}} \times \Delta w \\
q_{\text {mech.ven }}^{\prime}=q_{\text {mech.ven }}-q_{a}
\end{gathered}
$$

Furthermore, heat gains through opaque surfaces can be divided into conduction and solar heat gains, which vary depending on the thermal resistance of surfaces, outdoor ambient temperature, and the surface cooling factors $\left(C F_{1}\right.$ and $\left.C F_{2}{ }^{31}\right)$.

${ }^{31}$ Unit: Kelvin 


$$
\begin{gathered}
q_{o p q}=q_{o p q, c o n d}+q_{o p q, s o l a r} \\
q_{o p q, \text { cond }}=\mathrm{UA}\left(\Delta T \times C F_{1}\right) \\
q_{o p q, \text { solar }}=\mathrm{UA} \times\left(C F_{2}\right)
\end{gathered}
$$

\section{Section A2 - Humidity Ratio}

The calculation of latent load, Eq. A.1.4, requires the humidity ratio for a particular weather condition. The relative humidity, without a corresponding dry bulb temperature, provides no insight of the air characteristics. This section presents the full calculation processes of humidity ratio. First of all, the humidity ratio $(w)$ can be obtained from the perfect gas relationships for dry and moist air (ASHRAE, 2009):

$$
w=0.6219 \frac{\mathrm{P}_{w}}{\mathrm{P}_{a t m}-\mathrm{P}_{w}}
$$

The partial pressure of water vapour in moist air $\left(\mathrm{P}_{w}\right)$ can be related to the relative humidity and the saturation pressure of water vapour $\left(\mathrm{P}_{w s}\right)^{32}$.

$$
\mathrm{P}_{w}=\mathrm{P}_{w s} \times \phi
$$

In addition, the variable $\left(\mathrm{P}_{w s}\right)$ can be calculated from the correlations derived from Hyland-Wexler equations $^{33}$, which define the vapor pressure as a function of absolute temperature. The saturation pressure $\left(\mathrm{P}_{w s}\right)$ for temperature range of $173.15 \mathrm{~K}$ to $273.15 \mathrm{~K}$ is given as the following:

$$
\ln \left(\mathrm{P}_{w s}\right)=\frac{C_{1}}{\mathrm{~T}_{a b s}}+C_{2}+C_{3} \mathrm{~T}_{a b s}+C_{4} \mathrm{~T}_{a b s}{ }^{2}+C_{5} \mathrm{~T}_{a b s}{ }^{3}+C_{6} \mathrm{~T}_{a b s}{ }^{4}+C_{7} \ln \left(\mathrm{T}_{a b s}\right)
$$

where:

$\mathrm{C}_{1}=-5.675 \times 10^{3}$

\footnotetext{
${ }^{32}$ Unit: Pa

${ }^{33}$ ASHRAE HANDBOOK FUNDAMENTALS
} 


$$
\begin{aligned}
& C_{2}=6.396 \\
& C_{3}=-9.678 \times 10^{-3} \\
& C_{4}=6.222 \times 10^{-7} \\
& C_{5}=2.075 \times 10^{-9} \\
& C_{6}=-9.484 \times 10^{-13} \\
& C_{7}=4.164
\end{aligned}
$$

The saturation pressure $\left(\mathrm{P}_{w s}\right)$ for temperature range of $273.15 \mathrm{~K}$ to $473.15 \mathrm{~K}$ is given as the following:

$$
\ln \left(\mathrm{P}_{w s}\right)=\frac{C_{8}}{\mathrm{~T}_{a b s}}+C_{9}+C_{10} \mathrm{~T}_{a b s}+C_{11} \mathrm{~T}_{a b s}{ }^{2}+C_{12} \mathrm{~T}_{a b s}{ }^{3}+C_{13} \ln \left(\mathrm{T}_{a b s}\right)
$$

where:

$\mathrm{C}_{8}=-5.800 \times 10^{3}$

$\mathrm{C}_{9}=1.392$

$\mathrm{C}_{10}=-4.864 \times 10^{-2}$

$\mathrm{C}_{11}=4.177 \times 10^{-5}$

$\mathrm{C}_{12}=-1.445 \times 10^{-8}$

$\mathrm{C}_{13}=6.546$

\section{Section A3 - Furnace/AC Energy Consumption}

Air conditioning consumes a substantial amount of energy in the residential sector. The specific amount varies depending on many factors - from external factors such as building properties, orientation and the local climates, to internal factors such as the properties of the HVAC equipment. Section 4.5 already demonstrated the processes of calculations for space loads based on the external effects. In this section, the properties of HVAC equipment are concerned. One of the main purpose of ventilation heat recovery is to reduce dependency on the primary furnace and air conditioning systems. Therefore, Ebat was designed to be able to evaluate the annual end-use 
energy for a specific type (e.g., vintage and fuel type) of furnace and air conditioner, with and without ventilation heat recovery. According to the RESNET, the efficiency of a gas or oil furnace can be estimated based on the age of the system, as shown in Table A.3.1.

Table A.3.1 - Furnace age-based efficiency (RESNET, 2013)

\begin{tabular}{ccc}
\hline \multirow{2}{*}{ Year } & \multicolumn{2}{c}{ Fuel Type } \\
\cline { 2 - 3 } & Gas (AFUE) & Oil (AFUE) \\
\hline$<1960$ & $72 \%$ & $60 \%$ \\
\hline $1960-1969$ & $72 \%$ & $60 \%$ \\
\hline $1970-1974$ & $72 \%$ & $65 \%$ \\
\hline $1975-1983$ & $72 \%$ & $65 \%$ \\
\hline $1984-1987$ & $72 \%$ & $70 \%$ \\
\hline $1988-1991$ & $76 \%$ & $77 \%$ \\
\hline 1992 to present & $78 \%$ & $80 \%$ \\
\hline
\end{tabular}

The output of a furnace system for a particular weather condition was set to be equivalent to the heating load $q_{s}$ obtained from the previous section. By selecting the appropriated annual fuel utilization efficiency (AFUE) of the furnace system, the required input of that furnace can be calculated and thereby the natural gas consumption.

$$
E_{n g}=\frac{q_{s}}{\mathrm{AFUE}}
$$

The efficiency of an air conditioner is represented by the seasonal energy efficiency ratio (SEER), while its performance is rated by the coefficient of performance (COP) which is defined as a ratio of the output thermal energy to the input electricity consumption, as shown in Eq.A.3.3.

$$
\begin{gathered}
C O P_{\mathrm{A} / \mathrm{C}}=\frac{S E E R}{3.792} \\
\mathrm{E}_{\mathrm{A} / \mathrm{C}}=\frac{q_{S}}{\operatorname{COP}_{A / C}}
\end{gathered}
$$

\section{Section A4 - Heating and Cooling Period/Demand}

This section presents the defined heating and cooling periods for the cities that have been chosen for the sensitivity study presented in Section 4.14.2. The onset of cooling period was determined based on the daily average temperature. According to the metropolitan Lethbridge weather file 
from Meteotest, a daily average temperature of $19^{\circ} \mathrm{C}$ occurs on May $20^{\text {th }}$, see Table A.4.2. In addition, heating period was assumed to begin on September $30^{\text {th }}$ and end on May $19^{\text {th }}$. West Palm Beach has a tropical climate which is characterized by constantly hot and humid climate throughout the year, the TMY2 weather file shows that the minimum daily temperature of $7^{\circ} \mathrm{C}$ occurs on December $31^{\text {st }}$. Therefore, heating was assumed to be unnecessary. In contrast, Eureka has a polar climate with a daily maximum temperature of $11^{\circ} \mathrm{C}$ occurs on July $9^{\text {th }}$, and hence, heating was assumed to be always required.

Table A.4.1 - Heating and cooling period for Eureka and West Palm Beach

\begin{tabular}{|c|c|c|c|c|c|c|c|}
\hline \multirow{2}{*}{$\begin{array}{l}\text { Climate } \\
\text { Zones }\end{array}$} & \multirow{2}{*}{ Cities } & \multicolumn{3}{|c|}{ Cooling Season } & \multicolumn{3}{|c|}{ Heating Season } \\
\hline & & Begin & $\begin{array}{c}\text { End } \\
\text { (Inclusive) }\end{array}$ & $\begin{array}{l}\text { Min. Temperature } \\
\left({ }^{\circ} \mathrm{C}\right)\end{array}$ & Begin & $\begin{array}{c}\text { End } \\
\text { (inclusive) }\end{array}$ & $\begin{array}{l}\text { Max. Temperature } \\
\left({ }^{\circ} \mathrm{C}\right)\end{array}$ \\
\hline$A$ & $\begin{array}{c}\text { West Palm } \\
\text { Beach }\end{array}$ & Jan. $1^{\text {st }}$ & Dec. $31^{\text {st }}$ & $7.0\left(\operatorname{Jan} .18^{\text {th }}\right)$ & ---- & ---- & ---- \\
\hline$E$ & Eureka & ---- & ---- & ---- & Jan. $1^{\text {st }}$ & Dec. $31^{\text {st }}$ & 11 (Jul. $\left.9^{\text {th }}\right)$ \\
\hline
\end{tabular}

Table A.4.2 - Heating and cooling period for Köppen climate B, C, and D

\begin{tabular}{|c|c|c|c|c|c|c|c|}
\hline \multirow{2}{*}{$\begin{array}{l}\text { Climate } \\
\text { Zones }\end{array}$} & \multirow{2}{*}{ Cities } & \multicolumn{3}{|c|}{ Cooling Season } & \multicolumn{3}{|c|}{ Heating Season } \\
\hline & & Begin & $\begin{array}{c}\text { End } \\
\text { (inclusive) }\end{array}$ & $\begin{array}{c}\text { Temperature* } \\
\left({ }^{\circ} \mathrm{C}\right)\end{array}$ & Begin & $\begin{array}{c}\text { End } \\
\text { (inclusive) }\end{array}$ & $\begin{array}{c}\text { Temperature* } \\
\left({ }^{\circ} \mathrm{C}\right)\end{array}$ \\
\hline B & Lethbridge & May $20^{\text {th }}$ & Sep. $29^{\text {th }}$ & 19 & Sep. $30^{\text {th }}$ & May $19^{\text {th }}$ & 14 \\
\hline B & Albuquerque & May $1^{\text {st }}$ & Oct. $15^{\text {th }}$ & 19 & Oct. $16^{\text {th }}$ & Apr. $30^{\text {th }}$ & 15 \\
\hline $\mathrm{C}$ & San Francisco & Jun. $15^{\text {th }}$ & Oct. $31^{\text {st }}$ & 16 & Nov. $1^{\text {st }}$ & Jun. $14^{\text {th }}$ & 10 \\
\hline $\mathrm{C}$ & Nanaimo & May $20^{\text {th }}$ & Sep. $29^{\text {th }}$ & 19 & Sep. $30^{\text {th }}$ & May $19^{\text {th }}$ & 6 \\
\hline $\mathrm{D}$ & Edmonton & May $20^{\text {th }}$ & Sep. $24^{\text {th }}$ & 19 & Sep. $25^{\text {th }}$ & May $19^{\text {th }}$ & 12 \\
\hline $\mathrm{D}$ & Montreal & May $20^{\text {th }}$ & Sep. $30^{\text {th }}$ & 20 & Oct. $1^{\text {st }}$ & May $19^{\text {th }}$ & 7 \\
\hline
\end{tabular}

*daily average outdoor temperature on the beginning of the period

A good indication of the house heating and cooling demand in a selected region is the heating and cooling degree days (HDD \& CDD). The TRNSYS weather files were used to obtain the respective HDD, CDD and maximum/minimum temperatures. The HDD and CDD were calculated using the following equations (ASHRAE, 2009).

$$
\text { HDD }=\sum_{\mathrm{i}=1}^{\mathrm{N}}\left(\mathrm{T}_{\text {base }}-\overline{\mathrm{T}}_{\mathrm{i}}\right)^{+}
$$




$$
\mathrm{CDD}=\sum_{\mathrm{i}=1}^{\mathrm{N}}\left(\overline{\mathrm{T}}_{\mathrm{i}}-\mathrm{T}_{\text {base }}\right)^{+}
$$

where:

$\mathrm{N}$ : number days in a year

$\overline{\mathrm{T}}_{\mathrm{i}}$ : mean daily temperature

$\mathrm{T}_{\text {base }}$ : base temperature (heating: $18^{\circ} \mathrm{C}$, cooling: $10^{\circ} \mathrm{C}$ )

The resulting HDD and CDD, along with the maximum and minimum hourly average temperatures are given below in Table A.4.3.

Table A.4.3 - Calculated HDD, CDD, maximum and minimum temperature of different regions

\begin{tabular}{cccccc}
\hline Zone & Location & HDD & CDD & $\begin{array}{c}\text { Hourly Max. } \\
\text { Temp. }\left({ }^{\circ} \mathrm{C}\right)\end{array}$ & $\begin{array}{c}\text { Hourly Min. Temp. } \\
\left({ }^{\circ} \mathrm{C}\right)\end{array}$ \\
\hline A & Miami & 64 & 5225 & 33.9 & 3.3 \\
\hline A & West Palm Beach & 111 & 4963 & 33.9 & 0.6 \\
\hline B & Las Vegas & 1248 & 3680 & 44.4 & -4.4 \\
\hline B & Lethbridge & 4581 & 895 & 33.9 & -32.3 \\
\hline B & Albuquerque & 2424 & 2117 & 37.2 & -11.1 \\
\hline C & Vancouver & 3003 & 820 & 26.3 & -5.8 \\
\hline C & San Francisco & 1817 & 1226 & 35.0 & 0 \\
\hline C & Nanaimo & 3152 & 858 & 30.2 & -8.1 \\
\hline D & Metro-Toronto & 4096 & 1166 & 33.9 & -22.7 \\
\hline D & Edmonton & 5500 & 883 & 29.5 & -30.6 \\
\hline D & Montreal & 4487 & 1165 & 32.2 & -40.3 \\
\hline E & Iqaluit & 9985 & 14 & 19.8 & -49.8 \\
\hline E & Eureka & 13757 & 1 & 13.6 & \\
\hline
\end{tabular}

\section{Section A5 - Unit Price of Natural Gas and Electricity}

Marginal cost of natural gas from Enbridge is the sum of gas supply, delivery, and transportation

to Enbridge subtracts by the cost adjustment. Table A.5.1 lists the details of natural gas charges from Enbridge. Therefore, the marginal cost of natural gas is:

Marginal cost $=$ gas supply + delivery + transportation to Enbridge - cost adjustment

Marginal cost $=\$(0.121485+0.082453+0.056155-0.016697) / \mathrm{m}^{3}$

Marginal cost $=\$ 0.243396 / \mathrm{m}^{3} \approx \$ 0.243 / \mathrm{m}^{3}$ 
Table A.5.1 - Natural gas charges from Enbridge (Enbridge, 2013)

\begin{tabular}{cll}
\hline Natural Gas Charges & Unit & Rate \\
\hline Gas Supply Charge & $\$ / \mathrm{m}^{3}$ & 0.121485 \\
\hline Delivery to you & $\$ / \mathrm{m}^{3}$ & 0.082453 \\
\hline Transportation to Enbridge & $\$ / \mathrm{m}^{3}$ & 0.056155 \\
\hline Cost Adjustment & $\$ / \mathrm{m}^{3}$ & -0.016697 \\
\hline
\end{tabular}

Similarly, the Marginal cost of electricity from Toronto Hydro is the sum of baseline, average delivery, regulatory and debt retirement charges. Table A.5.2 lists the details of electricity charges from Toronto Hydro. Therefore, the marginal cost of electricity is:

Marginal cost $=$ baseline + average delivery + regulatory + debt retirement

Marginal cost $=\$(0.087+0.02736+0.0063+0.007) / \mathrm{kWh}$

Marginal cost $=\$ 0.128 / \mathrm{kWh}$

Table A.5.2 - Electricity charges from Toronto Hydro (Toronto Hydro, 2013)

\begin{tabular}{ccc}
\hline Electricity Charges & Unit & Pricing \\
\hline Tiered Pricing & $\$ / \mathrm{kWh}$ & 0.087 \\
\hline Average Delivery Charges & $\$ / \mathrm{kWh}$ & 0.02736 \\
\hline Regulatory Charges & $\$ / \mathrm{kWh}$ & 0.0063 \\
\hline Debt Retirement Charges & $\$ / \mathrm{kWh}$ & 0.007 \\
\hline
\end{tabular}




\section{Appendix B - TRNSYS Modelling and FORTRAN Source Code}

\section{Section B1 - Introduction of TRNSYS Studio}

TRNSYS is a transient system energy modeling software designed to solve complex energy problems. The software uses individual components referred as types connected to each other with each representing one part of the overall system. For example, the project shown in Figure 5.4.1 is constituted by a number of TRNSYS components which are interconnected by links. The link (or so called input-output connection) allows the users to define/specify the information flows from one component to another (Solar Energy Laboratory, 2012). Figure B.1 illustrates the required input-output connections that flow information from one component (or equipment) to another in order to determine the air properties at the final destination. In the figure, the weather processor sends out the information about the outdoor air properties to the heat recovery model for air precondition, and this process proceeds until the properties of the input air to a conditioned house are known. According to a study on various energy modeling programs (Crarley, Hand, Kummert, \& Griffith, 2005), TRNSYS is reasonably powerful in terms of HVAC system modeling. As a result, the program allowed the modeling of specific HVAC system performance.

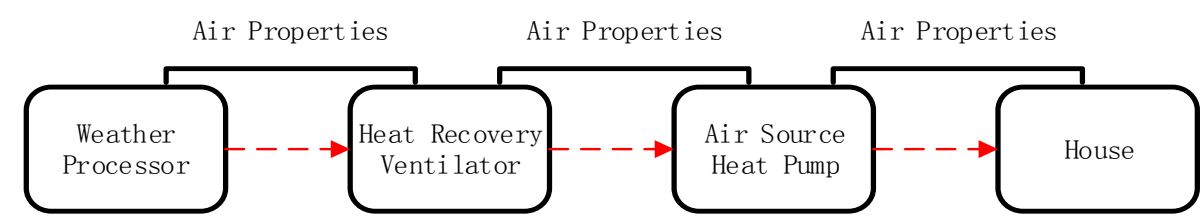

Figure B.1 - Flow chart illustrating the input-output connections

The components presented in Figure 5.4.1 can be categorized into four major types:

1. Building components that model the Archetype Sustainable House-A (e.g., building, wing wall, shading etc.).

2. Weather component (or processor) that reads the weather data file for the selected city.

3. TRNSYS components associated with space heating/cooling (e.g., ASHP, and thermostat etc.), these models were implemented by Safa (2012).

4. TRNSYS components associated with house ventilation (e.g., HERV, controller, and air plenum etc.).

Basically, stale air from each floor (or zone) is mixed using return air plenum (Exhaust Air Mixer), and then passes through the HERV model to perform either or both temperature and/or humidity 
regulation for the incoming fresh air. Thereafter, the preconditioned fresh air will be distributed equally to each control zone. The module 'Controller' is used to determine and send out signal for HERV mode control based on the indoor, outdoor and setpoint conditions (see Table 5.3.1). The properties of indoor air can be calculated using the module 'Mixed Air $1^{\text {st }}-3^{\text {rd }}$, while the properties of outdoor air can be obtained from the weather processor 'Weather data'. As long as an appropriate control mode is decided at each time step, the corresponding instruction(s) will be executed to achieve demand-controlled ventilation. For example, if one decides to have high power vent during the bypass mode, signal number 1 (see Table 5.3.2) will be sent to the HERV to inform that the free-cooling is available at the current time step, and the user defined airflow rate will be sent to the modules 'Intake Air' and 'Exhaust Air' to vary the total amount of air (both supply and exhaust air streams) that should be sent into the heat recovery ventilator.

\section{Section B2 - FORTRAN Source Code for TRNSYS Type-291}

SUBROUTINE TYPE291 (TIME, XIN, OUT, T, DTDT, PAR, INF0, ICNTRL, *)

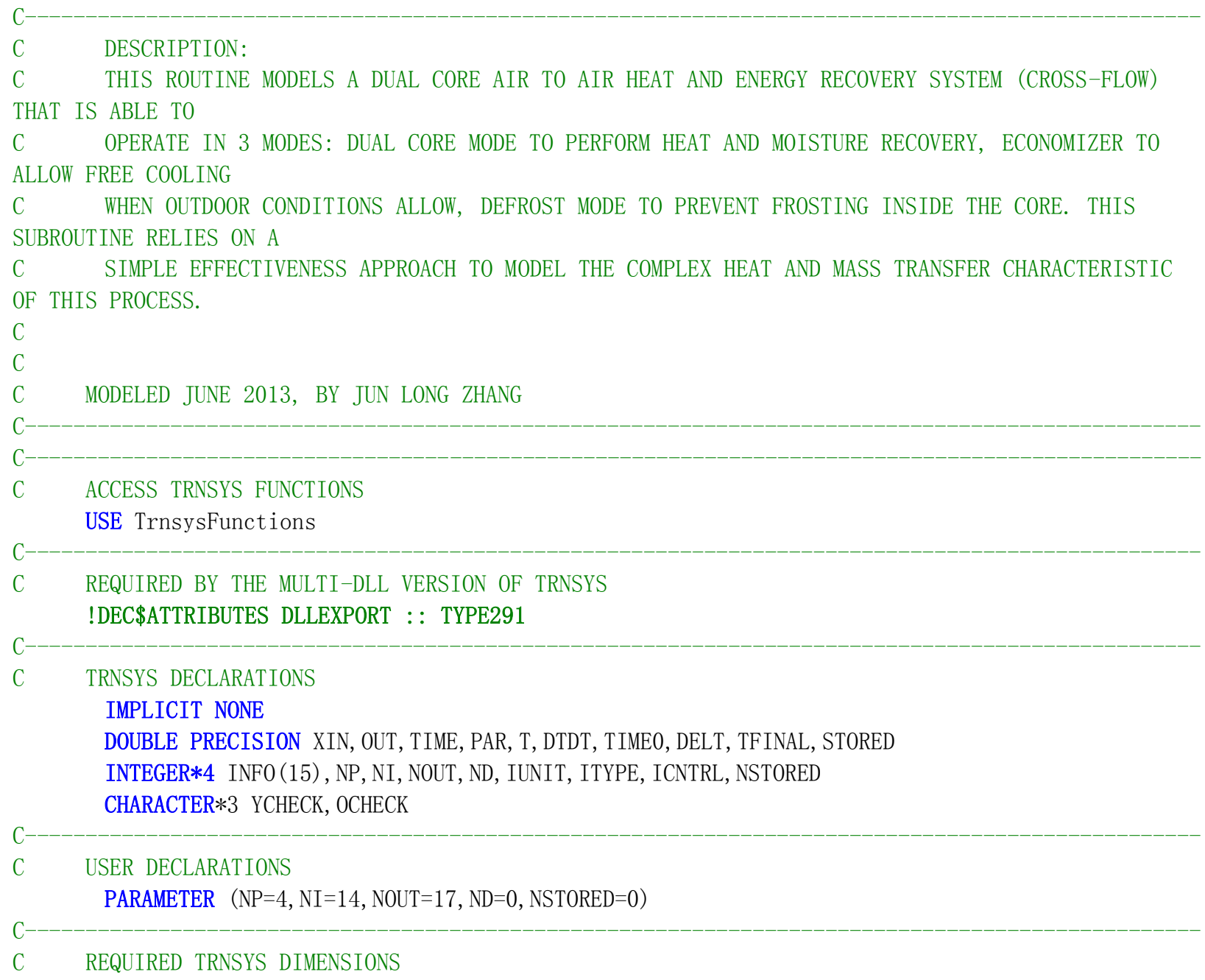


DIMENSION XIN (NI), OUT (NOUT), PAR (NP), YCHECK (NI), OCHECK (NOUT),

T (ND) , DTDT (ND), STORED (NSTORED)

C DECLARATIONS AND DEFINITIONS FOR THE USER-VARIABLES

DOUBLE PRECISION AIRPROPS (5), PROP (7), PSYDAT (9), RATED_POWER,

Q_TOT, POWER, SYSTEM_CONTROL, EFF_ERV_SENSIBLE, W_EXHAUST_OUT,

T_SET_IN, T_K, ECONOMIZER_CONTROL, T_FONSET, HV_EXHAUST,

P_KPA, Q_HRV_SENSIBLE, Q_ERV_SENSIBLE, Q_ERV_LATENT, Q_ERV_TOT,

Q_ERV_TOT_EXHAUST, Q_ERV_TOT_INTAKE, EFF_HRV_SENSIBLE,

EFF_ERV_LATENT, T_EXHAUST_IN, T_EXHAUST_OUT, W_EXHAUST_IN,

P_EXHAUST_IN, P_EXHAUST_OUT, RH_EXHAUST_IN, RH_EXHAUST_OUT,

H_EXHAUST_IN, CP_EXHAUST_HRV, H_INTAKE_MED, MW_E, MW_F,

H_EXHAUST_OUT, FLOW_EXHAUST, T_INTAKE_IN, T_INTAKE_OUT,

W_INTAKE_IN, W_INTAKE_OUT, P_INTAKE_IN, P_INTAKE_OUT, RH_INTAKE_IN,

RH_INTAKE_OUT, H_INTAKE_IN, H_INTAKE_OUT, FLOW_INTAKE,

CP_EXHAUST_ERV, CAP_EXHAUST_ERV, CP_INTAKE_ERV, CAP_INTAKE_ERV,

T_EXHAUST_MED, W_EXHAUST_MED, P_EXHAUST_MED, H_EXHAUST_MED,

CAP_EXHAUST_HRV, T_INTAKE_MED, W_INTAKE_MED, P_INTAKE_MED,

CP_INTAKE_HRV, CAP_INTAKE_HRV, M_FROM_E_TO_F, M_FROM_F_TO_E,

M_VAPOR, RH_EXHAUST_MED, RH_INTAKE_MED, HV_INTAKE, DEFROST_CONTROL,

STORAGESIZE, NZERO, NFINAL, MZERO, MFINAL, RH_SET_IN, W_SET_IN,

DP_EXHAUST, DP_INTAKE, T_INDOOR, FLOW_SIGNAL, TX_CURRENT, TX_PRE,

TY_CURRENT, TY_PRE, TX, TY, CAP_EXHAUST, CAP_EXHAUST_MED, CAP_INTAKE,

CAP_INTAKE_MED, CP_EXHAUST, CP_EXHAUST_MED, CP_INTAKE, CP_INTAKE_MED

INTEGER STATUS

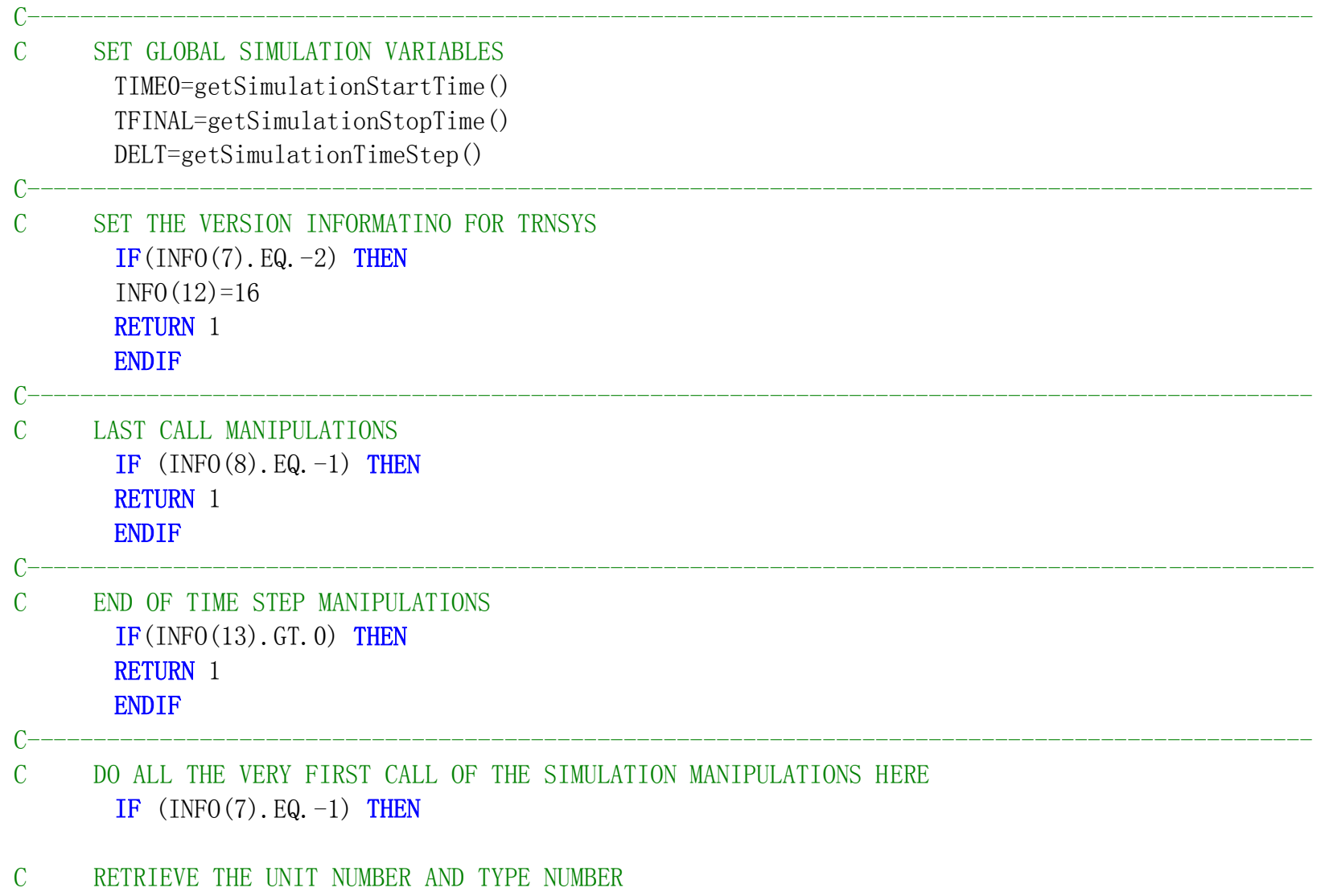


IUNIT=INFO (1)

ITYPE=INFO (2)

C SET SOME INFO ARRAY VARIABLES TO TELL THE TRNSYS ENGINE HOW THIS TYPE IS TO WORK

$\operatorname{INFO}(6)=\mathrm{NOUT}$

$\operatorname{INFO}(9)=1$

$\operatorname{INFO}(10)=0$

C

CALL TYPECK (1, INFO, NI, NP, ND)

DATA YCHECK/' TE1', ' DM1', ' PC1' , 'MF1' ,' PR4' , 'PR4',

1 ' TE1' , 'DM1' , 'PC1' , 'MF1' , 'PR4', , PR4' , ' $\mathrm{CF1}$ ' , ' $\mathrm{CF} 1$ ' /

DATA OCHECK/' TE1', ' DM1' , 'PC1' , 'MF1' , 'PR4', , TE1',

' DM1' , 'PC1' , 'MF1' , 'PR4' , ' $\mathrm{PW1}$ ', 'PW1' , 'PW1' , $\mathrm{PW1}$ ',

'PW1', , TE1', , TE1' /

CALL RCHECK (INFO, YCHECK, OCHECK)

RETURN 1

ENDIF

C START TIME MANIPULATIONS

IF (TIME. LT. (TIME0+DELT/2. D0)) THEN

C SET UNIT NUMBER

IUNIT $=\operatorname{INFO}(1)$

ITYPE=INF0 (2)

C READ IN THE VALUES OF THE PARAMETERS IN SEQUENTIAL ORDER

RATED_POWER=PAR (1)

EFF_HRV_SENSIBLE=PAR (2)

EFF_ERV_SENSIBLE=PAR (3)

EFF_ERV_LATENT=PAR (4)

C CHECK THE PARAMETERS TO MAKE SURE THEY ARE REASONABLE

IF (RATED_POWER. LT. 0) CALL TYPECK (-4, INF0, 0, 1, 0)

IF (EFF_HRV_SENSIBLE. LT. 0) CALL TYPECK $(-4, \operatorname{INF0,~0,~2,~0)~}$

IF (EFF_HRV_SENSIBLE. GT. 1) CALL TYPECK $(-4$, INF0, 0, 2, 0)

IF (EFF_ERV_SENSIBLE. LT. 0) CALL TYPECK $(-4$, INF0, 0, 3, 0)

IF (EFF_ERV_SENSIBLE. GT. 1) CALL TYPECK $(-4, \operatorname{INF0}, 0,3,0)$

IF (EFF_ERV_LATENT. LT. 0) CALL TYPECK $(-4, \operatorname{INF0,~0,~4,~0)~}$

IF (EFF_ERV_LATENT. GT. 1) CALL TYPECK $(-4, \operatorname{INF0,~0,~4,~0)~}$

C SET THE INITIAL VALUES OF THE OUTPUTS

$\operatorname{OUT}(1)=\mathrm{XIN}(1)$

$\operatorname{OUT}(2)=\mathrm{XIN}(2)$

$\operatorname{OUT}(3)=\mathrm{XIN}(3)$

$\operatorname{OUT}(4)=0$.

$\operatorname{OUT}(5)=\mathrm{XIN}(4)$

$\operatorname{OUT}(6)=\mathrm{XIN}(6)$

$\operatorname{OUT}(7)=\mathrm{XIN}(7)$

$\operatorname{OUT}(8)=\mathrm{XIN}(8)$

$\operatorname{OUT}(9)=0$. 


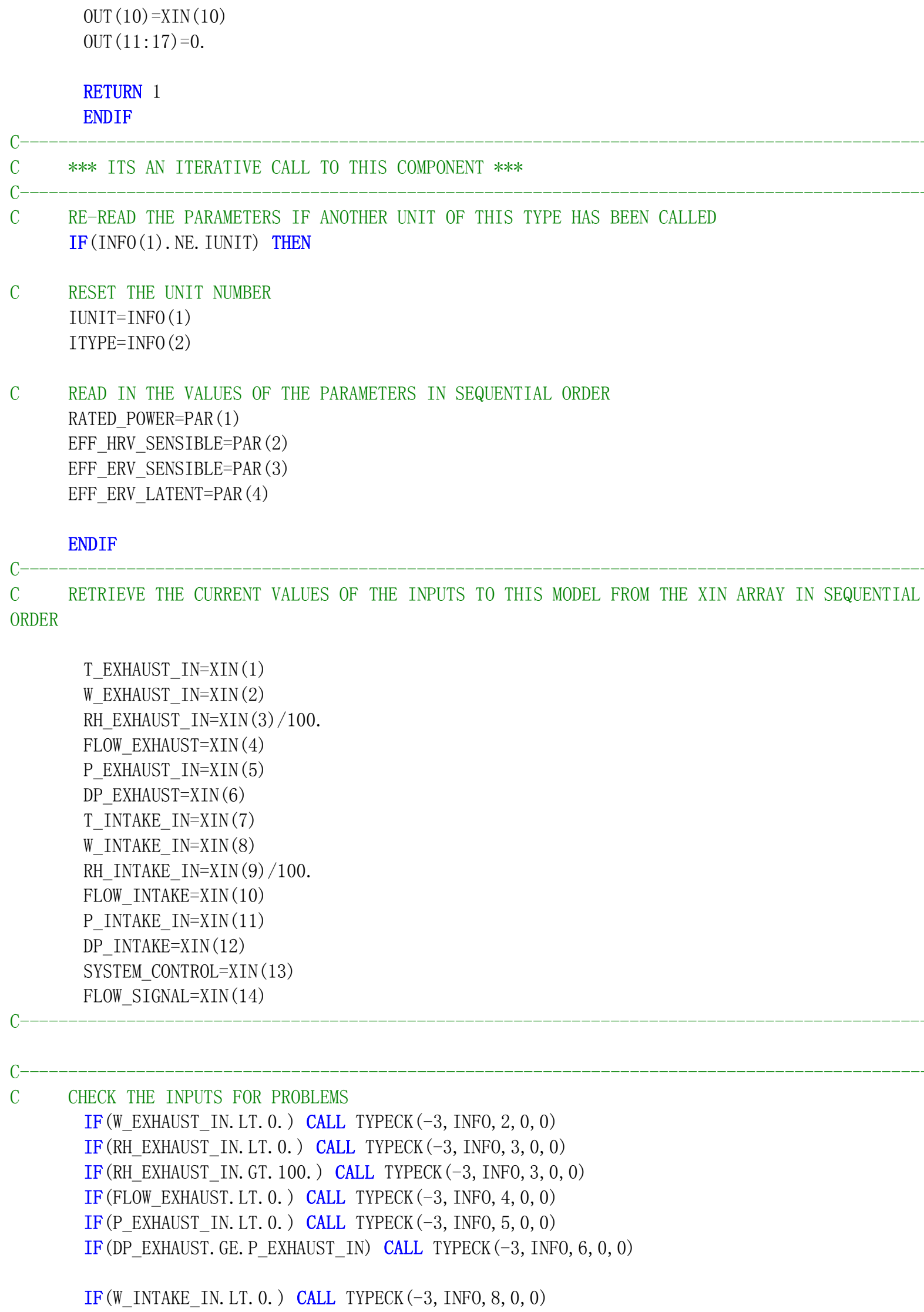


IF (RH_INTAKE_IN. LT. 0. ) CALL TYPECK $(-3$, INF0, 9, 0, 0)

IF (RH_INTAKE_IN. GT. 100.) CALL TYPECK $(-3$, INF0, 9, 0, 0)

IF (FLOW_INTAKE. LT. 0. ) CALL TYPECK $(-3$, INF0, 10, 0, 0)

IF (P_INTAKE_IN. LT. 0. ) CALL TYPECK $(-3, \operatorname{INF} 0,11,0,0)$

IF (DP_INTAKE. GE. P_INTAKE_IN) CALL TYPECK $(-3$, INF0, 12, 0, 0)

IF (SYSTEM_CONTROL. LT. 0. ) CALL TYPECK (-3, INFO, 13, 0, 0)

IF (SYSTEM_CONTROL. GT. 1.) CALL TYPECK ( -3 , INF0, 13, 0, 0)

IF (FLOW_SIGNAL. LT. 0. ) CALL TYPECK $(-3, \operatorname{INF} 0,14,0,0)$

IF (FLOW_SIGNAL. GT. 5. ) CALL TYPECK (-3, INFO, 14, 0, 0)

IF (ErrorFound ()) RETURN 1

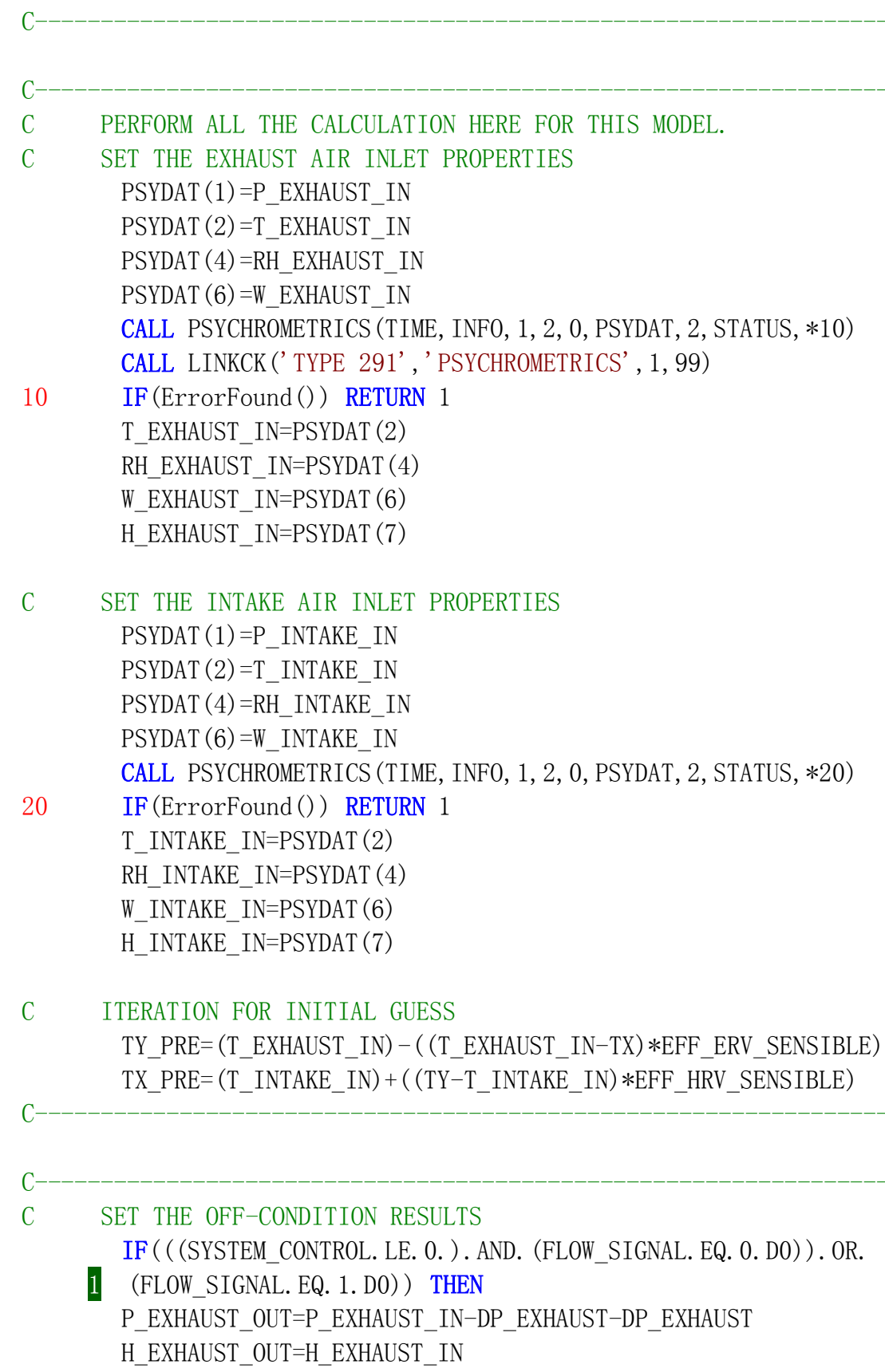




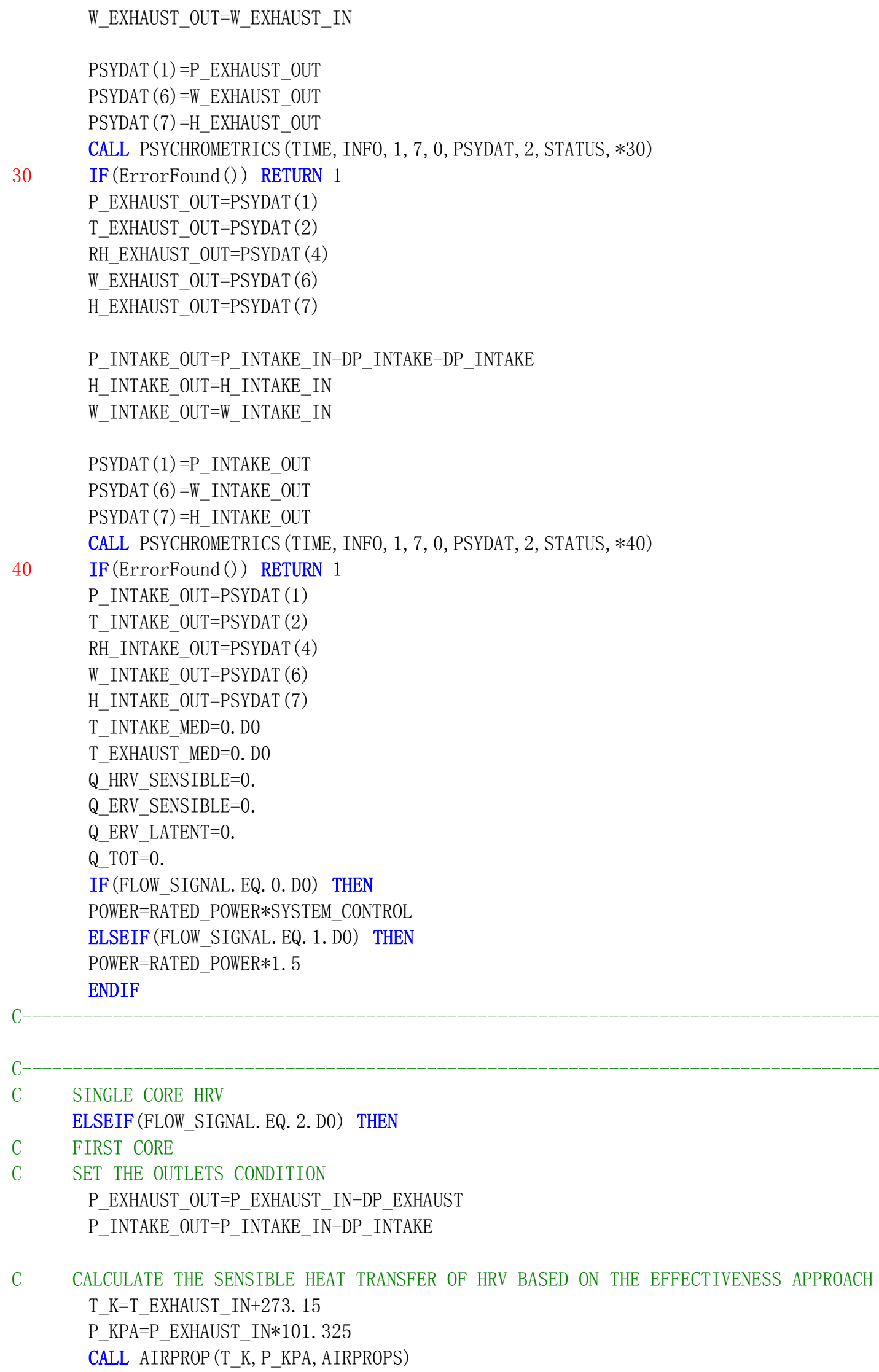




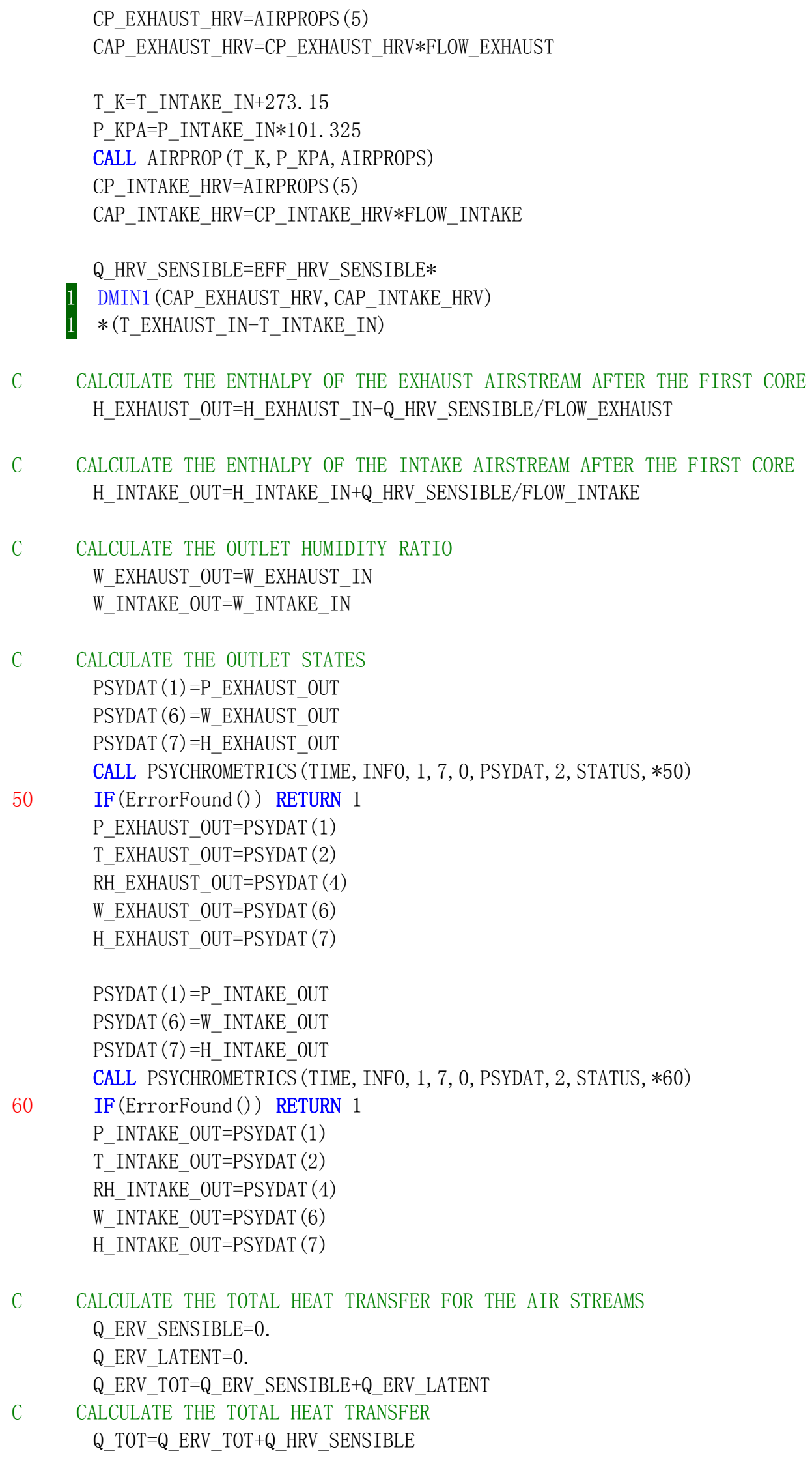


$\mathrm{C}$

C

SINGLE CORE ERV

ELSEIF (FLOW_SIGNAL. EQ. 3. D0) THEN

C SET THE OUTLETS CONDITION

P_EXHAUST_OUT $=$ P_EXHAUST_IN-DP_EXHAUST

$P \_$INTAKE_OUT $=$P_INTAKE_IN-DP_INTAKE

C CALCUlate THE SENSIBLE AND TOTAL HEAT TRANSFER THROUGH ERV CORE

T_K=T_EXHAUST_IN+273. 15

P_KPA=P_EXHAUST_IN $* 101.325$

CALL AIRPROP (T_K, P_KPA, AIRPROPS)

CP_EXHAUST_ERV=AIRPROPS (5)

CAP_EXHAUST_ERV $=$ CP_EXHAUST_ERV $*$ FLOW_EXHAUST

T_K=T_INTAKE_IN+273.15

P_KPA=P_INTAKE_IN*101. 325

CALL AIRPROP (T_K, P_KPA, AIRPROPS)

CP_INTAKE_ERV=AIRPROPS (5)

CAP_INTAKE_ERV $=$ CP_INTAKE_ERV $* F L O W \_I N T A K E$

Q_ERV_SENSIBLE=EFF_ERV_SENSIBLE

*DMIN1 (CAP_EXHAUST_ERV, CAP_INTAKE_ERV)

*(T_EXHAUST_IN-T_INTAKE_IN)

C GET THE ENTHALPY OF THE WATER VAPOR

$\operatorname{PROP}(1)=\mathrm{T} \_$EXHAUST_IN

$\operatorname{PROP}(5)=1$.

CALL STEAM_PROPS (' SI', PROP, 15, STATUS, *70)

CALL LINKCK (' TYPE 291', ' STEAM_PROPS' , 1, 99)

70 IF (ErrorFound ()) RETURN 1

HV_EXHAUST=PROP (3)

$\operatorname{PROP}(1)=$ T_INTAKE_IN

$\operatorname{PROP}(5)=1$.

IF (T_INTAKE_IN. LT. -34. ) THEN

HV_INTAKE $=2437.6$

ELSE

CALL STEAM_PROPS(' SI', PROP, 15, STATUS, *80)

80 IF (ErrorFound ()) RETURN 1

HV_INTAKE $=$ PROP $(3)$

ENDIF

C CALCUlate THE MOISTURE TRANSFER BASED ON THE EFFECTIVENESS APPROACH M_FROM_E_TO_F $=\mathrm{DMAX1}(0 .,(\mathrm{EFF}$ ERV_LATENT 


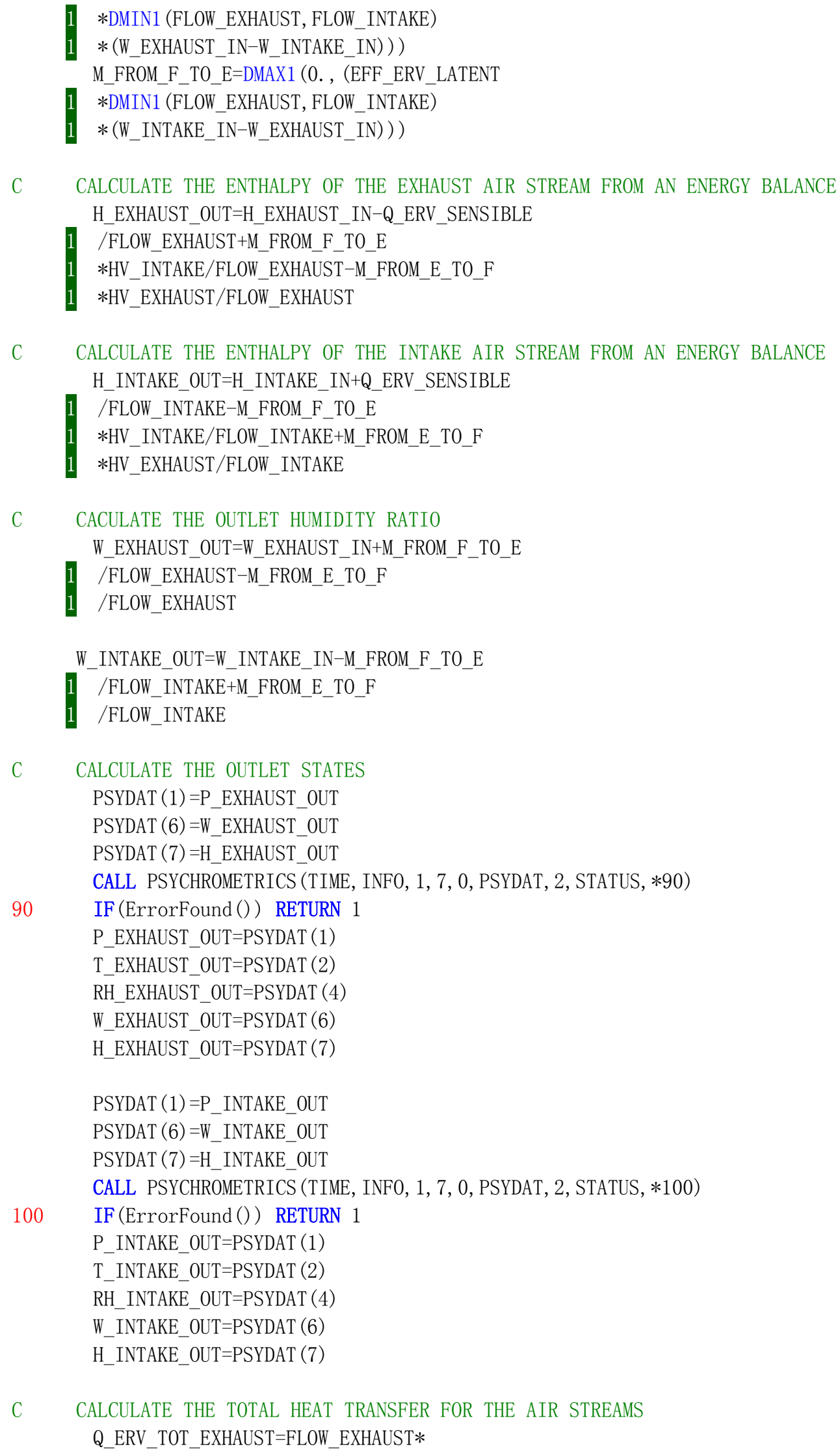




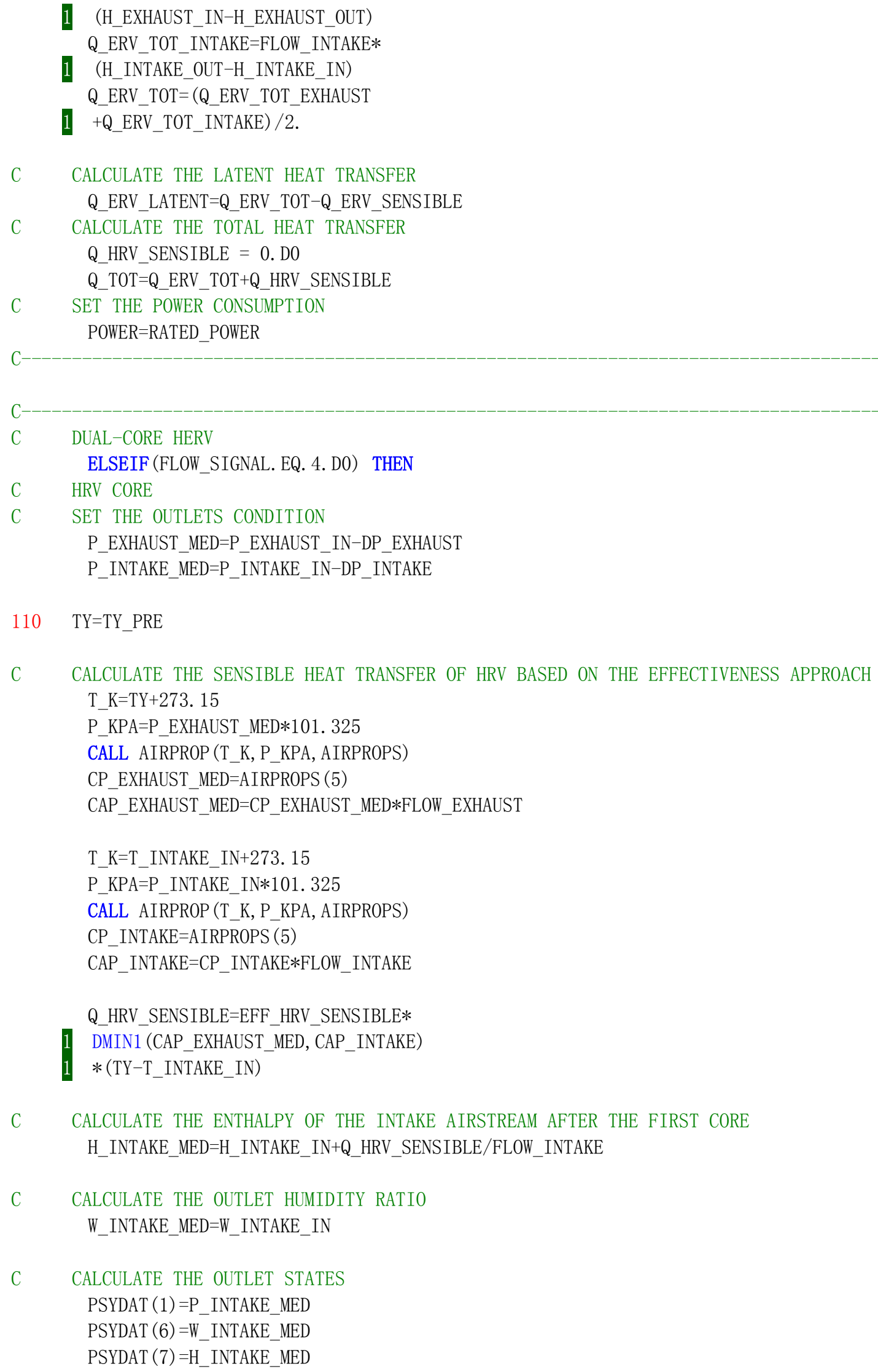


CALL PSYCHROMETRICS (TIME, INF0, $1,7,0$, PSYDAT, 2 , STATUS, $* 120$ )

120 IF (ErrorFound ()) RETURN 1

P_INTAKE_MED=PSYDAT (1)

T_INTAKE_MED=PSYDAT (2)

RH_INTAKE_MED=PSYDAT (4)

W_INTAKE_MED=PSYDAT (6)

H_INTAKE_MED=PSYDAT (7)

TX=T_INTAKE_MED

C ERV CORE

C SET THE OUTLETS CONDITION

P_EXHAUST_OUT=P_EXHAUST_MED-DP_EXHAUST

P_INTAKE_OUT $=$ P_INTAKE_MED-DP_INTAKE

C CALCulate the SENSible and total hEAT transfer through ERV CORE

T_K=T_EXHAUST_IN+273. 15

P_KPA=P_EXHAUST_IN $* 101.325$

CALL AIRPROP (T_K, P_KPA, AIRPROPS)

CP_EXHAUST $=$ AIRPROPS (5)

CAP_EXHAUST $=$ CP_EXHAUST $*$ FLOW_EXHAUST

T_K=TX+273. 15

P_KPA=P_INTAKE_MED*101.325

CALL AIRPROP (T_K, P_KPA, AIRPROPS)

CP_INTAKE_MED=AIRPROPS (5)

CAP_INTAKE_MED $=C P \_I N T A K E \_M E D * F L O W \_I N T A K E$

Q_ERV_SENSIBLE=EFF_ERV_SENSIBLE

*DMIN1 (CAP_EXHAUST, CAP_INTAKE_MED)

*(T_EXHAUST_IN-TX)

C GET THE ENTHALPY OF THE WATER VAPOR

PROP (1) =T_EXHAUST_IN

$\operatorname{PROP}(5)=1$.

CALL STEAM_PROPS('SI', PROP, 15, STATUS, *130)

CALL LINKCK (' TYPE 292' ,' STEAM_PROPS', 1, 99)

130 IF (ErrorFound ()) RETURN 1

HV_EXHAUST=PROP (3)

$\operatorname{PROP}(1)=T X$

$\operatorname{PROP}(5)=1$.

IF (TX. LT. -34. ) THEN

HV_INTAKE $=2437.6$

ELSE

CALL STEAM_PROPS (' SI', PROP, 15, STATUS, *140)

$140 \quad$ IF (ErrorFound ()) RETURN 1

HV_INTAKE=PROP (3)

ENDIF

C CALCULATE THE MOISTURE TRANSFER BASED ON THE EFFECTIVENESS APPROACH

M_FROM_E_TO_F=DMAX1 (0., (EFF_ERV_LATENT

1 *DMIN1 (FLOW_EXHAUST, FLOW_INTAKE) 


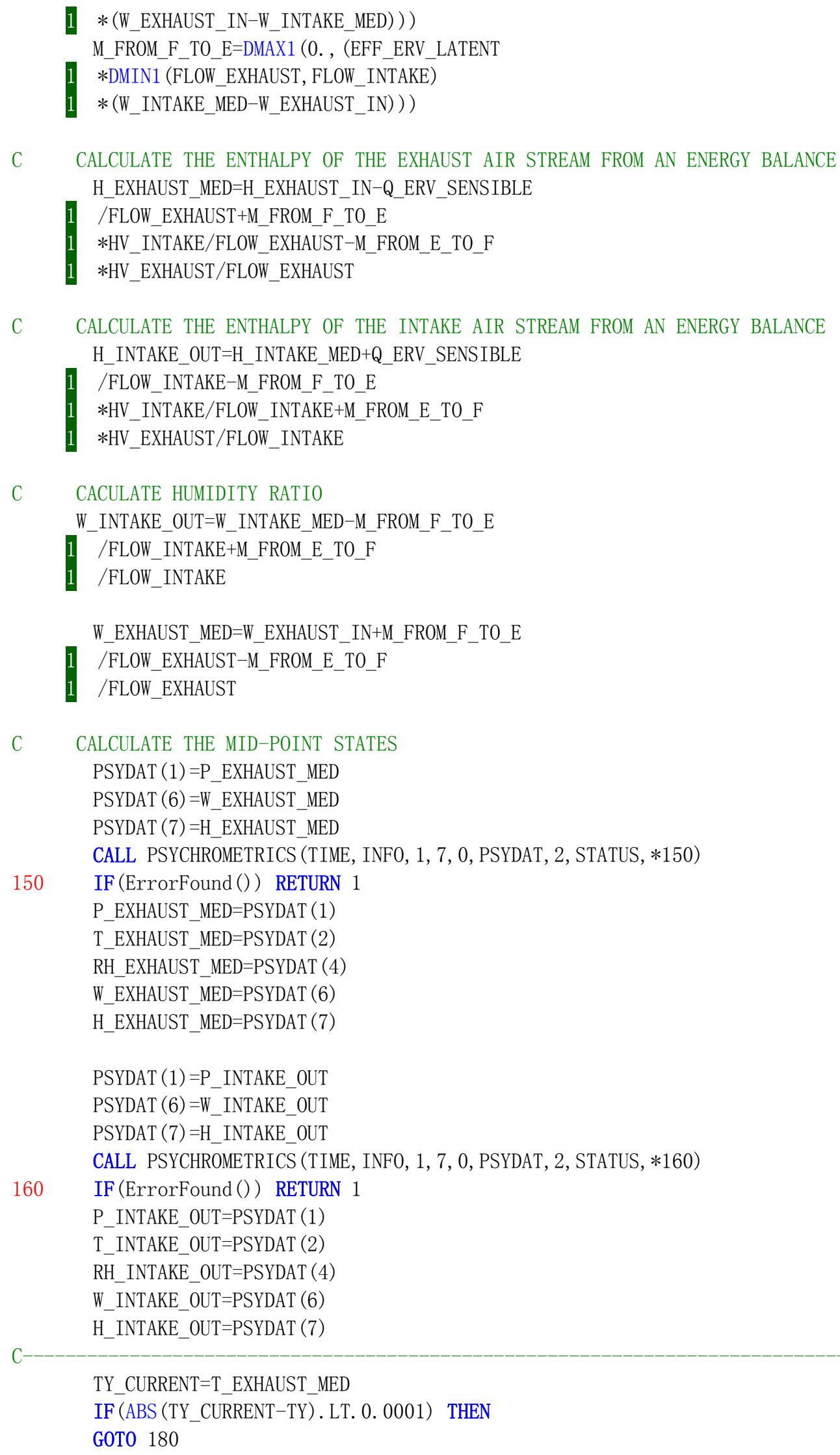




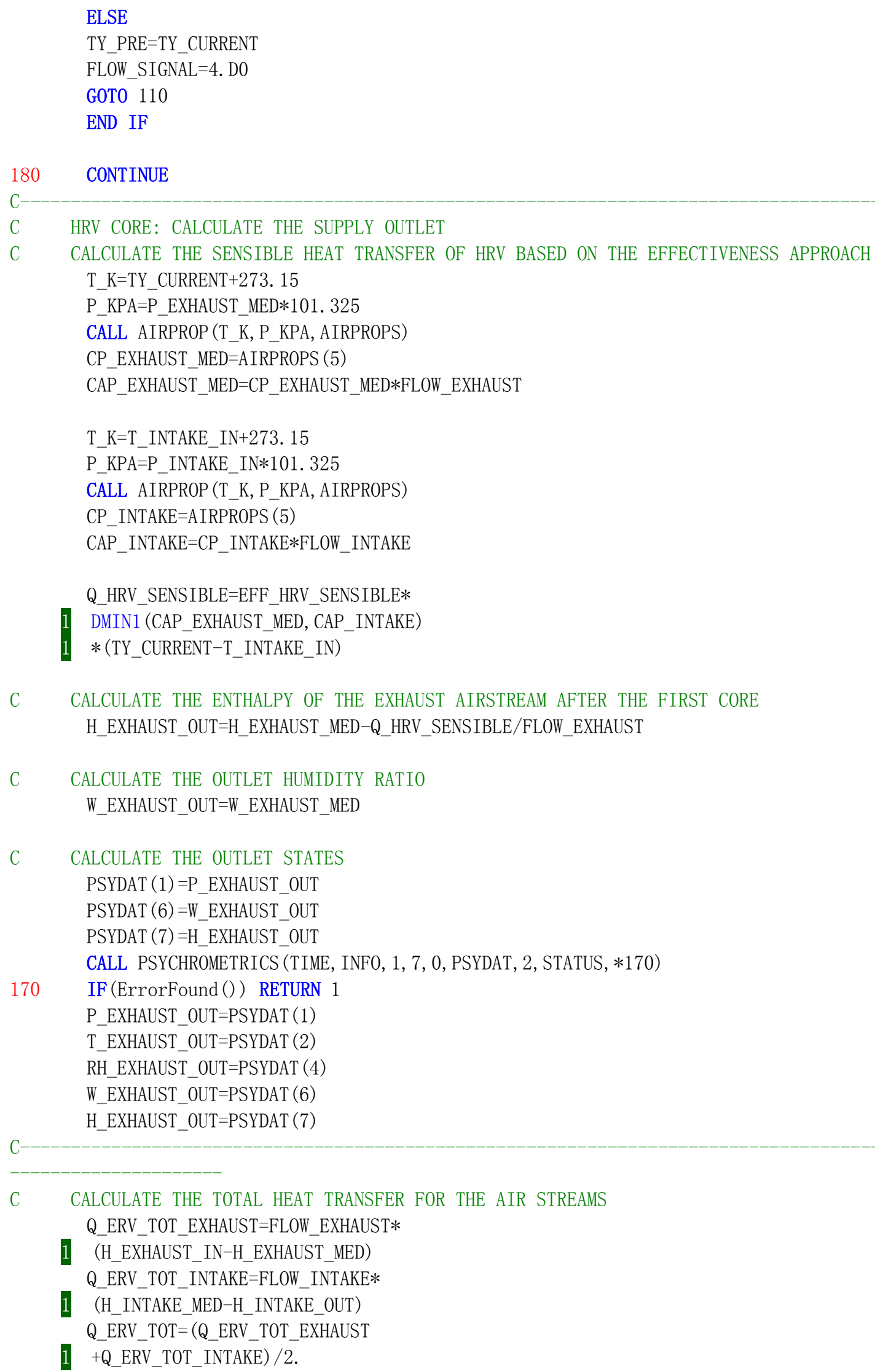


C CALCULATE THE LATENT HEAT TRANSFER

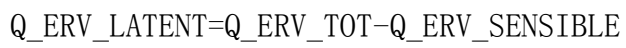

C CALCUlate THE TOTAL HEAT TRANSFER

Q_TOT $=$ Q_ERV_TOT + Q_HRV_SENSIBLE

C SET THE POWER CONSUMPTION

POWER=RATED_POWER

ENDIF

$\mathrm{C}$

C SET THE OUTPUTS FROM THIS MODEL IN SEQUENTIAL ORDER AND GET OUT

OUT (1) =T_EXHAUST_OUT

OUT $(2)=$ W_EXHAUST_OUT

OUT $(3)=$ RH_EXHAUST_OUT $* 100$.

OUT $(4)=$ FLOW_EXHAUST

OUT $(5)=$ P_EXHAUST_OUT

OUT $(6)=$ T_INTAKE_OUT

OUT $(7)=$ W INTAKE OUT

OUT $(8)=$ RH_INTAKE_OUT $* 100$.

OUT (9) =FLOW_INTAKE

OUT $(10)=$ P_INTAKE_OUT

$\operatorname{OUT}(11)=Q \_$TOT

OUT (12) $=$ Q_HRV_SENSIBLE

OUT (13) $=$ Q_ERV_SENSIBLE

OUT $(14)=$ Q_ERV_LATENT

OUT $(15)=$ POWER

OUT (16) $=$ EFF_HRV_SENSIBLE

OUT (17) =EFF_ERV_SENSIBLE

C EVERYTHING IS DONE - RETURN FROM THIS SUBROUTINE AND MOVE ON

RETURN 1

END

$\mathrm{C}$

\section{Section B3 - FORTRAN Source Code for TRNSYS Type-283}

SUBROUTINE TYPE283 (TIME, XIN, OUT, T, DTDT, PAR, INF0, ICNTRL, *)

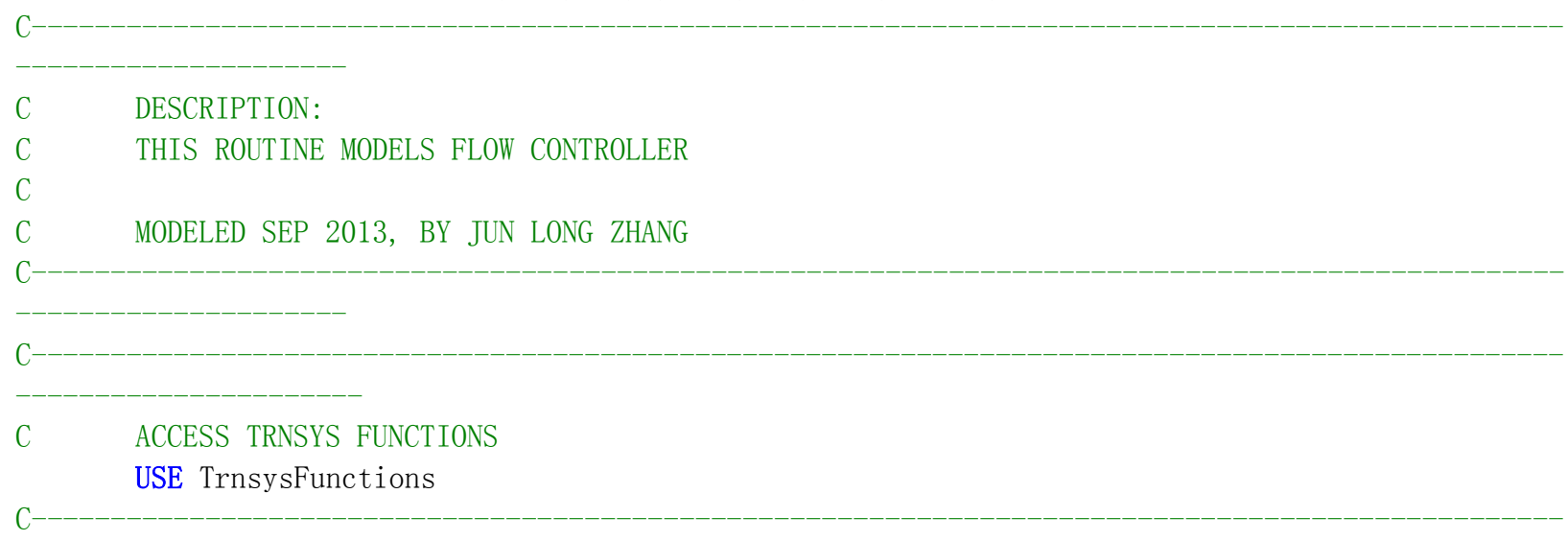


C REQUIRED BY THE MULTI-DLL VERSION OF TRNSYS

!DEC\$ATTRIBUTES DLLEXPORT :: TYPE283

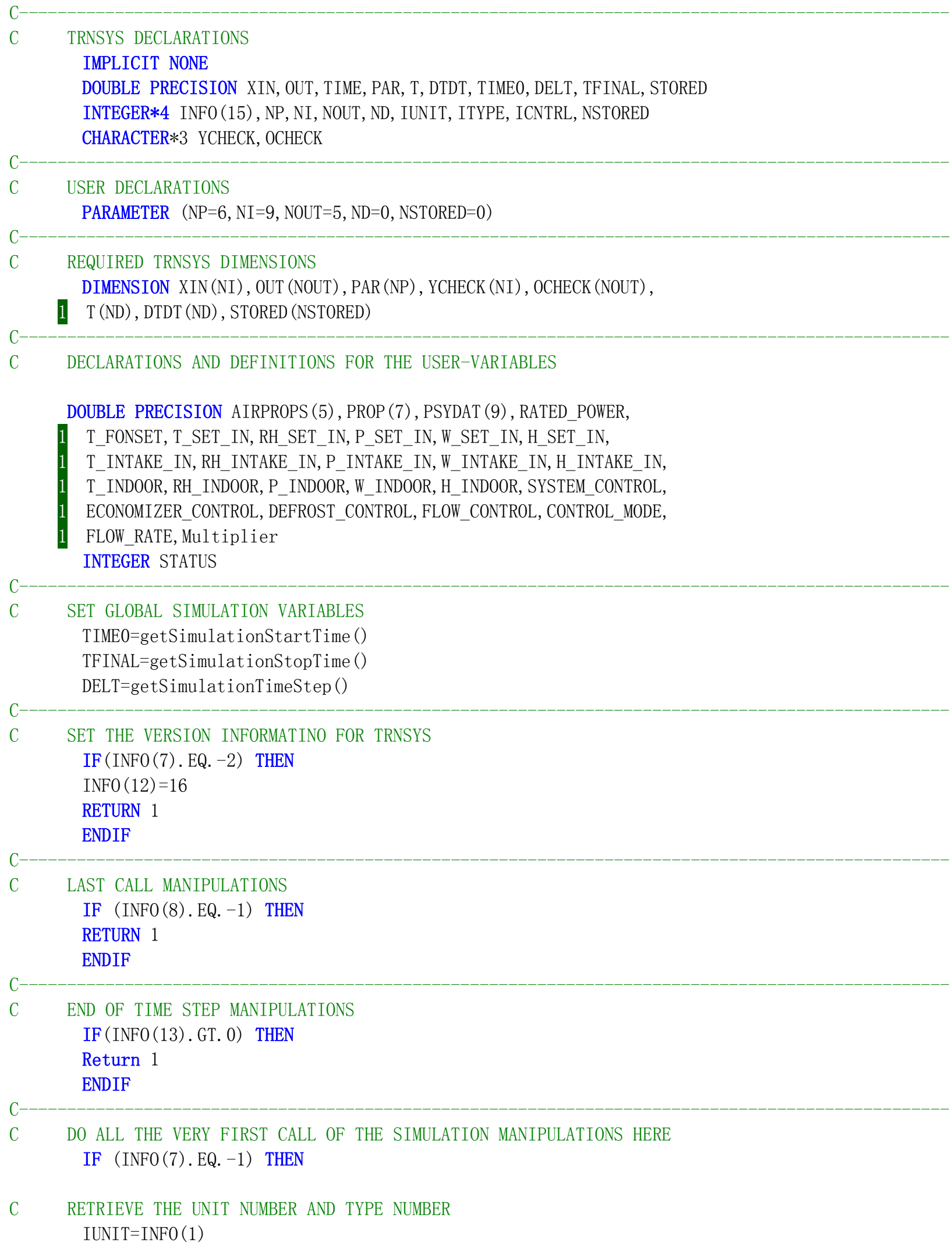


ITYPE=INFO (2)

C SET SOME INFO ARRAY VARIABLES TO TELL THE TRNSYS ENGINE HOW THIS TYPE IS TO WORK

$\operatorname{INFO}(6)=\mathrm{NOUT}$

$\operatorname{INFO}(9)=1$

$\operatorname{INFO}(10)=0$

$\mathrm{C}-$

CALL TYPECK (1, INF0, NI, NP, ND)

DATA YCHECK/' TE1' , 'PC1' ,' PR4' , TE1' , PC1' , 'PR4' , ' CF1' , ' CF1' , ' CF1' /

DATA OCHECK/' CF1' , ' DM1', ' DM1' , 'DM1', ' DM1' /

CALL RCHECK (INFO, YCHECK, OCHECK)

RETURN 1

ENDIF

C START TIME MANIPULATIONS

IF (TIME. LT. (TIME0+DELT/2. D0)) THEN

C SET UNIT NUMBER

IUNIT $=\operatorname{INF0}(1)$

ITYPE $=\operatorname{INF0}(2)$

C READ IN THE VALUES OF THE PARAMETERS IN SEQUENTIAL ORDER

T_SET_IN=PAR (1)

RH_SET_IN=PAR (2) /100.

P_SET_IN=PAR (3)

T_FONSET $=$ PAR (4)

CONTROL_MODE=PAR (5)

Multiplier=PAR (6)

IF (RH_SET_IN. LT. 0) CALL TYPECK $(-4, \operatorname{INFO}, 0,2,0)$

IF (RH_SET_IN. GT. 100) CALL TYPECK $(-4, \operatorname{INF0,0,2,0)}$

IF (P_SET_IN. LT. 0.) CALL TYPECK $(-4, \operatorname{INFO}, 0,3,0)$

IF (CONTROL_MODE. LT. 0. ) CALL TYPECK $(-3$, INF0, 0, 5, 0)

IF (CONTROL_MODE. GT. 2. ) CALL TYPECK $(-3$, INFO, 0, 5, 0)

IF (Multiplier. LE. 0. ) CALL TYPECK (-3, INF0, 0, 6, 0)

C SET THE INITIAL VALUES OF THE OUTPUTS

$\operatorname{OUT}(1)=4$. D0

OUT $(2)=1$. D0

$\operatorname{OUT}(3)=0.005$

$\operatorname{OUT}(4)=0.005$

$\operatorname{OUT}(5)=0.005$

RETURN 1

ENDIF

C-

$\mathrm{C}$

C *** ITS AN ITERATIVE CALL TO THIS COMPONENT ***

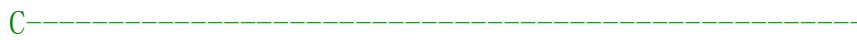

C RE-READ THE PARAMETERS IF ANOTHER UNIT OF THIS TYPE HAS BEEN CALLED 


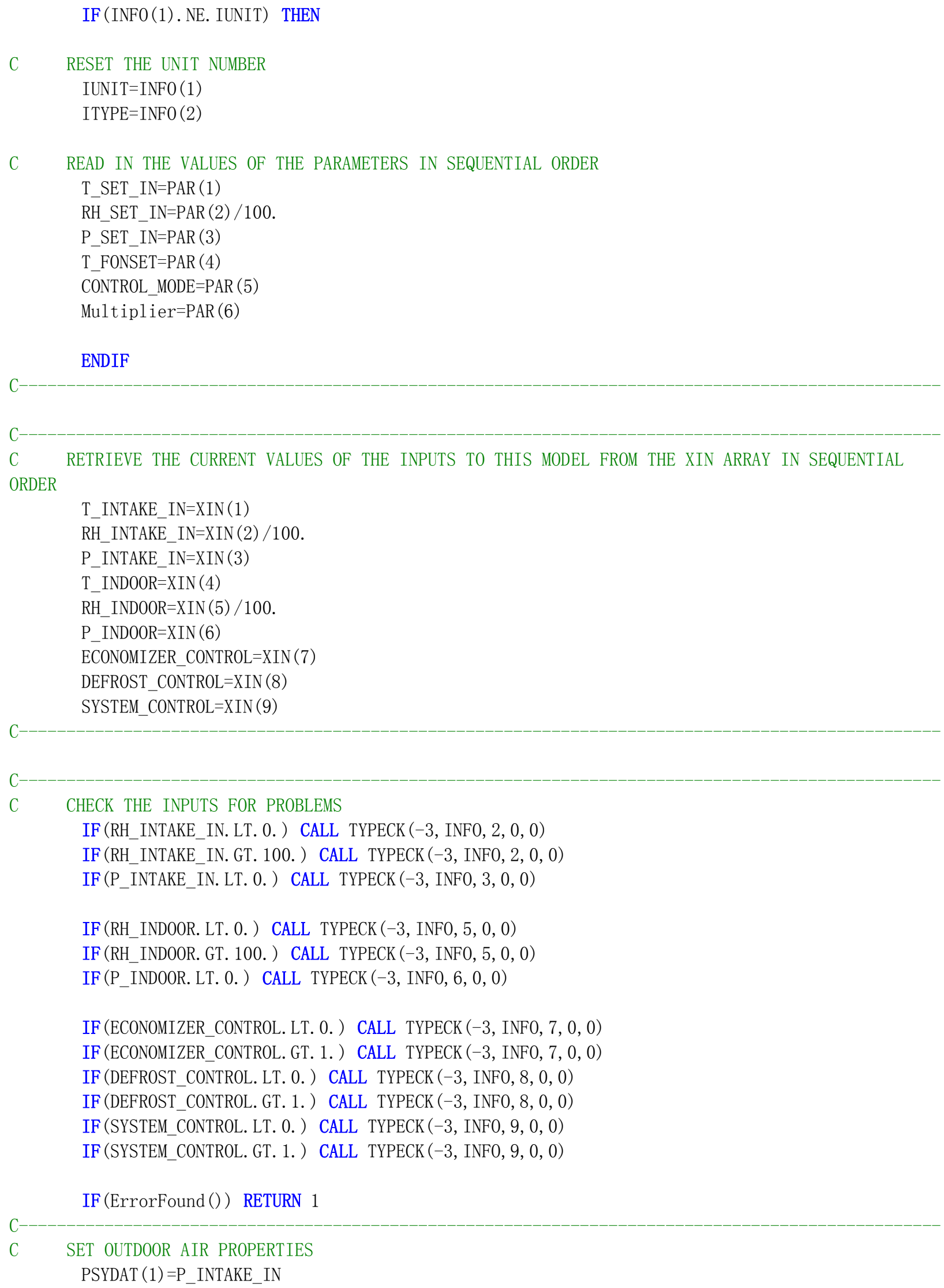




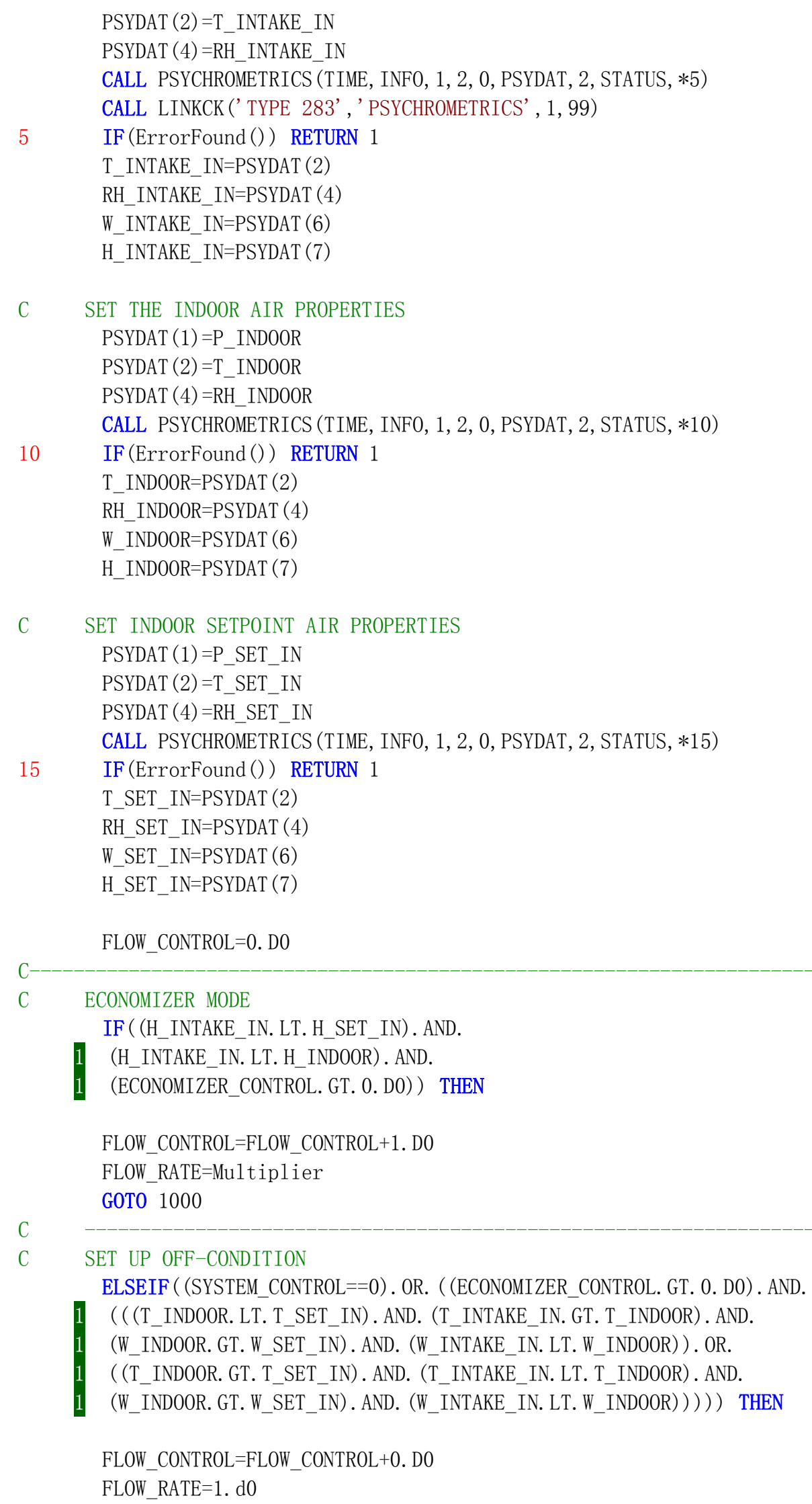


SINGLE CORE HRV MODE

ELSEIF ( ( (T_INDOOR. LT. T_SET_IN).AND. (T_INTAKE_IN. LT. T_INDOOR)). OR.

( (T_INDOOR.GT.T_SET_IN).AND. (T_INTAKE_IN.GT.T_INDOOR) )). AND.

( (W_INDOOR.GT.W_SET_IN).AND. (W_INTAKE_IN. LT.W_INDOOR) ) ) THEN

FLOW_CONTROL $=$ FLOW CONTROL +2. DO

FLOW RATE $=1 . \mathrm{d} 0$

$\mathrm{C}$

C SINGLE CORE ERV MODE

$\operatorname{ELSEIF}((($ T_INDOOR. GT. T_SET_IN).AND. (T_INTAKE_IN. LT. T_INDOOR) ). OR. ( (T_INDOOR. LT.T_SET_IN).AND. (T_INTAKE_IN.GT.T_INDOOR) ) ). AND. ( ( (W_INDOOR. LT.W_SET_IN).AND. (W_INTAKE_IN.GT.W_INDOOR) ). OR. ( (W_INDOOR. LT.W_SET_IN).AND. (W_INTAKE_IN. LT.W_INDOOR)). OR. $(($ W_INDOOR.GT.W_SET_IN).AND. (W_INTAKE_IN.GT.W_INDOOR $)))$ THEN

FLOW_CONTROL $=$ FLOW_CONTROL +3. D0

FLOW_RATE $=1 . \mathrm{d} 0$

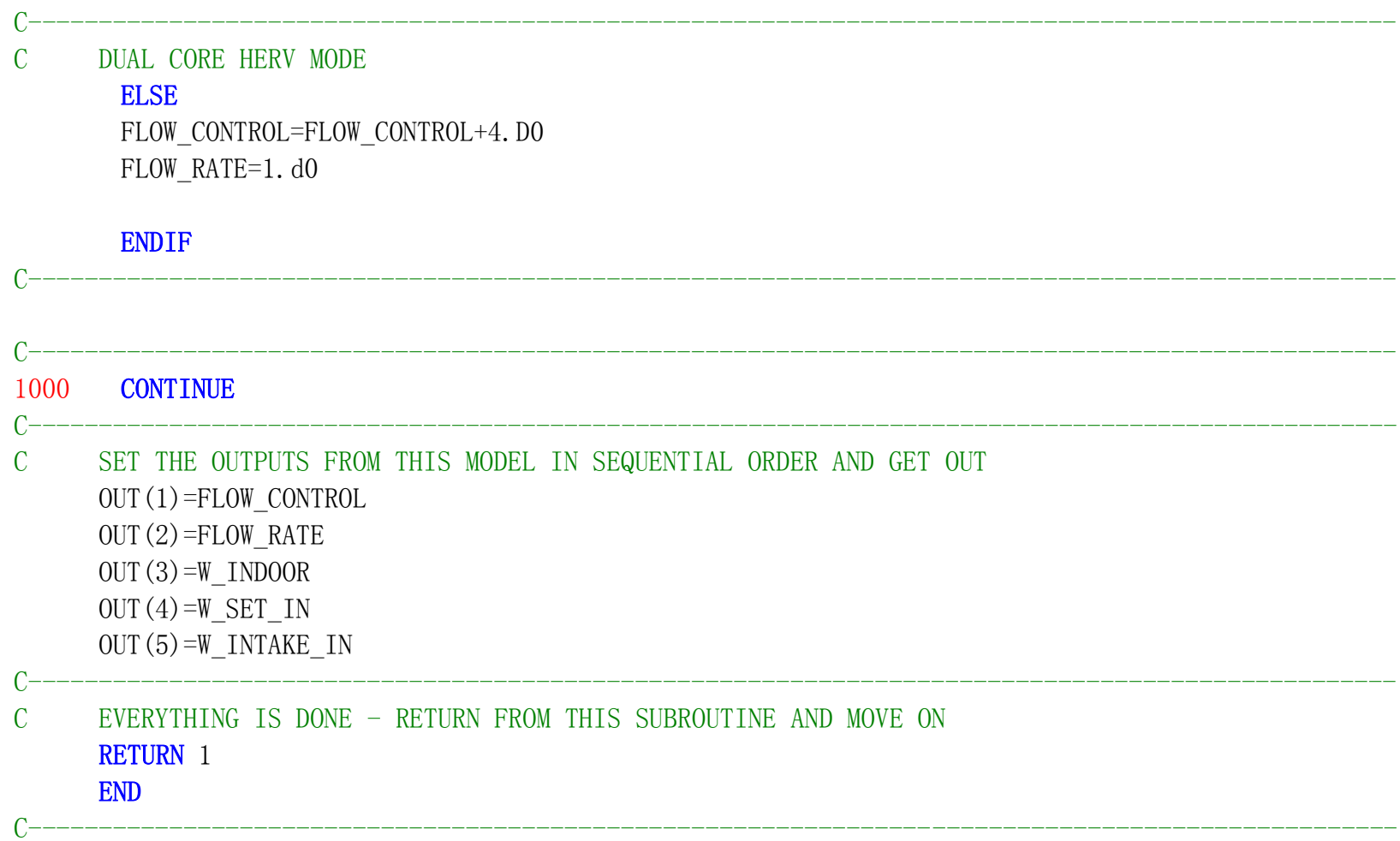




\section{Appendix C - Experimental Uncertainty Analysis}

The uncertainty analysis was performed on the HRV and ERV that were analyzed in Chapter 6. According to Barua (2010), Safa (2012), and Alzahrani (2014), the air temperatures observed in the experiments contained two error sources: the accuracy of sensors and calibrators. The use of high accuracy calibrators in the settings of this experiment led to a negligible error. However, the calibrator accuracy was included in the analysis. The accuracy value of calibrators is listed in Table C.1. In addition, the random errors have been neglected in this analysis. A list of the sensors and the accuracy is shown in Table C.2. To obtain the overall accuracy of sensors, the Square Root Sum of Squares (SRSS) method was adopted, see Equation C.1. The SRSS method suggests a simple arithmetic calculation that combines all accuracy by squaring them, adding the squares together and taking the square root of the sum of those squares (ASHRAE Guideline 2, 2005).

$$
\text { Overall accuracy of sensors }=\sqrt{A_{c}^{2}+A_{S}^{2}}
$$

The variables $\mathrm{A}_{c}$ and $\mathrm{A}_{s}$ denote calibrator accuracy and sensor accuracy, respectively. The overall accuracy of sensors from Equation (C.1) is used in the propagation of errors calibration to determine the accuracy of mechanical equipment. The propagation of errors is defined as the method of computing the uncertainty in a result which depends on the uncertainties from multiple variables. Generally, the quantities of interest (e.g., efficiency, mass flow rate) were not measuring directly in an experiment, and hence, it was necessary to determine the propagation of errors when mathematical operations are performed on measured quantities. Generally, the uncertainty of a result is expressed in terms of a standard uncertainty, $\sigma$, which has the same units as the quantity or in terms of a fractional (relative uncertainty), show as $\varepsilon$. For the uncertainty of $\mathrm{x}$, the relationship between $\sigma$ and $\varepsilon$ can be defined as:

$$
\epsilon \equiv \frac{\sigma_{x}}{x}
$$

The relative uncertainty is often expressed as a percentage. Suppose a measured height in the experiment is $20 \mathrm{~m}$, with an absolute error of $\pm 0.1 \mathrm{~m}$. The relative error is $100 \% \times(0.1 \mathrm{~m}) \div(20 \mathrm{~m})$ $\approx 0.5 \%$. The two expressions of the above results are:

$$
T=20 \pm 0.1 m \quad \text { or } \quad T=20 m \pm 0.5 \%
$$


Table C.3 shows the common formulas used for propagating uncertainty. When calculating the uncertainty for mixed operations (e.g., Eq. C.8), the propagation of uncertainty can be easily calculated by treating each operation separately using equations listed in the table (e.g., both sensible and latent efficiencies require operations \#1 and \#2).

Table C. 1 - List of calibrator accuracy

\begin{tabular}{cccc}
\hline Calibrator name & Manufacturer & Model number & Calibrator accuracy \\
\hline Precision Micro-Calibration Bath & SiKA & TPM 165S & $\pm 0.1^{\circ} \mathrm{C}$ \\
\hline $\mathrm{LiCl}\left(@ 23^{\circ} \mathrm{C}\right)$ & VAISALA & $19729 \mathrm{HM}$ & $\pm 0.3 \%$ \\
\hline $\mathrm{MgCl}_{2}\left(@ 23^{\circ} \mathrm{C}\right)$ & VAISALA & $19730 \mathrm{HM}$ & $\pm 0.2 \%$ \\
\hline $\mathrm{NaCl}\left(@ 23^{\circ} \mathrm{C}\right)$ & VAISALA & $19731 \mathrm{HM}$ & $\pm 0.1 \%$ \\
\hline
\end{tabular}

Table C.2 - List of sensor accuracy

\begin{tabular}{cccc}
\hline Sensor name & Manufacturer & Model number & Sensor accuracy \\
\hline $\begin{array}{c}\text { Air Temperature \& } \\
\text { Relative Humidity }\end{array}$ & Dwyer Instruments Inc. & Series RHT-D / & $\pm 1.5 \%$ \\
Series RHP-2D11 & $\pm 2.0 \%$ \\
\hline $\begin{array}{c}\text { Differential Pressure } \\
\text { Transmitter }\end{array}$ & Dwyer Instruments Inc. & Series 677B & $\pm 0.4 \%$ \\
\hline Wattnode & Omega & WNB-3Y-208-P & $\pm 1.0 \%$ \\
\hline
\end{tabular}

Table C.3 - Mathematical operation of propagating uncertainty (Harvey, 2000)

\begin{tabular}{|c|c|c|c|}
\hline Operation & Calculation & Formula & Uncertainty Formula \\
\hline$\# 1$ & Sum / Difference & $f=x+y \quad, \quad f=x-y$ & $\sigma_{f}=\sqrt{\sigma_{x}^{2}+\sigma_{y}^{2}}$ \\
\hline$\# 2$ & Multiplication / Division & $f=x y \quad, \quad f=\frac{x}{y}$ & $\epsilon_{f}=\sqrt{\epsilon_{x}^{2}+\epsilon_{y}^{2}}$ \\
\hline$\# 3$ & Products of powers & $f=x^{m} y^{n}$ & $\epsilon_{f}=\sqrt{\left(m \epsilon_{x}\right)^{2}+\left(n \epsilon_{y}\right)^{2}}$ \\
\hline
\end{tabular}

According to Table C.1 and C.2, the accuracy of the bath is given as standard value, while the sensor is given as relative value, therefore, the overall uncertainty should be calculated for a range of air temperature. When using relative uncertainty in temperature $\left(\epsilon_{T} \equiv \frac{\sigma_{T}}{T}\right)$, the temperature $\mathrm{T}$ must be expressed in absolute unit of degree Kelvin (Coleman \& Steele, 1999). For instance, the measured temperature is $20^{\circ} \mathrm{C}$ with an uncertainty of $\pm 1.5 \%, \sigma_{T}$ in this case is $\pm 4.4^{\circ} \mathrm{C}$ (which is $0.015 \times 293.15 \mathrm{~K}$ ) and not $0.3^{\circ} \mathrm{C}$ (which is $0.015 \times 20^{\circ} \mathrm{C}$ ). As shown in Figure C.1, the standard uncertainty varies from \pm 3.9 to $\pm 4.7 \mathrm{~K}$. 


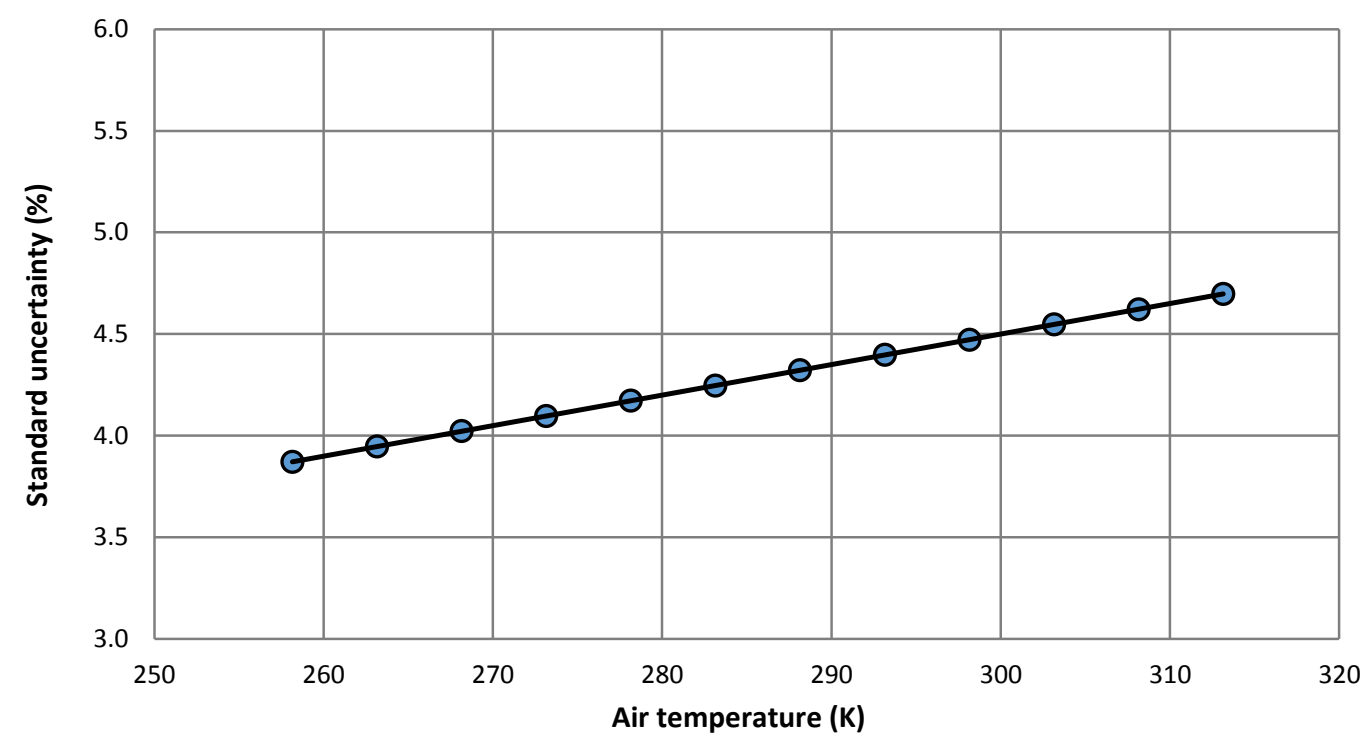

Figure C.1 - Relative and standard uncertainties at different air temperatures

According to Lu and Chen (2007), humidity sensor contains the following sources of uncertainty:

1. Uncertainty of the calibration equation (e.g., linear regression line).

2. Uncertainty of the reference standard (e.g., saturated salt solutions).

3. Uncertainty due to temperature variation.

4. Uncertainty due to repeatability and resolution.

5. Uncertainty due to hysteresis.

As shown in Table C.1, each calibration salt contains an uncertainty that differs from the others, and hence, no distribution pattern was found. For this, Lu and Chen (2007) suggested to consider the average uncertainty for the reference standard. For others, the uncertainty due to repeatability, resolution, and hysteresis can be calculated from Equation C.3. The deviation $\mathrm{U}$ due to the three sources are given in Table C.4.

$$
u= \pm \frac{\mathrm{U}}{2 \sqrt{3}}
$$

To calculate the uncertainty due to temperature variation, temperature coefficient $\left(\% \mathrm{RH} /{ }^{\circ} \mathrm{C}\right)$ is needed. Unfortunately, this value was not given by the manufacturer. The stability of the calibration bath is $\pm 0.05^{\circ} \mathrm{C}$, meaning that the temperature variation during test period was negligible. In this study, the uncertainty due to temperature variation was not considered. The uncertainty of source \#2 to \#5 are listed in Table C.5. 
Table C. 4 - Specifications of the humidity transmitter

\begin{tabular}{ll}
\hline Specifications & Series RHT-D /Series RHP-2D11 \\
\hline Measuring range & $0-100 \%$ RH \\
Repeatability & $\pm 0.1 \%$ \\
Resolution & $0.1 \%$ \\
Hysteresis & $\pm 1 \%$ \\
\hline & \\
& Table C.5 - Uncertainty of different sources \\
\hline Uncertainty & Series RHT-D /Series RHP-2D11 \\
\hline Reference standard & $\pm 0.2 \%$ \\
Repeatability & $\pm 0.029 \%$ \\
Resolution & $\pm 0.029 \%$ \\
Hysteresis & $\pm 0.29 \%$ \\
\hline
\end{tabular}

Another source of uncertainty was the calibration equation. According to the calibrating results listed in Table 6.4.5, a linear relationship between the sensor readings and the reference values can be established, as shown in Figures C.2. The linear regression yields an equation with a coefficient of determination $\left(\mathrm{R}^{2}\right)$ of 0.9994 for $\mathrm{HRV}$ and 0.9998 for ERV:

$$
\begin{aligned}
& y=m x+b=0.9933 x+1.5776 \\
& y=m x+b=0.9582 x+2.0315
\end{aligned}
$$

$\mathrm{Lu}$ and Chen (2006) reported that the uncertainty of calibration equation $\left(u_{p r e}\right)$ can be obtained from Equation C.4 and C.5:

$$
u_{\text {pre }}=\frac{s}{m}
$$

where

$$
S=\sqrt{\frac{(y-\hat{y})^{2}}{n-1}} \times \sqrt{\frac{1}{p}+\frac{1}{n}+\frac{\left(x-\bar{x}_{l}\right)^{2}}{\sum\left(x_{i}^{2}\right)-\sum\left(x_{i}\right)^{2} / n}}
$$

Where $y$ is the sensor reading, $x$ is the reference value, $s$ is the standard deviation of calibration equation, $\hat{y}$ is the sensor reading predicted from the linear regression equation, $p$ is the numbers of measurement for prediction, $n$ is total number of measurement for calibration equation. According to the calibrations presented in Chapter $6, n$ and $p$ is respectively 3 and 1 . The above equation yields an uncertainty due to calibration equation. Figures C. 3 shows the estimated uncertainty for different observed readings. For instance, the $u_{\text {pre }}$ for ERV at $30 \% \mathrm{RH}$ is $0.588 \%$, combining all the humidity uncertainties using Equation C.1, the standard uncertainty is $\pm 0.687 \%$ RH. 

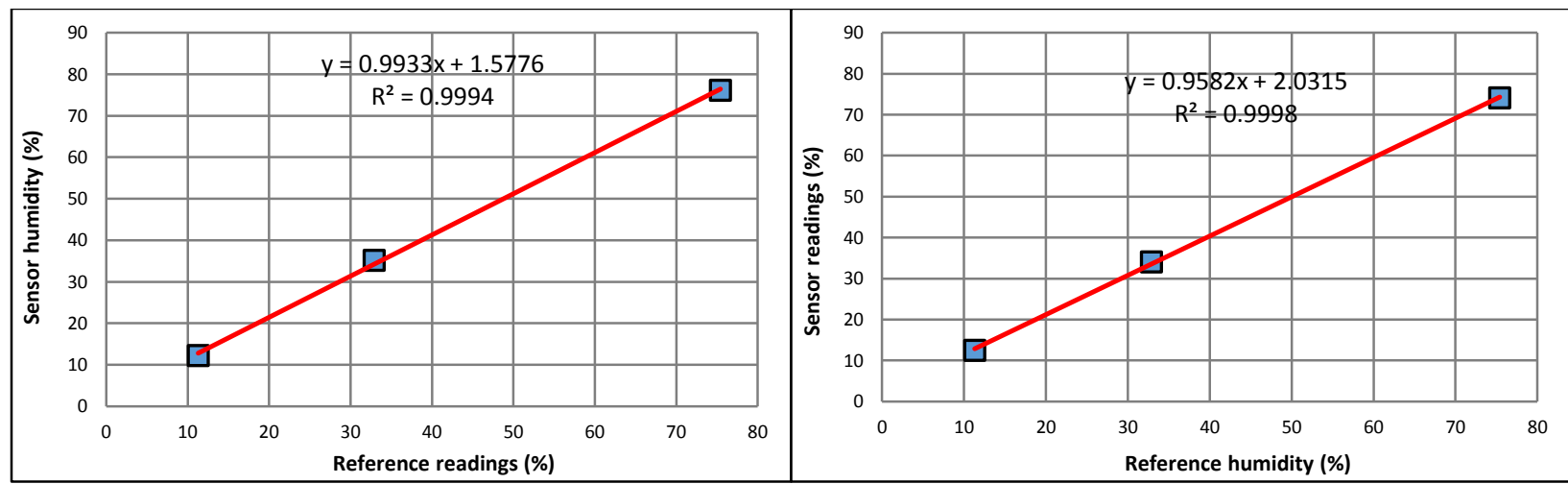

Figure C.2 - Linear relationship between sensor readings and reference values: left panel - HRV, right panel - ERV
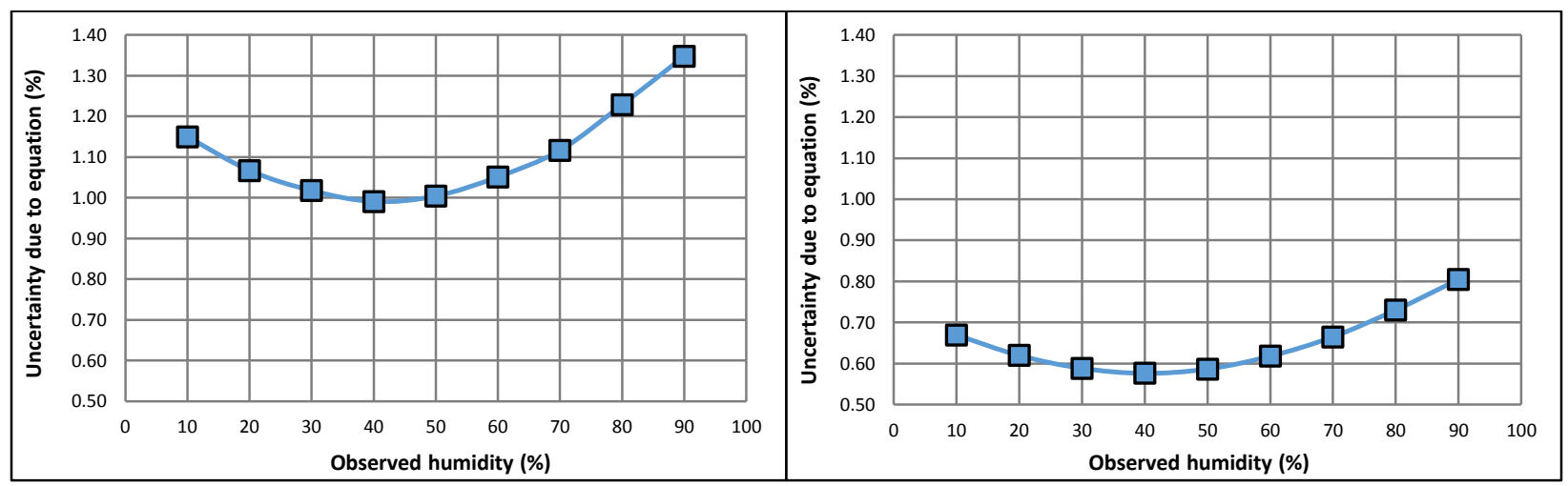

Figure C.3 - Estimated uncertainties due to calibration equation: left panel - HRV, right panel - ERV

As an illustration, the propagation of uncertainty for volumetric airflow rate (cfm), sensible and latent efficiencies (\%) are presented below. To calculate the volumetric airflow (cfm) rate for a certain input $\mathrm{mA}$ reading, two equations are use:

1. A linear equation that converts $\mathrm{mA}$ to differential pressure (in. $\mathrm{H}_{2} \mathrm{O}$ ).

$$
p=15.625 \times I-0.0625
$$

2. The equation that converts pressure to airflow rate $(\mathrm{cfm})-6$ " duct.

$$
\dot{\mathrm{Q}}=455 \sqrt{p}
$$

If the sensor reads $20 \mathrm{~mA}$ or $0.02 \mathrm{~A}$, the differential pressure is:

$p=15.625 *(0.02)-0.0625=0.25$ in. $\mathrm{H}_{2} \mathrm{O}$

Table C. 2 shows that the uncertainty of the pressure transmitter is $\pm 0.4 \%$, the uncertainty is:

$\sigma_{p}=15.625 *(0.004 * 0.02)= \pm 0.0012$ in. $\mathrm{H}_{2} \mathrm{O}$

Applying Eq. C.7, the airflow rate is:

$\dot{\mathrm{Q}}=455 * \sqrt{0.25}=227.5 \mathrm{cfm}$

The uncertainty of the airflow rate is: 
$\sigma_{\dot{Q}}=\frac{455}{2}(0.00125) \times(0.25)^{-\frac{1}{2}}= \pm 0.57 \mathrm{cfm}$

Figure C.4 shows the uncertainty at different airflow rates. For HRV with an average airflow rate of $147 \mathrm{cfm}$, the uncertainty is $\pm 0.47 \mathrm{cfm}$. For ERV with an average airflow rate of $88 \mathrm{cfm}$, the uncertainty is also $\pm 0.47 \mathrm{cfm}$.

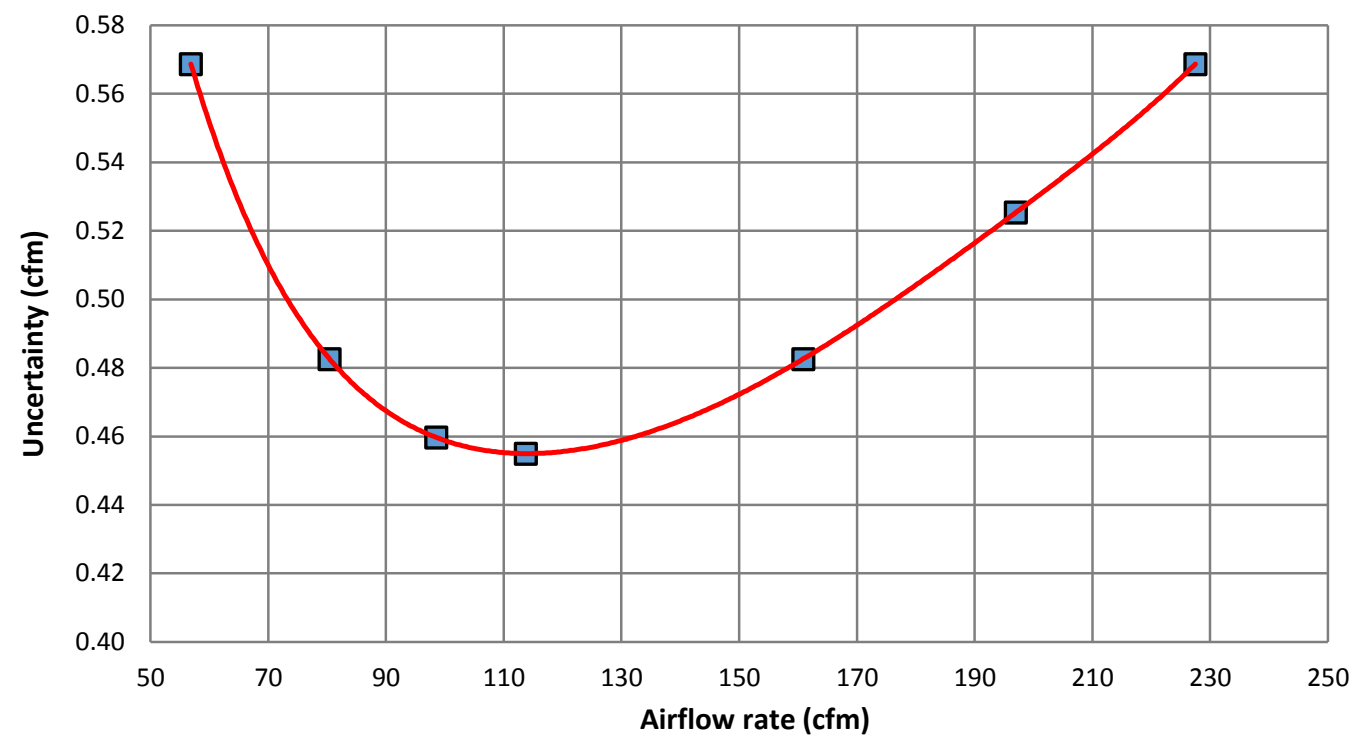

Figure C.4 - Uncertainty of airflow rate

To calculate the sensible efficiency, Eq. C.8 is needed. The propagation of uncertainty can be calculated using the equations of both operations \#1 and \#2, as listed in Table C.3. As an illustration, a sample calculation is provided below for the estimation of the uncertainty of sensible efficiency for Jan. $23^{\text {rd }}, 2014$, the air conditions are given in Table C.6.

$$
\varepsilon_{\mathrm{s}}=\frac{T_{f o}-T_{f i}}{T_{r i}-T_{f i}}
$$

Table C. 3 - Inlet/outlet air temperature and humidity

\begin{tabular}{cccc}
\hline & Fresh inlet & Exhaust inlet & Fresh outlet \\
\hline Temperature $\left({ }^{\circ} \mathrm{C}\right)$ & -20.10 & 21.75 & 11.88 \\
Relative humidity $(\%)$ & 68.54 & 28.40 & 22.71 \\
RH uncertainty & 0.748 & 0.690 & 0.706 \\
\hline
\end{tabular}

The temperature differences and the associated uncertainties are:

$T_{f o}-T_{f i}=(11.88+20.10)^{\circ} \mathrm{C} \pm \sqrt{(285.03 \times 0.015)^{2}+(253.05 \times 0.0015)^{2}}$

$T_{f o}-T_{f i}=31.98^{\circ} \mathrm{C} \pm 5.72^{\circ} \mathrm{C}$ 


$$
\begin{aligned}
& T_{e i}-T_{f i}=(21.75+20.10)^{\circ} \mathrm{C} \pm \sqrt{(294.9 \times 0.0015)^{2}+(253.05 \times 0.0015)^{2}} \\
& T_{f o}-T_{f i}=41.85^{\circ} \mathrm{C} \pm 5.83^{\circ} \mathrm{C}
\end{aligned}
$$

The sensible efficiency and the associated uncertainty are:

$\varepsilon_{\mathrm{s}}=\frac{T_{f o}-T_{f i}}{T_{r i}-T_{f i}}=\frac{31.98^{\circ} \mathrm{C}}{41.85^{\circ} \mathrm{C}} \pm \sqrt{0.0187^{2}+0.0185^{2}}$

$\varepsilon_{\mathrm{s}}=76.41 \% \pm 2.02 \%$

To calculate the latent efficiency, humidity ratio is needed (see Eq. C.9). The humidity ratio is a temperature dependent variable, and hence, the overall uncertainty is expected to be higher than sensible efficiency.

$$
\varepsilon_{\mathrm{L}}=\frac{w_{f o}-w_{f i}}{w_{r i}-w_{f i}}
$$

Where;

$$
w=3.91 \times 10^{-5} \times R H \times e^{(17.3 \times T) /(T+238.3)}
$$

For fresh inlet air with $-20.10^{\circ} \mathrm{C}$ and $68.54 \% \mathrm{RH}$, the exponential term is:

$e^{\left(\frac{17.3 \times \mathrm{T}}{T+238.3}\right)}=e^{-1.59 \pm 0.0338}$

$e^{\left(\frac{17.3 \times \mathrm{T}}{T+238.3}\right)}=0.203$

Where the uncertainty of exponential function can be evaluated from:

$\sigma_{e}=\sigma\left(e^{-\lambda}\right)=\sigma \lambda \times\left(e^{-\lambda}\right)$

$\sigma_{e}=0.0338 \times(0.203)= \pm 0.00687$

Therefore, Eq. C.10 becomes:

$w_{f i}=3.91 \times 10^{-5} \times(68.54 \% \pm 0.748 \%) \times(0.203 \pm 0.00687)$

Apply operation \#1 in Table C.3:

$w_{f i}=0.000545 \pm 1.93 \times 10^{-5}$

For exhaust inlet and fresh outlet, the similar procedures were followed:

$w_{e i}=0.00472 \pm 1.85 \times 10^{-4}$

$w_{f o}=0.00202 \pm 7.19 \times 10^{-5}$

The propagation of uncertainty can be calculated similar to the sensible efficiency. Applying operation \#1 and \#2 in Table C.3:

$$
\begin{aligned}
& w_{f o}-w_{f i}=(0.00202-0.000545)^{\circ} \mathrm{C} \pm \sqrt{\left(1.93 \times 10^{-5}\right)^{2}+\left(7.19 \times 10^{-5}\right)^{2}} \\
& w_{f o}-w_{f i}=0.00147 \pm 7.44 \times 10^{-5}
\end{aligned}
$$


$w_{e i}-w_{f i}=(0.00472-0.000545)^{\circ} \mathrm{C} \pm \sqrt{\left(1.85 \times 10^{-4}\right)^{2}+\left(1.93 \times 10^{-5}\right)^{2}}$

$w_{f o}-w_{f i}=0.00417 \pm 1.86 \times 10^{-4}$

The latent efficiency and the associated uncertainty are:

$\varepsilon_{\mathrm{L}}=\frac{w_{f o}-w_{f i}}{w_{r i}-w_{f i}}=\frac{0.00147}{0.00417} \pm \sqrt{(0.0506)^{2}+(0.0446)^{2}}$

$\varepsilon_{\mathrm{L}}=35.31 \% \pm 2.38 \%$ 


\section{Appendix D - Calibration Procedures and Suggestions}

In order to calibrate the Dwyer Series RHP sensor (both temperature and relative humidity readings), the Sika calibration bath plays a significant role (see Figure D.1). The calibration bath is a compact and stable calibrator which will be extremely useful for both temperature and humidity calibrations. The author strongly recommends to calibrate this sensor using at least four ${ }^{34}$ saturated salt solutions in order to obtain the deviations at different humidity levels.

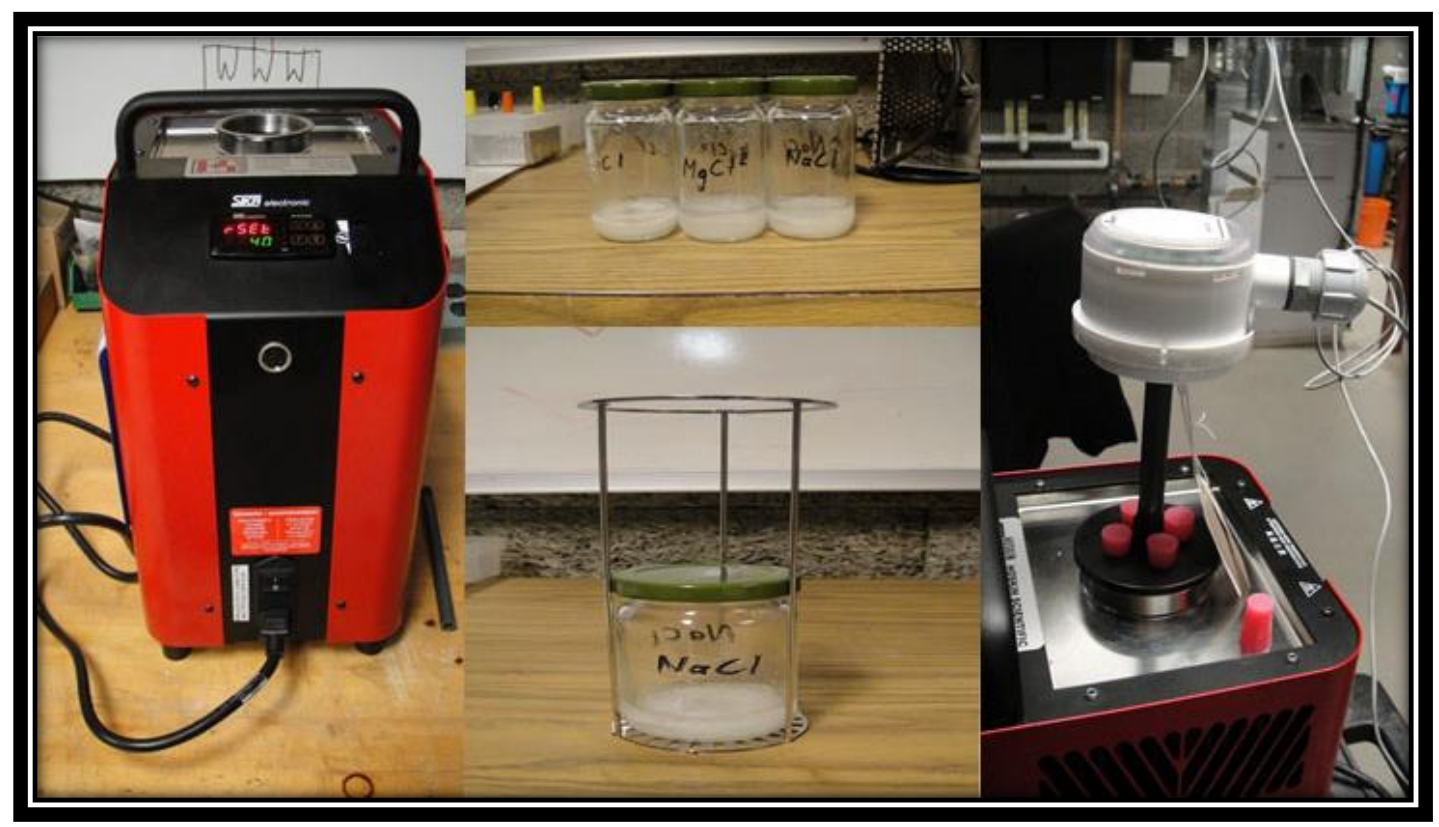

Figure D.1 - Equipment for Air temperature and humidity calibrations

*left panel shows the Sika micro-calibration bath, center panels show the 3 saturated salt solutions with the removable basket, right panel shows the AT/RH sensor that was being calibrated.

Firstly, the calibration of temperature reading is a straightforward but time-consuming process. Simply inserting the sensor into the calibration bath with a setup temperature (see Figure D.1 right panel), the calibration will be completed whenever the reading becomes stable. This process will take as long as 45 minutes per reading depending on the sensor sensitivity and the time to heat up or cool down the bath. One suggestion is to maintain the bath at much higher/lower temperature for the first 5 minutes so that the response of the sensor can be expedited. The author found that the overall calibration period for each reading was 5-10 minutes shorter, but still time-consuming. Therefore, it is very frustrating and tedious if one decides to perform calibration for the entire range of the sensor. To save time, the calibration range of a sensor should be adjusted depending

${ }^{34}$ Corresponding $11.3 \%(\mathrm{LiCl}), 32.8 \%\left(\mathrm{MgCl}_{2}\right), 75.3 \%(\mathrm{NaCl})$ and $97.3 \%\left(\mathrm{~K}_{2} \mathrm{SO}_{4}\right) \mathrm{RH}$ at $25^{\circ} \mathrm{C}$. 
on the range of use. For example, if the inlet fresh air temperature sensor of the ERV reads as low as $-20^{\circ} \mathrm{C}$ in the winter, and as high as $30^{\circ} \mathrm{C}$ in the summer, the calibration range should be $-20^{\circ} \mathrm{C}$ to $30^{\circ} \mathrm{C}$, with an increment of $5^{\circ} \mathrm{C}$. In contrast, the inlet exhaust air temperature (or room temperature) sensor reads as low as $10^{\circ} \mathrm{C}$ and as high as $30^{\circ} \mathrm{C}$, the calibration range should be $10^{\circ} \mathrm{C}$ to $30^{\circ} \mathrm{C}$. Therefore, it is unwise to calibrate the inlet exhaust sensor at $-20^{\circ} \mathrm{C}$.

Secondly, the calibration of the humidity is also a straightforward but time-consuming process. However, students must pay attention to the setup requirements, e.g., as shown in Figure D.2, a proper amount of water must be added, otherwise the salt will become $100 \%$ dissolved. In addition, the smaller the container, the faster the equilibrium relative humidity will reach. The required amounts of water are given in Table D.1 (use distilled water).

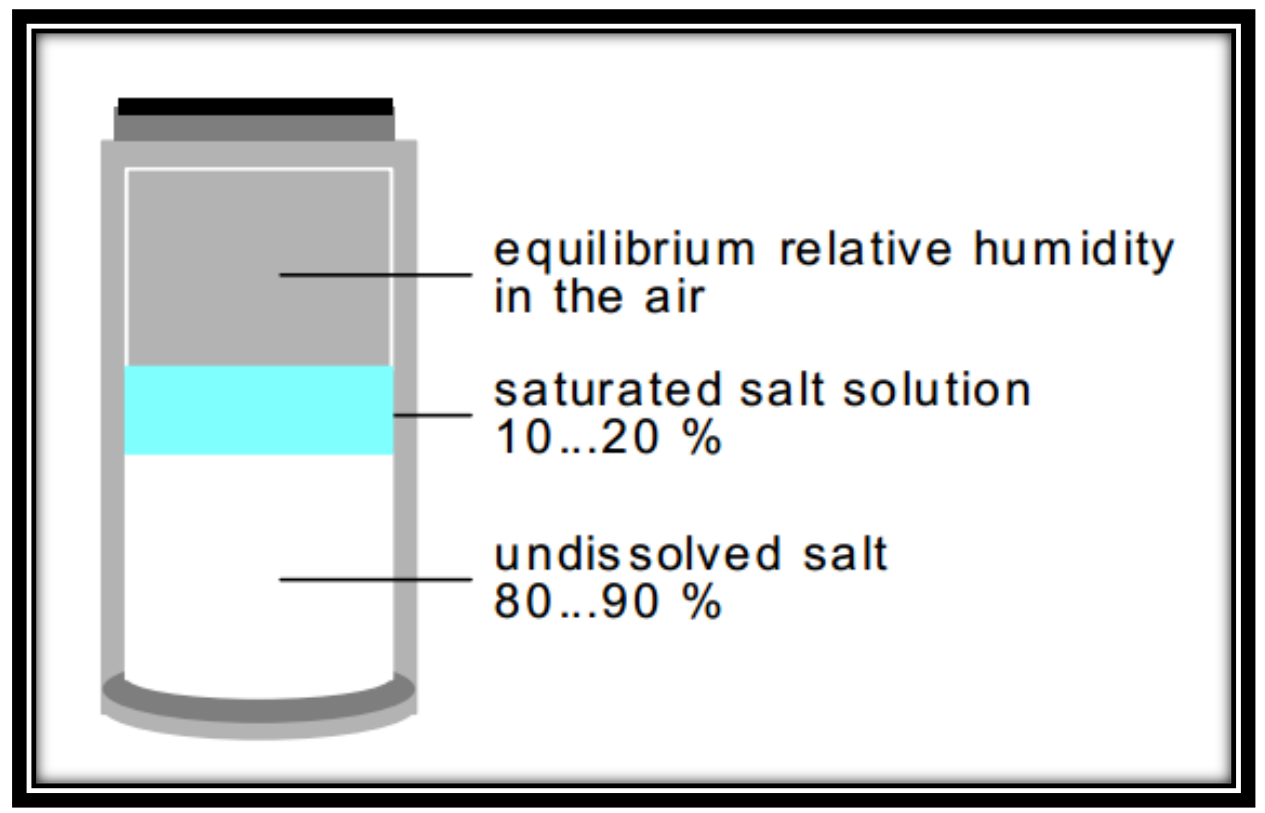

Figure D.2 - Preparation of salt solutions (McDuffee \& Shakya, 2010)

Table D.1 - Required amounts of water (Vaisala, 2006)

\begin{tabular}{c|c}
\hline Saturated salt solutions & Required amounts of water (ml) \\
\hline $\mathrm{LiCl}$ & 12 \\
$\mathrm{MgCl}_{2}$ & 3 \\
$\mathrm{NaCl}$ & 10 \\
$\mathrm{~K}_{2} \mathrm{SO}_{4}$ & 10 \\
\hline
\end{tabular}

The general procedures of salt calibration are:

1. Read all the warnings and cautions attached to each ready-dosed salt package, e.g., $\mathrm{LiCl}$ is harmful when swallowed. 
2. Do not store/use $\mathrm{LiCl}$ solution in temperature below $18^{\circ} \mathrm{C}$ because its equilibrium humidity changes permanently (Vaisala, 2006).

3. Clean up the jars, and pour out each of the salt solutions into a separated jar with proper amounts of distilled water.

4. Fit the jar into the removable basket (see Figure D.1 mid-panel), and then insert the basket into the calibration bath.

5. Put a circular-hollow paperboard on top of the jar to prevent direct touch between the sensor and the salt.

6. Insert the sensor and allow approximately 24 hours for stabilization.

7. It is recommended to keep the same temperature throughout the calibrations (e.g., $20^{\circ} \mathrm{C}$ to $\left.25^{\circ} \mathrm{C}\right)$.

8. Repeat procedure \#4 to \#6 for other salts, and remember to close the lid of the jar every time after use.

If time allows, repeat the above procedures for all sensors. Otherwise, use the reading of the calibrated sensor as a reference standard. One practical suggestion is to place all the sensors together and record the readings once they become stable. Therefore, the deviations to the reference reading can be applied into LabVIEW for adjustments. 


\section{Appendix E - Major Equipment Photos}

From Figure E.1 to E.2 show the HVAC systems of the Archetype Sustainble House-A, from

Figure E.3 To E.5 show the HVAC systems of the Archetype Sustainble House-B.

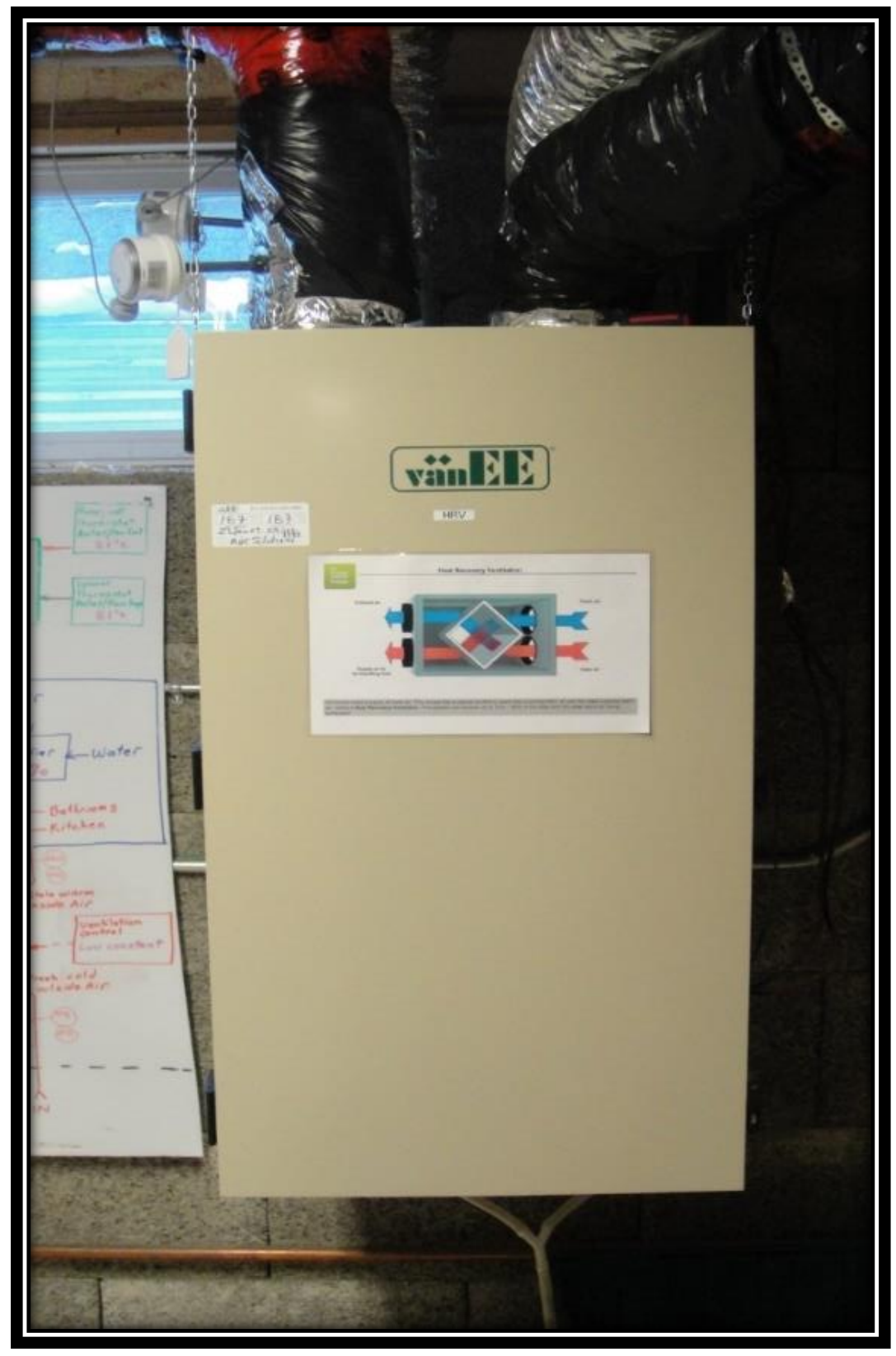

Figure E.1 - Heat recovery ventilator 


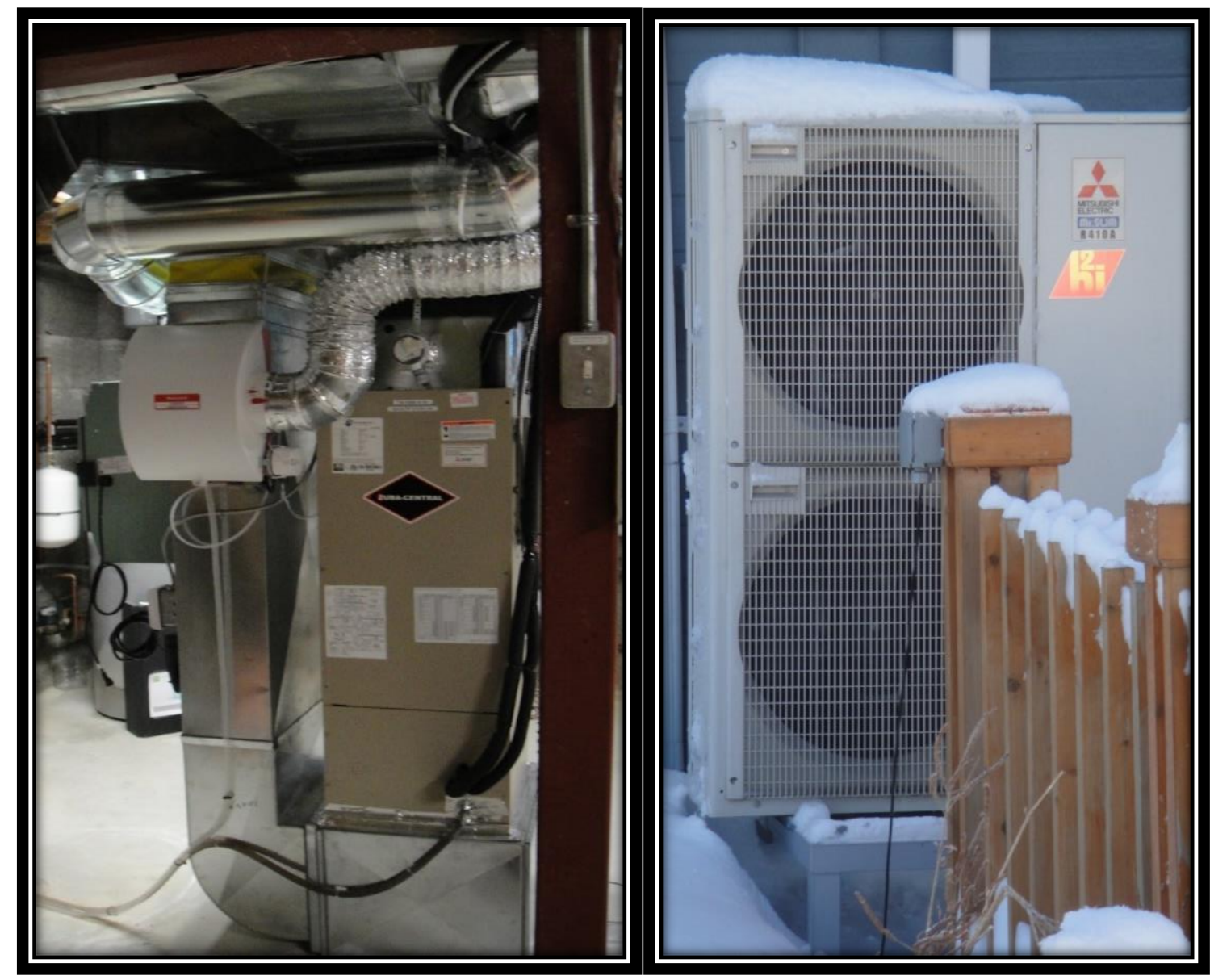

Figure E.2 - Air handling unit (left panel) and air-source heat pump (right panel) for the Archetype Sustainable House-A

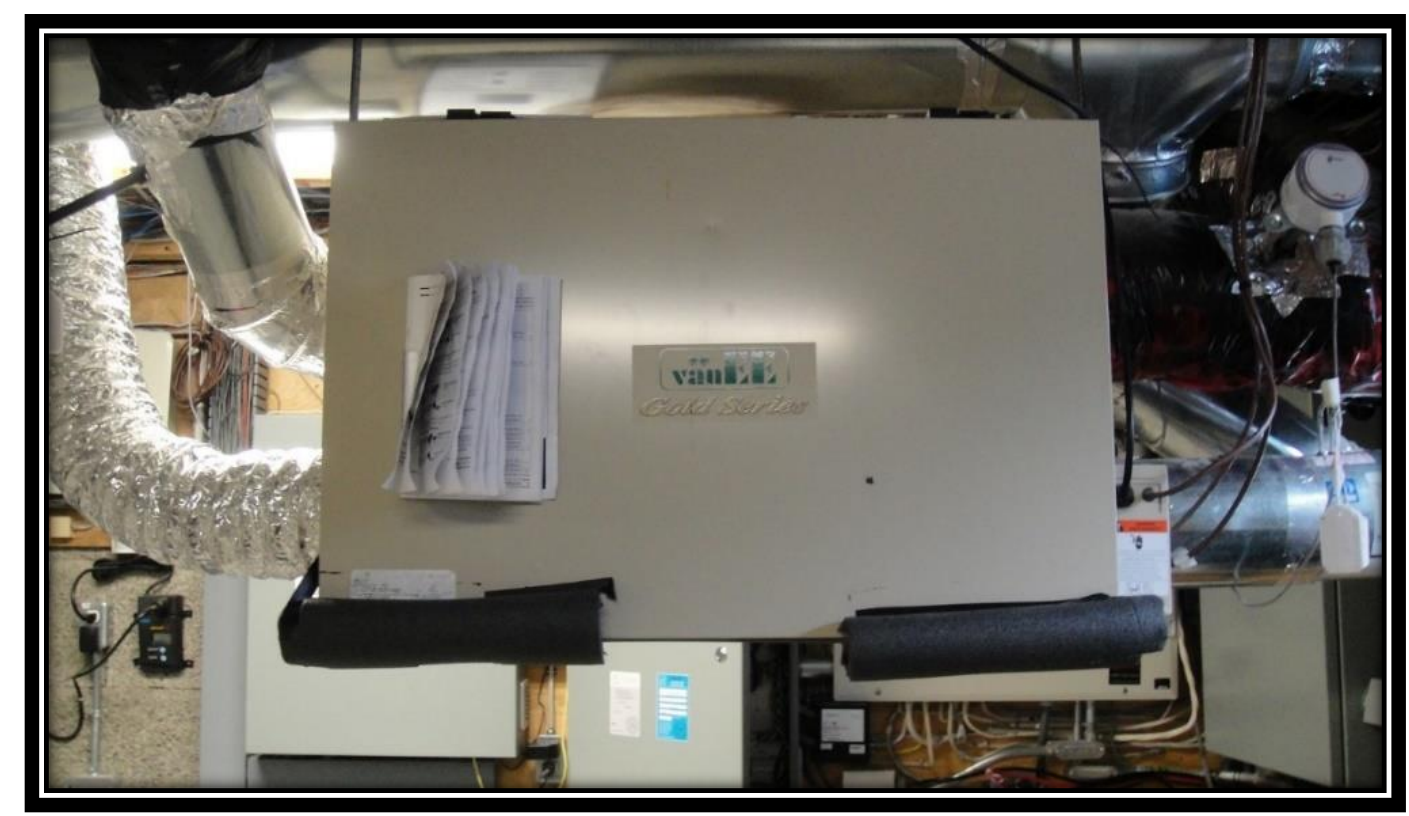

Figure E.3 - Energy recovery ventilator 


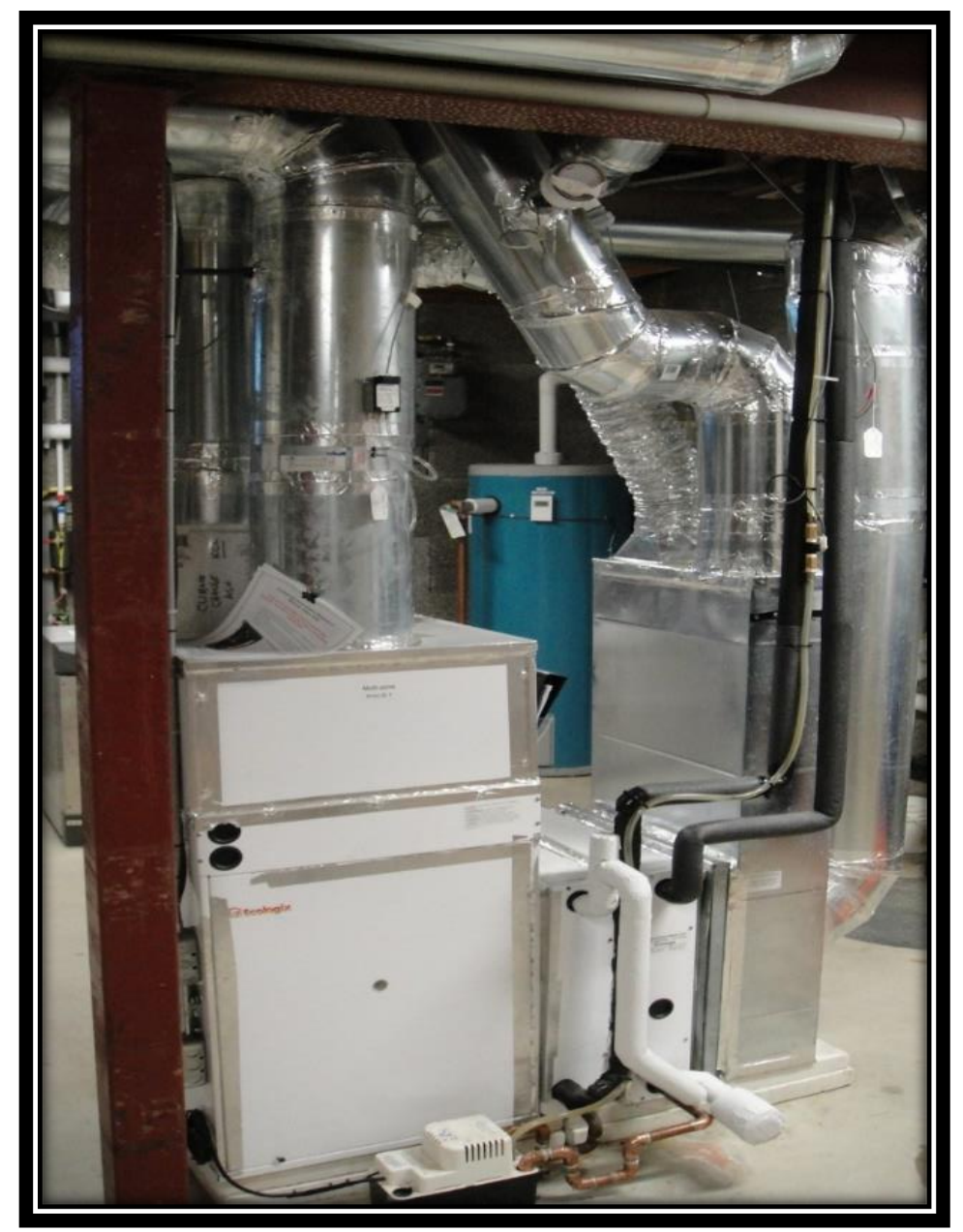

Figure E. 4 - Air handling unit for the Archetype Sustainable House-B

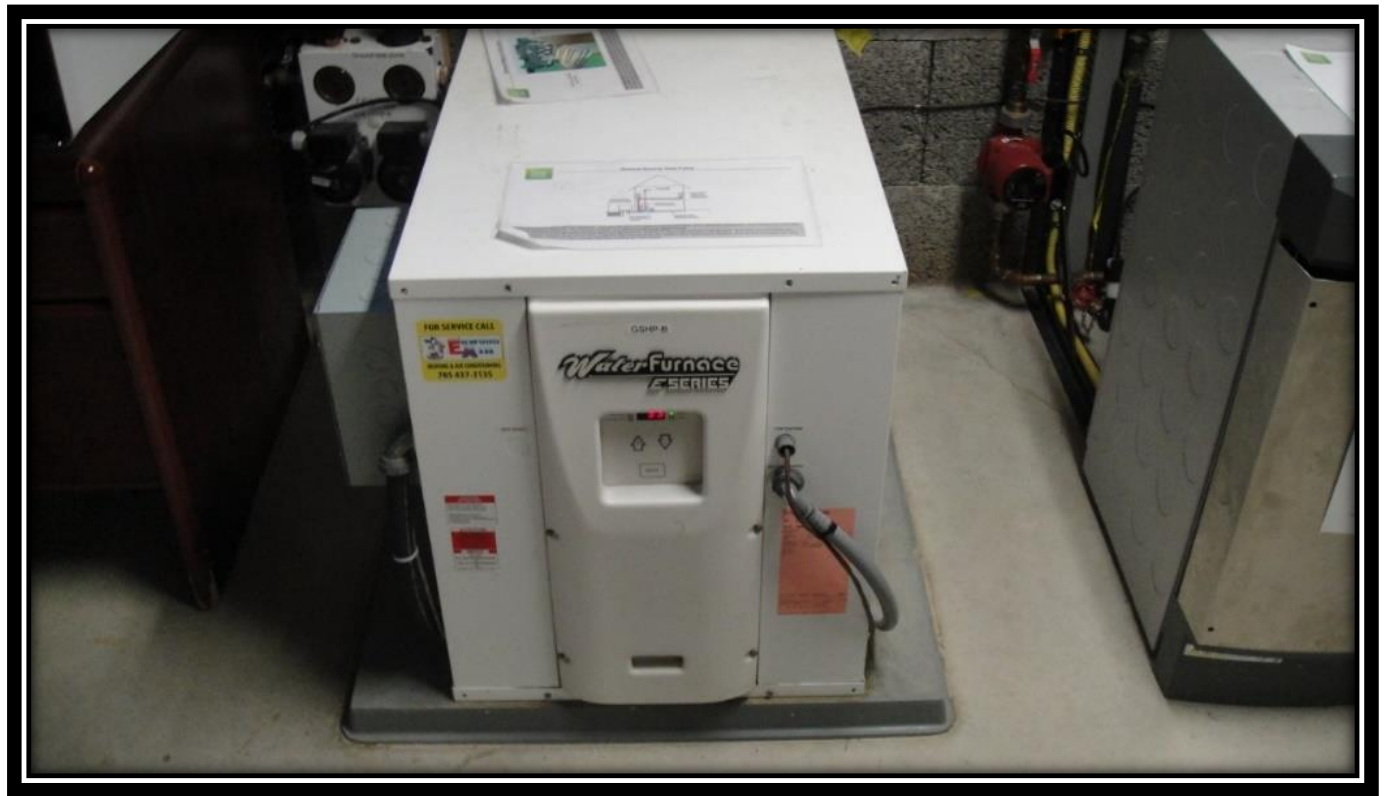

Figure E.5 - Ground source heat pump for the Archetype Sustainable House-B 


\section{References:}

Akbari, K. \& Oman, R. (2013). Impacts of Heat Recovery Ventilators on Energy Savings and Indoor Radon in a Swedish Detached House. WSEAS Transactions on Environment and Development, 9, 130-140.

Alzahrani, W.S. (2014). Experimental Study of The Performance of A Vertical and A Horizontal Ground Loops Coupled to A Ground Source Heat Pump System. MASc Thesis Report, Ryerson University.

Amos-Abanyie, S., Akuffo, F.O. \& Kootin-Sanwu, V. (2013). Effects of thermal mass, window size and night-time ventilation on peak indoor air temperature in the warm-humid climate of Ghana. The Scientific World Journal, 2013, 1-9.

Arkar, C. \& Medved, S. (2007). Free cooling of a building using PCM heat storage integrated into the ventilation system. Solar Energy, 81(9), 1078-1087.

Artmann, N., Jensen, R.L., Manz, H. \& Heiselberg, P. (2010). Experimental investigation of heat transfer during night-time ventilation. Energy and Buildings, 42(3), 366-374.

ASHRAE Guideline 2. (2005). Engineering Analysis of Experimental Data. Atlanta, USA, 16-20.

ASHRAE (2008). ASHRAE Handbook-HAVC Systems and Equipment. Atlanta, US: American Society of Heating, Refrigerating and Air-Conditioning Engineers.

ASHRAE (2009). ASHRAE Handbook-Fundamentals. Atlanta, US: American Society of Heating, Refrigerating and Air-Conditioning Engineers.

Barua, R., Zhang, D. H. \& Fung, A. S. (2010). Analysis of Energy Performance of the Sustainable Archetype House at Kortright Centre. $1^{\text {st }}$ International High Performance Buildings Conference, $3482,1-8$.

Barua, R. (2010). Assessment and energy benchmarking for two Archetype Sustainable Houses through comprehensive long term monitoring. MASc Thesis Report, Ryerson University.

Blondeau, P., Sperandio, M. \& Allard, F. (1997). Night ventilation for building cooling in summer. Solar Energy, 61(5), 327-335.

Bradshaw, V. (2006). The Building Environment, Active and Passive Control Systems (3rd ed.). Hoboken, NJ: John Wiley \& Sons, Inc.

Broniek, J., Brozyna, K., \& Stecher, D. (2010). Evaluating R-40 Above Grade Walls for a Production Built Zero Energy House. Retrieved January 8, 2014 from http://www.brikbase.org/sites/default/files/best2_broniek.pdf

Bulut, H. \& Aktacir, M.A. (2011). Determination of free cooling potential: A case study for Istanbul, Turkey. Applied Energy, 88(3), 680-689. 
Cengel, Y.A., \& Ghajar, A.J. (2011). Heat and Mass transfer Fundamentals and Applications (4th ed.). New York, NY: The McGraw-Hill Companies, Inc.

Chen, C.Y., Mistry, J., Fung, A.S., Leong, W.H. \& Jhingan, S. (2012). Design and Analysis of an Integrated Heat and Energy Recovery Ventilation System with Economizer Control for Net-Zero Energy Solar Houses. ASHRAE Transactions, 118(2), 82-89.

Crarley, D., Hand, J., Kummert, M., \& Griffith, B. (2005). Contrasting the Capabilities of Building Energy Performance Simulation Programs. Washington, DC: US Department of Energy Washington.

Coleman, H.W., \& Steele, W.G. (1999). Experimentation and Uncertainty Analysis for Engineers. New York, NY: John Wiley \& Sons.

Corky, B. (2003). Building Systems for Interior Designers. Hoboken, NJ: John Wiley \& Sons, Inc.

Dembo, A., Fung, A.S., Ng, K.L.R. \& Pyrka, A. (2010). The Archetype Sustainable House: Investigating its potentials to achieving the net-zero energy status based on the results of a detailed energy audit. $1^{\text {st }}$ International High Performance Buildings Conference, 3247, 1-8.

Dieckmann, J., Roth, K.W. \& Brodrick, J. (2003). Air-To-Air Energy Recovery Heat Exchangers. ASHRAE Journal, 57-58.

Dieckmann, J. (2008). Improving Humidity Control with Energy Recovery Ventilator. ASHRAE Journal, 38-45.

Dodoo A., Gustavsson L. \& Sathre R. (2011). Primary energy implications of ventilation heat recovery in residential buildings. Energy and Buildings, 43(7), 1566-1572.

Enbridge (2013). Residential Gas Rates - Purchasing Gas from Enbridge. Retrieved March 29, 2013 from https://www.enbridgegas.com/homes/accounts-billing/residential-gasrates/purchasing-gas-from-enbridge.aspx

Fehrm, M., Reiners, W. \& Ungemach, M. (2002). Exhaust air heat recovery in buildings. International Journal of Refrigeration, 25(4), 439-449.

Fernandez-Seara, J., Diz, R., Uhia, F.J., Dopazo, A. \& Ferro, J.M. (2011). Experimental analysis of an air-to-air heat recovery unit for balanced ventilation system in residential buildings. Energy Conversion and Management, 52(1), 635-640.

Fisk, W.J. \& Turiel I. (1983). Residential Air-to-Air Heat Exchangers: Performance, Energy Savings, and Economics. Energy and Buildings, 5(3), $197-211$.

Fisk, W.J., Chant, R.E., Archer, K.M., Hekmat, D., Offermann, F.J. \& Rederson, B.S. (1984). Onset of freezing in residential air-to-air heat exchangers. ASHRAE Transaction, 145, 57. 
Fisk, W.J., Chant, R.E., Archer, K.M., Hekmat, D., Offermann, F.J. \& Pedersen, B.S. (1985). Performance of Residential Air-to-Air Heat exchangers During Operation with Freezing and Periodic Defrosts. ASHREA Transactions, 91, 159-172.

Fouih, Y.E., Stabat, P., Riviere, P., Hoang, P. \& Archambault, V. (2012). Adequacy of air-to-air heat recovery ventilation system applied in low energy buildings. Energy and Buildings, 54, 29-39.

Fung, A. S., Guler, B., Aydinalp, M. \& Ugursal, V. I. (2000). Development of Canadian Residential Energy End-use and Emission Model. Halifax, Nova Scotia: CREEDAC.

Geros, V., Santamouris, M., Karatasou, A., Tsangrassoulis A., \& Papanikolaou, N. (2005). On the cooling potential of night ventilation techniques in the urban environment. Energy and Buildings, 37(3), 243-257.

Ghiaus, C. (2003). Free-running building temperature and HVAC climatic suitability. Energy and Buildings, 35(4), 405-411.

Gieseler, U.D.J., Bier, W. \& Heidt, F.D. (200). Cost efficiency of ventilation systems for lowenergy buildings with earth-to-air heat exchange and heat recovery. International Conference on Passive and Low Energy Architecture (PLEA), 577 - 582.

Harvey, D. (2000). Modern Analytical Chemistry. Columbus, OH: The McGraw-Hill.

GreenAngel ENERGY (2012). ERV's and HRV's: What's the Difference?. Retrieved August 3, 2013 from http://greenangelenergy.ca/erv-hrv-difference/

Han H., Choo, Y.B., \& Kwon, Y.I. (2007). An Experimental Study on the Effect of Outdoor Temperature and Humidity Conditions on the Performance of a Heat Recovery Ventilator. Retrieved March 10, 2014 from http://www.irbnet.de/daten/iconda/CIB7216.pdf

Handel, C. (2011). Ventilation with heat recovery is a necessity in "nearly zero" energy buildings. REHVA Journal, 18-22.

Hill, D. (1999). Field Survey of Heat Recovery Ventilation Systems. Retrieved April 26, 2013, from http://www.cmhc-schl.gc.ca/publications/en/rh-pr/tech/96215.htm

Jesper, K., Jørgen, R. \& Svend, S. (2005). Mechanical ventilation with heat recovery in cold climates. Proceedings of 7th Symbosium on Building Physics in the Nordic Countries.

Jonathan, C. (2010). Mattamy Homes Green Initiative Project: Phase II - Mechanical System Performance Analysis. Master's Research Paper, Ryerson University.

Juodis, E. (2006). Extracted ventilation air heat recovery efficiency as a function of a building's thermal properties. Energy and Buildings, 38(6), 568-573.

Kang, Y.B., Jiang, Y. \& Zhang, Y.P. (2003). Modeling and experimental study on an innovative 
passive cooling system - NVP system. Energy and Buildings, 35(4), 417-425.

Karjalainen S. (2012). Thermal comfort and gender: a literature review. Indoor Air, 22(2), 96-109.

Kavanaugh, S.P. \& Lambert, S.E. (2004). A Bin Method Energy Analysis for Ground-Coupled Heat Pumps. ASHRAE Transactions, 110(1), 535-542.

Kottek, M., Grieser, J., Beck, C., Rudolf, B. \& Rubel, F. (2006). World map of the Koppen-Geiger climate classification updated. Meteorologische Zeitschrift, 15(3), 259-263.

Lifebreath. (2009). TRV SERIES TOTAL RECOVERY VENTILATOR - Maximum Performance Year Round. Retrieved July 3, 2013 from http://www.lifebreath.com/downloads/83/trvsalessheet.pdf

Liu, J.J., Li, W.S., Liu, L. \& Wang, B. (2010). Efficiency of energy recovery ventilator with various weathers and its energy saving performance in a residential apartment. Energy and Buildings, 42(1), 43-49.

Lu, T. \& Chen, C. (2007). Uncertainty evaluation of humidity sensors calibrated by saturated salt solutions. ScienceDirect, 40, 591-599.

Malesevic, K., Olt, A., Tanielian, V. \& Crosbie, J. (2013). Design of a combined heat and energy recovery ventilator with economizer control for residential application. $4^{\text {th }}$ Year Engineering Capstone Project, Ryerson University.

Marsik, T. \& Johnson, R. (2008). Use of Simulink to evaluate the air-quality and energy performance of HRV-equipped residences in Fairbanks, Alaska. Energy and Buildings, 40(8), 1605-1613.

McDuffee, B. \& Shakya Y. (2010). Vaisala Humidity 101 - Calibration of the Humidity Instrument. $\quad$ Retrieved $\quad$ March $10, \quad 2014$ from http://www.vaisala.com/webinarrecordings/humidity_101_webinar_4_calibration.pdf

McQuiston, F.C., Parker, J.D. \& Spitler, J.D. (2005). Heating, Ventilating, and Air Conditioning Analysis and Design (6th ed.). Hoboken, NJ: John Wiley \& Sons, Inc.

Min, J.C. \& Su, M. (2010). Performance analysis of a membrane-based energy recovery ventilator: Effects of membrane spacing and thickness on the ventilator performance. Applied Thermal Engineering, 30(8), 991-997.

Mosaffa, A.H., Infante Ferreira, C.A., Talati, F. \& Rosen, M.A. (2013). Thermal performance of a multiple PCM thermal storage unit for free cooling. Energy Conversion and Management, 67, 17.

Nailor Industries Inc. (2009). THE ECM MOTOR STORY. Retrieved November 20, 2013 from http://www.nailor.com/AdShowCase/ECMmotorBro_2009.pdf 
National Energy Board (2013). Canada's Energy Future: Energy Supply and Demand Projections to 2035 - Energy Market Assessment. Retrieved August 5, 2013 from http://www.nebone.gc.ca/clf-nsi/rnrgynfmtn/nrgyrprt/nrgyftr/2011/nrgsppldmndprjctn2035-eng.html\#s2_1

Natural Resources Canada (2013). Energy Use Data Handbook - 1990 to 2010. Ottawa, Ontario: Natural Resources Canada.

Natural Resources Canada (2012). Heat Recovery Ventilators. Ottawa, Ontario: Natural Resources Canada.

OMEGA Engineering Inc. (n.d.). Equilibrium Relative Humidity Saturated Salt Solutions. Retrieved January 8, 2014 from http://www.omega.com/temperature/z/pdf/z103.pdf

Ottawa Sun (2013). \$4 million Net-Zero Energy Housing project funded by government and private sector. Retrieved August 5, 2013 from http://www.ottawasun.com/2013/05/10/4-million-net-zeroenergy-housing-project-funded-by-government-and-private-sector

Ouazia, B.K., Julien, M., Swinton, M.C., \& Manning, M. (2006). Assessment of the Enthalpy Performance of Houses Using Energy Recovery Technology. ASHRAE Journal, 112(1), 26-33.

Peel, M.C., Finlayson, B.L. \& McMahon, T.A. (2007). Updated world map of the Koppen-Geiger climate classification. Hydrology and Earth System Sciences, 11, 1633-1644.

Pellerin, N. \& Candas, V. (2003). Combined effects of temperature and noise on human discomfort, Physiology \& Behavior, 78(1), 99-106.

Pyrka, A. \& Fung, A. S. (2012). A Comparison of Thermal Comfort Between the Archetype Sustainable Homes at the Kortright Centre for Conservation. ASHRAE Transactions, 118(2), 98105.

Qarnia, H.E., Lacroix, M. \& Mercadier, Y. (2001). Use of a phase change material to prevent frosting in a compact crossflow air exchanger. Energy Conversion and Management, 42(10), 12771296.

Roulet, C.A., Heidt, F.D., Foradini, F. \& Pibiri, M.C. (2001). Real heat recovery with air handling units. Energy and Buildings, 33(5), 495-502.

Safa, A.A. (2012). Performance analysis of a two-stage variable capacity air source heat pump and a horizontal loop coupled ground source heat pump system. MASc Thesis Report, Ryerson University.

Santamouris, M., \& Wouters, P. (2006). Building Ventilation: The State of the Art. London, UK: Earthscan.

Schellenberg, R. (2002). The Trouble With Humidity: The Hidden Challenge of RH Calibration. 
Retrieved

March

10 ,

2014

from

http://www.vaisala.com/Vaisala\%20Documents/White\%20Papers/lsh-Trouble-with-

Humidity.pdf

Shaviv, E., Yezioro, A. \& Capeluto, I.G. (2001). Thermal mass and night ventilation as passive cooling design strategy. Renewable Energy, 24(3), 445-452.

Sherman, M.H. (1987). Estimation of infiltration from leakage and Climate indicators. Energy and Buildings, 10(1), 81-86.

Shurcliff, W. A. (1988). AIR-TO-AIR HEAT-EXCHANGERS FOR HOUSES. Annual Reviews Energy, 13, 1-22.

Solar Energy Laboratory (2005). TRNSYS 17 manual - Multizone Building Modeling with Type56 and TRNBuild. University of Wisconsin-Madison.

Solar Energy Laboratory (2012). TRNSYS 17 manual - Using the Simulation Studio. University of Wisconsin-Madison.

Toronto Hydro (2013). Electricity Rates \& Charges. Retrieved March 29, 2013 from http://www.torontohydro.com/sites/electricsystem/residential/yourbilloverview/Pages/Electricity Rates.aspx

University of La Rochelle (2009). Building energy performance evaluation by using the freerunning temperature. European Project ThermCo.

Vaisala (2006). Vaisala Humidity Calibrator HMK15 - USER'S GUIDE. Helsinki, Finland: Vaisala.

VanEE (2011). VanEE Air Exchanger Literature. Retrieved August 15, 2013 from http://vanee.edenenergy.com/res-air-exchangers-literature.php

Wellford, B. (2002) Enthalpy-Recovery Ventilation Systems Cost-effective design and installation considerations. HPAC Engineering, 74, 52-55.

Wujek, J.B. \& Dagostino, F.R. (2009). Mechanical and Electrical Systems in Architecture, Engineering, and Construction (5th ed.). Upper Saddle River, NJ: Pearson Education, Inc.

XeteX (2009). Air-to-Air Cross Flow Flat Plate Heat Exchangers: An Introduction. Retrieved March 20, 2014 from http://www.xetexinc.com/uploaded/Doc/22\%20Flat\%20Plate $\% 20$ Heat $\% 20$ Exchangers $\% 20-\% 20 \mathrm{An} \% 20$ Introduction $\% 20 \mathrm{v} 2.1$.pdf

Yang, L., \& Li, Y. (2008). Cooling load reduction by using thermal mass and night ventilation. Energy and Buildings, 40(11), 2052-2058.

Yoo, S.Y. Chung, M. H. \& Choi, J. H. (2005). A study on performance of paper heat exchanger for 
exhaust heat recovery. Proceedings of SAREK 2005 Summer Conference, 438-443.

Yunus, A.C. \& Afshin, J.G. (2011). Heat and Mass Transfer Fundamentals and Applications $4^{\text {th }}$. The McGraw-Hill Company, Inc., New York.

Zalba, B., Marin, J.M., Cabeza, L.F. \& Mehling, H. (2004). Free-cooling of buildings with phase change materials. International Journal of Refrigeration, 27(8), 839-849.

Zhai, C., Archer, D.H. \& Fischer J.C. (2007). The performance of an enthalpy recovery wheel in ventilation of CMU's IW. ASME International Mechanical Engineering Congress and Exposition, $46,81-88$.

Zhang, D.H., Barua, R. \& Fung, A.S. (2011). TRCA-BILD Archetype Sustainable House Overview of Monitoring System and Preliminary Results for Mechanical Systems. ASHRAE Transactions, 117(2), 597-612.

Zhang, L. Z. \& Jiang, Y. (1999). Heat and mass transfer in a membrane-based energy recovery ventilator. Journal of Membrane Science, 163(1), 29-38.

Zhang, L. Z. (2008). Total Heat Recovery - Heat and Moisture Recovery from Ventilation Air. Nova Science Publisher, Inc., New York.

Zhang, Y.P., Jiang, Y., Zhang, L.Z., Deng, Y.C. \& Jin, Z.F. (2000). Analysis of thermal performance and energy savings of membrane based heat recovery ventilator. Energy, 25(6), 515-527. 